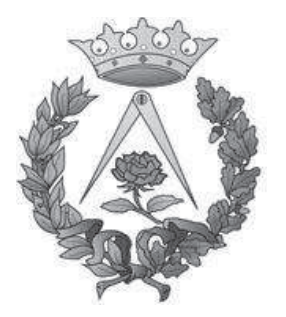

UNIVERSIDAD POLITÉCNICA DE MADRID

ESCUELA TÉCNICA SUPERIOR DE ARQUITECTURA DE MADRID

PROGRAMA DE DOCTORADO EN CONSERVACIÓN Y RESTAURACIÓN DEL PATRIMONIO ARQUITECTÓNICO

TESIS DOCTORAL

\title{
LAS FÁBRICAS DE TABACOS EN ESPAÑA (1731-1945)
}

\author{
CAROLINA CASTAÑEDA LÓPEZ \\ ARQUITECTA \\ DIRECTOR \\ FERNANDO VELA COSSÍO \\ DOCTOR EN GEOGRAFÍA E HISTORIA
}





\section{(a) \\ POLITÉCNICA}

Tribunal nombrado por el Magfco. y Excmo. Sr. Rector de la Universidad Politécnica de Madrid, el día de de 20

Presidente:

Vocal:

Vocal:

Vocal:

Secretario:

Suplente:

Suplente:

Realizado el acto de defensa y lectura de la Tesis el día de 20 en la Escuela Técnica Superior de Arquitectura de Madrid.

Calificación:

EL PRESIDENTE

LOS VOCALES 



A mis padres y a mis abuelos. Sin su comprensión, apoyo y cariño, el camino realizado hasta llegar a esta investigación doctoral no hubiese sido posible.

En primer lugar, quisiera brindar un reconocimiento especial a todos los autores que han abierto camino en la investigación sobre las fábricas de tabacos españolas. La deuda intelectual para con sus trabajos es innegable y sin ellos no habría sido posible establecer el marco teórico en el que se desarrolla.

También quisiera agradecer a mis profesores en la ETSAC, especialmente Celestino García Braña, Amparo Casares Gallego, Andrés Fernández-Albalat Ruíz y José Ramón Alonso Pereira, que con sus píldoras lectivas iniciaron mi interés por la arquitectura industrial sin ser conscientes de ello.

Un cariñoso agradecimiento a los compañeros de INCUNA y TICCIHEspaña por su interés y acertados consejos, en especial a Miguel Ángel Álvarez Areces por su contagioso entusiasmo en el estudio, conservación y difusión del patrimonio industrial. También una especial mención a Mercedes López García por su desinteresada ayuda, buenos consejos y apoyo en el desarrollo de la presente investigación.

También quisiera hacer mención a los docentes del programa "Conservación y Restauración del Patrimonio Arquitectónico" de la Universidad Politécnica de Madrid, por sembrar la semilla de lo que ha desembocado en esta investigación doctoral, en especial a su coordinador Javier García-Gutiérrez Mosteiro por su excelente disposición y asesoramiento en los momentos de duda.

Un afectuoso recuerdo a mis compañeros del proyecto red PHI "Patrimonio Histórico+cultural Iberomericano" y del Aula G+I_PAI Gestión e Intervención en el Patrimonio Arquitectónico e Industrial del programa Cátedra Universidad-Empresa de la Universidad Politécnica de Madrid en colaboración con la Fundación ACS, en especial a Joaquín Ibáñez Montoya por su constante confianza en mi trabajo. Cabe hacer una especial mención a Fundación ACS y a su director Francisco Menor Monasterio por el apoyo económico brindado a esta investigación y por permitir que continuase mi formación académica y profesional a través de su convenio con la UPM.

Quisiera agradecer a los miembros del tribunal de prelectura de esta tesis doctoral, los doctores Pedro Navascués Palacio, Enrique Nuere Matauco y Francisco Javier Neila González, sus valiosas indicaciones y acertados consejos que indudablemente contribuyeron al cierre definitivo de este documento de forma clara y rigurosa.

Un especial agradecimiento a todas aquellas instituciones que facilitaron enormemente el trabajo de campo en las diversas ciudades a las que me desplacé con motivo de la presente investigación: Archivo de la Villa, Archivo General de Guipúzcoa, Archivo General de Indias, Archivo General de La Rioja, Archivo General de Palacio, Archivo Histórico Municipal de Cádiz, Archivo Histórico Municipal de Valencia, 
Archivo Histórico Provincial de Cádiz, Archivo Histórico Provincial de Málaga, Archivo Histórico Provincial de Sevilla, Archivo Municipal de Alicante, Archivo Municipal de Gijón, Archivo Municipal de San Sebastián, Archivo del Reino de Galicia, Archivo de Tarragona, Archivo de la Villa, Associaciò d'Amics de Tabacalera, Ayuntamiento de Valencia, Biblioteca Koldo Mitxelena, Biblioteca Municipal de Estudios Locales de La Coruña, Biblioteca Pública Jovellanos de Gijón, Biblioteca de La Rioja, Centro Cultural Las Cigarreras, CSA La Tabacalera de Lavapiés, Dirección General de Bellas Artes y Patrimonio Cultural, Museo Automovilístico de Málaga, Museo del Ferrocarril de Asturias, Museo del Pueblo de Asturias, Palacio de Congresos y Exposiciones de Cádiz, Parlamento de La Rioja, Sala Amós Salvador, Tabakalera-Centro Internacional de Cultura Contemporánea y Universidad de Sevilla.

También quisiera reconocer en particular a aquellas personas que amablemente cedieron material documental para su consulta o accedieron a realizar entrevistas personales: Amaia Apraiz Sahagún, Luis Arias González, al estudio Carratalá arquitectos (Luis Carratalá y Diego Carratalá), Ángel Luis de Sousa Seibane, Amaya El Busto, Pablo García Bachiller, Paz García Quirós, Fernando Gil Sendino, Ainara Martínez Matía, Ángel Mato Díaz, Antonio Monte, Xavier Morato, Luis Miguel Piñera, Pablo Rivera Posse, José Sierra Álvarez, Julián Sobrino Simal, Rubén Vega García, Nuria Vila, Antoni Vilanova Omedas, Román Villasana (y los coautores del proyecto para la rehabilitación de la Tabacalera de Gijón, Carlos Pereda, Óscar Pérez e Ignacio Olite), Paul Smith, al estudio TAU Don (Naiara Montero y Jon Montero, y a Andrea Valoria por su visita guiada a la obra de San Sebastián), al estudio TAU Noriega (Ángel Noriega e Iván Iturbe). Así mismo, mi sentido agradecimiento a aquellos antiguos trabajadores que, pese a permanecer en el anonimato por decisión personal, aportaron testimonios y datos cruciales para el desarrollo de la presente investigación.

Por último, pero no menos importante, a mi director Fernando Vela Cossío por acompañarme y guiarme en el largo camino que ha supuesto esta investigación. A él mi agradecimiento más sentido, no sólo como docente, por la ayuda brindada a través de sus certeros consejos, sino también como persona, por su apoyo y ánimos en los momentos de duda, y que han conducido al buen término de la presente tesis doctoral. 


\section{ÍNDICE}

TOMO 1

RESUMEN .13

1. INTRODUCCIÓN. .17

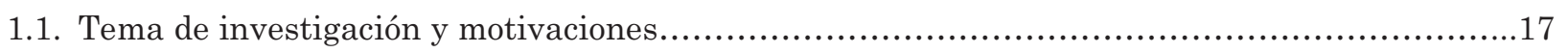

1.2. Justificación y relevancia de la investigación........................................................ 19

1.3. Marco contextual, hipótesis y objetivos de la investigación......................................21

1.4. Delimitación del ámbito de la investigación y propuesta de análisis: metodología y material de estudio..... .23

2. HISTORIOGRAFÍA: PATRIMONIO INDUSTRIAL， INICIOS DE LA ARQUITECTURA
INDUSTRIAL Y EL ESTUDIO DE LAS FÁBRICAS DE TABACOS EN ESPAÑA...........................27

2.1. Sobre cuestiones generales de interés al objeto de la presente investigación. .28

2.1.1.El patrimonio, la arquitectura y la arqueología industrial: bases para un corpus teórico. Criterios y buenas prácticas para la conservación del patrimonio industrial..................28

2.1.2.La arquitectura industrial y el espacio del trabajo: manufacturas y primeros conjuntos fabriles. . .39

2.1.3.La fábrica como tipo en la historia de la arquitectura y su presencia en la tratadística.....46

2.2. Aproximación a las fábricas de tabacos en España: contexto histórico, económico y social.......54

2.2.1.El monopolio hacendístico del tabaco en España y su contexto histórico.......................54

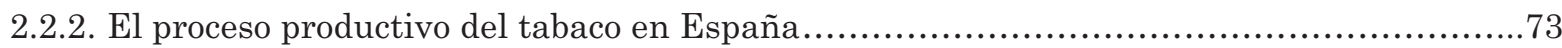

2.2.3. Las cigarreras y el espacio fabril: condiciones laborales, identidad colectiva y significación

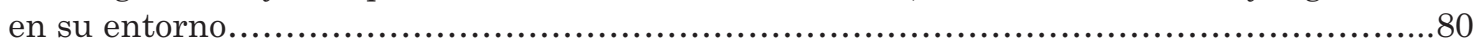

2.2.4. Las fábricas de tabacos en España: los conjuntos fabriles del monopolio peninsular.........97

2.2.5. Las fábricas de tabacos a nivel mundial: dos monopolios europeos y antiguos territorios coloniales.

\section{LAS FÁBRICAS DE TABACOS EN ESPAÑA: PROYECTOS Y FUNDACIONES FABRILES DE LA UNIVERSAL ADMINISTRACIÓN A TABACALERA S.A. (1731-1945).

3.1. Consideraciones acerca de la selección de casos estudio y criterios de análisis....................121

3.2. Las primeras fundaciones fabriles........................................................... 122

3.2.1. La Real Fábrica de Tabacos de Sevilla $(1620-1950)$............................................... 123

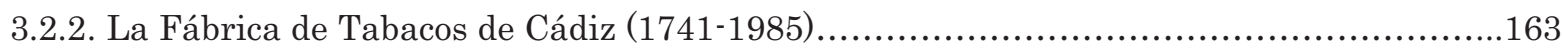

3.3. La primera generación de fábricas del S.XIX............................................... 174

3.3.1. La Fábrica de Tabacos de Alicante (1801-2001) ...................................................175

3.3.2. La Fábrica de Tabacos de La Coruña (1804-2002) ................................................190

3.3.3. La Fábrica de Tabacos de Madrid (1809-2000)................................................219

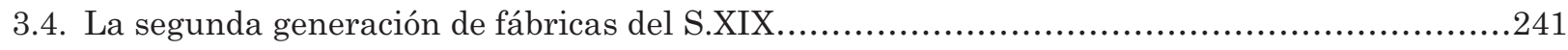

3.4.1. La Fábrica de Tabacos de Santander (1822-2002) .................................................242

3.4.2. La Fábrica de Tabacos de Gijón (1823-2002)......................................................257

3.4.3.La Fábrica de Tabacos de Valencia $(1828-2001)$.....................................................284 
3.5. La tercera generación de fábricas del S.XIX: los comienzos de la Compañía Arrendataria de

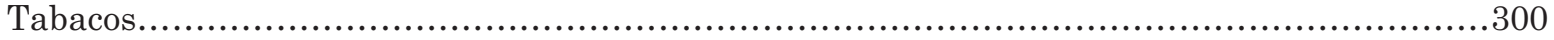

3.5.1. La Fábrica de Tabacos de San Sebastián (1878-2003).......................................301

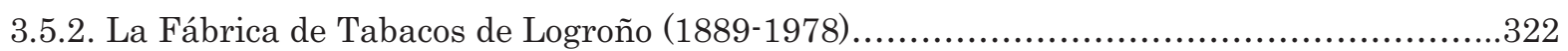

3.6. Fábricas tardías del S.XX: las últimas intervenciones de la Compañía Arrendataria de

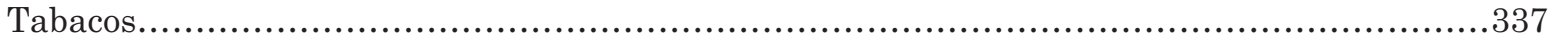

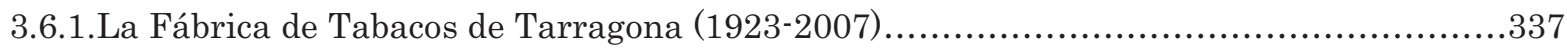

3.6.2. La Fábrica de Tabacos de Málaga (1923-2002)...................................................352

\section{EVOLUCIÓN PROYECTUAL DE LAS FÁBRICAS DE TABACOS EN ESPAÑA Y LECTURA A TRAVÉS DE SUS DIMENSIONES DE SIGNIFICACIÓN.

4.1. De la fábrica compacta al modelo en pabellones. Casos estudio seleccionados. 372

4.1.1. El origen. Sevilla: modelo compacto dieciochesco precursor y base para una reflexión

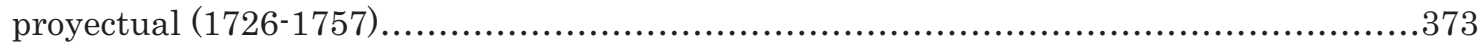

4.1.2. El inicio de un giro conceptual. La descompactación de entre-siglos..........................384

4.1.2.1. San Sebastián: modelo compacto decimonónico (1886-1913)..........................384

4.1.2.2. Valencia: modelo híbrido de principios del S.XX (1906-1914) ........................390

4.1.3.La evolución última de un modelo espacial productivo. Tarragona: modelo de fábrica en

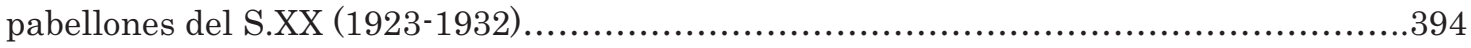

4.2. Las dimensiones de las fábricas de tabacos en España: niveles de interpretación para una

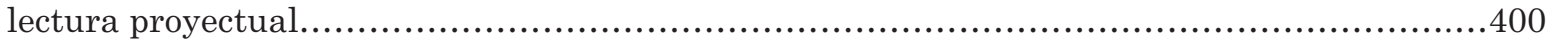

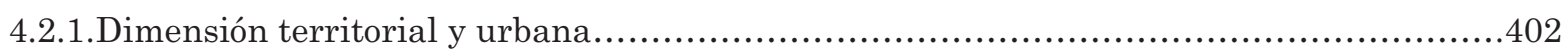

4.2.1.1. La expansión estratégica en el marco peninsular..................................402

4.2.1.2. Influencia de la fábrica de tabacos en su entorno próximo.........................403

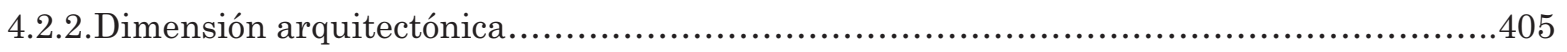

4.2.2.1. La fachada como elemento de representatividad y transición entre el ámbito exterior y el espacio productivo interior.............................................405

4.2.2.2. El patio como principio ordenador del modelo arquitectónico. Espacio como instrumento de coerción de la operaria..............................................406

4.2.2.3. La reutilización de edificios preexistentes: origen religioso o civil y paralelismos

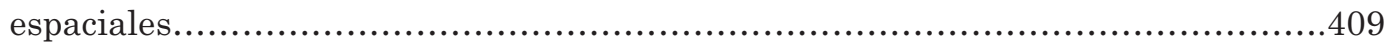

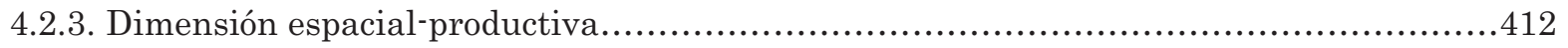

4.2.3.1. La ordenación del proceso productivo en el edificio: zonificación y gradación

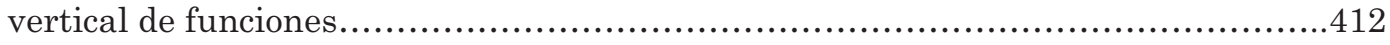

4.2.3.2. La polarización del espacio fabril. Espacio productivo vS espacio

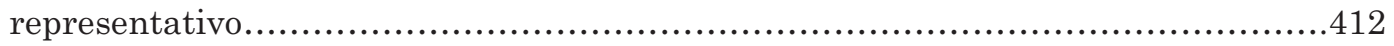

4.2.3.3. Evolución del proceso productivo y su significación en el espacio tabacalero.....413

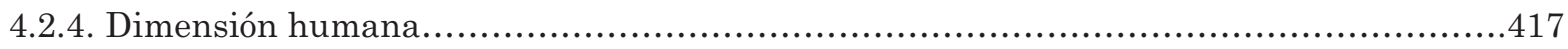

4.2.4.1. Condiciones del espacio de trabajo y creación de instalaciones específicas........417

4.2.4.2. La transferencia de roles entre espacio doméstico y espacio fabril. Espacios de sociabilidad ............................................................................. 418

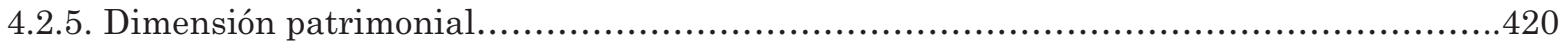

4.2.5.1. Las fábricas de tabacos en España como espacio de reflexión y oportunidad.....420

4.2.5.2. Estado actual de los casos analizados y valoración de las intervenciones acometidas sobre los mismos. 
5.1. El papel de los proyectistas: la concepción proyectual y la resolución de los problemas planteados....

5.2. La búsqueda de referentes tipológicos para una nueva función y su relación con la permanencia de invariantes arquitectónicos. 458

5.3. Relaciones con otros monopolios europeos: el caso francés como fuente de inspiración y los paralelismos con el monopolio italiano del tabaco. 467

5.4. Las fábricas tabacaleras como proceso arquitectónico. Resolución proyectual de las fábricas de tabacos en España en sus dimensiones de significación. 480

6. CONCLUSIONES. 489

6.1 Generales sobre el objeto de investigación. 489

6.1.1 Las fábricas de tabacos en España como objeto de estudio 489

6.1.2 Desarrollo de una metodología de comparación de las arquitecturas fabriles tabacaleras. Aportaciones inéditas. 492

6.2 Particulares sobre las hipótesis planteadas y la interpretación de resultados. 493

6.2.1 Las fábricas de tabacos en España como tipo fabril. Invariantes arquitectónicos en sus dimensiones de significación.

6.2.2 Las fábricas de tabacos en España como proceso proyectual. La construcción de la imagen arquitectónica 498

6.2.3 Las fábricas de tabacos en España como unidades de un sistema monopolístico. Paralelismos con Francia e Italia..... 501

6.2.4 Las fábricas de tabacos en España como patrimonio industrial. Revisión crítica sobre la intervención contemporánea en los inmuebles fabriles tabacaleros .503

6.3 Consideraciones finales. Recapitulación a partir de las conclusiones................................507

6.4 Líneas de investigación abiertas. .510

6.4.1 Apertura de nuevos enfoques para estudios monográficos que profundicen en las características de cada fábrica 511

6.4.2 Los monopolios tabacaleros europeos y las fábricas de tabacos en España: paralelismos

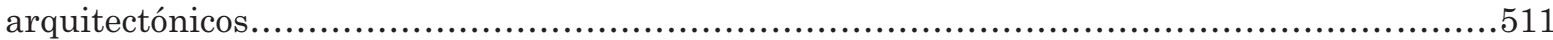

6.4.3 La influencia de la arquitectura fabril tabacalera peninsular en las colonias. .513

6.4.4 La mujer y el espacio fabril: condicionantes e influencia de la presencia femenina en su espacio de trabajo.

6.4.5 Fábricas en conventos: el caso tabacalero español.

7. FUENTES CONSULTADAS

7.1. Bibliografía y documentos audiovisuales

7.2. Documentos de archivo 
TOMO 2

\section{ANEXOS}

8.1. Selección de la documentación planimétrica en los archivos consultados .5

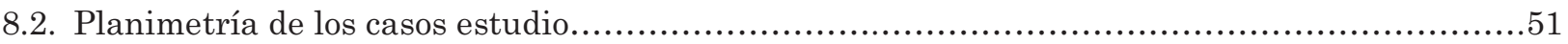

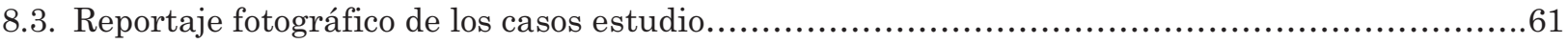

8.4. Reflexión gráfica de los casos estudio. Cuadros resumen y esquemas analíticos argumentales

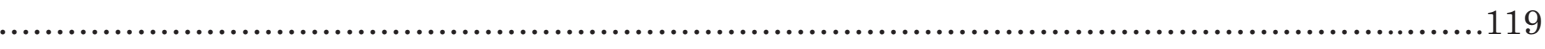

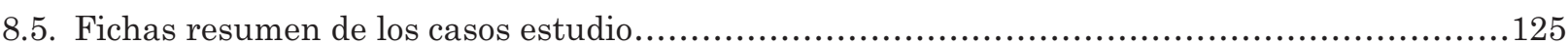

8.6. Cronologías del monopolio hacendístico del tabaco y de los casos estudio..........................149 


\section{RESUMEN}

El objeto de la presente tesis es el estudio comparativo desde un enfoque arquitectónico y patrimonial de las fábricas tabacaleras en España surgidas bajo la gestión del monopolio hacendístico del tabaco. Con ello se pretende profundizar en la realidad arquitectónica que engloba un proceso de producción determinado, como es el del tabaco, históricamente asociado a la figura de la mujer como trabajadora y que define un tipo fabril característico en la formalización arquitectónica del espacio productivo.

En este sentido, la investigación se ha centrado en aquellas fundaciones fabriles surgidas bajo la gestión de la Renta de Tabacos por parte de la Corona y el Estado desde 1731 hasta 1887 y por la Compañía Arrendataria de Tabacos desde ese año hasta 1945, en que el monopolio pasa a manos de Tabacalera. Los proyectos de nueva planta o adaptación de un edificio preexistente para la producción tabacalera encuadrados en dicho marco cronológico, además de su interés patrimonial, constituyen la expansión territorial del parque fabril tabacalero en España y presentan las características comunes escindidas del análisis de los casos estudio seleccionados, atendiendo al establecimiento de sus dimensiones de significación e interpretación como patrimonio industrial arquitectónico en su relación territorial, urbana, arquitectónica, productiva y humana.

En el periodo estudiado se puede establecer una lógica productiva general que va desde la caracterización del espacio tabacalero por su condición manufacturera, propia de los métodos productivos artesanales anclados en el Antiguo Régimen, hasta las reformas iniciadas a finales del S.XIX en pos de una modernización y racionalización del espacio productivo. De esta forma, en el primer periodo señalado se abordan la construcción del proyecto de nueva planta de la Real Fábrica de Tabacos de Sevilla y la fundación de su filial gaditana en el S.XVIII, así como la reutilización de inmuebles preexistentes pertenecientes a la Administración o desamortizados para tal fin, en la expansión territorial paulatina del parque fabril a lo largo del S. XIX -fábricas de Alicante, La Coruña, Madrid, Santander, Gijón, Valencia y San Sebastián-. En el segundo momento anteriormente señalado, se contemplan la creación de nuevas fábricas bajo la gestión de la CAT a partir de 1887 -fábricas de Logroño, Tarragona y Málaga- y el traslado de la producción de algunas de las fundaciones anteriores a nuevos conjuntos fabriles.

No obstante, el análisis de las características comunes que definen el tipo fabril tabacalero resulta más claro en aquellas fábricas cuya arquitectura ha sido concebida ex profeso para la actividad industrial tabacalera. De esta forma, el análisis enfocado a la respuesta de los interrogantes planteados se realiza sobre una selección de casos estudio correspondientes a proyectos de nueva planta que ocupan diversos puntos de la distribución geográfica del parque fabril del monopolio y suponen cortes temporales significativos en la evolución histórica del proceso productivo tabacalero en España.

Esta investigación ha abordado la necesaria elaboración de un análisis comparativo de los casos estudio seleccionados para aportar una visión 
inédita que contextualice el desarrollo arquitectónico de las fábricas de tabacos en España. De esta forma, se establece una explicación general del objeto de estudio, permitiendo una relectura de los trabajos realizados hasta el momento sobre las fábricas de tabacos en España y arrojando una nueva mirada interpretativa desde la lógica arquitectónica proyectual y patrimonial. El método seguido para el desarrollo del análisis abordado permite una lectura holística en las diversas dimensiones de interpretación y significación de estas fábricas tabacaleras encuadrando los resultados, no sólo en relación al objeto de investigación, sino también a su tratamiento como patrimonio industrial arquitectónico y vestigio material de la memoria del trabajo femenino.

\section{ABSTRACT}

The purpose of this Ph.D research is the comparative study from an architectural and heritage approach of the tobacco factories in Spain arisen under the management of the tobacco monopoly. This intends a deepening on the architectural reality that encompasses a specific production process, such as the tobacco one, historically associated to the female presence as worker and defining a characteristic factory type in the architectural formalization of the productive space.

In this sense, the research has focused on those factory foundations emerged under the management of the Tobacco Rent held by the Crown and the State from 1731 to 1887 and by the Compañía Arrendataria de Tabacos from that year to 1945, in which the monopoly is handed over to Tabacalera. The projects of new construction or the adaptation of preexisting buildings for tobacco production within this chronological framework, in addition to its heritage interest, constitute the territorial expansion of the tobacco industrial park in Spain and present the common characteristics derived from the analysis of this research, regarding the establishment of their dimensions of significance and interpretation as architectural industrial heritage in their territorial, urban, architectural, productive and human relationship.

In the study period, general production logic can be established from the characterization of the tobacco space by its manufacturing condition, typical of the artisanal production methods anchored in the Old Regime, until the reforms initiated at the end of the XIX century in pursuit of a modernization and rationalization of the productive space. This way, in the first mentioned period, the research addresses the construction of the Royal Tobacco Factory of Sevilla and the foundation of its Cádiz subsidiary in the XVIII century, as well as the reuse of preexisting buildings owned by the Crown or disentailed for this purpose in the gradual territorial expansion of the industrial park along de XIX century -factories of Alicante, La Coruña, Madrid, Santander, Gijón, Valencia and San Sebastián-. In the second moment previously mentioned, research contemplates the creation of new factories under the management of the CAT from 1887 - factories of Logroño, Tarragona and Málaga- and the transfer of production of some of the previous foundations to new factory ensembles. 
However, the analysis of the common characteristics that define the tobacco factory type is clearer in those factories whose architecture has been conceived specifically for tobacco industrial activity. Thus, the analysis focused on the response of the questions raised is carried out on a selection of case studies corresponding to new construction projects that occupy different points of the geographical distribution of the industrial park of the monopoly and suppose significant temporary cuts in the historical evolution of the tobacco production process in Spain.

This research has addressed the necessary elaboration of a comparative analysis of the selected case studies to provide an unprecedented vision that contextualizes the architectural development of the tobacco factories in Spain. In this way, general explanation of the subject of study is established, allowing a re-reading of the work done so far on the tobacco factories in Spain and throwing a new interpretive view from the architectural and heritage logic. The method used for the development of the analysis allows a holistic reading in the various dimensions of interpretation and significance of this tobacco factories, framing the results, not only in relation to the object of research, but to its treatment as an architectural industrial heritage and material vestiges of the memory of female work. 



\section{INTRODUCCIÓN}

1.1 Tema de investigación y motivaciones

1.2 Justificación y relevancia de la investigación

1.3 Marco contextual, hipótesis y objetivos de la investigación

1.4 Delimitación del ámbito de la investigación y propuesta de análisis: metodología y material de estudio

\subsection{Tema de investigación y motivaciones}

La primera toma de contacto con las fábricas de tabacos en España fue a través de mi interés personal por el patrimonio industrial, su estudio y conservación. Cuando descubrí la arquitectura industrial durante mis estudios en la Escuela Técnica Superior de Arquitectura de La Coruña, me di cuenta de que a través de mi vocación era capaz de comprender e interpretar la realidad industrial que me había rodeado desde niña en mi ciudad natal, Gijón. Desde ese momento, mediante los nuevos conocimientos adquiridos durante mi formación forjé un vínculo con la estética y especificidad de la arquitectura fabril, de forma que mi nueva mirada hacia los conjuntos industriales me devolvía una imagen inédita para mí y llena de significados.

Posteriormente, a través de la especialización en el Máster en Conservación y Restauración del Patrimonio Arquitectónico de la Universidad Politécnica de Madrid, se renovó mi interés por la investigación sobre el patrimonio industrial, reforzando mi dedicación a dicha materia con un carácter más científico. De igual forma, en esa época se iniciaron también mis colaboraciones con entidades como INCUNA y TICCIH-España conduciendo mis intereses hacia el estudio y conservación del patrimonio industrial. Durante el curso académico en el que realicé dicho máster, mis inquietudes sobre la realidad industrial de Gijón me motivaron a indagar sobre arquitecturas fabriles desaparecidas o en estado de abandono y su posible recuperación como patrimonio perteneciente a un tiempo histórico cercano.

Estas pesquisas me remitieron a un edificio muy presente en el imaginario colectivo de mi ciudad natal: la Fábrica de Tabacos de Gijón. Abandonado desde 2002, año en el que cesó su actividad productiva y se hizo efectivo su cierre, siempre había permanecido como fondo escénico de la popular plaza de Arturo Arias en la que transcurre parte fundamental del tiempo de ocio de los gijoneses entre culines de sidra, sardinas y bígaros en los concurridos chigres que proliferan en el popular barrio de Cimadevilla. De esta forma, comencé a interrogarme sobre dicho edificio que, aún ocupando una posición tan destacada en el tejido urbano del casco histórico gijonés, se presentaba ante a mí como un misterio infranqueable debido a su hermetismo y al desconocimiento total de su espacio interior.

En una búsqueda posterior de información y ampliando el alcance de mis indagaciones al contexto territorial, descubrí la extensa red de fábricas tabacaleras que en su día habían surtido a la península del antaño preciado producto tabacalero. Sistematizadas a través de la 
gestión del monopolio hacendístico del tabaco, las fábricas tabacaleras tuvieron gran repercusión en sus ciudades de implantación como generadoras de empleo femenino, potenciadoras de la economía local y como polo catalizador de las dinámicas de expansión urbana. De igual forma, pude apreciar que se trataba de un tipo especial de patrimonio industrial -en la mayoría de los casos centenario- que revertía interés en la formalización monumental y solemne de sus fábricas, tan propia de las primeras arquitecturas industriales manufactureras, pero cuyas circunstancias particulares las habían erigido como contenedores de una industria viva hasta inicios del S.XXI.

Mi curiosidad amplió el nivel de profundidad en la búsqueda de una explicación sobre las características comunes a esta arquitectura industrial centenaria. Muchos de los estudios que existen actualmente sobre el mundo del tabaco aluden a aspectos socioeconómicos de la época, como la importancia del contexto y la creación del Estanco del Tabaco en España y su evolución histórica -por constituir una industria que sentó las bases de una estructura fiscal basada en el monopolio hacendístico que se prolongaría hasta la última veintena del S.XXTambién se han analizado aspectos relacionados con la figura de la cigarrera y la memoria de su trabajo, sus condiciones laborales y su carácter -objeto de mitos y relatos literarios por la fuerza de su presencia como figura femenina trabajadora desde el S.XVIII-. Más recientemente, se han desarrollado diversos estudios sociológicos de carácter científico con la cigarrera como una de las figuras precursoras del asociacionismo colectivo de principios del S.XX.

Sin embargo, tras un primer estudio sobre el estado de la cuestión y, en particular, sobre todo lo publicado en relación a las fábricas de tabacos en España, no se encontraron trabajos específicos que se centrasen en un análisis transversal de este patrimonio industrial desde la óptica de la arquitectura. Tan sólo se hallaron aproximaciones parciales a cada fábrica desde el punto de vista socioeconómico e histórico -a través de los distintos estudios de los archivos de las fábricas llevados a cabo por historiadores al cierre de las mismas- y sociológico -a través de la investigación sobre el asociacionismo y la casuística de la cigarrera como trabajadora-.

Ni siquiera los estudios parciales sobre las fábricas más destacadas en términos arquitectónicos planteaban la comparación de características entre las mismas. Era evidente la relevancia de determinados ejemplos en la historia de la arquitectura en España como la Real Fábrica de Tabacos de Sevilla, así como la importancia de otras muchas en la preocupación por la recuperación del patrimonio industrial urbano como la Fábrica de Tabacos de Madrid o la Fábrica de Tabacos de San Sebastián, objeto en tiempos recientes de interesantes debates sobre su reutilización como espacios abandonados de la ciudad. En este sentido, contaba con un extenso compendio de antecedentes que nutrían un estado de la cuestión sobre el que poder arrojar una nueva visión que interpretase la arquitectura de las fábricas de tabacos en España de un modo integral, desde la visión holística propia del estudio del patrimonio integrado por los vestigios materiales de la cultura 
industrial.

A la luz de las consideraciones anteriores, se abrió ante mí un nicho de oportunidad para ahondar en el tratamiento de la arquitectura fabril tabacalera peninsular desde una aproximación transversal al conjunto de fábricas de tabacos centenarias que actualmente ocupan una posición destacada como patrimonio industrial inserto en el tejido urbano consolidado. Me propuse, entonces, conocer de forma profunda y sistemática todo el catálogo de casos estudio de las fábricas tabacaleras peninsulares y comenzar un análisis pormenorizado de todas ellas que me permitiese un acercamiento a su realidad como arquitectura industrial de forma precisa y completa, aportando un enfoque novedoso e inédito a dicha cuestión.

De esta forma, la investigación propuesta daría respuesta a los interrogantes que me había formulado y de los que no encontraba ningún estudio que aportase una resolución satisfactoria. En definitiva, se trataba de desentrañar el misterio que rodeaba a aquella fábrica gijonesa que había despertado mi curiosidad inicial, profundizando en las claves que podrían dar explicación a un posible tipo de arquitectura fabril tabacalera en España.

\subsection{Justificación y relevancia de la investigación}

La originalidad y aporte de conocimiento de este trabajo radica en que, si bien muchos de los estudios que existen actualmente sobre las fábricas de tabacos en España aluden a aspectos históricos, económicos y sociológicos, la presente investigación se centra en un estudio comparativo que profundice sobre las características espaciales y arquitectónicas de la producción tabacalera, constituyendo un nuevo enfoque al citado tema. Desde una visión holística del hecho espacial tabacalero, la investigación se basa en su interpretación proyectual y espacial-productiva como arquitectura industrial y en la evolución de estos espacios paralela a los cambios de la producción con el tiempo, así como la influencia de la presencia femenina como colectivo trabajador.

A este objeto, se consideraba necesario abordar una investigación que constituyese un estudio profundo de las características arquitectónicas del espacio tabacalero -en su concepción como proyecto de nueva planta o en su incursión en un edificio preexistente-. A través de este estudio analítico y multidimensional que abarca los distintos campos de interés del conjunto de fábricas tabacaleras peninsulares, se profundiza en las características comunes o invariantes arquitectónicos de una posible tipología tabacalera, estableciendo incluso similitudes a través de su comparación con conjuntos tabacaleros de otros ámbitos geográficos, como los monopolios del tabaco de Francia e Italia o las primeras fundaciones reales fabriles coloniales. Mediante su estudio comparativo, se arroja una nueva mirada sobre el conjunto de fábricas tabacaleras peninsulares que permite establecer nuevas conexiones e interpretar cada caso singular desde un nuevo punto de vista integral, desentrañando la formalización particular de su arquitectura a través de una explicación general más amplia y compleja. 
Por otra parte, pese a la importancia que en su día tuvieron estas fábricas tanto en su contexto local como en el territorial, se observa que, exceptuando a los historiadores que se habían acercado de forma profunda a la historia del monopolio hacendístico del tabaco, pocos arquitectos eran conscientes de la casuística de las fábricas de tabacos en España y de sus conexiones mutuas, afirmando en muchos casos que tal relación no existía. Este trabajo muestra un especial interés en la concepción y evolución proyectual de estas arquitecturas fabriles de origen manufacturero, en las que prima en gran medida la influencia de la mano de obra femenina y en las que el espacio cobra significado por el tipo de producción existente en el mismo, caracterizándolo y transformándolo a través del discurso industrial de sus tareas. De igual forma, estos inmuebles se ven constantemente abocados a la obsolescencia debido a la rigidez de su esquema original y al numeroso aforo de cigarreras, junto a la complejización progresiva de la producción con la introducción de la mecanización.

Esta investigación, así mismo, contribuye a la suma de conocimiento al creciente interés actual en el estudio, conservación y difusión del patrimonio industrial que, si bien cuenta desde los últimos años con instrumentos para su puesta en valor -como el Plan Nacional de Patrimonio Industrial en España o la Carta de Nizhny Tagil en el ámbito internacional- se encuentra relegado a una posición inferior en importancia social y administrativa frente a otros tipos de patrimonio, quizás precisamente por su desconocimiento. A la falta de concienciación en la sociedad, se le suma el hecho de que es un patrimonio muy abundante, del que se deben seleccionar los conjuntos más representativos y que, al mismo tiempo, se caracteriza por una fragilidad propia de la obsolescencia y abandono a los que se ve abocado por la rápida evolución de los procesos industriales. Por tanto, la relevancia del objeto de la investigación se justifica por la contribución de este trabajo a la puesta en valor de unos conjuntos arquitectónicos que, por su ubicación urbana, en numerosas ocasiones se encuentran sometidos a grandes presiones urbanísticas que amenazan su integridad -lamentablemente, ya descontextualizados en algunos casos-, viéndose en la obligación de acometer una rehabilitación con un nuevo uso para su conservación.

De la conservación de los vestigios fabriles tabacaleros depende en buena medida la permanencia en la memoria colectiva de esta actividad. En la presente investigación se defiende que esto es posible a través de la correcta preservación de los valores arquitectónicoespaciales de dichas fábricas, actuales depositarias de los valores histórico-culturales de este patrimonio importante para la comprensión de nuestro pasado reciente. A través del estudio minucioso de los elementos arquitectónicos que confieren a estos vestigios su identidad como patrimonio industrial tabacalero es posible la extracción de pautas para una correcta intervención sobre los mismos en una futura reutilización. Dada su localización urbana, el abandono de muchos de ellos y su titularidad pública, constituyen espacios de oportunidad para acometer proyectos que den servicio a la sociedad. 


\subsection{Marco contextual, hipótesis y objetivos de la investigación}

Tomando como modelo la tipología manufacturera francesa, las reales fábricas españolas comenzaron a instaurarse por toda la geografía peninsular como industrias creadoras de un producto cuya renta resultaba muy beneficiosa para la Corona. En el caso de la producción del tabaco, las fábricas tabacaleras dieron lugar a una realidad laboral muy especial centrada en la figura femenina que realizaba la práctica totalidad de las labores. La concepción de las primeras manufacturas supuso un ensayo de soluciones arquitectónicas para la definición de un tipo fabril. De esta forma, se constituyó la sistematización de contenedores que albergarían a las trabajadoras y que, debido a los diversos cambios que experimentaría la industria a partir del S. XIX, adaptarían su estructura edilicia -inicialmente pensada para el obreroa las nuevas condiciones establecidas por la presencia de la máquina.

Las fábricas de tabacos en España constituyen un ejemplo especial de patrimonio industrial debido a las circunstancias particulares de su constitución, a la elección urbana de su ubicación y a su carácter eminentemente manufacturero. La producción tabacalera en España surge a raíz de la constitución en el S.XVII del monopolio hacendístico sobre la producción y comercio del tabaco, ostentado por la Corona a partir del S.XVIII. La incipiente industria, iniciada con la importación del producto colonial, se consolidó definitivamente reportando beneficios directos a las arcas reales a través de la gravación de impuestos sobre el tabaco como producto suntuario. El aumento de su consumo entre la población, junto a los ingentes gastos del Estado con la sucesión de conflictos bélicos durante el S.XIX y los esfuerzos por combatir el pernicioso contrabando, provocó la expansión periódica de establecimientos tabacaleros en la península, en una serie de generaciones de factorías, desde la pionera de Sevilla del S.XVIII, hasta las más tardías de Tarragona y Málaga del primer tercio del S.XX. Con la privatización del sector a finales del S.XX y la creación de Altadis, se procedió al cierre de todas aquellas fábricas centenarias remanentes que constituían una rémora para la producción, dejando en el paisaje urbano valiosos vestigios patrimoniales de la industria tabacalera en espera de una reutilización.

A la luz de estas consideraciones, se comienzan a plantear las hipótesis que guiarían la investigación centrando las siguientes cuestiones:

- Las posibles conexiones entre los casos estudio que conforman el conjunto de fábricas de tabacos en España desde un enfoque arquitectónico y patrimonial.

- La existencia de un tipo o patrón proyectual al que todas obedecieran.

De esta forma, fijado el marco contextual de la presente investigación, los objetivos principales de la tesis se centran en:

- El estudio comparativo de las distintas arquitecturas fabriles de la industria tabacalera surgidas en España a consecuencia de la importación de este producto desde las colonias americanas. 
- La profundización en la realidad arquitectónica que engloba un proceso de producción determinado, como es el del tabaco, históricamente asociado a la figura de la mujer, y que supone el hilo conductor de las diversas arquitecturas destinadas a la función tabacalera.

- El establecimiento de los invariantes de un tipo fabril tabacalero característico en su formalización arquitectónica.

Por tanto, se trata de confirmar la existencia de una tipología de fábrica de tabacos en España a través del análisis argumentado de todos los casos estudio existentes en España, basándose para ello en la búsqueda de una relación espacial y arquitectónica común a las mismas desde un enfoque de interés patrimonial. De esta forma, a través de un análisis comparativo multidimensional -atendiendo a diversos niveles o capas de información como son el contexto territorial, urbano, espacial-productivo y humano- de la fábrica tabacalera como hecho espacial, se establece una interpretación arquitectónica desde una visión holística del proceso de producción tabacalero.

De las hipótesis y los objetivos principales de la investigación se escinden otras cuestiones colaterales de capital importancia para el establecimiento de una argumentación coherente y completa que abarque todas peculiaridades e implicaciones sobre una investigación de estas características. De esta forma, se establece una doble lectura que atiende, por una parte, a los aspectos proyectuales de las fábricas de tabacos en España como proceso arquitectónico, y por otra, a la lectura del espacio productivo como hilo conductor de las arquitecturas a través del programa de necesidades específico del proceso industrial tabacalero.

En este sentido, respecto a la primera interpretación surgieron cuestiones como la existencia de invariantes arquitectónicos comunes a todas las fábricas y su relación con el entorno circundante en su implantación como nuevo elemento urbano. En cuanto a la segunda lectura, resulta de interés la búsqueda de un posible patrón espacial en la distribución de los espacios productivos por su ubicación relativa o las condiciones del espacio -orientación, ventilación, iluminación, aforo, localización en función de la zonificación establecida, etc.- Todas estas consideraciones han de ser interpretadas, necesariamente, desde la posible influencia de la presencia femenina como principal mano de obra de esta industria y sus particulares requerimientos espaciales.

De igual forma, la longevidad de esta industria y la permanencia en activo de sus inmuebles fabriles hasta las postrimerías del S.XX obliga a una interpretación más compleja que debe abordar, no sólo la definición de los elementos que caracterizan a estas arquitecturas fabriles, sino la evolución de las mismas a lo largo del tiempo con la transformación del espacio productivo a través de los cambios experimentados a lo largo de la historia del monopolio hacendístico del tabaco, desde la manufactura hasta la mecanización total de las fases productivas. 
1.4 Delimitación del ámbito de la investigación y propuesta de análisis: metodología y material de estudio

Dado el ambicioso plan de trabajo acorde a la complejidad del tema propuesto, se comienza la investigación elaborando un estado de la cuestión lo más completo posible. Esta primera profundización sobre los materiales de estudio ya publicados atiende, no sólo al ámbito peninsular, sino también a otros casos similares en el ámbito internacional -Latinoamérica, Italia y Francia, fundamentalmente.- Así mismo, son objeto de consideración para una revisión crítica temas de interés como la casuística general de las fábricas manufactureras, el espacio del trabajo en los primeros tiempos industriales, la arquitectura, arqueología y el patrimonio industrial, la historia del monopolio hacendístico del tabaco en España y sus métodos de producción o los estudios sociológicos realizados sobre la figura de la cigarrera.

La variada casuística de las fábricas tabacaleras en España y la especial relación de estas arquitecturas con su proceso de producción, caracterizan una serie de campos de interés considerados en la definición de las hipótesis que plantea la presente investigación. Estas dimensiones o campos de interés surgen de una selección de los aspectos particulares a tratar en esta nueva visión holística del estudio comparativo de las fábricas de tabacos en España que a modo de acercamiento progresivo escalar configuran diversos niveles de lectura. De esta forma, estas dimensiones no sólo estructuran una aproximación completa a cada caso de estudio, sino que ayudan a configurar el análisis para la extracción de características comunes a las distintas fábricas en los diversos niveles de lectura: territorial, urbano, arquitectónico, productivo-espacial, humano y patrimonial.

\section{Delimitación del ámbito de la investigación}

Se ha observado que los resultados arrojados por el análisis llevado a cabo en la presente investigación responden a la casuística de las fábricas tabacaleras fundadas o construidas entre mediados del S.XVIII y principios del S.XX, correspondientes a la época de la gestión directa de la Renta de Tabacos por parte de la Corona -y posteriormente del Estado- en 1731, y a la cesión del arriendo sobre el monopolio a la Compañía Arrendataria de Tabacos entre 1887 y 1945. En todas las fundaciones fabriles del periodo acotado se observa su correspondencia en términos arquitectónicos con la evolución de un modelo de espacio productivo manufacturero a una incipiente mecanización que desembocaría en la casi total automatización de las fases que integran el proceso productivo a finales del S.XX. Las fábricas construidas a partir de la cesión del arriendo a Tabacalera en 1945, no compartirían los mismos invariantes observados, ni en la significación de la arquitectura ni en la relación del edificio con la ciudad, y las premisas proyectuales de partida serán de diversa índole.

En una primera aproximación al objeto de estudio, se constató que la realidad tratada era muy compleja. A la propia historia del monopolio hacendístico del tabaco en España y a las circunstancias particulares de 
la historia intrínseca de cada fábrica, se superponía una lógica general que explicaba la posible evolución de los conjuntos fabriles tabacaleros. Por una parte, históricamente y de acuerdo con la evolución y expansión territorial del monopolio, se podía deducir que las fundaciones fabriles tabacaleras en España respondían a una serie de generaciones de fábricas que comenzaban con el proyecto de la Real Fábrica de Tabacos de Sevilla y la fundación de la Fábrica de Tabacos de Cádiz en el S.XVIII y que continuaba a lo largo del S.XIX en otras tres generaciones que correspondían aproximadamente a cada tercio del siglo, finalizando en la tercera década del S.XX con dos fábricas tardías establecidas en Tarragona y Málaga.

De esta forma, los casos estudio resultantes en el ámbito peninsular se han catalogado según su pertenencia a las generaciones en que se encuadran las fundaciones de las distintas fábricas de tabacos en España, y que respondían a los sucesivos periodos de expansión territorial de la producción a iniciativa de la Renta del Tabaco:

- Primeras fábricas (mediados del S.XVIII): Sevilla y Cádiz.

- Primera generación del S.XIX (primer tercio del S.XIX): Alicante, La Coruña y Madrid.

- Segunda generación del S.XIX (mediados del S.XIX): Santander, Gijón y Valencia.

- Tercera generación del S.XIX (finales del S.XIX): Bilbao, San Sebastián y Logroño. De estas tres, se excluye del análisis específico el caso de Bilbao por su corto periodo de funcionamiento y la inexistencia de vestigios patrimoniales.

- Tardías del S.XX (primer tercio del S.XX): Tarragona y Málaga. De estos dos casos, la fábrica de Tarragona revierte mayor interés puesto que la fábrica malagueña fue construida con arreglo al proyecto de la fábrica catalana y no funcionó como conjunto productivo tabacalero hasta la década de los años setenta.

Tras estas consideraciones, cabe explicar de forma detallada los criterios seguidos para la selección de los casos estudio más representativos de los analizados en la presente investigación. Para ello se debe aclarar que las arquitecturas estudiadas no siempre responden al inmueble original en el que se fundaron las fábricas de tabacos en España. Pese a la apertura seriada de establecimientos tabacaleros en la sucesión de generaciones de fábricas entre mediados del S.XVIII y principios del S.XX, frecuentemente la actividad manufacturera no permanecía en el edificio provisional al que se destinaba en un primer momento, sino que se trasladaba a otro inmueble preexistente que contase con cualidades más aptas para la industria tabacalera o se construía un inmueble de nueva planta ex profeso cuando el estado financiero de la Renta de Tabacos lo permitía, muchas veces con la concurrencia de recursos del propio ayuntamiento de la localidad que acogía la actividad fabril. De esta forma, la arquitectura de muchos de los inmuebles analizados no se corresponde con el momento histórico de su fundación fabril, sino con una etapa posterior en el proceso evolutivo de la industria del tabaco. En este sentido, muchos de los casos significativos para la resolución de las incógnitas planteadas no se corresponden, pues, con el edificio 
original en el que se fundó la fábrica en cuestión, sino con un proyecto posterior, de forma que los ejemplos aportados suponen cortes temporales representativos del proceso evolutivo histórico de la fabricación tabacalera en España materializados en el inmueble analizado.

Por otra parte, no se debe olvidar que este denominador común que es la producción tabacalera, pese a la especialización de labores en cada fábrica, tiene un desarrollo similar en todas ellas y su devenir dependía en gran medida de las directrices generales de la sede central, debido a la situación monopolística. Esto podría afectar a unas características comunes de formalización en las distintas arquitecturas, respecto a la circulación de producto, de trabajadoras, orientación óptima para el desarrollo de las labores, etc. Incluso hay que pensar que estas directrices de la sede central conformaban reglamentos orgánicos que habían de ser cumplidos por todas las fábricas en conjunto y que afectaban a los modos de producción y al propio personal; sin olvidar los sucesivos planes de modernización que se dieron a lo largo del S.XX y que reconfiguraron los espacios para albergar una progresiva mecanización.

\section{Metodología}

El método de trabajo para abordar el desarrollo organizado de la presente investigación responde a los siguientes hitos:

Fase preliminar

- Elaboración del estado de la cuestión.

- Documentación de la investigación en archivos.

- Trabajo de campo en los conjuntos fabriles seleccionados.

- Entrevistas a expertos en la temática y a antiguos trabajadores.

- Sistematización de la información recogida en fichas estructuradas en campos de interés para el enfoque arquitectónico y patrimonial.

Fase de profundización

- Presentación de la información en las dimensiones de interés patrimonial de cada caso estudio: historia, contexto territorial, contexto urbano, arquitectura, espacio productivo y dimensión humana.

- Comparación entre los diversos casos estudio analizando de forma transversal cada uno de los campos de interés anteriores.

$\underline{\text { Fase de análisis }}$

Análisis pormenorizado sobre la selección de casos estudio correspondientes a proyectos de nueva planta atendiendo a su condición de:

- Tipo fabril e invariantes arquitectónicos que lo caracterizan.

- Proceso proyectual en la construcción de su imagen arquitectónica.

- Unidades de un sistema monopolístico aplicado en otros países. 
- Patrimonio industrial a salvaguardar y potencialmente reutilizable.

Por tanto, la metodología a emplear para resolución de las incógnitas consiste en el estudio sistemático de los casos estudio elegidos, tanto en la consulta de fuentes primarias a través de los propios archivos de las fábricas -así como de los archivos histórico-provinciales y municipales de las ciudades en las que se localizan las mismas-, la visita documental de los propios edificios y la profundización en el conocimiento del tema a través de las fuentes secundarias integradas por la numerosa bibliografía de distinta índole sobre la historia del monopolio hacendístico del tabaco en España y de las fábricas de tabacos objeto de esta investigación. Paralelamente, se realizan entrevistas a diversos expertos en la materia -documentalistas, historiadores, arquitectos, arqueólogos, antiguos trabajadores- que de alguna forma han estado vinculados personalmente a cada caso estudio y que han aportado datos fundamentales para el entendimiento del objeto de investigación y su enfoque final.

A través de la sistematización de la información recogida en una ficha creada ex profeso para los casos estudio analizados y estructurada según campos de interés objetivables, se instrumentalizan los datos de forma que puedan ser comparables entre sí para poder arrojar conclusiones sobre los interrogantes planteados. Desde un primer momento, esta ficha se convertiría en una herramienta de catalogación y de identificación de todos los campos de interés de las fábricas de tabacos en España al objeto de esta investigación, que comenzarían a orientar la estructura del cuerpo de la tesis y de las conclusiones obtenidas atendiendo a las implicaciones de las características de las fábricas tabacaleras en cuanto a su evolución histórica y las dimensiones que configuran su interpretación -territorial, urbana, arquitectónica, espacial-productiva, humana y patrimonial, como se ha citado anteriormente-.

El cruce de datos obtenidos en la investigación sobre los diversos casos estudio arroja los resultados que se persiguen con el desarrollo de esta tesis. A través de este análisis comparativo general se extraen claves y argumentos que permiten una relectura transversal del conjunto de fábricas de tabacos peninsulares y una posterior investigación monográfica más profunda sobre cada caso estudio que remita a esta visión general y completa.

Por otra parte, una revisión crítica de las intervenciones efectuadas hasta el momento en este tipo de edificios patrimoniales, unida a los resultados obtenidos en la presente investigación, permiten extraer conclusiones propositivas acerca de las buenas prácticas a emplear en la conservación de este tipo de patrimonio industrial. Por medio de la presente investigación se combinan el estudio del patrimonio arquitectónico industrial tabacalero y la significación de la memoria del trabajo, ya que la interpretación arquitectónica y espacial-productiva de las fábricas de tabacos es indisoluble al tratamiento de estas cuestiones de índole humanística o social. 


\section{HISTORIOGRAFÍA: PATRIMONIO INDUSTRIAL, INICIOS DE LA ARQUITECTURA INDUSTRIAL Y EL ESTUDIO DE LAS FÁBRICAS DE TABACOS EN ESPAÑA}

2.1. Sobre cuestiones generales de interés al objeto de la presente investigación

2.1.1. El patrimonio, la arquitectura y la arqueología industrial: bases para un corpus teórico. Criterios y buenas prácticas para la conservación del patrimonio industrial

2.1.2. La arquitectura industrial y el espacio del trabajo: manufacturas y primeros conjuntos fabriles

2.1.3. La fábrica como tipo en la historia de la arquitectura y su presencia en la tratadística

2.2. Aproximación a las fábricas de tabacos en España: contexto histórico, económico y social

2.2.1. El monopolio hacendístico del tabaco en España y su contexto histórico

2.2.2. El proceso productivo del tabaco en España

2.2.3. Las cigarreras y el espacio fabril: condiciones laborales, identidad colectiva y significación en su entorno

2.2.4. Las fábricas de tabacos en España: los conjuntos fabriles del monopolio peninsular

2.2.5. Las fábricas de tabacos a nivel mundial: dos monopolios europeos y antiguos territorios coloniales

El tratamiento del amplio estado de la cuestión atiende a los diversos campos de interés relacionados con la presente investigación, pudiéndose distinguir entre temas generales y temas específicos que ayuden a encuadrar la complejidad y las diversas implicaciones de los interrogantes planteados. Entre los temas generales se encuentran cuestiones relativas a los modelos y tipologías arquitectónicas en la historia de la arquitectura, a cuestiones metodológicas sobre la disciplina de la arqueología industrial y la conservación del patrimonio industrial, así como la arquitectura industrial y particularmente las manufacturas en la materialización arquitectónica del espacio del trabajo. De esta forma, se abordan todos los temas que definen el contexto general en el que se encuadra la presente investigación.

El estado de la cuestión sobre los temas específicos ayuda a una profunda toma de contacto con el contexto particular de las fábricas de tabacos. De esta forma, se adquieren los conocimientos concretos para abordar la investigación en toda su complejidad. Las materias específicas sobre las que se han profundizado son la historia del monopolio hacendístico del tabaco, desde su enfoque socioeconómico y la historia y evolución del proceso productivo tabacalero; los numerosos estudios sociológicos sobre la figura de la obrera femenina en el caso particular de las cigarreras; y las fábricas de tabacos, tanto a nivel mundial con una atención especial al caso francés e italiano por su proximidad geográfica y su gestión a través de un monopolio hacendístico, como en el caso español, para elaborar un catálogo preciso de los casos estudio a tratar en la investigación, adelantando los 
criterios de selección de los ejemplos más representativos para el posterior análisis.

Por tanto, las labores previas de profundización sobre el estado de la cuestión, han permitido adquirir un conocimiento sobre cuestiones vertebrales que permitan contextualizar el objeto de estudio de la presente investigación:

- Contexto metodológico: sobre el concepto de patrimonio industrial, de arquitectura industrial y de arqueología industrial y sus implicaciones en la presente investigación. Historia de los tipos arquitectónicos y la fábrica como objeto de los tratados de arquitectura en su lectura como proyecto arquitectónico.

- Contexto socioeconómico y político: cuestiones socioeconómicas en torno al proceso de producción del tabaco y su evolución, su historia y orígenes. El monopolio fiscal y el Estanco del Tabaco, y la red de circulaciones de la materia prima y el producto acabado.

- Contexto histórico-social y productivo: el espacio del trabajo y condiciones de los trabajadores, la presencia de la fábrica y su influencia en la ciudad y las necesidades espaciales de la producción y de las trabajadoras.

- Contexto arquitectónico: sobre las arquitecturas de la producción manufacturera, las reales fábricas y sus conexiones con el objeto de estudio. Influencia de las premisas venidas del despotismo ilustrado francés y referentes tomados de otros tipos arquitectónicos. Elaboración de un censo de tabacaleras españolas y extranjeras y características arquitectónicas de las mismas, así como estudio del espacio de trabajo y su transformación con la evolución técnica.

\subsection{Sobre cuestiones generales de interés al objeto de la presente investigación}

\subsubsection{El patrimonio, la arquitectura y la arqueología industrial: bases para un corpus teórico. Criterios y buenas prácticas para la conservación del patrimonio industrial}

Para comprender el ámbito en el que se inserta la presente investigación, es interesante ahondar sobre cuestiones concernientes a su conceptualización como patrimonio y a las herramientas metodológicas para el estudio, puesta en valor y conservación del mismo. No en vano, en los últimos tiempos existe un especial interés por el estudio del patrimonio industrial en el seno del ámbito académico que ha dado lugar a una amplia producción científica en torno a este tema ${ }^{1}$.

\footnotetext{
1 Sin ahondar en la cuestión, se quieren resaltar algunas tesis desarrolladas en el ámbito universitario español sobre el conocimiento del patrimonio industrial, en materia de valorización y conservación del mismo, entre ellas MARRODÁN CIOCARDIA, E. (2005) Lugares en espera. Industria y ciudad contemporánea, Universidad de Navarra; MOLINA SÁNCHEZ, J. (2016) Patrimonio industrial hidráulico. Paisaje, arquitectura y construcción en las presas y centrales hidroeléctricas españolas del Siglo XX. Universidad Politécnica de Madrid; MURIEL RAMÍREZ, M. (2011) Patrimonio industrial y Economía de la Cultura. Los Ferrocarriles turísticos británicos y el caso andaluz, Universidad de Sevilla; PALAZÓN BOTELLA, M. D. (2011) De la arquitectura al patrimonio industrial en la Región de Murcia, Universidad de Murcia; PÉREZ MOLINA, R. I. (2011) La protección del
} 
Existe una cierta indefinición en cuanto al concepto de patrimonio industrial, confundiendo habitualmente dicho término con la arqueología industrial y la arquitectura industrial. De esta forma, el patrimonio industrial serían aquellos vestigios materiales e inmateriales producidos por la cultura industrial sujetos a una valorización por parte del conjunto de la sociedad por sus cualidades histórico-culturales, no debiendo confundirlo con el estudio arqueológico de las huellas materiales de la sociedad de trabajo o aquellas construcciones que surgen a lo largo de la historia para dar cabida a una actividad de carácter industrial en sus múltiples manifestaciones, desde las primeras construcciones preindustriales y manufactureras hasta los tipos fabriles concebidos desde la lógica de los materiales que surgieron con la industrialización como el acero y los productos estandarizados.

Es por ello que uno de los objetivos del Plan Nacional de Patrimonio Industrial, del que se hablará más adelante, consistía en superar este escollo mediante la redacción de una precisa definición del patrimonio industrial:

se entiende por patrimonio industrial el conjunto de los bienes muebles, inmuebles y sistemas de sociabilidad relacionados con la cultura del trabajo que han sido generados por las actividades de extracción, de transformación, de transporte, de distribución y gestión generadas por el sistema económico surgido de la «revolución industrial». Estos bienes se deben entender como un todo integral compuesto por el paisaje en el que se insertan, las relaciones industriales en que se estructuran, las arquitecturas que los caracterizan, las técnicas utilizadas en sus procedimientos, los archivos generados durante su actividad y sus prácticas de carácter simbólico ${ }^{2}$,

de lo que se deduce que bienes industriales serán aquellos elementos y conjuntos que componen el patrimonio industrial y que se pueden clasificar en paisajes, conjuntos, bienes inmuebles, bienes muebles y patrimonio inmaterial.

En el año 2001 Inmaculada Aguilar Civera publicó un artículo en el que hacía una revisión crítica de las obras españolas concernientes a la arquitectura industrial según su significado y concepto. Remarcando el diverso carácter que presentan los tipos de edificios que se denominan como arquitectura industrial, se define como aquella arquitectura que tiene una finalidad industrial, de explotación y expresión de la actividad comercial y que tiene su fundamento en las necesidades socioeconómicas propias del sistema capitalista. Por tanto, y en la línea de las cuestiones que ocupan a la presente investigación

patrimonio industrial en Andalucía: el caso del patrimonio industrial en Granada, Universidad de Sevilla; RÍOS DÍAZ, C. (2007) Arquitectura industrial y posible reutilización, Universidad de Oviedo; SÁNCHEZ MUSTIELES, D. (2013) Metodología para la recuperación y puesta en valor del patrimonio industrial arquitectónico. Antiguas fábricas del Grao de Valencia, Universitat Politècnica de València; SUÁREZ ANTUÑA, F. (2004) La organización de los espacios hulleros asturianos: paisaje y patrimonio industrial, Universidad de Oviedo.

2 "Definición, categorías y ámbito de aplicación” en VV. AA. (2011a) Plan Nacional de Patrimonio Industrial, Madrid: IPCE, p. 9. 

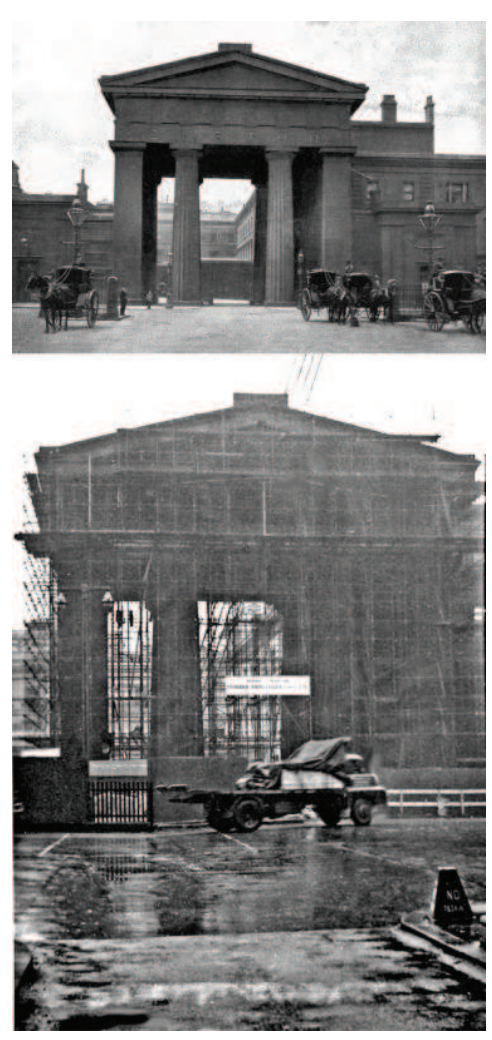

Figura 2.1. Estación de Euston en 1896, en Wikimedia commons; y demolición de 1962,

Ben Brooksbank, Wikimedia commons. todos aquellos edificios construidos o adaptados a la producción industrial cualquiera que sea o fuese su rama de producción [...] así como todo lo referido a la extracción de materias primas. A su vez, la arquitectura Industrial no es sólo la arquitectura de edificios de uso genuinamente industrial, sino también la de aquellos edificios que son concebidos con unos modelos de pensamiento y praxis derivados de los paradigmas de la era mecánica ${ }^{3}$.

De esta forma, dentro del concepto de arquitectura industrial no sólo se incluyen los edificios fabriles, sino también las reutilizaciones de otros a tal fin, las infraestructuras, obra pública y construcciones auxiliares que se derivan de la actividad industrial, así como los equipamientos y edificios habitacionales para los obreros. Se trata, por tanto, de contemplar todas las manifestaciones arquitectónicas e infraestructuras sobre el territorio que tengan que ver con las funciones productivas, distributivas y de consumo ${ }^{4}$.

La concienciación sobre la defensa y conservación de los restos de valor histórico-cultural dejados por la actividad industrial tomó cuerpo a raíz de las protestas de la sociedad londinense ante la inminente demolición de la Estación de Ferrocarril de Euston en 1962. Sin embargo, la consideración del patrimonio industrial como tal y el desarrollo académico de un corpus teórico para el estudio y conservación del mismo, ha tenido un largo recorrido en un debate que se prolonga hasta nuestros días. Desde las primeras propuestas inglesas de una metodología para el desarrollo de la arqueología industrial en los años 60, hasta las revisiones francesas e italianas de los años 80, o las españolas de los años $90 \mathrm{y}$ del presente siglo ${ }^{5}$, se han dado una serie de debates en el seno del ámbito académico sobre el concepto de patrimonio industrial, los criterios para su conservación y su

\footnotetext{
${ }^{3}$ AGUILAR CIVERA, I. (2001) "La investigación sobre el patrimonio industrial. Una revisión bibliográfica" en Tst: Transportes, Servicios y Telecomunicaciones, ${ }^{\circ} 1$, p. 176.

${ }^{4}$ Es importante citar la obra de otros autores sobre la arquitectura industrial, bien de forma general o centrada en una región concreta, como CORREDOR-MATHEOS, J. y MONTANER, J. M. (1984) Arquitectura Industrial en Cataluña. Del 1732 al 1929, Barcelona: C.G. Creaciones Gráficas-Caja de Barcelona; HELGUERA QUIJADA, J. (1990) "Las empresas industriales del estado en la España del siglo XVIII: tipología y evolución de las «reales fábricas»" en L’impresa, industria comercio baca, Prato, Datini; y SEBASTIÀ TALAVERA, J. (2007) "La fábrica: el espacio del trabajo. Un palacio para trabajar: las Reales Fábricas" en La belleza industrial. Historia de la fábrica y su estética, Fundación Bancaja, pp. 33-65.

${ }^{5}$ Entre las numerosas obras existentes sobre la arqueología industrial como instrumento metodológico cabe destacar ÁLVAREZ ARECES, M.A. (2007) Arqueología Industrial. El Pasado Por Venir, Gijón: CICEES-INCUNA; CANDELA SOTO, P.; LÓPEZ GARCÍA, M. y CASTILLO ALONSO, J.J. (2002) Arqueología industrial y memoria del trabajo: el patrimonio industrial del sudeste madrileño, 1905-1950, Aranjuez: Doce Calles; CASADO GALVÁN, I. (2009) "La arqueología industrial: una investigación multidisciplinar" en Contribuciones a las Ciencias Sociales, $\mathrm{n}^{\circ}$ 6, Diciembre 2009. www.eumed.net/rev/cccss/06/icg18.htm [acceso el 3-5-2013]; CASTELLANO, A. (1982) La machina arruginita. Materiali per un'archeologia dell'industria, Milano; CERDÀ ANTÓN, M. (2008) Arqueología industrial. Teoría y práctica, Valencia: Universitat de València; DAUMAS, M. (1980) L'archéologie industrielle en France, Paris, Robert Laffont; FLORIDO CASTRO, A. (1999) Arqueología industrial en Las Palmas de Gran Canaria durante la Restauración (1869-1931), Cabildo Insular de Gran Canaria Departamento de ediciones; HOLT, E. y PERHAM, M. (1980) Industrial archaeology; London, Evans Bros; IBÁÑEZ, M.; TORRECILLA, M. J.; ZABALA, M.; (1990) Arqueología industrial en Gipuzkoa. Bilbao, Consejería de Cultura y Turismo del Gobierno VascoUniversidad de Deusto; NEGRI, A. y NEGRI, M. (1978) L'archeologia industriale, Florencia: G. D'Anna; y PALMER, M. y NEAVERSON, P. (1998) Industrial archaeology: principles and practice, London: Routledge; entre otros, así como los autores Dianne Newell y Kenneth Hudson citados frecuentemente en las obras anteriores. Cabe destacar en el ámbito español el número especial de la revista Ábaco (1998) Abaco: Revista de cultura y ciencias sociales, $\mathrm{n}^{\circ}$ 19, (Ejemplar dedicado a Arqueología industrial. Testimonios de la memoria).
} 
documentación y estudio.

La superación de esta situación pasa por la creación de un corpus teórico que dé lugar a una definición precisa de aquello que es considerado como patrimonio industrial, y el desarrollo de una metodología de estudio y conservación crítica y pluridisciplinar a través de la arqueología industrial. Dentro de la Ley de 16/85 del Patrimonio Histórico Español y en las diversas leyes autonómicas escindidas de la misma, el patrimonio industrial adolece de una escasa consideración, siendo asimilado a otros tipos de patrimonios o con otras denominaciones como patrimonio etnográfico, científico-técnico, etnológico, etc.

Sin embargo, dentro de la misma se encuentra el soporte para la creación de planes de carácter nacional como "instrumentos de gestión del Patrimonio Cultural que, partiendo del estudio de los bienes que lo integran, permiten racionalizar y optimizar los recursos destinados a su conservación y difusión, asegurando la coordinación de las actuaciones de los organismos de la Administración estatal autonómica y local"6. Volviendo sobre el caso del Plan Nacional de Patrimonio Industrial del año 20017 , nace debido a "la necesidad de protección y conservación de este tipo de bienes que, por su propia especificidad, se transforman constantemente y presentan un rápido deterioro"8. La revisión del plan de 2011 cuenta, así mismo, con el antecedente europeo de la Carta de Nizhny Tagil sobre el Patrimonio industrial de 2003 elaborada por el Comité Internacional para la Conservación del Patrimonio Industrial $(\mathrm{TICCIH})^{9}$ que reseña los valores del patrimonio industrial, la importancia de su catalogación, registro e investigación, la protección legal del mismo o su mantenimiento y conservación. Ambos constituyen una base intelectual consensuada para la caracterización de buenas prácticas que configuren una metodología de trabajo en la preservación de los bienes industriales.

Todos los esfuerzos de definición de este tipo de patrimonio y la disposición de instrumentos para su estudio y catalogación, se encaminan a un fin primordial que es su conocimiento, difusión y conservación. Sin embargo, dadas las peculiaridades de los bienes industriales y su gran extensión material, resulta pertinente hacer referencia al debate generado en torno a su conservación.

\footnotetext{
${ }^{6}$ Definición de los Planes Nacionales en http://ipce.mcu.es/conservacion/planesnacionales.html [acceso el 6-4-2013]. En el marco normativo de referencia del Plan Nacional de Patrimonio Industrial (2011) se especifica que "en su artículo treinta y cinco, la Ley de Patrimonio Histórico declara que «para la protección de los bienes integrantes del Patrimonio Histórico Español y al objeto de facilitar el acceso de los ciudadanos a los mismos, fomentar la comunicación entre los diferentes servicios y promover la información necesaria para el desarrollo de la investigación científica y técnica se formularán periódicamente Planes Nacionales de Información sobre el Patrimonio Histórico Español», y atribuye al Consejo de Patrimonio Histórico Español la competencia para elaborar y aprobar dichos planes". VV. AA. (2011a) op. cit., p. 8.

${ }^{7}$ Actualmente, existe una revisión del mismo que data de marzo de 2011.

${ }^{8}$ Es interesante la consulta de VV. AA. (2007) Bienes Culturales. Revista del Instituto de Patrimonio Histórico Español. El Plan Nacional de Patrimonio Industrial, ${ }^{\circ}$ 7, en la que participan distintas autoridades involucradas en la redacción del plan y en la conservación del patrimonio industrial como Alberto Humanes, Linarejos Cruz, Inmaculada Aguilar o Esperanza Marrodán.

9 Cabe destacar entre la labor científica y de difusión de la sección española de TICCIH la publicación BIEL IBÁÑEZ, M. P. y CUETO ALONSO, G. J. (coord.) (2011) 100 elementos del Patrimonio Industrial en España, Gijón: CICEES.
} 


\section{La vulnerabilidad del patrimonio industrial}

Desde mediados del S.XX, asistimos a una ampliación del marco epistemológico sobre el concepto de patrimonio que traspasa el umbral histórico marcado por la revolución industrial y que tiene en consideración los vestigios materiales e inmateriales heredados de la industrialización capitalista. Los bienes objeto de estudio de esta época pasan a ser valorados con la categoría de patrimonio industrial que, por su carácter científico-técnico y didáctico, constituye un tipo distinto respecto a otros bienes culturales, además de su pertenencia a un pasado reciente. La abundancia de vestigios de la cultura industrial desde el S.XVIII hasta nuestros días, unida a la necesidad de establecer un criterio de conservación de los mismos, conlleva a una ingente labor de estudio para seleccionar los más representativos.

Una de las aportaciones sobre esta cuestión que arroja luz sobre la principal problemática que presenta la adopción de un criterio para la conservación del patrimonio industrial es la de la autora francesa Françoise Choay ${ }^{10}$ :

[Sobre la expansión del campo cronológico de la arqueología] Las fronteras de su dominio han franqueado en particular los límites de la era industrial que parecían infranqueables y se desplazan hacia un pasado cada vez más próximo del presente. Así, los productos técnicos de la industria han adquirido los mismos privilegios y los mismos derechos de conservación que las obras de arte arquitectónicas y que las pacientes realizaciones de los artesanos [...] La preocupación por conservar el patrimonio arquitectónico e industrial del siglo XX (incluyendo las últimas décadas), frecuentemente amenazado de demolición por mal estado, engendra actualmente un complejo de Noé que tiende a salvar en el arca patrimonial el conjunto exhaustivo de nuevos tipos constructivos aparecidos durante este periodo.

Por otra parte, tal y como apunta Rafael Aracil ${ }^{11}$, la fragilidad de este patrimonio se explica a través de la obsolescencia de las fábricas, que asumen la condición de caducidad de los propios productos que elaboran. El patrimonio industrial se ve afectado por la rápida evolución tecnológica del último siglo, sufriendo constantes modificaciones y, en ocasiones, el abandono total. La gran escala de muchos conjuntos industriales y su ubicación en áreas urbanas sometidas a presión urbanística, aceleran el proceso de degradación y desmantelamiento de los mismos a favor de nuevos usos del terreno,

10 CHOAY, F. (1992 [2007]) Alegoría del patrimonio, Barcelona: Gustavo Gili, especialmente el capítulo "El patrimonio histórico en la era de la industria cultural", pp. 189-219.

11 "R. Aracil intenta justificar su postura al decir que en el mismo momento en que nace un monumento industrial, es decir, una empresa, una máquina, etc., lleva asociada naturalmente su propia muerte, ya que una máquina, una empresa o una fábrica es un centro de producción, un centro por tanto extractor de la plusvalía y extractor de los beneficios. Como la técnica progresa rápidamente estos centros de producción invariablemente quedan obsoletos [...] aquí se producen materialmente cosas y productos, y estos en el momento que nacen llevan asociada su propia muerte”. AGUILAR CIVERA, I. (1999) El patrimonio arquitectónico industrial, Madrid: Cuadernos de Restauración. Cuadernos del Instituto Juan de Herrera de la Escuela de Arquitectura de Madrid, vol. VII, p. 12; haciendo referencia a la intervención del profesor Rafael Aracil en 1989 en las "Jornadas sobre teoría y métodos de Arqueología Industrial". Sobre Aracil se recomienda también la consulta de ARACIL, R. (1984) "La investigación en Arqueología Industrial" en I Jornadas sobre la Protección y Revalorización del Patrimonio Industrial, Bilbao: Departamento de Cultura del País Vasco. 
con la pérdida de testimonios materiales de la industrialización.

Con la crisis industrial acaecida en España en los años ochenta, muchas ciudades fueron objeto de una reconversión industrial que conllevó a su depresión económica, repercutiendo en el tejido urbano y social. Los efectos de degradación se vieron agudizados con el aumento de baldíos industriales, por lo que las administraciones locales incentivaron estrategias de regeneración mediante la creación de planes que buscaban la terciarización de la ciudad y la reconstrucción de su imagen. En la práctica, las intervenciones acometidas se centraron en sectores parciales como frentes de agua o centros históricos, eliminando muchos de los vestigios industriales remanentes para dar paso a nuevas áreas de viviendas, zonas verdes y edificios dotacionales. Aquellos vestigios fabriles que pudieron permanecer, se rehabilitaron como equipamientos urbanos en sintonía con soluciones importadas de EE.UU. o Inglaterra. En estos modelos la creación de una dotación cultural emblemática constituía el proyecto estrella de una estrategia de marketing que perseguía la regeneración de la imagen urbana y el refuerzo del sentimiento de identidad y pertenencia de sus ciudadanos $^{12}$.

Existe, por tanto, un desinterés por parte de la sociedad y de la administración en la recuperación de este tipo de bienes, ya sea por la presión del mercado inmobiliario, o por la tradicional valoración del patrimonio cultural por cualidades de naturaleza artística e histórica ${ }^{13}$. Estos aspectos desplazan la significación científico-técnica y el refuerzo de la memoria colectiva del trabajo de los vestigios industriales, así como su condición de testigos de una época histórica determinada, mediante la que desempeñan una labor didáctica que explica nuestra realidad actual, independientemente de su valoración estética ${ }^{14}$.

De esta forma, se advierten ya los principales problemas que conlleva el planteamiento de conservación de este tipo de patrimonio. Por una parte, se trata de un tipo de bienes que carecen de la distancia histórica suficiente como para desarrollar una metodología de estudio eficaz para su correcto conocimiento, debido a que su uso y consideración se encuentran muy recientes en la memoria colectiva presente. A esto se añade el rápido deterioro al que están abocados debido a su abandono y su fragilidad en el contexto actual, tanto por su ubicación como por su escala, en muchos casos, territorial.

Por tanto, estos bienes se enfrentan a una serie de particularidades que les confieren una vulnerabilidad frente a otros tipos de patrimonio. Por una parte, su valor científico-técnico muchas veces se minusvalora frente al tradicional reconocimiento del patrimonio cultural por consideraciones histórico-artísticas y estéticas. La distancia respecto a la concepción tradicional de patrimonio conlleva una ingente labor de

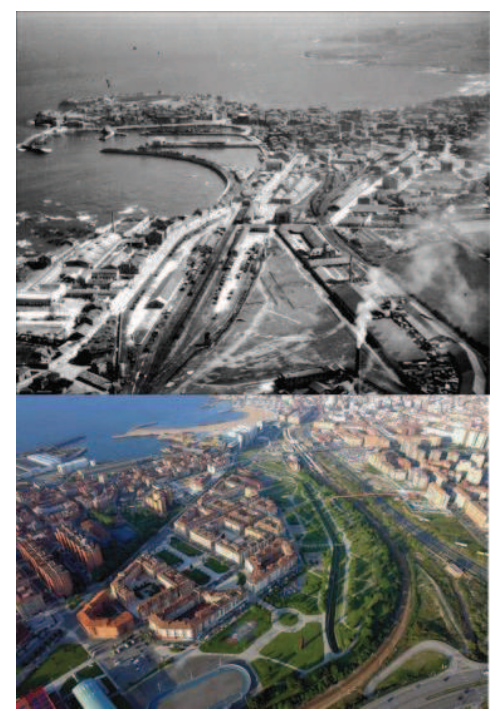

Figura 2.2. Gijón en las inmediaciones del barrio ferroviario y la Fábrica Moreda a mediados del S.XX, en "Gijón (Asturias)" de Felipe Fernández García disponible en http://age.ieg.csic.es/v2/recursos_ didacticos/gijon.php?TB_iframe= true; y en la actualidad, en EI Comercio edición digital http://gijon.elcomercio.es/fotograt ialfotos-agasparim/parquemoreda-942097.html.

\footnotetext{
12 Ver GÓMEZ GARCíA, M. V. (2008) La metamorfosis de la ciudad industrial. Glasgow y Bilbao: dos ciudades con un mismo recorrido, Madrid: Talasa.

13 MARRODÁN CIORDIA, E. (2007) "De la fascinación formal a la nostalgia. La ruina industrial en el paisaje contemporáneo" en Revista Bienes Culturales. Plan nacional de Patrimonio Industrial, n 7, IPCE, pp. 103-117.

${ }^{14}$ CASANELLES RAHOLA, E. (1998) "Recuperación y uso del patrimonio industrial" en Ábaco. Revista de cultura y ciencias sociales, $2^{\text {a }}$ época, $\mathrm{n}^{\circ} 19$, pp. 11-18.
} 
estudio y difusión para darlo a conocer y facilitar la valoración del mismo por parte de la población. No obstante, muchas de las iniciativas encaminadas a la conservación del patrimonio industrial parten de la propia sociedad. Sin embargo, como se ha apuntado anteriormente, su cercanía histórica provoca que la escasa consideración que se tiene de los vestigios industriales, conlleve a actuaciones ahistóricas impensables en los restos de otras épocas ${ }^{15}$. La necesidad de dar una nueva función y permitir que los vestigios patrimoniales sigan vivos mediante su reutilización no se puede realizar a cualquier coste ya que

el mayor daño que puede sufrir el patrimonio industrial hoy [...] son las intervenciones irreflexivas a golpe de partidas presupuestarias, fechas de inauguraciones y valoraciones superficiales que justifican con "que no tenía valor arquitectónico" la demolición de los vestigios o la conservación de piezas aisladas y descontextualizadas ${ }^{16}$.

\section{Criterios para la conservación del patrimonio industrial}

Si bien la propia rehabilitación de edificios patrimoniales suscita un complejo debate en cuanto al maridaje entre el nuevo uso y el inmueble preexistente, la funcionalidad específica de la arquitectura en el caso del patrimonio industrial supone un gran reto en la inserción de una nueva función compatible que diste de la simple musealización. Como apunta Julián Sobrino ${ }^{17}$, las consecuencias de los estudios sobre el patrimonio industrial se plasman en cuatro tipos de actuaciones, como son la creación de ecomuseos, la inclusión de la disciplina de la arqueología industrial en los planes de estudio de algunas universidades, la creación de numerosas asociaciones con el objetivo de fomentar la conservación del patrimonio industrial y la realización de jornadas, congresos y conferencias.

Resulta fundamental reflexionar sobre el carácter del nuevo uso mediante el que se recupera el patrimonio industrial, y la influencia del mismo en sus valores identificativos. Una ciudad que se recicla y reutiliza sus infraestructuras, es una ciudad viva ${ }^{18}$, pero no se debe buscar la conservación del patrimonio industrial a cualquier precio, sobre todo cuando las intervenciones desvirtúan los elementos característicos del mismo o lo convierten en simple contenedor de nuevas actividades, ignorando su memoria. Así, una de las reutilizaciones más habituales en el patrimonio industrial suele ser la reconversión en equipamientos culturales, siguiendo la tradición de aunar arte y técnica, mientras que la configuración de los esquemas clásicos de las reales fábricas y primeras industrias, resultan idóneos para la ubicación de dependencias educativas y administrativas. La

\footnotetext{
15 CERDÀ ANTÓN, M. (2008) op. cit., p. 189.

16 TRACHANA, A. (2008) Arqueología Industrial y Restauración Ambiental, Buenos Aires: Nobuko, p. 57.

17 SOBRINO SIMAL, J. (1996) Arquitectura Industrial en España 1830-1990, Madrid: Cátedra. Para el objeto que ocupa la presente investigación son especialmente relevantes los capítulos "Metodología para el estudio de la arquitectura industrial", pp. 13-67, "La arquitectura industrial y su concepto", pp. 67-103, y "Antecedentes Históricos", pp. 103-131.

18 MARRODÁN CIORDIA, E. (2011) "Espacios industriales y nuevos programas: Restauración de las centrales Térmicas de Alcudia (Baleares) y de Ponferrada (El Bierzo, León)” en Ábaco. Revista de cultura y ciencias sociales, $2^{\mathrm{a}}$ época, vol.4, n $\mathrm{n}^{\circ} 70$, p. 106.
} 
diafanidad de muchos espacios industriales, también permite una polivalencia de uso que, en muchas ocasiones, sugiere la continuidad de actividades de carácter productivo, mediante la ubicación de nidos de empresas y afines. Finalmente, existen casos en los que la propia relevancia del bien industrial justifica su musealización, inclusión en el contexto territorial de un ecomuseo, o la existencia de fábricas en activo en las que convive la sección musealizada con el espacio en el que continúa la actividad productiva.

La reutilización de las arquitecturas industriales ubicadas en el tejido urbano para su conservación y puesta en valor a través de nuevos usos, constituye una acción de salvaguardia fundamental debido a las presiones urbanísticas a las que se ven sometidas. Así mismo, como elementos fabriles patrimoniales, se convierten en la expresión material de complejas relaciones arquitectónicas, productivas y sociales que se imbrican en su espacio con el devenir del tiempo, formando parte de una memoria colectiva.

Por otro lado, en su extensa obra para la conservación y difusión del patrimonio industrial, Miguel Ángel Álvarez Areces refiere en su publicación junto a Diego Peris Sánchez que

no es el principio de restauración como política primordial el que permitirá recuperar el espacio, pues un edificio o conjunto histórico que mantiene sus espacios obsoletos en los usos y con una rentabilidad no actualizada hace inviable una operación restauradora. El costo del patrimonio restaurado debe estar en relación con la planificación del patrimonio rehabilitado y esta ecuación lleva implícita una sincronización de los contenidos políticos, económicos y culturales ${ }^{19}$,

remarcando la idea de que una correcta política conservativa del patrimonio industrial debe estar en consonancia con las necesidades planteadas en una planificación estratégica en la que concurra el aparato administrativo, la participación de la ciudadanía y el interés de las entidades patronales anteriormente propietarias de los bienes industriales. Se deben evitar las operaciones vacías de contenido con el único fin de conservar los espacios obsoletos, puesto que las intervenciones de rehabilitación deben enmarcarse dentro de unos criterios de sostenibilidad con un planteamiento a largo plazo que implique una previsión de mantenimiento. De lo que se concluye la evidencia de que una operación restauradora cuyo único fin sea la conservación, se cierra en sí misma sin posibilidad de evolución en el uso del bien restaurado, con el inevitable fracaso de la rehabilitación.

La consideración del patrimonio industrial y la valoración del mismo en su reutilización, pasa por una actitud asociada a la condición posmoderna de nuestro pensamiento actual en la que se contempla la ruina industrial con nostalgia, como un elemento reutilizable ${ }^{20}$. La rápida evolución de la industria aboca a sus elementos a una obsolescencia que debe paliarse mediante la reconversión de los

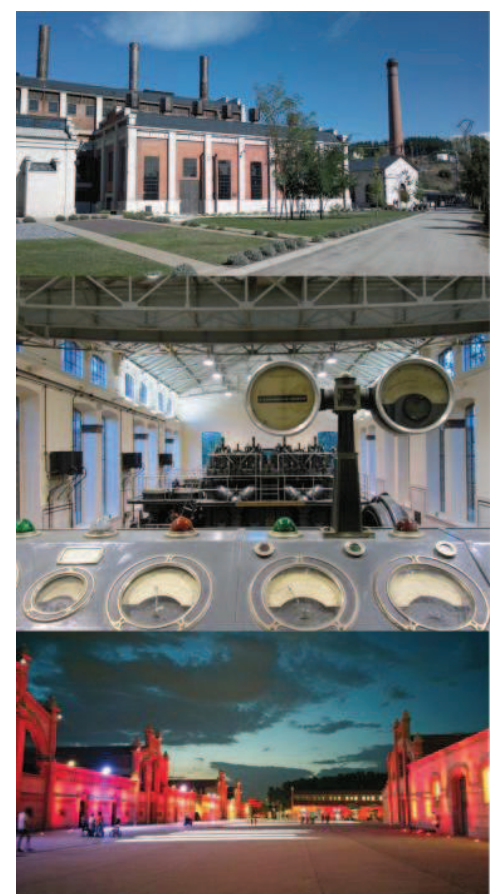

Figura 2.3. Ejemplos de intervenciones contemporáneas para la reutilización del patrimonio industrial: ENE Museo Nacional de la Energía, antigua central térmica de la MSP, Ponferrada, 2012; Nave de Motores de Pacífico de Metro, Madrid, 2013; y Matadero Madrid, 2015.

19 ÁLVAREZ ARECES, M. A. y PERIS SÁNCHEZ, D. (2005) El proyecto en los espacios industriales, documento presentado en el Foro de Arquitectura Industrial organizado por la Consejería de Obras Públicas y Transportes de la Junta de Andalucía, Sevilla, septiembre de 2005.

${ }^{20}$ MARRODÁN CIORDIA, E. (2011) op. cit., p. 106. 
mismos. Los bienes industriales asumen una significación como memoria colectiva, trasladando a los vestigios unos valores hacia los que la sociedad genera una empatía por la cercanía contextual a la época presente ${ }^{21}$.

La ruina industrial urbana contemplada desde la mentalidad posmoderna, se sitúa en un tiempo de ruptura que permite una actitud melancólica hacia lo perdido y una revalorización del objeto obsoleto. La mirada contemporánea hacia la fábrica abandonada establece una recodificación de sus valores como lugar patrimonial y como espacio de oportunidad en relación a su entorno y a las necesidades de éste. Un lugar como sedimentación del tiempo en el espacio ${ }^{22}$, como construcción mental de la memoria colectiva, como contenedor de la memoria histórica del trabajo.

En palabras de Esperanza Marrodán “el pensamiento postmoderno ha generado otra nueva sensibilidad respecto a los restos físicos de la etapa industrial [...] Observando la ruina como elemento ajeno a una historia, desvinculada de juicios, trata de configurar un nuevo elemento en el que la arquitectura abandonada pase a formar parte de la geografía" 23 . De esta forma, entendiendo que tanto el valor afectivo y estético como didáctico y testimonial que aportan estos vestigios industriales abandonados constituyen un elemento patrimonial de importancia, cuya salvaguarda resulta una operación fundamental para la transmisión de la memoria industrial hacia las generaciones venideras, cabe reflexionar sobre el modo correcto de intervenir sobre los mismos, y realizar un proceso selectivo que caracterice su reutilización.

El patrimonio industrial debe ser considerado como un nuevo bien cultural representado e interpretado a través de una lectura actualizada, integrada y científica. No debemos limitarnos a estudiar o intervenir en objetos aislados o extrapolados de los contextos en los que están inscritos [...] sino a realidades territoriales como base de las actividades humanas consolidadas en el tiempo y en continua evolución [...] incidiendo en todo aquello que resaltaba Alois Riegl, es decir: valor simbólico, emocional, histórico o artístico, cultural y práctico ${ }^{24}$.

Esta postura se alinea con la premisa fundamental sobre la que se basa el razonamiento del presente trabajo, según el cual las nuevas intervenciones sobre los vestigios patrimoniales industriales deben conservar los elementos que definan los valores arquitectónicoespaciales de los mismos que han llegado a nuestros días, por erigirse como los depositarios de la significación histórico-cultural de la actividad realizada, manteniendo viva la memoria del patrimonio intangible de la producción industrial y las vivencias aparejadas a la

21 ÁLVAREZ ARECES, M. A. (2011) "Conservación y restauración del patrimonio industrial en el ámbito internacional” en Ábaco. Revista de cultura y ciencias sociales, $2^{a}$ época, vol. 4, nº 70, pp. 23-39.

22 MUNTAÑLLA, J. (1978) Topos y logos, Barcelona: Kairós, p. 84, citando a Hegel.

${ }^{23}$ MARRODÁN CIORDIA, E. (2007) op. cit., pp. 106 y109.

24 ÁLVAREZ ARECES, M. A. (2010) "La herencia industrial y cultural en el paisaje: Patrimonio Industrial, Paisaje y Territorios Inteligentes" en Conferência Internacional sobre Patrimônio e Desenvolvimento Regional, CONFERENCIA INTERNACIONAL SOBRE PATRIMÔNIO E DESENVOLVIMENTO REGIONAL, Campinas e Jaguariúna [São Paulo], Brasil. Disponible en <www.conpadre.org>. [Consulta 03/09/2013] 
misma.

Por ello es importante el desarrollo de una metodología de trabajo que establezca un correcto estudio previo a la intervención, para el completo conocimiento del bien industrial. Las intervenciones en el patrimonio industrial deben, por tanto, buscar una reutilización con un impacto mínimo en la preexistencia, una reversibilidad de la actuación y el mantenimiento de los elementos que confieran al bien su identidad como elemento representativo de una industria determinada. De igual forma, se debe contar con un proyecto de reutilización consensuado entre los distintos agentes sociales, de forma que participen en el proceso íntegro de recuperación del bien patrimonial industrial, desde la elección del proyecto de intervención, hasta las actuaciones de seguimiento del mismo.

Por tanto, se debe generar una visión global de la intervención en una aproximación holística en la lectura del patrimonio industrial y su significación en el entorno inmediato, conectándola con otros recursos patrimoniales del territorio. El bien industrial constituye la base histórica, cultural y proyectual de la nueva intervención y su recuperación debe caracterizarse por el aporte de significados que se sumen a lo que Julián Sobrino denomina "densimetría histórica" del bien, conservando en lo posible su escala espacial, recorridos, distribución e iluminación, y conformándose como un episodio constructivo más del objeto "cliodiverso" que supone el elemento patrimonial industrial ${ }^{25}$.

Sin embargo, como se señaló anteriormente, los vestigios industriales adolecen de una escasa consideración con lo que, tal y como cita Manuel Cerdà, se permiten actuaciones conservativas ahistóricas en los mismos, impensables en otro tipo de patrimonio. En su importante obra para el desarrollo de una metodología arqueológica para el estudio de los restos industriales insiste en la necesidad de que todos los territorios cataloguen, registren y protejan su patrimonio industrial mediante estudios de áreas y de distintas tipologías industriales a través de la elaboración de inventarios como base de una investigación apropiada y la protección mediante medidas legales de los elementos recogidos en los mismos, así como una cooperación internacional. Incide, así mismo, en que "el patrimonio que goza de mayor protección es el que socialmente tiene mayor consideración [...] La consideración académica de la arqueología industrial puede sacar al patrimonio industrial de su estado de indefensión dentro del patrimonio cultural" aunando "esfuerzos con el fin de clarificar el estatus académico de la disciplina" 26.

Frecuentemente, esto se traduce en una indefinición conceptual en la instrumentación legal, y en una heterogeneidad de criterios en los inventarios que documentan el patrimonio industrial27. Por tanto, para

\footnotetext{
25 SOBRINO SIMAL, J. (2011) "La Real Fábrica de Artillería de Sevilla: hacia un espacio patrimonialmente activo y de producción creativa" en Ábaco. Revista de cultura y ciencias sociales, $2^{\mathrm{a}}$ época, vol. 4, nº 70, pp. 89-94.

${ }^{26}$ CERDÀ ANTÓN, M. (2008) op. cit, pp. 244-245.

27 Da fe de ello el proyecto Estudio de la situación del Patrimonio Industrial en España desarrollado por INCUNA entre junio y diciembre de 2012 dentro de las actuaciones de seguimiento del Plan Nacional de Patrimonio Industrial y en el que la doctoranda ha participado.
} 
una correcta conservación del patrimonio industrial es necesario el desarrollo de una metodología que lo catalogue y documente, con el objetivo de promover una difusión en torno al mismo que le dé mayor visibilidad y, por tanto, conlleve al aumento de su consideración social. Pero en estas líneas, al igual que en la obra de Françoise Choay, se aprecia el principal dilema en la conservación del patrimonio industrial.

Evidentemente, dadas las características de los bienes industriales, resulta inviable llevar a cabo la recuperación de todos y en su totalidad. Sin embargo, todos los componentes del bien deben ser documentados en el estudio previo del mismo, y se debe poner especial atención en aquellos elementos identificativos que caracterizan al bien industrial como conjunto destacable frente a otros, puesto que su eliminación descontextualiza los valores patrimoniales del mismo. Es importante destacar que la correcta conservación del patrimonio industrial deviene un largo proceso de estudio y planificación de la intervención mediante el desarrollo de un plan director, la intervención de recuperación con un nuevo uso consensuado y las actuaciones de seguimiento correspondientes, que garanticen la calidad de la intervención y su sostenibilidad en un desarrollo futuro.

Pero, ante la inconveniencia e imposibilidad de fosilizar los restos industriales a escala territorial, ¿cómo dilucidar sobre los bienes pertenecientes al patrimonio industrial que deben ser objeto de una conservación o intervención de rehabilitación, y qué bienes deben ser simplemente documentados sin propuesta de reutilización? En este punto es donde se debe considerar la creación de una metodología para el estudio del mismo, como ya se viene apuntando a lo largo del presente epígrafe, como es la arqueología industrial.

\section{Según el Plan Nacional de Patrimonio Industrial,}

el patrimonio industrial dispone de una metodología propia de carácter interdisciplinar que se denomina Arqueología Industrial. Esta disciplina científica estudia y pone en valor los vestigios materiales e inmateriales como testimonios históricos de los procesos productivos. Su estudio nos aproxima a una mejor comprensión de las estructuras y los procesos que han generado el desarrollo de las sociedades técnico-industriales, sus fuentes de energía, sus lugares y espacios de trabajo, su organización productiva y su forma de responder a una economía basada en la mecanización de los procesos productivos ${ }^{28}$.

La arqueología industrial como método abierto e interdisciplinar trata los restos materiales e inmateriales culturales generados por la época histórica del hombre en el que se pasa a un sistema capitalista de producción, y constituye la instrumentalización de las herramientas para el estudio y conocimiento de su realidad particular ${ }^{29}$. De este método deben servirse tanto los historiadores de la arquitectura como los geógrafos, sociólogos, economistas que trabajen en este campo para

28 "Definición, categorías y ámbito de aplicación" en VV. AA. (2011a) op. cit., p. 9.

29 En la presente investigación no se ha empleado dicho método dado que todos los casos estudio se encuentran rehabilitados o en vías de rehabilitación. 
una correcta difusión y posterior conservación de los bienes considerados como patrimonio industrial. Pero se debe insistir en el hecho de que el objetivo de estudio de la arqueología industrial no es el patrimonio en sí mismo, sino los bienes culturales que la industrialización ha dejado en el contexto particular de la historia española. A partir de este estudio y la catalogación de los elementos inventariados se deben concluir aquellos que son objeto de conservación e interés por su representatividad y dotarles, por tanto, de consideración patrimonial; y aquellos que sólo deben ser documentados a modo de ejemplo, evitando la fosilización del territorio y promoviendo una conservación sostenible de los bienes para erradicar el "complejo de arca de Noé" del que hablaba Françoise Choay.

\subsubsection{La arquitectura industrial y el espacio del trabajo: manufacturas y primeros conjuntos fabriles}

Para situar el campo epistemológico en el que se encuadra este trabajo, es necesaria una revisión de los estudios abordados anteriormente sobre el tratamiento teórico de la arquitectura industrial y el espacio del trabajo, especialmente aquellos que se encuadran en la producción manufacturera de los primeros tiempos por sus conexiones con el contexto de las fábricas de tabacos en España. No hay que olvidar que un importante grupo de autores de diversas disciplinas también han aportado conocimiento sobre cuestiones concernientes a las primeras arquitecturas industriales y su espacio de trabajo que deben ser consideradas en la presente investigación.

\section{Sobre la arquitectura industrial y las fábricas de los primeros tiempos}

Sobre las consideraciones de la presente investigación en torno a la arquitectura industrial, se tienen en cuenta, principalmente, las aportaciones de autores españoles, dadas las peculiares características en las que se desarrolla el proceso de industrialización, propias de cada país e, incluso, de cada región. Estas connotaciones de carácter local se materializarán, por tanto, en una arquitectura industrial característica fruto de la época, del tipo de producción y de los gustos y concepciones predominantes.

Sobre los inicios de la producción industrial en la península, Esteban Canales $^{30}$ señala que en el contexto español la revolución industrial es un fenómeno que se caracteriza por su gradualidad, con un desarrollo más tardío y heterogéneo. Citando a Maxine Berg, recuerda que:

como modelo, la manufactura suponía la existencia de grandes talleres en los que trabajaban artesanos bajo el control capitalista. Era un paso intermedio entre la industria artesanal, con la que compartía una tecnología manual y la industria fabril, a la que se asemejaba por la división del trabajo y por la sujeción del trabajador. Estos límites

${ }^{30}$ CANALES GILI, E. (1995) "A vueltas con la Revolución Industrial: avatares recientes de un viejo concepto" en Manuscrits: Revista d'Història Moderna, nº13, pp. 309-332. 
serían rotos con la introducción de las máquinas, el signo de identidad de la producción industrial moderna ${ }^{31}$.

Por tanto, aunque las condiciones de inicio de la industrialización en España denotasen una heterogeneidad propia de cada contexto particular regional y su comienzo fuese tardío respecto a otros países como Inglaterra o Francia, existen una serie de características intrínsecas al proceso industrializador que se repiten por igual, en el paso de una producción gremial artesanal propia del sistema feudal a una producción agrupada y racionalizada en fábricas. Sin embargo, las circunstancias particulares de la industrialización española produjeron ejemplos de arquitectura industrial que reproducían un maridaje de modelos ensayados en otros países junto a las características particulares propias de la arquitectura ibérica.

Uno de los autores que más conocimiento ha producido sobre la cuestión de la arquitectura industrial en España, y especialmente en el contexto andaluz, es Julián Sobrino Simal. En su obra Arquitectura industrial en España 1830-1990 de 1996, además de realizar un compendio de los casos más sobresalientes agrupados según su sector productivo, trata de establecer un corpus teórico en los primeros capítulos referente al concepto de arquitectura industrial y a la sistematización de una metodología para su estudio. Defiende la importancia de una profundización en el conocimiento de la arquitectura industrial debido a su escaso tratamiento como sujeto de la historia de la arquitectura frente a otros tipos edilicios, exceptuando el ejemplo de la Real Fábrica de Tabacos de Sevilla que es objeto de interés por su parecido con las arquitecturas de tipo palaciego o urbano.

Las tipologías arquitectónicas como concreciones de modelos adaptados a determinadas necesidades y caracterizados por su repetición invariante en diversas localizaciones se ven influenciadas por las variables estilísticas de su época concreta y de su país, junto a la importación de modelos arquitectónicos venidos del exterior y la influencia de las corrientes imperantes desarrolladas en el seno de las academias y las escuelas técnicas. En el caso de la arquitectura industrial, este prototipo surgirá en el S.XVIII con el paso del sistema de producción feudal al capitalista, y con la necesidad de dar respuesta a las necesidades espaciales de los nuevos ámbitos productivos.

Sin embargo, es crucial para el entendimiento y contextualización de la presente investigación el hecho de que la falta de modelos culturales para desempeñar esta labor conlleva la reproducción de esquemas

\footnotetext{
${ }^{31}$ CANALES GILI, E. (1995) op. cit., p. 325 sobre el análisis de Maxine Berg en torno a la concepción marxista de la manufactura. "La manufactura describe una fase de industria artesanal, una fase que precedería a la de la producción basada en las modernas máquinas. Se interesó por la organización y los progresos tecnológicos que habrían de diferenciar la «manufactura» de la producción industrial previa. La nueva forma de organización de la «manufactura» descrita por Marx consistía en un taller donde los artesanos estaban bajo control capitalista y desempeñaban una o varias tareas. En cuanto a la nueva tecnología, se introducía la división del trabajo, aunque las operaciones realizadas manualmente aún dependían de la pericia de los individuos y conservaban las características de la artesanía”. BERG, M. (1985 [1987]) La era de las manufacturas 1700-1820. Una nueva historia de la Revolución industrial británica, Barcelona: Crítica, p. 83.
} 
espaciales anteriores en las primeras fábricas, sin crear un orden arquitectónico nuevo. De esta forma, se presentan similitudes con los palacios, en el caso de las fábricas reales, o con las viviendas, en el caso de las fábricas de pisos. Estos esquemas importados de otras tipologías se combinarán con los modelos ya establecidos por las actividades productivas anteriores como los espacios manufactureros, molinos o lonjas y depósitos portuarios.

En su evolución, la arquitectura industrial se relaciona con el medio rural y el entorno histórico, de los que adopta una tradición constructiva particular, así como los modelos tipológicos característicos de la misma. La realidad socioeconómica marcará las necesidades de la producción y la organización laboral, que se traducirán en un modo de expresión específico de la arquitectura industrial. Finalmente, este lenguaje arquitectónico propio de la industria surgirá de un proceso anónimo en el que confluyen las intenciones de constructor y empresario.

Por otra parte, también se ocupa de las relaciones entre la península y la exportación de modelos arquitectónicos a las colonias americanas, con el papel de las islas Canarias como lugar de intercambio de experiencias entre la Corona Española y América Latina. En este trasvase de conocimiento, los estilos que mayoritariamente se trasladaban a las colonias eran propios de la época y gusto imperantes en la península: Renacimiento, Barroco y Neoclásico, correspondientes a los tres periodos estilísticos de la colonización. Sin embargo, la industrialización en las colonias fue muy tardía, y se caracterizaba más por una ubicación de tipo rural a la manera de las fábricas inglesas y francesas, construyéndose fábricas exentas con complementos como las viviendas del director y de los trabajadores. De la misma forma, también algunos conventos e iglesias fueron reutilizados para tal fin y la producción más usual era la relacionada con la obtención de azúcar, tabaco o vidrio. No obstante, la industrialización en las colonias tuvo su auge a partir del S.XIX, cuando ya no formaban parte de la Corona Española.

Se trata sin duda de una importante obra para el conocimiento de la arquitectura industrial española, sentando las bases para su estudio y difusión, y otorgándole un papel en la historia de la arquitectura. De igual forma, no hay que olvidar que los primeros trabajos sobre arquitectura y arqueología industrial en España datan de la década de los 80 y son elaborados frecuentemente desde enfoques diversos a la disciplina arquitectónica.

Otro autor que se ocupa de tratar el papel de la arquitectura industrial en España en su obra de 1989 Arquitectura en España 1770-1900, es Javier Hernando ${ }^{32}$. Si bien se trata de un capítulo específico dentro de una obra más general, define claramente las características propias de las primeras arquitecturas industriales en España y sus condicionantes fundamentales. Según Hernando, la arquitectura industrial está caracterizada por dos factores como son la funcionalidad y el control de los trabajadores, y ambos confluyen en la finalidad última de explotación que es favorecer de la mayor forma posible la eficacia del

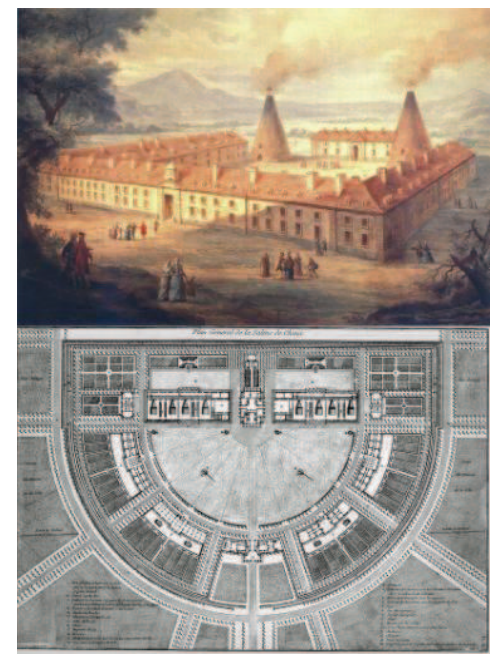

Figura 2.4. Cristalería de la Reina de Le Creusot de 1875, en SEBASTIA TALAVERA, J. (2007) op. cit., p. 33; y reales salinas de Chaux construidas entre 1778-1804, en PEVSNER (1976 [1997]) op. cit., p. 333.

32 HERNANDO, J. (1989) "La arquitectura industrial” en Arquitectura en España 1770-1900, Madrid: Cátedra, pp. 353-371. 


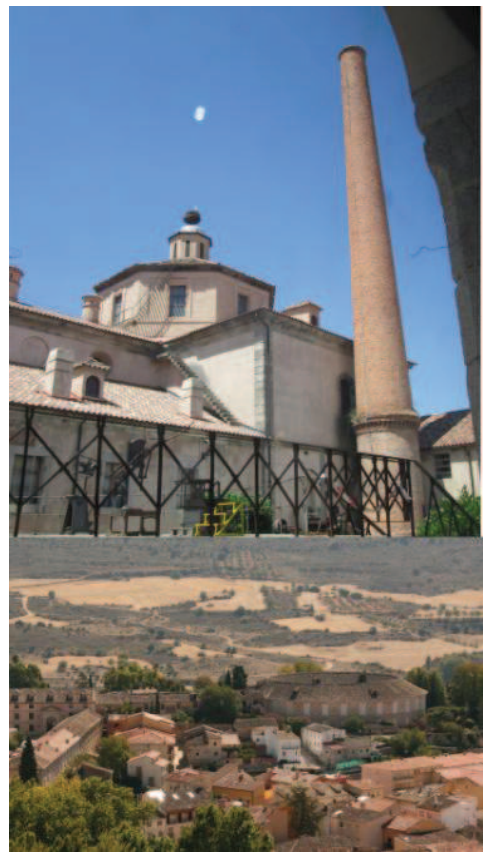

Figura 2.5. Real Fábrica de Cristales de La Granja, 2015; y Real Fábrica de Paños de Brihuega, en brihuega.es. proceso productivo.

Las primeras grandes manufacturas fabriles que precedieron a la revolución industrial fueron casi siempre de organización estatal. Famosísimas serían en Francia Le Creusot, Rouen o Chaux [...] [En España] la mayor parte de estos conjuntos se inspiraban tipológicamente en la arquitectura culta, debido a que aparte de racionalizar el momento productivo, se buscaba establecer fórmulas y relaciones que interpretasen la nueva organización social y transmitiesen sus contenidos según una tendencia que atraviesa el S.XVIII. En consecuencia, los mismos valores de axialidad y simetría que dominan en las composiciones de las arquitecturas residenciales, pueden observarse en estas construcciones fabriles ${ }^{33}$.

Retomando el fragmento anterior y fijando la atención sobre el caso francés, que tanta influencia tendría para el objeto que ocupa a la presente investigación, nos encontramos con formulaciones muy diversas en el caso de las reales manufacturas, que adoptan esquemas distributivos tan variados como la real fábrica de porcelana de Sèvres, la Real fundición de Le Creusot, la fábrica de cristales Saint-Gobain, la fábrica de tapices de Gobelins o la singular formalización de las salinas de Chaux. No hay que olvidar que la total falta de referentes culturales inducía a una búsqueda de soluciones en las construcciones populares y en la reutilización de modelos anteriores para la nueva función industrial, junto al lenguaje académico y racionalista propio de la ideología del despotismo ilustrado. En el caso de las reales manufacturas mencionadas anteriormente, se advierten en sus esquemas distributivos ecos de composiciones palaciegas o de conjuntos funcionales como pequeñas unidades agrarias.

En el caso de España, se advierte, también, un variado muestrario de ejemplos con ciertas particularidades propias de cada caso. En este sentido, destacan Reales Fábricas como la de Cristales de La Granja, la de Paños de Brihuega, la de Tapices de Madrid, la de Sedas de Talavera y un importante capítulo dedicado a la producción armamentística con fábricas de armas como Eugi y Orbaiceta, Trubia, Toledo o la Real Fundición de Artillería de Sevilla.

\section{Sobre la conformación del espacio del trabajo y características particulares de las reales manufacturas}

Como se ha referido anteriormente, el contexto específico de la embrionaria industrialización, junto a la falta de referentes culturales y la voluntad de optimizar el proceso de producción mediante su racionalización y la vigilancia del obrero, darían lugar a una espacialidad del trabajo particular que caracterizaría las primeras manufacturas y fábricas sistematizadas a tal fin. Fundamental para el conocimiento de estas cuestiones es la obra de Ornella Selvafolta, todo un referente a tener en cuenta para abordar, no sólo el caso de las manufacturas y reales fábricas que ocupa esta investigación, si no la evolución del espacio del trabajo en general en Europa. Sobre el

${ }^{33}$ HERNANDO, J. (1989) op. cit., p. 354. 
carácter monopolístico de algunas manufacturas reales destaca:

el carácter del monopolio y la naturaleza extremadamente preciosa del producto determinaron medidas capaces de garantizar una clausura y defensa del mundo exterior, formando al mismo tiempo una primitiva instalación productiva y proponiendo los medios para una integración total de la vida de los trabajadores en las estructuras de producción ${ }^{34}$.

Por tanto, las manufacturas reales se caracterizaban por una distribución que, a través de esquemas formales, forzaba la atención hacia el espacio en el que se significaba el poder real y desde el que se ejercía la salvaguarda del orden social. Este paralelismo entre las primeras fábricas y los modelos de las arquitecturas coercitivas como cuarteles, conventos o cárceles, se observan en las propuestas de Jeremy Bentham para edificios penitenciarios en las que incluye como posibles usos de su modelo panóptico las fábricas manufactureras con objeto de controlar al trabajador ocioso.

Requisito esencial eran los alojamientos para los Directores e Inspectores encargados de velar por el orden. La producción era inseparable del orden y el trabajo de la moral: la fábrica como espacio institucionalizado en el que ejercer el control a través de la previsión de particulares dispositivos funcionales que incidía directamente sobre su organización espacial.

El patio, elemento constante, era dimensionado a través de complejos esquemas geométricos, a veces, reconducible al modelo histórico de unidades productivas cistercienses o al de la explotación y trabajo agrícola. El patio había sido también el principio ordenador de otro ejemplo de unidad productiva del SXVIII, innovadora pero vinculada a la tradición ${ }^{35}$.

Por tanto, la lógica de la proyección espacial obedecía a la voluntad racionalizadora del proceso de producción en la localización funcional subordinada al modelo arquitectónico que genera sus propios mecanismos de sistematización y control del espacio y del trabajador. Se trata de una suerte de acción moralizadora del mismo a través elementos como barrotes, pasillos de circunvalación, puestos de guardia, calabozos y recorridos convergentes hacia el interior de la fábrica, de forma que tras la fachada de carácter palaciego se esconde un auténtico espacio de reclusión, garantizando el orden y la disciplina.

Posteriormente, las innovaciones del progreso técnico y la introducción de la mecanización en el proceso productivo, sustituyen la subordinación al contenedor arquitectónico por soluciones distributivas abiertas y extensibles, favoreciendo la máxima flexibilidad en la racionalización de recorridos y circulaciones propios de la lógica de un sistema de producción mecanizado ${ }^{36}$. No obstante, este paso no implica

34 SELVAFOLTA, O. (1985) "El espacio del trabajo (1750-1910)" en Debats. Institució Alfons El Magnánim. Institució Valenciana d'Estudis i Investigació, Septiembre, $\mathrm{n}^{\circ} 13$, p. 52. Este trabajo, además de constituir una completa revisión a la evolución de las características del espacio del trabajo a lo largo del tiempo, reúne una extensa bibliografía sobre cuestiones relativas a la espacialidad industrial en Europa.

35 SELVAFOLTA, O. (1985) op. cit., p. 53.

36 A la formulación de estos espacios contribuiría el desarrollo de las técnicas constructivas de nuevos materiales como el hierro que tuvieron gran importancia a lo largo del S.XIX. Sobre la arquitectura en hierro en España cabe destacar NAVASCUÉS PALACIO, P. (2007) Arquitectura e ingeniería del hierro en España (1814-1936), Madrid: El 
la abolición del control sobre el operario: el poder ejercido por la administración pasa a materializarse en la autoridad patronal.

La evolución de los procesos industriales provoca un serio conflicto en el tipo de factorías que trata la presente investigación, ya que

desde finales del S.XVIII estos espacios industriales verán alterada su fisonomía hasta concretarse en nuevas tipologías que harán del edificio industrial un objeto con personalidad propia. Las razones de tal cambio no deben buscarse tanto en la alteración de las condiciones de trabajo que continuarán basadas en el control material y social de los trabajadores, cuanto en "las innovaciones que habían marcado el progreso técnico de las máquinas de trabajo" [...] El acoplamiento de los nuevos útiles mecánicos de producción no era posible en los viejos espacios. El motor, base de la nueva industria, malamente podría aplicarse en un laberíntico espacio como el de la Fábrica de Tabacos de Sevilla ${ }^{37}$.

De igual forma, a los problemas endémicos que presentarían este tipo de arquitecturas por sus dificultades y carencias en la adaptación a la evolución industrial, se uniría también la problemática que supondría su ubicación urbana en una periferia próxima que con la expansión urbana de los últimos siglos terminaría por incorporar la fábrica al tejido urbano consolidado.

Es importante hacer referencia en este punto a la importante obra de Gillian Darley La fábrica como arquitectura, por cuanto supone como aporte de conocimiento a las particularidades de la arquitectura industrial desde los inicios manufactureros hasta las concepciones fabriles de nuestros días. En especial, es importante el epílogo de la edición española a cargo del profesor de la Universidad Politécnica de Madrid Rafael García García ${ }^{38}$, en el que se trata de forma somera pero precisa el caso de las fábricas ilustradas. En el mismo se citan también otros casos de reales fábricas de Tabacos francesas como la Real Fábrica de Tabacos de Morlaix, diseñada por Jean François Blondel o el ejemplo de EE.UU de la Ciudad Tabaquera de Ybor en Florida.

Para ahondar en las características propias de las manufacturas reales en las que se encuadran las fábricas tabacaleras objeto del presente trabajo, conviene dar un repaso a su contexto histórico y al ideal ilustrado imperante que daría lugar a una concepción determinada de las mismas. Tal y como señala Julián Sobrino,

las Reales Fábricas constituyen un objetivo de primera magnitud para las monarquías absolutas del S.XVIII como instrumento intervencionista óptimo capaz de producir bienes que hagan progresar sus naciones y

Viso, Fundación Iberdrola; y el interesante epígrafe dedicado a la influencia francesa y la aparición del hierro durante el reinado isabelino en NAVASCUÉS PALACIO, P. (1993) "Arquitectura española, 1808-1914" en Summa Artis: historia general del arte, vol. 35, Madrid: Espasa-Calpe, pp. 263-288.

${ }^{37}$ HERNANDO, J. (1989) op. cit., pp. 354-355. El entrecomillado es una cita de SELVAFOLTA, O. (1985) op.cit.

38 DARLEY, G. (2010) La fábrica como arquitectura. Facetas de la construcción industrial, Barcelona: Reverté. Hay que destacar especialmente el capítulo "La fábrica como modelo: primeras versiones", pp. 51-81, y el epílogo a cargo de GARCÍA GARCÍA, R. (2010) "Epílogo. Arquitectura e industria: también los primeros pasos", pp. 197-254. 
eliminen las costosas importaciones de productos de lujo demandados por la aristocracia y la propia monarquía. En España fue la monarquía borbónica, con Fernando VI y Carlos III, la que puso en marcha un ambicioso programa de renovación económica que pretendía producir en fábricas dependientes de la Corona objetos de uso suntuario. Algunos ilustrados, como Jovellanos, promoverían una serie de reformas encaminadas a la mejora y dignificación de las enseñanzas técnicas, a la contratación de expertos extranjeros y a la formación de técnicos españoles fuera de nuestras fronteras [...]

La reunión en un mismo edificio de distintos trabajos tendrá un efecto de transformación radical de la organización del espacio, que primero irá destinado a contener hombres y máquinas y, ya en el S.XIX se transformará en una auténtica máquina global. Las primeras tipologías copian al palacio e instaurarán en sus pisos un sistema de circulación horizontal para la producción de manufacturas escasamente mecanizadas [...] Eran ejecutadas por los arquitectos de la administración y exteriormente presentan un aspecto solemne y clasicista $^{39}$.

Como bien señala Aurora Rabanal Yus, la situación económica española de principios del S.XVIII adolecía de un grave estancamiento demográfico, un fuerte desfase productivo y una importante contracción comercial, de forma que tanto la metrópoli peninsular como sus colonias satélites abastecían sus mercados con productos extranjeros. Ante este panorama económico, la nueva dinastía borbónica decide llevar a cabo una política reformadora estatal que, siguiendo el pensamiento mercantilista, permitía el papel del Estado como promotor de la renovación industrial mediante la creación de reales manufacturas productoras de artículos de lujo, promoviendo la iniciativa privada a través de prerrogativas de tipo monopolístico y exenciones fiscales. De esta forma, se prohibía tanto la entrada de productos manufacturados como la salida de materias primas ${ }^{40}$.

Por su parte, Ramón Gutiérrez y Cristina Esteras apuntan que, la ilustración española iniciada con las reformas borbónicas promulgaba una modernización desde la corte metropolitana que se subordinaba a los intereses de la Corona, no sin cierto complejo de atraso respecto a la ilustración europea y los logros conseguidos fundamentalmente en Francia e Inglaterra. A ello se añade la reflexión de estos autores sobre las connotaciones de la aplicación del pensamiento ilustrado en el marco específico de la península y sus colonias, puesto que

el pensamiento enciclopedista, la preocupación por la capacitación de los artesanos y el oficio útil se proyectan en España no como fortalecimiento de las antiguas estructuras laborales, sino con el desmontaje de las mismas. Es que se arrastraba la contradicción entre los intereses de la corona y el pensamiento ilustrado. Y allí con certeza hubo más de despotismo que de ilustración ${ }^{41}$.

A la luz de las consideraciones anteriores, se puede concluir que las

\footnotetext{
39 SOBRINO SIMAL, J. (1996) op. cit., p. 113.

${ }^{40}$ RABANAL YUS, A. M. (1990) Las reales fundiciones españolas del siglo XVIII, Madrid: Servicio de Publicaciones el EME, p. 15.

41 GUTIÉRREZ, R. y ESTERAS, C. (1993) Arquitectura y fortificación de la ilustración a la independencia americana, Madrid: Tuero, p. 14.
} 
características del desarrollo industrial en España fueron heterogéneas tanto por su contextualización geográfica y temporal como por el tipo de producción, lo que deviene en unas arquitecturas en las que confluyen tradición, búsqueda de soluciones para la nueva función y empleo de modelos preexistentes pertenecientes a otras tipologías. Se da, sin embargo, un interés común de las monarquías absolutas europeas que, mediante el apoyo en las directrices francesas del despotismo ilustrado, instauran la creación de una serie de manufacturas o reales fábricas para la producción de bienes suntuarios para la propia Corona o la aristocracia. En España, estos modelos se aplicarían durante los reinados de Fernando VI y Carlos III, siguiendo la máxima de "territorio ordenado, territorio dominado" 42.

Por tanto, y retomando las consideraciones anteriores, estas reales fábricas se caracterizaban por su paralelismo con las arquitecturas coercitivas y una rigidez de distribución espacial al servicio del propio contenedor arquitectónico que distribuía circulaciones y estancias de producción según la máxima de vigilancia y control del espacio. Para ello contaba con una serie de recursos espaciales como puestos de control, calabozos, circulaciones confluyentes hacia el interior y la ordenación claustral en torno a patios. Este contexto particular se ocultaba tras una envolvente palaciega que asumía las significaciones culturales de cara al exterior y representaba la autoridad real que auspiciaba el establecimiento fabril. La concepción de estos espacios fundamentalmente para el trabajo manufacturero, así como su ubicación urbana, conllevará a una serie de problemas endémicos que pondrán en crisis el modelo arquitectónico de las reales fábricas con la progresiva evolución de la industria y la acuciante necesidad de la introducción de la mecanización en las labores productivas.

\subsubsection{La fábrica como tipo en la historia de la arquitectura y su presencia en la tratadística}

Dadas las características de la presente investigación, cuyo objetivo se centra en la búsqueda de posibles invariantes que definen un tipo fabril tabacalero en el contexto del monopolio hacendístico español, se estima necesaria la profundización en cuestiones relativas a la historia de las tipologías, y en concreto, al tratamiento de la fábrica como tipo arquitectónico en la tratadística de la época -S.XVIII y S.XIX-. No obstante, estas consideraciones deben realizarse a la luz de las cuestiones tratadas en el epígrafe anterior, particularmente sobre el contexto en el que se desarrolla la concepción arquitectónica fabril en España.

En primer lugar, las circunstancias políticas y culturales en las que se inicia el desarrollo particular de una industria de origen real con la aparición de las reales fábricas durante el S.XVIII,

consolidará la percepción que de la industria tienen los españoles de

42 SOBRINO SIMAL, J. (1996) op. cit., p. 84, en referencia a REGUERA RODRÍGUEZ, A. J. (1993) Territorio ordenado, territorio dominado. Espacios, políticas y conflictos en la España de la Ilustración, Universidad de León. 
finales de la Edad Moderna muy unida a los cambios que se producen en el tejido urbano de nuestras ciudades allá por los comienzos de la revolución industrial. Estas transformaciones en el paisaje serán una consecuencia de la política económica y científica de las monarquías ilustradas, que promovía la instrucción pública, la formación de técnicos cualificados, la industria y las artesanías populares, la repoblación de baldíos por medio de colonizaciones y nuevos poblados, la mejora del trazado urbano de las principales ciudades ${ }^{43}$.

No hay que olvidar que, como se ha tratado anteriormente, las especificidades de la producción arquitectónica en los primeros momentos del desarrollo industrial español recurría a referentes tipológicos procedentes de otros ámbitos que, unidos a la tradición arquitectónica particular peninsular, generaban manifestaciones edilicias muy particulares. En palabras de Aurora Rabanal Yus,

la implantación de este nuevo modelo económico originó pues, el nacimiento de un nuevo tipo arquitectónico: la fábrica, que había de satisfacer unas necesidades y funciones completamente nuevas, permitiendo el desarrollo de un proceso completo de producción, sin interrupciones ni pérdidas de tiempo, con una rigurosa organización racional de su espacio interior, según las sucesivas fases del trabajo en cadena, facilitando el ejercicio de un imprescindible control sobre el producto y sobre las diferentes operaciones realizadas, conseguir un ritmo constante de trabajo y una máxima eficacia en la producción ${ }^{44}$.

Como apunta Julián Sobrino, en este contexto de iniciativas ilustradas de raíz francesa, las reales fábricas inauguraron un nuevo modelo tipológico al concentrar en un solo espacio arquitectónico los procedimientos y máquinas que permitían el trabajo colectivo en cadena. A este respecto, "se puede constatar en esta instalación fabril [haciendo referencia a la Real Fábrica de Cristales de La Granja de San Ildefonso] la aplicación de la doctrina económica del mercantilismo expresada en los escritos de Colbert, que los Borbones pondrán en práctica en España durante el S.XVIII"45. Profundizando en el tema de la influencia francesa sobre las manufacturas reales españolas, cabe destacar que

fue el mismo siglo XVIII el que vio la consolidación de las principales industrias creadas por iniciativa real -es decir, las manufactures royales y las manufactures d'état, según la diferenciación francesa- y surgidas en buena medida en sintonía con los ideales ilustrados. Aunque el modelo conceptual lo ideó en la Francia de Luis XIV su ministro Jean-Baptiste Colbert, no fue en realidad hasta ya entrado el siglo XVIII cuando el programa de construcciones comenzó a adquirir su verdadera dimensión. Como periodo de la historia de la arquitectura industrial, debe reconocerse que esta época fue la primera desde la Antigüedad en la que se construyeron establecimientos fabriles de gran escala y según planes prefijados singularmente ambiciosos [...] De este planteamiento -que impregna las iniciativas de toda la época-, es

\footnotetext{
${ }^{43}$ SOBRINO SIMAL, J. (1996) op. cit., p. 84

44 RABANAL YUS, A. M. (1988) "Las fábricas en Madrid en la segunda mitad del siglo XVIII" en SAMBRICIO, C. (ed.) Carlos III, alcalde de Madrid: bicentenario de Carlos III, 1788-1988 [exposición], Ayuntamiento de Madrid, pp. 317-318.

45 SOBRINO SIMAL, J. (1996) op. cit., p. 114
} 
importante resaltar que tuvo un destacado eco en todas las monarquías europeas, las cuales siguieron en mayor o menor medida las directrices francesas.

En España fueron los reinados de Fernando VI y Carlos III los de mayor protagonismo en cuanto a realizaciones de fábricas y manufacturas reales $^{46}$

Sin embargo, no se puede entender el desarrollo de los tipos fabriles en los primeros momentos manufactureros sin prestar atención a la figura disciplinar que de forma mayoritaria se ocuparía de la concepción proyectual de los nuevos inmuebles industriales. Sobre este aspecto, Sobrino Simal destaca que los ingenieros o arquitectos de la Corona debían dar una doble respuesta ante el desafío de concebir un edificio fabril: por una parte, arquitectónica, iniciando una tipología que hasta entonces no había existido; y en segundo lugar, económica, respondiendo a un nuevo modelo de producción. De esta forma, las reales fábricas españolas, a imitación de las manufacturas francesas debían responder a una serie de funciones concretas: la organización del espacio en torno a un proceso productivo completo, fomentar el ahorro de tiempo y la facilitación del trabajo ininterrumpido, la organización racional de las diversas fases productivas y el control eficaz sobre el producto y los trabajadores. Ante estas premisas, el desarrollo en planta se realizaría preferentemente siguiendo una configuración en bloque cuadrangular o rectangular, articulado internamente en torno a uno o más patios interiores, y ubicado en una localización urbana o periférica cercana al núcleo poblacional ${ }^{47}$.

No obstante, para entender la labor de los ingenieros y arquitectos que realizaron los primeros planteamientos fabriles, cabe profundizar en el marco epistemológico y disciplinar integrado por la definición del tipo fabril en la tratadística de la época. En este sentido, resulta fundamental la consulta de la excelente relación de autores que a tal efecto ha realizado Aurora Rabanal Yus ${ }^{48}$. Señala esta autora la significación que las definiciones de la fábrica como nueva tipología representa en los diccionarios y tratados de arquitectura, destacando su acepción general en el área de la teoría de la arquitectura "como un conjunto de talleres, almacenes, patios y alojamientos, reunidos en un mismo edificio, cuya planta se había de adecuar a la función que el establecimiento había de desempeñar y al tipo de producción que debía albergar" 49 .

Ya en 1755 D'Avilier identifica en su Dictionnaire d'Architecture el término "manufacture" con un gran edificio compuesto de varias estancias, salas, laboratorios, galerías, almacenes, etc. donde los obreros son alojados para desempeñar su trabajo, en el que se destaca

${ }^{46}$ GARCÍA GARCÍA, R. (2010) op. cit., pp. 211-213.

47 SOBRINO SIMAL, J. (1996) op. cit., p. 118

48 A destacar el capítulo específico dedicado a la figura de la fábrica en la tratadística de los S.XVIII y S.XIX en RABANAL YUS, A. M. (1990) "Planteamientos teóricos" en Las reales fundiciones españolas del SXVIII, Estado Mayor del Ejército, Servicio de Publicaciones, pp. 23-33. En este epígrafe se seguirán los autores e informaciones destacadas por Rabanal Yus en la citada obra.

49 RABANAL YUS, A. M. (1990) op. cit., p. 24. 
su carácter de complejo contenedor que, no sólo atiende a la organización de las tareas, si no también a la ubicación de los operarios que las desarrollan. Por otra parte, señala Rabanal Yus el matiz específico que se otorga en esta definición al hecho de que la fábrica no sólo supone una compleja instalación industrial reunida en un único edificio, sino que implica también el alojamiento de los operarios en su interior.

Sin duda, uno de los textos que más influyeron en la formación disciplinar de la época fue el Cours d'Architecture de 1771 de Jacques François Blondel, en el que se afirma que cada tipo de fábrica requiere un manejo especial en el planteamiento funcional que determina la situación y distribución de los diversos edificios que lo componen, aconsejando la inclusión de unas estancias especiales para el alojamiento de los Directores e Inspectores encargados de velar por el buen orden del complejo. De igual forma, se insiste en que la complejidad de su planta se debe adecuar al objetivo para el que se construye el inmueble fabril, de forma que según la naturaleza del objeto a producir, los edificios deberán estar provistos de grandes salas, talleres, laboratorios, almacenes, patios y dependencias varias que determina la situación y distribución del edificio principal, adoptando todas las comodidades necesarias en función de la importancia de la manufactura en cuestión. Sobre las características de la arquitectura que materialice estos establecimientos fabriles, Blondel incide en el carácter simple y racional de los mismos, puesto que la ordenación de la arquitectura debe ser simple y de construcción sólida, sin por ello presentar un carácter marcial. En cuanto a la implantación de la fábrica en el territorio,

Jacques François Blondel apoya [...] la introducción de la gran industria en la ciudad, que se había de situar en sus arrabales: "on doit placer ces édifices a l'extrémité des Faubourgs des capitales, le terrain qu'ils occupent étant trop considérable pour être renfermé dans le sein des Villes, on doit leur procurer des eaux abondantes, soit per le secours d'une machine hydraulique, soit par la courant d'une petite rivière, plus propre que celle de source pour tous les genres de travaux $»^{50}$,

aludiendo a la necesidad de una gran superficie de ocupación y de disposición de una fuente de agua cercana como recurso indispensable tanto para sus actividades como para los obreros empleados en dicho establecimiento.

Sobre su antecesor y casi de nombre homónimo François Blondel, y en particular la interpretación de su obra en paralelo a los planteamientos del ministro Colbert, resulta de capital importancia la consulta de la obra de Anthony Gerbino François Blondel. Architecture, Erudition and the Scientific Revolution. Señala Gerbino que el objetivo del primer Cours d'architecture no era el de proporcionar una simple enciclopedia, sino establecer un discurso público en el que se señalasen los cometidos

\footnotetext{
50 ["Se deben situar los edificios en los extremos de los arrabales de las capitales, puesto que el terreno que ocupan es demasiado considerable como para encerrarlo en el seno de las villas, se les debe procurar abundancia de agua, sea con ayuda de una máquina hidráulica, sea con la corriente de un pequeño río, como fuente más limpia para todo tipo de trabajos"]. RABANAL YUS, A. M. (1990) op. cit., p. 31.
} 
adjudicados a los arquitectos del rey. Este discurso debería ser crítico y prescriptivo, sirviendo como base para el entendimiento de la arquitectura clásica. El tratado, por tanto, defendía el ideal de pureza decorativa y precedentes clásicos en oposición al abuso y al exceso en arquitectura estableciendo dos puntos cruciales: la censura de Blondel a la sobre-ornamentación y la crítica a una aplicación del vocabulario clásico sin ningún tipo de guía tutorada. Sobre la relación particular que se estableció entre los planteamientos de Colbert y Blondel, cabe destacar que el primero entendió que la especificidad nacional de cualquier estilo arquitectónico implicaba la creación de una importante dimensión estética que se identificase con dicho objetivo ${ }^{51}$.

En 1785, Francesco Milizia se limitaría a recoger en sus Principi di Architettura Civile los postulados anteriormente enunciados por Blondel $^{52}$, puesto que afirma que cada manufactura exige un tipo de fábrica con diversa situación y disposición aconsejando la inclusión de alojamiento para los operarios, directores e inspectores encargados de vigilar a los primeros, llevando el establecimiento al buen orden, economía y mejora del producto a elaborar, lo que básicamente convierte el texto del italiano en una réplica de los criterios expuestos por Blondel. Por otra parte, al igual que Blondel y D'Avilier, Milizia incide en que en el aspecto funcional, la fábrica debe estar provista de grandes salas, laboratorios, almacenes y patios, así como de todas las comodidades particulares repartidas en función de la importancia de la manufactura, lo que lleva a pensar que conocía el texto original del Cours d'architecture y simplemente se limitó a su traducción al italiano puesto que no aporta ninguna novedad. Nuevamente, reitera como características definitorias de la arquitectura fabril su orden simple y de construcción sólida, sin presentar un carácter fiero y marcial.

Milizia establece incluso la misma diferenciación que Blondel entre la situación urbana, suburbana o rural de los establecimientos industriales atendiendo al tipo de producción, puesto que en las ciudades deben ubicarse aquellas manufacturas "delicadas y de gran lujo" dependientes de las artes del diseño, situándose cerca de las murallas o fuera de la ciudad por el gran terreno que ocupan. Por su parte, en el entorno rural debían establecerse otras manufacturas "gruesas" como las de paños, ropa, cuero, vidrio o fundiciones que debían ubicarse lejos de las grandes ciudades, en aquellos pueblos de mayor abundancia y fácil comunicación. Se debía, así mismo, procurar a estos edificios acopio de agua, bien con la ayuda de máquinas hidráulicas o bien mediante corrientes fluviales.

En el contexto francés, además del importante tratado de Blondel, cabe destacar otros autores. Pevsner menciona el raro tratado de F.

51 GERBINO, A. (2010) François Blondel. Architecture, Erudition, and the Scientific Revolution, Londres: Routledge, Taylor \& Francis Group, pp. 66-69. Cabe diferenciar entre François Blondel coetáneo al ministro Colbert, su sucesor en la Académie Jacques-François Blondel de finales del S.XVIII, y Jean-François Blondel tío del anterior y arquitecto autor de la Manufacture de Tabacs de Morlaix entre 1736 y 1740.

52 Pevsner también señala las similitudes del tratado de 1785 de Francesco Milizia con el precedente de Blondel. PEVSNER, N. (1976 [1997]) A history of building types, Princeton University Press, p. 273. 
Coitereaux Traité sur la construction des manufactures de 1791 que contiene la descripción de la reconstrucción realizada por Coitereaux de las Reales Fábricas Textiles en el Faubourg Saint Sever, en Rouen ${ }^{53}$.

Pero más relevantes fueron los cursos de arquitectura de comienzos del S.XIX de J.N.L. Durand con su Précis des leçons d'architecture données à l'Ecole Polytechnique, publicado a principios del S.XIX en 1802-1805. El tratado de Durand continúa la tradición de Jacques-François Blondel, que en su segundo volumen del Cours d'architecture civile, publicado en 1771, trataba los edificios según sus tipos arquitectónicos. Siendo un tratado arquitectónico, muchos de sus conocimientos iban dirigidos al ingeniero que se enfrentaba al problema de abordar la concepción proyectual de nuevos temas arquitectónicos. Durand era consciente de que era preciso superar los planteamientos del Antiguo Régimen, así como facilitar el ejercicio de la arquitectura a los ingenieros que disponían de "más ocasiones de realizar obras que los arquitectos propiamente dichos [...] se encuentran por su condición llamados a levantar hospitales, prisiones, cuarteles, arsenales, almacenes, puentes, puertos, faros [...]"54. Muchas de las planimetrías de la parte gráfica de sus lecciones de arquitectura servirían de inspiración para algunos de los proyectos enfocados hacia una función industrial como se ha comprobado a lo largo de la presente investigación.

Finalmente, sin abandonar la tratadística de origen francés, completaría esta serie de publicaciones Quatrémere de Quincy con su Dictionnaire historique d'Architecture editado en 1832 en el que específicamente alude a una doble tipología fabril consistente en un planteamiento en "bloque" en los inmuebles fabriles cuyas dependencias se hallaban reunidas en un único edificio, y otra tipología en la que la planta se organizaba en diferentes pabellones. Este autor define la fábrica en su tratado como un área de terreno en la que se distribuyen diversos cuerpos edilicios que encierran alojamientos, salas para laboratorios, almacenes y todas las piezas necesarias para la fabricación de los productos que deben ser ejecutados en el complejo, descripción que retoma las nociones de D'Aviler, Blondel y Milizia. Por otra parte, distingue una doble tipología en su planteamiento: las manufacturas que forman una gran masa edilicia -como por ejemplo la Real Fábrica de Porcelana de Sèvres- y aquellas que se dividen en varias patios y pabellones -como la Real Fábrica de Tapices de Gobelins-, anticipándose a la posible formulación del espacio fabril en un modelo compacto o reunido y un modelo en pabellones o disperso. Apunta Rabanal Yus la insistencia de Quatrémere de Quincy en la necesaria sencillez y funcionalidad de los tipos fabriles puesto que una manufactura es un edificio en el que la condición primordial es su utilidad y, como el principio de todo establecimiento comercial es la economía, se entiende que la arquitectura de tal función exige únicamente lo necesario, rehuyendo la decoración, por lo que el carácter

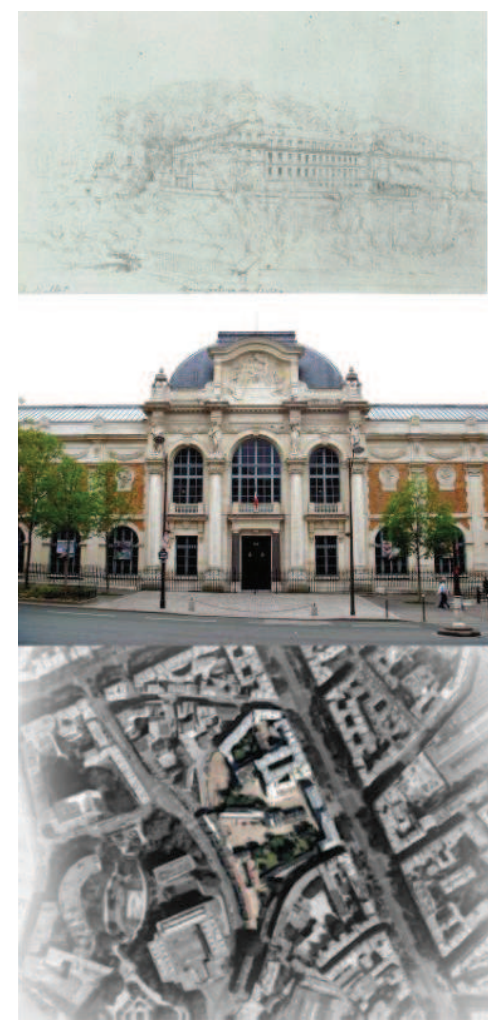

Figura 2.6. Fábrica en bloque, Real Fábrica de Porcelana de Sèvres, en PEVSNER (1976 [1997]) op. cit., p. 273; y fábrica en pabellones, Real Fábrica de Tapices de Gobelins, en Wikimedia Commons.

\footnotetext{
53 PEVSNER, N. (1976 [1997]) op. cit., p. 281.

54 DURAND, J.N.L. (1802-9 [1981]) Compendio de lecciones de arquitectura. Parte gráfica de los cursos de arquitectura, Madrid: Pronaos, p. VI.
} 
principal de las manufacturas debe ser la simplicidad.

Finalmente, y cerrando la relación de autores a los que Rabanal Yus dedica su capítulo sobre planteamientos teóricos, cabe destacar su reflexión sobre cómo a lo largo del S.XIX la tipología fabril

ha ido aumentando su complejidad e importancia, aunque manteniendo una articulación básica en torno a uno o más patios, generando toda una serie de talleres complementarios, que ahora presentan un mayor desarrollo y relevancia, sin duda provocado por un deseo de mejorar los resultados del proceso de producción [...] y permitiendo un complejo crecimiento de los talleres creados en función de aquéllos, sin duda causado para conseguir aumentar las cifras y la calidad de producción ${ }^{55}$.

Por otra parte, ya se ha hecho referencia anteriormente al carácter de las tipologías arquitectónicas como concreciones de modelos adaptados a necesidades concretas viéndose influidas por las variables estilísticas de su época o espacio geográfico de desarrollo. En el caso de las reales fábricas españolas

tipológicamente se concretan en un edificio bloque con uno o más patios interiores. La Fábrica de Tabacos de Sevilla es paradigmática en este sentido. Sin embargo, ya en el propio siglo XVIII surgirá una nueva tipología compuesta por la agrupación de pabellones en plena naturaleza [...] Ambas tipologías respondían con eficacia no sólo a la producción sino a la implantación de un orden moral y de un control social que les acercaba a los edificios penitenciarios ${ }^{56}$.

De esta forma, se observa cómo en la arquitectura de las reales fábricas españolas se opta por un modelo de carácter compacto frente a la disposición fabril en pabellones que se citaba anteriormente.

Viendo la importancia que el concepto de tipo arquitectónico adquiere en la presente investigación, se hace necesaria la profundización en cuestiones que tienen que ver con la historia de las tipologías y las posibles relaciones entre la formalización de la tipología tabacalera en España y la toma de referentes de otros tipos de diverso origen ante la falta de referentes culturales o modelos en la época en la que fue desarrollada.

Sobre esta cuestión, la obra de Nikolaus Pevsner Historia de las tipologías arquitectónicas de 1976 resulta de obligada consulta al objeto que persigue este trabajo. En dicha publicación, el autor aborda un estudio que a la sazón aún no había sido realizado, sobre la historia de los edificios en sus diversos tipos, permitiendo la demostración de la evolución de los mismos tanto en su estilo como en su función.

Se centra, pues, esta obra en una selección de tipos arquitectónicos que el autor considera como poco estudiados en las publicaciones que preceden a su trabajo, y en los que deliberadamente se excluyen algunos tipos interesantes para la presente investigación como los palaciegos -especialmente los urbanos-, por las conexiones observadas

${ }^{55}$ RABANAL YUS, A. M. (1990) op. cit., p. 27.

56 HERNANDO, J. (1989) op. cit., p. 354. 
en la concepción de las fábricas de tabacos en España. No en vano, además del capítulo dedicado específicamente a la historia de la tipología fabril, merecen atención los apartados dedicados a hospitales y prisiones. Sobre estos tipos, señala Pevsner con carácter general que sus planteamientos de distribución tienen mucho en común; no en vano, en sendos tipos edilicios "la gente está en un lugar donde preferirían no estar y en ambos casos se precisa una constante vigilancia"57.

Se ha de recordar que, ya en el epígrafe anterior se han recogido reflexiones interesantes sobre este punto en el carácter coercitivo de los primeros espacios del trabajo y sus conexiones con otras tipologías en las que se precisa el alojamiento de una ingente masa de personas junto al control y orden de las mismas. Estas premisas pueden compartirlas tanto hospitales y prisiones como cuarteles y, en este caso, edificios de carácter fabril, especialmente los dedicados a una producción manufacturera. Nuevamente, Pevsner recuerda la importancia de las teorías de Bentham en la concepción de un proyecto de esquema radial basado en la ubicación de celdas en la periferia de un círculo y un puesto de observación central, destacando sus posibilidades de uso como escuela, fábrica, hospital y especialmente prisión ${ }^{58}$, que entroncan con los postulados enunciados en el epígrafe anterior por Ornella Selvafolta.

Es especialmente relevante en la investigación que al caso ocupa el capítulo dedicado al estudio de los tipos fabriles, en el que se hace un repaso a las principales realizaciones de los primeros momentos manufactureros, desde las manufactures royales con la relevante figura del ministro Colbert como impulsor de modelos fabriles de carácter real, pasando por los distintos planteamientos teóricos de Ledoux o Robert Owen y llegando finalmente a los tipos desarrollados al amparo de los avances técnicos, especialmente los posibilitados por la construcción en hormigón armado, destacando la figura de Pier Luigi Nervi -en especial su Fábrica de Tabacos de Bolonia del año 1952-.

En particular, resultan de interés las analogías que Pevsner establece con otros "tipos o estilos" como en el caso de la Fábrica de porcelana de Sèvres del arquitecto Lindet, de cuyos establecimientos destaca que "tenían una nueva escala, un estilo palaciego, con un centro y dos pabellones terminales que juntos hacían un total aproximado de 425 pies de largo y de cuatro plantas". Sobre esta obra en particular, hace hincapié en la descripción que el Marqués D’Argenson realiza en 1755, refiriéndose a la real manufactura como "una construcción inmensa y casi tan grande como el Hôtel des Invalides", afirmación que Pevsner estima exagerada aunque se refiere al gran tamaño de algunas reales manufacturas como la Real Fábrica de Tabacos de Sevilla. Nuevamente, nos encontramos con un paralelismo entre otros tipos como palacio y hospital, en relación al análisis de una construcción fabril.

57 PEVSNER, N. (1976 [1997]) op. cit., p. 188. Sobre estas tipologías, se seguirá el discurso de Pevsner en los capítulos "Hospitals", pp. 139-158; y "Prisons", pp. 159-168. Por otra parte, resulta de obligada lectura para esta investigación el capítulo "Factories", pp. 273-288.

58 Cabe recordar en España el singular caso de la Real Fábrica de Paños de Brihuega fundada por Fernando VI, cuyo primer proyecto de Manuel Villegas y el finalmente construido de Ventura Padierne presentan un esquema en planta en rotonda, con un claro carácter de experimentación teórica en la definición de un inmueble fabril. 
Retomando el contexto francés, tan relevante en el estudio de los orígenes tipológicos de las reales manufacturas, Pevsner se ocupa de algunos casos de interés como la gran fundición de Le Creusot, construida en 1779 en tiempos de Luis XVI y cuya concepción se encargó al ingeniero Touffaire y a los hermanos arquitectos Raimbaud. También resulta interesante la relación que establece entre diversos postulados teóricos como la Utopía de Ledoux que parece inspirar el "Proyecto para un pueblo de cooperación" de Robert Owen y que en materia de formalización de utopías arquitectónicas industriales, culmina en el Falansterio de Charles Fourier presentado en 1829 en su obra Le nouveau monde industriel, que retoma la inspiración monumental en un conjunto fabril compuesto por un gran edificio simétrico que seguía un esquema en $U$ presentando sendas alas y configurado internamente en torno a grandes patios.

En el apartado de conclusiones a su obra, cabe señalar la importancia que Pevsner otorga a la planimetría como instrumento de análisis y definición de los tipos arquitectónicos y su evolución con el curso del tiempo. Resulta significativa la reflexión que realiza en torno a la "historia de la planta de cruz y su derivada, la planta radial" que empieza en los hospitales del S.XV y cuyo esquema se continúa empleando en las prisiones. Destaca que en ambos tipos edilicios, "las consideraciones humanitarias e higiénicas corren paralelas" y señala cómo el pensamiento funcional rige los cambios establecidos en un tipo determinado como es el hospitalario ${ }^{59}$. Sin duda, esta afirmación puede trasladarse a otros tipos arquitectónicos, especialmente en la producción tabacalera que ocupa a la presente investigación, puesto que en el periodo estudiado se produce una significativa transformación conceptual en el paso de una producción casi preindustrial, de carácter artesanal y manufacturero, al intento de implantar nuevos métodos productivos basados en la racionalización espacial y organizativa y en el empleo de la incipiente mecanización.

\subsection{Aproximación a las fábricas de tabacos en España: contexto histórico, económico y social}

\subsubsection{El monopolio hacendístico del tabaco en España y su contexto histórico}

Una de las premisas que postula la presente investigación es el carácter indisociable del espacio del trabajo con el proceso productivo que alberga. Por tanto, para una mayor comprensión de las tabacaleras como espacio industrial, así como su consideración como patrimonio industrial arquitectónico, es necesario examinar las cuestiones relativas a la historia del tabaco en España y en particular al desarrollo del monopolio hacendístico sobre el mismo, al igual que las características y evolución de su producción y las implicaciones del establecimiento de una jerarquía laboral que estructuraba la realidad social de las fábricas.

\footnotetext{
${ }^{59}$ PEVSNER, N. (1976 [1997]) op. cit., p. 289.
} 
Sobre este particular, cabe destacar la deuda intelectual que el desarrollo del presente epígrafe tiene con la labor de algunos estudiosos fundamentales para el estudio de la historia del monopolio hacendístico del tabaco en España. Además de aquellos pioneros en la interpretación de sus orígenes y evolución ${ }^{60}$, destaca particularmente la extraordinaria labor que ha realizado el Grupo de Estudios del Tabaco ${ }^{61}$ en la última década. En palabras del recientemente desaparecido José Manuel Rodríguez Gordillo, una autoridad en este campo ${ }^{62}$,

asistimos en el año 1999 a la firma de un Convenio de Colaboración entre la Fundación Altadis [...] con el grupo GRETA constituido a tal efecto. El grupo de estudios se conforma contando con seis profesores de cuatro prestigiosas universidades españolas: José Manuel Rodríguez Gordillo de la Universidad de Sevilla, Montserrat Gárate Ojanguren de la Universidad del País Vasco-Euskal Herriko Unibersitatea, Agustín González Enciso y Rafael Torres Sánchez de la Universidad de Navarra y Santiago de Luxán y Sergio Solbes Ferri de la Universidad de Las Palmas de G.C. Más adelante se incorporaría al grupo el profesor Óscar Bergasa Perdomo, de la Universidad de Las Palmas de G.C. La empresa tabaquera española, a través de su Fundación [...] ha venido financiando asimismo una línea de publicaciones -Los Libros de Altadis-, con Alberto Sanjuanbenito Aguirre como coordinador general de la colección [...]

Las líneas de investigación desarrolladas por el grupo GRETA se refieren de modo predominante al ámbito del Antiguo Régimen y, de manera especial, al siglo XVIII [...] En los primeros momentos analizamos y estudiamos de forma individualizada determinados aspectos parciales del monopolio tabaquero español tales como su estructura administrativa, la actividad manufacturera, el uso de la materia prima o los mercados de abastecimiento y consumo [...] Muchos de los propios miembros del GRETA han publicado monografías particularizadas dentro de esta misma colección. El

\footnotetext{
${ }^{60}$ Diversos autores han contribuido al estudio del monopolio hacendístico sobre la producción tabacalera en España desgranando claves importantes para su conocimiento. Es fundamental la consulta, entre otros, de GARCÍA DE TORRES, J. (1884) Las rentas estancadas. Apuntes históricos, observaciones y datos estadísticos. Madrid: Imp. De Loterías; DELGADO y MARTín, E. (1892) La Renta de Tabacos, Madrid: Tipografía de Manuel Ginés Hernández; PÉREZ VIDAL, J. (1959) España en la historia del tabaco, Madrid: CSIC; TAMAMES GÓMEZ, R. (1972) "El monopolio de tabacos" en Hacienda Pública Española, no 18, pp. 15-44; ALBIÑANA, C. (1987) "El arriendo del monopolio del tabaco en España: notas históricas" en Hacienda Pública Española, n¹08-109, pp. 377-392; ALONSO ÁLVAREZ, L. (1993) La modernización de la industria del tabaco en España, 1800-1935, Madrid: Fundación Empresa Pública, Programa de Historia Económica; y ESCOBEDO ROMERO, R. (2006) El Tabaco del Rey. La organización de un monopolio fiscal durante el Antiguo Régimen, Pamplona: EUNSA.

${ }^{61} \mathrm{Al}$ objeto de la presente investigación, se destacan las publicaciones del GRETA ALONSO ÁLVAREZ, L.; GÁLVEZ MUÑOZ, L.; y DE LUXÁN, S. (coord.) (2006) Tabaco e Historia económica. Estudios sobre fiscalidad, consumo y empresa (siglos XVII-XX), Madrid: Fundación Altadis; BERGASA PERDOMO, Ó. (ed.) (2007) EI Monopolio Español de Tabacos en el siglo XVIII. Consumos y valores: una perspectiva regional, Madrid: Fundación Altadis; COMÍN COMÍN, F. y MARTÍN ACEÑA, P. (1999) Tabacalera y el estanco del tabaco en España (16361998), Madrid: Fundación Tabacalera; y GONZÁLEZ ENCISO, A. (coord.) (2008) Política Económica y Gestión de la Renta del Tabaco en el Siglo XVIII, Madrid: Fundación Altadis; además de las obras monográficas sobre algunas de las unidades fabriles del monopolio de las que se hará referencia en el presente capítulo.

62 Se recomienda la consulta, entre otros, de sus trabajos sobre el contexto del monopolio hacendístico de 2002: RODRÍGUEZ GORDILLO, J. M. (2002a) La creación del estanco del tabaco en España, Madrid: Fundación Altadis; RODRÍGUEZ GORDILlO, J. M. (2002b) La difusión del tabaco en España. Diez estudios, Sevilla: Altadis; y las obras generales RODRÍGUEZ GORDILLO, J. M. (2007) "La renta del tabaco en el primer tercio del siglo XVIII" en BERGASA PERDOMO, Ó. (ed.) op. cit, pp. 25-105; RODRÍGUEZ GORDILLO, J. M. (1993) Diccionario Histórico del Tabaco, Madrid: Tabapress; y RODRÍGUEZ GORDILLO, J. M. (1984a) Un archivo para la historia del tabaco, Madrid: Fundación Tabacalera.
} 
impulso del GRETA ha sido por tanto causa y consecuencia de que el tabaco captase durante estos años la atención de otros investigadores españoles como Francisco Comín, Pablo Martín Aceña, Luis Alonso Álvarez, Lina Gálvez o Rafael Escobedo63.

Precisamente Rodríguez Gordillo señala dos autores de una obra de referencia para el conocimiento general del monopolio hacendístico del tabaco en España: la publicación de Francisco Comín Comín y Pablo Martín Aceña Tabacalera y el Estanco del Tabaco en España (16361998) de 1999 que supone un exhaustivo compendio sobre la historia socioeconómica del monopolio, su producción y las unidades fabriles que lo integran. En este sentido, tanto esta obra como las anteriores han contribuido significativamente para la elaboración de un estado de la cuestión sobre la historia del monopolio hacendístico del tabaco en España y las vicisitudes por las que pasó el proceso de producción tabacalero que se detallarán a continuación.

\section{Los inicios de la producción tabacalera}

Para encuadrar el objeto de atención del presente epígrafe, cabe comenzar destacando que el monopolio hacendístico del tabaco en España se estableció siguiendo un voluntarismo político-administrativo motivado por la organización del pujante consumo en torno al tabaco y como método para combatir el contrabando y controlar el abastecimiento $^{64}$. No en vano, con la expansión del hábito del tabaquismo en la sociedad del S.XVIII ${ }^{65}$, la renta obtenida por el tabaco pasó a ser objeto de interés por parte de la Corona al representar una parte fundamental de la Hacienda borbónica. A la etapa inicial de los siglos XVII y XVIII en la que se estableció la regulación administrativa y la estructura productiva y distributiva del tabaco, le siguió la consolidación definitiva de la red industrial manufacturera del S.XIX con la expansión de la elaboración y consumo del tabaco, el inicio de los cultivos en la península y el establecimiento de una red de fábricas tabacaleras en diversas localidades que se caracterizaban mayoritariamente por una localización costera.

El consumo del tabaco en Europa comienza con el descubrimiento del continente americano y la importación desde las colonias a las monarquías europeas. Precisa Guarnido Olmedo sobre los orígenes de la expansión del tabaco en el mundo:

63 RODRÍGUEZ GORDILlO, J. M. (2009) Grupo de Estudios del Tabaco. Breve bosquejo sobre el proceso de su creación y trayectoria, texto disponible en www.yumpu.com/es/document/view/14434979/grupo-de-estudios-deltabaco-breve-bosquejo-sobre-el- [acceso 07-4-2016] y subido por grupodeestudiosdeltabaco.com. En el año 2012, durante el estudio del estado de la cuestión de la presente investigación, esta última página web aún estaba en activo y permitió la consulta y descarga de gran parte de la bibliografía elaborada por el GRETA. Lamentablemente, en estos momentos se encuentra inactiva y, por tanto, su contenido es inaccesible.

64 GONZÁLEZ ENCISO, A. (2008) op. cit., p. 22.

65 "Sobre los consumos de tabaco en aquellas fechas [...] contando con todas las variedades que entonces se comercializaban: tabaco polvo fundamentalmente, en segundo lugar rollo brasileño y a gran distancia, y en menor medida aún, manojos habanos y cigarros". RODRÍGUEZ GORDILLO (2007) op. cit, p. 44. Señala, así mismo, que algunas partidas de los mismos, sobre todo el brasileño, no llegaban por Sevilla si no a través de alguna factoría, por compra directa en navíos de las Indias o por negociaciones bajo licencia realizadas por los administradores en puertos amigos. 
las primeras noticias que tenemos sobre el tabaco fueron aportadas por los descubridores y exploradores españoles tras su regreso de las tierras del Nuevo Continente, en algunas de las cuales era conocido [...]

[El tabaco es una planta] perteneciente a la familia de las Solanáceas y al género Nicotiana [...] Se cuenta que cuando los españoles desembarcan en la isla de Guanahani o de "San Salvador" quedaron asombrados por la costumbre que tenían los antillanos de conservar entre sus labios unos tubitos de hoja enrollada, al par que lanzaban bocanadas de humo. Pero esta misma costumbre pudieron observarla en todos los habitantes de las demás islas que descubrieron, especialmente en la isla de $\mathrm{Cuba}^{66}$.

Señala el citado autor que las condiciones climatológicas de aquellas tierras favorecían en alto grado el desarrollo de la planta del tabaco, siendo la isla de Cuba la que figuraba a la cabeza, aunque la planta se daba en una amplia región del continente americano cuyos límites podrían ser aproximadamente el Norte de México, Sur de Bolivia y Este de Venezuela. Resulta interesante el hecho de que el léxico en torno al hábito tabacalero parece provenir de las costumbres de sus primeros consumidores indígenas.

El ermitaño fray Romano Pane, que en 1496 estuvo evangelizando aquellas tierras de Haití, nos habla de las plantas que fumaban los indígenas y que llamaban "cohoba" o "cogiaba", en cambio en la isla de Santo Domingo la llamaban "cogiva", pero los españoles la denominaron "tabaco". Así, Fernández de Oviedo nos habla de uno de los vicios de los indios, el de tomar una ahumada, que ellos llaman "tabaco", para salir de sentido. Por otra parte, existen historiadores que afirman que el nombre de tabaco se le daba al utensilio que les servía para aspirar y que tenía forma de "Y", pues lo hacía por la nariz ${ }^{67}$.

Sobre los inicios del uso de la planta del tabaco en España, son interesantes los apuntes realizados por Guarnido Olmedo en los que señala que dicha práctica comenzó a principios del S.XVI como planta ornamental, que posteriormente pasaría a emplearse con fines medicinales y terapéuticos ${ }^{68}$. Finalmente, durante el S.XVII pasaría a consumirse como tabaco de mascar y tabaco picado para pipa, cigarrillo o cigarro puro, siendo predominante su consumo entre las clases pudientes en forma de rapé o tabaco en polvo para ser aspirado.

Certezas tenemos sólo a partir de los años centrales del siglo XVI, aunque ya para entonces no fueran exclusivas de Sevilla y de su inmediato hinterland. En Portugal, en Inglaterra, en Francia, en los
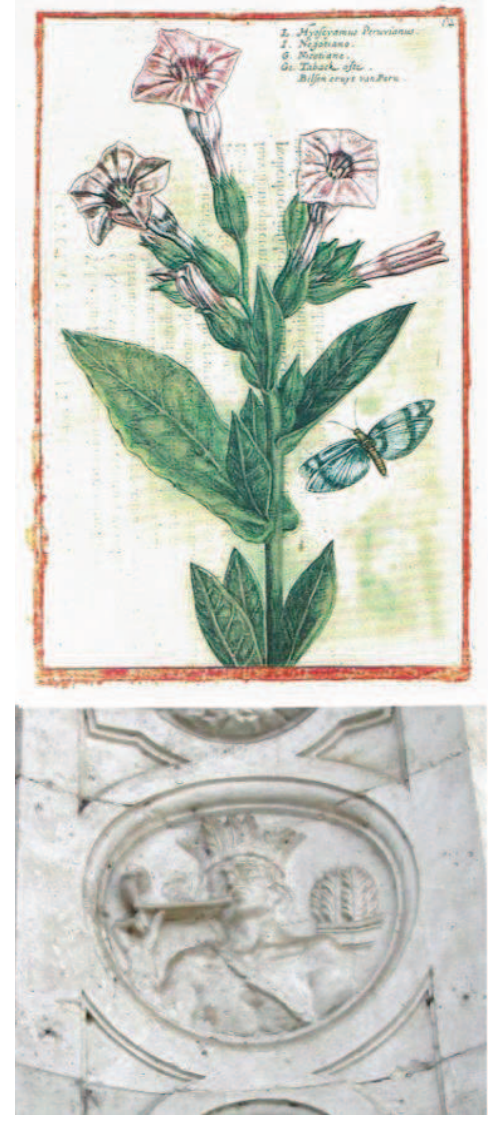

Figura 2.7. Planta del tabaco, en RODRÍGUEZ GORDILLO, J. M. (2005) op. cit., p. 16; y representación de indígena fumando en pipa en la portada de la Real Fábrica de Tabacos de Sevilla, 2015.

\footnotetext{
66 Sobre los comienzos de su uso en Francia, país que habrá de constituir una importante referencia en el contexto de esta investigación, señala Guarnido Olmedo: "En Francia su introducción se cree que fue debida a su embajador en Portugal Don Juan Nicot, que, en 1556, envió unas semillas de tabaco a la corte francesa y regaló una planta a la reina Catalina de Médicis [...] Como consecuencia del papel desempeñado por Nicot, los botánicos de París bautizaron con este nombre a la planta de tabaco", GUARNIDO OLMEDO, V. (1983) "Orígenes, expansión, producción y mercado de tabaco en España” en Cuadernos geográficos de la Universidad de Granada, n 13, p. 148.

${ }^{67}$ GUARNIDO OLMEDO, V. (1983) op. cit., p. 149.

68 Aunque no es objeto de esta investigación, Guarnido Olmedo recoge algunas apreciaciones interesantes sobre su caracterización como cultivo industrial. Clasifica así mismo el proceso de cultivo en cuatro fases: siembra, secado, fermentación y añejamiento, tras lo cual el tabaco pretratado se enviaría a la fábrica correspondiente para la siguiente fase de transformación. Los primeros cultivos los realizaron los españoles en Cuba, extendiéndose posteriormente a Filipinas, Formosa y el Sur de China. GUARNIDO OLMEDO V. (1982) "Características generales del tabaco en España” en Cuadernos geográficos de la Universidad de Granada, n 12, pp. 103-124.
} 
restantes países occidentales y, al mismo tiempo, por todo el norte de África, el tabaco era ya conocido y experimentaba un incipiente arraigo. En todos los casos, y de manera muy especial en la capital andaluza, la labor de los hombres de ciencia contribuyó de manera decisiva a este inicial conocimiento de la nueva y medicinal planta indiana ${ }^{69}$.

Por su parte, Rodríguez Gordillo señala algunos datos de interés que precisan los aspectos antes apuntados sobre las formas que adopta el tabaco en los inicios de su consumo en España:

Las noticias que se tienen, llevan al convencimiento de que a lo largo de las primeras décadas del siglo XVIII sólo se producían distintas variedades de tabaco "polvo" en Sevilla. Según todos los indicios eran las labores más primorosas, más complejas en su manufactura y, al mismo tiempo y como era de suponer, las más costosas. En gran medida su particular arraigo era prioritario entre las clases acomodadas de aquella sociedad. De cualquier forma, parece posible que el influjo desde estos grupos privilegiados hacia otras capas inferiores -mero mimetismo de usos o comportamientos superiores tan habituales en todo momento- ya se dejaba sentir en la elaboración de cierta variedad de tabaco polvo de inferior calidad y menor precio, cuyo consumo se había extendido de forma extraordinaria ${ }^{70}$.

Resulta crucial, así mismo, la aclaración que realiza sobre la habitual identificación de la Real Fábrica de Tabacos de Sevilla con la elaboración de cigarros y cigarrillos destinada en exclusiva a la mano de obra femenina, apreciación quizás alentada por el mito literario construido en torno a la figura de Carmen de Mérimée -no en vano, como se verá en el epígrafe siguiente, también crea una concepción errónea sobre la figura real de la cigarrera-. Trascendiendo la generalización de este particular gracias -o a pesar- de las licencias literarias, la fábrica hispalense, desde su fundación en el caserío conocido como Fábrica de San Pedro en el S.XVII hasta la generalización a principios del S.XIX de la elaboración de tabaco de humo -torcido o liado- se dedicó de manera mayoritaria a la elaboración de tabaco en polvo.

A lo largo del siglo XVII, como ya se ha dicho, se elaboró tabaco polvo casi en exclusiva; tan reducida era, y apenas en sus últimos quince años, la producción de cigarros, que entonces comenzaba su incipiente desarrollo manufacturero con tan sólo unas miles de unidades producidas [se refiere a la primera tabacalera hispalense conocida como "Fábrica de San Pedro"]. En el siglo XIX, por el contrario, estos últimos son los que ya se han afianzado con carácter definitivo, mientras que el tabaco polvo se bate en retirada con mínimas cifras de producción, podría decirse que casi testimoniales [...]

El siglo XVIII es, por tanto, el único en el que ambas variedades se expanden con plenitud entre los consumidores, forzando a la Real Fábrica a evolucionar en consecuencia para adaptarse y poder cubrir esta demanda creciente y en permanente cambio.

69 RODRÍGUEZ GORDILlO, J. M. (2005) Historia de la Real Fábrica de Tabacos de Sevilla, Sevilla: Fundación Focus-Abengoa, Universidad de Sevilla, p. 17.

70 Este fragmento y siguiente en RODRÍGUEZ GORDILLO (2005) op. cit., pp. 21 y 77. 
Pronto estos hábitos se trasladarán de la aristocracia a las clases populares, por lo que esta demanda sobre su consumo creará las condiciones propicias para establecer un mercado basado en su producción y comercialización. Debido a su consideración como un producto de lujo y a los beneficios que conllevaba la gravación de impuestos sobre un consumo de este tipo, las monarquías absolutas de los siglos XVII y XVIII implantaron una política intervencionista sobre el mercado del tabaco.

En España, esto se tradujo a priori en el establecimiento de un control sobre las importaciones de su cultivo delegadas en asentistas a los que se les otorgaba un arriendo por medio de privilegios. Posteriormente, el establecimiento del monopolio hacendístico que supuso la creación del Estanco del Tabaco sobre su producción y venta en 1636 como medida para aumentar los ingresos del rey a través de la gravación del consumo del tabaco, se afianzó con la asunción de la Administración Directa por parte de la Corona en 1731 -anteriormente se cedía la gestión del monopolio a particulares-. Señala Óscar Bergasa Perdomo que la Administración Directa -también se refieren en otros escritos como Universal Administración- permitía el control fiscal industrial y comercial a través del monopolio, puesto que tabaco y renta eran una regalía del soberano que no se discutía ${ }^{71}$. De igual forma, Campos Luque incide que desde la segunda mitad del S.XVIII y hasta 1887 el Estado delegaría en el Ministerio de Hacienda la administración de la renta hasta su arrendamiento a la Compañía Arrendataria de Tabacos $^{72}$.

No obstante, esta circunstancia no era ajena al resto de manufacturas reales, cuyos productos se elaboraban para el propio beneficio de la Casa Real o para las clases pudientes por su consideración de bienes de lujo, circunstancia que beneficiaba directamente a las arcas reales a través del gravamen de impuestos sobre su adquisición. Señala Alonso Álvarez que la Real Hacienda obtenía unos ingresos elevados a través de la venta del tabaco que, junto con los monopolios "de la sal, el papel sellado, los naipes y otros menores, constituían las llamadas rentas estancadas".

En un primer momento, tras el estanco sobre la venta del tabaco, se liberaliza la importación del tabaco elaborado o semielaborado procedente de las Antillas, en particular de Cuba -con la salvedad del pago de gravámenes por su introducción en la Península, de forma análoga a las restantes mercancías coloniales-, pero su comercialización pasaría a formar parte del monopolio, siendo cedida desde finales de 1636 a particulares en concepto de asiento. Alonso Álvarez refiere, además, que esta situación se mantendría hasta finales del S.XVII, momento en el que el funcionamiento a pleno rendimiento de la Real Fábrica de Tabacos de Sevilla permitirá al Estado ampliar el estanco al terreno de la producción creando dos calidades de tabacos: el de

${ }^{71}$ BERGASA PERDOMO, O. (2007) "El monopolio español de tabacos en el siglo XVIII: Reforma o continuidad" en BERGASA PERDOMO, O. (ed.) op. cit., p. 503.

72 CAMPOS LUQUE, C. (2004) Las cigarreras malagueñas: tecnología, producción y trabajo en la Fábrica de Tabacos de Málaga, Madrid: Fundación Altadis, p. 22. 
consumo suntuario, importado de Cuba ya manufacturado, y el de consumo popular que se fabricaba en Sevilla.

A partir de ese momento, "la estrategia de la Real Hacienda respecto a la renta es la de conseguir el monopolio sobre el ciclo completo de producción-comercialización, rescatando el asiento sobre las ventas"73. Con el tiempo, se igualó el monopolio de fabricación al de consumo, con la expansión del mismo entre las clases populares, con lo que la Renta del Tabaco comenzó a instituirse como una administración similar a una empresa ${ }^{74}$. Así, en el intervalo de casi un siglo se consigue el control directo por parte del Estado sobre el ciclo completo, estableciendo la Hacienda Pública la regulación administrativa monopolística sobre la producción y comercialización del tabaco, alentada por los impuestos establecidos sobre el tabaco como producto suntuario y por la expansión de su consumo a partir del S.XVIII.

\section{El periodo manufacturero de los siglos XVIII y XIX}

Durante el S.XVIII, dentro de la política intervencionista auspiciada por la monarquía de los Borbones que continuaban la línea establecida por la dinastía anterior, el Estanco pasó a ser administrado directamente por la Corona -la citada Administración Directa de 1731en el reinado de Felipe V, aboliendo los arriendos previos que se adjudicaban como regalía del rey a los asentistas, y pasando a controlar la producción tabacalera desde la fase de cultivo a la administración en los puestos de venta. Las reformas que instauraron el control directo sobre el Estanco del Tabaco en 1731 tuvieron su precedente en Carlos II y se basaban en las ideas de la Ilustración francesa que pretendían renovar la obsoleta estructura hacendística del Antiguo Régimen.

Mediante la Universal Administración se liquidaría el régimen de arrendamientos de forma progresiva, manteniéndose siempre desde un primer momento bajo el control de la Corona los de Sevilla, Madrid o Valladolid. En el resto de partidos, se finalizaba el arriendo a medida que se concluían los pactos establecidos en cada caso con los asentistas.

El proyecto que pretendía la implantación de su control directo por parte de la Real Hacienda [...] era una señal inequívoca de la importancia que los rendimientos derivados del tabaco alcanzaban ya para la corona española, y del interés por controlarlos de una manera más firme y, al mismo tiempo más eficaz, por parte de la nueva Administración borbónica. En ello, la Renta fue pionera entre todas las que se

\footnotetext{
73 ALONSO ÁLVAREZ, L. (1984) "De la manufactura a la industria: la Real Fábrica de Tabacos de La Coruña (1804-1857)" en Revista de Historia Económica - Journal of Iberian and Latin American Economic History, Año ${ }^{\circ}{ }^{2}$, $n^{\circ} 3$, p. 15. Según este autor, es en 1670 cuando se establece la primera fábrica de Sevilla en el barrio de San Pedro, aunque Rodríguez Gordillo apunta que la actividad industrial tabacalera se inicia en Sevilla medio siglo antes, en el año 1620. RODRÍGUEZ GORDILLO, J. M. (2005) op. cit., p. 19.

74 "La realidad se fue imponiendo en el sentido de que el monopolio de las ventas exigía también el monopolio de la fabricación [...] Aunque el monopolio del tabaco presente unas características básicas de monopolio fiscal [...] la implementación de tal realidad convierte la Renta en una institución administrativa con un organigrama que toma características de gran empresa”. GONZÁLEZ ENCISO, A. (2008) “A modo de introducción. El monopolio fiscal del tabaco como rasgo típico del mercantilismo estatal” en GONZÁLEZ ENCISO, A. (coord.) (2008) op. cit., pp. 17-27.
} 
integraban en la hacienda castellana en aquellos momentos ${ }^{75}$.

Por tanto, "durante el primer tercio del S.XVIII el tabaco se consolida como producto de consumo masivo en la sociedad española de la época y sus ingresos fiscales representan una parte fundamental de la renta de la Hacienda con tendencia clara a crecimiento"76. De esta forma, se reforzaba la idea del fortalecimiento del control del Estado sobre una de las rentas prioritarias de la monarquía ${ }^{77}$.

Como se señalaba anteriormente, en la primera mitad del S.XVIII el tabaco en rama procedente de América se desembarcaba en ciudades portuarias en las que se disponía de un depósito general o "factoría". Según Torres Sánchez, en 1772 existían factorías en Sevilla, Málaga, Almería, Cartagena, Alicante, Valencia, Palma, Gijón, Santander, San Sebastián y La Coruña ${ }^{78}$. Se hace notar que muchos de estos enclaves se corresponderían posteriormente con la localización de la futura red de fábricas de tabacos en España.

Ante esta enorme capacidad recaudatoria del monopolio se necesitaba la creación de una estructura productiva y distributiva eficaz contando con una administración y una estructura económica propias, autonomía financiera, una jurisdicción especial y una fuerza policial y paramilitar -el denominado como cuerpo de guardia-79. Para ello se establecieron una serie de puertos -además de Sevilla, otros repartidos por la costa peninsular como Cádiz, Alicante, Valencia, La Coruña o Gijón- en los que se descargaba la materia prima importada de Cuba, Brasil y Estados Unidos que se dirigía, bien directamente a Sevilla, que se constituyó como centro neurálgico de la producción fabril, bien a Madrid donde se establecieron los Almacenes Generales de la Corte, de donde partía a las distintas fábricas de la península.

Por otra parte, señala Aguilá Solana que

existían unos pequeños centros tabaqueros en Alicante, Bilbao, Gijón, Madrid, Ronda (Málaga), Betanzos y La Palloza (La Coruña), pero el hecho de que estuvieran ubicados en regiones a las que se enviaban regularmente tabacos elaborados desde Sevilla, induce a pensar "que su papel fuera exclusivamente de distribuidoras de los productos fabricados en la capital andaluza"80,

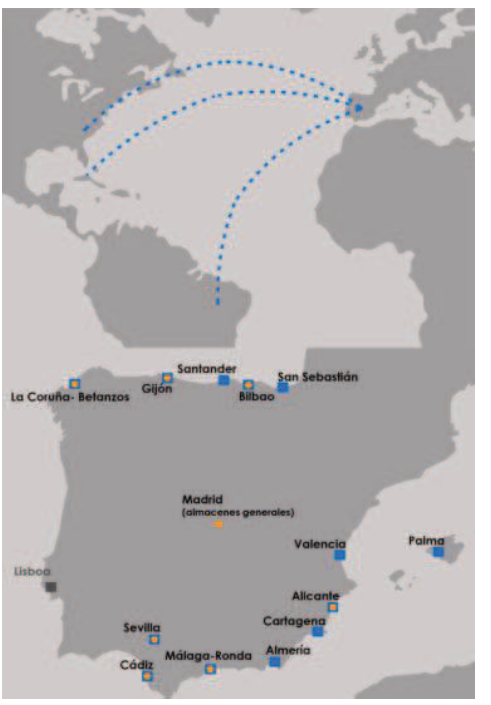

Figura 2.8. Procedencia de la materia prima y puertos de llegada en España destacando la ubicación de depósitos de tabaco.

\footnotetext{
75 RODRÍGUEZ GORDILLO, J.M. (2007) op. cit., p. 103.

76 BERGASA PERDOMO, O. (2007) op. cit., p. 497.

77 Se trata de un proceso lento ya que, como indica Rodríguez Gordillo, se ve obstaculizado por la superación de la crisis del siglo anterior, la dependencia del exterior para el abastecimiento de materia prima para las labores, la vigencia de modelos ideológicos del pasado y el deterioro de los vínculos con las colonias. RODRÍGUEZ GORDILLO, J. M. (2007) op. cit., p. 31.

78 TORRES SÁNCHEZ, R. (1999) "Capitalismo internacional y política estatal. Los asientos de tabaco en España durante la segunda mitad del siglo XVIII” en GONZÁLEZ ENCISO, A. y TORRES SÁNCHEZ, R. (1999) Tabaco y economía en el siglo XVIII, Pamplona: Eunsa.

79 BERGASA PERDOMO, O. (2007) op. cit., p. 501. En el caso de La Habana, por ejemplo, las tabacaleras contaban en el S.XIX con un cuerpo de bomberos propio que daba servicio, así mismo, al resto de la ciudad.

80 AGUILÁ SOLANA, I. (2006) "La Real Fábrica de Tabacos de Sevilla en el siglo XVIII según algunos viajeros franceses” en BRUÑA CUEVAS, M.; GRACIA CABALLOS BEJANO, M. de; ILLANES ORTEGA, I.; RAMÍREZ GÓMEZ, C.; RAVENTÓs BARANGÉ, A., Actas Congreso la cultura del otro: español en Francia, francés en España, Sevilla: APFUE, SHF, Departamento de Filología Francesa de la Universidad de Sevilla, pp. 97-107, citando RODRÍGUEZ GORDILLO, J. M. (2002b) op. cit., p. 84, nota 12. En este sentido, cabe pensar que esta denominación pudo ser motivo de confusión en los orígenes manufactureros de otras fábricas como Cádiz, La Coruña -o en
} 
lo que indica la confusión habitual debida a la denominación de "factoría" que recibían en la época los locales destinados a depósitos o almacenes y que se ha detectado en numerosas ocasiones en los intentos de datación de los casos estudio analizados como indicador de la presencia de una "fábrica".

El Estanco del Tabaco se mantuvo a lo largo de los siglos bajo dos premisas fundamentales: se trataba de una renta segura y se podía aumentar a voluntad según las necesidades debido a la consideración del tabaco como producto suntuario. Sin embargo, en la práctica su consumo se extendía rápidamente entre las clases populares que, no pudiendo asumir los costes del precio oficial, acudían al contrabando como remedio para obtener el producto ${ }^{81}$. Las causas del contrabando y el fraude eran, fundamentalmente, las deficiencias en la distribución o la imposibilidad de satisfacer la demanda de consumo que se acrecentaba a pasos agigantados. La popularización del consumo de producto tabacalero implicaba que el monopolio debía iniciar un posicionamiento estratégico en el territorio con objeto de controlar los enclaves estratégicos peninsulares mediante la ubicación de una fábrica que diese servicio directo y suministrase producto a su demarcación concreta -que en el caso de la Renta de Tabacos adoptaba el nombre de partidos-.

Por tanto, a pesar de su consideración como bien de lujo, los dictados de las prácticas instauradas en la sociedad alentaban un mercado ilegal y el consiguiente fraude al monopolio. No hay que olvidar que desde la primera mitad del S.XVIII el mercado legal experimentó una baja mientras que el ilegal aumentaba, puesto que la actividad de distribución y labores venía precedida de fábricas de elaboración preexistentes -junto a la elaboración informal realizada por particulares en aquellos puertos a los que llegaba la hoja de tabaco-, así como la creación clandestina de medios de transporte para su acceso a potenciales compradores que suponía un gran montante económico oculto a la vigilancia de la Renta.

Por otra parte, los conflictos bélicos del último tercio del S.XVIII y el aumento del gasto público por las tensiones con Inglaterra provocaron un enorme déficit en las arcas reales, alentando el aumento del coste del producto a voluntad. De esta forma, se apreciaba un descenso del consumo tabacalero "oficial" por las subidas de los precios ${ }^{82}$-en parte motivadas por el establecimiento del precio en función de las necesidades de la Hacienda y no de la demanda real-, a la par que el hábito se extendía cada vez más en una población que recurría al contrabando donde se obtenía tabaco de mayor calidad a un coste más

Betanzos-, y en Málaga, además de Alicante. Sobre este tema, refiere Alonso Álvarez que "é moi significativo que na xiria da Renda do tabaco a denominación de factoría -que na actualidade constitúe un sinónimo de fábrica- se utilizase daquela para designar os depósitos [de tabaco] existentes nalgúns portos peninsulares co fin de facilitar a almacenaxe e a distribución do tabaco". ALONSO ÁLVAREZ, L. (1998) As tecedeiras do fume. Historia da Fábrica de Tabacos da Coruña, Vigo: A Nosa Terra, p. 22.

81 BERGASA PERDOMO, O. (2007) op. cit., p. 504.

82 ALONSO ÁLVAREZ, L. (1984) op. cit., p. 16. 
ventajoso ${ }^{83}$.

Dado que la voluntad de la Renta de Tabacos no contemplaba la bajada de los precios -manteniendo los sustanciosos ingresos generados por el impuesto sobre el tabaco como producto suntuario-, estableció una estrategia de reorganización que se focalizó en la mejora de la calidad del producto y la ampliación de variedades que cubriesen plenamente el mercado, a lo que se unió el inicio de la expansión territorial estratégica de la producción. Por otra parte, la situación bélica venida con la ocupación francesa a principios del S.XIX, provocó la incomunicación y el aislamiento de las tabacaleras existentes en aquel momento -Sevilla, Cádiz, Alicante y La Coruña-, lo que repercutía en el mal funcionamiento de la distribución y abastecimiento de los diversos partidos en los que se organizaba la Renta de Tabacos en el territorio peninsular tanto de materia prima como de productos elaborados, desembocando en la creación de la Fábrica de Tabacos de Madrid en plena capital peninsular ${ }^{84}$.

Para estimular el consumo que había descendido desde finales del siglo anterior,

se redujeron los precios en espera de que descendiese el consumo ilegal y aumentase el estancado, al tiempo que la producción se concentró en las labores más rentables (entre las de calidad, mixtos y virginias; entre las intermedias, el tabaco en polvo, y entre las populares, el de mascar) y se relanzó en las factorías existentes, creándose, además, las de Santander y Gijón ${ }^{85}$.

La situación del Estanco entre 1820 y 1830 no experimentó mejoras notables. Los problemas de abastecimiento no afectaban sólo a los estanquillos de la Corte, sino también a otras administraciones de la provincia. A ello se añadía el creciente consumo de producto tabacalero por lo que el Gobierno hubo de adoptar una serie de medidas basadas fundamentalmente en el aumento de la producción de las fábricas de Alicante y La Coruña -que no se llevó a cabo, puesto que el aumento de plantilla había resultado contraproducente en la fábrica sevillana-, la creación de tres nuevas fábricas en Valencia, Gijón y Santander, y la reapertura de la fábrica madrileña ${ }^{86}$.

Sin embargo, muchas de las causas que abocaron la industria tabacalera a un retraso respecto a otros sectores residen en la tradición de la responsabilidad de la financiación de la manufactura por parte de la Real Hacienda, y de la Compañía Arrendataria de Tabacos y Tabacalera posteriormente. Este hecho inherente al monopolio hacendístico, conllevaría una serie de consecuencias que se trasladarían a la materialidad de los espacios e instalaciones tabacaleras. Como se apuntó anteriormente, la comercialización de tabacos también recaía

\footnotetext{
83 "Desde os comezos do século XIX xeneralizouse o tabaco para fumar, o consumido en fume, que foi desprazando ao que dominara ata mediados do século XVIII, o tabaco en po para aspirar". ROMERO MASIÁ, A. (2007) "As cigarreiras que coñeceu doña Emilia" en La Tribuna: cadernos de estudios da Casa Museo Emilia Pardo Bazán, n 5 , p. 42.

${ }^{84}$ CANDELA SOTO, P. (1997) Cigarreras madrileñas: trabajo y vida (1888-1927), Madrid: Tecnos, p. 57.

${ }^{85}$ ALONSO ÁLVAREZ, L. (1984) op. cit., pp. 29-30.

86 CANDELA SOTO, P. (1997) op. cit., pp. 59-60.
} 


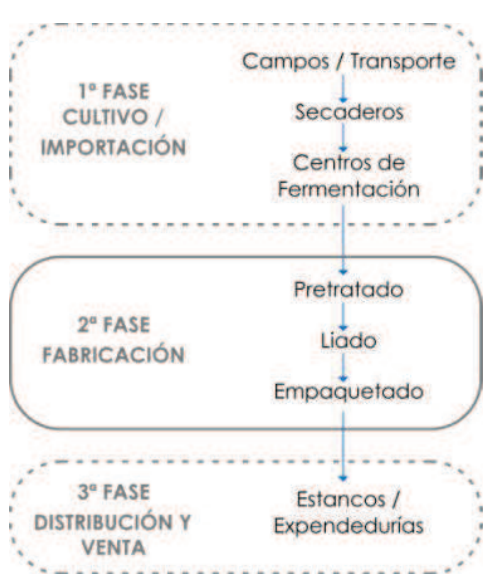

Figura 2.9. Esquema del ciclo productivo del tabaco. sobre la Hacienda Pública y cada fábrica se especializaba en un mercado determinado que variaba coyunturalmente dependiendo de los flujos de consumo. El producto se enviaba desde las fábricas a las administraciones provinciales y de ahí, se distribuían a los establecimientos de venta tales como estanquillos y expendedurías. La altísima rentabilidad de las fábricas se debía a la política establecida por el proteccionismo mercantilista del monopolio de fabricación, y el establecimiento de precios artificiales que respondían a necesidades públicas de ingresos, en vez de a la demanda real del consumidor ${ }^{87}$.

\section{El inicio de la modernización bajo la gestión de la Compañía Arrendataria de Tabacos S.A. desde finales del S.XIX}

A finales del S.XIX daría inicio un nuevo hito en la historia de la producción tabacalera con la cesión por concurso del arriendo del monopolio hacendístico a la Compañía Arrendataria de Tabacos S.A. con participación del Banco de España y otros accionistas- que vendría a ser la encargada de aplicar las reformas administrativas, productivas y espaciales requeridas por el monopolio para la modernización y mecanización de la producción tabacalera. Ante la imposibilidad del Estado de asumir dicha reestructuración, la CAT asumiría el papel desde la iniciativa privada con importantes consecuencias para las fábricas existentes y las que se fundarían en el seno de la nueva gestión, no sólo en términos de adquisición de maquinaria, sino en el diseño de nuevos espacios industriales, la adecuación de las condiciones del espacio productivo a los estándares requeridos por la higiene y seguridad laboral, las nuevas formas de energía, los nuevos espacios productivos, etc.

\section{Señala Gárate Ojanguren que}

años atrás y bajo la tutela del Ministerio de Hacienda, los responsables económicos de la Renta habían estado muy lejos de una visión empresarial conjunta de las diferentes unidades de producción. La "gran empresa" contaba con varias unidades, cuya estructura en cuanto a su origen como a su propia organización y características de personal, no respondían a una concepción unitaria de producción, a pesar de la uniformidad burocrática y reglamentaria aplicada. En este sentido, el modelo de explotación directa por parte del Estado resultaba casi agotado, por lo que la cesión de la explotación del tabaco en 1887 mediante la fórmula del arriendo, fue en aquel momento una solución oportuna en términos económicos ${ }^{88}$.

Ante el retraso técnico, el hacinamiento y las malas condiciones de los talleres se producen una serie de mejoras que repercuten en la organización y distribución del trabajo y que se encaminan hacia la supresión del contrabando. El denominado "Plan General de

87 "La altísima rentabilidad de las fábricas [...] obedece a la política del proteccionismo mercantilista en el monopolio de fabricación y en el establecimiento de precios artificiales que fluctúan de acuerdo con las necesidades públicas de ingresos y, por ello, con tendencia general al alza [...] lo que hacía que el consumidor acudiese a proveerse en fuentes marginales, como el contrabando". ALONSO ÁLVAREZ, L. (1984) op. cit., pp. 25-26.

88 GÁRATE OJANGUREN, M. M. (2006) La Fábrica de Tabacos de San Sebastián. Historia y Estrategia Empresarial 1878-2003, Madrid: Fundación Altadis, pp. 144-145. 
Fabricación" tenía como finalidad racionalizar la gestión de las fábricas, para lo que establecía unos requisitos claros para la preparación del personal técnico y superior que dirigiera la reorganización ${ }^{89}$.

La nueva gestión del monopolio se completa con la elaboración del "Reglamento Orgánico de las Fábricas" de 1888 en el que se establecen las nuevas líneas productivas a seguir, que indudablemente influyen en gran medida en el espacio laboral. Este documento, refleja un cambio de mentalidad en la lógica de explotación del monopolio, que abandona la concepción preindustrial específica de las labores del tabaco para paliar las carencias de las que adolecen las obsoletas fábricas tabacaleras e iniciar una modernización que optimice los costes y los recursos humanos de acuerdo con la producción. Este reglamento incidía en la organización interna y funcionamiento de las fábricas, y en la regulación de la preparación y la conducta de los empleados. De esta forma, se trataba de renovar la producción de las tabacaleras mediante una reconversión del sector que implicase la introducción de la mecanización en determinadas labores aprovechando la implementación de las instalaciones con nuevas formas de energía aptas para el inicio de la producción mecanizada, abaratando los costes, optimizando la producción y reduciendo la masificada plantilla.

Por tanto, los espacios deberían ser acondicionados para la presencia de las nuevas máquinas, reforzando las estructuras de las vetustas fábricas y redistribuyendo a las operarias, que sufrirían una progresiva reducción de plantilla, así como el aumento de la presencia masculina especializada en el mantenimiento de la maquinaria. Las restricciones de expansión dentro de los propios edificios, que se veían obligados a crecer hacia su interior en una suerte de laberíntica sucesión de espacios contenedores, generaron nuevos añadidos arquitectónicos en lenguaje contemporáneo industrial que se contraponía a la solemne arquitectura original.

Las unidades fabriles que se habían ido sucediendo a lo largo del S.XIX contaban con una situación de atraso y dificultades en muchos niveles $y$, en sus pretensiones de ensayar una nueva organización empresarial, la CAT debía afrontar una situación que conduciría a una asimetría en el acondicionamiento de las distintas fábricas. La experimentación de los nuevos métodos en estas fábricas existentes se realizó de forma paulatina por la inadecuación de los locales y las instalaciones, la resistencia opuesta por la mano de obra existente, etc., por lo que durante mucho tiempo convivirían las elaboraciones tradicionales con los nuevos sistemas propios de un proceso mecanizado. De esta forma, las primeras labores objeto de la modernización serían la picadura y los cigarrillos, mientras que los cigarros experimentarían durante muchos años una elaboración semimanual.

La acción fue genérica a todo el entramado para la gestión del monopolio y específica en el empeño de reorganización y reforma de las fábricas, en el que es posible contemplar que el ritmo no fue uniforme a

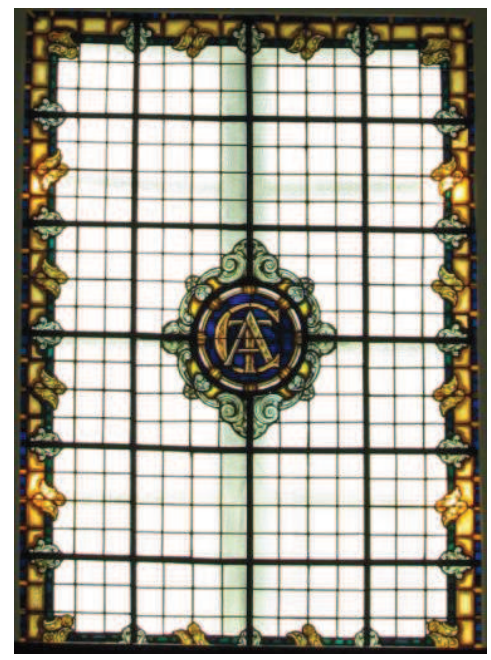

Figura 2.10. Anagrama de la CAT en el lucernario del pabellón de entrada de la fábrica malagueña, 2015.

\footnotetext{
${ }^{89}$ CANDELA SOTO, P. (1997) op. cit., pp. 43-44.
} 
todas ellas. No obstante, es cierto que la transformación en profundidad habría de tardar años en la mayoría de los $\operatorname{casos}^{90}$.

Sin embargo, las nuevas fundaciones fabriles y los proyectos de nueva planta sobrevenidos con la cesión del arriendo del monopolio a la CAT facilitaron el ensayo de la nueva organización productiva en los nuevos inmuebles concebidos a tal efecto, con una mayor presencia de parque de máquinas y una menor contratación de mano de obra, encaminando estas reformas hacia una mayor eficiencia y rendimiento de la producción y un mayor aprovechamiento de la materia prima. De igual forma, la estructura productiva del monopolio no atendía sólo a las unidades fabriles, sino que como apuntan Teixidor de Otto y Hernández Soriano su

tejido funcional abarcaba las fábricas, los almacenes de reconocimiento de la materia prima y los depósitos portuarios, como los de Santander y Cádiz, que actuaban de grandes almacenes desde donde, por orden de la Dirección, se distribuía convenientemente el tabaco a todas las factorías o a otros almacenes. Además de dichos establecimientos existían las representaciones de las fábricas en las provincias con sede en la capital, que eran una especie de almacenes de elaborados para la venta ${ }^{91}$.

Los procesos de renovación de la disciplina industrial a través de los sucesivos planes generales que tendrán lugar a lo largo del S.XX, constituirán un intento de erradicar la práctica institucionalizada de las fábricas que adolecía de una serie de hábitos heredados de la época preindustrial, a favor de la reconversión de las fábricas de tabacos en modernos centros de trabajo capitalistas. Ya en las primeras décadas del S.XX la CAT realiza un gran esfuerzo para implantar estas mejoras en las unidades fabriles existentes y construir nuevas factorías -el proceso se inicia con la fábrica de nueva planta de San Sebastián, la reutilización del convento mercedario de Logroño y la nueva planta fabril valenciana y continuaría con la construcción en la década de los 20 de las tabacaleras de Tarragona y Málaga- con arreglo a proyectos que cumpliesen los nuevos requerimientos espaciales de la producción.

Donde se apreciaron de forma más profunda e irreversible los nuevos cambios fue en el sistema de trabajo, ya que se sustituyó la antigua división espacial en ranchos y talleres por la de secciones, más acorde al proceso de industrialización y la presencia masiva de máquinas y automatismos atendidas por varias obreras bajo supervisión de una capataza. De igual forma, se eliminó el trabajo a destajo para pasar a un sistema salarial fijo con incentivos como premios a la producción y turnos de trabajo preestablecidos.

Sin embargo, las consecuencias de la mecanización no sólo afectaron al proceso productivo, sino también a la contratación del personal femenino. Mientras que el empleo de personal masculino aumentaba

90 RODRÍGUEZ GORDILLO, J. M. (2005) op. cit., p. 188.

91 TEIXIDOR DE OTTO, M. J. y HERNÁNDEZ SORIANO, T. (2000) La Fábrica de Tabacos de Valencia: Evolución de un Sistema Productivo (1887-1950), Valencia: Universitat de València, p. 72. 
debido a la necesidad de mecánicos y capataces para el mantenimiento de la maquinaria, las cigarreras veían como sus puestos de trabajo peligraban con la aparición de las nuevas máquinas. Esto desembocó en el estallido de una serie de motines luditas que supusieron un freno al desarrollo de la mecanización y que fueron particularmente virulentos, como el de 1906 en Madrid o el de 1908 en Alicante. No obstante, como señala Candela Soto, las ventajas de la mecanización eran evidentes. Mediante el empleo de torrefactores y refrescadores se ponía fin a los inconvenientes tradicionales del oreo puesto que anteriormente se precisaba de locales espaciosos con la humedad exacta. Por otra parte, mediante el empleo de las laminadoras y tiruleras se conseguía un mayor aprovechamiento de la hoja y los recortes. No obstante, como se apuntó anteriormente, durante el periodo final de la CAT y los inicios de Tabacalera se mantendría la convivencia entre los talleres manuales y los mecánicos.

$\mathrm{Al}$ año de apertura de la nueva fábrica donostiarra en 1913, el contexto general peninsular no distaba mucho de la situación de partida pese a los esfuerzos e intenciones de la CAT desde hacía casi década y media:

Aunque en 1914, la Arrendataria contaba con maquinaria moderna para la elaboración de cigarrillos, cigarros y otras operaciones, aún no se había alcanzado la mecanización integral del sector. Tras la mecanización de Valencia y Logroño, las mejoras de todo tipo habían llegado a otras unidades. Así, se había ampliado la fábrica de La Coruña y renovado las antiguas dependencias, al tiempo que se introdujo maquinaria para la confección de cigarros, lográndose compaginar el procedimiento manual y el semimecánico. En Sevilla y Madrid se hallaban mecanizadas sólo una parte de las labores, sobre todo las de cigarros, gracias a la adquisición que había hecho la Arrendataria de tiruleras Perfecto y Du Brul ${ }^{92}$.

La situación daría un giro con el establecimiento de la Dictadura de Primo de Rivera en septiembre de 1923. La política económica de este periodo, que fomentó un mayor intervencionismo, favoreció las aspiraciones de la CAT, de forma que la época de los años 1924 a 1928 fueron los más propicios para el plan de renovación tecnológica de todas las factorías: se completó la mecanización de aquellas unidades que habían nacido bajo las premisas organizativas de la CAT y se llevó a cabo una profunda reestructuración en términos mecanizadores de las fábricas centenarias que abandonaron progresivamente las elaboraciones tradicionales.

Un problema con el que se había encontrado la CAT a finales del XIX era que las fábricas estaban ubicadas en antiguos edificios, muchos de ellos viejos hospitales o conventos desamortizados, muy poco adecuados a los principios de modernización tecnológica y racionalización del trabajo que se pensaban instaurar [...]

La construcción de las fábricas de Tarragona y Málaga coincide con la puesta en marcha de todo un programa de modernización de los establecimientos fabriles que abarca la ampliación, reformas, saneamiento y mejora de la organización del trabajo. Por tanto, los

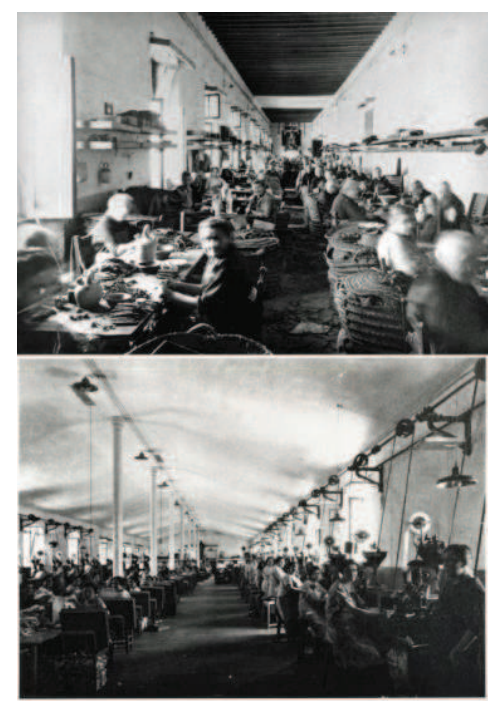

Figura 2.11. El espacio de trabajo en los talleres manuales y en los talleres mecanizados en la Fábrica de Tabacos de Alicante, en $A M A$.

\footnotetext{
92 GÁRATE OJANGUREN, M. M. (2006) op. cit., p. 220.
} 
proyectos de ambas fábricas tratan de recoger las últimas tendencias en materia de edificios fabriles, materiales constructivos, funcionalidad y adaptabilidad a las necesidades futuras, sobre todo en cuanto a la mecanización del proceso productivo y la energía eléctrica ${ }^{93}$.

En términos cualitativos, si se observa la evolución de las fábricas hasta la víspera de la Guerra Civil se puede llegar a la conclusión de que

la producción de las fábricas de tabaco había crecido notablemente, se había modernizado parcialmente la producción, y también se había conseguido una mayor especialización entre las distintas unidades, lográndose elevar la productividad. Sin embargo, el balance general no fue tan positivo como hubiera sido deseable. La renovación integral del sector no se pudo llevar a cabo y aún en 1935 seguía manteniéndose la dualidad entre fábricas modernas y "tradicionales"94.

Sin embargo, todas las fábricas vivirían una lógica situación de retroceso con el estallido de la Guerra Civil y con el periodo de racionamiento de posguerra. La división provocada por el conflicto bélico conllevó a una división interna en la gestión del monopolio provocando no pocos problemas en el abastecimiento del territorio peninsular por el aislamiento entre fábricas. Tal y como había ocurrido durante la Guerra de Independencia decimonónica, las fábricas sitas en sendos territorios combatientes se vieron incomunicadas entre sí. Durante el conflicto bélico se realizaron labores complementarias gracias a la especialización de cada fábrica en una marca determinada, así como el establecimiento de una producción basada en las denominadas "labores de guerra" 95.

\section{El impulso de la mecanización bajo la gestión de Tabacalera CGMTSA en la segunda mitad del S.XX}

Aunque traspasa el marco temporal acotado en la presente investigación, conviene conocer de forma somera la historia de la producción tabacalera posterior a la CAT, puesto que forma parte fundamental de la vida en activo de los casos estudio tratados en la presente investigación.

Tras la etapa de la CAT y una vez superado el retraso técnico y organizativo provocado por la Guerra Civil y posterior periodo autárquico, el proceso de renovación continuaría en 1945 mediante la apertura de un nuevo concurso para la concesión del arriendo del monopolio hacendístico del tabaco. En esta ocasión, se falló nuevamente a favor de la propia CAT que se instituyó con el nombre

93 CAMPOS LUQUE, C. (2004) op. cit., pp. 35-36.

94 GÁRATE OJANGUREN, M. M. (2006) op. cit., p. 222.

95 "Durante la Guerra Civil, la Fábrica de Tabacos de Valencia tuvo un especial protagonismo ya que fue en esta ciudad donde se instaló la sede de la CAT en diciembre de 1936, permaneciendo aquí hasta su traslado a Barcelona en noviembre de 1937. Nos referimos a la CAT de la zona republicana, porque con la contienda, la Compañía se dividió y en la zona nacional y concretamente en Burgos, capital política de la España sublevada y sede del Gobierno, estuvo la otra CAT [...] Por otra parte, en el último trimestre de 1937 se cerraba la factoría bilbaína por falta de personal, pues únicamente quedaba una treintena de personas lo que imposibilitaba su mantenimiento". TEIXIDOR DE OTTO, M. J. y HERNÁNDEZ SORIANO, T. (2000) op. cit., p. 210. 
Tabacalera Sociedad Anónima Compañía Gestora del Monopolio de Tabacos y Servicios Anejos. La sociedad arrendataria acometería un segundo plan de modernización, así como la creación del Servicio Nacional de Cultivo y Fermentación del Tabaco -que contaba con antecedentes en el organismo creado en 1919-, dependiente del Ministerio de Agricultura y encargado en exclusiva de los procesos de cultivo, secado y fermentación previos al tratamiento del tabaco en las plantas fabriles. A lo largo del año 1945 distintas circulares emitidas desde la Dirección de la Empresa establecieron criterios homogéneos y comunes para el funcionamiento de las fábricas -contabilidad, labores, producción y distribución-, y para la organización de las plantillas, estableciendo medidas laborales y asistenciales sobre rendimientos, salarios, prestaciones sociales, seguros obligatorios y jubilaciones, contenidos que quedaron sistematizados en el nuevo Reglamento de Tabacalera de $1946^{96}$.

En estos momentos, las limitaciones de la producción tras el conflicto bélico prolongaron durante un tiempo el racionamiento del tabaco, impidiendo la continuación del proceso de reorganización y mecanización. La mayor parte de los nuevos equipos instalados en las fábricas eran obsoletos y procedían de la reutilización de aquellos que se desechaban en otras unidades fabriles o que se adquirían del extranjero, llegando a contar algunos de ellos con veinte años de antigüedad. Por tanto, el primer periodo de arriendo se dividió en tres fases distintas: el periodo de 1945 a 1950 en el que la incorporación de nueva maquinaria fue muy escasa y de procedencia nacional, la década de los 50 en la que se inicia una leve renovación de los equipos viejos, y la década de los 60 en la que se acomete una profunda mecanización. Es significativa la comparación con el resto de países europeos en los que la renovación tecnológica se acometió en la década anterior y fue claramente más rápida ${ }^{97}$.

La primera etapa estará marcada por los objetivos de la nueva sociedad gestora encaminados a la renovación de la obsoleta industria tabacalera mediante un plan de modernización que sustituya el arcaico modo de producción preindustrial. Para ello, se aprovechará el repunte de la economía en la etapa autárquica tras la posguerra y el levantamiento del racionamiento en la venta de tabaco en 1950 para renovar la industria tabacalera y remodelarla según nuevos criterios de organización del trabajo. Sin embargo, las innovaciones propuestas no se materializarían hasta la época desarrollista de mediados de los años 50 hasta finales de los 60, en que se acomete por primera vez un plan de modernización que promueve la especialización de cada factoría y la total mecanización de todas las fases productivas con la incorporación de nueva maquinaria y la mejora de las técnicas de la fabricación.

En cuanto a las condiciones del parque fabril heredado de la CAT,

96 ARIAS GONZÁLEZ, L. y MATO DÍAZ, A. (2005) Liadoras, cigarreras y pitilleras. La Fábrica de Tabacos de Gijón (1837-2002), Madrid: Altadis, p. 207.

${ }_{97}$ COMÍ́N COMÍN, F. y MARTÍN ACEÑA, P. (1999) op. cit., p. 454. 
hubo además otro problema añadido que afectó a la modernización de la empresa en general, y a las distintas fábricas en particular, como era el estado de los edificios. Algunos inmuebles seguían manteniendo una estructura totalmente inadecuada para incorporar equipos completos de producción, y casi todos contaban con unos espacios escasos para almacenar la primera materia que se requería para atender a una producción en aumento. Por estas razones, Tabacalera se planteó la construcción de nuevos edificios, abandonando en algunos casos antiguas instalaciones $[. .$.

Algunas labores de la fábrica sevillana abandonaron su histórica sede ya en 1959, para ocupar una nueva a orillas del Guadalquivir [se refiere a la nueva planta de Los Remedios], antes del traslado de toda la actividad en 1966. La nueva planta, al igual que ocurrió en Tarragona, acogió tecnología avanzada, y ambas fábricas se convirtieron en el ejemplo de modernidad dentro del conjunto del Monopolio ${ }^{98}$.

La inversión realizada durante el periodo de gestión de Tabacalera tendía a modernizar las plantas antiguas para paliar sus problemas estructurales, además de destinarse partidas importantes a las nuevas instalaciones de tratamiento de rama -Palazuelo- y acondicionamiento -Cádiz, Alicante y Santander-. En este sentido, la especialización de las unidades conlleva a que con el "Plan de modernización" de 1961 se centralicen en determinadas dependencias ajenas a las fábricas la preparación de la rama, mientras que cada fábrica completará el proceso de elaboración y se especializará en una serie de marcas determinadas ${ }^{99}$.

Esta especialización supondría un auge en la productividad a corto plazo, pero perjudicaría a la plantilla ulteriormente debido a la sujeción de los productos tabacaleros y su elaboración a los gustos cambiantes del consumidor, que prefería cigarrillos rubios y de hebra. Pese a que en el periodo delimitado entre 1945 y 1970 la producción tabacalera pasó del racionamiento a una intensa especialización de los productos, asignando cada labor determinada a una planta fabril específica con la instalación y el empleo intensivo de maquinaria, las distancias entre fábricas en 1970 parecían más consolidadas que nunca.

Finalmente, a partir de los años 70, coincidiendo con la renovación del contrato entre Tabacalera y el Estado y con la implantación del "Plan de modernización" de 1969, se da una reconversión del sector en la que se produce una reestructuración de la plantilla y el establecimiento de nuevas categorías profesionales, así como la modificación de la política salarial estipulando un sueldo fijo. Las medidas llevadas a cabo por Tabacalera en estas últimas décadas del S.XX pasaron por una especialización mayor de sus plantas, unida a la modernización técnica de las mismas, su reorganización interna y la fabricación de nuevas

98 GÁRATE OJANGUREN, M. M. (2006) op. cit., p. 324.

99 "El sentido de las innovaciones de este momento es evitar el despilfarro, no sólo en la utilización de materiales, sino sobre todo en el tiempo. Conectar todos los procesos, eludir traslados no automatizados (bandas de transporte), integrar la maquinaria en sus diferentes procesos (llenado, colocación de filtro, liado, empaquetado) con conjuntos elaboradores y, como resultado de todo lo anterior, establecer líneas de producción". MUIÑOS VILLAVERDE, M. J. y TEROL GRAU, V. (2008) La realidad de un mito: la Fábrica de Tabacos de Tarragona (1932-2007), Madrid: Dirección de Comunicación de Altadis, p. 108. 
labores de tabaco.

De igual forma, se produce la salida al mercado de nuevas marcas de cigarrillos y una reconversión de las instalaciones para la elaboración de tabaco rubio -el predilecto por los consumidores siguiendo la tendencia americana-, así como la introducción de máquinas de tercera y cuarta generación y la renovación de los equipos. La especialización de la producción desde una organización científica del trabajo conllevó a la aparición de nuevas secciones fundadas sobre los principios de control de calidad del producto, con la creación de laboratorios de ensayo y evaluación de los elaborados. Esta situación determinó la reconversión espacial de una parte fundamental de las plantas fabriles, al tiempo que se comenzaba el traslado de las centenarias fábricas a nuevos edificios de tipología productiva horizontal y ubicados en polígonos industriales como en el caso de Logroño, que contaba con el precedente del cierre de la planta hispalense y su traslado a la nueva fábrica del barrio de Los Remedios-.

Con la crisis de 1973 se encarecieron los costes de las materias primas y se estimularon las mejoras en materia de innovación, incentivando la inversión en tecnología para el aprovechamiento de la hoja, eliminando al máximo los recortes y residuos. Como señala Campos Luque,

\begin{abstract}
en esa dinámica se enmarca la creación y el posterior desarrollo de las secciones de Métodos y Tiempos y de Control de Calidad en las Fábricas [...] La introducción del sistema de Métodos y Tiempos en la organización del trabajo se inició en la fábrica de Tarragona y posteriormente se fue implantando en las demás. Se trataba de obtener una organización del trabajo más racional "un mayor control y garantía de la calidad de las labores y un mejor rendimiento del material mecánico y de los medios humanos que se traducirá en un incremento de la productividad"100.
\end{abstract}

\title{
El declive de la producción tabacalera a finales del S.XX
}

El periodo final del monopolio vendrá marcado por el ingreso de España en la Comunidad Económica Europea en 1986, que penalizaba la condición monopolística y favorecía la libre competencia del mercado. Esto provocó muchos cambios en el panorama económico español y afectó especialmente a los monopolios, como el tabacalero ${ }^{101}$, lo que conllevó a la introducción de importantes reajustes para equiparar la producción española a los nuevos estándares competitivos. Por una

100 CAMPOS LUQUE, C. (2004) op. cit., p. 182, citando TSA, Memoria, 1973. Por otra parte, indica que "la carestía de la materia prima fue lo que impulsó el desarrollo de técnicas y métodos de trabajo orientados hacia un mejor aprovechamiento del tabaco destinado a la tripa y especialmente, del tabaco capero que era el más caro y escaso, sobre todo en las calidades superiores. La mejora de la producción del tabaco de tripa requería perfeccionar el proceso de batido mediante controles de humedad y temperatura para conseguir el tamaño óptimo de la tripa. En cuanto al capero el mejor rendimiento se consiguió por medio de la experimentación con plantillas hasta lograr una combinación de matrices que aprovecharan al máximo la hoja de capa y que el recorte de capa, lo que sobraba, fuera cada vez menor". CAMPOS LUQUE, C. (2004) op. cit., p. 123.

101 La Ley 38/1985 del 22 de noviembre, modificó la situación anterior del Monopolio Fiscal del Tabaco suprimiéndose la Renta de Tabacos y el impuesto de lujo y quedando absorbida la carga fiscal por el impuesto especial sobre las labores del tabaco y el IVA; se mantuvo el monopolio de fabricación, importación y distribución de tabacos no comunitarios, cuya gestión se encomendó a Tabacalera SA y se liberalizó la importación y comercio mayorista de labores de procedencia comunitaria, aunque se mantuvo el monopolio en la venta minorista. 
parte, se disolvió el monopolio de las marcas nacionales en la comercialización de elaborados del tabaco, entrando en competencia con las empresas internacionales. Por otro lado, el descenso del consumo provocó un reajuste de las plantillas y una aceleración del cambio tecnológico en las fases de liado y empaquetado, confluyendo hacia el "Plan Estratégico de Diversificación” del año 1986.

Este proceso de decadencia culminará en el periodo de entre-siglos con la privatización del sector en 1999 tras la creación de Altadis, fruto de la fusión de la compañía productora española Tabacalera S.A. y la francesa Seita - de origen también monopolístico- que iniciará un plan de saneamiento y racionalización de los costes de producción ${ }^{102}$. Junto a la disminución en el consumo del tabaco por sus nocivos efectos y el aumento de medidas legislativas para tal fin, esta privatización traería consigo el llamado "Plan Industrial" del año 2000, concebido ya con anterioridad a la fusión con Seita.

Entre los objetivos de este proyecto estaba el de llevar a cabo una reestructuración y concentración de la empresa en unos pocos centros de última generación cuya finalidad era incrementar la productividad y la eficiencia y reducir los costes ${ }^{103}$, aspiraciones a las que difícilmente favorecían las condiciones espaciales de las centenarias tabacaleras. Entre las medidas contempladas para alcanzar estos objetivos, se estableció el cierre de ocho fábricas de las catorce existentes ${ }^{104}$, con el consiguiente abandono de las vetustas fábricas tabacaleras españolas que pasarían a ostentar una titularidad pública y comenzarían a valorarse por sus cualidades histórico-culturales como patrimonio industrial arquitectónico y potencial objeto de una conservación a través de la reutilización de sus espacios.

De esta forma, con la irrupción de Altadis, el panorama de la industria tabacalera en España respondía a cuatro grandes especializaciones. En primer lugar, los procesos primarios de elaboración que se situarían en las fábricas de Cádiz - el centro de nueva planta construido al cierre del centenario inmueble de la calle Plocia- y Palazuelo. En segundo lugar, la producción de cigarrillos negros se concentraría en la nueva planta alicantina denominada "Costa" y en la fábrica sevillana del barrio de Los Remedios, absorbiendo las producciones de San Sebastián, Valencia, La Coruña y la antigua fábrica de Alicante. En tercer lugar, la nueva planta cántabra denominada fábrica "Norte" se especializaría en la producción de cigarros que anteriormente se realizaba en Gijón, Málaga y en la antigua fábrica de Santander. Por último, la fabricación de cigarrillos rubios se concentraría en la nueva planta logroñesa -a la sazón la más competitiva de las unidades que se encontraban en activo en materia de fabricación de cigarrillos- absorbiendo la producción de

\footnotetext{
102 Tal y como señala Campos Luque, este proceso "se enmarca en el fenómeno internacional de liberalización de mercados y globalización que ha propiciado un movimiento de concentración empresarial y de fusiones a escala mundial". CAMPOS LUQUE, C. (2004) op. cit., p. 237.

${ }^{103}$ MUIÑOS VILLAVERDE, M. J. y TEROL GRAU, V. (2008) op. cit., p. 215.

104 Las fábricas que cierran son las de Alicante, Santander, Málaga, La Coruña, San Sebastián, Madrid, Gijón y Valencia. Al mismo tiempo, se proyecta la construcción de dos nuevas fábricas: una en Cantabria, la Fábrica Norte en Entrambasaguas, y otra en Alicante, la fábrica Costa.
} 
la planta coruñesa.

De los casos estudio abordados en la presente investigación, la fábrica de Tarragona sería la única que pasaría esta primera criba de cierres y continuaría su producción especializada en tabaco rubio en series cortas y muy cortas, como venía haciendo desde mediados de la década de los noventa, fabricando principalmente Ducados Rubio. Su cierre definitivo se produjo con el plan estratégico para el periodo 2003-2005, junto con las plantas de Sevilla de los Remedios y la segunda planta fundada en Cádiz. Actualmente, tan sólo se encuentra en activo la fábrica cántabra sita en Solares puesto que se ha determinado el cierre de la planta logroñesa junto a la alicantina de nueva planta.

\subsubsection{El proceso productivo del tabaco en España}

Tras las consideraciones anteriores, es interesante ahondar en las características particulares del proceso productivo para alcanzar una mayor comprensión de las condiciones que la producción específica tabacalera transfiere al espacio fabril. Su producción en España generaría un modo particular de organización industrial con un carácter eminentemente manufacturero en los primeros tiempos, que evolucionaría con el desarrollo industrial en la península y el intento de renovación de la industria tabacalera a través de mejoras propias de la mecanización.

Se distinguen dos periodos muy significativos dentro de la historia de la producción tabacalera en España: la primera fase de producción manufacturera con tintes preindustriales y la época impulsora de la mecanización de todas las fases de producción y la reestructuración de las fábricas en términos de renovación técnica y organizativa. Durante el S.XIX el trabajo en la producción tabacalera tendrá un marcado carácter preindustrial determinado por la tradición de emplear a miembros de una misma familia, la producción a destajo de las cigarreras y la permisividad en el absentismo para atender sus obligaciones domésticas y familiares; en contraposición, las medidas introducidas a partir de finales del S.XIX y principios del S.XX por los planes de modernización instauraban una racionalización del proceso productivo y del espacio fabril a favor de la mecanización total de todas las fases productivas, el establecimiento de unas directrices en materia de organización de las operarias y la sistematización de las labores hacia una moderna producción tabacalera, propia de la organización científica del trabajo.

El proceso productivo desarrollado en los centros fabriles se distinguía por su división en tres fases claramente diferenciadas: las operaciones de pretratado de la materia -desvenado, moja, oreo y picado-, el proceso de liado en los talleres -que se dividían según el tipo de elaboración o "marca"- y el acabado final mediante el encelofanado y empaquetado. El proceso de elaboración del producto en el seno de la fábrica ha sido descrito por muchos de los autores a los que se ha hecho referencia hasta el momento. Sin embargo, cabe destacar por su sencillez y claridad la descripción que Alonso Álvarez realiza de la elaboración en 
su periodo manufacturero:

El proceso productivo, una vez transportadas las materias primas del muelle a la fábrica y habiéndose procedido a su examen y tasación, comenzaba en el almacén de hoja, al procederse a su selección, reservándose las de mejor textura para confeccionar la capa de los cigarros y las restantes para incluir como tripa. Seguidamente se procedía a su distribución entre las trabajadoras, operación que recibía el nombre de data, y que, en circunstancias normales, solía realizarse semanal o quincenalmente, entregándose a cada cuadrilla la cantidad de hoja que se estimaba ajustada a su óptimo de producción. Tras el humedecimiento de las maniquetas (hojas destinadas a capa), que proporcionaban al tabaco la necesaria maleabilidad para su manipulación, se iniciaba el liado, cuya perfección dependía de la habilidad de la trabajadora, y que había de compaginarla con la rapidez en la realización de la tarea, al depender su salario del número de piezas rematadas. El utillaje, muy elemental -pesas y medidas, tijeras, tablas, espuertas y paños- era propiedad de las obreras.

Cada conjunto de 51 cigarros constituía un atado, que había de entregarse a la maestra del taller respectivo, la cual podía rechazarlo por imperfecto o por carecer del peso estipulado. Los atados eran periódicamente retirados al almacén de oreo y expuestos en estantes, para completar su tiempo de secado, y de allí conducidos al almacén de embalado, donde quedaban empapelados y encajonados, listos para su distribución a los centros de consumo [...] el descanso de tres horas para el almuerzo, que habían de realizar en la propia fábrica. Durante este tiempo, las cigarreras habían de trabajar silenciosamente bajo la atenta vigilancia de las maestras ${ }^{105}$.

El sistema de elaboración de cigarros en los talleres comenzaba con el reparto de la hoja por la maestra -la data- entre ranchos de seis operarias, que mojaban la cantidad de capa o cubierta que iban a necesitar al día siguiente, por aspersión o con un paño mojado, mientras que la tripa o el relleno interior se conservaba seco. Al día siguiente, se desvenaba la hoja necesaria para la tripa de los cigarros que habían sido programados, así como la capa, de la que salían medias hojas cortadas con tijeras en forma curva para facilitar el liado óptimo. Después se comenzaba a torcer los puros, cogiendo la cantidad de tripa que debía tener cada cigarro, que era estirada y abierta para su empalme manual en un rollo que se envolvía en una hoja pequeña o capillo que se liaba con cuidado en la capa, desde la parte inferior o boquilla, a la superior. Cuando la cigarrera había elaborado un número suficiente de cigarros que agrupaba formando mazos, los colocaba en unos estantes hasta que al finalizar la quincena se llevaban en grandes bateas al despacho de recibo para su control de calidad y pago.

En cuanto a la elaboración artesanal del cigarrillo, esta comenzaba en el taller de desvenado donde se despalillaba la hoja, que posteriormente se introducía en la máquina de picar donde se graduaban las distintas calidades -cigarrillos o paquete de picadura-. Los talleres de elaboración de cigarros variaban según la calidad

105 ALONSO ÁLVAREZ, L. (1984) op. cit., pp. 20-21. 
pudiendo ser Finos, Entrefinos, y Fuertes, y posteriormente eran empaquetados en cajetillas en otro taller. En cuanto a la picadura al cuadrado, ésta era embotada por las "funderas".

En lo que respecta al laboreo, los talleres se organizaban en unidades básicas de producción denominadas ranchos y formados por ocho o quince cigarreras incluyendo aprendizas. Este sistema comenzó a establecerse en la producción de puros, aunque a lo largo del S.XIX se trasladó también a las labores de desvenado y a la confección de cigarrillos. Cada rancho estaba regido por una capataza o ama de rancho que controlaba la disciplina laboral y productiva y representaba a la administración de la fábrica en los niveles inferiores. Los talleres se conformaban como la agrupación de ranchos de un mismo tipo de elaboración y estaban gobernados por una maestra que tenía la misma función que la capataza a un nivel superior, supervisando además la entrada y salida de las cigarreras y dando apoyo a las operaciones de registro a la salida del trabajo. El superior de las maestras era el inspector de labores, que se responsabilizaba en última instancia de la supervisión de la calidad del producto final y de la disciplina laboral. Dando apoyo a las medidas de control y vigilancia se conformaba el cuerpo de porteras junto al portero del acceso principal y al cuerpo de guardia $^{106}$.

Por otra parte, como señalan Teixidor de Otto y Hernández Soriano, los almacenes eran un elemento auxiliar e imprescindible del espacio productivo puesto que

agrupaban a un personal laboral considerable que era exclusivamente masculino. Podían ser de tres tipos: el de Repuesto o Rama, donde se almacenaba el tabaco en rama llegado de los depósitos situados en los puertos de entrada de la materia prima; el de Escogido o Distribución, que contenía las hojas clasificadas y seleccionadas según procedencia y calidad para una adecuada aplicación; por último, el de Elaborados, donde se guardaban las labores hechas hasta su salida de la fábrica. En 1887 se estudia la manera de dotar a las factorías de locales propios y capaces para depósito de la materia prima, repeso y recuento, dado que los almacenes existentes hasta el momento eran en su mayoría arrendados y el pago del alquiler sumado al coste de los traslados entre las fábricas y dichos depósitos, resultaba a veces demasiado oneroso para la Compañía ${ }^{107}$.

Durante el S.XIX y hasta mediados del S.XX, el rendimiento de la producción no recaía tanto en la productividad de las propias trabajadoras sino en el número de las mismas. A efectos de uso y condiciones del espacio fabril, los diáfanos talleres destinados al desempeño de las labores se veían frecuentemente congestionados ante las malas condiciones de iluminación y ventilación para un volumen de mano de obra que se cuantificaba en varios millares.

Esta situación se acentuó a partir de 1845, puesto que la Renta experimentó un repunte de sus ingresos, situándose a niveles

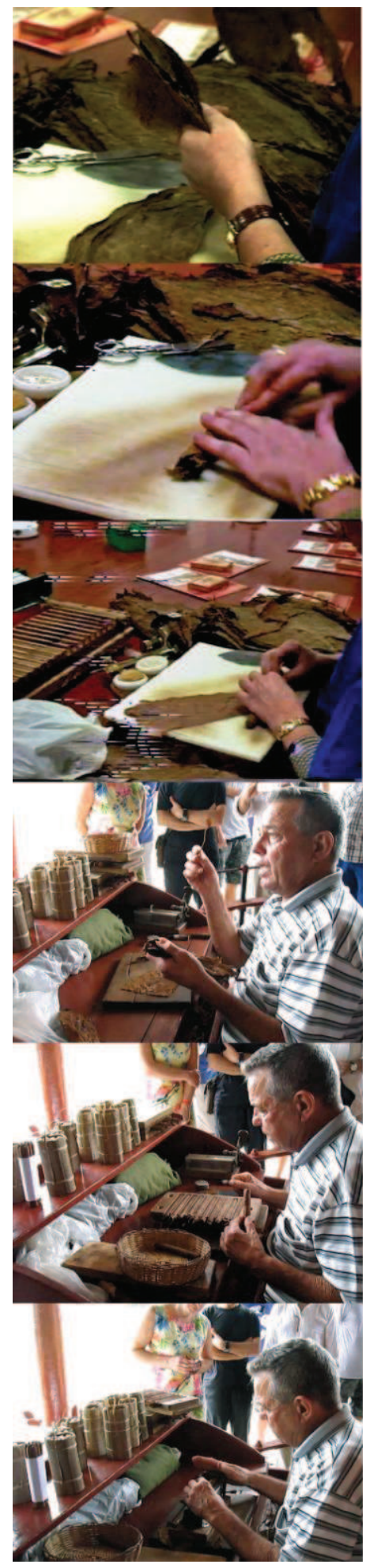

Figura 2.12. Liado o torcido manual del cigarro. Fotogramas del vídeo realizado por Antoni Vilanova Omedas en la Fábrica de Tabacos de Gijón en 1999, cortesía de Antoni Vilanova Omedas; y fotogramas del vídeo grabado en Viñales (Cuba), 2016 
superiores a los adquiridos a finales del S.XVIII, cubriendo la distancia entre los niveles de consumo y la capacidad productiva de las fábricas existentes mediante el incremento y diversificación de la producción y la construcción de nuevos espacios fabriles. A ello se añadía la tímida mecanización que ya comenzaba a valorar la Renta del Tabaco, no sin significativas dificultades, aspirando a seguir el ejemplo establecido por las fábricas europeas en la incorporación de tecnología a los procedimientos manufactureros.

Respecto al segundo momento productivo apuntado inicialmente, en las primeras décadas del S.XX se difundieron nuevos procesos industriales en el sector tabacalero que buscaban la adaptación al gusto del consumidor. El tabaco en rama previamente fermentado llegaba de los centros de recogida de los países productores -fundamentalmente Cuba, Filipinas y EE.UU.- a las fábricas embalado o enfardado, habiéndole extraído la mayor parte de la humedad para evitar fermentaciones o putrefacciones indeseadas que dañasen la hoja durante el transporte, dejando la imprescindible para aportar elasticidad durante el embalado. La materia prima llegaba del puerto y se depositaba en los almacenes de rama que debían contar con locales adecuados que mantenían una temperatura constante independiente de las variaciones estacionales y horarias, no resultando alterado por las variaciones higrométricas que podían alterar sus cualidades.

Tras ser debidamente pesado, se almacenaba en la fábrica, al igual que en la época precedente, en almacenes de rama en condiciones higrométricas constantes para evitar que la materia prima viese alteradas las cualidades de aroma y sabor adquiridas durante la fermentación previa. Sobre los cambios experimentados en el proceso productivo con el desarrollo de la mecanización en la tercera década del S.XX, señala Alonso Álvarez ${ }^{108:}$

a difusión de produtos de maior calidade nos anos vinte exixiu a introdución de modernas tecnoloxías de control de humidade e temperatura, o que só podería realizarse en recintos moi especiais: os depósitos de rama [...]

A operación da molla -primeira manipulación da folla despois do seu ingreso na factoría- devolvíalle ao tabaco a elasticidade orixinal, perdida durante o traslado aos centros de produción industrial, pero de novo imprescindíbel para o seu posterior tratamento mecánico. De non realizarse, o produto tornaríase quebradizo. A molla, ademais, non debía ser excesiva porque do contrario podería desenvolverse na folla algunha fermentación indesexábel. O procedemento máis usual de molla -á parte dos sistemas manuais de aspersión e imersión, reservados unicamente para as follas de gran calidade que se usaban como capa nos puros- era o de humectación [...] realizada con vapor.

Por tanto, la hoja era previamente seleccionada según el tipo de labor a la que fuese destinada, tras lo cual se procedía a las primeras fases del proceso productivo en la fábrica. Se aprecia, por tanto, cómo desde la

108 Además de las referencias a la obra de Alonso Álvarez, cabe citar la descripción de cada una de las fases de la producción a inicios del S.XX en CANDELA SOTO, P. (1997) op. cit., p. 69. Este fragmento y siguientes en ALONSO ÁLVAREZ (1998) op. cit., pp. 190-191. 
primera fase de pretratado de la materia prima en la fábrica se empleaban métodos mecanizados con la ayuda de maquinaria específica. En el caso de la moja se empleaban humectadores de vapor, que en algunos casos incluían aspiradores, y que reducían considerablemente los tiempos de trabajo respecto a las elaboraciones manuales.

A folla sufría posteriormente o desveado, operación dirixida a retirar os nervios centrais, os irritantes paus, inclusión denunciada no século XIX e que terían resultados molestos para os fumadores máis exixentes do século XX. O desveado podería ser manual (para as follas de capa) ou mecánico, e neste caso efectuábase con máquinas desveadoras. A vea adoitábase vender como subproduto, xuntamente co po que xeneraba o proceso seguinte de elaboración da picadura.

O tabaco convenientemente humedecido pasaba así ás picadoras, que podían ser de dous tipos, en función do produto elaborado: de fibra consumir en cigarros, en farias ou directamente en pipa- e ao cadrado.

Tras el desvenado o despalillado, manual o empleando máquinas desvenadoras, se procedía al oreo, en el que nuevamente se advierte el empleo de maquinaria específica, para lo cual se empleaban oreadores o torrefactores. Este proceso no era necesario si el humectador ya incluía un sistema de aspiración.

Retomando el fragmento anterior de Alonso Álvarez, las labores de picadura fueron las primeras que vieron completada su mecanización, sin olvidar la invención del cigarro mecanizado Farias por el mexicano de origen gallego Heraclio Farias, que en 1889 ideó el mencionado sistema de fabricación cigarros puros -con tripa de picadura de tabaco en hebra larga en lugar de hoja de tabaco torcida- mediante un sistema mecanizado que permitía producir varios centenares de cigarros por minuto, incrementando la productividad y reduciendo los costes ${ }^{109}$. La implantación de este sistema por parte de la CAT en varias de sus unidades fabriles -entre ellas La Coruña, Gijón o Santander- provocó no pocos altercados con las cigarreras, que defendían sus elaboraciones tradicionales. También se introdujeron máquinas laminadoras que reutilizaban los residuos originados con el picado y consumían la vena retirada de la hoja en el proceso del desvenado.

Seguidamente, o tabaco picado pasaba ao clasificador, que separaba os distintos tipos de picadura segundo tamaños e evitaba en parte os graves problemas de contaminación no interior das fábricas ao aspirar o po residual, e aos torrefactores, responsábeis da evaporación do exceso de humidade que, de non retirarse, provocaría fermentacións indesexábeis nas picaduras na súa manipulación posterior.

Tras este proceso, la picadura pasaba directamente a los talleres de elaboración de cigarros y cigarrillos o se prensaba y empaquetaba mecánicamente para su comercialización directa como producto final.

Como se puede apreciar, el nivel de mecanización alcanzado por la producción tabacalera en la época final de la CAT aún quedaba lejos de

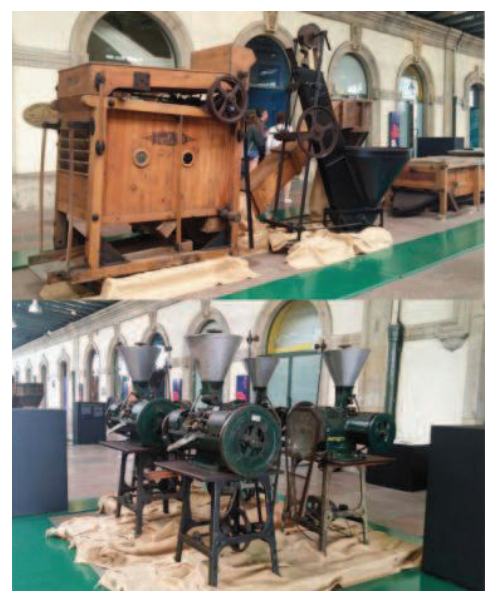

Figura 2.13. Conjunto de selección y distribución y liadoras Vilaseca de finales del S.XIX expuestas en el Museo del Ferrocarril de Asturias, 2016.

${ }^{109}$ La producción del Farias se ensayó en la fábrica madrileña con éxito, por lo que se asignó el 12 de febrero de 1889 un contrato para su la producción en serie, siendo presidente de la CAT Amós Salvador. 
Figura 2.14. Cuadro comparativo del proceso manual y mecanizado. abarcar todas las fases del proceso. Esta mecanización por fases se limitaba al pretratado de la hoja y a la producción de picadura, contando para el liado del producto tan sólo en algunos casos con máquinas tiruleras que se limitaban a envolver el tirulo correspondiente en la capa u hoja final. Se trataba, por tanto, de un proceso semimecanizado que convivía con los talleres manuales, situación que se mantendría en algunas variedades incluso hasta las décadas finales de la vida en activo del monopolio.

Con el S.XX se mantuvieron en paralelo la producción manual y la mecanizada, con ayuda de moldes y prensas en el primer caso, y el empleo de máquinas tiruleras Dubrull o Vilaseca en el segundo. En el método mecanizado también se contaba con máquinas laminadoras Quester que permitían el aprovechamiento de la vena y la colocación manual de la capa. Por su parte las mesas de succión complementaban el liado manual. En la década de los años 30 el proceso de elaboración del cigarro se hallaba prácticamente mecanizado en su totalidad.

\begin{tabular}{|c|c|c|}
\hline FASES & MANUAL | Proceso empleado & MECANIZADO | Tipo de maquinaria \\
\hline Desvenado & Desvenado manual de tripa y capa & Desvenadoras \\
\hline Moja & $\begin{array}{l}\text { - Por sistema de aspersión } \\
\text { - Por sistema de inmersión }\end{array}$ & $\begin{array}{l}\text { Humectadores de vapor: } \\
\text { - Con sistema de aspiración fovita } \\
\text { torrefactado posterior) } \\
\text { - Sin sistema de aspiración }\end{array}$ \\
\hline Oreo & Ventilación natural en repisas & Torrefactores, oreadores sistema fouché \\
\hline Picado & Cuchillas manejadas por dos operarios & $\begin{array}{l}\text { Picadoras: } \\
\text { - Hebra: Fombuena. Climent } \\
\text { - Al cuadrado: Sesé. Flinsch }\end{array}$ \\
\hline \multirow[t]{2}{*}{ Liado } & \multirow[t]{2}{*}{$\begin{array}{l}\text { Torcido o liodo: } \\
\text { - Cigamillos de papel } \\
\text { - Cigarros: tripa, capillo y capa }\end{array}$} & $\begin{array}{l}\text { Mecanizado completo ILiadoras: } \\
\text { Vilaseca. Rapid, Bonsack, Molins, Arenco. } \\
\text { Universal, Sistema farias }\end{array}$ \\
\hline & & $\begin{array}{l}\text { Semimanual I Tiruleras. laminadoras. } \\
\text { mesas de succión: Dubrull, Perfecto, } \\
\text { Vilaseca | Quester | Dubrull }\end{array}$ \\
\hline Empaquetado & Embotado por funderas & Empaquetadoras: Quester. Pollard Flinsch \\
\hline
\end{tabular}

En cuanto a la elaboración de picadura y la fabricación de cigarrillos, en el primer caso se hallaba totalmente mecanizada produciendo dos clases de elaborado: hebra, mediante máquinas Fombuena o Climent y al cuadrado, mediante máquinas Sesé y Flinsch. Como la picadura debía mojarse previamente, una vez obtenida la variedad deseada se sometía nuevamente a oreo en torrefactores. La elaboración de cigarrillos, por su parte, se mantuvo de forma manual durante mucho tiempo, extendiéndose a partir de la década de los 30 el empleo de máquinas para cigarrillos Rapide, Bonsack, Molins o Arenco. El empaquetado de todas las labores se realizaba mediante máquinas Quester o Pollard y constituía la última fase de preparado para el envío del elaborado a los correspondientes estanquillos o expendedurías.

Por tanto, a principios del S.XX y a pesar de las medidas tomadas por la CAT para impulsar la implantación de los métodos mecanizados en el seno de las unidades fabriles del monopolio, la organización productiva no distaba mucho de la desarrollada en el siglo anterior. Salvando las distancias en cuanto a cualificación del espacio productivo se refiere, con la reducción de plantilla y la reorganización de los talleres experimentada con la introducción de los nuevos métodos, el proceso de fabricación del tabaco continuaba distinguiendo tres 
secciones: la preparación de materias, el trabajo de elaboración y la preparación final.

Por otra parte, los talleres auxiliares creados en el año 1908 daban ocupación en tareas menores a aquellas trabajadoras que por su avanzada edad o por sus condiciones físicas habían perdido la destreza necesaria para el desarrollo de determinadas labores. No contaban con un espacio físico en sí, a pesar de su denominación de "talleres", si no que funcionaban más bien como una suerte de jubilación encubierta. Así mismo, el espacio de almacenaje era otra de las dependencias clave en las fábricas tabacaleras, de tal forma que las fábricas decimonónicas llegaron a experimentar graves deficiencias al destinar los espacios intramuros a esta función. Para suplir esta necesidad recurrían frecuentemente al alquiler de espacios externos a la fábrica, en la propia ciudad.

Dado el establecimiento del Servicio Nacional del Cultivo del Tabaco en esta época y el destino final de la Fábrica de Tabacos de Málaga como centro de fermentación, cabe en este punto hacer mención de forma somera a las características del proceso de fermentado del tabaco ${ }^{110}$. Como ya se ha comentado anteriormente, el proceso productivo del tabaco se divide en tres fases fundamentales consistentes en el cultivo y pretratado de la materia prima, la fabricación y su empaquetado y distribución. Mientras que las dos segundas atañen a los inmuebles analizados en la presente investigación y componen la parte industrializada del proceso, la primera consiste en el cultivo, curado, fermentación y acondicionamiento de la hoja de tabaco que dependen del sector agrícola y en cuyo proceso el centro de fermentación malagueño constituiría la última etapa. De esta forma, en el centro de Málaga se recibían manojos de hojas de tabaco de muy diversas y lejanas procedencias, que tras el triturado y adición de aditivos de sabor y aroma, eran manufacturados y expedidos a las plantas de elaboración ${ }^{111}$.

Para la descripción del proceso de fermentado se ha partido del trabajo de Campos Luque ${ }^{112}$. La fase de curado del tabaco se realiza tras la recolección de la hoja cultivada en construcciones específicas denominadas secaderos por diversos métodos como aire caliente, aire natural, al sol y al fuego. Sin embargo, en algunos de los casos estudio de la presente investigación se integraban estancias en las que se realizaba esta fase del proceso, como en las buhardillas de la fábrica madrileña, el espacio de secadero de la fábrica alicantina o las azoteas de la Real Fábrica de Tabacos de Sevilla. En los primeros tiempos, estos secaderos ocupaban cobertizos dispuestos en los propios campos de cultivo, pero la exposición del tabaco a las condiciones ambientales daba lugar a un curado imperfecto, por lo que a medida que se extendió el

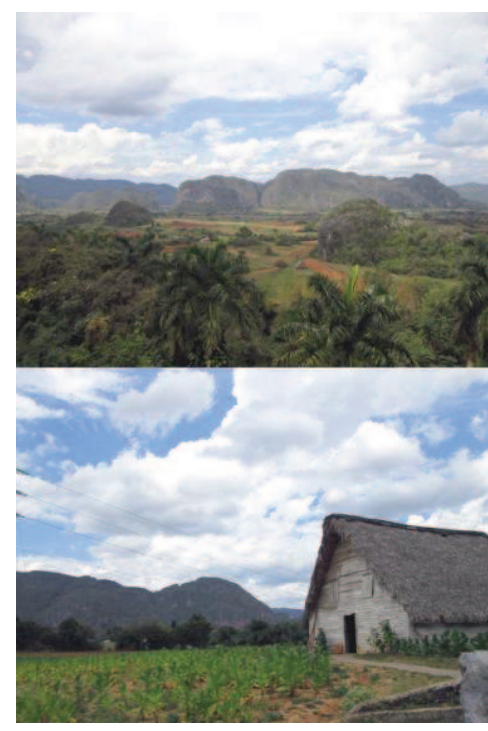

Figura 2.15. Campos de cultivo de tabaco en Viñales (Cuba), 2016.

\footnotetext{
110 Sobre la red productiva de la industria tabacalera y el papel de Sevilla en otras fases del proceso de elaboración: hasta 1924 todo el tabaco se fermentaba en la fábrica de tabacos de Sevilla. Al aumentar la extensión de áreas cultivadas y la producción, se crearon nuevos Centros de fermentación en Madrid, Málaga (1929), Navalmoral de la Mata (1939) y Granada (1932). GUARNIDO OLMEDO, V. (1983) op. cit., p. 158.

111 CALDERÓN DELGADO, S. (2013) El patrimonio industrial de Málaga como recurso turístico [TFG de la Universidad de Málaga, Facultad de Turismo], p. 14.

112 Sobre los procesos desarrollados en el Centro de Fermentación de Málaga, CAMPOS LUQUE, C. (2004) op. cit., pp. 59-63.
} 


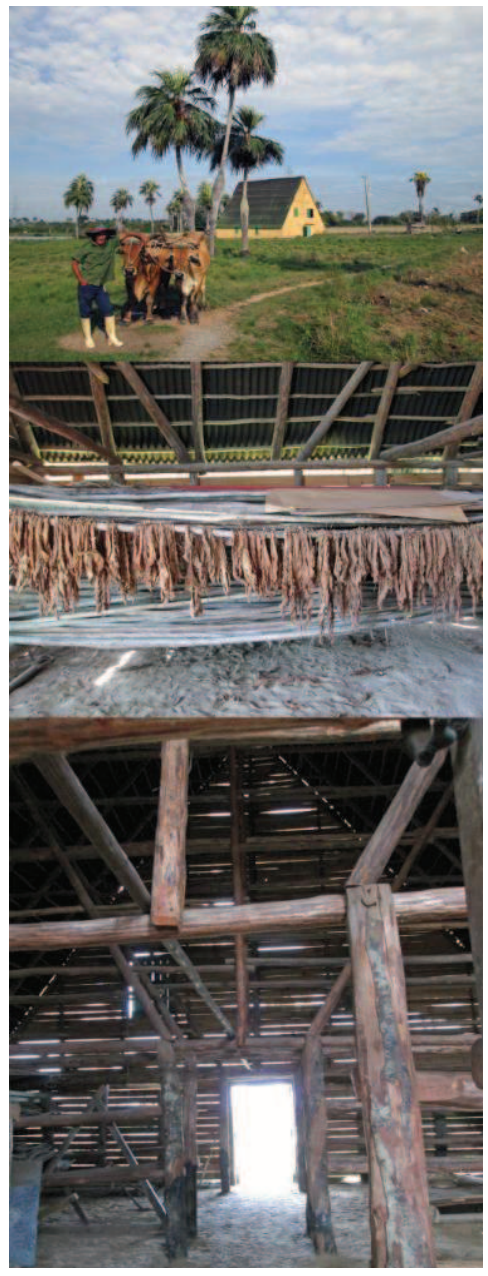

Figura 2.16. Secaderos de tabaco en Viñales (Cuba), 2016 cultivo, se fueron construyendo secaderos que incorporaban diversas características dependiendo de la zona de cultivo.

El proceso de fermentación constituye la última fase de pretratado de la hoja anterior a las tareas de elaboración y en la misma se da continuidad a las transformaciones químicas y biológicas que se inician en la fase de curado. Este proceso permite que en el momento de su consumo, la hoja de tabaco arda con un humo aromático y sabor agradable, existiendo para ello los métodos natural o enzimático y en cámara. Los requerimientos espaciales del centro de fermentación responden, por tanto, al proceso de transformación de la hoja del tabaco que consiste en la recepción y pesado de los fardos de cada partida entregada por los cultivadores, la determinación de su grado de humedad y su posterior clasificación. Para esta última tarea, el tabaco debía ser extendido en la nave de clasificación según su variedad. Posteriormente, se formaban unas masas prismáticas o pilones de manillas de tabaco clasificado de unas 10 a 12 manillas por pilón atados con una cuerda. Estos atados recibían el nombre de matules, que se disponían por capas formando un cilindro o prisma recto de unos 3,50 metros de altura y una dimensión de 3,75 metros en la base. De esta forma, en el tabaco apilado se producía un proceso químico espontáneo de oxidación o transformación de los componentes de la hoja.

En el proceso de fermentación, la dimensión de los pilones junto a la aireación, humedad y luz eran los factores que más influían en la cualificación del espacio. Dado que en el proceso de fermentación la masa de tabaco aumenta su temperatura, se debe cambiar su posición para rebajar la temperatura alcanzada y conseguir que el proceso se realice de forma homogénea en todo el pilón. Esta temperatura se controlaba a través de un termómetro central que se consultaba varias veces al día y con cuyas lecturas se elaboraban las curvas de fermentación. Una vez se alcanzaban los 45 o $50{ }^{\circ} \mathrm{C}$, se deshacía el pilón para enfriar el tabaco y cambiar las manillas del interior al exterior, realizándose esta operación un mínimo de dos veces a lo largo del proceso total.

Cabe señalar cómo este proceso recuerda en gran parte a otras producciones industriales del sector agroalimentario, como por ejemplo el proceso de fermentación de las bebidas alcohólicas en grandes bodegas, con la salvedad de los diferentes requerimientos higrométricos del ambiente. En el caso del tabaco, además, los espacios de almacenaje debían contar con una cantidad justa de iluminación y ventilación para evitar que se produjesen fermentaciones indeseadas o la putrefacción parcial de la hoja.

\subsubsection{Las cigarreras y el espacio fabril: condiciones laborales, identidad colectiva y significación en su entorno}

La influencia femenina en el espacio de las tabacaleras es uno de los aspectos más importantes a tratar en la presente investigación, ya que con ella se persigue poner en valor la importancia de los inicios del 
empleo laboral femenino en España en su materialización espacial en las tabacaleras como patrimonio industrial arquitectónico que puede trasladar esos valores inmateriales a las generaciones venideras. El carácter indisociable de la historia del monopolio con las condiciones laborales de las cigarreras hace que muchos aspectos comentados en el epígrafe anterior se retomen, en este caso, para dar explicación a los numerosos aspectos a interpretar sobre el papel de la cigarrera en el espacio fabril.

Para indagar sobre la posible feminización del espacio de trabajo en las fábricas de tabacos españolas a través de la figura característica de la cigarrera como obrera que habita y condiciona el espacio fabril, cabe tratar algunas cuestiones colaterales al hilo principal de la presente investigación y que ayudan a una comprensión íntegra de la realidad de la mujer en las tabacaleras a través de los diversos trabajos que se han ocupado de su estudio. Aunque algunas de ellas resulten anecdóticas respecto a la argumentación principal que trata de resolver las hipótesis planteadas en el capítulo inicial, resultan de gran ayuda para contextualizar correctamente la interpretación de la fábrica desde la influencia que la cigarrera como tipo obrero particular ejerce sobre el espacio fabril, integrando una memoria del trabajo femenino muy característica que ensalza los valores de las tabacaleras como patrimonio industrial arquitectónico.

\section{Desmitificación de la figura de la cigarrera}

En primer lugar, cabe destacar numerosos trabajos que en las últimas décadas han tratado la realidad de la cigarrera desde un punto de vista científico, fundamentalmente desde el ámbito de la sociología del trabajo, tratando de desmitificar a las cigarreras como personaje y ahondando en las condiciones particulares que atañen a su vida como trabajadora y como núcleo del espacio doméstico. La figura de la cigarrera ha sido objeto de numerosas leyendas e historias como arquetipo de mujer, como personaje, sobre todo a raíz de la famosa obra de Prosper Mérimée "Carmen" adaptada como libreto de ópera por Bizet.

Ha de saber usted que podrá haber de cuatrocientas a quinientas mujeres empleadas en la Fábrica. Ellas son las que hacen los cigarros en una sala grande, en donde los hombres no pueden entrar sin un permiso especial expedido por un caballero veinticuatro, cosa que se explica porque, cuando hace calor, las jóvenes principalmente se aligeran de ropa. A la hora de entrada al trabajo, numerosos muchachos van a ver pasar a las operarias, que vuelven de comer, y las requiebran en todos los tonos [...]

Pues figúrese usted que al entrar al salón lo primero que me echo a la cara son trescientas mujeres, en camisa o poco menos, chillando todas, vociferando, gesticulando, armando un barullo como para taparse los oídos ${ }^{113}$.

\footnotetext{
${ }^{113}$ MÉRIMÉE, P. (1847 [1924]) Carmen, Madrid: Calpe, pp.33-34 y 36.
} 


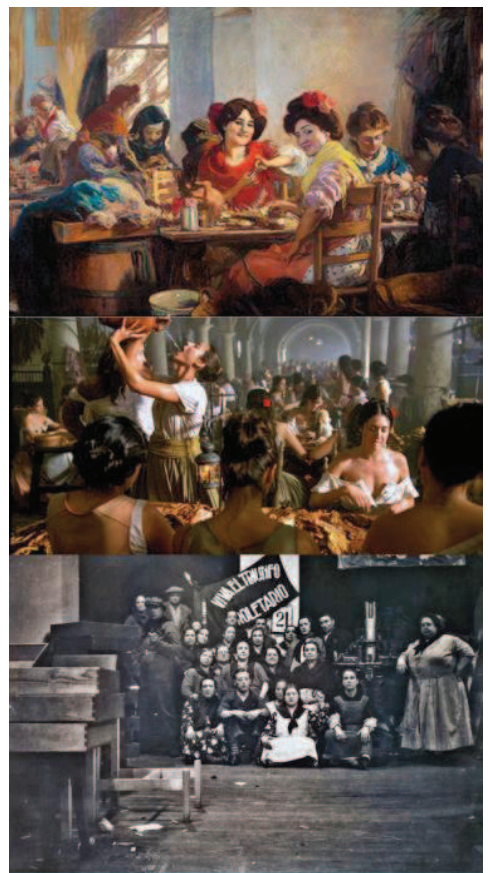

Figura 2.17. "Cigarreras en la fábrica” de Gonzalo Bilbao, 1910,

Colección Altadis, en

RODRÍGUEZ GORDILLO, J. M. (2005) op. cit., p. 157; fotograma de la película "Carmen", Vicente Aranda, 2003; y cigarreras madrileñas en 1936, en archivo gráfico online de latabacalera.net.
Recientemente, se ha colaborado con el colectivo LaLiminal114 en unos recorridos temáticos por el Lavapiés de las cigarreras en los que se ha tratado de profundizar sobre la realidad de la cigarrera como trabajadora y mujer y la influencia que la presencia tanto de la fábrica como de sus operarias tenía en todo el barrio. A través de esta caracterización literaria de la figura de la cigarrera se observa un intento implícito de desfigurar la imagen real de estas mujeres, representándolas como una suerte de mujer fatal al estilo del mito de Carmen ${ }^{115}$, añadiendo connotaciones negativas o caracterizadas por una suerte de folclore impostado que nada tenían que ver con la realidad cotidiana de estas mujeres.

Quizás por este motivo, a lo largo de las últimas décadas se han sucedido publicaciones de numerosos autores que han profundizado en el estudio científico de las cigarreras como colectivo laboral femenino, adentrándose en su realidad y alejándose del cliché mitificado de las mismas ${ }^{116}$. Desde estudios sobre su organización laboral, sus condiciones de trabajo, hasta las relaciones entre las mismas, su voluntad de asociacionismo como colectivo de mujeres trabajadoras, su carácter y reivindicaciones, e incluso las tradiciones festivas en las que participaban. En este sentido, cabe destacar muy especialmente el trabajo de Paloma Candela Soto sobre las cigarreras madrileñas en el ámbito de la sociología del trabajo, cuya investigación de tesis doctoral y las publicaciones derivadas de la misma han resultado de capital importancia para el estado de la cuestión sobre los contenidos de este epígrafe ${ }^{117}$.

114 El colectivo LaLiminal realiza periódicamente recorridos temáticos por los barrios madrileños de extracción social obrera interpretando desde la perspectiva de género la historia olvidada de los mismos. El mencionado recorrido "Cigarreras de Madrid. La huella de la vida obrera en el barrio de Lavapiés" se realizó entre el 12 de marzo y el 22 de abril de 2016 y se ha participado en el mismo con carácter de asesoramiento.

115 También en otras obras literarias como La hermana San Sulpicio de Armando Palacio Valdés de 1889 se hace referencia al carácter fiero de las cigarreras. Resulta muy significativo de este rasgo el fragmento en el que describe la primera impresión que recibe un personaje masculino -Ceferino- al entrar en uno de los talleres de la fábrica hispalense. PALACIO VALDÉS, A. (1889 [1984]) La hermana San Sulpicio, Barcelona: Orbis, p. 184.

116 Existen numerosos trabajos que atienden al estudio de la figura de la cigarrera desde un enfoque de interés sociológico. Aunque algunos de ellos se referirán a lo largo del presente epígrafe, cabe destacar de forma general sobre las distintas fábricas estudiadas en esta investigación especialmente sobre la fábrica sevillana: BAENA LUQUE, E. (1993) Las cigarreras sevillanas. Un mito en declive (1887-1923), Málaga: Universidad de Málaga; CAPEL MARTÍNEZ, R. M. (1999) "Life and work in the tobacco factories: female industrial workers in the early Twentieth Century" en ENDERS, V. L. y RADCLIFF, P. B. (coord.) (1999) Constructing Spanish womanhood: female identity in modern Spain, SUNY press, pp. 131-150; GÁLVEZ, L. (1999) "Breadwinning Patterns and Family Exogenous Factors: Workers at the Tobacco Factory of Seville during the Industrialization Process, 1887-1945" en International review of social history / International Instituut voor Sociale Geschiedenis, Amsterdam, vol. 42, suplemento 5, pp. 87-128; RODRÍGUEZ GORDILLO, J. M. (1984b) "El personal obrero en la Real Fábrica de Tabacos" en VV. AA. (1984) Sevilla y el tabaco. Catálogo de la exposición en el Rectorado de la Universidad (Antigua Real Fábrica de Tabacos), Sevilla: Tabacalera, pp. 67-76; y ORTIZ DE LANZAGORTA, J. L. (1988) Las cigarreras de Sevilla, Sevilla: RC, Gayban Grafic. Sobre otras fábricas RADCLIFF, P. (1993) "Elite women workers and collective action: the cigarette makers of Gijon, 1890-1930" en Journal of Social History, vol. 27, $\mathrm{n}^{\circ}$ 1, pp. 85-108; RADCLIFF, P. y DE FRANCISCO, M. J., (1998) Las cigarreras de Gijón, Gijón: El Comercio; y SORIANO, T. (1998) "El trabajo de la mujer en las labores del tabaco: La fábrica de València (1887-1914)" en Cuadernos de geografía, $\mathrm{n}^{\circ}$ 64, Valencia, pp. 339-354.

117 A destacar muy especialmente, CANDELA SOTO, P. (1997) op. cit. y los artículos CANDELA SOTO, P. (1995a) "La organización del trabajo en la industria del trabajo: las cigarreras de la fábrica de Madrid a comienzos de siglo" (Septiembre 1992) en VIII Congreso Internacional para la Conservación del Patrimonio Industrial, Madrid: CEHOPU, pp. 123-136; CANDELA SOTO, P. (1995b) "Condiciones de vida (y trabajo) de las cigarreras madrileñas a comienzos del siglo XX" en Actas del II Congreso de Historia Social "El trabajo a través de la historia", Santiago Castillo ed., pp.373-381; CANDELA SOTO, P. (1993-1994) "Trabajo y organización en la industria del tabaco: Las 


\section{La jerarquía dentro de la fábrica}

Para comprender la posición que la cigarrera ocupaba dentro de la fábrica es fundamental conocer la jerarquía de carácter vertical establecida en el seno de la misma. Dentro de las fábricas tabacaleras, el cuerpo de trabajadores estaba polarizado en dos grupos característicos: la dirección de la fábrica con su aparato administrativo y radicada en un espacio propio definido diferenciado del ámbito propiamente productivo, y las cigarreras y personal masculino de tareas auxiliares y de mantenimiento. La dirección de la fábrica representaba el poder del Estado a través de la organización del monopolio y estaba confiada a un administrador superintendente o director de procedencia distinta a la ciudad de destino y dependía jerárquicamente del subdelegado de rentas o juez conservador. La administración, por otra parte, la constituían un contador y sus oficiales, un tesorero y sus ayudantes, y un fiel con el personal de almacenes. El conjunto de producción quedaba integrado por un inspector de labores, varias maestras responsables cada una de un taller, y las operarias agrupadas en cuadrillas con la organización descrita en el epígrafe anterior. El control y la vigilancia de las mismas eran ejercidos por las porteras gobernadas por la portera mayor, por el portero y por el cuerpo de guardia $^{118}$.

Con el establecimiento del Reglamento Orgánico de las Fábricas en 1888 se produjo un cambio de mentalidad y actitud en la lógica de explotación del monopolio. Este giro conceptual se aplicó en dos niveles: la organización y funcionamiento de las fábricas y la regulación de la situación y normas de actuación de los empleados. A tal efecto, el jefe de la fábrica era la cúspide de una clase "privilegiada" constituida por la sección de intervención -la parte administrativa y contable- y la sección pericial, integrada por el ingeniero inspector y ayudantes bajo los que se situaba el personal subalterno -porteros, capataces, porteras, maestras $\mathrm{y}$, finalmente, personal obrero-119. Muchos de los testimonios de antiguas trabajadoras dan cuenta de la autoridad que ostentaban las maestras y las porteras y de las frecuentes diferencias con la dirección de la fábrica. En este sentido, las diferencias jerárquicas en la fábrica no sólo se aplicaban en el cargo, sino también en la segregación que estas suponían en el espacio físico ${ }^{120}$.

cigarreras madrileñas, 1890-1920” en Sociología del Trabajo, nueva época, n²0, pp. 91-115. También se recomienda la consulta de otras publicaciones como GARCÍA SÁNCHEZ, M. L. (1993) "Las cigarreras madrileñas" en Revista de Folklore, no 147, pp. 91-97; y VALLEJO, S. (1987) "Las cigarreras madrileñas" en Historia 16, vol. 12, n 130 , pp. 2330.

118 ALONSO ÁlVAREZ, L. (1984), op. cit., p. 20. El cuerpo de guardia era un grupo característico de la producción monopolística y denota el carácter coercitivo de las fábricas tabacaleras. Surge ya con el proyecto de la Real Fábrica de Tabacos de Sevilla, por influencia francesa, y en esta primera fábrica contaba incluso con un espacio carcelario en el propio recinto de la fábrica. Generalmente, su función era la de mantener el orden y sofocar motines o sublevaciones de las cigarreras.

119 CANDELA SOTO, P. (1997) op. cit., p. 46.

120 Cabe agradecer especialmente a Conchi, antigua trabajadora del taller de Farias de la tabacalera gijonesa que ingresó en la fábrica en 1974 y que, a su cierre en 2002, fue trasladada a la fábrica de Solares hasta su jubilación, así como a sus compañeras de la Asociación Les cigarreres. Se agradecen muy especialmente todos los detalles aportados a través de diversas entrevistas durante el verano de 2016, puesto que ha confirmado datos sobre las condiciones de los talleres -muy oscuros en planta baja y luminosos en las restantes plantas-, el buen estado de la fábrica en el momento de su cierre con la cubierta recién reparada, la segregación por estatus de los trabajadores mediante la disposición de la entrada noble en la antigua vicaría y la de servicio en el nuevo acceso de los años 70, la 


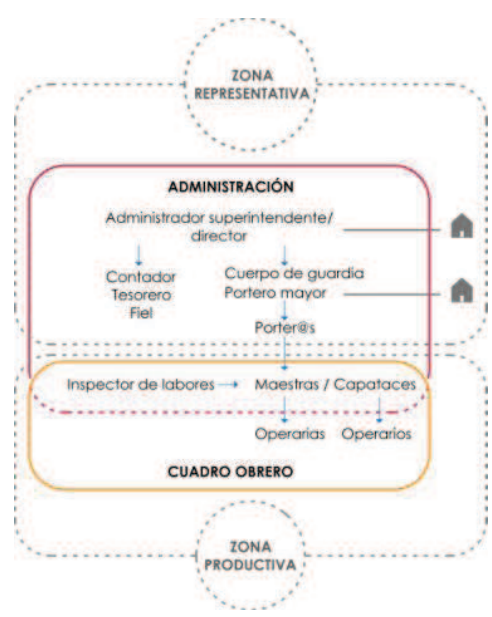

Figura 2.18. Esquema de la jerarquía de la fábrica y espacios que ocupan.
[Sobre las maestras y capatazas y control de la plantilla] Ellas como los oficiales, los jefes estos que estaban en la oficina. Eran... Parecían señores feudales. Las maestras intervenían... Había alguna que era muy buena gente "Neñes, no os meter en líos", pero había otras que estaban vigilando, ¿eh? Y que enseguida iban al oficial y decir: "Hay una que tal, hay esta que no sé qué" [...] [Pregunta: ¿Cómo se llegaba a Maestra?] A dedo. Después ya hubo maestras, pero te estoy hablando también de los años ochenta, que ya después fue más profesional y se presentaba la gente a los cargos $^{121}$.

Para las cigarreras, el trabajo en la fábrica no era una mera etapa de su vida, sino que se trataba de un empleo permanente que formaba parte vertebral de su existencia. En cierta manera, las cigarreras eran empleadas del Estado y, como acertadamente señalan Pamela Radcliff y María Jesús de Francisco, "lo significativo de estas mujeres es no sólo su importancia numérica en términos absolutos sino también la forma en que dominaban su ambiente laboral. Tenían polivalencia para todos los puestos de trabajo" 122 .

Centrando, por tanto, la cuestión en la figura concreta de las cigarreras, pese a la horizontalidad de este grupo, había ciertas diferencias en el tipo de labores que realizaban, siendo algunas más duras que otras. Generalmente, ingresaban muy jóvenes en las fábricas, por lo que a las aprendizas se las destinaba a tareas menores hasta que adquirían la destreza para ostentar el papel de liadoras. Este era el puesto más codiciado por las mejores condiciones del espacio de trabajo y la remuneración más alta, y generalmente lo desempeñaban las cigarreras jóvenes más expertas. Esta diversidad de cualificación se traducía en un estatus determinado dentro de la fábrica y marcaba la diferencia en las condiciones de las empleadas. Un pasaje de $L a$ Tribuna de Emilia Pardo Bazán da cuenta de esta diferenciación entre las tareas desempeñadas en la fábrica a través de las aspiraciones de su protagonista Amparo:

Quiso Amparo mudarse de taller, y solicitó pasar al de cigarrillos, donde le agradaban más el trabajo y la compañía [...]

Preponderaban en el taller de pitillos las muchachas de Marineda; apenas se veían aldeanas; así es que abundaban los lindos palmitos, los rostros juveniles. Abajo, la mayor parte de las operarias eran madres de familia, que acuden a ganar el pan de sus hijos, agobiadas de trabajo, arrebujadas en un mantón, indiferentes a la compostura, pensando en las criaturitas que quedaron confiadas al cuidado de una vecina; en el recién, que llorará por mamar, mientras a la madre le revientan los pechos de leche... Arriba florecen todavía las ilusiones de los primeros

disposición de vestuarios masculinos en planta baja y femeninos en planta alta, etc. Actualmente, se mantiene en activo la Asociación Les Cigarreres que ha solicitado al ayuntamiento la disposición de un local en la antigua fábrica para celebrar sus encuentros y adecuar un espacio expositivo que preserve la memoria de sus vivencias en la misma. ${ }^{121}$ Fragmento extraído de la entrevista inédita realizada por el equipo de documentación del Museo del Ferrocarril de Asturias a Mari Paz Puente González, antigua cigarrera de la Fábrica de Tabacos de Gijón el 20 de marzo de 2009. La autora agradece a Nuria Vila y Paz García Quirós la cesión de esta documentación.

122 RADCLIFF, P. y DE FRANCISCO, M. J., (1998) op. cit., p. 18. 
años y las inocentes coqueterías que cuestan poco dinero y revelan la sangre moza y la natural pretensión de hermosearse ${ }^{123}$.

Pese a lo reflejado en este fragmento de La tribuna, el cambio de cigarreras entre talleres no era habitual. Tal y como señala Paloma Candela Soto, durante las primeras décadas del S.XX la tendencia general fue que el personal femenino permaneciera trabajando en el mismo tipo de labor. Aunque la ampliación del número de partidos y ranchos existentes afectó a la movilidad de las obreras, la rotación a nivel de taller fue débil, siendo la mayor parte de los cambios de una clase de cigarro a otra ${ }^{124}$.

\section{El trabajo realizado en la fábrica}

Sobre el trabajo específico desarrollado por las cigarreras en el seno de la fábrica, cabe nuevamente recordar que se distinguen dos periodos muy significativos dentro de la historia de la producción tabacalera en España que de forma relevante influirán en la figura de la cigarrera y en las condiciones de su espacio de trabajo: la primera época de producción manufacturera con tintes preindustriales, y la época de impulso de la modernización de todas las fases de producción y reestructuración de las fábricas hacia la mecanización total.

Señalan Arias y Mato que la forma de producción artesanal de la primera etapa manufacturera confiere un carácter preindustrial a la misma que se traducía en varios aspectos ${ }^{125}$. En primer lugar, se trataba de un modelo organizativo basado en la tradicional división de las labores tabacaleras en talleres gobernados por una maestra que, a su vez, se subdividían en ranchos o agrupaciones de 8 a 15 operarias. Por otra parte, la flexibilidad en el horario y la ausencia de control del absentismo de las cigarreras denotaba una cierta permisividad para la atención de sus hijos y obligaciones domésticas, facilitado en gran parte por el sistema de pago en jornales a destajo. En tercer lugar, el establecimiento de medidas disciplinarias para evitar robos y comportamientos considerados no adecuados dentro de la fábrica se inscribe en el marco común del carácter coercitivo de los espacios fabriles tabacaleros en España que atendían tanto a la erradicación del fraude como al mantenimiento de una correcta moralidad de la operaria. De igual forma, durante muchas décadas se permitirá la posibilidad de cuidar a niños pequeños dentro de la fábrica, favoreciendo la incorporación femenina y la reducción del absentismo

123 PARDO BAZÁN, E. (1882 [1978]) La Tribuna, Madrid: Cátedra, pp. 114-115. En la introducción, Benito Varela Jácome resalta la importancia de esta obra literaria "por tratarse de un documento testimonial, del análisis «implacable» de una capa social, de una interpretación audaz de la efervescencia de las ideas de la revolución de 1868" indicando que para ello "Doña Emilia acude durante varios meses a la fábrica de tabacos de La Coruña", p .48. Sobre la acción asociacionista en la fábrica herculina también se puede consultar BARBOSA, A. M. (1998) "Asociacionismo y acción colectiva: la formación de la conciencia femenina reivindicativa en la Fábrica de Tabacos de La Coruña” en ORTIZ DE ORRUÑO LEGARDA, J.M. y CASTILLO ALONSO, S. (coord.), Estado, protesta y movimientos sociales: actas del III Congreso de Historia Social de España: Vitoria-Gasteiz, julio de 1997, pp. 423434.

124 CANDELA SOTO, P. (1997) "El trabajo dentro de la fábrica: experiencia y trayectoria laboral de la cigarrera madrileña" en CANDELA SOTO, P. (1997) op. cit., pp. 96-138.

125 Sobre las cuestiones que atañen a este epígrafe, ARIAS GONZÁLEZ, L. y MATO DÍAZ, A. (2005) op. cit., pp. 4648, 60 y 137. 


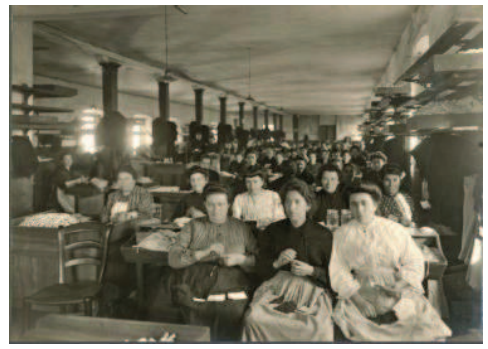

Figura 2.19. Ranchos de cigarreras en el taller de cigarrillos superiores de la Fábrica de Tabacos de Gijón. Julio Peinado, 1909, en Fototeca del MUPA. laboral de las madres lactantes. Por último, era común otorgar preferencia en el ingreso a la fábrica de familiares de las trabajadoras, reforzando el carácter familiar de la planta fabril.

En etapas posteriores, bajo la gestión de la CAT se regularía a través del Reglamento Orgánico de 1927 el descanso nocturno de las mujeres obreras, estableciendo una pausa obligatoria independiente de la establecida para el cuidado de los hijos, pudiendo abandonar el lugar de trabajo. Esto demuestra que a las mejoras en la mecanización se suma un especial cuidado por las condiciones de trabajo de las operarias femeninas en cuanto a su condición de mujeres y la conciliación en su papel de madres, pero también supone la limitación y control del absentismo femenino. No obstante, pese a la progresiva mecanización, se da una permisividad hacia las labores manuales, adecuadas para estas condiciones de flexibilidad en el horario de trabajo gracias al destajo, mientras que en los talleres mecanizados el horario fijo se establece por la regulación de entrada y salida, que por otra parte goza de premios a la productividad. Cabe destacar que ya en el año 1908 se instauran los talleres de Faenas Auxiliares que, como se ha comentado anteriormente, se trataba de una suerte de jubilación encubierta y no contaba con un espacio específico dentro de la fábrica.

Con el inicio de la mecanización y el cambio en la organización productiva que supondrán los sucesivos planes de modernización, se establecerá un horario fijo con salarios preestablecidos y la posibilidad de ganar incentivos a través de los premios a la producción. Por otra parte, la organización de la producción abandonará la división en talleres y ranchos para pasar a constituirse en secciones y la cualificación para ocupar un puesto de trabajo en la fábrica se volvió más exigente. Se erradicó el ingreso por lazos familiares y se establecieron una serie de pruebas de acceso que valoraban la idoneidad de las candidatas. La incipiente mecanización también influiría en el espacio de trabajo femenino: el número de cigarreras necesarias para la producción disminuiría, mientras que el personal masculino encargado de tareas de mantenimiento de la maquinaria sufriría un aumento. No obstante, este hecho no impidió que históricamente se mantuviese una mayoría de empleo de mano de obra femenina. Sin embargo, la maquinaria empleada en las labores tabacaleras no constituía una organización en serie, como en otro tipo de industrias, sino que mantenía las características específicas de las etapas productivas y el carácter individual y especializado del trabajo de cada cigarrera.

[Sobre la entrada en la fábrica de Gijón en 1964] Bueno y entré, llamáronme, pasé el examen y el médico y entré a trabajar. [Pregunta: ¿El examen en qué consistía?] Pues mira, de aquella ya era avanzáu, los dibujinos y todo eso. Nos lo hacíen pa entrar. No era tampoco mucha 
complicación pero de aquella había gente que no sabía ni leer ni escribir bien ${ }^{126}$.

Con la firma del contrato del Estado con Tabacalera en 1945 se heredó la organización laboral que había establecido la CAT. De esta forma, se vio necesaria la reestructuración y organización de las plantillas en función de los nuevos requerimientos de la producción y su prevista modernización. Al igual que con la cesión del arriendo a la CAT a finales del S.XIX, estas modificaciones se recogieron en un reglamento de trabajo del 28 de junio de 1946 en el que se establecieron unas mejoras para los trabajadores consistentes en el aumento de sueldo y jornal, así como ayudas a la vivienda, manejo de fondos, servicios prestados, mejora de las condiciones del ambiente nocivo de trabajo, el establecimiento de quinquenios, carestía de vida o cargas familiares. El tradicional carácter familiar de tabacalera se adecuaba a las políticas en materia social industrial de la etapa de autarquía en la que las medidas introducidas por la compañía ostentaban un claro carácter paternalista. De hecho, trabajar en Tabacalera estaba muy bien considerado en la época por los sueldos que se obtenían y las prestaciones dadas a sus trabajadores.

En la década de los 70 se reorganizó la estructura de la plantilla de acuerdo a las nuevas medidas introducidas en el proceso productivo. Con la reestructuración de los talleres de elaboración en diversas secciones y la supresión de algunas denominaciones de puestos de trabajo, desaparecen las figuras de portera primera, maestra de labores y operarias encargadas de grupo, pasando a constituir el mando operativo, en el caso de porteras y maestras, y de especialista operativo a las encargadas de grupo ${ }^{127}$. Otra de las medidas introducidas fue la supresión del registro general que tantas protestas y motines había provocado históricamente ${ }^{128}$.

Con la intensificación de la mecanización se desarrollaron otras formas de vincular a las operarias con el espacio fabril a través del trabajo. La responsabilidad sobre el producto elaborado, el manejo unipersonal de la máquina y la utilización de consignas y lemas para el refuerzo de la confianza de los trabajadores, además del ambiente familiar, eran los métodos empleados para estrechar el vínculo de la operaria con el espacio de trabajo, de forma que a las relaciones afectivas entre compañeras se unía la consideración de la fábrica como "casa".

Se encaminaba a su trabajo, a ese otro mundo suyo [...] a ese edificio lleno de historias [...] Ese lugar que la había visto crecer, donde había puesto los pies siendo una niña y donde, poco a poco se había hecho mujer [...] Ese, sin lugar a dudas, era su refugio, su medio de vida, su

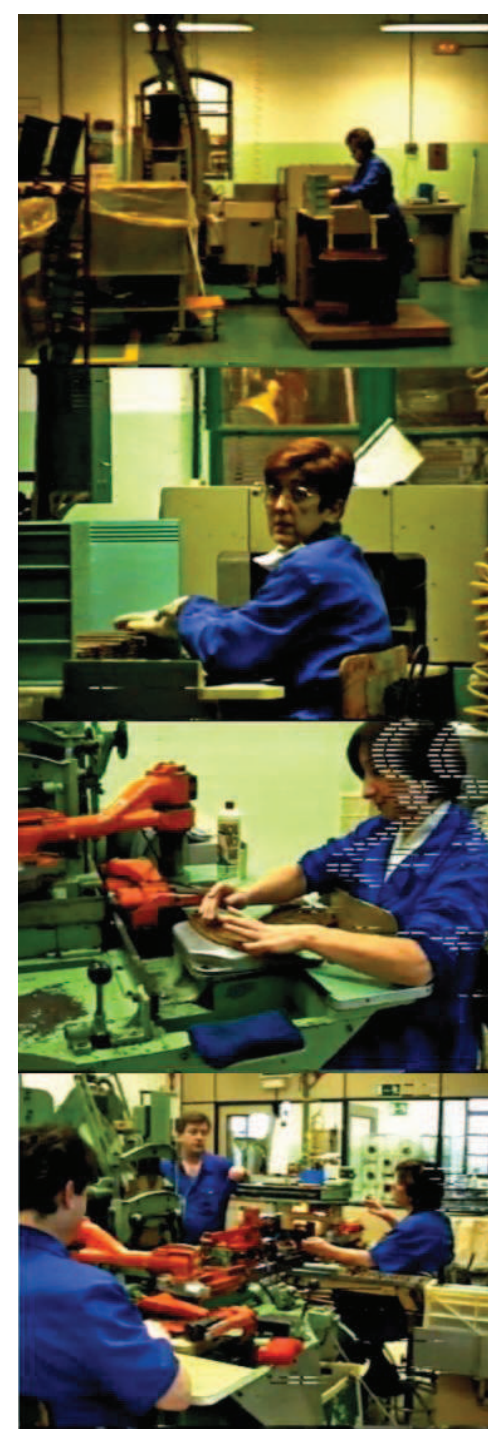

Figura 2.20. Fotogramas de la grabación de Antoni Vilanova Omedas en los talleres mecanizados y semimecanizados de la Fábrica de Tabacos de Gijón, 1999, cortesía de Antoni Vilanova Omedas.

\footnotetext{
${ }^{126}$ Fragmento extraído de la entrevista inédita realizada por el equipo de documentación del Museo del Ferrocarril de Asturias a Liliana Fernández García, antigua cigarrera de la Fábrica de Tabacos de Gijón, el 27 de marzo de 2009. La autora agradece a Nuria Vila y Paz García Quirós la cesión de esta documentación.

127 CAMPOS LUQUE, C. (2004) op. cit., pp. 199-202.

128 No obstante, en la entrevista realizada en 2015 a un antiguo empleado de la factoría de Tarragona que ingresó en esta época, se advierte que los registros humillantes se continuaron realizando y que el trato de algunos mandos masculinos a las operarias era sexista en muchos casos.
} 
acompañante, su alegría y su pena. Su fatiga. Era algo tan simple como su vida ${ }^{129}$.

Así, el objetivo era conseguir la vinculación de las trabajadoras con la labor que producían a través de la experimentación del proceso productivo completo, de forma que a través de esta experiencia íntegra se reforzaba el orgullo por el trabajo bien hecho y la operaria identificaba su trabajo con el producto final. El hecho de que se siguiesen contratando mujeres, incluso tras la intensa mecanización, continúa aparejado al hecho de que el sector femenino demostraba mayor agilidad y destreza en el manejo del producto. Una labor, la de la industria del tabaco, que pese a las reestructuraciones de la producción, la sofisticación de la misma y la reorganización de las plantillas se mantendría fuertemente asociado a la figura femenina y sus capacidades.

\section{La preferencia por la contratación femenina}

La historia de la producción tabacalera en España y la sujeción de la misma a los cambios de gusto en el consumidor influyeron en gran parte en el volumen de contratación de operarias femeninas. La preferencia por el tabaco de humo o torcido a finales del S.XVIII e inicios del S.XIX fue el que motivó el cambio de modelo productivo, de la producción de rapé o tabaco en polvo -que implicaba el empleo de personal masculino debido a la necesidad de fuerza para manejar los molinos que trituraban la hoja de tabaco, acompañado del empleo de tracción animal-, al tabaco de humo, en las variedades de cigarros y cigarrillos, además de picadura para liar. Para ello sería más adecuado el empleo de mano de obra femenina, más precisa y eficaz en este tipo de labores. Como señalan Arias y Mato, "la mano de obra femenina era más hábil, paciente y precisa en la elaboración del cigarro, actividad que no requería de fuerza física" ${ }^{130}$. La destreza de la mano femenina en el liado, junto a la reducción de costes en el ajuste a un salario más bajo y la errónea -como se verá más adelante- creencia general de que el sector femenino resultaba una mano de obra más dócil, fueron algunos de los puntos clave para que la producción tabacalera adquiriese esta connotación femenina. Señalan Comín Comín y Martín Aceña que

los cigarros elaborados por los operarios, a principios del siglo XIX, eran de peor calidad que los de las operarias, sencillamente por las prisas con que aquéllos producían [...] Pero la cuestión fundamental radicaba en que las cigarreras podían ganar menores salarios porque tenían menos facilidades para encontrar un empleo alternativo ${ }^{131}$.

Esta destreza en el liado se reflejó sobre todo en el primer periodo manufacturero en el que algunas fábricas españolas llegaron a emplear a 4.000 mujeres, con las diversas repercusiones que esto conllevaba tanto en el espacio fabril como en el entorno de la fábrica. Pese a que

129 REVUELTA, C. (2013) Aromas de tabaco y mar, Popum Books, p. 432.

130 ARIAS GONZÁLEZ, L. y MATO DÍAZ, A. (2005) op. cit., p. 43.

131 COMÍN COMÍN, F. y MARTÍN ACEÑA, P. (1999) op. cit., p. 79. 
anteriormente se ha descrito el proceso de liado con minuciosidad, cabe destacar el pasaje de la obra de Pardo Bazán dedicado a esta tarea por los matices aportados en su observación como método de documentación de la novela La Tribuna dentro de la fábrica coruñesa:

Primero era preciso extender con sumo cuidado, encima de la tabla de liar, la envoltura exterior, la epidermis del cigarro y cortarla con el cuchillo semicircular trazando una curva de quince milímetros de inclinación sobre el centro de la hoja para que ciñese exactamente el cigarro, y esta capa requería una hoja seca, ancha y fina, de lo más selecto, así como la dermis del cigarro, el capillo, ya la admitía de inferior calidad, lo propio que la tripa o cañizo. Pero lo más esencial y difícil era rematar el puro, hacerle la punta con un hábil giro de la yema del pulgar y una espátula mojada en líquida goma, cercenándole después el rabo de un tijeretazo veloz. La punta aguda, el cuerpo algo oblongo, la capa liada en elegante espiral, la tripa no tan apretada que no deje aspirar el humo ni tan floja que el cigarro se arrugase al secarse, tales son las condiciones de una buena tagarnina. Amparo se obstinó todo el día en fabricarla, tardando muchísimo en elaborar algunas, cada vez más contrahechas y estropeando malamente al hoja. Sus vecinas de mesa le daban consejos oficiosos; había diversidad de pareceres; las viejas recomendaban que cortase la capa más ancha, porque sale el cigarro mejor formado, y porque "así lo habían hecho ellas toda la vida”; y las jóvenes, que más estrecha, que se enrolla más pronto. Al salir de la fábrica le dolían a Amparo la nuca, el espinazo, el pulpejo de los dedos ${ }^{132}$.

Con los sucesivos planes de modernización del S.XX que impulsan la mecanización y especialización de las labores, se aprecia un retroceso en la contratación de personal femenino, mientras que la presencia de personal masculino inicia un repunte debido a la necesidad de emplear personal de mantenimiento y manejo de la maquinaria pesada empleada, manteniéndose siempre en porcentaje inferior. En su obra Mujeres e industria tabaquera en Alicante, Teresa Lanceta Aragonés recoge algunos apuntes sobre el trabajo específico que realizaban las operarias en las últimas décadas de funcionamiento de la fábrica. A través de estas descripciones se puede apreciar el diverso carácter de la producción en relación a los espacios y a las tareas a realizar por las cigarreras en contraposición al carácter manual y artesanal que recogía la novela de Emilia Pardo Bazán:

Las operarias tenían que ir revisando que el proceso se desarrollara bien, sin roturas, ni arrugas ni manchas. También tenían que llenar las bateas que circulaban por unos monocarriles llevando los cigarrillos a las empaquetadoras. Después, se pasaba a las encelofanadoras y a las empaquetadoras finales. Las máquinas estaban conectadas pero necesitaban de un elemento manual que uniera el proceso y de eso se encargaban las mujeres ${ }^{133}$.

De igual forma, también recoge algunos aspectos colaterales que implicaba la convivencia con los compañeros masculinos con el inicio de la producción mecanizada y su presencia destinada a llevar el

\footnotetext{
132 PARDO BAZÁN, E. (1882 [1978]), op. cit., p. 92.

133 LANCETA ARAGONÉS, T. (2013) Mujeres e industria tabaquera en Alicante, Picanya: del Bullent, p. 34.
} 
mantenimiento de las máquinas:

La elaboración del tabaco, primero manual y después industrial, estuvo, hasta época muy reciente, siempre en manos de las mujeres; los hombres se encargaban del funcionamiento de las máquinas y del mantenimiento de los talleres y la fábrica. Esta rigidez de género en los puestos de trabajo acarreó malestar y conflictos ${ }^{134}$.

\section{El ambiente de trabajo en la fábrica: carácter reivindicativo y compañerismo del colectivo}

Las cigarreras debían realizar sus tareas en silencio y bajo la atenta mirada de las maestras, teniendo que costear sus propios útiles de trabajo en la primera etapa manufacturera. Solían trabajar en la fábrica hasta su defunción y resulta característica, en este aspecto, la creación de un taller especial denominado como de "tareas auxiliares" anteriormente citado $^{135}$, que daba empleo en tareas menores a las cigarreras que por su avanzada edad no podían realizar de forma satisfactoria los trabajos que exigían mayor destreza. No constituía un espacio físico propiamente dicho como el resto de los talleres, si no que frecuentemente constituían tareas simples como el desvenado de la hoja o tareas de barrido y adecentamiento de talleres.

Resulta interesante comprobar la analogía en algunos aspectos del espacio de trabajo fabril tabacalero con una espacialidad propia de un convento, acentuando su carácter de reclusión. Al igual que en los refectorios conventuales, en las fábricas tabacaleras existía la figura de la lectora que amenizaba la tarea de sus compañeras leyendo en voz alta obras literarias de distinto carácter o la actualidad publicada en prensa. Precisamente en un viaje de trabajo de campo a la isla de Cuba, se ha comprobado que esta práctica existe actualmente en las fábricas tabacaleras de La Habana, en las que el lector dispone de un espacio propio en el que se retransmiten a través de megafonía las lecturas que realiza de novelas o periódicos ${ }^{136}$. Sin embargo, cabe destacar que las lecturas no eran siempre distendidas, sino que también en épocas especialmente convulsas la lectura de artículos periodísticos de carácter político alentaba los ánimos reivindicativos de las cigarreras ${ }^{137}$.

Ya se hizo referencia en el anterior epígrafe al cambio cualitativo que se produjo con la introducción de la mecanización en las fábricas y cómo esto afectaba a las cigarreras, no sólo porque debían adaptarse a los nuevos métodos, sino porque veían en la llegada de la maquinaria una amenaza a sus puestos de trabajo. Efectivamente, esta

${ }^{134}$ LANCETA ARAGONÉS, T. (2013) op. cit., p. 37.

135 En Madrid, el taller de faenas auxiliares se inaugura en 1906 y permanece hasta 1929. Representaba el 6\% del empleo total y se creó en otros centros como Alicante, Sevilla o Gijón, normativizándose en el Reglamento Orgánico de 1927. CANDELA SOTO, P. (1997) op. cit., p. 108.

136 Precisamente, algunas de las novelas que se leían durante la tarea del liado, dieron nombre a algunas marcas de cigarros, como los "Romeo y Julieta" o los "Montecristo". Sobre la figura del lector se recomienda la consulta de TINAJERO, A. (2010) El lector: a history of the cigar factory reader, [Judith E. Grasberg traducc.], Austin: University of Texas Press.

137 Ver PARDO BAZÁN, E. (1882 [1978]) op. cit., pp. 107-108. Precisamente, el título de la obra hace referencia al apodo dado a la protagonista por su función de lectora en la fábrica coruñesa. 
circunstancia provocó no pocas revueltas luditas que incluso desembocaban en actos violentos como destrozos del propio parque mueble de la fábrica. Por este motivo, inicialmente se introducen los nuevos métodos productivos en fábricas de reciente creación en las que se podía implantar con normalidad el proceso mecanizado puesto que no contaban con una tradición de gran volumen de mano de obra y las nuevas cigarreras ingresaban ya con vocación de operaria, aleccionadas en los nuevos métodos y carentes de oposición a los mismos.

En otras ocasiones, las protestas tenían su origen en el mal estado de la materia prima que se consignaba a las cigarreras o en el carácter abusivo de algunos registros. Nuevamente, la obra de Pardo Bazán recoge una escena que se corresponde con estas protestas:

Otros motivos de irritación ayudaban a soliviantar los ánimos. Escaseaban las consignas y la hoja tan pronto era quebradiza y seca, como podrida y húmeda. No, trabajo habían de pasar los que fumasen semejante veneno; pero las que lo manejaban también estaban servidas. Al ir a estirar la hoja para hacer las capas, en vez de extenderse, se rompía, y en fabricar un cigarro se tardaba el tiempo que antes en concluir dos; [...] Las operarias alzaban los brazos ejecutando la desesperada pantomima popular, llevándose ambas manos a la cabeza, a la frente, al pecho señalando con enérgicos ademanes el tabaco averiado e inútil, de imposible elaboración. Tan alteradas estaban, que al pasar las maestras les metían puñados de hoja en las narices, gritando que "olía a berzas"; y envalentonándose, lo hicieron también con los inspectores, y si el jefe se hubiese presentado en los talleres, apostaban que con el jefe repetirían la escena ${ }^{138}$.

Como colectivo trabajador, las cigarreras siempre fueron un grupo unido y combativo, en unas fábricas en mayor grado que otras. Aunque contaban con precedentes en la segunda mitad del S.XIX, fue a principios del S.XX cuando comenzaron a organizarse en la lucha por sus derechos laborales, creándose los primeros sindicatos de cigarreras. Pero ya anteriormente en el S.XIX, las cigarreras tenían un carácter particular que les dio fama. En la fábrica de Gijón, por ejemplo, no sólo denunciaban injusticias sufridas por las compañeras, sino que con un carácter solidario del que hacían gala, se situaban siempre del lado de los más necesitados apoyando a los vecinos del barrio cuando no se escuchaban sus peticiones, paralizando el trabajo para apoyar a los comerciantes por la subida de impuestos u organizando recolectas para los pobres o para viudas de soldados y pescadores.

[Sobre las reivindicaciones que planteaban y disciplina fabril] $\mathrm{Y}$ otra comiendo un caramelo, la misma historia. Estabas trabajando allí, comiendo un caramelo y no se podía. O sea, eran cosas como de... Yo ahora pensándolo, lo ves como tan raro que parece de esas películas de internados. [...] Estas comiendo, llega un oficial: "iMaestra tal” -muy autoritario- "esa chica...". O la mandaban a un taller de abajo, la castigaba o decían: "ique se quede mañana en casa!" o lo que fuera.

[Sobre la relación con los mandos y los castigos y sanciones frecuentes] Simplemente, contestar a una maestra. Una maestra que te dijera no

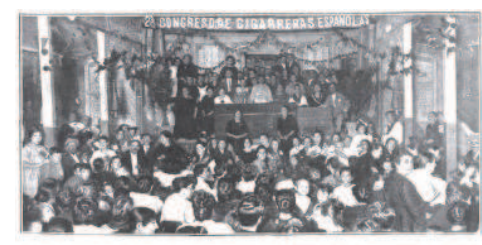

Figura 2.21. Segundo congreso de cigarreras españolas. Julio de

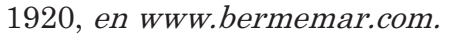

138 PARDO BAZÁN, E. (1882 [1978]), op. cit., p. 207. 


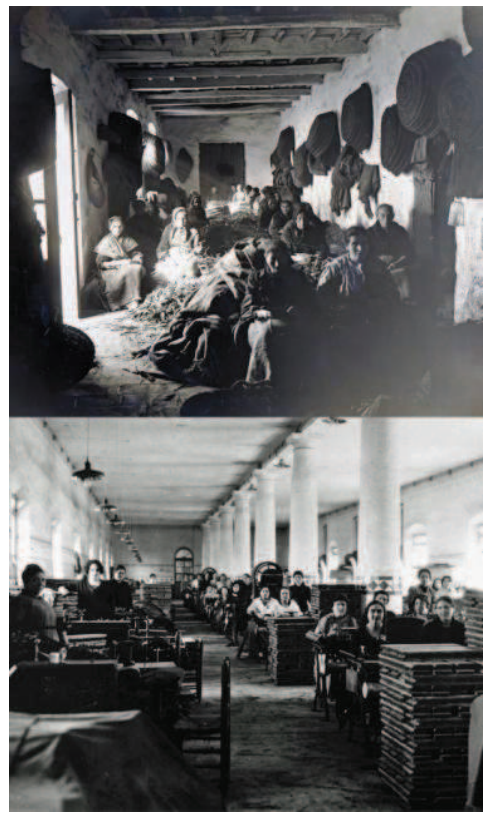

Figura 2.22. Taller de desvenado fuerte de la Fábrica de Tabacos de Gijón, Julio Peinado, 1909, en

Fototeca del MUPA; y taller de liado de la Fábrica de Tabacos de Alicante, en $A M A$. sé qué. O estabas parada, ibas al baño y: “Puente!”. Ah, bueno, cuando yo entré, ¡nos llamaban por el número!, ¿eh? ¡Ojo! Eso era otra cosa, la ficha. No se me olvidó la ficha a mí: ¡306! ¡Como los presos!: “¡A ver, 306!” [...]

[Sobre huelgas y registros] Otra vez hubo otra huelga mayor también. Por una compañera, otra chica, que era muy combativa, ¿no? Y fue un contrarregistro. A nosotras nos registraban y nos tocaban todos los días. Hacías una fila, había que descalzarse si llevabas botas. Era muy humillante ${ }^{139}$.

Posteriormente, la represión de la posguerra amainó los ánimos reivindicativos hasta la entrada de una nueva generación de cigarreras en los años 60 que protagonizaban frecuentemente protestas por las condiciones represivas del entorno del trabajo y los humillantes cacheos a la salida del mismo, en la línea de la situación que refleja el fragmento anterior ${ }^{140}$.

[Sobre la relación con la generación de cigarreras de la guerra y posguerra] Eran unas señoras muy mayores y cuando decíamos cosas que nos parecían muy naturales, a pesar de que estábamos en pleno Franquismo, pero ellas siempre tenían miedo. Decían: "Neñes, cuidáu, no se dice tal", "Neñes, cuidáu”... Y no querían. Algunas contaban algunas cosas de las cosas que hubo en la fábrica. Hubo bastante gente represaliada ${ }^{141}$.

\section{El espacio fabril y las cigarreras}

El análisis de la relación entre las cigarreras y su espacio de trabajo resulta fundamental para las cuestiones que atañen a la presente investigación. La evolución del proceso productivo desde su etapa manufacturera hasta la total mecanización de todas las fases condicionaría de forma sustancial la relación de las trabajadoras con su espacio de trabajo, desde el carácter de indeterminación programática de los primeros momentos, hasta la aparición de espacios específicos para las mismas.

En cuanto a las condiciones del espacio fabril, la verticalidad que se manifestaba en la zonificación del proceso productivo tenía también sus consecuencias en la calidad ambiental del lugar de trabajo. Como si de una suerte de alegoría bíblica se tratase, Emilia Pardo Bazán describe los talleres de picadura como Infierno -situados en la planta baja del

${ }^{139}$ Equipo de documentación del Museo del Ferrocarril de Asturias (2009) Entrevista a Liliana Fernández García, op. cit.

140 Sobre este epígrafe en particular, es muy valiosa la información inédita aportada por Nuria Vila y Paz García Quirós, documentalistas del Museo del Ferrocarril de Gijón que realizaron el trabajo de documentación de la fábrica de la citada ciudad antes de que fuesen desmanteladas sus naves exteriores. Entre el interesante trabajo inédito que se encuentra en el archivo del museo, existen unas grabaciones a diversas cigarreras de la generación de los años 60 -como las que se han citado a lo largo del capítulo- que aportan su visión sobre las condiciones de trabajo, huelgas, características de su puesto, visión del espacio de la fábrica, etc. Cabe resaltar la colaboración de Carlos Gordon Rodríguez en dicho trabajo, destacando el trabajo inédito realizado entre agosto de 2008 y agosto de 2009 "La Fábrica de Tabacos de Gijón y su entorno", y muy especialmente GORDON RODRÍGUEZ, C. (2010) "Trabajo femenino y acción colectiva en la fábrica de tabacos de Gijón (1937-1977)" en ÁLVAREZ ARECES, M.A. (ed.) (2010) Patrimonio industrial y paisaje. V Congreso sobre Patrimonio industrial y Obra Pública en España, Gijón: CICEES, pp. 605-612.

${ }^{141}$ Equipo de Documentación del Museo del Ferrocarril (2009) Entrevista a Mari Paz Puente González, op. cit. 
edificio-, mientras que los de cigarros comunes y los de cigarrillos -estos últimos en la planta más superior- se comparan respectivamente con el Purgatorio y el Paraíso. Las minuciosas descripciones de Pardo Bazán proporcionan referencias que ayudan a generar una imagen bastante precisa sobre las condiciones de estos talleres en los inicios del segundo tercio del S.XIX:

se deja entender la opresión que experimentaron en los primeros tiempos de cautiverio en los talleres, donde la atmósfera estaba saturada del olor ingrato y herbáceo del virginia humedecido y de la hoja medio verde, mezclado con las emanaciones de tanto cuerpo humano y con el fétido vaho de las letrinas próximas. Por otra parte, el aspecto de aquellas grandes salas de cigarros comunes era para entristecer el ánimo. Vastas estanterías de madera ennegrecida por el uso, colocadas en el centro de la estancia, parecían hileras de nichos [...]

Entre el taller de cigarros comunes y el de cigarrillos, que estaba un piso más arriba, mediaba gran diferencia: podía decirse que éste era a aquél lo que el Paraíso de Dante al Purgatorio. Desde las ventanas del taller de cigarrillos se registraba hermosa vista de mar y país montañoso, y entraban sin tasa por ellas luz y aire. A pesar de su abuhardillado techo, las estancias eran desahogadas y capaces, y la infinidad de pontones y vigas de oscura madera que soportaban el armazón del tejado le daban cierto misterioso recogimiento de iglesia, formando como columnatas y rincones sombríos en que puede descansar la fatigada vista [...]

Si los pitillos eran el Paraíso y los cigarros comunes el Purgatorio, la analogía continuaba en los talleres bajos, que merecían el nombre de Infierno [...] En el taller del desvenado daba frío ver, agazapadas sobre las negras baldosas y bajo sombría bóveda, sostenida por arcos de mampostería, y algo semejante a una cripta sepulcral, muchas mujeres, viejas la mayor parte, hundidas hasta la cintura en montones de hoja de tabaco, que revolvían con sus manos trémulas, separando la vena de la hoja [...] Dentro de una habitación caleada, pero negruzca ya por todas partes, y donde apenas se filtraba luz al través de los vidrios sucios de alta ventana, vieron las dos muchachas hasta veinte hombres vestidos con zaragüelles de lienzo muy arremangados y camisa de estopa muy abierta, y saltando sin cesar. El tabaco los rodeaba; habíalos metidos en él hasta media pierna; a todos les volaba por hombros, cuello y manos, y en la atmósfera flotaban remolinos de él ${ }^{142}$.

Otro punto interesante en el estudio particular de las cigarreras en su contexto laboral, es la percepción que éstas tenían del espacio del trabajo ${ }^{143}$. Al constituirse la organización de la producción de cada labor según un esquema horizontal en el propio taller y ser poco frecuentes los cambios entre talleres, las empleadas tenían una conciencia parcial de la dimensión espacial de la fábrica - excepto en casos particulares como castigos o cambio de puesto a petición de las interesadas-. Los tiempos de descanso los pasaban habitualmente en el mismo taller donde trabajaban o fuera de la fábrica, por lo que tampoco contaban con

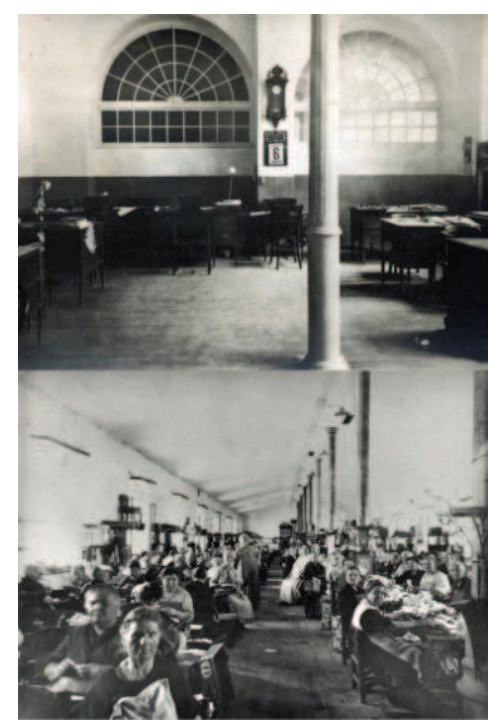

Figura 2.23. Oficinas y espacio productivo en la Fábrica de Tabacos de Alicante, en AMA.

142 PARDO BAZÁN (1882) op. cit., pp. 93, 114 y 163-165.

143 Relacionada también con esta cuestión, pero referente a la percepción de los cuerpos en el espacio fabril tabacalero, es interesante la consulta de SERO, L. (1993) Cuerpos del Tabaco. La percepción del cuerpo entre las cigarreras, Buenos Aires: Editorial Universitaria-Universidad Nacional de Misiones. 


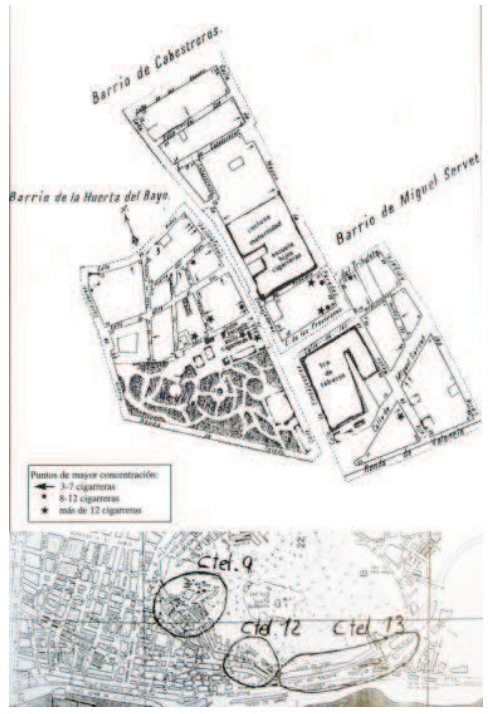

Figura 2.24. Inmuebles relacionados con las cigarreras madrileñas en el entorno de la fábrica sita en Lavapiés, en CANDELA SOTO, P. (1997) op.

cit., p. 150; y cuarteles habitados por cigarreras en Alicante en

1886, según la documentación de VALDÉS CHÁPULI, C. (1990) op. cit.

espacios específicos de relación fuera del propio puesto de trabajo, hasta las estancias sociales que se integrarían en el programa de usos a partir del S.XX.

De igual forma, el espacio de la fábrica se polarizaba entre las estancias representativas de la cúspide jerárquica y el espacio propiamente productivo que ocupaban las cigarreras. Esta distinción social se marcaba incluso en el acceso a la fábrica, ocupando los cargos administrativos las estancias de mayor solemnidad del conjunto. Por otra parte, las cigarreras debían pasar un riguroso filtro a la entrada y salida de la fábrica mediante los frecuentes registros que, como se ha señalado anteriormente, eran motivo de protestas y revueltas.

\section{Medidas de carácter social en el espacio fabril}

Gracias a las publicaciones de los diversos autores citados a lo largo del presente epígrafe, se observa como a lo largo del S.XIX surgen diversos proyectos a modo de obra social por parte de la Renta de Tabacos, siendo la Fábrica de Tabacos de Madrid uno de los establecimientos pioneros en este tipo de propuestas. A iniciativa del filántropo y político Ramón de La Sagra ${ }^{144}$, se proponen tres espacios de atención a las necesidades de los hijos de las cigarreras empleadas en la factoría madrileña: una sala de lactancia, un parvulario y una escuela primaria para niños y niñas ${ }^{145}$. De las tres propuestas sólo se llevarían a cabo el parvulario y las escuelas primarias, que tendrían una corta vida tras la construcción en 1860 del Colegio San Alfonso en la misma manzana de la fábrica. Aunque este proyecto se truncó, sirvió como germen de iniciativas similares que sí tuvieron un desarrollo completo, como el Asilo de Lactancia construido frente a la nueva Fábrica de Tabacos de Valencia a principios del S.XX en la margen izquierda del río Turia que tenía su precedente en el asilo construido junto a la antigua fábrica por orden de Amadeo de Saboya-. Estas medidas se encaminaban a erradicar el absentismo laboral de gran número de elaborantas que se ausentaban de sus puestos de trabajo para atender sus obligaciones domésticas.

En otras ciudades se llevaron a cabo proyectos similares que bajo el

144 Ramón de la Sagra (1798-1871) no será el único filántropo que propondrá públicamente propuestas para la mejora de las condiciones de trabajo de las cigarreras y para una adecuada atención a sus hijos, encontrando otras figuras de importancia como la del líder sindicalista Severino Chacón (1884-1978) en la Fábrica de Tabacos de La Coruña. Sobre las figuras de Ramón de la Sagra y Severino Chacón se recomienda la consulta de DE LA SAGRA, R. (1842) "Noticia sobre el establecimiento de educación para los niños de las operarias de la Fábrica de Cigarros de Madrid", Boletín de Instruc. púb. de 15 de Enero de 1842; y ROMERO MASIÁ, A. (2003) Severino Chacón. Líder sindical do mundo do tabaco, La Coruña: Fundación Luis Tilve.

145 "Las escuelas funcionaron en la fábrica durante más de una década, hasta que en 1860 se fundó el Colegio de San Alfonso, instalado en la parte posterior del edifico, que continuó con la tarea educativa de los hijos de las cigarreras. La Sala de Lactancia, como tal propuesta, nunca llegó a realizarse, aunque sí parece que, con el paso de los años, algunas de las ideas reformistas de De la Sagra inspiraron la práctica habitual de la lactancia durante la jornada de trabajo". CANDELA SOTO, P. (1997) op. cit., p. 128. En cambio sí que se utilizaron algunos edificios cercanos al Casino de la Reina y la Inclusa como Asilo de Cigarreras y otros espacios destinados a las obreras y sus hijos. Sobre los equipamientos al servicio de la fábrica en su entorno CANDELA SOTO, P. (1997) "Fuera de la fábrica: una "atmósfera industrial" particular" en CANDELA SOTO, P. (1997) op. cit., pp.138-168. Sobre este aspecto particular de la Fábrica de Tabacos de Madrid se recomienda la consulta de SANCHIDRIÁN BLANCO, C. (1983) "Las escuelas de párvulos de la Fábrica Nacional de Tabacos de Madrid (1841-1859)” en Historia de la Educación, n 2, pp. 77-86. 
nombre de Casas de Cigarreras agrupaban en un espacio independiente al conjunto fabril todos los servicios complementarios demandados por las empleadas. Además de incluir espacios para los hijos de las cigarreras, también contaban con salas para reuniones y desarrollo de actividades extralaborales de carácter lúdico y cultural. Estos proyectos se costeaban con participación económica de la propia plantilla, y en el caso de la producción tabacalera española cabe destacar los proyectos de La Coruña y Alicante que, si bien llegaron a construirse, el estallido de la Guerra Civil y su confiscación posterior por la Falange impidieron que finalmente fuesen destinados al uso para el que fueron concebidos.

Con la progresiva mecanización, la reducción de la plantilla y la reestructuración de los talleres $-\mathrm{y}$, por ende, de la distribución programática de los usos- permitirían la liberación de estancias que pasarían a destinarse a las necesidades de la plantilla, como comedores, servicios higiénicos, locales de reunión y formación o vestuarios separados por sexos. Esta circunstancia tiene su explicación en las preocupaciones de índole social que trataban de mejorar la habitabilidad y el confort en la fábrica a través de una racionalización del espacio interior.

Esta preocupación por la mejora de las condiciones sociales y de la calidad de los servicios complementarios al espacio del trabajo se materializó durante los años 60 con la construcción de comedores y la mejora de los servicios higiénico-sanitarios con la contratación de médicos de empresa desde finales de la década de los cincuenta. En este sentido, "las enfermedades más frecuentes entre las operarias son «enfermedades nerviosas de todas fases, reumatismos agudos y crónicos, afecciones catarrales de toda índole, tuberculosis pulmonar, herpetismo, metritis agudas y crónicas, hemorragias activas y pasivas»"146. De esta forma, se consolidaban las medidas que se habían comenzado a instaurar a principios del S.XX tras los informes de finales del S.XIX que constantemente denunciaban el ambiente nocivo del trabajo y las enfermedades que acarreaba -mala ventilación, hacinamiento, alta concentración de polvo de tabaco en el ambiente, variación de temperaturas entre invierno y verano, estado deplorable de los servicios higiénicos, etc.- así como otro tipo de iniciativas sociales como la creación de economatos característica del periodo autárquico que fueron puestos en marcha en 1958.

\section{La dualidad laboral y doméstica de la cigarrera}

Uno de los aspectos más notables de la contextualización de la cigarrera en su espacio de trabajo era la conciliación entre el ámbito laboral y el doméstico, que formaban el eje vertebral de su experiencia vital. Sobre esta cuestión, cabe destacar nuevamente la importancia capital de la obra de Paloma Candela Soto en la contextualización de la cigarrera madrileña tanto en el espacio fabril como en el entorno urbano de la

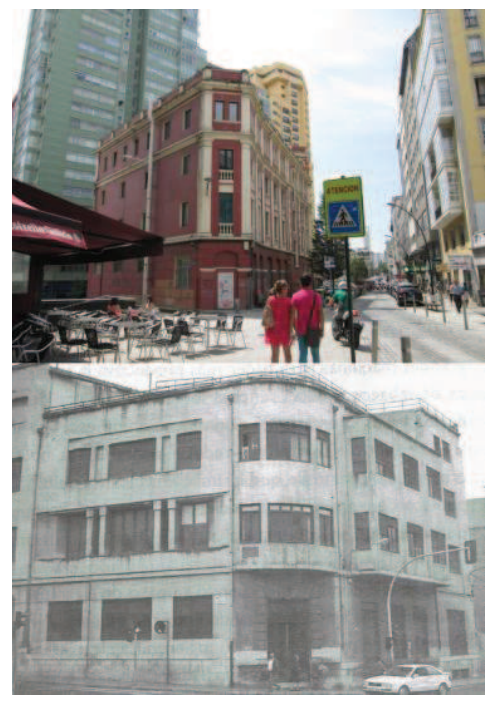

Figura 2.25. Casa de las Cigarreras de La Coruña, 2014; y de Alicante, en LANCETA ARAGONÉS, T. (2013) op. cit., p.68.

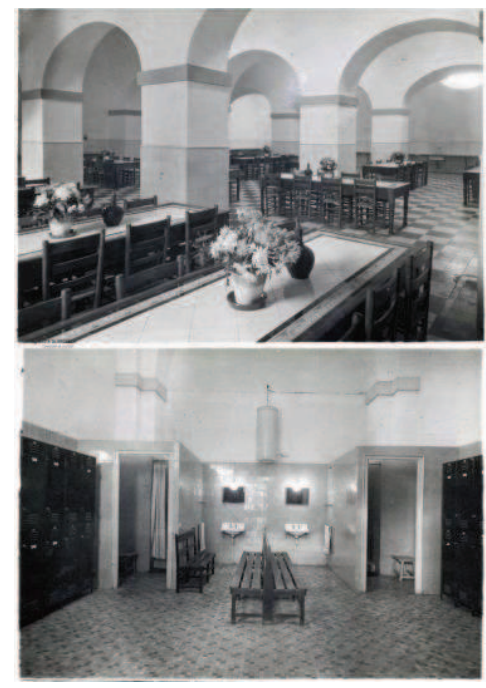

Figura 2.26. Comedor y vestuario de la Real Fábrica de Tabacos de Sevilla, en AHPS, 3134FT_034y 3134FT_036.

146 ARIAS GONZÁLEZ, L. y MATO DÍAZ, A. (2005) op. cit., p. 68, citando Comisión de Reformas Sociales (1893) Información oral y escrita practicada por la Comisión de Reformas Sociales en las provincias de La Coruña, Jaén, Navarra, Oviedo, Palencia y Vizcaya, tomo V, Madrid, p. 473 y p. 480. 


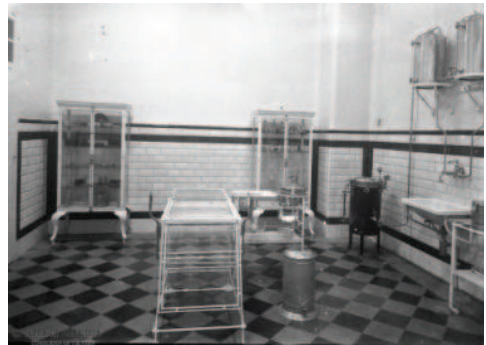

Figura 2.27. Servicios médicos de la Real Fábrica de Tabacos de Sevilla, en AHPS, 3134FT_086. fábrica y la interrelación establecida entre barrio y fábrica.

No cabe duda que el trabajo dentro de la fábrica ocupó un espacio esencial en la vida de las cigarreras, y en torno a su rol de trabajadora se estructura una parte fundamental de su experiencia y comportamiento colectivo. Sin embargo, la condición de mujer trabajadora llevaba implícito que, además, tuviera que hacerse cargo de las obligaciones domésticas y reproductivas que la sociedad reservaba al género femenino [...]

Así, en su comportamiento y compromiso colectivo a lo largo del período estudiado, se mezclan asuntos públicos y privados, rasgos preindustriales y modernos, reivindicaciones laborales y domésticas, es decir, el taller y la casa como dos caras del mismo universo ${ }^{147}$.

Sobre la presencia de la fábrica en el ámbito doméstico y como influía en la vida cotidiana de los familiares de las cigarreras, recoge Lanceta Aragonés en su obra interesantes testimonios que ayudan a completar esta contextualización de la cigarrera más allá del espacio fabril y en la conciliación de su trabajo en el mismo con su papel de madre y pilar familiar:

A mi madre la recuerdo como una heroína, con treinta y tres años muere mi padre, mi madre treinta y se encuentra con dos chavales pequeñitos y trabajando. Prisas para arriba, para abajo. La sirena aquella que la tenía metida en el alma. Siempre he pensado que la pobre ha vivido una vida muy dura [...]

Vivíamos casi enfrente de la fábrica y la avenida de Jijona cada vez que llovía se inundaba y me acuerdo de verla cruzar saltando los charcos con la sirena esa de las narices... ${ }^{148}$

La proximidad entre fábrica y vivienda fomentaba el enraizamiento de los lazos entre compañeras y vecinas y conformaba un contexto en el que difícilmente se disolvían las relaciones entre el centro de trabajo y el espacio doméstico. De igual forma, esta situación configuraba un particular paisaje urbano en torno a la figura femenina y a la fábrica, puesto que era frecuente la estampa de las familias que acudían a la fábrica en los descansos para comer en torno a la madre, que había llevado el guiso a la fábrica para que se lo calentasen las compañeras de cocina. No sólo esta red de relaciones se tejía en torno a la fábrica y al espacio doméstico, sino que económica y afectivamente, se extendía a los comercios cercanos que establecían una fuerte vinculación con las cigarreras y que, como se apuntaba anteriormente, forjaba el sentido comunitario y de cooperación del barrio.

[Sobre la relación de las cigarreras gijonesas con el barrio de Cimadevilla] La relación era muy buena. Como en otros testimonios, las vinculaciones principales son la procedencia de una parte de la plantilla de ese mismo barrio, la relación con los comerciantes, como el zapatero, que las conocía por el nombre, carnicerías, bares, tiendas de ultramarinos. Además, yo creo que le dio mucha vida al barrio, porque 
éramos mucha gente. Con la instalación del comedor se hizo algo de competencia a los bares donde se iba a desayunar, aunque se prefería salir, para tomar el aire y ver gente ${ }^{149}$.

Respecto a la significación de la fábrica para la mano de obra, es común a todos los casos estudio observados el establecimiento de unos fuertes vínculos afectivos entre los trabajadores y su espacio de trabajo, de forma que el orgullo por las labores desempeñadas en el mismo se proyecta al conjunto del inmueble, en una suerte de respeto por la fábrica. Esta situación se ha observado tanto en las entrevistas realizadas en las fábricas de Tarragona, Gijón o Alicante ${ }^{150}$, como en la documentación facilitada por otros autores. En este sentido, resulta interesante reproducir un fragmento de La Tribuna en la que se recoge el sentir de la protagonista hacia la fábrica:

discurriendo así, cruzó la calzada y se halló en el patio de la fábrica, la vieja Granera. Embargó a la muchacha un sentimiento de respeto. La magnitud del edificio compensaba su vetustez y lo poco airoso de su traza, y para Amparo, acostumbrada a venerar la fábrica desde sus tiernos años, poseían aquellas murallas una aureola de majestad, y habitaba en su recinto un poder misterioso, el Estado, con el cual sin duda era ocioso luchar, un poder que exigía obediencia ciega, que a todas partes alcanzaba y dominaba a todos. El adolescente que por vez primera pisa las aulas experimenta algo parecido a lo que sentía Amparo $^{151}$.

Esta situación determinó la fuerte empatía que las cigarreras desarrollaron hacia su lugar de trabajo y que se prolongó incluso más allá de su vida activa laboral en el interior de la fábrica, constituyendo una memoria colectiva que, como se apuntó anteriormente, se hacía extensiva al conjunto del núcleo familiar y del barrio en el que se localizaba la fábrica:

Casi todas las noches sueño con la fábrica, no lo puedo evitar: sueño que subo las escalinatas, con el ruido de las máquinas, sueño que estoy trabajando y toca la sirena y que hay mucho revuelo y veo a mis compañeras y eso que han muertos muchas, casi todas... ${ }^{152}$.

\subsubsection{Las fábricas de tabacos en España: los conjuntos fabriles del monopolio peninsular}

Si bien a lo largo de su historia, las tabacaleras han contado con trabajos parciales sobre las mismas como informes ingenieriles o artículos especializados de los propios ingenieros jefe, es con el cierre de la mayor parte de las históricas tabacaleras a principios del S.XXI con la fusión de Tabacalera y la francesa Seita en la compañía Altadis, cuando se comienzan a publicar las primeras monografías sobre la

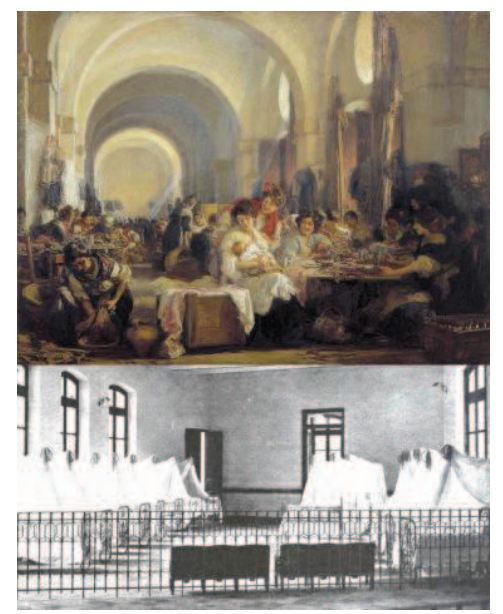

Figura 2.28. 'Las cigarreras", Gonzalo Bilbao, 1915, en Museo de Bellas Artes de Sevilla; y sala del Asilo de Lactancia de Valencia, en VEGAS LÓPEZMANZANARES, F. (2003) op. cit., p. 519 .

\footnotetext{
149 Equipo de documentación del Museo del Ferrocarril de Asturias (2009) Entrevista a Mari Paz Puente González, op. cit.

150 En agosto de 2015 se ha entrevistado a Xavier y Manolo, antiguos empleados de las fábricas de tabacos de Tarragona y Alicante, respectivamente. En junio de 2016 se han mantenido diversos encuentros con Conchi, antigua trabajadora de las fábricas de tabacos de Gijón y Santander, como ya se ha referido anteriormente.

151 PARDO BAZÁN (1882) op. cit., p. 91.

152 Antonia del Río, 1992. Cigarrera madrileña entrevistada por Paloma Candela Soto. Trabajó en la fábrica desde 1921 a 1963. Recogido en CANDELA SOTO, P. (1997) op. cit., p. 52.
} 
historia productiva y las características particulares de cada centro fabril a partir del estudio y la interpretación de los archivos de los mismos. En este aspecto, resulta de capital importancia la elaboración de publicaciones por parte de los integrantes del Grupo de Estudios del Tabaco que documentaron la historia económica y productiva de las diversas fábricas tabacaleras españolas, así como el contexto sociopolítico y económico en el que surgió el monopolio fiscal sobre el tabaco en los siglos XVII y XVIII ostentado por la Real Hacienda.

Entre el conjunto de publicaciones relativas a ingenieros y autoridades del monopolio durante el periodo de actividad del mismo, destacan aquellas realizadas en el conocido como ARTE Anuario de la Renta de Tabacos de España y Año Financiero, en el que en numerosas ocasiones se publicaron artículos monográficos relativos a las características espaciales y operativas de determinadas unidades fabriles del monopolio. Bien es cierto que surgen otras muchas publicaciones interesantes como la de Alberto Santías y Donato Lera que tiene por sugerente título Origen de los edificios que ocupan las once fábricas de tabacos de España y su organización actual153 y que recoge una información interesante para conocer el estado de las once fábricas de tabacos en España existentes en la época de entre-siglos en la que fue publicado. Coincidiendo estas publicaciones con la cesión del arriendo del monopolio a la Compañía Arrendataria de Tabacos, cabe pensar que la nueva sociedad gestora inició una política de difusión en el conocimiento tanto de los nuevos métodos productivos a implantar, como de las excelencias de su parque fabril, centenario en muchos casos.

Por otra parte, cabe destacar nuevamente la obra de referencia que supone la publicación de Francisco Comín Comín y Pablo Martín Aceña Tabacalera y el Estanco del Tabaco en España (1636-1998) de 1999, en la contextualización histórica del monopolio y las unidades fabriles e infraestructuras que lo integran, así como la labor del Grupo de Estudios del Tabaco, especialmente en el caso de las publicaciones monográficas de diversas fábricas que se citarán posteriormente.

En el apartado de tesis generales sobre las fábricas de tabacos en España, cabe destacar como única investigación la tesis doctoral de Tamar Awad Parada Arquitectura industrial tabacalera en la España peninsular: secaderos y fábricas leída en la Escuela Técnica Superior de Arquitectura de Madrid el 19 de noviembre de 2015, y que se centra en un estudio específico de los secaderos y tres fábricas de tabacos en tres zonas climáticas de la península ibérica con especial atención a su comportamiento como arquitectura bioclimática y a la definición gráfica de los mismos.

$\mathrm{Al}$ objeto que persigue la presente investigación, se debe hacer mención a la variada bibliografía relativa a los estudios monográficos de las fábricas de tabacos que integran el conjunto de casos de estudio desde diversos puntos de vista disciplinares. Para ello se realizará un

153 SANTÍAS, A. y LERA, D. (1898) Origen de los edificios que ocupan las once fábricas de tabacos de España y su organización actual, Madrid: Compañía Arrendataria de Tabacos, Hijos de M. G. Hernández. 
recorrido bibliográfico siguiendo la cronología de las fundaciones fabriles relativas a los casos estudiados.

Comenzando por el caso de la Real Fábrica de Tabacos de Sevilla, entre las fuentes documentales más importantes que se han manejado en la presente investigación, destaca la numerosa documentación planimétrica custodiada en el Archivo Histórico Provincial de Sevilla, de capital importancia para el entendimiento de los planteamientos proyectuales tanto de implantación de la fábrica en su contexto urbano, como de la propia concepción arquitectónica y las sucesivas reformas que experimentó a lo largo de su vida en activo. También cuenta esta institución con una interesante colección de fotografías que permite completar el conocimiento sobre el espacio fabril de la tabacalera hispalense y las condiciones particulares de la mano de obra empleada.

Nos encontramos probablemente ante la fábrica de tabacos que más extensamente ha sido estudiada por otros autores debido a su relevancia en la historia de la arquitectura española. Existen variados escritos fechados en la época de funcionamiento de la fábrica -ya se ha mencionado la obra de Santías y Lera de 1898- entre los que destaca un escrito de Luis Cuevas Alcober ${ }^{154}$, ingeniero de gran importancia en el contexto monopolístico y que también desarrolló artículos monográficos sobre otras fábricas, como se verá más adelante. También destaca el artículo de Mariano G. Morales ${ }^{155}$ sobre los trabajos de restauración de la fábrica en una fecha próxima al cese de su actividad y traslado a la nueva factoría del hispalense barrio de Los Remedios, que recoge una importante muestra fotográfica de diversos aspectos arquitectónicos de la fábrica a mediados del S.XX. Precisamente, en los años siguientes al cierre de la misma, cabe resaltar varias publicaciones de interés como la de José Pérez Vidal ${ }^{156}$ e incluso el artículo publicado en The Architectural Review por René Taylor ${ }^{157}$, hecho que da cuenta del interés suscitado por la fábrica desde época temprana y casi coincidiendo con los inicios de la consideración sobre el patrimonio industrial en Inglaterra.

Con posterioridad al cese de la actividad productiva en la fábrica y su reconversión en sede universitaria, han sido numerosos los trabajos realizados en torno a la arquitectura de este complejo fabril. Sin ánimo de menospreciar otras obras que no serán citadas en esta relación, cabe destacar algunos escritos que han sido de fundamental importancia en el estudio del estado de la cuestión de la presente investigación ${ }^{158}$.

154 CUEVAS ALCOBER, L. (1946) Un ejemplar español de arquitectura industrial del Siglo XVIII, Asociación Nacional de Ingenieros Industriales.

${ }^{155}$ MORALES, M. G. (1947) "La fábrica de tabacos de Sevilla y sus obras de restauración” en Cortijos y rascacielos, $\mathrm{n}^{\circ} 42$, pp. $13-20$.

156 PÉREZ VIDAL, J. (1966) La industria tabaquera española, a través de las fábricas de Sevilla, Madrid: Tabacalera.

${ }_{157}$ TAYLOR, R. (1959) "Royal Tobacco Factory" en The Architectural Review, nº753, pp. 267-268.

158 Además de los autores que se destacan, es también interesante la contribución al conocimiento de la Fábrica de Tabacos de Sevilla, entre otros, de VV. AA. (1988) "Dossier dedicado a la Historia de la Fábrica de Tabacos de Sevilla" en Cigarrera. Revista informativa CCOO de Tabacalera SA, nº 1, mayo 1988; IGLESIAS, H. (ed.) (1992) Fábrica Real De Tabacos De Sevilla [Dibujos De Alumnos De La Segunda Cátedra De Análisis De Formas Arquitectónicas De La ETSAM], Madrid: Tabapress; SOBRINO SIMAL, J. (1995) "La arquitectura de la industrialización. Sevilla 1830-1950" (Septiembre 1992) en Actas VIII Congreso Internacional para la Conservación 
En primer lugar, destacar nuevamente la labor de José Manuel Rodríguez Gordillo en este sentido, que en 1984 comisarió la exposición "Sevilla y el tabaco" celebrada en el Rectorado de la Universidad de Sevilla del 18 al 28 de mayo del mismo año y cuyo resultado fue una interesante publicación que, además del catálogo de la exposición, recoge escritos de capital importancia para entender diversos aspectos de la historia de la fábrica, su contexto, arquitectura y las condiciones de su mano de obra ${ }^{159}$. De igual forma, para cualquier tema relativo a la tabacalera hispalense resulta recomendable la consulta de su publicación sobre la historia de la fábrica ${ }^{160}$, que contribuye a arrojar conocimiento sobre aspectos históricos, arquitectónicos y sobre los trabajos de reconversión en dependencias universitarias.

Otra publicación de capital importancia para la presente investigación ha sido la obra derivada de la tesis doctoral de José Morales Sánchez ${ }^{161}$ sobre la Real Fábrica de Tabacos de Sevilla y que ha resultado muy relevante, tanto en la aportación de datos documentales como en los planteamientos de contenidos para el estudio de la fábrica y su entorno. La aportación de este autor ha sido fundamental, no sólo en el estudio del estado de la cuestión, sino en los propios planteamientos metodológicos de la presente investigación.

Actualmente, las publicaciones relacionadas con el estudio de la Real Fábrica de Tabacos de Sevilla tienen que ver con el Plan Director de Remodelación de la Fábrica de Tabacos ${ }^{162}$ redactado por el profesor Miguel González Vílchez y las obras acometidas con arreglo al mismo, que tiene por objeto la adecuación de los espacios e infraestructuras de forma correlativa a su categoría de Bien de Interés Cultural, tratando de efectuar las restauraciones y eliminación de añadidos innecesarios realizados a lo largo de las décadas en las que ha venido funcionando como sede universitaria.

Más recientemente, el Archivo Histórico Provincial de Sevilla ha llevado a cabo la exposición "El Tabaco del Rey" del 14 al 30 de octubre de 2015, una muestra coordinada por Amparo Alonso García, Directora

del Patrimonio Industrial, CEHOPU-Ministerio de Obras Públicas, Transporte y Medio Ambiente, pp. 433-448; GÁlVEZ, L. (1997) La mecanización de la Fábrica de Tabacos de Sevilla bajo la gestión de la Compañía Arrendataria de Tabacos (1887-1945), Madrid: Fundación Empresa Pública; y AGUILÀ SOLANA, I. (2006) op. cit. 159 Se quieren destacar especialmente las contribuciones de Antonio Bonet Correa y José Manuel Rodríguez Gordillo dentro de esta publicación coral, por la relevancia que han tenido particularmente en esta investigación. BONET CORREA, A. (1984) "La Fábrica de Tabacos de Sevilla, primer edificio de la arquitectura industrial en España" en VV.AA (1984) op. cit., pp. 47-65; y RODRÍGUEZ GORDILLO, J. M. (1984) op. cit.

160 RODRÍGUEZ GORDILLO, J. M. (2005) op. cit. Resulta una revisión monográfica en la que incluye datos de todos los estudios ya realizados por este autor sobre la cuestión particular de la Real Fábrica de Tabacos de Sevilla, como RODRÍGUEZ GORDILLO, J. M. (2002b) "Primeros proyectos de las nuevas fábricas de tabacos de Sevilla en el siglo XVIII" en La difusión del tabaco en España. Diez estudios, Sevilla: Altadis, pp. 25-57.

161 MORALES SÁNCHEZ, J. (1991) La Real Fábrica de Tabacos: arquitectura, territorio y ciudad en la Sevilla del siglo XVIII, Sevilla: Fundación Fondo de Cultura de Sevilla, D.L. Tesis doctorales, Colección "Focus"; n. 2. [edición de la tesis doctoral mecanografiada (1988) Arquitectura, territorio y ciudad en la Sevilla del siglo XVIII. Proyectos y construcción de las Nuevas Fábricas de Tabacos de Sevilla, Sevilla].

162 GONZÁleZ VÍlCHEZ, M. (2009) Plan Director de Remodelación de la Fábrica de Tabacos de la Universidad de Sevilla, Sevilla. Sobre esta cuestión ver GONZÁLEZ GARCÍA DE VELASCO, C. y GONZÁLEZ VÍLCHEZ, M. (2011) "La cimentación del edificio histórico de la Fábrica de Tabacos de la Universidad de Sevilla" en Informes de la Construcción, vol. 63, $\mathrm{n}^{\circ}$ 521, enero-marzo 2011, pp. 5-11, publicación derivada de los trabajos realizados sobre la cimentación del edificio. 
del Archivo, realizada en la sede de la institución. La exposición estaba integrada por más de setenta objetos entre documentos, fotografías y piezas relacionadas con la Real Fábrica de Tabacos de Sevilla como testimonio documental del hacer del monopolio tabacalero del Estado en el recorrido de su historia en la fábrica hispalense. Esta reciente muestra contribuye a corroborar el interés que la tabacalera sevillana sigue despertando como patrimonio industrial arquitectónico pese a la profusión de estudios sobre la misma. Así mismo, y aunque atienda a una figura literaria relacionada con la fábrica, la exposición "Carmen. Lecturas de un mito" exhibida en la Casa del Lector de Matadero Madrid del 21 de abril al 16 de octubre de 2016 alberga una interesante sección sobre las características espaciales de la fábrica hispalense con un didáctico audiovisual a partir de trabajos de Rodríguez Gordillo en el que se explica con todo detalle la configuración del conjunto industrial sevillano.

Respecto a la Fábrica de Tabacos de Cádiz, es sorprendente que, pese a su importancia en el conjunto de la historia fabril tabacalera peninsular, no existan muchas publicaciones sobre esta unidad fabril, y resulta complicado localizar documentación sobre la misma. El Archivo Histórico Provincial de Cádiz cuenta con unos 250 documentos provenientes del Archivo Histórico Provincial de Sevilla relativos a documentación administrativa de la fábrica. Sin embargo, la documentación que ha resultado fundamental para la presente investigación ha sido la custodiada en el Archivo Histórico Municipal de Cádiz relativa a fotografías y planimetría histórica de la fábrica.

Entre las pocas publicaciones a destacar, cabe mencionar el artículo de Antonio Muncunill publicado en ARTE en el año $1906^{163}$ sobre las condiciones de la fábrica a principios del S.XX. Ya cumplido el cese de actividad de la fábrica, se ha publicado una breve monografía anónima ${ }^{164}$ de la misma en la que destacan algunos datos de interés así como documentación fotográfica relevante para el conocimiento de los espacios históricos del edificio previos a su reutilización como Palacio de Congresos. Exceptuando esta pequeña publicación y artículos de carácter general, principalmente de Rodríguez Gordillo ${ }^{165}$, las restantes obras en las que se encuentra información sobre el inmueble de la Fábrica de Tabacos de Cádiz son de carácter muy general -como la citada de Comín Comín y Martín Aceña-, así como guías de arquitectura o de patrimonio industrial ${ }^{166}$.

163 MUNCUNILL, A. (1906) "Fábrica de Tabacos de Cádiz" en ARTE Anuario de la Renta de Tabacos de España y Año Financiero, pp. 25-51.

164 VV. AA. (2003) La Fábrica de Tabacos de Cádiz. Reseña histórica, Sevilla: Signatura, Cádiz: Diputación, Relaciones Institucionales, Fundación Municipal de Cultura del Ayuntamiento de Cádiz, Junta de AndalucíaConsejería de Turismo y Deporte.

165 RODRÍGUEZ GORDILLO, J.M. "La Fábrica de Cádiz, esa gran desconocida" del que se hace referencia en la base de datos Cadizpedia dinamizada por la Junta de Andalucía http://cadizpedia.wikanda.es/wiki/F\%C3\%A1brica_Nacional_de_Tabacos_(C\%C3\%A1diz) [acceso el 10-8-2015] desconociendo tanto la publicación a la que pertenece como el año de la misma. No obstante, cabe destacar RODRÍGUEZ GORDILLO, J.M. (2002b) “Aspectos tabaqueros en el Cádiz ilustrado" en RODRÍGUEZ GORDILLO, J.M. (2002b) op. cit., pp. 221-245 y la información dedicada al edificio en la obra general de COMÍN COMÍN, F. y MARTÍN ACEÑA, P. (1999), op. cit.

166 Algunos ejemplos de estas obras de carácter general: MALO DE MOLINA, J.; JIMÉNEZ MATA, J. (1995) Guía de arquitectura de Cádiz, Consejería de Obras Públicas y Transportes; y SANTOFIMIA ALBIÑANA, M. (2012) "El 
En cuanto a las publicaciones sobre la fábrica alicantina, cabe destacar meritoriamente y casi en exclusiva la labor de Caridad Valdés Chápuli167, que ya una década antes del cese de actividad del establecimiento firmaba una obra fundamental para el conocimiento de la historia de la fábrica y sus espacios. Su obra preludió de forma significativa los trabajos monográficos que una década después se realizarían sobre la historia particular de las fábricas restantes del monopolio hacendístico del tabaco. De igual forma, tanto esta autora como Teresa Lanceta -que se ha mencionado anteriormente en el estado de la cuestión sobre la figura de la cigarrera- han colaborado en diversas actividades en los antiguos almacenes de la fábrica alicantina recuperados como centro cultural que tiene por significativo nombre "Las Cigarreras"168, contribuyendo de forma sustancial con sus trabajos al conocimiento sobre esta unidad fabril del monopolio del tabaco. Así mismo, ha resultado de gran ayuda tanto la planimetría como la colección de fotografías históricas de la fábrica alicantina custodiadas en el Archivo Municipal de Alicante.

Para la profundización en el caso coruñés han resultado fundamentales las fuentes custodiadas en la Biblioteca Municipal de Estudios Locales de La Coruña y la documentación planimétrica custodiada en el Archivo del Reino de Galicia, ambos ubicados en la ciudad herculina. Sin embargo, en cuanto a publicaciones específicas, cabe destacar en este punto la extraordinaria labor de dos autores concretos. Luis Alonso Álvarez, además de resultar un estudioso fundamental de la historia del monopolio del tabaco en España -algunas de estas obras en solitario o como coautor se han citado en el epígrafe correspondiente a la historia socioeconómica del monopolio hacendístico del tabaco- ha generado importantes publicaciones sobre la historia de la fábrica herculina en particular, entre artículos científicos que datan de la época en la que la planta fabril se mantenía en activo, y una monografía específica al cierre de la misma ${ }^{169}$.

Mediando entre ambas fechas, destaca de igual forma la importante labor de Ana Romero Masiá170 que un lustro antes del cierre de la fábrica publicó una obra monográfica con importantes referencias documentales y la reproducción de planimetrías y documentos fotográficos cruciales para el conocimiento del conjunto fabril coruñés. Aunque con menor entidad que las obras anteriormente mencionadas, se pueden destacar trabajos de estudiosos del patrimonio industrial ${ }^{171}$,

patrimonio industrial en la Bahía de Cádiz: un itinerario cultural" en Revista ph, Instituto Andaluz del Patrimonio Histórico, no 83, octubre 2012, pp. 12-49.

167 VALDÉS CHÁPULI, C. (1990) La fábrica de tabacos de Alicante, Alicante: Caja de Ahorros del Mediterráneo.

168 Cabe destacar la publicación de VALDÉS CHÁPULI, C. (2011) La Fábrica de Alicante: la producción del tabaco: el trabajo de La Cigarrera: la gestión empresarial, (sala municipal de exposiciones, Complejo Cultural Las Cigarreras), Alicante: Ayuntamiento, Alicante Cultura. De igual forma, parte de los trabajos de Teresa Lanceta han sido recogidos en exposiciones colectivas en el Centro Cultural Las Cigarreras: en 2013 Miradas de Mujer en el Centro Cultural Las Cigarreras y en 2011 Camino de Las Cigarreras; así como la conferencia de 2013 "La fábrica de tabacos: una industria en el centro de Alicante" dentro del ciclo Tres proyectos de paisaje con Olga Diego, Tomás Amat y Pablo Belda en la Universidad de Alicante.

169 ALONSO ÁLVAREZ, L. (1998) op. cit; y ALONSO ÁLVAREZ, L. (1984) op. cit.

170 ROMERO MASIÁ, A. (1997) A Fábrica de Tabacos da Palloza, La Coruña: Fundación Luis Tilve.

${ }^{171}$ Especialmente, por la relevancia que tienen sus estudios en materia de difusión y conocimiento del patrimonio industrial gallego, CARMONA BADÍA, X. y NADAL OLLER, J. (2005) "La Fábrica de Tabacos de A Coruña" en El 
así como los artículos derivados de las obras de acondicionamiento de la fábrica y su entorno tras su rehabilitación con un nuevo uso ${ }^{172}$.

En el caso de la Fábrica de Tabacos de Madrid, además de la documentación planimétrica custodiada en el Archivo de la Villa y en el Archivo General de Palacio en Madrid, existen numerosas obras relativas a la arquitectura de la Real Fábrica de Aguardientes y Naipes $\mathrm{y}$, fundamentalmente, del periodo en el que ha funcionado como fábrica de tabacos -que es prácticamente la totalidad de su vida como edificio industrial-. De igual forma, y concerniente al proceso que el edificio ha vivido tras su cierre, existen algunos artículos que se interesan por las propuestas de reutilización de su arquitectura en el contexto socioeconómico del Madrid actual.

Respecto a las publicaciones sobre la arquitectura del proyecto original, es fundamental la consulta del artículo de Ángel Urrutia publicado en la obra coral general Establecimientos tradicionales madrileños ${ }^{173}$, que resulta muy relevante para contextualizar los orígenes del inmueble. De igual forma, existen reportajes y reseñas periodísticas de la época de funcionamiento de la fábrica cuyo acompañamiento gráfico ayuda a componer el relato histórico-arquitectónico de la misma ${ }^{174}$.

Sobre el conjunto de publicaciones realizadas en el periodo de funcionamiento de la fábrica ${ }^{175}$, hay que destacar indiscutiblemente la labor de Paloma Candela Soto176. Aunque su obra se encuadra en el campo de los estudios sociológicos que se han citado en el epígrafe relativo a la figura de las cigarreras, la interpretación de las condiciones sociales de las mismas a partir del espacio fabril y la cuidada descripción del mismo, convierten sus publicaciones en un documento fundamental para el conocimiento de la arquitectura de la tabacalera madrileña.

En último lugar, cabe destacar $\operatorname{artículos}^{177}$ y otras iniciativas ${ }^{178}$ centradas en reutilización posterior del edificio tras su cierre en el año

empeño industrial de Galicia: 250 años de historia (1750-2000), La Coruña: Fundación Barrié de la Maza, pp. 106107.

172 Relativo a la adecuación del entorno de la antigua fábrica tras su cierre COLLARTE RODRÍGUEZ, L. (2011) "Rehabilitación del entorno de la Fábrica de Tabacos A Coruña" en ConArquitectura: arquitectura con arcilla cocida, $n^{\circ} 38$, pp. 54-57.

173 URRUTIA, A. (1982) "La Real Fábrica de Aguardientes y Naipes" en VV. AA. (1982) Establecimientos tradicionales madrileños. Del Centro a las Rondas, Tomo III, Madrid: Cámara de Comercio e Industria, pp. 119-132.

${ }^{174}$ Cabe destacar, entre otros (1890) "Incendio de la Fábrica Nacional de Tabacos de Madrid" en La Ilustración Española y Americana, Año XXXIV, n42, 15-11-1890, p.292; (1898) "La fábrica de tabacos" en La revista moderna, Año II, no 84, 08-10-1898, pp.696-699; (1906) "Madrid incendio en la Fábrica de Tabacos" en La Ilustración Española y Americana, año L, n³7, 08-10-1906, p. 201; VELASCO ZAZO, A. (1917) "La fábrica de Tabaco" en Blanco y Negro, n 1385, 2-II-1917; y MARTÍN DE MENDOZA, M. (1924) "Madrid antiguo y contemporáneo: La fábrica de Tabaco" en El Heraldo de Chamberí, n ${ }^{\circ} 153,4-\mathrm{V}-1924$.

175 CASAS TORRES, E. (1988) "La Fábrica de Tabacos de Madrid: un ejemplo de arquitectura madrileña" en Villa de Madrid, vol. 26, nº 97-98, pp. 74-79, contiene, además de interesantes apuntes históricos, documentación gráfica muy relevante sobre el edificio.

176 A destacar CANDELA SOTO, P. (1997) "La Fábrica de Tabacos de Madrid: origen y trayectoria histórica" en CANDELA SOTO, P. (1997) op. cit., pp. 52-68.

177 Especialmente interesante el artículo DELGADO BERROCAL, S. (2011) "Arquitectura expandida. Tabacalera. Dotación pública autogestionada" en Axa. Una Revista de Arte y Arquitectura, no 1, pp. 2-17, febrero de 2011, sobre la acción autoprogramática del Centro Social Autogestionado Tabacalera como posible estrategia proyectual de reutilización del edificio. 
2000, que también permiten profundizar sobre la espacialidad de la fábrica y sus posibilidades para la reconversión de uso del inmueble. Cabe agradecer especialmente al arquitecto Pablo Rivera Posse ${ }^{179}$ que realizó su Trabajo de Fin de Máster sobre la tabacalera madrileña y que desinteresadamente ha facilitado los resultados de dicho trabajo para la documentación de la presente investigación.

Al igual que ocurre con la Fábrica de Tabacos de Cádiz, la inusual escasez de información y publicaciones que profundicen sobre la Fábrica de Tabacos de Santander es sorprendente, teniendo en cuenta que llegó a ser una de las más relevantes del monopolio hacendístico y que aún conserva una planta en activo en la localidad de Solares tras su cierre en 2002. No se ha localizado el archivo de la fábrica, ni se ha encontrado colaboración para poder acceder a la misma, llegando en ocasiones a ser dudosa la institución responsable de la titularidad del inmueble. Ni siquiera, como ha ocurrido en otros casos estudio, se ha encontrado información, por menor que fuese, en el Archivo Histórico Provincial de Cantabria -que curiosamente se encuentra en un inmueble que anteriormente cumplió la función de depósito portuario de tabaco- .

Es por esto que, para el estudio de caso de la tabacalera montañesa, se ha tenido que recurrir a obras de carácter general relativas al origen conventual del inmueble180. En su caso, se han podido también consultar documentos y artículos publicados en la época en activo de la fábrica ${ }^{181}$. En este aspecto, cabe señalar la fundamental ayuda que ha resultado la generosa colaboración del profesor de la Universidad de Cantabria José Sierra Álvarez que desinteresadamente procuró a esta investigación documentos de difícil acceso, así como trabajos académicos inéditos sobre la Fábrica de Tabacos de Santander ${ }^{182}$.

Para el caso de la tabacalera gijonesa ha resultado muy relevante la consulta de los fondos documentales del Archivo Municipal de Gijón ${ }^{183}$ y del Archivo Histórico de Asturias, así como parte del archivo de la fábrica custodiado en el Museo del Ferrocarril de Asturias. En esta última institución, cabe agradecer especialmente la colaboración de las documentalistas Nuria Vila y Paz García Quirós que también han proporcionado un estudio inédito sobre la fábrica gijonesa elaborado entre 2006 y 2010 de gran importancia para la documentación de la

178 El blog "Cigarreras" creado dentro de las acciones del Centro Social Autogestionado Tabacalera con la participación de las antiguas empleadas de la Fábrica de Tabacos de Madrid y su repositorio de documentación fotográfica constituyen un banco de memoria de la fábrica valiosísimo y abierto al conjunto de la sociedad que ha resultado muy relevante para la presente investigación. www.blogs.latabacalera.net/cigarreras/ [acceso 4-3-2015].

179 RIVERA POSSE, P. (2014) La fábrica de tabacos de Madrid: evolución y propuestas de gestión, TFG del Máster Universitario en Gestión de la Edificación de la UPM, [inédito].

${ }^{180}$ GUERÍN, P. (1986) El Convento de Santa Cruz, Santander: Delegación de Cultura, Ayuntamiento de Santander. 181 AMOR, J. (1907) "Fábrica de tabacos de Santander" en ARTE Anuario Administrativo, Económico, Financiero y de la Renta de Tabacos, pp. 27-47; y VV. AA. (1986) "El tabaco en Cantabria" en Cigarrera Revista Informativa de CCOO de Tabacalera $S A, \mathrm{n}^{\circ} 7$, marzo 1986.

182 LERMA BRAGADO, C., CALLEJO SÁIZ, M. y BILBAO MARTÍNEZ, S. (1991) Diez años en la historia de la fábrica de cigarros de Santander 1930-1940: una década de transformaciones en las relaciones laborales y de producción, Trabajo de Curso Universidad de Cantabria 1991-1992 proporcionado por José Sierra, mecanografiado [inédito].

183 Ver GONZÁLEZ ORDÓÑEZ, A. (1990) "Expedientes Especiales n7-26 Expediente Fábrica de Tabacos" en Catálogo de los Expedientes especiales de la Fábrica de Tabacos, Ayuntamiento Gijón, Archivo Municipal de Gijón. 
presente investigación. Precisamente en el Museo del Ferrocarril ha tenido lugar recientemente la exposición "Un edificio, dos mil años de historia. La Fábrica de Tabacos de Gijón" relativa a la Fábrica de Tabacos de Gijón y su pasado histórico a través de los hallazgos arqueológicos de época romana en su solar y de la historia del edificio previa a la fábrica como inmueble conventual ${ }^{184}$. De igual forma, cabe agradecer a Román Villasana y los coautores de su proyecto para la rehabilitación de la Tabacalera de Gijón, Carlos Pereda, Óscar Pérez e Ignacio Olite por su ayuda facilitando documentación planimétrica y fotográfica de la fábrica, así como al estudio TAU Noriega por su desinteresada ayuda en la cesión de planimetría del estado previo a las demoliciones acometidas en el año 2006.

Nuevamente se destaca la consulta de artículos publicados durante el periodo de funcionamiento de la fábrica ${ }^{185}$ custodiados en la gijonesa Biblioteca Pública Jovellanos, así como obras de carácter general ${ }^{186}$ que aportan aspectos relevantes para la investigación. Cabe reseñar, no obstante, la obra monográfica de Vidal de la Madrid Álvarez ${ }^{187}$ sobre el edificio en su periodo conventual, y sobre todo la publicación de Luis Arias González y Ángel Mato Díaz188 que en la presente investigación ha resultado de capital importancia para el entendimiento y la toma de referencias sobre el caso estudio de la Fábrica de Tabacos de Gijón y que amablemente concedieron una entrevista para profundizar en las cuestiones tratadas en su publicación.

Para abordar el estudio específico de la Fábrica de Tabacos de Valencia, se ha consultado la documentación que custodia el Archivo Histórico Municipal de Valencia; no obstante, relativo a la documentación planimétrica del estado previo de la fábrica antes de acometer su proyecto de rehabilitación como dependencias municipales, este trabajo ha contado con la inestimable colaboración del estudio de arquitectura Carratalá arquitectos, autores de la intervención de recuperación del conjunto fabril y que han aportado desinteresadamente, tanto planimetría como la Memoria del Proyecto Básico y de Ejecución de la

\footnotetext{
${ }^{184}$ La exposición tuvo lugar en el Museo del Ferrocarril de Asturias del 13 de agosto al 31 de diciembre de 2015 en colaboración con Museos Arqueológicos de Gijón. Dicha exposición dio lugar a la publicación FERNÁNDEZ OCHOA, C.; OREJAS SACO DEL VALLE, A.; GARCÍA DÍAZ, P. y GIL SENDINO, F. (2016) La Fábrica de Tabacos de Gijón. Arqueología e Historia de un espacio milenario, Gijón: Ayuntamiento de Gijón. Posteriormente, se celebró la exposición "Las máquinas del tabaco" entre mayo y agosto de 2016 en la que se mostraron diversas piezas importantes de maquinaria antigua trasladadas al museo en 2010.

185 ORTIZ DE LA TORRE, J. M. (1908) "Fábrica de Tabacos de Gijón" en Anuario de la Revista de Tabacos de España y Año Financiero, pp. 29-51; CUEVAS ALCOBER, L. (1955) "El tabaco en Asturias" en Conferencias sobre economía asturiana, Oviedo: IDEA, pp. 31-42; y TERÁN, A. (1975) "Historia de la Fábrica de Tabacos de Gijón” en Actualidad Tabaquera, ${ }^{\circ}$ 141, noviembre de 1975, pp. 17-23.

186 ÁLVAREZ ARECES, M. A. (coord.) (2009) "Fábrica de Tabacos de Gijón” en Patrimonio industrial de Asturias. 33 propuestas de Industria, Cultura y Naturaleza. Guías INCUNA, Gijón: INCUNA-CICEES, pp. 80-83; GARCÍA QUIRÓS, P. y FLORES SUÁREZ, J. M. (2000) Gijón. La ciudad de vapor. Historia de la industria y el comercio, Gijón: GEA Distribuciones gráficas; PIÑERA ENTRIALGO, L. M. (2011) "La Fábrica de Tabacos de Gijón y algunas huelgas obreras" en Fábricas y viviendas obreras en el primer Xixón Industrial, Gijón: KRK, pp. 133-155; y "Las primeras fábricas en Xixón" en Fábricas y viviendas obreras en el primer Xixón industrial, Gijón: KRK, pp. 35-43. 187 DE LA MADRID ÁLVAREZ, V. (2010) El Convento del Santísimo Sacramento y Purísima Concepción de Nuestra Señora de Agustinas Recoletas de Gijón (1668-1842), Gijón: Trea.

188 ARIAS GONZÁLEZ, L. y MATO DÍAZ, A. (2005) op. cit., obra importantísima para el conocimiento de la fábrica gijonesa. Posteriormente a su consulta, se produjo un intercambio de impresiones con los propios autores que permitió una mayor profundización del caso. Cabe agradecer especialmente, tanto a Luis Arias como a Ángel Mato su ayuda y excelente disposición para la documentación de esta investigación.
} 
rehabilitación y adaptación de la fábrica de tabacos de Valencia para dependencias municipales. Así mismo, relativo a esta obra de rehabilitación existen artículos específicos en publicaciones especializadas ${ }^{189}$.

Sobre el estudio particular de la Fábrica de Tabacos de Valencia como conjunto edilicio existen obras generales que la contextualizan dentro de un estilo propio, como la obra de Daniel Benito Goerlich ${ }^{190}$, o como parte del amplio conjunto urbanístico ya desaparecido que formaron la Exposición Regional de 1909 y la Exposición Nacional de 1910, en el caso de la publicación del arquitecto Fernando Vegas LópezManzanares ${ }^{191}$.

Más significativa ha resultado la extraordinaria labor realizada por María Jesús Teixidor de Otto y Teresa Hernández Soriano en la profundización del estudio sobre la tabacalera valenciana, tanto del edificio que ocupó inicialmente ${ }^{192}$, como de su contexto histórico socioeconómico, productivo y social ${ }^{193}$.

Dado que la factoría de Bilbao tan sólo tuvo 60 años de vida, y no existen vestigios materiales del inmueble en el que se instaló, se ha considerado irrelevante en el cuerpo general de la investigación. De igual forma, se ha conocido la existencia de sendas fábricas en Alcoy y Oviedo, filiales respectivamente de las fábricas de Alicante y Gijón. Aunque no se incluyen entre los casos estudio de la presente investigación, cabe destacar la existencia de material interesante para su estudio ${ }^{194}$.

Para la elaboración del estado de la cuestión sobre la tabacalera donostiarra, se ha consultado información parcial custodiada en la biblioteca Koldo Mitxelena Kulturunea y en el Archivo Histórico Provincial de Guipúzcoa; sin embargo, al igual que en el caso de Gijón y Valencia, ha resultado fundamental la colaboración desinteresada del Estudio de Arquitectura TAU de Jon Montero y Naiara Montero, autores del proyecto de rehabilitación de la Fábrica de Tabacos de San Sebastián en espacio cultural Tabakalera que han aportado abundante documentación planimétrica histórica, así como el levantamiento del

189 CARRATALÁ CALVO, L. (2011) "Proyecto de rehabilitación y adaptación de la Fábrica de Tabacos para dependencias municipales" en ConArquitectura: arquitectura con arcilla cocida, $\mathrm{n}^{\circ}$ 38, pp. 51-53.

190 BENITO GOERLICH, D. (1983) La arquitectura del eclecticismo en Valencia. Vertientes de la arquitectura valenciana entre 1875 y 1925, Valencia: Ayuntamiento de Valencia, pp. 171-361.

191 VEGAS LÓPEZ-MANZANARES, F. (2003) "Aspectos arquitectónicos" en La Arquitectura de la Exposición Regional Valenciana de 1909 y de la Exposición Nacional de 1910, Valencia: Ediciones Generales de la Construcción, pp. 128-140.

192 TEIXIDOR DE OTTO, M. J. y HERNÁNDEZ SORIANO, T. (1997) "La vieja fábrica de tabacos de Valencia" en Cuadernos de geografía, n ${ }^{\circ} 61$, Valencia, p. 77-96.

193 TEIXIDOR DE OTTO, M. J. y HERNÁNDEZ SORIANO, T. (2006) "La industria tabaquera en la fábrica de Valencia. Dinámica del proceso productivo (1887-1950)" en ALONSO ÁLVAREZ, L.; GÁLVEZ MUÑOZ, L.; y DE LUXÁN, S. (Eds.) (2006) op. cit., pp. 525-550; cabe destacar especialmente TEIXIDOR DE OTTO, M. J. y HERNÁNDEZ SORIANO, T. (2000) op. cit., como obra de cabecera para el estudio del caso valenciano.

194 PAREJA ALONSO, A. (2012) "Liadoras de cigarrillos en Bilbao: esposas, madres y huelguistas" en Vasconia, $\mathrm{n}^{\circ}$ 38, pp. 297-312. De igual forma, la fábrica de Alcoy cuenta con estudios específicos como BENEITO LLORIS, A. y SALINAS SALINAS, C. (1991) "La Fábrica de Tabacos de Alcoy" en Arqueología industrial. Actas del Primer Congrés del País Valencià (Alcoy 9-11 nov. 1990), Diputación de Valencia, pp. 265-277. 
conjunto según el estado previo a su intervención.

Además de la presencia de este edificio en obras generales de carácter local ${ }^{195}$ por su importancia en el contexto histórico urbanístico y arquitectónico de San Sebastián, se debe resaltar el apartado dedicado a la fábrica en la obra general sobre arquitectura industrial en Guipúzcoa de las historiadoras Amaia Apráiz Sahagún y Ainara Martínez Matía ${ }^{196}$, expertas en el campo del patrimonio industrial en el País Vasco. Se destaca muy especialmente la monografía de María Monserrat Gárate Ojanguren sobre la fábrica easonense, obra de cabecera en la presente investigación que, además, intercala aspectos comparativos del caso vasco con las fábricas que en aquel momento se estaban construyendo en paralelo a las obras del conjunto de San Sebastián -Logroño y Valencia-197.

Al igual que en el caso de la Fábrica de Tabacos de Cádiz y la Fábrica de Tabacos de Santander, la tabacalera logroñesa es una de las menos estudiadas resultando difícil encontrar publicaciones específicas sobre la misma. En este sentido, ha resultado crucial la consulta de los fondos del Archivo de la Fábrica de Tabacos de Logroño, cuya publicación hasta ahora ha sido inédita, y que se encuentran custodiados en el Archivo General de La Rioja. De igual forma, ha resultado fundamental la consulta de documentación y publicaciones específicas en la Biblioteca de La Rioja -fortuitamente ubicada en la antigua tabacalera, así como los resultados de la visita de campo a la parte de la fábrica acondicionada como actual Parlamento de La Rioja y cuyo personal facilitó desinteresadamente una publicación monográfica sobre el mismo con abundantes detalles de la historia del edificio y su intervención de recuperación como pleno del gobierno riojano ${ }^{198}$.

A su dedicación parcial en obras generales de arquitectura logroñesa'199, se unen publicaciones específicas de la época en la que se acometieron las obras de reconversión del conjunto fabril en Parlamento de La Rioja, Biblioteca de La Rioja y Sala Cultural Amós Salvador, como las de Jerónimo Jiménez Martínez ${ }^{200}$ y Francisco Bermejo y Rafael Levenfeld201, editores del catálogo sobre la exposición titulada "Amós Salvador: exposición conmemorativa del centenario de la instalación de la Fábrica de Tabacos en Logroño" y cuya documentación previa a la muestra fotográfica de que fue objeto constituye una obra coral de suma importancia en la contextualización histórica y urbana de la tabacalera

195 ARSUAGA, M. y SESÉ, L. (1996) Donostia-San Sebastián. Guía de Arquitectura, San Sebastián: Colegio Oficial Vasco-Navarro de Arquitectos.

196 APRAIZ SAHAGÚN, A. y MARTÍNEZ MATÍA, A. (2008) "Una fábrica de propiedad estatal: la fábrica de tabacos" en Arquitectura industrial en Gipuzkoa, San Sebastián: Diputación Foral de Guipúzcoa, pp. 449-470. Disponible en www.artxibogipuzkoa.gipuzkoakultura.net/libros-e-liburuak/bekak-becas06.pdf [acceso el 22-01-2014].

197 GÁRATE OJANGUREN, M. M. (2006) op. cit.

198 VV. AA. (1991) Parlamento de La Rioja, Oyón-Álava: Argraf, Parlamento de La Rioja, Facultativos autores del proyecto de obra.

199 GARCÍA-POZUELO ASINS, D. y HERNÁNDEZ VITORIA, E. (1980) Arquitectura de Logroño: breve historia del desarrollo de la ciudad con la reseña de algunos conjuntos y edificios, Logroño: Colegio Oficial de Arquitectos de Aragón y La Rioja, p. 35.

200 JIMÉNEZ MARTíneZ, J. (1989) El Parlamento de La Rioja en el antiguo convento de "Nuestra Señora de la Merced", Logroño: Ochoa.

201 BERMEJO, F., y LEVENFELD, R. (1990) Amós Salvador y su tiempo: exposición conmemorativa del centenario de la instalación de la Fábrica de Tabacos en Logroño; catálogo, Ochoa. 
logroñesa. De igual forma, ha resultado de interés la consulta del número específico de 1982 de la Revista de Arquitectura de los Colegios Oficiales de Arquitectos de Aragón y Rioja ${ }^{202}$ que se ocupó del concurso de ideas para la reutilización del conjunto tabacalero logroñés.

Para abordar el estudio particular del caso tarraconense ha resultado fundamental la extraordinaria documentación gráfica y planimétrica del Archivo de la Fábrica de Tabacos de Tarragona que se encuentra en el Archivo de Tarragona, felizmente ubicado en uno de los almacenes de la propia fábrica que ha sido reutilizado como dependencias administrativas y culturales municipales.

Además del conocimiento fundamental que aportan estas fuentes primarias, resulta interesante la consulta de artículos sobre aspectos anecdóticos relativos a los yacimientos arqueológicos que se encontraron en el solar de la fábrica durante las obras de construcción que aportan una visión completa de la importancia de este palimpsesto patrimonial que integra el conjunto fabril de la tabacalera tarraconense ${ }^{203}$. Sin embargo, las obras que han resultado de capital importancia para profundizar en el conocimiento sobre este conjunto fabril han sido la publicación de 1982 de Diego Bertrán Vallvé204 y, sobre todo, la obra de María Jesús Muiños Villaverde y Vicent Terol Grau de $2008^{205}$, siendo esta última una obra de referencia para el conocimiento sobre la realidad socioeconómica y productiva y la historia de la Fábrica de Tabacos de Tarragona.

En el desarrollo específico del caso de estudio malagueño, ha resultado fundamental la consulta de los fondos del archivo de la fábrica custodiados en el Archivo Histórico Provincial de Málaga, que cuentan con abundante documentación planimétrica.

$\mathrm{Al}$ igual que sucede en otras unidades fabriles estudiadas, se pueden consultar referencias parciales en obras generales que ayudan a contextualizar la fábrica en el marco de la realidad socioeconómica de la industria malagueña ${ }^{206}$. También resultan interesantes algunos estudios sobre una posible primera ubicación de la fábrica en un palacete de la calle Salinas ${ }^{207}$, así como artículos específicos sobre el

202 FERNÁNDEZ LÁZARO, F.; NAVARRO LOMBA, C.; GARCÍA POZUELO, D. (Red.) (1982) "Concurso de ideas sobre la reutilización del edificio de la antigua tabacalera" en ALDABA. Revista de Arquitectura de los Colegios Oficiales de Arquitectos de Aragón y Rioja, nº 1, febrero 1982, pp. 46-60.

203 A destacar REMOLÀ VALLVERDÚ, J. A.; VILASECA, A. (1997-1998) "Intervenciones arqueológicas en el PERI2, sector Tabacalera, de Tarragona" en Tribuna d'Arqueologia, pp. 77-95; y RUIZ DE ARBULO, J. y MAR, R. (2007) "Arqueología y planificación urbana en Tarragona. Tradición historiográfica y realidad actual” en Recuperar la memoria urbana. La Arqueología en la rehabilitación de las ciudades históricas, Tarragona: URV / Fund. La Caixa, [Traducción castellana del original publicado en catalán].

204 BERTRÁN VALLVÉ, D. (1982) Tarragona y su Fábrica de Tabacos. Un sueño hecho realidad. Cincuentenario de la puesta en marcha de la Fábrica de Tabacos de Tarragona, Madrid: Tabacalera.

205 MUIÑOS VILLAVERDE, M. J. y TEROL GRAU, V. (2008) op. cit.

206 CAMACHO MARTINEZ, R. (dir.) (1992) Guía Histórico - Artística de Málaga, Arguval, Colegio de Aparejadores y Arquitectos Técnicos, p. 343 y pp. 350-352; RODRÍGUEZ MARÍN, F. J.; CANDAU, M. E.; DÍAZ PARDO, J. I. (2005) Málaga: Guía de Arquitectura. Consejería de Obras Públicas y Transportes y Colegio de Arquitectos de Málaga.

207 PÉREZ MALUMBRES, A.; GONZÁLEZ HERNÁNDEZ, S. (1992) "La primera fábrica de tabaco de Málaga. El palacete de calle Salinas $n^{\circ} 6$ (II)" en Jábega, no 72, pp. 29-44; LUQUE NIEVES, M. y DÍEZ OCEJO, M. P. (2001) "La Fábrica de Tabacos de Málaga. Estudio histórico-artístico de un símbolo de nuestro pasado industrial" en Boletín de arte, $\mathrm{n}^{\circ} 22$, pp. 283-308. 
conjunto fabril malagueño ${ }^{208}$. Pero, sin duda, la obra de referencia para el conocimiento del presente caso de estudio es la realizada por Concepción Campos Luque ${ }^{209}$, que forma parte de las monografías publicadas por la Fundación Altadis tras el cierre de los centros fabriles -ya se ha hecho referencia a Arias y Mato (2005), Gárate Ojanguren (2006), Muiños y Terol (2008) que, al igual que la obra de Campos Luque (2004) forman parte de la colección "Los libros de Altadis"- y que analiza de forma rigurosa la complicada historia productiva de la tabacalera malagueña, que se reconvirtió en centro de fermentación durante gran parte de su vida en activo.

\subsubsection{Las fábricas de tabacos a nivel mundial: dos monopolios europeos y antiguos territorios coloniales}

Como complemento al epígrafe anterior, resulta conveniente hacer referencia a la casuística de los monopolios tabacaleros europeos vecinos, así como a las realizaciones arquitectónicas fruto del breve periodo del establecimiento del monopolio hacendístico tabacalero español en las colonias hasta su independencia, especialmente en el caso americano y en Filipinas ${ }^{210}$. No se trata de un estudio exhaustivo, que sin duda tendría cabida en una investigación monográfica más detallada, si no de referenciar una serie de apuntes que ayuden a entender los posibles paralelismos y conexiones entre la casuística fabril del monopolio hacendístico tabacalero español y los ejemplos acontecidos más allá de la península ibérica. Cabe destacar que, en el caso de la producción tabacalera francesa e italiana se comparte el rasgo común con la española en el empleo mayoritario de mano de obra femenina, por lo que los valores patrimoniales de esta industria en los países vecinos manifiestan claramente esa importancia de la memoria del trabajo femenino que a los objetivos de esta investigación interesan.

Por tanto, a continuación se realizará un recorrido a través de aquellas realidades externas al monopolio hacendístico del tabaco español que guardan conexiones y similitudes con el mismo, fundamentalmente en lo que aspectos de formalización arquitectónica de su parque fabril se refiere. De esta forma, se puede contextualizar de forma holística el análisis que se realizará en capítulos subsiguientes y que tendrá por objeto la correcta interpretación de los invariantes encontrados a lo largo del análisis de los casos estudio seleccionados en la formalización de un tipo fabril tabacalero español y su evolución paralela a los cambios organizativos y técnicos de la producción.

\footnotetext{
208 RODRÍGUEZ MARÍN, F. J. (1991) "La Fábrica de Tabacos de Málaga: un proyecto industrial en clave regionalista" en Péndulo, n 1 , diciembre 1991, pp. 26-34; y NARANJO, M. L. R. (2012) "La Fábrica de Tabacos de Málaga en el S. XXI: Patrimonio industrial para todos. Recuperación de un edificio industrial para nuevos usos museísticos y culturales" en Jornadas Andaluzas de Patrimonio Industrial y de la Obra Pública: Jornadas Andaluzas de Patrimonio Industrial y de la Obra Pública (1. 2010. Sevilla.), pp. 43-54. 209 CAMPOS LUQUE, C. (2004) op. cit.

210 Aunque no se encuadre dentro de los ejemplos recogidos, cabe hacer mención a la tesis doctoral de Luciana Guerra Santos Mota sobre las fábricas de tabaco sitas en Salvador de Bahía, Brasil y cuya autora ha tenido la gentileza de compartir para la consulta de la presente investigación. GUERRA SANTOS MOTA, L. (2014) Manufaturas de fumo do recôncavo baiano: vestigios de patrimonio industrial, Universidade Federal da Bahía, Programa de pós-graduação em arquitetura e urbanismo.
} 


\section{El monopolio de tabacos francés}

En primer lugar, cabe destacar el especial interés del monopolio de tabacos francés en un posible análisis comparativo con el caso español. No en vano, tal y como se ha apuntado en epígrafes anteriores, Francia adquiere gran importancia en la contextualización de la presente investigación como referente de España en la implantación de los sistemas de manufacturas reales. Para profundizar sobre la arqueología industrial en Francia resulta de capital importancia la consulta de la obra de Maurice Daumas L'archéologie industrielle en France de 1980. En las cuestiones que interesan a este trabajo, dicha publicación dedica un capítulo especial a las fábricas tabacaleras en Francia, constituyendo uno de los primeros estudios de referencia sobre la arquitectura fabril tabacalera en el país galo ${ }^{211}$. Más específicamente, resulta fundamental la obra de Laurent Fièvre sobre la arquitectura de las tabacaleras francesas, proyecto de investigación que fue tema de su tesis doctoral y que dio como fruto la publicación Les manufactures de tabacs et d'allumettes. Morlaix, Nantes, Le Mans et Trélazép ${ }^{212}$. A la producción científica de estos autores se une el conocimiento específico del especialista Paul Smith ${ }^{213}$, que amablemente ha colaborado en el proceso de documentación de la presente investigación.

Sobre los paralelismos que se pueden establecer entre el caso de la producción tabacalera francesa y la española como patrimonio industrial arquitectónico se profundizará en los capítulos dedicados al desarrollo de la investigación. No obstante, se puede avanzar que España toma referencias del caso francés para la conformación de sus características particulares en diversos ámbitos como el modelo de gestión monopolístico, los requerimientos espaciales de la producción tabacalera, la definición de los condicionantes ambientales de implantación, la reutilización de edificios preexistentes y la evolución experimentada en la sistematización arquitectónica del proceso productivo.

Ya se apuntó anteriormente el hecho de que la dinastía de los borbones estableció en España una política económica de centralización, proteccionismo e impulso de la producción industrial con la creación de las reales fábricas que tomarían el ejemplo de las manufactures royales que surgirían en Francia en el S.XVII a partir de las ideas ilustradas de Jean Baptiste Colbert, ministro de Luis XIV. En el caso

\footnotetext{
211 DAUMAS, M. (1980) op. cit. Tienen especial interés al objeto de la presente investigación los capítulos "Les manufactures royales" pp. 93-148 y el epígrafe "A propos du papier et du tabac" en el capítulo "De la manufacture à l'usine", pp. 235-245.

212 FIÈVRE, L. (2004) Les manufactures de tabacs et d'allumettes. Morlaix, Nantes, Le Mans et Trélazé (XVIIIeXXe siècles), PU Rennes. Sobre la fábrica de Morlaix también se recomienda la consulta de GUILLOU, A. (2009) La Manufacture des tabacs de Morlaix: quatre siècles d'histoire, Skol Vreizh.

213 A destacar su contribución SMITH, P. (2012) "Un regard de l'étranger: les manufatures de tabacs en France, un patrimoine privilégié?" en CHIERICI, P ; COVINO, R.; y PERNICE, F. (eds.) Le fabbriche del tabacco in Italia, Torino: Celid, pp. 39-48. Así mismo, la autora quiere agradecer muy especialmente la colaboración de Paul Smith en la documentación de la presente investigación sobre las tabacaleras francesas que ha permitido la consulta de referencias específicas sobre el tabaco en Francia y la historia de sus monopolios de tabacos y cerillas, así como informes inéditos sobre la fábrica de tabacos de Lyon.
} 
francés, el monopolio hacendístico del tabaco se establece en el S.XVII y se refuerza a partir de 1721 con la fundación de nueve fábricas que se localizan en algunas de las principales urbes del país galo ${ }^{214}$. La aparente falta de homogeneidad del parque imperial manufacturero del tabaco en tiempos de Napoleón respondía a que la mayoría de las fábricas se implantaban en edificios reutilizados de diverso carácter: sanitarios, preindustriales, religiosos, residenciales, etc ${ }^{215}$.

Durante este primer periodo dieciochesco y hasta mediados del S.XIX, a estas estructuras reutilizadas se unirían otras plantas de nueva creación, como la Manufacture de tabacs de Morlaix, caracterizadas por una tipología de fábrica compacta que se inspira claramente en las arquitecturas nobles palaciegas. Sin embargo, a partir de 1848 se adoptará el modelo concebido por el ingeniero Eugène Rolland que constituirá una tipología de fábrica vertical en pabellones según esquemas tomados de las reales fábricas y que, con ciertas variaciones, se aplicará con carácter general en los nuevos conjuntos industriales a construir. Finalmente, a partir de 1960 seguiría una tipología de fábrica horizontal acorde a los nuevos métodos productivos.

En 1926 la Caisse Autonome d'Amortissement de la Dette Publique crearía el SEIT (Service d'Exploitation Industrielle des Tabacs) que nueve años después se convertiría en la SEITA al integrar el monopolio la fabricación de cerillas -allumettes en francés-. Este organismo gestionaría el monopolio hasta que en 1970 se abolen las barreras aduaneras en el seno del Mercado Común Europeo con la subsiguiente supresión del monopolio del tabaco. Curiosamente, en paralelo a estos cambios estructurales, durante la década de los 60 y 70 del S.XX se procede a la demolición de algunas fábricas tabacaleras desafectadas, como Reuilly, Dijon, Limoges y Niza.

Sin embargo, en 1980 surge una nueva sensibilidad hacia este patrimonio industrial, iniciándose una política de conservación de los inmuebles pertenecientes al monopolio tabacalero francés y realizando intervenciones de rehabilitación arquitectónica de los mismos para su reutilización con nuevos usos, fundamentalmente culturales, educativos y de alojamiento. Estas obras se realizarían en diversas fábricas como Toulouse, Burdeos, Morlaix, Riom o Nantes entre los años 80 y principios del S.XXI. Precisamente, la SEITA se privatizaría en 1995 y, posteriormente, en 1996, se anunciaría la intención de fusionar la entidad francesa con la española Tabacalera, dando lugar a lo que finalmente se conoció como Altadis.

\section{El monopolio de tabacos italiano}

$\mathrm{Al}$ igual que en el caso francés, el desarrollo arquitectónico fabril del monopolio tabacalero italiano guarda paralelismos con la evolución observada en la Renta del Tabaco española, con la salvedad de que en

\footnotetext{
214 Como se apuntó anteriormente, en el caso español, tras la instauración de la Renta del Tabaco en 1636 se establece la Universal Administración en 1731 y se comienza la construcción de la Real Fábrica de Tabacos de Sevilla en 1728, en fechas similares al vecino país galo.

215 Para el estudio de la historia del monopolio francés se seguirá el trabajo de Laurent Fièvre, especialmente FIÈVRE, L. (2004) op. cit., pp. 241-242.
} 
ambas penínsulas, las circunstancias socioeconómicas e históricas determinaron que la evolución de sendos monopolios se desarrollase al amparo del ejemplo galo. Para conocer en profundidad la casuística tanto de la historia socioeconómica del monopolio italiano como de sus fábricas resulta fundamental la consulta de la obra Le fabbriche del tabacco in Italia, publicación de los resultados del congreso del mismo nombre organizado por AIPAI (Associazione Italiana per il Patrimonio Archeologico Industriale), el Politecnico de Torino y la Soprintendenza per i Beni Architettonici e Paesaggistici en mayo de 2009, en una edición a cargo de Patrizia Chierici, Renato Covino y Francesco Pernice $^{216}$. Cabe destacar la colaboración desinteresada en la presente investigación de Antonio Monte, que también participó en el citado congreso y que ha realizado diversas publicaciones especializadas en la obra de Pier Luigi Nervi al servicio del monopolio del tabaco italiano ${ }^{217}$.

La península italiana contaba prácticamente con una factoría tabacalera en cada Estado, surgiendo al amparo de la popularización del consumo tabacalero durante el S.XVIII. Con la unificación italiana a mediados del S.XIX, se heredó un sistema de pequeñas manufacturas gestionadas de forma diversa, así como un sector productivo igualmente fragmentado y heterogéneo. Para formalizar esta situación se estableció el monopolio estatal sobre tabacos a través de la ley del 13 de julio de 1862, momento en el cual se encontraban en activo quince factorías $^{218}$. Esta desfragmentación ocasionaba la ineficacia y escasa racionalidad productiva debida a la proliferación de fundaciones fabriles y el numeroso personal empleado, así como otras deficiencias coyunturales como la carencia de cuadros técnicos, el atraso tecnológico, los bajos índices de productividad y los altos costes de gestión.

Esta situación vendría a ser paliada por el establecimiento de un monopolio hacendístico asociado a entidades privadas, conjugando ya desde la creación del Estanco sobre el Tabaco capitales públicos y privados. Esta solución establecida en 1868 con la creación de la Regìa Cointeressata dei Tabacchi del Regno d'Italia con capital perteneciente a entidades bancarias, implantaba una solución similar a la que dos décadas después se acometería en España con la Compañía Arrendataria de Tabacos.

La evolución del monopolio italiano estuvo condicionada por la sucesión de conflictos bélicos acaecidos en la primera mitad del S.XX. En vísperas de la primera Guerra Mundial, la elaboración manual de cigarros por parte de las trabajadoras convivía con la mecanización total de las restantes líneas productivas que ocasionaron importantes

216 CHIERICI, P ; COVINO, R. ; y PERNICE, F. (eds.)(2012) op. cit.

217 Además de su contribución en las citadas actas del congreso Le fabbriche del tabacco in Italia, Antonio Monte ha colaborado amablemente en la presente investigación cediendo documentación sobre su conferencia "Manifatture, Agenzie Coltivazione Tabacchi, Magazzini per il sale nell'opera di Pier Luigi Nervi", celebrada en el Teatro Puccini de Florencia el 25 de marzo de 2015, así como DEL PRETE, R. (ed.) (2012) Dentro e fuori la fabbrica. Il Tabacco in Italia tra Memoria e Prospettive, Milano: Franco Angeli.

218 Para la contextualización histórica del monopolio italiano, cabe destacar GARBINI, L. (2012) "L’industria del tabacco in Italia" en CHIERICI, P.; COVINO, R. y PERNICE, F. (eds.) (2012) op. cit., pp. 17-38. 
reestructuraciones para la electrificación de las plantas. Sin embargo, en términos organizativos, la inadecuación arquitectónica y espacial de muchos inmuebles ocasionaba serios problemas en la organización racional de las elaboraciones mecanizadas y obstaculizaba el rendimiento productivo. Por este motivo, se resolvió la construcción de nuevos establecimientos fabriles que paliasen las carencias de los edificios heredados de la red fabril inicial. Este proceso desembocó en la creación entre 1927 y 1928 de la Amministrazione Autonoma dei Monopoli di Stato (AAMS) en lo que vendría a ser el cuarto cambio de gestión institucional de la historia del monopolio italiano, y que llevaría a cabo en 1935 uno de los proyectos edilicios más importantes en la historia de la producción tabacalera italiana: la gran fábrica de Florencia.

El cese de la actividad productiva en la península italiana dejó en el paisaje urbano vestigios fabriles en posiciones estratégicas cuya centralidad urbana los convertía en áreas apetecibles para la especulación inmobiliaria, en un contexto general de transformación urbana de los baldíos industriales que, en este caso, se hallaban tutelados por la administración pública a través de Ente Tabacchi Italiani. En 2002 se produjo el desmantelamiento de los edificios tabacaleros en activo y, con arreglo a una operación de rapidez inusual, el conjunto de bienes patrimoniales tabacaleros fue cedido a la sociedad Fintecna -que cuenta con la participación del Ministerio de Economía italiano- con objeto de su enajenación y posterior aprovechamiento económico. La celeridad de esta operación impidió que los entes propuestos para su tutela -las Soprintendenze- pudiesen catalogar y evaluar el interés histórico-artístico de los vestigios patrimoniales tabacaleros italianos.

\section{Algunos casos de tabacaleras en antiguos territorios coloniales}

Por otra parte, ahondando en la casuística de la actividad del monopolio tabacalero español en sus colonias, se encuentran ejemplos destacados de arquitecturas fabriles que gozan de una especial atención en el presente epígrafe. Algunos casos, como la Fábrica de Tabacos de México, perviven como vestigios materiales de la implantación de reales fábricas tabacaleras por parte de la Corona española en territorio colonial. Por el contrario, otros ejemplos destacados como la Real Fábrica de Tabacos de Lima, tan sólo pueden documentarse a través de la planimetría custodiada en el Archivo General de Indias, dado que lamentablemente ya no quedan vestigios de la misma.

La influencia del tipo fabril tabacalero español se aprecia en las primeras fundaciones de reales fábricas de tabacos americanas del S.XVIII. Pese a que no existen vestigios de muchas de ellas, el Archivo General de Indias custodia documentación planimétrica relativa a la definición arquitectónica de las mismas. Los invariantes que definen el tipo fabril estudiado en la presente investigación se reflejan en estas arquitecturas, siendo constantes el empleo del patio como principio organizador del espacio y la cuidada composición lingüística de la fachada como envolvente representativa del espacio productivo. 
Especial atención merecen otras estructuras productivas ajenas a la Renta de Tabacos española. Cabe destacar el interés de la planimetría encontrada sobre la Fábrica de Tabacos de Manila, con una organización similar al tipo Rolland francés y que pertenecía a la Compañía General de Tabacos de Filipinas creada tras el desestanco en la citada colonia asiática. De igual forma, resulta interesante el conocimiento de ejemplos como las fábricas tabacaleras de La Habana, pese a su pertenencia al ámbito de la iniciativa privada y a un contexto urbano diverso. Estas arquitecturas fabriles tabacaleras sitas en la capital cubana constituyen ejemplos vivientes de las características estudiadas a lo largo de este trabajo, compartiendo rasgos semejantes con los casos estudio seleccionados en el ámbito español. La profundización sobre el caso cubano, no sólo se ha producido a través de la documentación bibliográfica del estado de la cuestión de la presente investigación, sino que se realizó un trabajo de campo durante la asistencia al VIII Coloquio Latinoamericano sobre Patrimonio Industrial ${ }^{219}$.

El continente americano contó con notables exponentes en materia de arquitectura fabril del tabaco que surgirían en la segunda mitad del S.XVIII con la política de fomento industrial de los Borbones, especialmente a través de las medidas modernizadoras de Carlos III en términos de una incipiente industrialización. Si bien no fueron muy numerosos, su importancia radica en la apertura de nuevas temáticas arquitectónicas en América que se verían muy influidas por los planteamientos proyectuales venidos de la península ibérica y que en su conjunción con el lenguaje empleado en la producción arquitectónica colonial abriría las puertas a un nuevo tipo arquitectónico industrial ${ }^{220}$.

Los rasgos que definirían la arquitectura fabril tabacalera en el continente americano presentarían notables paralelismos con el caso español. De ello darían cuenta ejemplos destacables tanto en el seno monopolístico, con la Dirección de Tabaco de Buenos Aires de 1781221, como en el ámbito de la iniciativa privada, con las célebres fábricas de cigarros habaneras de Calixto López de 1886 y la Fábrica de Tabacos "Partagás" fundada en la época de entre-siglos. Al objeto que ocupa la presente investigación conviene señalar dos ejemplos de fundaciones

\footnotetext{
219 En el citado congreso, celebrado del 14 al 16 de marzo de 2016 en La Habana (Cuba), se expusieron resultados de la presente investigación mediante la ponencia "Un patrimonio industrial arquitectónico complejo y contradictorio: claves espaciales de las Fábricas de Tabacos en España a través de sus dimensiones escalares" el 14 de marzo de 2015 en el Colegio de San Gerónimo de La Habana. Así mismo, se visitaron las fábricas Partagás y Romeo y Julieta, y las plantaciones y secaderos sitos en las vegas de tabaco del Valle de Viñales.

${ }_{220}$ GUTIÉRREZ, R. (1983) "La Arquitectura de Gobierno" en GUTIÉRREZ, R. (1983) Arquitectura y Urbanismo en Iberoamérica, Cátedra, pp. 275-298. Al objeto de la presente investigación, tiene especial interés el epígrafe de dicho capítulo "Fábricas y otros edificios urbanos", pp. 289-291.

221 "En un comienzo vuelve a darse la estructura de integración de estos edificios en contextos de otras obras de gobierno, lo que impide dilucidar con claridad la existencia de tipologías autónomas. Un ejemplo claro de este sentido es el de la Dirección de Tabaco de Buenos Aires que tiene incorporados dos grandes salones destinados a la fábrica de tabacos junto a patios amplios y zonas de fabricar "picadura de tabaco". Sin embargo, aun sumando las áreas de almacenamiento, el conjunto de la superficie que ocupaban las oficinas y la residencia del Director de la Real Factoría superaban ampliamente el área productiva [...] Este edificio tuvo la peculiaridad de ser realizado por el constructor, escultor y empresario Isidro Lorea para arrendarlo a la real Factoría. Concluido en 1781, fue adquirido un lustro más tarde a su propietario quien había realizado en él dos notables portadas rococó". GUTIÉRREZ, R. (1983) op. cit., pp. 289-290.
} 
reales que demuestran la relación entre los planteamientos proyectuales de las fábricas de tabacos en España y las primeras fundaciones fabriles tabacaleras en América: las Reales Fábricas de Tabacos de México y Lima.

\section{El caso de México}

La tabacalera mexicana conocida como la "Ciudadela" fue proyectada en 1793 por el arquitecto Antonio González Velásquez procedente de la Real Academia de San Carlos de México, concluyéndose los trabajos de construcción en 1807 con la colaboración del ingeniero Miguel Constanzó ${ }^{222}$. Actualmente, y tras diversos cambios de uso como cuartel general y cárcel ${ }^{223}$, el edificio se recuperó como biblioteca en el año 1946 a iniciativa de José Vasconcelos.

El inmueble se articuló mediante cuatro patios rodeados por corredores porticados que definían un volumen cruciforme en cuya intersección se ubicaba el cernidor, empleando sus azoteas como secaderos. Completando los cuatro patios principales cuadrangulares se situaban dos patios auxiliares en el eje compositivo desde el acceso principal oriental que permitían el oreo del tabaco. Este eje reforzaba su importancia por el hecho de articular y concentrar en dicho acceso algunos de los espacios más significativos para el funcionamiento de la factoría: las oficinas de tesorería y contaduría, así como las estancias de control de acceso, disponiendo los almacenes y patios de labores en la parte trasera.

El cinturón perimetral se componía de diversos espacios diáfanos de traza rectangular disponiendo una clara separación por sexos de las estancias de labores de cigarros y puros, de tal manera que las de los hombres se ubicaban en la mitad Norte respecto al eje central, mientras que las de las mujeres se disponían en la parte Sur. Estos espacios productivos se completaban con estancias para el picado del tabaco, la creación de sellos o el encajonado de las labores.

\section{El caso de Lima}

El caso de la Real Fábrica de Tabacos de Lima comporta otras

\footnotetext{
222 "Quien comenzó con las clases de Arquitectura en la Academia de San Carlos en 1785, hasta la llegada de Antonio González Velásquez desde España, fue Miguel Constanzó. Nacido en Barcelona en 1739, Constanzó ingresó al Real Cuerpo de Ingenieros Militares en 1762 y casi sin experiencias profesionales, recién egresado de la Academia de Matemáticas, pasa México en 1764 [...] Constanzó demostró una notable ductilidad para trabajar no solamente en obras de arquitectura militar como el Castillo de San Diego de Acapulco (1776) sino también en edificios industriales como la Fábrica de Pólvora (1780), la de Azufre (1798) y la de Tabacos (La Ciudadela, terminada en 1807). Participará en la ampliación de la Casa de Moneda (1772), en un proyecto para Jardín Botánico (1789) y en la preparación de cartografía del Virreynato y de la ciudad de México (1777). Antonio González Velásquez fue el primer y único arquitecto académico que vino específicamente para la nueva Academia de San Carlos. Era hijo de Alejandro González Velásquez que ocupó con Ventura Rodríguez las primeras titularidades de San Fernando a partir de 1752. [...] Paco de la Maza recuerda la actuación de González Velásquez como impulsor del neoclasicismo". GUTIÉRREZ, R. y ESTERAS, C. (1993) op. cit., pp. 183-184.

223 Al igual que en las tabacaleras españolas, el origen manufacturero del edificio producía una suerte de indeterminación programática que permitía su reutilización para otros usos, principalmente coercitivos. En el caso de la fábrica mexicana, tras el cese de la actividad productiva tabacalera se reconvirtió en cuartel y cárcel, uso del que tomó el nombre de "Ciudadela" con el que se la conoce popularmente.
} 


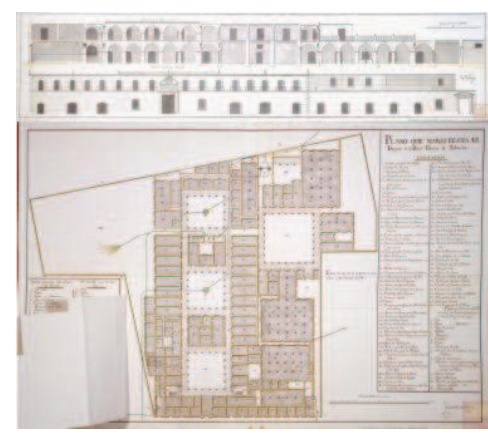

Figura 2.30. Planimetría de la Real Fábrica de Tabacos de Lima de Vicente de Veza, 1790, en $A G I$ MP-Peru_Chile 197 y $M P$ Peru_Chile 196.
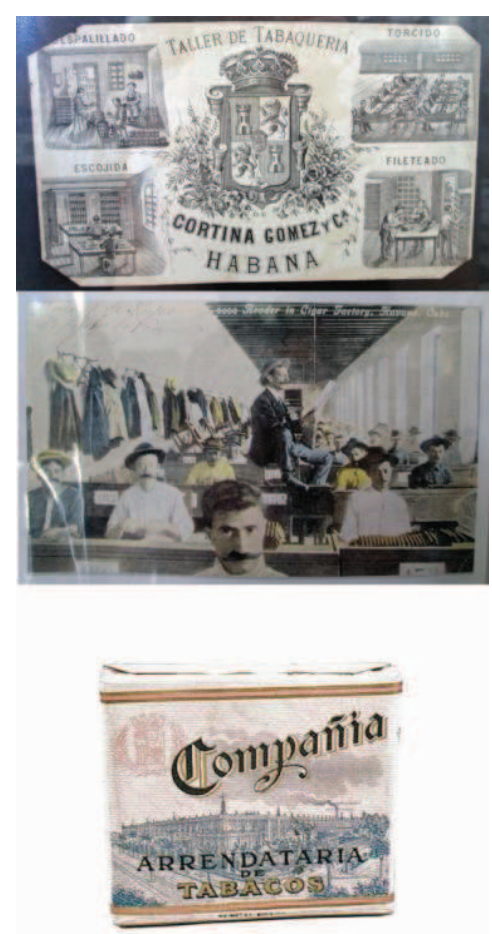

Figura 2.31. Marquillas de tabaco expuestas en el Palacio del Segundo Cabo en La Habana

(Cuba), marzo 2016; y paquete de cigarrillos de la CAT con una perspectiva de la Real Fábrica de

Tabacos de Sevilla, en COMÍN COMÍN, F. y MARTÍN ACENAA, P. (1999), op. cit., p. 373. particularidades. Si bien no se conservan vestigios materiales que permitan conocer su configuración espacial final, se sabe que el recinto fabril se encontraba frente a la actual Casona de San Marcos en el área denominada como chacarilla de San Bernardo, aproximadamente en el lugar que actualmente ocupa el edificio Alzamora Valdez ${ }^{224}$. El origen de la actividad productiva y venta del tabaco en la ciudad de Lima data de mediados del S.XVIII y en origen se repartía en diversos estanquillos ubicados en residencias particulares de la ciudad. Sin embargo, en 1780 se decide reagrupar la actividad tabacalera en un único edificio ubicado en las antiguas huertas conventuales de los jesuitas que habían sido expulsados en 1767.

Partiendo del análisis del proyecto de 1786 de Vicente de Veza, cuya planimetría conservada documenta profusamente el funcionamiento espacial de la fábrica, se puede afirmar que la fábrica limeña presentaba una distribución completamente diversa a la de la tabacalera mexicana ${ }^{225}$. El complejo general se desdoblaba en dos sistemas espaciales conectados entre sí, accediendo por la fachada principal a través de una portada barroca que, mediante una estancia intermedia, daba paso al primer sistema de espacios.

Este sistema se estructuraba mediante una sucesión de tres patios cuadrangulares porticados de iguales dimensiones que se destinaban a patio de honor, patio de almacenes y patio de administración y que marcaban la dirección del eje principal desde el acceso. De esta forma, en torno al primer patio se aglutinaban la casa del administrador de almacenes y el denominado como laboratorio de mujeres, así como las principales comunicaciones verticales a la primera planta. El segundo patio concentraba en su perímetro veinticinco almacenes, y el tercero, estancias destinadas al cuerpo de guardia y la administración de la fábrica. Como filtro de separación entre los tres patios se disponían dos volúmenes: el primero alojaba las dependencias de la casa del tesorero y el segundo estancias para la administración de almacenes. A través del tercer patio se podía acceder al jardín que lindaba con las huertas del convento de Santa Teresa y al segundo sistema espacial.

La organización de este segundo conjunto espacial resulta menos clara. Desde el paso anteriormente mencionado se llegaba a un gran patio cuadrangular denominado como "patio de la fábrica de cigarros" que contaba con mayores dimensiones que los tres anteriores. Este gran espacio determinaba la zonificación del segundo sistema, disponiendo en la parte trasera del conjunto la fabricación de puros y picadura de tabaco y en la parte cercana al acceso, la elaboración de cigarros de

${ }^{224}$ Para determinar la posición exacta de la fábrica ha sido fundamental la consulta de la planimetría publicada en BURNEO, R. A. (2002) Orígenes y Evolución del Conjunto Arquitectónico de la Casona de San Marcos, Programa para la Conservación del Patrimonio Cultural, Universidad Nacional Mayor de San Marcos, Agencia Española de Cooperación Internacional, Instituto Nacional de Cultura, Lima: UNMSM-Fondo Editorial.

225 Si bien la falta de vestigios materiales impide constatar si la construcción siguió fielmente el proyecto de Vicente de Veza, se sabe que el complejo lindaba con fincas particulares al Oeste, y con el desaparecido convento de Santa Teresa al Este -que se encontraba en la intersección de los actuales Jirón Puno y avenida Abancay-. El único inmueble que ha llegado a nuestros días es el edificio del Estanco del Tabaco y la Sal de de la tercera década del S.XX, que se construyó en el espacio anteriormente ocupado por el Paseo de Acho junto al Rímac. 
papel. Finalmente, las estancias cercanas a la fachada principal se destinaban a diversas necesidades para las mujeres empleadas en la fábrica.

En la crujía de la fachada principal, además de espacios de registro y control, administración y cuartos para el cuerpo de guardia, se disponían una serie de estancias que daban directamente a la vía pública destinadas a puestos de venta. Los únicos accesos al complejo desde el exterior eran la entrada principal a través de la portada barroca y una entrada auxiliar situada a la derecha de la fachada principal que comunicaba directamente con los espacios de elaboración.

No queriendo ahondar exhaustivamente en el estado de la cuestión sobre las fábricas de tabacos habaneras y filipinas, cabe destacar que, además del tratamiento del contexto socioeconómico histórico de la producción tabacalera en las colonias en las obras generales citadas en epígrafes anteriores, destacan diversos autores que han realizado trabajos específicos sobre esta cuestión y que se citarán en los párrafos subsiguientes. Se remarca, así mismo, la importancia de la producción litográfica en las vitolas y marquillas de cigarros y tabacos como base documental para el conocimiento de las arquitecturas fabriles tabacaleras cubanas y filipinas, que empleaban imágenes de sus fábricas como reclamo publicitario -al igual que en otras industrias- $\mathrm{y}$ que permiten conocer en ocasiones la evolución de los edificios fabriles tabacaleros ${ }^{226}$.

\section{El caso de La Habana}

Resulta interesante la comparación del tipo tabacalero español estudiado con la producción edilicia fabril tabacalera en La Habana tras el desestanco sobre la producción y comercialización del tabaco en Cuba en 1817. Gracias al trabajo de Alain Marrero Cordero ${ }^{227}$, se puede observar que la arquitectura desarrollada para este fin en el contexto habanero no difiere en las conclusiones finales sobre las características observadas de los preceptos proyectuales de las fábricas españolas de la presente investigación.

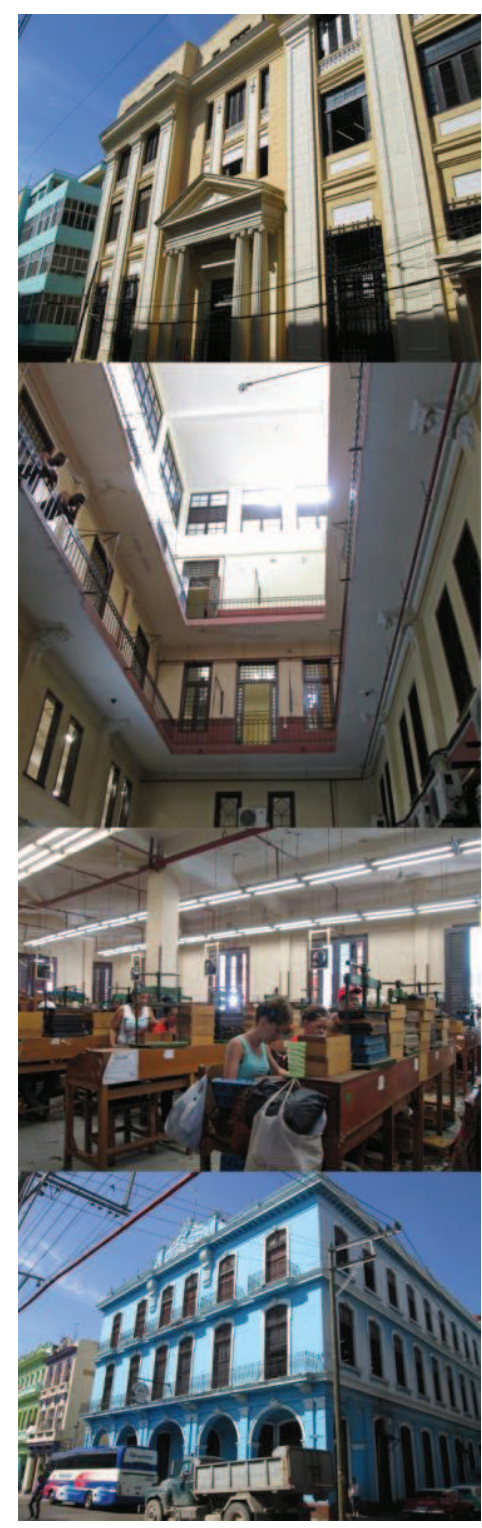

Figura 2.32. Exterior e interior de la Fábrica Partagás, y exterior de la Fábrica Romeo y Julieta. La Habana (Cuba), 2016.

En este sentido, cabe remarcar el diverso contexto en el que se fundaron las tabacaleras habaneras, cuyo auge coincidió con el desarrollo urbano

226 La Msc. Arquitecta Florencia Peñate pronunció el 15 de marzo de 2016 en el citado VIII Coloquio Latinoamericano sobre Patrimonio Industrial la interesante ponencia "Las marquillas de tabacos y cigarros del siglo XIX realizadas en talleres litográficos habaneros, un patrimonio cultural cubano" en la que trató tanto la importancia patrimonial de las marquillas y vitolas de cigarros puros y cigarrillos, así como las técnicas y temáticas tratadas en las mismas. La autora quiere agradecer a la arquitecta Peñate la cesión desinteresada de la documentación de su ponencia para su consulta en la presente investigación.

${ }^{227}$ MARRERO CORDERO, A. (2015) "La arquitectura tabacalera en La Habana. Las fábricas palaciegas (ss. XIXXX)" en Actas del Noveno Congreso Nacional y Primer Congreso Internacional Hispanoamericano de Historia de la Construcción, Segovia, 13 a 17 de octubre de 2015, Vol. 2, pp. 999-1009. La autora agradece especialmente al arquitecto Marrero toda su ayuda en el proceso de documentación de las fábricas de tabacos habaneras, así como la cesión desinteresada de material. Junto al trabajo de Alain Marrero Cordero, caben destacar otros artículos de referencia como CÁRDENAS, E. (2009) "El patrimonio de la producción en la historiografía cubana" en Arquitectura y Urbanismo, vol.XXX, nº 2-3, La Habana: ISPJAE, pp. 6-12 -se agradece especialmente a Joaquín Ibáñez Montoya de la UPM la facilitación de este texto-; y VENEGAS, C. (1989) "Las fábricas de tabaco habaneras" en Arquitectura y Urbanismo, vol. X, nº 3 , La Habana: ISPJAE. 


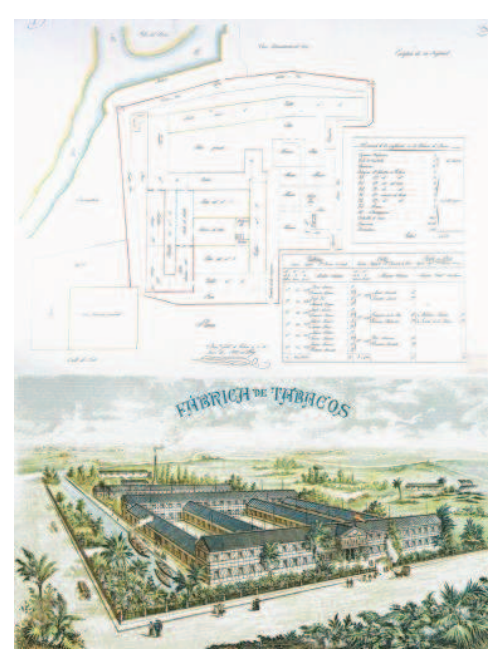

Figura 2.33. Planimetría de la fábrica de puros de Manila,

1832, en AGI, ES-AGI-41091$U D-1931454-E S-A G I-41091-U D$ -

18970; y perspectiva de "La Flor de la Isabela" de 1889, en

COMÍN COMÍN, F. y MARTÍN ACENA, P. (1999), op. cit., p. 90. y arquitectónico decimonónico en La Habana tras el derribo de las Murallas, la expansión urbana y el asentamiento del ferrocarril como medio de transporte ${ }^{228}$. En este marco general, las Ordenanzas de Construcción de 1861 influirían notablemente en el desarrollo de las nuevas áreas urbanas y, por ende, en la construcción de las fábricas tabacaleras de iniciativa privada, que adoptarían el estilo neoclásico de la arquitectura habanera decimonónica.

De esta forma, el tipo de palacio habanero sería adoptado por las nuevas fábricas de tabacos, que adecuarían el esquema organizativo del mismo para adaptarlo a la función productiva. De igual forma, las ordenanzas urbanas permitían una suerte de mimetización de las fábricas tabacaleras en áreas de nueva creación que promulgaban un estilo neoclásico que abandonaba las fórmulas barrocas coloniales. $\mathrm{Su}$ ubicación en las principales arterias creadas con la expansión urbana y la riqueza compositiva de su formulación lingüística en fachada les otorgaron un carácter relevante inusual en un edificio industrial.

\section{El caso de Ilang-Ilang}

Especial atención merece también el caso de las fábricas tabacaleras establecidas en Filipinas. Pese a la larga relación comercial con la colonia asiática y a la existencia de documentación planimétrica sobre proyectos de construcción de fábricas tabacaleras en la capital filipina $^{229}$, al objeto de la presente investigación cabe destacar el proyecto de construcción de la fábrica La Flor de la Isabela inaugurada en 1885 tras el desestanco del tabaco en Filipinas ${ }^{230}$ de 1883 y la posterior creación de la Compañía General de Tabacos de Filipinas ${ }^{231}$.

La citada fábrica se construyó en Ilang-Ilang en el término jurisdiccional de San Fernando Dilan, junto al estero de San Marcelino. Esta ubicación permitía la disposición de un embarcadero propio al que llegaban embarcaciones menores que se conectaba a la fábrica mediante un ferrocarril que facilitaba el transporte de materias primas y elaborados. El diseño arquitectónico del complejo fabril se realizó con

\footnotetext{
228 Señala Carlos Venegas la existencia previa de la Real Factoría de Tabacos en la zona portuaria dieciochesca puesto que "el Arsenal fue ubicado dentro de un recinto propio adicionado al sur de la muralla terrestre entre 1736 y 1740, y a su lado se hallaba el muelle de Tallapiedra con la localización de la Real Factoría de Tabacos, monopolio real. Ambos establecimientos llegaron a desempeñar las actividades más importantes de la bahía después de las fortalezas, y desde ellas se ejerció un control sobre los cortes de madera y el tabaco, recursos lejanos diseminados por toda la Isla, que aumentó la irradiación económica de la ciudad" VENEGAS, C. (2006) "Puerto, arquitectura y ciudad en La Habana colonial" en Arquitectura y Urbanismo, vol. XXVII, nº 1, La Habana: ISPJAE, pp. 14-23.

${ }^{229}$ En el Archivo General de Indias se custodia el "Plano de la fábrica de puros de Manila" que data de 1832 (ESAGI-41091-UD-1931454-ES-AGI-41091-UD-18970) y cuyas trazas recuerdan a la posterior fábrica "La Flor de la Isabela", que gozaría de mayor orden y racionalización en términos de diseño arquitectónico.

230 Ver RODRIGO Y ALHARILLA, M. (2009) "Del desestanco del tabaco a la puesta en marcha de la Compañía General de Tabacos de Filipinas (1879-1890)" en Boletín Americanista n 59, pp. 199-221. Sobre el caso particular de Filipinas, especialmente la Compañía General de Tabacos de Filipinas, se recomienda también la consulta de GIRALT I RAVENTÓs, E. (1981) La Compañía General de Tabacos de Filipinas, 1881-1981, Compañía General de Tabacos de Filipinas; y GONZÁLEZ, D. (1998) "La Compañía Arrendataria de Tabacos y el mercado filipino, 18871918" en Revista de Indias, vol. 58, n⿳0 213, pp. 429-447.

231 Sobre este particular, ver COMÍN COMÍN, F. y MARTÍN ACEÑA, P. (1999), op. cit., p. 90; y RODRIGO Y ALHARILLA, M. (2009) op. cit., p. 213.
} 
arreglo a los avances técnicos de la época ${ }^{232}$, poniendo especial atención en la prevención de los posibles daños que podrían ocasionar los frecuentes seísmos y huracanes de la zona. Destaca, así mismo, el interés de este edificio en sus trazas similares al tipo fabril ideado por Eugène Rolland en la Francia decimonónica, mediante la vertebración de los espacios productivos en un cuerpo frontal de honor y diversos pabellones perpendiculares entre los que se dispusieron amplios patios.

232 Juan Alberto Berni González, vitófilo, ha publicado en su página web abundante información sobre la historia de la producción del tabaco, en la que refiere sobre la fábrica filipina: "era de forma rectangular, de 180 x 121 metros y una superficie de $21.870 \mathrm{~m}^{2}$ distribuidos en dos pisos; contaba con seis naves formando tres patios interiores. La distribución de las distintas actividades en las naves estaba pensado para disminuir largos desplazamientos y facilitar la manipulación. Según los planos iniciales diseñados por el ingeniero Villemer, la fábrica podría albergar con holgura a 3.000 mujeres y 1.500 hombres." www.jaberni-coleccionismo-vitolas.com [acceso el 21-09-2015]. 



\section{LAS FÁBRICAS DE TABACOS EN ESPAÑA: PROYECTOS Y FUNDACIONES FABRILES DE LA UNIVERSAL ADMINISTRACIÓN A TABACALERA S.A. (1731-1945)}

3.1 Consideraciones acerca de la selección de casos estudio y criterios de análisis

3.2 Las primeras fundaciones fabriles

3.2.1 La Real Fábrica de Tabacos de Sevilla (1620-1950)

3.2.2 La Fábrica de Tabacos de Cádiz (1741-1985)

3.3 La primera generación de fábricas del S.XIX

3.3.1 La Fábrica de Tabacos de Alicante (1801-2001)

3.3.2 La Fábrica de Tabacos de La Coruña (1804-2002)

3.3.3 La Fábrica de Tabacos de Madrid (1809-2000)

3.4 La segunda generación de fábricas del S.XIX

3.4.1 La Fábrica de Tabacos de Santander (1822-2002)

3.4.2 La Fábrica de Tabacos de Gijón (1823-2002)

3.4.3 La Fábrica de Tabacos de Valencia (1828-2001)

3.5 La tercera generación de fábricas del S.XIX: los comienzos de la Compañía Arrendataria de Tabacos

3.5.1 La Fábrica de Tabacos de San Sebastián (1878-2003)

3.5.2 La Fábrica de Tabacos de Logroño (1890-1978)

3.6 Fábricas tardías del S.XX: las últimas intervenciones de la Compañía Arrendataria de Tabacos

3.6.1 La Fábrica de Tabacos de Tarragona (1923-2007)

3.6.2 La fábrica de Tabacos de Málaga (1923-2002)

3.1 Consideraciones acerca de la selección de casos estudio y criterios de análisis

Los resultados arrojados por el análisis llevado a cabo en la presente investigación responden a la casuística de las fábricas tabacaleras fundadas o construidas entre mediados del S.XVIII y mediados del S.XX, correspondientes a la época de la gestión directa de la Renta de Tabacos por parte de la Corona -y posteriormente del Estado- en 1731, y a la cesión del arriendo sobre el monopolio a la Compañía Arrendataria de Tabacos entre 1887 y 1945. Todos los casos estudio del periodo acotado comparten una correspondencia en términos arquitectónicos con la evolución del espacio productivo de carácter manufacturero hacia una mecanización que tendría su máximo desarrollo a partir en el último tercio del S.XX.

Son muchos los criterios en torno a los cuales se pueden analizar las fábricas de tabacos objeto de la presente investigación, desde su evolución histórica común, su agrupación en generaciones de fábricas, la tipología a la que pertenece el edificio en el que se introduce la producción, el proyecto arquitectónico de nueva planta o la adaptación a un edificio preexistente o el estudio transversal de las distintas fábricas 
atendiendo a las etapas edificatorias que se relacionan con el momento histórico del proceso productivo -la época manufacturera, las reformas de la CAT y su incipiente mecanización, el periodo de guerra y posguerra, el desarrollismo de la década de los 60 y 70 con Tabacalera o el periodo final hacia la privatización del sector-

Al objeto de la presente investigación, se ha optado por presentar cronológicamente los diversos casos estudio agrupados en las distintas generaciones en que fueron fundados pormenorizando su casuística en el periodo acotado en la presente investigación y atendiendo a las dimensiones de interpretación que tendrán gran importancia en los capítulos siguientes: entorno, arquitectura, espacio productivo y dimensión humana. Todos ellos se introducen con un epígrafe relativo a la historia de la fábrica que permite contextualizarla en el marco general del monopolio hacendístico del tabaco y en relación a las restantes unidades fabriles del mismo. De esta forma, se permite desgranar las características comunes a todas ellas y los paralelismos que a lo largo del tiempo desembocarán en la definición de unos invariantes arquitectónicos proyectuales comunes. No hay que olvidar que en este recorrido cronológico la secuencia de aparición de las fábricas tabacaleras es gradual, pero también su continuidad o cierre, y que las diversas fundaciones o proyectos fabriles corresponden a distintas etapas históricas de la secuencia evolutiva de la producción.

\subsection{Las primeras fundaciones fabriles}

Durante los primeros momentos de la producción tabacalera en España, la actividad fabril se concentraría en la fábrica hispalense, fundada a principios del S.XVII y que sería la primera de su tipo a nivel mundial. Esta primera fundación tendría su explicación en la importancia de Sevilla como principal puerto comercial de conexión con el continente americano y al inicio del consumo tabacalero, que desembocaría en la fundación de un establecimiento en pleno núcleo urbano consolidado conocido como Fábrica de San Pedro. La producción inicial correspondería a la elaboración de rapé o polvo de tabaco para aspirar, por lo que los requerimientos espaciales de la producción diferían de las características que más tarde desarrollarían los proyectos fabriles de mediados del S.XVIII hasta principios del S.XX.

Esta primera fábrica, que se configuraba como un conjunto de espacios resultantes de la adaptación improvisada de un caserío a la producción tabacalera, agrupaba oficialmente toda la producción del reino. Sin embargo, pronto se vio necesario el traslado de la misma a un edificio más adecuado al volumen productivo alcanzado, y localizada extramuros de acuerdo a los preceptos de la época. La construcción de la Real Fábrica de Tabacos de Sevilla -o Fábrica de San Diego, para distinguirla de la anterior-, coincidiría con un cambio importante de índole administrativa sustancial para la producción tabacalera en España, con el establecimiento de la Universal Administración de la Renta del Tabaco en 1731, según la cual quedaba bajo los auspicios de la Corona y el Estado, adscrita al Ministerio de Hacienda. 
Pronto se impuso el consumo de tabaco de humo o torcido entre las clases populares, teniendo que recurrir a la fundación a mediados del S.XVIII de una fábrica filial sita en Cádiz para el desarrollo de dichos elaborados. La popularización de este tipo de labores frente al rapé, desembocaría en la adopción de la producción gaditana como sistema modelo para la fábrica hispalense y para las fundaciones fabriles que se sucederían a lo largo del S.XIX dentro de la expansión geográfica de las fábricas tabacaleras como estrategia de control territorial.

\subsubsection{La Real Fábrica de Tabacos de Sevilla (1620-1950)}

\section{Contexto histórico hasta su cierre}

La historia de la industria tabacalera está fuertemente ligada a la ciudad de Sevilla en su condición de principal puerto comercial con el continente americano en la época colonial, como localidad receptora de la hoja del tabaco y pionera de la manufactura tabacalera cuyos orígenes se remontan a inicios del S.XVII. Si bien fue Fray Bartolomé de las Casas el primero en referir la hoja de tabaco en un documento escrito, se sabe que el primer cultivador fue el médico y farmacólogo sevillano Nicolás Monardes a mediados del S.XVI entre 1550 y 1554, evidenciando el primer uso medicinal y ornamental de la planta traída del continente americano. De esta forma, la importación del tabaco y su entrada en la península a través de la ciudad hispalense provocó la proliferación de plantaciones de tabaco y pequeñas instalaciones para su manufactura con el inicio de su consumo, fundamentalmente en la variedad de polvo o molida.

La ciudad hispalense tuvo un importante papel en la historia de la industria tabacalera y en las vicisitudes por las que pasó la regulación administrativa sobre la producción y venta del tabaco. Estas estaban fuertemente sujetas a los intereses, primero de la Corona de los Austrias, y después de la de los Borbones con la consolidación de las medidas de la anterior dinastía. El papel principal de Sevilla como centro neurálgico se justificaba por establecerse como la ciudad por excelencia para el intercambio con las colonias americanas. No en vano, ya en 1503 se crearía la Casa de la Contratación fortaleciendo la exclusividad de la ciudad hispalense en el comercio con las colonias americanas. El arraigo del consumo y comercio de los productos tabacaleros y el establecimiento de la fábrica de San Pedro a inicios del S.XVII, confirmarían la relevancia de Sevilla en el ciclo comercial y productivo del tabaco, que se veía coadyuvada por la mayor proximidad de su población a los productos venidos de América, incrementando el número potencial de consumidores y, por tanto, la expansión económica de la industria tabacalera ${ }^{1}$.

\footnotetext{
${ }^{1}$ Rodríguez Gordillo apunta las características de la red distribuidora del producto tabacalero que contaba con un entramado para la distribución de las labores tabaqueras con dos tercenas "de la fábrica" y "de Triana", y 31 estancos o estanquillos. En los últimos lustros del S.XVII se produciría una fuerte expansión de éstos últimos y una destacada remodelación, adquiriendo los establecimientos nombres que harían referencia a su emplazamiento en la ciudad. RODRÍGUEZ GORDILLO, J. M. (2007) op. cit, pp. 63-64.
} 


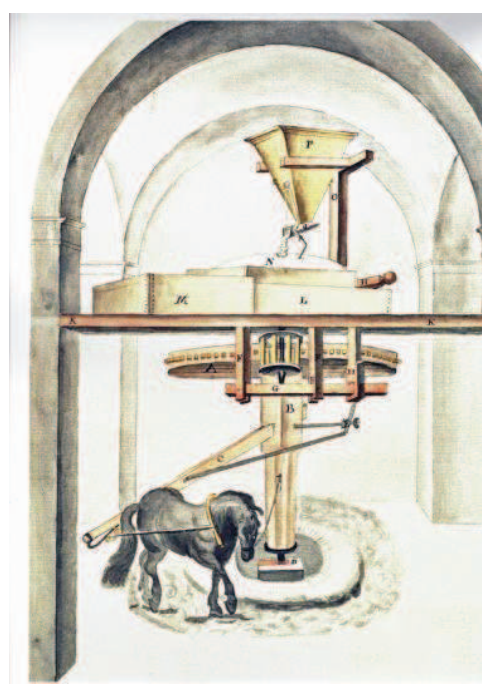

Figura 3.1. Funcionamiento de uno de los molinos de la fábrica sevillana en sección según Juan

Sardinero, en RODRÍGUEZ GORDILLO, J. M. (2005) op. cit., p. 91.

\section{Historia de la fábrica de tabacos: la Fábrica de San Pedro}

La primera fábrica de tabacos del mundo occidental se instaura en Sevilla hacia 1620 en un conjunto de casas cercanas a la iglesia de San Pedro a iniciativa de Jorge Bautista Carrafa ${ }^{2}$. Ya en 1684 se postulaba como centro y cabecera de la renta de tabacos española ${ }^{3}$, no sin ciertas vicisitudes que implicarían sucesivas ampliaciones del establecimiento debido a la expansión de la producción en el mismo y al carácter de improvisación que imperaba en su adaptación a una construcción preexistente.

Además de constituir el establecimiento principal de elaboración del producto tabacalero, la fábrica se instauraría como la principal manufactura de la urbe hispalense. Para la instalación de la primera fábrica, se concentró toda la actividad en un único inmueble disponiendo los diversos talleres y obradores de tabaco existentes en la ciudad en una agrupación de casas. No tardaron en sucederse las protestas de los vecinos ante las molestias producidas por esta actividad, por lo que se resolvió trasladar la producción y concentrarla en un nuevo recinto. El lugar elegido fue un caserón que había servido como casa de comedias y albergue de mujeres de mala reputación cercano a la iglesia de San Pedro de la que esta primera fábrica tomaría su nombre. La necesidad de expansión espacial de la producción motivaría la anexión de los inmuebles aledaños convirtiendo la primera fábrica hispalense en un conjunto de casas que pasaría a conocerse como "Casas de la Galera o Fábrica de San Pedro".

La principal variedad producida en la fábrica hispalense era el tabaco polvo para el que se necesitaban fundamentalmente molinos movidos por sangre que molturasen la hoja seca de tabaco hasta conseguir la textura de un polvo fino o rapé. De hecho, como se verá más adelante, el proyecto de la Real Fábrica de Tabacos o Fábrica de San Diego fue concebido para albergar los espacios productivos de este tipo de elaboración, de forma que la manufactura del cigarro o tabaco torcido no fue preponderante hasta el último tercio del S.XVIII. Sin embargo, ya en las primeras décadas del S.XVIII la manufactura de cigarros había alcanzado una cierta independencia, de forma que se consolidaron ambos tipos de labores y se hubo de diferenciar ambas manufacturas en 1701. Esta división se acentuaría con el transcurso de los años hasta el punto de que, tras la elaboración casi exclusiva de tabaco en polvo durante el S.XVII, esta cedería su posición privilegiada a favor del tabaco liado o torcido a lo largo del S.XVIII, hasta inclinar la balanza de la producción hacia este segundo tipo de elaboración a finales del S.XVIII y principios del S.XIX.

Como se comentaba anteriormente, el establecimiento de la Universal

\footnotetext{
2 RODRÍGUEZ GORDILlO, J. M. (2005) op. cit., p. 19. Para el desarrollo del caso sevillano se seguirá especialmente esta publicación y MORALES SÁNCHEZ, J. (1991) op. cit. Se recomienda la consulta de la investigación sobre la figura de Jorge Bautista Carrafa en BELVIS COSTES, F. X. (2012) "En torno a "J." Bautista Carrafa, primer fabricante de tabaco" en Tiempos modernos: Revista Electrónica de Historia Moderna, vol. 7, $\mathrm{n}^{\circ}$ 25, pp. 1-33.

${ }^{3}$ AGUILÁ SOLANA, I. (2006) op. cit., p. 98.
} 
Administración en 1731 supuso la homogeneización del sistema administrativo en todo el territorio que constituyó una innovación trascendental en la organización tradicional de la Hacienda española, dado que la manufactura del tabaco había sido gestionada hasta el momento por arrendadores particulares que pujaban por la misma. Este hecho supuso la continuidad y afianzamiento de la hegemonía manufacturera de la fábrica sevillana de San Pedro que mantuvo esta situación hasta su traslado definitivo entre 1758 y 1760 a la fábrica de nueva planta que se construyó extramuros de la ciudad hispalense.

\section{Historia de la fábrica de tabacos: la Fábrica de San Diego}

A comienzos del S.XVIII la Fábrica de San Pedro evidenciaba sus carencias espaciales para los requerimientos demandados por una producción manufacturera en expansión como era la del tabaco. De esta forma, en 1725 se ordena la construcción de un nuevo edificio que reuniese las características necesarias para albergar la producción tabacalera y permitir su natural crecimiento espacial. Inicialmente, se valoró la posibilidad de concentrar la producción nuevamente en un edificio existente, pero dotado de una mayor amplitud y diafanidad, en lo que llegaría a ser una práctica habitual en las fundaciones fabriles tabacaleras a lo largo del S.XIX. Para esta empresa se consideraron diversos edificios, entre ellos las antiguas atarazanas, muy próximas a la Torre del Oro y el entorno de la catedral ${ }^{4}$. Sin embargo, tras el fracaso de esta primera opción, se resolvió, finalmente, proyectar un edificio de nueva planta ex profeso que reuniese las condiciones idóneas para el desarrollo de la producción de una real fábrica, así como todos los adelantos técnicos alcanzados en aquellos momentos. Para ello se eligieron como emplazamiento los terrenos colindantes al Colegio de San Telmo que habían pertenecido anteriormente al Convento de San Diego, previa adquisición a sus propietarios.

El nuevo proyecto de fábrica tabacalera concentraría gran parte de los esfuerzos de la Renta a lo largo del S.XVIII. Pese al entusiasmo volcado en la construcción de la nueva fábrica y a la disposición de ingentes recursos para la consecución de la obra en un corto espacio de tiempo, las expectativas no pudieron estar más alejadas de la realidad, dado que transcurrieron tres décadas desde el inicio de la construcción, en el año 1728, y la puesta en marcha de la producción en la nueva fábrica, entre junio y agosto de 1758. De esta forma, tras la culminación de la construcción de las dependencias fabriles, transcurrieron décadas hasta que el recinto se hubo rematado con todos sus elementos en el año 1770 con la finalización de la capilla, la cárcel, las viviendas y el foso de resguardo.

Mientras el nuevo centro fabril se construía, la Fábrica de San Pedro continuó en funcionamiento y, dado el dilatado periodo que tomó la construcción de la nueva fábrica, hubo de ser objeto de sucesivas mejoras y ampliaciones para satisfacer la demanda de producto

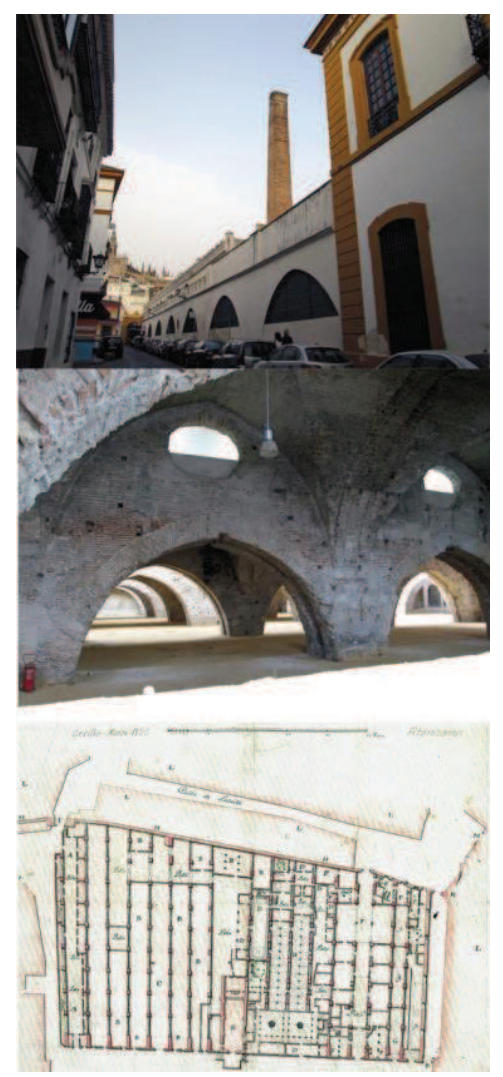

Figura 3.2. Antiguas atarazanas de Sevilla en la actualidad, 2015; y planimetría de 1725 , en RODRÍGUEZ GORDILLO, J. M. (2005) op. cit., p. 45.

\footnotetext{
${ }^{4}$ Sobre este particular, ver RODRÍGUEZ GORDILLO, J. M. (2005) op. cit., pp. 45-51; “Aspectos arquitectónicos de las antiguas fábricas de tabacos" en MORALES SÁNCHEZ, J. (1991) op. cit., pp. 11-21; y "El primer proyecto sobre nuevas fábricas" en MORALES SÁNCHEZ, J. (1991) op. cit., pp. 22-82.
} 
tabacalero hasta que las nuevas instalaciones fuesen operativas. De hecho, el traslado final de la Fábrica de San Pedro se prolongaría por espacio de dos años, desde junio de 1758 hasta abril de 1760, bienio durante el cual ambas instalaciones solapan su funcionamiento.

Se ha hecho referencia anteriormente al proyecto frustrado de ubicación de la nueva fábrica en un edificio existente en la ciudad, concretamente en las atarazanas. El ingeniero militar Jorge Próspero Verboom ${ }^{5}$ fue el encargado de realizar la inspección de dicho inmueble con objeto de valorar su idoneidad para la instalación de la nueva fábrica de tabacos hispalense. Sin embargo, su examen determinó que se había hallado abundancia de agua en la cimentación y que esta humedad provocaría grandes inconvenientes a la manufactura de tabacos, dictaminando que el inmueble se debía construir en otro lugar6.

Una vez resuelta la construcción de una fábrica de nueva planta en el emplazamiento cercano al Colegio de San Telmo, fue el propio Verboom el que sugirió el encargo del nuevo proyecto al ingeniero militar Ignacio Sala $^{7}$ que anteriormente se había ocupado de la ampliación de las instalaciones de la Fábrica de San Pedro y que era uno de los principales representantes del Cuerpo de Ingenieros Militares, institución que se encargaría de la renovación de los planteamientos arquitectónicos en España en numerosos proyectos ejecutados en la etapa dieciochesca. La concepción y redacción del proyecto se demoraría por espacio de dos años y medio, desde junio de 1725 hasta su presentación en enero de 1728, lo que testimonia la gran importancia y entidad otorgada a esta fábrica que se instauraría como buque insignia de la manufactura tabacalera española.

Si bien los aspectos arquitectónicos y la significación de los diferentes proyectos concebidos en torno a la figura de la Real Fábrica de Tabacos de Sevilla serán pormenorizados en epígrafes siguientes, resulta pertinente dedicar este espacio a la explicación de las vicisitudes por las que pasó el proyecto y a los diversos autores que en el mismo participaron.

\footnotetext{
5 Jorge Próspero de Verboom (1665-1744) ingeniero militar de origen flamenco, fundó el Real Cuerpo de Ingenieros en 1711 y fue una figura importante en la construcción de diversos proyectos de carácter militar, llegando a ser gobernador de la ciudadela de Barcelona. Ver MUÑOZ CORBALÁN, J. M. (2015) Jorge Próspero Verboom. Ingeniero militar flamenco de la monarquía hispánica, Madrid: Fundación Juanelo Turriano.

${ }^{6}$ Cabe recordar en este punto que las labores de manufactura del tabaco siempre han requerido espacios con unas condiciones determinadas de luz, temperatura y ventilación, dado que la humedad o el calor podían producir fermentaciones parciales indeseadas en la hoja de tabaco o la propia putrefacción de la misma, estando la humectación requerida para el proceso totalmente controlada según la fase de elaboración y procediéndose a secados intermedios -como en la fase de oreo, que eliminaba la humedad excesiva producida por la moja-

${ }^{7}$ Ignacio Sala y Garrigó (1686-1754) "tuvo una dilatada experiencia constructiva y militar durante la primera mitad del S.XVIII, la cual le valió el reconocimiento de la monarquía hispana, conocedores de su protagonismo en las fortificaciones de la ciudad de Cádiz y su entorno [...] Tras su experiencia en combate pasó a formar parte del Real Cuerpo de Ingenieros bajo la tutela de Jorge Próspero de Verboom [...] No obstante, el ingeniero vio interrumpidos sus trabajos gaditanos para ocuparse de los proyectos de la Real Fábrica de Tabacos de Sevilla. Desde 1726 hasta 1731 permaneció en este cargo, hasta que nuevamente fue requerido en la plaza de Cádiz". CRUZ FREIRE, P. (2013) "El ingeniero militar Ignacio Sala, gobernador y comandante general de Cartagena de Indias. Noticias de su pase a Indias y de su labor en las defensas de la ciudad" en Laboratorio de Arte, n²5, pp. 469-481.
} 
El primer proyecto para la fábrica, que sentaría las bases para las concepciones posteriores de sus sucesores, fue el del ingeniero militar Ignacio Sala. Los primeros trabajos fueron realizados, de igual forma, bajo la dirección del propio Sala, comenzando en 1728 la excavación de los cimientos y desarrollándose con normalidad hasta 1730. Dado que la experimentación con nuevos tipos de molinos en la Fábrica de San Pedro había resultado un éxito, puesto que se había demostrado que este sistema aumentaba notablemente la producción con una disminución del esfuerzo empleado ${ }^{8}$, la nueva fábrica estaba obligada a elevarse respecto a la cota inicialmente señalada dado que el invento implicaba el empleo de molinos con dos muelas a distintas alturas. Este hecho generó una polémica que instó a Sala a crear un tercer cuerpo en sección, como se verá en el análisis arquitectónico, lo que le acarreó no pocos enfrentamientos con los responsables de la Renta. Finalmente, el propio ingeniero Verboom, inicial valedor de Sala, emitió un informe negativo a la solución adoptada por este último, subrayando la falta de adecuación del edificio a las mejoras tecnológicas, la mala circulación de aire que generaba el diseño y la poca funcionalidad de la distribución, incidiendo en el escaso espacio propuesto para las viviendas en términos de habitabilidad ${ }^{9}$. De igual forma, aconsejaba un aumento de la altura total del edificio a tres plantas, así como la eliminación del ochavamiento del patio central y la ampliación de los corredores que desembocaban en el mismo.

Tras la destitución de Sala, en septiembre de 1731 se resolvió el encargo de un nuevo proyecto al ingeniero Diego Bordick ${ }^{10}$. Pese a este nuevo nombramiento y a la continuación de las obras con arreglo al nuevo proyecto de Bordick de 1734 -deudor en muchos aspectos, como se verá más adelante, del proyecto inicial bajo la autoría de Ignacio Sala- a mediados de 1735 el ritmo del trabajo decae y el proyecto comienza a estancarse.

Desde finales de 1730 a 1733 la actividad, en lo que se refiere a cantería es muy grande [...] fundamentalmente para el aplantillamiento de las pilastras, las zapatas y parte del zócalo modificado [...] Esta intensa actividad constructiva irá "in crescendo" hasta finales de 1733, complementándose la redacción de los "asientos"

\footnotetext{
8 Recordemos que en este periodo histórico de la Renta el consumo de tabaco torcido o liado aún no había experimentado la relevancia que tendría a finales del S.XVIII y, por tanto, la nueva fábrica hispalense nacía con la voluntad de acoger una producción manufacturera de tabaco en polvo o rapé.

9 "En 1731 fue retirado de la dirección por las quejas que contra el proyecto hizo el Superintendente de la Fábrica, Sebastián Caballero Enriquez [...] que la planta baja no tenía luz suficiente, que las dependencias no estarían bien ventiladas, que los entresuelos destinados a viviendas eran pequeños y que las fachadas del edificio estaban alejadas de las «reglas de la arquitectura», pues con toda lógica, Sala había planteado un edificio digno y noble, aunque su aspecto exterior fuera de fabril y no monumental, pues en realidad no era éste el que le correspondía al conjunto por su destino". CANTERA MONTENEGRO, J. (2012) "Aportaciones singulares de los ingenieros a la obra civil" en Revista de Historia Militar, $\mathrm{n}^{\circ}$ extra, 1, (ejemplar dedicado a: Los ingenieros militares en la historia de España. III Centenario de la creación del arma de ingenieros), pp. 13-32.

10 Diego Bordick Deverez de Langford (-1756) coronel de Infantería de origen flamenco, figuró en la dirección de la obra desde 1731 hasta 1737. Entre otras obras, realizó el proyecto de la batería y torre cubierta en Ranchería (Panamá) en 1731, el plano de un reductillo de una de las torres y resguardo de las cercanías de la plaza de Orán en 1736, el plano del frente principal de la plaza de Ceuta en 1737 y el proyecto para la expedición del sitio de Manhia (Argelia) en 1745. Paralelamente, como director de las obras de la Fábrica de Tabacos de Sevilla realizó los planos del proyecto en 1734 y 1736 y según Horacio Capel también realiza algunos planos en 1741, cuatro años más tarde de la destitución que refiere Rodríguez Gordillo. CAPEL SÁEZ, H. (1983) Los Ingenieros militares en España, siglo XVIII: repertorio biográfico e inventario de su labor científica y espacial, Barcelona: Universitat Barcelona, pp. 7778.
} 
para las primeras obras de albañilería [...] En cualquier caso, las obras de cimentación se van cerrando en las zonas más generales y, sin abandonar las que restaban, se comienzan las fundaciones de menor entidad, como podrían ser las de las áreas de viviendas situadas en el interior de las fábricas.

El progresivo avance de la construcción comenzará a sufrir perturbaciones a mediados de 1733 a causa de los problemas económicos surgidos por la prolongación de las obras. Parece seguro que hasta ese momento no se había comenzado siquiera la elevación del cuerpo del edificio, y que restaban por hacer algunas partes de los fundamentos del cuerpo principal ${ }^{11}$.

Según Morales Sánchez, además del avance en la construcción del edificio y de la práctica finalización de las cimentaciones, en 1736 se completarían las instalaciones de agua y alcantarillado. No en vano, esto no evitó nuevamente un informe desfavorable que databa de 1737 en el que se cuestionaban las soluciones constructivas empleadas por el ingeniero Bordick. De esta forma, en el periodo de 1738 a 1750 se realizarían dos proyectos alternativos para la fábrica, sufriendo importantes cambios en la dirección de la obras.

En las fuentes se aducen problemas económicos de la Renta. En este contexto comienza a ponerse en entredicho el trabajo de Bordick y su equipo, principalmente por los motivos que acabamos de ver y por considerar los responsables de la Renta que se habían guiado por planteamientos en exceso teóricos, descuidando necesidades o realidades importantes. Para mediados del año 1737 sabemos que ya habían sido cesados tanto Bordick como su equipo ${ }^{12}$.

Este nuevo cambio en la dirección de la obra supondría un gran mazazo para el programa previsto en la misma, puesto que en mayo de de 1738 el Gobierno resuelve la paralización de las obras y cualquier trabajo relacionado con la nueva tabacalera sevillana hasta 1750 . Por tanto, se intuye que los problemas del proyecto no sólo se limitaban a desacuerdos sobre las características del mismo, sino también a una falta de recursos para afrontar una empresa de tal calibre en la construcción de una real fábrica dedicada a la manufactura del tabaco de proporciones monumentales. Hasta el momento sólo se había completado la cimentación y en algunas partes se había iniciado la disposición del zócalo, además de completarse el abovedamiento del río Tagarete, del que se hará referencia en epígrafes sucesivos.

Parte de esta paralización tiene también su explicación en las vicisitudes por las que atravesó la dirección de la obra y la concepción del proyecto durante las décadas sucesivas. Diego Bordick será sustituido por el arquitecto Vicente Acero ${ }^{13}$ que había estado ligado al

\footnotetext{
${ }^{11}$ MORALES SANCHEZ, J. (1991) op. cit., pp. 246-247.

12 RODRÍGUEZ GORDILLO, J. M. (2005) op. cit., p. 61.

13 Vicente Acero y Arebo (1675-1739) fue un arquitecto de origen cántabro entre cuyas obras más destacadas se encuentra el proyecto de la Catedral Nueva gaditana, siendo nombrado en octubre de 1721 director de la obra. La disparidad de criterios en torno a la cimentación de las torres le llevó a enfrentarse al cabildo de Cádiz, abandonando la obra en 1729. Entre sus intervenciones en catedrales también destaca la realizada sobre la fachada de la catedral de la localidad granadina de Guadix. Fue el autor del diseño de la entrada a la ciudad gaditana conocida como Puerta del Mar que fue ejecutada por Torcuato Cayón. Su colaboración con el ingeniero militar Diego
} 
proyecto del ingeniero Bordick desde sus comienzos, pero que fallece en 1739. Ante este nuevo contratiempo en la obra de la fábrica, los responsables de la Renta comienzan a abandonar su interés sobre la misma y optan por ocuparse de las necesidades de la aún activa Fábrica de San Pedro, que fue objeto de una última ampliación en el año 1740. Desde la paralización de las obras el 1 de mayo de 1738, el problema a resolver no consistirá en cómo deba desarrollarse la construcción, sino en decidir quién debe continuarla, habida cuenta de los sucesivos problemas experimentados tanto con los directores de obra como con su equipo. En este sentido, se establece que la línea a seguir serán las ideas proyectuales del recién destituido Bordick.

Finalmente, será el Marqués de la Ensenada el que reactive el plan con su llegada al Gobierno en 1743, aunque de nuevo se vería marcado por el cambio de reinado tras morir Felipe V y coronarse Fernando VI. Dado el retraso generado en la obra con los dos proyectos truncados de Sala y Bordick, y las constantes diferencias habidas entre los criterios de opinión de los autores y la administración de la Renta, se resuelve involucrar a esta última en el debate sobre el rumbo que debería seguir a continuación la obra, tratando de evitar la frecuente disparidad de criterio entre el proyecto y los fines perseguidos por el órgano monopolístico. Cualquier error o demora podría ser muy grave habida cuenta de que la obra se encontraba en un estado avanzado en cuanto a cimentación y proyecto de distribución de espacios.

El nuevo plan se acometería tras estudiar los nuevos informes y proyectos formulados por los administradores de la Renta y por los ingenieros Ventura Padierne y José Barnola, optándose por el de éste último y Félix Davalillo, y encomendando al propio Barnola la dirección del mismo ${ }^{14}$.

El ingeniero encargado de organizar los trabajos a partir de 1750 sería, pues, el ingeniero José Barnola contando con la ayuda de Félix Davalillo como responsable por parte de la Renta del Tabaco. Este último, como administrador general, redactaría un informe sobre la distribución de las funciones que acogerían los espacios de la fábrica, evitando con este procedimiento las diferencias de opinión entre los administradores, superintendentes locales y los ingenieros proyectistas, que desembocaban frecuentemente en la demora de las obras. De esta forma, aprovechando los trabajos que ya se habían completado, se continúa el proyecto en una dirección que marcaría de manera definitiva tanto la planta como el alzado, para lo cual el ingeniero Barnola se serviría de los resultados del informe antes mencionado.

Bordick durante el periodo en el que recayó sobre este último la obra de la Real Fábrica de Tabacos de Sevilla le llevaron a asumir la dirección de dicha construcción con la destitución de Bordick, hasta la fecha de su muerte en 1739. Sobre la relación de Vicente Acero con la Catedral Nueva de Cádiz, MARÍAS, F. (2007) "La Catedral de Cádiz de Vicente de Acero: La provocación de la arquitectura "crespa»" en Anuario del Departamento de Historia y Teoría del Arte (UAM), vol. XIX, pp. 79-103.

${ }^{14}$ RODRÍGUEZ GORDILLO, J. M. (2005) op. cit., p. 63. El ingeniero militar José Barnola trabajó entre 1731 y 1743 en los proyectos y obras del Arsenal de La Carraca en Cádiz. Desde 1749 a 1751 elabora los proyectos del frente de la Puerta de Tierra de Cádiz, compatibilizándola con su incorporación a la dirección de las obras de las fábricas de tabaco en 1750, año en el que diseña los planos del terreno en el que se asientan los cimientos de las mismas, contando como coautor con Félix Davalillo. Destaca el levantamiento de los planos que realizó de la villa de Puerto Real en Cádiz y el plano y perfil del baluarte de San Antonio y puerta de la Caleta en 1753. Ver CAPEL SÁEZ, H. (1983) op. cit, pp. 60-62. 
Las obras avanzan rápidamente, puesto que la portada, que era la parte más atrasada, estaría prácticamente acabada hacia mediados de 1755, dado que el 28 de septiembre de ese año se realizan ya los diseños de la escultura de la Fama, labor que comparten Van der Borcht y Cayetano Da Costa, asistidos por el aparejador Vicente Bengoechea ${ }^{15}$.

De igual forma, por Real Orden del 9 de agosto de 1750 se encomendará la dirección de la obra al ingeniero Sebastián Van der Borcht16, quedando bajo la jefatura de José Barnola que continuará realizando algunos diseños hasta su muerte en 1756. El tandém Barnola-Van der Borcht iniciaría la etapa final de las obras que se sucedió sin pausa pese a la muerte del primero y al cese del segundo en 1766 tras el motín de Esquilache en el que fue apartado de las obras de la real fábrica por el nuevo Ministro de Hacienda José de Muzquiz por su amistad con el ministro italiano. En esta etapa se continuó con la construcción del cuerpo principal de la fábrica, dando término al edificio principal que fue puesto en funcionamiento en 1758 , junto a la finalización de los patios en 1755 y la construcción de algunos elementos del entorno como la Puerta Nueva o de San Fernando en 1760, las viviendas que formaban la alineación opuesta en la calle de San Fernando en 1761 o la capilla y la cárcel en 1763.

Las obras contarían en ese momento con la importante participación de Vicente Catalán Bengoechea ${ }^{17}$, afamado experto en obra de cantería y que actuó como maestro mayor de las obras. Por último, otra figura importante en esta última fase de las obras sería el escultor portugués Cayetano da $\operatorname{Costa}^{18}$ autor de la portada de la fachada principal.

A la pareja Van der Borcht-Bengoechea le correspondió la construcción del núcleo fundamental del edificio, como es la crujía de la fachada principal, los patios, las galerías, gran parte del foso y los dos pequeños

${ }^{15}$ MORALES SANCHEZ, J. (1991) op. cit., p. 319.

${ }^{16}$ El ingeniero militar de origen flamenco Sebastián Van der Borcht (h. 1725-h. 1787) además de asumir la dirección de las obras de la Real Fábrica de Tabacos de Sevilla en 1750, realizó otros importantes encargos a lo largo de su vida como la restauración de la Torre del Oro y los Reales Alcázares tras el terremoto de Lisboa de 1755. Así mismo, es el autor de la portada de la Real Casa de la Moneda y del Palco Real de la Plaza de Toros de la Maestranza en la ciudad hispalense. Para más información POZO RUIZ, A. Sebastián van der Borcht (o van der Beer) arquitecto militar en http://personal.us.es/alporu/fabricatabaco/vanderborcht.htm\#biografia [acceso el 5-7-2015] y ESPIAU EIZAGUIRRE, M. (1986) "La fachada de la Casa de la Moneda de Sevilla, obra de Sebastián Van der Borcht" en Archivo Hispalense: Revista histórica, literaria y artística, tomo 69, n 212, pp. 193-196.

17 Vicente Catalán Bengoechea figuró como maestro mayor de la fábrica en un peritaje de la Capilla de San José realizada en 1754. "En calidad de experto en obras de cantería, fue autorizado a inspeccionar e incluso a reconstruir una serie de iglesias de la diócesis, construidas en sillería. Así en 1756 inicia la reconstrucción de la torre de la iglesia de Santa María de la Oliva de Lebrija (Sevilla); al año siguiente la iglesia y torre de Espera (Cádiz) y en 1758 dio las condiciones para la construcción de la torre y fachada de Santa María de Arcos (Cádiz)”. FALCÓN, T., BERNALES, J., VALDIVIESO, E., SANZ, M. J. y otros (1992) Patrimonio artístico y monumental de las universidades andaluzas. Sevilla: Universidad de Sevilla, p. 61.

18 Cayetano da Costa (h. 1711-1780) arquitecto retablista y escultor portugués del tercer cuarto del S.XVIII, desarrolló en Sevilla algunos de los conjuntos más notables de su época. Entre sus obras en la Real Fábrica de Tabacos destacan la fuente del patio principal, los remates de la fachada y la escultura de la Fama entre otros. Destacan otras obras como sus intervenciones en los retablos de la iglesia del convento de Santa Rosalía y los de la Colegial del Salvador, ambos en Sevilla. POZO RUIZ, A. Cayetano Alberto da Costa, escultor y retablista del siglo XVIII en http://personal.us.es/alporu/fabricatabaco/cayetanodacosta.htm [acceso el 5-7-2015] y PLEGUEZUELO HERNÁNDEZ, A. (1982) "Sobre Cayetano de Acosta, escultor en piedra" en Revista de Arte Sevillano, n², pp. 3542. 
edificios que finalmente se hicieron flanqueando la fachada principal: la capilla y la cárcel19.

En la época de entre-siglos, el frecuente colapso del abastecimiento de materias primas, la falta de caudales o la suspensión de pagos y actividades fueron consecuencia de la crisis económica surgida de los sucesivos conflictos, lo que provocaba una carestía de producto y el consiguiente recurso al contrabando entre la población. Además, el afianzamiento de los cigarros o labores de humo provocaron una transformación del enfoque dado a la producción del monopolio en la fábrica hispalense. Por una parte, durante el S.XIX se resuelve la creación de nuevas fábricas por todo el territorio peninsular que se dedicasen en exclusiva a la elaboración de cigarros o tabaco de humo para satisfacer la cada vez mayor demanda de este tipo de producto por la sociedad. Se tomará como modelo a tal efecto tanto el sistema productivo de la fábrica gaditana como su preferencia por el empleo de mano de obra femenina para la elaboración de cigarros.

De esta forma, se advierte que, pese a la relevancia como proyecto arquitectónico y la pretensión de convertir a la Real Fábrica de Tabacos de Sevilla en buque insignia y centro aglutinador de la producción del monopolio, su proceso productivo pronto queda obsoleto, teniendo que adaptarse a las nuevas pautas establecidas según las directrices de la Renta de Tabacos y acomodándose a los gustos del mercado. Por tanto, contrariamente a lo se suele asumir, la Real Fábrica de Tabacos de Sevilla no comenzó su actividad según el modelo productivo tabacalero que se impondría posteriormente en la manufactura del tabaco, sino que habría de adaptarse al nuevo sistema nacido con la fundación de la Fábrica de Tabacos de Cádiz a mediados del S.XVIII como filial especializada en la elaboración de tabaco de humo.

No obstante, desde la cesión del arriendo del monopolio a la Compañía Arrendataria de Tabacos a finales de 1887, la Real Fábrica de Tabacos de Sevilla ostentaría la condición de fábrica tabacalera de primera categoría junto a Madrid, Valencia y Alicante, perteneciendo a la segunda categoría las fábricas de Cádiz, La Coruña, Santander y Gijón, y ocupando la tercera categoría las fábricas vascas de Bilbao y San Sebastián, fundadas en 1878 tras la incorporación del País Vasco al Estanco del Tabaco.

Las vicisitudes de la fábrica de tabacos hispalense durante el periodo de gestión de la CAT desde la cesión del monopolio a dicha compañía hasta la Guerra Civil Española no difieren de las apuntadas en el estado de la cuestión sobre la historia del monopolio, sufriendo una progresiva pero lenta mecanización que se analizará en epígrafes siguientes en relación a la configuración del espacio productivo y su evolución. Cabe destacar que el sobredimensionamiento de la superficie fabril en relación a los espacios que finalmente fueron puestos en servicio para la actividad tabacalera, provocó como en muchas otras fábricas el empleo de parte del inmueble para otras actividades de distinto carácter, como fue la creación del cuartel en la parte oriental del edificio ${ }^{20}$.

${ }^{19}$ RODRÍGUEZ GORDILLO, J. M. (2005) op. cit., p. 63. 


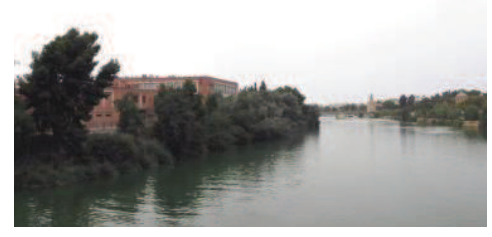

Figura 3.3. Fábrica de Tabacos de Los Remedios, 2015.

Tras la dura época de posguerra y la cesión del monopolio en 1945 a Tabacalera, se resuelve cerrar la Real Fábrica de Tabacos de Sevilla trasladando sus dependencias a un complejo de nueva construcción en la margen derecha del río Guadalquivir, en el barrio de Los Remedios. De esta forma, veía efectivo su cierre el primer gran edificio fabril tabacalero español que por su relevancia histórica y arquitectónica fue objeto de la mayor consideración por parte de las instituciones que velaban por la conservación del patrimonio y objeto de un interesante proyecto de reconversión en sede universitaria que será tratado en capítulos posteriores.

\section{Motivos estratégicos de la fundación fabril e implantación en su entorno}

Como bien señala Rodríguez Gordillo "son varios los factores que convierten a Sevilla en punto de interés del comercio tabaquero en la época"21. De un lado, Sevilla pertenecía a una región que experimentó un fuerte crecimiento en el volumen de suministros del tabaco durante las primeras décadas del S.XVII, dado que la ciudad hispalense se sumaba a las andaluzas Cádiz, Granada y Málaga como urbes con una fuerte ligazón al tráfico colonial, facilitando la entrada de tabaco a bajo precio que se veía coadyuvada por las prácticas contrabandistas. Además, contaban con una fuerte densidad de población como consumidor potencial del nuevo hábito. Por otra parte, Sevilla contaría ya desde el año 1620 con la primera industria tabacalera europea establecida en un caserío cercano a la iglesia de San Pedro.

El emplazamiento elegido para la Real Fábrica de Tabacos a principios del S.XVIII inició una nueva área de expansión para la ciudad, situándose entre el desaparecido convento de San Diego -del que tomaría su nombre para distinguirla de la precedente Fábrica de San Pedro y de la posterior Fábrica de Los Remedios-, el Colegio de San Telmo y las murallas del Jardín del Alcázar. El solar elegido se enclavaba en el cruce de cuatro caminos reales y, además de las condiciones de entorno creadas por el Guadalquivir y el arroyo Tagarete, se encontraba próximo a la Puerta de Jerez y a la huerta del Alcázar Real.

Sin embargo, no había sido la primera opción a considerar, puesto que inicialmente se pensó en ubicarla a la derecha de la Puerta de Jerez, en

${ }^{20}$ Por la fortificación del edificio y su ubicación estratégica en el acceso Sur de la ciudad, fue frecuente la presencia militar en el edificio a lo largo del S.XIX, concretamente en el ala Este que linda con el Prado de San Sebastián. Este uso militar del edificio fue siempre eventual hasta finales de la centuria, puesto que en 1883 se instala el Regimiento Montado de Artillería "Brunete" $\mathrm{n}^{\circ} 1$, precisamente en la zona Este del espacio fabril antes mencionada. Se le conocía como el "cuartel del foso" y cohabitó con la fábrica de tabacos hasta que en 1929 se finalizó el cuartel de Pineda. Poco después la fábrica volvería a ser la sede del Tercer Batallón del Regimiento de Carros de Combate "Alcázar de Toledo", así como el batallón C.C.C. no XXVI, que permanecería en el edificio hasta que en 1950 cesa la actividad en el mismo para iniciar las obras de reconversión en dependencias universitarias. POZO RUIZ, A. La Real Fábrica de Tabacos de Sevilla: Visión histórica general en http://personal.us.es/alporu/fabricatabaco/vision_general.htm [acceso el 3-5-2015].

21 Ver RODRÍGUEZ GORDILLO, J. M. (2002b) "El consumo de tabaco en Andalucía en la primera mitad del siglo XVIII” en RODRÍGUEZ GORDILLO, J. M. (2002b) op. cit., pp. 115-140. 
una posición más cercana al puerto, o reutilizar las antiguas Reales Atarazanas como inmueble existente del tejido urbano que por sus dimensiones y diafanidad podía resultar adecuado para tal función. Estas tres opciones - de las cuales se eligió la ubicación en los terrenos del convento de San Diego- bien diferentes entre sí, respondían a una serie de criterios comunes, tales como la cercanía al río, la ubicación en un emplazamiento extramuros de la ciudad y la proximidad al puerto y a los centros de poder capitalinos, así como la disposición del acceso principal en el mismo muro de la ciudad.

El ingeniero Ignacio Sala, primer proyectista de la fábrica, se atuvo desde un primer momento a la idea central de la necesaria proximidad del nuevo recinto al río.

Sin embargo, optaba por una ubicación algo más alejada de éste en claro beneficio de la amplitud de espacios que se podía alcanzar para el desarrollo del proyecto y de una mayor libertad de movimientos con relación a las extremas dificultades que se habrían tenido que afrontar en el entorno de las Atarazanas ${ }^{22}$.

No en vano, como apunta Julián Sobrino,

si reparamos en su situación urbana, calles angostas que les daban acceso, lejanía laberíntica respecto a las principales vías de comunicación y embarque de mercancías y materias primas, el puerto y la estación, la industrialización sevillana reviste las características de auténtica proeza ${ }^{23}$.

No obstante, la elección de Sala también planteaba serios problemas tales como la creación de una nueva conexión con la ciudad, así como el resguardo del recinto o la remodelación de los accesos del área urbana hacia el Sur. Según el plan presentado en 1728 por el propio ingeniero Sala,

este edificio necesita de una capacidad tal que no era bastante el sitio elegido a la derecha de la Puerta de Jerez, con que me pareció elegir por más propio y conveniente el sitio de la izquierda de la Puerta de Jerez entre San Telmo y San Diego, dejando la fábrica agregada a la ciudad por medio de las paredes del recinto, las cuales, quedando unidas con las murallas de la ciudad, cortan todas las comunicaciones y dejan más resguardada la fábrica, a la que se entrará por una puerta que se ha de abrir en la muralla ${ }^{24}$.

El emplazamiento elegido, como se apuntaba anteriormente, integraba el prado de San Sebastián y estaba cruzado por el arroyo Tagarete en su camino hacia el Guadalquivir, bordeando la muralla de la ciudad hasta su desembocadura junto a la Torre del Oro. Propiedad del Cabildo

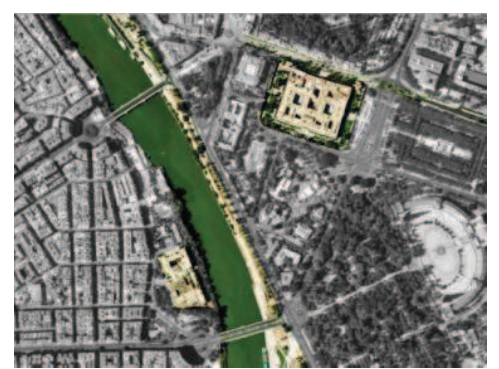

Figura 3.4. Relaciones del emplazamiento de la fábrica.

${ }^{22}$ En el caso de las Atarazanas, se incidía en la proximidad al centro urbano y que tuvieran su puerta principal en la propia muralla de la ciudad, destacando la ventaja que suponía su cercanía a la Catedral, la Aduana y la Casa de la Contratación. En relación al edificio, se destacaban su solidez y buena conservación en cuanto a obras y arcos junto a su capacidad suficiente. RODRÍGUEZ GORDILLO, J. M. (2005) op. cit., p. 54.

23 SOBRINO SIMAL, J. (1996) op. cit., p. 98.

24 RODRÍGUEZ GORDILLO, J. M. (2005) op. cit., p. 54, citando AFTS, DGR, Construcción de Nuevas Fábricas, 1727-1732, M. Pablo Díaz a Sebastián Caballero, Madrid, 28 de octubre y 4 de noviembre de 1727 y 27 de enero y 3 de febrero de 1728. 


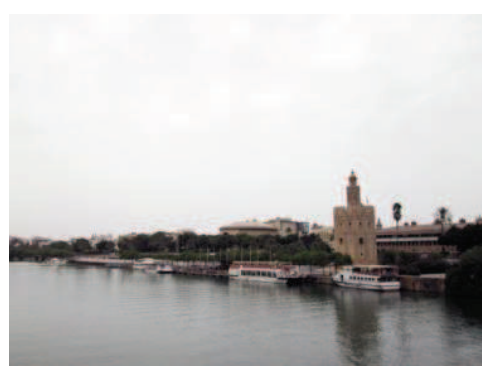

Figura 3.5. Vista del puerto histórico de Sevilla en la actualidad, 2015. municipal hispalense y de la Universidad de San Telmo, el lugar debía ser acondicionado para el nuevo centro fabril y la disposición urbanística que adecuaría el entorno.

De ese modo, el recinto de la fábrica quedaría delimitado por tres lados de tapia y la muralla de la ciudad en el cuarto. En esta última se debía abrir el acceso principal, que conectaría con el ámbito urbano a través de una estrecha calle de nueva apertura que se segregaría de la huerta de la Alcoba, que era parte del recinto del Alcázar. En la parte opuesta y mirando al Guadalquivir, plantea abrir una puerta que debía acoger el tránsito hacia el puerto ${ }^{25}$.

Una construcción de tal magnitud como la Real Fábrica de Tabacos requería una reinterpretación urbanística del área que remarcaría, junto a las proporciones y la monumentalidad otorgada a un edificio de carácter industrial, la relevancia de la representación de la monarquía en la urbe. Por otra parte, como apunta René Taylor, la Real Fábrica de Tabacos de Sevilla estaba llamada a ser el mayor edificio industrial durante la segunda mitad del S.XVIII y uno de los ejemplos más significativos de la historia de la arquitectura industrial. Durante las primeras décadas de su existencia, concentraría todo el monopolio tabacalero, configurándose para ello como una auténtica ciudadela fortificada, lo que preludiaría uno de los invariantes más notables del resto de inmuebles fabriles tabacaleros analizados en la presente investigación en cuanto a la disposición de elementos propios de las arquitecturas coercitivas. Inicialmente aislado del resto de la ciudad, cuyas murallas daban a la fachada principal, poseía un foso con tres puertas que constituían los puntos de control contra el contrabando.

Como señala Morales Sánchez, la significación otorgada tanto al edificio como a la ordenación urbanística que conllevaba su implantación no se reducía a una cuestión estilística, sino que formaba parte de las inquietudes principales de los ingenieros, especialmente por su interés en las relaciones territoriales, espaciales y de imagen de la ciudad. De ello dan cuenta las diferentes propuestas realizadas por los sucesivos proyectistas que intervinieron en la construcción de la Real Fábrica de Tabacos de Sevilla.

Tradicionalmente, los proyectos de carácter militar plantearían la necesidad de establecer una conexión entre arquitectura y lugar, que se complejizaría a medida que el conjunto se relacionase con la ciudad. "El lugar, las condiciones físicas del mismo, habían sido una de las preocupaciones más constantes en las reflexiones de los ingenieros, aunque no la habían planteado de forma explícita"26. De igual forma, esta condición se vería reforzada por la presencia de la muralla que influiría la localización y el trazado del proyecto, así como la presencia del arroyo Tagarete que necesariamente sería canalizado y abovedado para el propio provecho de la fábrica.

En el informe de Ignacio Sala de 1728, la solución de la relación de la

${ }^{25}$ RODRÍGUEZ GORDILLO, J. M. (2005) op. cit., p. 58.

${ }^{26}$ MORALES SANCHEZ, J. (1991) op. cit., p. 103. 
fábrica con la ciudad pasaría por la formalización de una tapia y una muralla a modo de conexión de la fábrica con la puerta de Jerez. Morales Sánchez apunta que en la documentación consultada para su investigación se pone claramente de manifiesto el deseo de los responsables de formalizar y construir uno de los dos frentes principales del edificio de manera que su intervención fuese visible desde lejos en la ciudad. De igual forma, se establecería una línea de fuga que partiría del edificio fabril y, pasando entre el convento de San Diego y el colegio de San Telmo, alcanzaría el meandro del Guadalquivir.

Por su parte, Diego Bordick elaboraría un proyecto en el que se sentaron las bases de lo que sería la relación del edificio con la ciudad, abordando la dimensión real de la formalización de los límites de la ciudad hispalense.

La primera innovación que podemos constatar consiste en la eliminación de la tapia que rodeaba al edificio de la fábrica y que planteaba tantas ambigüedades en el diseño de Sala. Este ingeniero impedía con ello que el edifico se proyectara hacia fuera. Bordick sin embargo, empujado por la comprobación que requería su proyecto, invertirá la relación [...]

Aunque Bordick había admitido en un principio lo propuesto por Sala para este punto, la ejecución del paso a través de la muralla que iba desde el espacio frontal de las fábricas a la calle que se iniciaba detrás de aquélla se detuvo al poco tiempo de iniciarse las obras [...] Entre otras razones ésta sería la causa de que Bordick propugnase una solución bastante diferente que no afectaba materialmente a la muralla histórica de la ciudad [...]

Ello implicaba que la solución que fuese adoptada tendría que evitar que el nuevo espacio que se estaba construyendo quedara discontinuo y puntual en el contexto de la periferia de la Sevilla del XVIII; es decir, tendría que resolver satisfactoriamente el nuevo proyecto y la ciudad ${ }^{27}$.

La implantación de la Real Fábrica de Tabacos de Sevilla se trataba, pues, de un problema de resolución de bordes y de una reflexión sobre la relación de un proyecto extramuros con la ciudad y la formalización de sus conexiones, o más concretamente de la ligazón entre la periferia y la ciudad, desde la escala territorial hasta la escala del tejido consolidado.

De esta forma, la eliminación de la tapia del proyecto de Sala suponía replantear la relación entre arquitectura y territorio en el proyecto de Bordick. La presencia del convento de San Diego y el Colegio de San Telmo más próximos a la margen del río que el nuevo edificio, obligaría a establecer una relación jerárquica respecto a los mismos, por lo que se decidió elevar la cota de arranque de la fábrica una vara más de lo que hizo Sala. Por otro lado, se establecería un canal que prolongaba el eje de composición de la fábrica hacia el río, extendiendo el recorrido principal de distribución interna de la fábrica hacia el territorio. Este canal organizaba los edificios circundantes a través de una simetría planteada por su eje de desarrollo, materializando una intención urbanizadora del área que constituía el acceso hacia el núcleo urbano

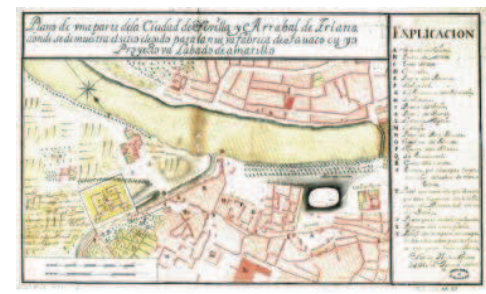

Figura 3.6. Emplazamiento del proyecto de Ignacio Sala de 1728, en RODRÍGUEZ GORDILLO, J. M. (2005) op. cit., p. 53.

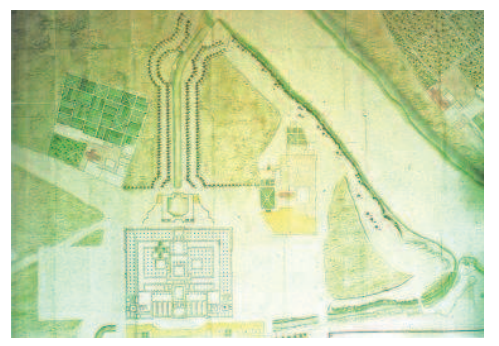

Figura 3.7. Plano de situación del proyecto de Diego Bordick de 1741, en MORALES SÁNCHEZ, J. (1991) op. cit., p. 237.

\footnotetext{
${ }^{27}$ MORALES SANCHEZ, J. (1991) op. cit., p. 212.
} 


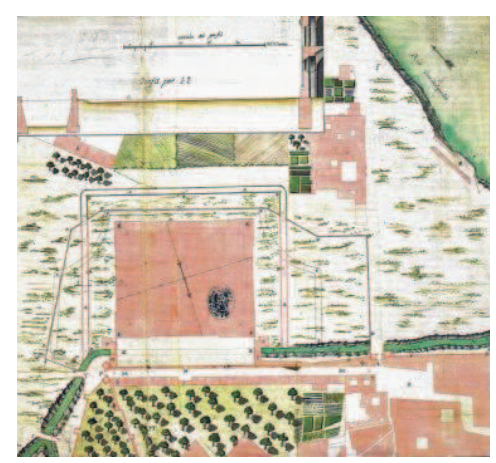

Figura 3.8. Plano de emplazamiento del proyecto de Sebastián Van der Borcht de 1760, en RODRÍGUEZ GORDILLO, J. M. (2005) op. cit., p. 67.

hispalense desde el Sur. De igual forma, se ponía en valor la presencia del río planteando nuevas perspectivas en la relación del nuevo edificio con el mismo, como eje de comunicación y transporte. Se establecía pues, a través del proyecto de Bordick, una reflexión sobre la resolución de la transición entre paisaje y ciudad a través de la arquitectura.

No menos relevancia ocupa en el análisis de este proyecto el límite inmediato de la fábrica con el borde urbano. Entre su propuesta de conexión con el río, que adquiere matices paisajistas, y la resolución de la relación del acceso principal de la fábrica con la ciudad, la Real Fábrica de Tabacos adopta una posición intermedia como rótula entre el núcleo urbano consolidado y el territorio. El proyecto de Bordick propone una nueva ordenación urbana con la construcción de viviendas que sirviesen de alojamiento para aquellos trabajadores que estuvieran a cargo de servicios permanentes de la factoría, y a este respecto, su sucesor Van der Borcht intentará retomar y satisfacer dicha necesidad.

Sebastián Van der Borcht daría un paso más en los planteamientos anteriores y conectaría la fábrica como parte del sistema urbanístico de la ciudad barroca, integrando una de las intervenciones más importantes en términos urbanos de las que se realizaron en la Sevilla del S.XVIII. El edificio, que perdía su individualidad plástica para formar parte de un sistema de mayor escala, formalizaba su borde con la ciudad a través de unas viviendas intramuros, paralelas a la muralla de la huerta de la Alcoba, mediante las que se definía la calle que lindaba con el acceso principal. Estas viviendas se enlazaban con la plazuela de la Universidad en las inmediaciones de la puerta de Jerez hasta el quiebro de la muralla en la que se situaba la Puerta Nueva.

Como apunta Morales Sánchez, "si bien fue Ignacio Sala el ingeniero que fijó el lugar donde se construiría el edificio, con gran intuición si lo entendemos desde el punto de vista del desarrollo de la ciudad, el planteamiento de su proyecto en términos territoriales era bastante conservador"28. No obstante, el edificio trascendía la mera concepción local en su emplazamiento y estaba llamado a entenderse como pieza que formaba parte de la estructura territorial formada por el río.

Por tanto, esta posición intermedia del edificio como rótula entre campo y ciudad y como medio de integración del circuito fluvial y terrestre, llevaría a complejizar los primeros planteamientos del ingeniero Sala, pasando por la necesaria integración con el borde urbano a través de un espacio de entidad propia, más que mero acompañamiento del cinturón fortificado, con la incorporación de la fábrica como elemento del recorrido festivo de la escenografía barroca

\footnotetext{
28 Sobre este aspecto, señala Morales Sánchez que "en efecto, a medida que va avanzando el siglo se consigue conjugar la concepción colbertiana del edifico industrial con la idea -vía Uztarriz- del ministro de Hacienda de Luis XVI, Turgot, de transformar el territorio, especialmente a través de la apertura de nuevas vías de comunicación, para aumentar la riqueza del país. Esta toma de conciencia se va a plasmar en un proyecto en el que se articularía el soporte, tanto fluvial como terrestre, de aquél, base de la actividad comercial”. MORALES SÁNCHEZ, J. (1991) op. cit., p. 403.
} 
urbana, con la ordenación de las viviendas y con la presencia de la Puerta Nueva como apoyo formal urbano del mismo. La conexión con el río no se realizaría hasta 1754 , periodo de las obras a cargo de Barnola y Van der Borcht, a través del denominado como proyecto "de entrada y resguardo" y que se desarrollaba a través de la apertura de la nueva calle en terrenos que se segregaban de la huerta de la Alcoba, constituyéndose como la nueva entrada a la ciudad a través de la disposición de la Puerta Nueva ${ }^{29}$ y continuando el límite de la muralla mediante el muro que franqueaba el acceso al recinto fabril.

Por otra parte, se disponía una vía arbolada que conectaba la Real fábrica con el puerto, en las inmediaciones de la Torre del Oro, para facilitar las labores de carga, descarga y acarreo hacia el recinto industrial, estableciendo una conexión virtual entre ciudad y territorio mediante la proyección hacia el infinito del paseo. De esta forma, se conectaba a través de la industria extramuros el centro urbano con el barrio portuario, en una operación que anticipaba el carácter periférico de las arquitecturas industriales respecto a la ciudad central ${ }^{30}$.

Se refuerza de manera notable la concepción del edificio autónomo, exento, cuyas conexiones con la ciudad antigua se realizan a través de elementos representativos, como la puerta principal, único testigo en el interior de aquélla de la introducción del edificio. Se trasluce un cierto sentimiento de protección contra el medio, que se plasma en numerosas referencias urbanas que se deben proyectar en el interior de las fábricas: el gran patio, la calle interior, etc... ${ }^{31}$.

Por tanto, la Fábrica de Tabacos de Sevilla supondría un elemento revulsivo para la creación de ciudad en el territorio periférico al núcleo urbano en su relación con el puerto, cuya tradicional conexión con el río como soporte geográfico de desarrollo se mantendría en la localización de la nueva factoría de los Remedios, a la que se trasladaron los efectivos de la Fábrica de San Diego tras su cierre a mediados del S.XX.

\section{Características de la arquitectura fabril}

\section{La preexistencia: la Fábrica de Tabacos de San Pedro}

Dada la relevancia de la primera fundación fabril tabacalera sevillana en la historia del monopolio español e incluso en la historia mundial de la industria tabacalera, cabe hacer referencia a los episodios más destacados de su evolución arquitectónica. Su convivencia en paralelo a la concepción y construcción de la Real Fábrica de Tabacos de Sevilla

\footnotetext{
${ }^{29}$ La expansión de la ciudad hacia el área en la que se ubicaba el edificio a principios del S.XX reforzó su condición de elemento vertebrador de la misma como la rótula de articulación entre el núcleo urbano consolidado y la extensión rural periférica hacia el río. Cabe mencionar aquí el Plan de 1912 de Miguel Sánchez Dalp así como la Exposición Iberoamericana de 1929 como planeamientos urbanos que condicionaron el destino final de la fábrica en el primer caso, y completaron la definición urbana del área en el segundo.

${ }^{30}$ Las relaciones establecidas por la fábrica no se limitaban a la conexión de la centralidad urbana con la periferia portuaria, si no que la inauguración del ferrocarril a Cádiz y la nueva línea Córdoba-Madrid, entre 1856 y 1860 , supondría una expansión territorial en la que la fábrica de tabacos se situaba como mediadora entre la ciudad y el campo.

${ }^{31}$ MORALES SANCHEZ, J. (1991) op. cit., p. 93.
} 


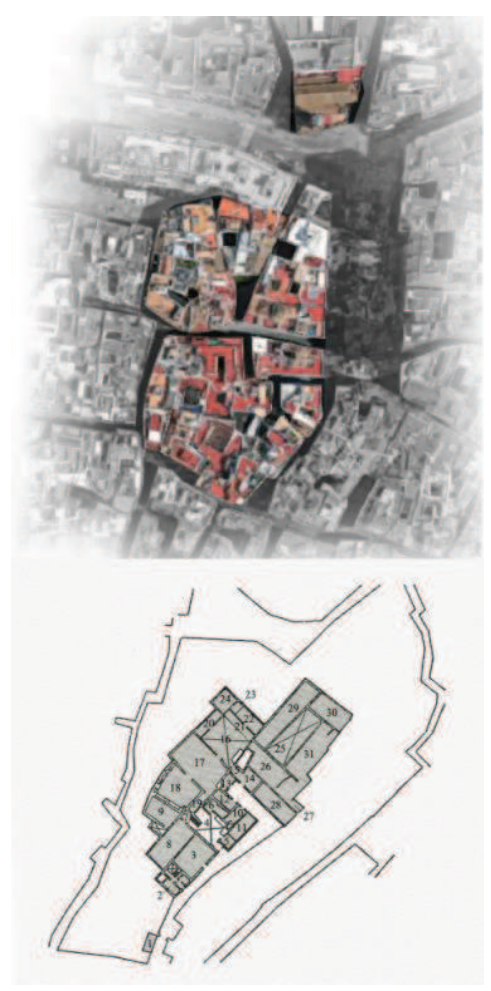

Figura 3.9. Parroquia de San Pedro y área del emplazamiento de la primera tabacalera sevillana, elaboración propia, 2016; y planta de la Real Fábrica de Tabacos de San Pedro de 1687, en RODRÍGUEZ GORDILLO, J. M. (2005) op. cit., p. 28. junto a la exportación de su modelo productivo a dicho proyecto de forma monumentalizada, dan cuenta de la relevancia de una aproximación a esta fábrica precursora de lo que se convertiría en una de las industrias objeto del mayor interés por parte del Estado español.

Como se apuntaba en epígrafes anteriores, la fábrica conocida como "de San Pedro" se instaló en un caserío cercano a la iglesia del mismo nombre en torno al año 1620, hecho relevante habida cuenta de que la Renta del Tabaco se estancaría en el año 1636. Según Rodríguez Gordillo este primer establecimiento fabril sería objeto de tres ampliaciones durante el S.XVII ${ }^{32}$. En primer lugar, en 1647 culminaría el proceso de adaptación a la manufactura tabacalera del primitivo mesón e inmuebles aledaños conocidos como las "Casas de la Galera" que se situaban frente a la iglesia de San Pedro, posiblemente en la manzana que hoy alberga la plaza del Buen Suceso ${ }^{33}$. Según Rodríguez Gordillo, en aquel momento la Fábrica de San Pedro constaba de un conjunto de patios, almacenes y cuadras para las bestias que se empleaban para mover los molinos. Se había creado, así mismo, un ámbito diáfano para albergar la instalación de cuatro molinos, conformando una planta rectangular que se hallaba compartimentada únicamente por grandes arcadas sobre pilares que permitían cubrir la estancia con entrevigados de madera. Este sistema recuerda en parte al que se emplearía posteriormente en muchas fábricas de tabacos.

Dos décadas después, entre 1669 y 1674 se acometería una segunda reforma que consistiría en la adaptación de espacios de los edificios aledaños que sucesivamente se habían ido añadiendo con objeto de aumentar la superficie útil del espacio productivo. El recinto se extendía progresivamente colonizando la manzana, pero su complejidad y escasa funcionalidad precisaba con frecuencia de constantes remodelaciones parciales que permitían la expansión de las labores.

Finalmente, a través de una instrucción real de 1684 se resuelve "que la fábrica de Sevilla se aumente lo que fuere menester para que sólo en ella se dispongan todos los tabacos que se han de consumir en estos mis reinos" ${ }^{34}$, de forma que se perseguía la centralización de las labores en la fábrica hispalense, suprimiendo todos los pequeños centros manufactureros que pese al Estanco del Tabaco seguían activos en diversos puntos de la península como Betanzos, Gijón, El Puerto de Santa María, Ronda, etc.

Con independencia de la incorporación de algún nuevo solar, las obras en sí mismas alcanzaron una gran envergadura. Según el citado autor [Carlos Oliver], «se levantaron de nueva planta una casa en la calle interior [...] y un almacén contiguo a ella» y «se rehízo el complejo administrativo: contaduría, caja y tesorería nuevas». Además debió

\footnotetext{
32 RODRÍGUEZ GORDILLO, J. M. (2005) op. cit., pp. 24-26.

33 Aunque el tejido urbano de la zona se halla muy alterado y no resulta fácil identificar de forma precisa los inmuebles que anteriormente pertenecían a la fábrica de San Pedro, por la nomenclatura de calles y las descripciones referidas por los autores consultados, todo indica que se trata de la manzana referida.

${ }^{34}$ Del Art. 9 de la Instrucción de 1684, referido en RODRÍGUEZ GORDILLO, J. M. (2005) op. cit., p. 26.
} 
realizarse una portada nueva en la entrada de la fábrica, frente a la iglesia de San Pedro [...]

Con toda esta actuación, «las fábricas ocupaban completamente las casas de la Galera», quedando el núcleo productivo articulado por dos patios en torno a los que se ubicaban ahora «siete cuadras para molinos [...] una pieza para morteros, dos almacenes y otras pequeñas dependencias auxiliares». Pese a la expansión que todo ello supuso, al año siguiente tuvieron que incorporarse mediante arriendo un nuevo solar y un mesón, con lo que se alcanzó la mayor expansión superficial de la fábrica durante aquel siglo [...] unos $1.812 \mathrm{~m}^{2} 35$.

De esta forma, la Fábrica de San Pedro llegaría a su última etapa en el S.XVIII como un conjunto de viviendas agregadas que se transformaron con objeto de constituir un único recinto manufacturero, pero que evidentemente no satisfacía las necesidades reales de una manufactura de tal envergadura ni respondía a los requerimientos espaciales que progresivamente iba demandando el espacio productivo. Entre sus carencias fundamentales se encontraba la escasa funcionalidad de su espacio, dada la configuración que adquiría a partir de la agregación de las distintas piezas que conformaban la manzana, además de encontrarse en una localización del tejido urbano consolidado poco apta para las circulaciones que se producían en torno a una actividad de este tipo, con el consiguiente perjuicio tanto para el proceso productivo como para la vecindad.

Con el S.XVIII se inicia, por tanto, la última etapa de la Fábrica de San Pedro, época en la que el auge experimentado por la Renta del Tabaco representó según Rodríguez Gordillo un impulso decisivo para la manufactura hispalense que, como único centro productor, comenzó a vivir su etapa de máximo esplendor. Precisamente, esta circunstancia obligó a los responsables de la Renta a redoblar sus esfuerzos para dotar a la Fábrica de San Pedro de equipamientos y medios necesarios que posibilitaran cubrir la demanda de producto tabacalero que en aquellos momentos había superado cualquier umbral de expectativa posible.

A partir de este momento, la dirección de la Renta comprenderá que ninguna reforma posible en la Fábrica de San Pedro conseguirá equilibrar la relación entre producción y demanda, por lo que se resolvió la construcción de una nueva fábrica en otro emplazamiento que cumpliese con todos los requerimientos arquitectónicos, espaciales y técnicos necesarios para el cumplimiento de los objetivos de acuerdo a la demanda del momento. No obstante, aún habrían de sucederse hasta tres nuevas ampliaciones en la Fábrica de San Pedro, antes de su abandono y traslado definitivo a la nueva construcción situada en las inmediaciones del Colegio de San Telmo y el Convento de San Diego. El motivo de esta dilación en el cierre de la misma fue la constante demanda de producto que debía ser satisfecha de alguna forma, así como la demora que experimentaron los trabajos de construcción de la nueva fábrica tabacalera, referidas en epígrafes anteriores, y que

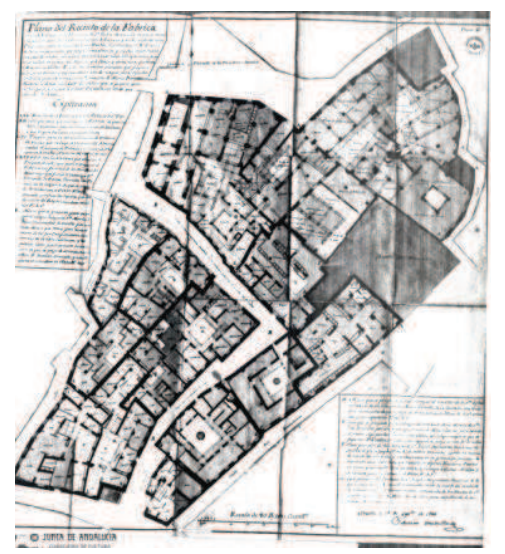

Figura 3.10. Planimetría de la Fábrica de San Pedro de Sebastián Van der Borcht de 1760, en AHPS, 3134FT_0128.

35 RODRÍGUEZ GORDILLO, J. M. (2005) op. cit., pp. 28-29. Las citas a las que hace referencia pertenecen a OLIVER CARLOS, A. (1987) La Arquitectura y el lugar, Sevilla: Diputación Provincial de Sevilla, pp. 53-56. 
determinaron el funcionamiento en paralelo de ambos establecimientos durante un periodo de adaptación y transferencia completa de las dependencias.

En 1701 se aumentó la superficie de la fábrica incorporando algunas casas que habían servido de mesón en la calle Morería, junto a un solar de la misma calle, y unas casas principales junto a dos accesorias de la plazuela de los Descalzos de la Santísima Trinidad. Así, el complejo se ampliaba en unos $700 \mathrm{~m}^{2}$ con el objeto de acoger nuevos molinos, pajares y almacenes y alguna otra dependencia auxiliar de menor porte.

La segunda ampliación del S.XVIII se acometería entre los años 1714 y 1716, poco después de la Guerra de Sucesión Española y a iniciativa de Juan Tovar, responsable de la Renta en Sevilla en aquel momento. De esta forma se agregaron unas edificaciones colindantes a la fábrica hacia la calle de la Morería, que debían ampliar la factoría para albergar nuevas caballerizas, pajar y granero.

La tercera ampliación en la fábrica de San Pedro constituye la más ambiciosa y compleja, habida cuenta de la redacción de hasta tres proyectos para su realización -en 1722 , en 1723 y el final de $1726^{-}$. Los dos primeros proyectos, siempre rechazados por su elevado coste, desembocaron en la tercera y definitiva propuesta de 1726 que aunaba el complicado programa de expansión en un momento en el que el ingeniero Ignacio Sala ya se encontraba en plena redacción del proyecto para la nueva fábrica tabacalera hispalense.

En este intento se pretendía adquirir todos los inmuebles colindantes de la fábrica, a excepción del Mesón del Rey y los situados junto a él con la idea de racionalizar los usos del heterogéneo conjunto sin recurrir a demasiadas reformas [...] Para reforzarlo todavía más, se logró al fin, en 1727, la incorporación del Mesón del Rey, con lo que, al parecer, concluyó el capítulo de adquisiciones en aquellos momentos [...]

Sala optó por una solución de conveniencia movido por la idea, hemos de suponer, de que sólo se trataría de que las tradicionales fábricas soportaran con decoro el breve período de obras que se suponía habrían de necesitar las nuevas dependencias. Su propuesta se limitó, pues, a la implantación de diez nuevos molinos y varias oficinas (entresuelos y azoteas, fundamentalmente) que permitiesen aumentar la producción sin un excesivo dispendio de recursos ${ }^{36}$.

Ignacio Sala, primer ingeniero al que se le otorgaría el papel de proyectista de la Real Fábrica de Tabacos de Sevilla resultó ser, pues, el último que intervino sobre la primitiva Fábrica de San Pedro, dirigiendo las reformas que se ejecutaron en el ocaso de la misma. La Fábrica de San Pedro, que había iniciado las labores de producción según el sistema productivo de fabricación del tabaco en

${ }^{36}$ RODRÍGUEZ GORDILLO, J. M. (2005) op. cit., p. 44. 
polvo, había empleado aproximadamente a un millar de trabajadores y en total contó con más de un centenar de molinos y unas 250 caballerizas, lo que indica la importancia que alcanzó a pesar de las dificultades que su configuración arquitectónica y su emplazamiento ocasionaban al adecuado curso de la producción.

\section{La Fábrica de Tabacos de San Diego: aportaciones al proyecto de los distintos autores}

Como se apuntó en el primer epígrafe, muchos fueron los avatares que rodearon la concepción y construcción de este inmueble, con la sucesión de proyectistas y jefes de obra que mediante su criterio personal configuraron la imagen final que tendría la fábrica. Si bien se han realizado consideraciones de tipo histórico sobre la aportación de cada uno de estos proyectistas al resultado final del edificio, cabe en este punto analizar la evolución del proyecto en términos arquitectónicos.

\section{El informe y proyecto de Ignacio Sala (1728)}

El proyecto del ingeniero Sala surgiría de las necesidades específicas de la producción tabacalera en el momento en que fue concebido, requerimientos que pudo comprobar con precisión en sus trabajos para la Fábrica de San Pedro. A este respecto, dado que la producción de la época se centraba en la elaboración de tabaco en polvo, Sala fijó su atención hacia los requerimientos espaciales de los molinos como pieza fundamental del proceso, cuyas dimensiones fijarían el módulo principal a partir del cual se escalaría la dimensión total de la fábrica. De esta forma, se preveía la necesidad de idear un recinto industrial que albergase unos 150 molinos, con lo que el número de naves necesarias resultantes sería mayor que en el proyecto frustrado de traslado de las dependencias productivas al edificio de las Reales Atarazanas.

Otra de las principales preocupaciones de Sala en el proyecto de la nueva fábrica de tabacos fue la resolución de la introducción de luz a un edificio de tales proporciones, para lo cual establecería unos patios interiores que articularían y organizarían las naves de elaboración y que se convertiría en uno de los invariantes comunes en la organización del espacio interno tabacalero. El proyecto resultante de 1728 sentaba, pues, las bases para la formulación del concepto de edificio-máquina, capaz de asumir todo el proceso de elaboración tabacalero.

Muchas de las características del proyecto de Sala no se pueden entender sin el informe elaborado por el administrador general de la Renta del Tabaco de Sevilla, Carlos Mirail y Callava ${ }^{37}$. Este documento resulta fundamental para la comprensión total del funcionamiento del espacio productivo tabacalero, sus características fundamentales y la materialización arquitectónica de dichos requerimientos. La disposición del espacio productivo en la fábrica configuraría muchas de las decisiones proyectuales posteriores que constituirían un modo de

${ }_{37}$ Informe dirigido a la Dirección General de la Renta del Tabaco, Sevilla, 15 julio 1727, A.G.S., D.G.R., $2^{\mathrm{a}}$ remesa, leg. 4378. Citado por MORALES SÁNCHEZ, J. (1991) op. cit., p. 91. 
proceder común en las restantes fundaciones fabriles.

La estructuración del edificio se realizaría en función de los cinco "beneficios" que se debían dar a los tabacos fijando la capacidad del mismo, como se ha apuntado, en función del módulo proporcionado por la dimensión de los 150 molinos y las medidas de los correspondientes andenes. Estos molinos se pondrían en relación con el patio principal y éste con los cernedores, previendo también la disposición de los almacenes en un lugar conveniente y estimando variaciones en su construcción según los requerimientos de peso del enfardado y grado de humedad del tabaco.

En el citado informe, también se detalla la posición del despacho del administrador general y la contaduría con el puesto para pesar el producto, situándolos en las proximidades del ingreso principal. Por su parte, las caballerizas debían acoger un total de 350 caballos a las que se añadía la vivienda del caballerizo, aconsejando la disposición de estas estancias fuera del cuerpo de la fábrica pero cercanas a los molinos.

Papel importante adquirirá la definición preliminar de los patios como uno de los elementos configuradores del espacio interior, que se mantendrá prácticamente inalterable en los diferentes proyectos hasta la construcción definitiva. Los cuatro lados de los patios se rodearían de corredores columnados de al menos tres varas de ancho de forma que los pórticos dispuestos permitiesen trabajar tanto en invierno como en verano.

Sobre las fachadas, se establecerá la necesidad de que el edificio conste de dos accesos que atenderían a diversas funciones, diferenciando ambas puertas según su relación con la ciudad. En la fachada principal, los accesos se mantendrían dentro de la ciudad disponiendo frente a la misma un amplio callejón que condujese al patio principal, de forma que existiese una comunicación inmediata para aquellos que tuviesen su lugar de residencia dentro de la fábrica. Por otro lado, se distingue del acceso principal la "puerta del río" mediante la que se produciría la entrada del tabaco que llegaba al muelle procedente de otros puertos, así como la salida del producto elaborado. Esta puerta estaba en relación directa con lo que posteriormente se materializaría como eje configurador de la fábrica alineándola, así mismo, con el patio principal. De esta forma, tanto los accesos como las fachadas se instaurarían como los elementos de diálogo con la ciudad.

Finalmente, se definían dos elementos auxiliares que se materializarían de forma independiente al inmueble principal: la capilla, que inicialmente se disponía como un espacio autónomo pero inserto en los corredores del patio principal, y la cárcel, que desde un primer momento mantendría un programa mínimo e independiente de la configuración general de la fábrica.

Continuando con la definición del proyecto de fábrica tabacalera de Ignacio Sala, su diseño apunta algunas de las características 
fundamentales y novedosas que serían seguidas por sus sucesores. La opción de Sala por un diseño en bloque debía a su vez resolver las condiciones de borde del emplazamiento, mediante el aprovechamiento del arroyo Tagarete que sería abovedado y el diseño del frente de fachada que daba a la muralla y, por tanto, a la ciudad.

Las reflexiones del proyecto de Sala se estructuran en dos aspectos fundamentales: la propia construcción del edificio y la distribución general de las piezas dentro del mismo. Entre los primeros cabe destacar la ubicación del edificio y su elevación frente a las riadas del Guadalquivir, la solidez, la propiedad de los materiales, la seguridad y protección y el resguardo frente a robos y fraude característicos de la actividad tabacalera. Entre los segundos cabe destacar la distribución dentro del conjunto en piezas independientes o aisladas dentro de la misma fábrica y en dependencias propiamente fabriles. En este aspecto, como refiere Morales Sánchez, el proyecto daría especial importancia a la vigilancia y resguardo del producto, disponiendo todos los elementos y mecanismos espaciales necesarios para su control. De esta forma, "una característica general de toda la distribución será la escasa conexión entre las dependencias, que facilita el control de cada unidad de trabajo, como queda de manifiesto cuando se describe la manera en que han de estructurarse los «lugares comunes»" 38 .

En cuanto a la funcionalidad del espacio interior, separa claramente los recintos destinados a diversas funciones que no tendrían más comunicación entre sí que la realizada a través del patio principal. El edificio se estructuraba verticalmente en dos plantas, destinando la gran superficie de las azoteas para su reaprovechamiento como secaderos. Constructivamente, la fábrica emplea recursos tradicionales como bóvedas y arcos para la cubrición de los espacios, justificando dicha elección desde el punto de vista económico y estructural dada la dimensión de los amplios vanos a cubrir, así como del resultado formal y estético de dicha elección.

En el proyecto de Sala, el espacio interior se polariza entre la zona ocupada por la cúspide jerárquica de la fábrica y el espacio propiamente productivo. De esta forma, los primeros espacios se instalarán en la crujía tras la fachada principal a la ciudad, mientras que el espacio productivo ocupará los dos tercios restantes. Ahondando en las características de la zona productiva,

de puertas para adentro ubicaba ciento dieciséis molinos de desmonte con sus cernideros en una atarazana y próximas a ésta nueve atahonas con un almacén. Los cuarenta molinos de repaso que tenía previstos se ubicaban en el otro costado repartidos en tres naves, con la intención de mantener tanto la simetría del edificio como la de dar espacio entre las cuadras que labraban las diferentes variedades de tabaco. Por último, quedaban situados en aquella planta baja diferentes almacenes para las materias primas y para los tabacos ya elaborados, incluidos

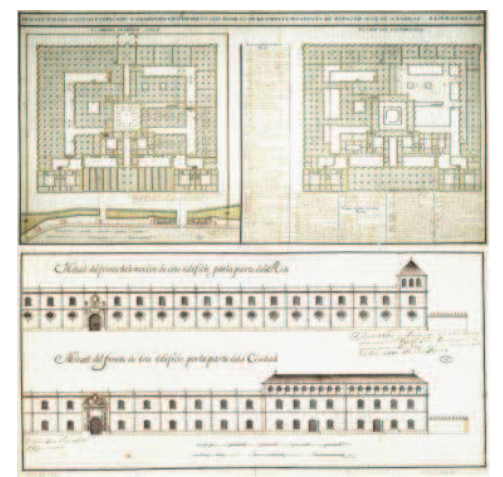

Figura 3.11. Planimetría del proyecto de Ignacio Sala de 1728 , en RODRÍGUEZ GORDILLO, J. M. (2005) op. cit., p. 54.

\footnotetext{
${ }^{38}$ MORALES SANCHEZ, J. (1991) op. cit., p. 92.
} 
aquellos que los comerciantes y armadores traían en flotas y galeones ${ }^{39}$.

El patio como recurso de articulación del espacio interior constituye el núcleo del eje que organizaría el edificio y que se convertiría en uno de los aspectos más interesantes del proyecto. Desde el zaguán de entrada hasta el patio principal se proyectaría una calle que conectaría la puerta principal del edificio con la interior de la fábrica. A ambos lados de esta calle se dispondrían las diferentes dependencias que presentarían una configuración similar a las de los grupos de viviendas de las esquinas. La última crujía de las oficinas serviría de linde con el patio principal en cuyo interior se desarrollaba un soportal octogonal en planta baja, pudiéndose acceder al mismo desde los talleres colindantes.

Por su parte, del patio partían calles interiores que conectaban las diversas áreas de "beneficios", convirtiéndose en el centro distribuidor de la circulación. La malla de la zona industrial se estructuraba en base a un módulo con una dimensión entre ejes de siete varas castellanas $(5,87 \mathrm{~m})$, medida tomada directamente en base al ámbito de la acémila circundante a los molinos empleados en la producción. Cerraban el conjunto, en la parte colindante con el río, seis almacenes para el alojamiento del tabaco procedente del puerto fluvial.

En la planta superior y siguiendo la polarización anteriormente descrita, lindando con la fachada principal se encontraban las plantas altas de las viviendas y un gran bloque de tres naves destinadas a graneros para las caballerizas que se conectaban verticalmente con los patios rectangulares entre estas y las viviendas a través de dos escaleras adosadas a las medianeras de los mismos. Por su parte, la calle principal que conectaba el zaguán y el patio principal, así como las zonas de oficinas y parte de las atarazanas de repaso se desarrollaban a doble altura. Además del beneficio de "azoteas", en esta planta se ubicarán el de entresuelos y el de moja. Finalmente, la cubierta de la segunda planta albergaba las azoteas destinadas a secaderos que se hallaban rodeadas en tres de sus lados por una nave perimetral que se utilizaba como cobertizo para resguardar los tabacos de las lluvias.

La composición de la fachada revertiría fundamental importancia en el proyecto, distinguiendo el carácter urbano y representativo del frente hacia la ciudad de la modulación rígida del lienzo envolvente hacia el río que denotaría un carácter más cuartelario. Resulta novedosa la reproducción de la estructura del interior en fachada a través de la

39 RODRÍGUEZ GORDILlO, J. M. (2005) op. cit., p. 56. También en esta página, señala Rodríguez Gordillo en referencia a la descripción espacial que se comentará posteriormente, la parquedad de Sala en la definición de la distribución en la segunda planta, hecho sorprendente habida cuenta que en la misma se concentraban varios de los beneficios esenciales para la producción del tabaco en polvo, así como la disposición de estancias destinadas a la creciente manufactura de cigarros. Tan sólo hace referencia al alojamiento de entresuelos, moja, cuadras de cigarreros, almacenes y azoteas para secar tabacos. Señala dicho autor, así mismo, que el esquematismo de esta parte del programa puede responder al hecho de que estas actividades no revertían mayor complicación en el aspecto constructivo sino que tan sólo requerían estancias amplias, diáfanas y funcionales, quedando suficientemente resueltas en la solución adoptada. 
manifestación de los 27 módulos que configuraban el mismo.

El alzado que se enfrenta a la muralla del alcázar posee tres cuerpos. En los extremos se colocan grupos simétricos de dos casas enmarcadas por pilastras. Poseen dos plantas y ático y quedan unificadas por una cubierta a dos aguas. Cada una de estas casas posee una entrada desde el exterior de las fábricas, colocada simétricamente respecto del eje de la pilastra que las divide. De esta manera, se acentúa su independencia respecto al cuerpo central. Este traduce en su alzado la modulación de las caballerizas mediante un apilastrado, dejando en el centro de las diez naves un módulo para la puerta principal. Cada módulo posee una ventana por planta. Un pretil corrido macizo unifica este cuerpo.

El alzado que mira al río es diferente del anterior: una modulación rígida de veintisiete tramos que traducen la estructura interior y sendas torres de tres plantas en las esquinas, cubiertas a cuatro aguas, formalizan un frente tenso y más uniforme que el primero. En el centro, y coincidiendo con un módulo impar, se coloca la portada al río. Cada uno de aquéllos tiene dos ventanas, una por planta, de las que la inferior es elíptica. Este alzado queda unificado por un pretil macizo, coronado con piñas, que conecta con las torres ${ }^{40}$.

En cuanto a las soluciones constructivas establecidas por Sala, se propondrán diversos sistemas que dependerán de la función concreta de la estancia a la que se destinen, siempre y cuando garanticen la incombustibilidad, resistencia de cargas, grado de humedad constante de las estancias y una disposición funcional que facilite la higiene interior a través de la instalación de sumideros, esto último coadyuvado por la configuración en calles y patios interiores del edificio. En cuanto a cubriciones, los almacenes presentarían bóvedas de rosca cuya funcionalidad se constataría por el empleo posterior en numerosas factorías tabacaleras. Procedente de las fortificaciones, esta tipología constructiva evitaba el ascenso por capilaridad del agua presente en el suelo y ofrecía una gran resistencia a las cargas. Las restantes estancias, por su parte, presentaban soluciones abovedadas de diversa índole tanto en planta baja como en planta alta: mientras que las caballerizas presentaban bóvedas de medio cañón, el resto del edificio presentaba bóvedas vaídas en las cubriciones correspondientes al módulo cuadrado de siete varas castellanas. Estas soluciones nuevamente bebían de las tipologías constructivas procedentes del mundo de la fortificación.

\section{El proyecto de Diego Bordick Devérez de Langfort (1731)}

Como sucesor de Sala, el ingeniero Diego Bordick introdujo modificaciones respecto al proyecto dispuesto por su predecesor que afectarían principalmente a la zona administrativa y al eje de los patios. De esta forma, realizará una redistribución de las dependencias con motivo del estudio del perfil de la fábrica para encajar un molino doble, no añadiendo ninguna modificación sustancial en materia de arquitectura, puesto que la introducción de las diversas articulaciones en planta se produjo con arreglo a la malla formal propuesta por Sala.

\footnotetext{
${ }^{40}$ MORALES SANCHEZ, J. (1991) op. cit., p. 122.
} 


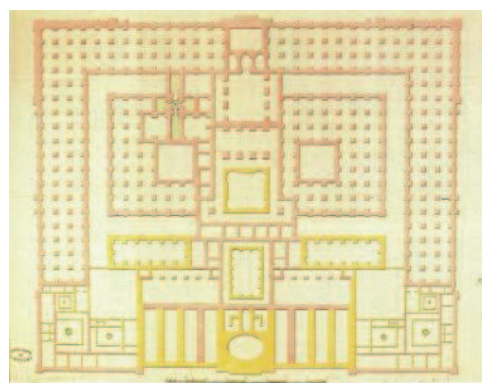

Figura 3.12. Planimetría del proyecto de Diego Bordick de 1736, en MORALES SÁNCHEZ, J. (1991) op. cit., p. 243.
Si en el proyecto de éste último la homogeneidad en planta se obtenía a través del módulo constructivo formado por una bóveda y cuatro pilares, Bordick obtiene dicha homogeneidad a través de la simetría, regularizando las articulaciones en planta del diseño de Sala.

Este planteamiento le permitiría realizar tres transformaciones sobre el proyecto precedente que modificarán el carácter de las áreas sobre las que actúa. En primer lugar, dispondrá un anillo exterior de una anchura de tres módulos que recorre el contorno del edificio en tres fachadas excluyendo la principal que mira a la ciudad, de forma que proporciona una mayor racionalidad al enlace de la zona fabril con las viviendas cuyas medianeras entestarán con el ámbito industrial y fortalecerá formalmente las esquinas que miran al río. Este anillo mejorará la articulación del espacio interior con la puerta hacia el río, simétricamente opuesta al acceso principal. En segundo lugar, potenciará las perspectivas interiores mediante la disposición de triples naves de bóvedas vaídas y en la configuración de las calles interiores que recorrerán el inmueble en una única fuga y permitirán la formación de puntos de conexión espacial en su encuentro con los patios. Por último, esta mayor homogeneidad de la solución estructural comportará una mayor efectividad del funcionamiento industrial.

El eje compositivo desde el acceso principal hasta la puerta del río en la fachada trasera que se intuía en el proyecto de Sala, será potenciado en la propuesta de Bordick, a través de su materialización arquitectónica en el recorrido de la fábrica desde la ciudad hacia el río. De esta forma, se compondría una secuencia de dos vestíbulos situados a la entrada de sendas puertas y se conectarían con tres patios de distinta entidad, siendo necesario para la introducción de este gran eje la ruptura de los límites que imponía la cuadrícula, de forma que en esta zona se pierden todas las referencias relativas a la misma. Constructivamente, se emplearían tipologías distintas a las de la malla formal para la configuración de estos nuevos espacios y el acceso principal cambiaría completamente a través de su enriquecimiento formal que ya bebía claramente de referentes palaciales.

Funcionalmente, esta propuesta resultaba más eficaz en materia de circulaciones interiores permitiendo el paso de carretas al primer patio o patio de cuadras. Las escaleras que se disponían a ambos lados de este paso desembocaban en los corredores del patio anterior desarrollando una secuencia espacial de referentes claramente franceses que articularían ambas zonas. De esta forma, la articulación vertical de las plantas quedaba claramente definida y resuelta en este nuevo proyecto de Bordick.

La definición del patio de cuadras se configuraría de manera diversa al proyecto de Sala, que planteaba una calle interior. Se trata ahora de una formalización ambigua, puesto que no llega a ser estrictamente ni un patio ni una calle en el sentido del proyecto predecesor, sino más bien una logia cubierta por una bóveda de cañón que se modularía mediante arcos fajones desde los pilares del muro perimetral. 
Siguiendo el recorrido del eje central, en el paso hacia el segundo patio o patio central se interpone un pequeño núcleo de oficinas que formaría la testera del primer patio y daría paso al segundo. La concepción de este patio central también cambiará respecto al proyecto de Sala, pasando a constituirse como una auténtica apertura higiénica para la introducción de luz y ventilación al interior de la fábrica y como elemento articulador de las circulaciones y funciones del recinto. Al dilatar su espacio en profundidad mediante la construcción de un atrio cubierto que aleja el muro perimetral y la eliminación del ochavamiento propuesto por Sala, se consigue una gran diafanidad y amplitud de este espacio exterior intramuros. La representatividad de este segundo patio queda claramente manifiesta al compararlo escalarmente con los que se abren a izquierda y derecha en el interior de la fábrica; pese a su proporción semejante, su posición relativa los relega a simples aperturas higiénicas y funcionales.

Remataría este eje compositivo interior un tercer y último patio que introduce una variante funcional respecto al proyecto de Sala, que en esta zona preveía un estrecho callejón interior que supliese la función de espacio de descarga de tabacos que llegaban desde el puerto y debían ser distribuidos a los diversos talleres. Bordick, por el contrario, define claramente un patio de descarga que sirve de rótula espacial para las calles interiores del anillo perimetral a través de las cuales se distribuiría la materia prima. Precediendo a este patio en el acceso trasero, se encontraba un vestíbulo cubierto que resolvía el espacio de entrada desde el río y remataba el eje proyectual interior, que como se apuntó en el epígrafe relativo al entorno, en el proyecto de Diego Bordick se prolongaba virtualmente a través de un canal navegable que conectaba la parte trasera de la fábrica con el río.

Bordick realiza también modificaciones sobre el bloque "palacial" correspondiente a caballerizas y viviendas, reduciendo el número de las primeras a cuatro cuadras a cada lado del vestíbulo por la ampliación de la dimensión de éste respecto al proyecto de Sala. Disminuyendo el programa funcional de éste área, permitía una clara definición de los espacios dotándolos de una escala adecuada, dando mayor representatividad al acceso, puesto que la solución anterior era fruto de la primitiva herencia cuartelaria de principios del S.XVIII. De igual forma, por razones higiénicas, el espacio de caballerizas se ubicó al exterior de la fábrica. El programa de las viviendas que rematan las esquinas de la fachada principal apenas varía del proyecto predecesor, resolviendo únicamente la conexión de las viviendas con el resto del conjunto.

En cuanto a la formulación de fachada, Bordick emplea un orden toscano que hace alusión a la reforma arquitectónica que entronca con la política económica introducida por la dinastía borbónica y que pretende representar debidamente mediante la composición lingüística de los alzados del nuevo proyecto. Compuesto por dos alturas, la continuidad que asumirá en este nuevo proyecto la fachada del edificio romperá con la herencia cuartelaria del proyecto del predecesor Sala en la disposición de pabellones en esquina. Bordick no sólo se limita a 


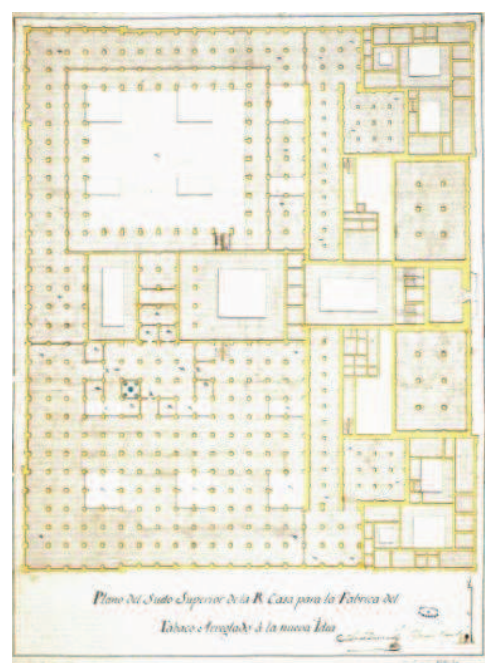

Figura 3.13. Planimetría de José Barnola y Félix Davalillo de 1750, en RODRÍGUEZ GORDILLO, J. M. (2005) op. cit., p. 66 . redefinir la fachada, sino que adosa a la muralla de la ciudad una serie de viviendas y una larga pieza de caballerizas que compensasen la reducción de esta parte del programa en el conjunto fabril. De esta forma, potencia la configuración de una calle hacia la puerta de Jerez conectando el flanco derecho del alzado principal de las fábricas con otro grupo de viviendas que reproducían simétricamente la disposición de las adosadas a la muralla. La formulación de este trazado urbano intentaría reproducir el que se estaba disponiendo en el interior de la fábrica como propuesta social residencial.

\section{El proyecto de José Barnola y Félix Davalillo (1750)}

Los sucesores de Bordick serán el ingeniero José Barnola y el administrador general Félix Davalillo, redactando el primero un proyecto que sería consecuencia directa del informe del segundo sobre la distribución de funciones en el seno de la fábrica.

En cuanto a la articulación interior del espacio, la modificación fundamental al proyecto de Bordick será la desaparición de la calle interior en forma de $\mathrm{U}$ que simetrizaba la planta y saneaba el interior del conjunto, a favor de la disposición de doce pequeños patios para la introducción de luz y a la colmatación del antiguo espacio ocupado por el vacío en $U$ por dos pequeñas naves de conexión entre patios cubiertas por bóvedas que daban cabida a un mayor número de molinos. De esta forma, la planta baja se uniformaba en el área manufacturera a través del establecimiento de una malla que se compartimentaba a voluntad en función de los requerimientos espaciales futuros. Mediante la racionalización de la construcción se potenciaba la versatilidad para admitir una mayor variedad de funciones, pero se perdían los efectos de espacialidad lineal en la repetitividad de pilares y grandes espacios abiertos del anterior proyecto, que se verán cuajados de molinos. Esta compactación se extiende a otras zonas de la planta baja como las viviendas situadas en las esquinas, en cuyos jardines traseros se introducen sendas mallas de $4 \times 4$ módulos destinadas a caballerizas de asistencia a los molinos del espacio manufacturero.

El proyecto de Barnola también se encargaría de introducir modificaciones sobre otra de las insignias del proyecto de Bordick, como era el eje secuencial de patios. El vestíbulo perdería la formalización elíptica para volver a ser rectangular lo que implicaba la redefinición de la relación entre las escaleras y dicho espacio. Desde el patio de la fieldad o patio central hasta la fachada que forma el frente con el río se introduce una malla de pilares de $5 \times 3$ módulos conteniendo divisiones destinadas espacios de almacenaje. Como continuación de la malla anterior, se introducía un patio porticado rectangular destinado a la descarga de barricas de ingreso y se cierra al Sur mediante pequeños obradores de tres módulos integrados en la malla, truncando la salida hacia el río, de forma que se elimina el acceso trasero anterior. 
En lo que se refiere al sistema constructivo, al introducirse una malla formal de igual medida en todas las áreas -a excepción de las realizadas para las caballerizas-, se uniformiza el empleo de la bóveda vaída, desapareciendo aquellas zonas cubiertas por bóvedas de cañón del proyecto de Bordick mediante la introducción de pilares en sus tramos.

En cuanto a la planta superior, sobre esta se proyecta el esquema de la planta baja, puesto que en la zona izquierda del área industrial se repite el mismo planteamiento, destinándose a entresuelos, áreas de moja y almacenes. Los pequeños patios introducidos ventilan a través de esta planta pero, dadas sus pequeñas dimensiones, no cumplían con su pretendido objetivo higiénico. Por su parte, en la parte derecha se mejorará la ventilación al introducir ya en planta primera las azoteas.

En cuanto a las consideraciones sobre los alzados en el proyecto de José Barnola, estos renuncian a las complicadas articulaciones de orden del anterior proyecto, pero también a la imagen de tipo cuartelario propio de la primera mitad del S.XVIII del proyecto de Sala, distanciándose en parte de este carácter mediante el ennoblecimiento de algunos detalles. De esta forma, no se hace referencia a las articulaciones entre los pabellones extremos de oficiales y el tramo central, tendiendo a unificar el frente para dotarlo de un carácter noble mediante un orden de ventanas vertical que potencia el apilastramiento del edificio y que se extiende por todos los frentes laterales de las viviendas. Esta configuración se remarca sustituyendo la forma ovalada de las ventanas de los entresuelos por cuadrados.

En cuanto a los patios de las viviendas, se opta por una configuración apilastrada con arcos, de forma que el empleo de pilastras en lugar de columnas ayuda a "tensar el plan de los patios y [...] extenderlo desde la cota del suelo hasta la cornisa" ${ }^{41}$. De esta forma, se define claramente el volumen paralepipédico del patio, mientras que el empleo de columnas se reservará los espacios en planta baja.

\section{El proyecto de Ventura Padierne y Martín Loynaz (1750)}

Contemporáneamente al proyecto anterior surge la propuesta del administrador general de la Renta Martín Loynaz y el arquitecto Ventura Padierne, primer representante de esta disciplina que participará en las propuestas proyectuales. El diseño de estos autores, procedente de Madrid, representaría las aspiraciones de la renovada administración que trataba de poner en marcha el Marqués de la Ensenada. Aunque el proyecto se presenta el 18 de julio de 1750, finalmente el Marqués de la Ensenada se decantó por la versión de Barnola, encargando su realización en agosto del mismo año. No obstante, pese a que esta propuesta no se realizó finalmente, reviste características interesantes en cuanto a su concepción proyectual.

\footnotetext{
41 "No cabe duda de que éste, como otros cambios, hay que relacionarlos con las corrientes conceptuales, y artísticas de la época. El apilastramiento adoptado en lugar de las columnas ayuda a tensar el plan de los patios y, en cierto modo, a extenderlo desde la cota del suelo hasta la cornisa [...] Sin embargo, la clarificación de los espacios y la recuperación del plano murario serán algunas de las características de la arquitectura más distante del Barroco y más próxima a la de la Ilustración”. MORALES SANCHEZ, J. (1991) op. cit., p. 278.
} 
En palabras de Morales Sánchez el proyecto de Loynaz y Padierne presentará una "falta de realismo [...] pudiendo hablarse de modelo impuesto, con lo que ello implica, entre otras cosas, de ausencia de diálogo entre el edificio y la urbe". De esta forma, el que el administrador general de la Renta del Tabaco mediase directamente en el proceso proyectual con la asistencia de arquitectos cercanos a la Corte, desembocaba en una falta de referencias tanto lingüísticas como urbanas en la solución final, resultando cuanto menos sorprendente que sean en esta empresa los ingenieros militares los que enriquezcan el proyecto con variadas referencias tipológicas civiles y cuartelarias, entroncando el discurso del edificio con la reflexión sobre su papel en la ciudad.

No parece casual que el edificio no contenga referencias al entorno cuando, además, esto planteaba una serie de problemas importantes. El edificio es principio y fin de su relación con el lugar [...] Podría decirse que el lugar, el territorio, está dentro del edificio, pues desde la puerta principal se articula una gran plaza porticada y una calle larguísima y descubierta que dotan al edificio de una autosuficiencia referencial respecto a la ciudad muy evidente, y ello a pesar de que por sus dimensiones era casi ineludible establecer semejante relación. Por el contrario, el proyecto da completamente la espalda a la urbe lanzando como único factor de diálogo la torre de la campana ${ }^{42}$.

Parte de las incongruencias de este proyecto surgen de la escala desmesurada del mismo que pasa de los $187 \times 147$ metros a $265 \times 217$ metros, lo cual indica según Morales Sánchez una intencionalidad de diseño para acoger otras funciones además de la propia elaboración de tabacos. Se sigue la misma disposición en retícula como recurso compositivo del espacio interior, pero no perpetúa la novedosa solución de Sala en la interposición de una pieza de referencias tipológicas palaciegas para la conexión del resto del edificio con la ciudad como nexo articulador y recurso de control de las medidas infinitas de la malla. En este proyecto, la retícula adquiere una doble articulación para expandir las dimensiones de la planta del edificio, tomando como base una nave con un ancho de tres módulos que se entrecruza y que delimita patios y calles interiores. Este planteamiento define la geometría de edificio y, a la vez, formaliza diversos espacios que responden a las necesidades funcionales, dotando al espacio interior de una racionalidad fruto de la lógica distributiva.

El módulo según el cual se escala esta triple nave se dimensiona nuevamente a partir de la célula mínima necesaria para el encaje del molino (5,87x5,87 m o siete varas castellanas), continuando con la solución modular propuesta en los anteriores proyectos. En el diseño de Padierne la doble articulación entre módulo y nave desarrolla espacios más orgánicos, de forma que los patios ya no se insertan en la malla para introducir ventilación y luz, sino que surgen de forma natural a la propia formulación de la nave. El eje compositivo central de los anteriores proyectos se convierte ahora en una calle axial que atraviesa todo el edificio y que permite controlar el espacio de labores

${ }^{42}$ MORALES SANCHEZ, J. (1991) op. cit., p. 295. 
dotándolo a su vez de una mayor funcionalidad en la racionalidad de los recorridos.

En este sentido, se advierte una simplificación del espacio interior frente a las complicadas conexiones que se establecían en el proyecto de Barnola y Davalillo. La calle axial no implica una solución constructiva ni una modulación arquitectónica distinta, sino que se formaliza a través de la separación de dos naves que se configuran como logias cubiertas recorriendo todo el eje central. De esta forma, será la nave la formalización arquitectónica que asuma todas las funcionalidades, estableciendo un espacio de corte basilical a través de la doble altura de la nave central que permitirá la introducción de luz y ventilación en el interior.

El edificio se organiza de forma modular dejando 24 patios abiertos jerarquizados a ambos lados de la calle central y que cuentan con diversas funciones -entre ellas, las operaciones de secado puesto que con la nueva sección basilical no se dispone de azoteas para acoger dicha función-. Sin embargo, este esquema distributivo entra en crisis en la resolución del bloque de oficinas y viviendas, que se disponen en una nave en la que se hace patente el encorsetamiento de estos espacios para el modelo planteado. En el espacio de la malla restante se organizan las funciones manufactureras complementarias que no encuentran una singularización espacial determinada: almacenes, cuadras que abastecen a los molinos e incluso lugares comunes de estancia entre los patios.

Los alzados exteriores del edificio e interiores de los patios se definen con gran fidelidad al carácter del mismo en una solución intermedia entre la arquitectura civil y una interpretación de lo que podría ser un estilo arquitectónico industrial, expresando literalmente el alzado en correspondencia a la sección. De esta forma, se observa una intencionalidad compositiva claramente veraz que manifiesta la función del edificio y cómo funciona, materializando en fachada la sección de la nave basilical como recurso espacial que organiza el conjunto. En este sentido, el plano frontal de fachada reproducirá el recorrido perimetral realizado por la nave lateral, mientras que en un segundo plano se observa el cuerpo alto de la doble altura, que se retranquea mostrando los óculos a modo de aperturas para la introducción de luz en el interior del edificio.

Por otra parte, el proyecto de Padierne invierte el programa realizado en los proyectos anteriores, situando las oficinas y viviendas en la fachada que mira al río, siendo en esta ocasión el frente sujeto a alguna concesión estilística, disponiendo huecos verticales y balcones en los cuerpos dobles de los extremos y manteniendo un carácter indefinido o poco expresivo en las fachadas que miran hacia la ciudad. El empleo de piedra en zócalos, pilastras y cornisas, así como en los recercados de los huecos, disponiendo un lienzo de ladrillo visto en el resto del plano de los alzados, subraya la correspondencia deseada entre lenguaje compositivo y sistema constructivo que potenciaría el carácter del edificio como "máquina".

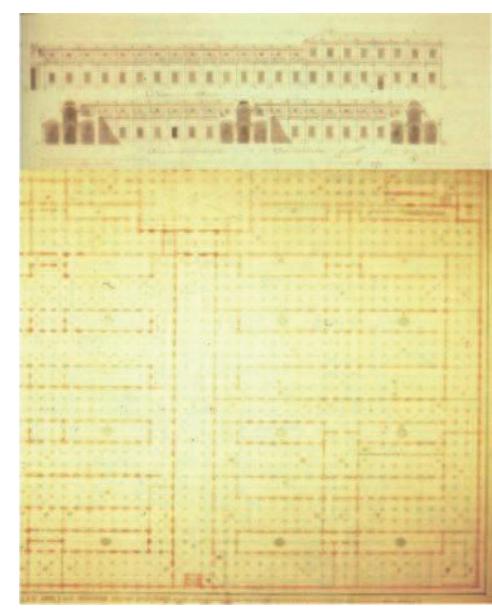

Figura 3.14. Planimetría de Ventura Padierne y Martín Loynaz de 1750, en MORALES SÁNCHEZ, J. (1991) op. cit., pp. 288-289. 


\section{El proyecto de Sebastián Van der Borcht (1750)}

El último proyectista que intervendría en la obra de la Real Fábrica de Tabacos y construiría el núcleo fundamental del edificio así como sus zonas más representativas según la imagen que ha llegado a nuestros días, fue el ingeniero militar y arquitecto holandés Sebastián Van der Borcht, que retomó los trabajos en agosto de 1750. Todo indica que Van der Borcht dirigió la obra guardando bastante fidelidad, en su mayor parte, al proyecto elaborado por el ingeniero jefe José Barnola junto a Félix Davalillo completando los trabajos relativos a la crujía de la fachada principal, patios, galerías, gran parte del foso y la capilla y cárcel que flanquean la fachada principal.

Comenzando por los trabajos que realizó en el entorno, cabe destacar la terminación del foso que constituiría cronológicamente la última obra. Finalizado en 1770, su carácter castrense se remataría con las torres garita y el puente levadizo que cruzaría el mismo en la puerta Este del conjunto, además del cierre del recinto con su característica tapia. Este elemento, más propio de una construcción militar, contrastaba con el carácter palacial que adquiriría el resto del conjunto, aunque se justificaba en la necesidad de proteger el inmueble frente al ámbito exterior.

Según Morales Sánchez "el frente principal, que no perdió su originaria procedencia compositiva de los castillos y hoteles franceses del XVIII, es el único que permanece según lo levantó Van der Borcht". Siguiendo un ritmo de 7-4-3-4-7, su composición de pilastras duplicadas -repetidas en las alas que se unen con las viviendas en esquina- asumen la composición general del tramo central, aproximando según Morales Sánchez este orden apilastrado gigante a los planteamientos de Bernini para el Louvre, lo que le permite organizar la composición general y escalar el edificio según las soluciones ensayadas por Palladio en algunos palacios urbanos. De esta forma, se aleja definitivamente de los planteamientos cuartelarios compositivos iniciados por el ingeniero Sala, matizando el lenguaje y "dulcificando" la rigidez de la composición volumétrica propia de las obras de la ingeniería militar. El enriquecimiento lingüístico no se obtiene de la profusión de ornamentación o la repetición de placas o almohadillados, sino a través de la composición general que rige y controla la pequeña escala en el diseño menor. El remate compositivo de la fachada principal en su ornamentación se completaría con la obra realizada sobre la misma por el escultor portugués Cayetano da Costa.

Por otra parte, los alzados laterales doblan el esquema de las viviendas, pero adoptan una solución que en la interpretación de Morales Sánchez responde a la presencia de la tapia que circunda el conjunto. El carácter ambiguo de estos frentes laterales, así como del frente Sur hacia el río cuida en extremo el cuerpo alto de la fachada, no así la parte baja, entendiendo que, de esta forma, se establecía una relación con la percepción del edificio desde el otro lado de la tapia, concebido para ser observado por encima de la misma. Cabe pensar también que los propios condicionantes funcionales del interior 
precisaban de un lienzo más hermético en la parte inferior, dadas las tareas que se realizaban en el mismo, abriendo tan sólo los pequeños óculos que se definían en esta planta.

La nueva torre de vigilancia que se situaría en el centro de la fachada Sur, conectaría el edificio con la ciudad una vez truncado el eje interior que recorría el edificio de Norte a Sur a través de sus patios en su remate trasero. Esta significación trata de recomponerse con la ubicación de la torre en una lectura más abstracta de la proyección de dicho eje compositivo interior hacia el territorio. Esta relación del edificio con el paisaje circundante tiene su origen en el foso, que permite al conjunto asomarse a la ciudad sin perjuicio de la función defensiva inicial. Al establecer un discurso horizontal con la ciudad y el territorio, se manifiesta el carácter de la fábrica en su condición de edificio límite como transición arquitectónica que vincula la acción antrópica con el medio natural.

La capilla y la cárcel atribuidas a Van der Borcht completarían el conjunto flanqueando la entrada principal, de forma que el alzado principal junto con la muralla y estos dos elementos arquitectónicos, integrarían la configuración de representatividad de la misma. Organizados según un esquema formal de planta en L, reforzaban las esquinas del edificio en el frente que presentaba hacia la ciudad.

Los alzados interiores continuarán empleando esta inspiración palacial a través de esquemas vignolescos para el patio principal en los que la adaptación al programa produce ligeras deformaciones del canon propuesto, estableciendo de nuevo un discurso con otros edificios de la ciudad. En cuanto al patio de entrada o de arrieros, este retoma el carácter que tuvo en el proyecto de Sala como articulador de la transición entre el espacio interior y el exterior, precediendo con su vestíbulo de imagen palacial la sensación de franquear un gran conjunto monumental como preludia la imagen del lienzo de la fachada principal.

En cuanto a la resolución del espacio interior y comenzando por su planta baja, se observa cómo la estructuración de Van der Borcht se corresponde con los diseños de Barnola con alguna que otra variación en los sentidos del trazado de las subidas de las escaleras principales del vestíbulo. Si las casas interiores, patios de caballerizas, almacenes, patios menores y la estructuración de la secuencia de tres patios responden al proyecto original, el carácter hermético del edificio se manifiesta en cambio en el cierre completo de la fachada Sur no dejando salida al eje central en su proyección hacia el territorio, como planteaba Barnola.

Finalmente, la definición de la planta superior tampoco varió la solución propuesta en el diseño de José Barnola, puesto que las azoteas y los patios mantienen la misma posición elegida por dicho ingeniero, aunque la definición de toda la azotea de la segunda planta se atribuye al ingeniero Van der Borcht, que desarrolla así mismo, las características linternas sobre los salones y la escalera principal.

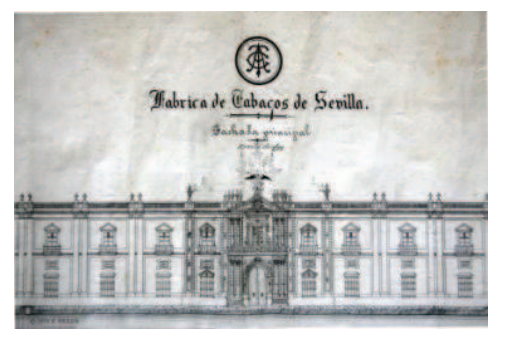

Figura 3.15. Fachada principal de la Fábrica de Tabacos de Sevilla tras la intervención de Sebastián Van der Borcht y Cayetano da Acosta, en AHPS, PL185. 


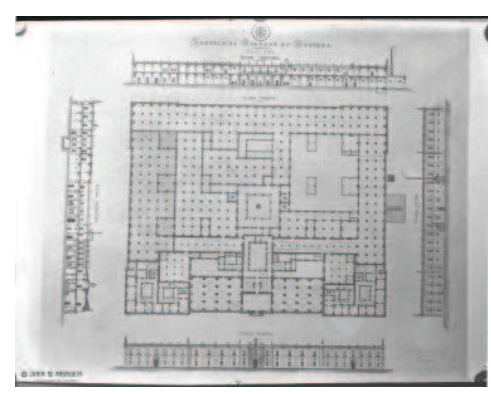

Figura 3.16. Planimetría de la Fábrica de Tabacos de Sevilla de 1905, en AHPS, 3134FT_077.

\section{El espacio productivo y su evolución hasta 1945}

La Fábrica de Tabacos de Sevilla sufriría una transformación espacial parcial en base a la evolución propia del proceso industrial acorde con la introducción paulatina de la mecanización que, en el acoplamiento de la nueva maquinaria a los espacios planteados por la producción manufacturera, malamente podría aplicarse al laberíntico espacio original. Si bien fue proyectada para un tipo de producción tabacalera basada en el empleo masivo de molinos para la elaboración del tabaco en polvo -que explica las dimensiones de su módulo principal-, se optaría definitivamente medio siglo después del inicio de la actividad industrial por la elaboración de tabaco de humo, de carácter fuertemente manufacturero y que implicaba la contratación masiva de cigarreras, siguiendo el modelo de la fábrica gaditana y reinterpretando las posibilidades espaciales del proyecto.

Como se ha descrito en epígrafes anteriores, la fábrica fue proyectada distinguiendo claramente dos partes que constituirían la polarización de la misma como materialización arquitectónica de la estructura jerárquica del monopolio y que sería tomado como recurso proyectual y programático en las fundaciones fabriles posteriores. Como indica René Taylor ${ }^{43}$ la primera parte sería el palacio o residencia del superintendente y sus principales asistentes, así como los usos destinados a la administración del complejo, ubicándose en la crujía paralela a la fachada principal y disponiendo una entrada monumental compuesta por la secuencia de portada, zaguán y escaleras. La segunda parte que ocuparía dos tercios de la superficie total, estaría destinada a la actividad fabril, desarrollada a través de extensas galerías conectadas por patios de diversa significación y que se conformarían mediante la repetición del módulo constructivo formado por pilares y bóveda vaída. Pronto se verá como este principio de extensibilidad infinita de la malla y el carácter casi isotrópico del espacio, únicamente orientado direccionalmente por la materialización del eje central en la secuencia de patios, sería compartimentado en diversos espacios de acuerdo a las necesidades espaciales de la producción.

El análisis sobre el espacio productivo de una tipología arquitectónica industrial debe efectuarse en razón de los cambios tecnológicos, cómo estos afectan al edificio y cómo interaccionan con el trabajador y su relación con el espacio. Pese a los diversos avatares por los que pasó el diseño del proyecto, conviene recordar que la contribución del planteamiento inicial del ingeniero Sala fue muy importante para la resolución de la arquitectura final a través de la comprensión del funcionamiento del espacio fabril. La planta ideada por Ignacio Sala dividía el espacio según criterios funcionales delimitando, como se ha visto, la zona fabril de la administrativa y residencial, organizándola a través de cinco áreas independientes que se correspondían con las

43 TAYLOR, R. (1959) op. cit., p. 268. 
cinco fases de elaboración del tabaco -también llamadas "beneficios"- a inicios del S.XVIII. A estas zonas que ocupaban la mayor parte de la extensión del espacio interior se le añadían espacios complementarios como almacenes, la crujía de oficinas y viviendas, así como las cuadras para el alojamiento de las caballerías necesarias para el funcionamiento de los molinos y que se hallaban inmediatas al espacio de producción, pero convenientemente separadas. Como apunta Rodríguez Gordillo,

como la experiencia en San Pedro había demostrado que las labores del tabaco requerían no sólo mucho espacio sino un espacio muy dúctil dados los cambios relativamente frecuentes exigidos por la evolución de las tecnologías y los cambios en los consumos-, Sala evita en su diseño ubicar barreras arquitectónicas o constructivas que no fuesen inevitables, por tanto, el ingeniero proyecta toda la parte fabril de la primera planta del edificio mediante unidades cuadradas abovedadas que podían unirse o segregarse sin dificultad eliminando o incorporando tabiques. Sin duda, como sostiene Bonet Correa, esa versatilidad y adaptabilidad a necesidades cambiantes constituyen un rasgo de marcada modernidad, y no sólo para el siglo XVIII [...]

Cada una de las zonas tendría su función y debería constituir compartimentos casi estancos, comunicados unos con otros de acuerdo con la cadena de los procesos, comunicaciones que Sala hizo girar en torno al núcleo constituido por el patio principal ${ }^{44}$.

Se entiende, por tanto, que la versatilidad en el planteamiento de la malla modular de Sala, permitía su subdivisión y compartimentación según las necesidades de la producción, manteniendo la independencia de los espacios destinados a los distintos procesos productivos y comunicándolos únicamente a través de los ambientes comunes. Esto refleja, en parte, el carácter laberíntico deseado por el monopolio en la creación de un espacio coercitivo totalmente controlado a través de estos recursos espaciales que dificultaban el hurto o el acceso al producto, tanto de personas empleadas como ajenas, coadyuvando de igual forma a la vigilancia y control circulatorio de las primeras.

El funcionamiento de la fábrica en sus primeras décadas se puede intuir a través de las Instrucciones Generales de 1761 y 1763 que constituyeron un precedente de los Reglamentos Orgánicos establecidos casi un siglo después por la CAT. Esta norma regulaba la vida de la fábrica tanto en los aspectos productivos de las diferentes labores de tabaco polvo y cigarros como en la vida del operario, en cuestiones relativas al orden de entradas, vestimenta, comunicación entre los empleados en el seno de la fábrica, así como las posibles penalizaciones por fraude, robo, sustracciones, rotura o desidia en el empleo de los útiles de trabajo o planificación ante el peligro de incendios.

En el caso de la Instrucción de 1763 incluso se describen las innovaciones establecidas en las diversas dependencias atendiendo a los distintos "beneficios" del tabaco: monte o molturación de la hoja, moja, entresuelos que denominaba con el nombre del espacio de destino la tarea de oreo, y por último el repaso o tareas finales que perfeccionaban

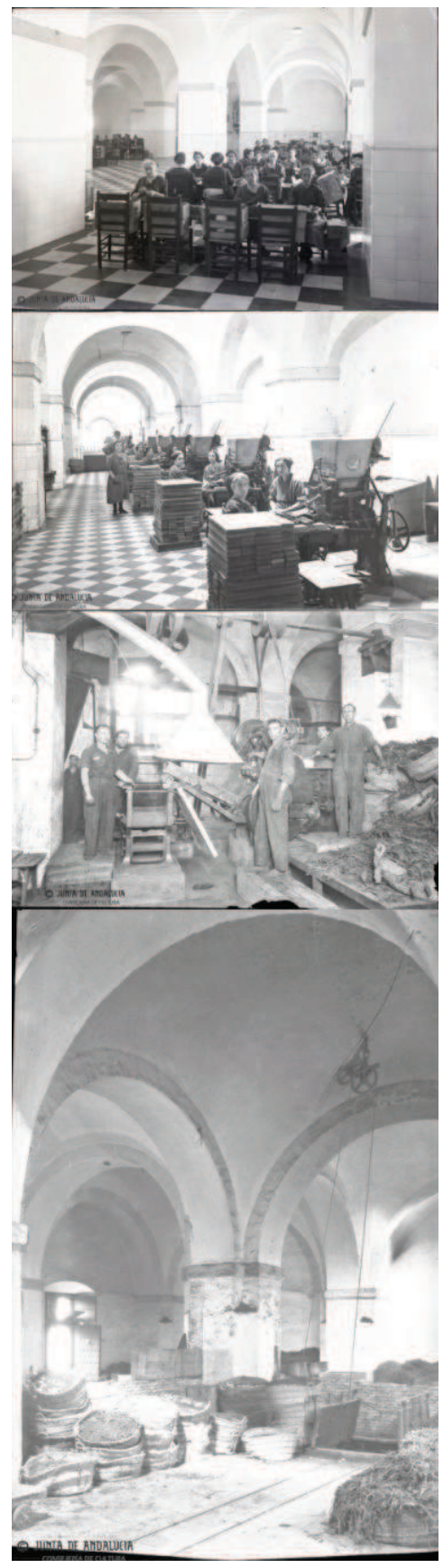

Figura 3.17. Espacios productivos de la Fábrica de Tabacos de Sevilla, en AHPS, FT3134-098, FT3134-093, 3134FT_0100 y 3134FT_080.

\footnotetext{
${ }^{44}$ RODRÍGUEZ GORDILLO, J. M. (2005) op. cit., p. 59.
} 
las cualidades y características deseadas para los tabacos. Siguiendo el recorrido vertical de la producción característico de las tabacaleras, en la planta baja se dispondrían las dependencias de los servicios permanentes como tercenas y estancos para la venta de tabacos en la crujía principal, que no se conectaban con las oficinas ni las viviendas. La parte productiva albergaría en planta baja los diversos molinos para la molturación característica del tabaco en polvo. A la misma cota y cercanas a la zona industrial pero separadas de la misma, se dispondrían las cuadras, mientras que una parte del espacio se reservaba para el almacenaje de la materia prima.

Por su parte, el entresuelo fue concebido como una planta diáfana en la que la simple introducción de tabiques podía reconfigurar el espacio para establecer la división necesaria entre las diversas fases del proceso como las mojas correspondientes a las distintas variedades de tabaco o el oreo. Para finalizar, las azoteas constituían la gran superficie ventilada y necesaria para el secado de los tabacos, disponiendo pretiles o antepechos que impedían que los fuertes vientos volasen las hojas dispuestas en las mismas.

Sin embargo, la puesta en marcha de la Fábrica de San Diego se realizó en un momento en el que se estaba experimentando un cambio de orientación en la producción, pasando a albergar espacios destinados al tabaco de humo cuyo consumo se hallaba en alza frente al de tabaco en polvo para el que había sido concebida. La transición en la adaptación de los espacios hacia la variedad de tabaco torcido o de humo y el empleo masivo de cigarreras para tal cometido, se realizó, no obstante, de modo gradual, en un periodo en el que ambos tipos de labores convivieron por espacio de cuarenta años.

Una vez implantado el nuevo modelo productivo del liado, se tomó como referencia el precedente sentado por la fábrica gaditana, pionera de este tipo de producción por su fundación original como filial de apoyo a la fábrica hispalense en la elaboración de cigarros. La distribución a mediados del S.XIX, una vez reformado el espacio del establecimiento sevillano para la producción cigarrera ya consolidada, se puede intuir a través de la referencia que recoge Bonet Correa del testimonio de Félix González de León en 1844, dado que

en la parte fabril la construcción «toda de pilares, arcos y bóvedas y las divisiones (excepto las principales) son y han sido accidentales, pues han levantado tabiques y citarones y se han abierto y cerrado puertas donde ha sido necesario según las circunstancias, variando las formas cuando ha convenido». La posibilidad de variación "accidental» o versatilidad espacial es signo de toda arquitectura moderna. Dentro de una trama modular la Fábrica de Tabacos era un edificio que, como los de planta libre modernos, se adaptaba funcionalmente a las necesidades cambiantes de la fabricación del tabaco ${ }^{45}$.

45 BONET CORREA, A. (1984) op. cit., p. 64. El entrecomillado es una cita de GONZÁLEZ DE LEÓN, F. (1844 [1973]) Noticia Artística de todos los edificios públicos de esta muy Noble Ciudad de Sevilla, 2vls., Sevilla: Reimpresión Gráficas del Sur. 
El anterior fragmento trata, por tanto, el fenómeno ya comentado de la compartimentación y subdivisión del espacio productivo atendiendo a las necesidades propias e intrínsecas del proceso industrial. Siguiendo el recorrido vertical descrito anteriormente, en este momento se compartían en planta baja usos como molinos y cuadras de cernido, disponiendo en la parte central del edificio los almacenes de tabaco en rama y elaborados que se alejaban deliberadamente del perímetro exterior del complejo garantizando su escasa iluminación y ventilación así como las variaciones de temperatura para la correcta conservación del tabaco. En planta alta, se distribuirían los talleres de cigarros, así como los espacios destinados a moja y oreos, precisando estos últimos de grandes corrientes de aire. En esta misma cota se ubicarían también los operarios que atendían las acémilas de los molinos, quedando estas en un espacio falto de luz y ventilación en planta baja, y pudiendo dotar al operario de un espacio de calidad situado en la planta alta.

Con la cesión del arriendo del monopolio a la CAT, daría comienzo una profunda reorganización de la producción de labores que trataría de implantar mayor funcionalidad, diversidad y mejora progresiva del proceso productivo para la adecuación y equilibrio de la oferta de tabacos a los niveles que demandaban los consumidores. En este sentido, la transformación del programa de la fábrica sevillana se vio abocado a un ritmo más lento que en los restantes establecimientos del monopolio debido a las características inherentes a su fundación y su plasmación en el planteamiento espacial. De un lado, pesaban las características estructurales del propio edificio que, pensado para las elaboraciones tradicionales del S.XVIII, se había reconvertido en un espacio apto para el establecimiento de los talleres manuales correspondientes a las labores de humo, aunque ofrecía serias dificultades para su adaptación a una actividad industrial moderna. Por otra parte, el alto contingente de mano de obra suponía un importante lastre por su rechazo a que la nueva compañía gestora llevase a cabo sus planes de reestructuración. En última instancia, la fábrica tenía una gran relevancia en la ciudad en términos de contratación directa, así como en la generación de empleo indirecto, por lo que la renovación técnica contaba con la firme oposición de los interesados.

En la obra de Santías y Lera ${ }^{46}$ se recoge una descripción de la fábrica a través de la cual se pueden entresacar las principales características de la distribución de su espacio a finales del S.XIX. La planta baja albergaba, además de las oficinas y diversas dependencias administrativas, los talleres de empaquetado de picaduras finas, y los de preparación y perfeccionamiento del tabaco-polvo y del rapé -lo cual indica que este tipo de elaboración aún no estaba erradicada en la fábrica sevillana a finales del S.XIX-, señalando que en los mismos sólo trabajaban hombres. Los amplios almacenes de tabacos en rama y de elaborados se distribuían convenientemente por locales, conteniendo unos la rama procedente de Cuba y otros los venidos de otras procedencias, y disponiéndose el producto en los espacios de almacenaje de elaborados por pilas clasificadas según el tipo de labor.

${ }^{46}$ SANTÍAS, A. y LERA, D. (1898) op. cit., pp. 31-35 


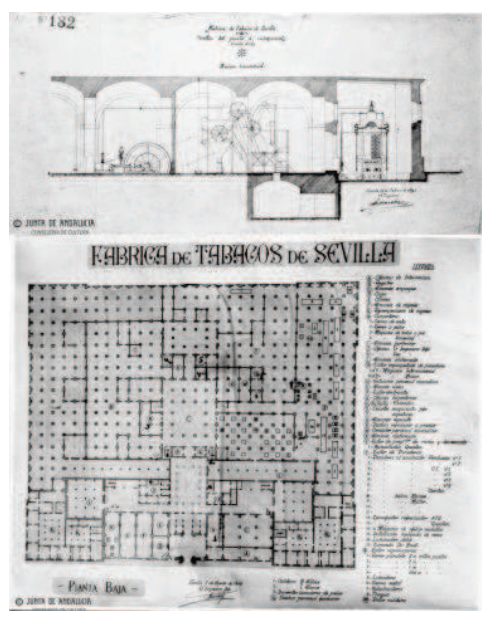

Figura 3.18. Sección del taller de picado a máquina de 1891 , en AHPS, FT_12PL; y planimetría de 1948 con la zonificación de la fábrica, en AHPS, 3134FT_005.
En la planta baja también se ubicaba el denominado taller de máquinas, espacio de gran amplitud y diafanidad y que en la época era considerado el más destacable del establecimiento por responder a los criterios e innovaciones de la CAT. Tal es su importancia que se dedica un párrafo específico a la descripción de esta estancia situada en la parte occidental del inmueble: en una inmensa sala de cien metros de longitud y anchura de dieciséis metros correspondientes a tres módulos de la división espacial, se albergaban seis máquinas picadoras de tabaco, así como seis de laminación, un ventilador que recorría una estantería de cincuenta metros en la que se realizaba el oreo de las picaduras, máquinas afiladoras y prensas de las que se obtenía el jugo de la hoja de tabaco. Este espacio gozaba de tal popularidad que se destacaba el contraste entre la construcción tradicional de carácter monumental y la disposición en su interior de los últimos adelantos técnicos en materia de mecanización del proceso, señalando que esta sala representaba claramente el concepto deseado desde su planteamiento proyectual como "palacio de la industria". Por último, en la planta alta se ubicaban los talleres de cigarros peninsulares marca chica, cigarros comunes fuertes, cigarrillos superiores, finos $y$ entrefinos y el empaquetado de picaduras entre finas y comunes, elaboraciones que daban empleo a unas 4.800 mujeres.

Eloísa Baena Luque ${ }^{47}$ plantea que el proceso de mecanización de la fábrica sevillana se produjo en tres fases entre finales del S.XIX y las dos primeras décadas del S.XX. De esta forma, de 1889 a 1907 se produciría la incorporación de maquinaria auxiliar sin relevancia en el aumento productivo, de 1908 a 1910 se incorporaría nueva tecnología que repercutiría en la reestructuración del proceso de elaboración de cigarros y picaduras, y ya en el año 1917 se producirían incorporaciones muy especializadas destinadas a la producción de picaduras y cigarrillos de hebra. De esta forma, señala Lina Gálvez que hasta 1909 se produciría la preparación de la mecanización mediante la adaptación de los espacios fabriles, preferentemente para los talleres de picado. Por tanto, se reordenaría el interior liberando el espacio preciso para las nuevas máquinas a través de una considerable transformación realizada hasta 1896 por el ingeniero jefe Miguel de Quesada y la reestructuración propuesta en 1903 por Luis de Alarcón. En el segundo periodo de mecanización hasta la Primera Guerra Mundial se incorporarían talleres semimecánicos que afectaban tan solo a la elaboración de cigarros. Ya en el tercer periodo hasta la Guerra Civil española, el impulso tecnológico acometido incluiría la mecanización de los procesos de elaboración de los cigarrillos ${ }^{48}$.

No obstante, para controlar un cierto descontento entre la mano de obra que motivase motines luditas, se mantuvieron las elaboraciones tradicionales de los talleres manuales a pesar del escaso relieve que

\footnotetext{
47 BAENA LUQUE, E. (1993) op. cit.

48 GÁLVEZ MUÑOZ, L. (2000b) "Género y cambio tecnológico: rentabilidad económica y política del proceso de industrialización del monopolio de tabacos en España (1887-1945)" en Revista de Historia Económica-Journal of Iberian and Latin American Economic History, año n ${ }^{\circ} 18, \mathrm{n}^{\circ} 1$, pp. 11-45; y más genéricamente en GÁLVEZ MUÑOZ, L. (2000a) Compañía Arrendataria de Tabacos, 1887-1945. Cambio tecnológico y empleo femenino, Madrid: LID Editorial Empresarial.
} 
estos alcanzaban en el conjunto de actividades de la fábrica y, en general, en todo el monopolio. Por otra parte, se amortizó la mano de obra antigua y se introdujo un importante número de nuevas aprendizas destinadas al sector de labores mecánicas afianzando su vinculación con los nuevos métodos de producción.

La época de posguerra truncó las aspiraciones de mecanización de la CAT y retrotrajo la producción a niveles anteriores a la década de los veinte. El laboreo de guerra durante el conflicto bélico y la política de racionamiento de la posguerra fueron el marco común en el que se movieron las elaboraciones del conjunto fabril del monopolio. Con la cesión del arriendo a Tabacalera, la fábrica de Sevilla tendría sus días contados, puesto que pronto se resolvió su cierre y traslado a la fábrica de nueva planta de Los Remedios. Hay que recordar que el mayor impulso de mecanización de todas las fases del proceso productivo tuvo lugar entre las décadas de los sesenta y los setenta, que ya no viviría el establecimiento que nos ocupa.

A pesar de la conjunción entre forma y función a finales del S.XVIII, la Fábrica de Tabacos de Sevilla sería objeto del distanciamiento entre ambos caracteres a lo largo del tiempo ${ }^{49}$. Sujeta a las variaciones espaciales en función del consumo, los cambios en los hábitos del mismo afectaban al uso que se hacía del establecimiento, ocupando o liberando espacio en función del aumento o disminución de la demanda de tabaco y a la introducción de nuevas labores. La progresiva mecanización del proceso productivo y la introducción de mejoras tecnológicas redujeron el número de trabajadores y espacio necesarios por lo que se producía, al igual que en sus homólogas, una ocupación incompleta del espacio que abría las puertas a la posibilidad de que se cediera temporalmente parte del edificio para otros usos.

La concepción del propio edificio como verdadera fortaleza o ciudadela por sucesivos ingenieros militares que intervinieron en su diseño, la indeterminación programática de su espacio interior propio de su carácter manufacturero, así como su carácter estatal, facilitaba la disponibilidad del edificio para su ocupación por otros usos de carácter castrense debido a la liberación de espacio creada por las sucesivas reestructuraciones ${ }^{50}$. Su situación en el borde de la ciudad histórica y en proximidad estratégica al puerto y, a partir de 1861, a la estación de ferrocarril de San Bernardo y a la puerta de San Fernando como acceso a la ciudad, potenciaban las cualidades del inmueble para la consecución de este objetivo. Como resultado de esta situación, se resolvería en 1880 la cesión temporal de una parte de la fábrica como cuartel, ocupando el tercio oriental del inmueble junto al prado de San Sebastián y disponiendo, así mismo, una nueva apertura hacia la ciudad que se aprovecharía para el programa de circulaciones en su

49 ROJAS-MARCOS RODRÍGUEZ DE QUESADA, S. (2005) "Nuevos tiempos, nuevos usos. La instalación de la Universidad” en RODRÍGUEZ GORDILLO, J. M. (2005) op. cit., p. 225.

50 Ya en 1821 se solicitaba la petición de uso penitenciario en la zona de San Telmo que, sin embargo, no prospera. Hay que tener en cuenta que la sucesión de conflictos bélicos en el S.XIX alteró el funcionamiento normal de muchas de las fábricas tabacaleras existentes por entonces en el territorio peninsular -la ocupación francesa de 1810 a 1812 , la primera guerra carlista de 1833 a 1840, el alzamiento de O'Donnell en Vicálvaro en 1854, etc.-, como se verá en los casos del inmueble logroñés que se reconvertiría en fábrica tabacalera o en el caso de la Fábrica de Tabacos de La Coruña. 


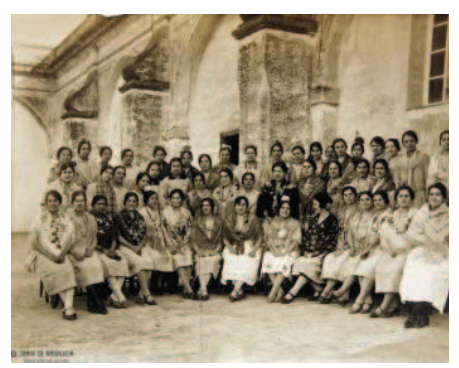

Figura 3.19. Cigarreras de la Real Fábrica de Tabacos de Sevilla, en AHPS, 3134_16. reconversión en dependencias universitarias a mediados del S.XX. Esta situación conllevó el planteamiento de la permuta de uso y la acometida de trabajos de aislamiento del espacio destinado a cuartel para garantizar su independencia respecto a la fábrica. Finalmente, esta situación se mantuvo hasta el traslado final y cierre de la Fábrica de San Diego, tras la apertura de la Fábrica de Los Remedios.

\section{Las cigarreras y la dimensión humana de la fábrica}

La Fábrica de Tabacos de Sevilla vivió en su primer establecimiento de San Pedro y en las posteriores dependencias de San Diego una situación inusual en cuanto a la tónica general de empleo de mano de obra femenina que se extendería en las restantes fundaciones fabriles y que se convertiría en uno de los rasgos característicos de la actividad industrial tabacalera en España. Dado que la industria se inicia con la elaboración de tabaco en polvo, todos los procesos a realizar eran mucho más acordes a las condiciones físicas de los hombres, como el transporte de fardos de tabaco, el picado, la colocación de las piedras de los molinos, el cuidado y manejo de los caballos o el duro trabajo de las artesas de moja. Incluso la incipiente elaboración de cigarros en el caso sevillano empleó mano de obra masculina de forma exclusiva a lo largo del S.XVIII tanto en la Fábrica de San Pedro como en la de San Diego. Sin embargo, el ahorro de costes en la mano de obra, así como la mayor destreza demostrada por las cigarreras en el liado o torcido de tabaco de humo, determinó que Sevilla adoptase el sistema de la fábrica gaditana en las primeras décadas del S.XIX ${ }^{51}$.

Los primeros pasos se dieron a finales del S.XVIII ante el aumento vertiginoso de la demanda de cigarros. Fue entonces cuando se acrecentaron las protestas de los consumidores ante la baja calidad de las labores sevillanas, en comparación con los productos traídos de Cuba o los fabricados por mujeres en Cádiz. De esta forma, en la segunda década del S.XIX se habilitó una dependencia en la fábrica sevillana llamada "Establecimiento de mujeres" en la que las trabajadoras gaditanas se empleaban en formar a las futuras cigarreras sevillanas ${ }^{52}$. Este cambio en la balanza de ocupación por sexos motivaría no pocas dificultades al poner en la calle a unos setecientos hombres, muchos de los cuales se reintegrarían en las redes de fabricación clandestina.

Por tanto, la entrada de la mujer en la fábrica sevillana -en una época de crisis generalizada motivada por la invasión napoleónica y el conflicto de la Guerra de la Independencia-, se produjo cuando ya constituía una realidad, no sólo de la fábrica gaditana, sino también de las que se habían fundado hasta ese momento -Alicante, La Coruña y Madrid-. Pese a ello, se precisaron dos décadas para que se implantase definitivamente el nuevo modelo en la fábrica sevillana y más de medio siglo para que las labores quedasen en exclusiva en manos femeninas

${ }^{51}$ SANTÍAS, A. y LERA, D. (1898) op. cit., p. 9.

52 CANDELA SOTO, P. (1997) op. cit., pp. 27-28. 
tras la desaparición de los últimos cigarreros.

Como se ha señalado, la ocupación francesa de Sevilla en 1810 provocó la desarticulación de los distintos procesos productivos, no pudiendo reinstaurarse la producción hasta 1812, momento que se aprovecha para la implantación de la mano de obra femenina en la Fábrica de San Diego. Esta medida refrendó la vía seguida por la primera generación de centros tabacaleros del S.XIX impidiendo la marcha atrás del proceso hacia la contratación exclusiva femenina para las tareas de liado. Sintomático de esta nueva situación es el apoyo normativo que se facilitó a través del nuevo Reglamento de $1813^{53}$.

Se sentarían las bases, por tanto, no sólo para un cambio cualitativo en cuanto a las labores producidas en la Fábrica de Tabacos de Sevilla, sino también para una característica que acompañará su memoria y que marcaría sus espacios de trabajo a través de la presencia de la mujer y la inmortalización de la figura de la cigarrera a través de obras literarias de escritores como Pierre Loüys, Armando Palacio Valdés, José Luis Ortiz de Lanzagorta, Prosper Mérimée, Georges Bizet o pintores como Gonzalo Bilbao. Baste señalar la importancia de la presencia femenina para el desarrollo de la producción tabacalera en el hecho de que en 1868 se contaba con una plantilla de 6.300 mujeres y 350 varones.

Una vez normalizada la mayoría de presencia femenina en el laboreo de los talleres y con su aumento constante durante toda la centuria, la fábrica de Sevilla alcanzaría la imagen que la haría mundialmente famosa. El esquema de división del trabajo respondía al modelo establecido en Cádiz en la agrupación de las cigarreras en ranchos que conformaban los diversos talleres y que se describió en el anterior capítulo. Por otra parte, el frecuente abandono voluntario del taller o absentismo junto al fraude -sustracción de alguna porción de tabaco por pequeña que fuese- eran las causas más habituales de despido e implicaba la imposibilidad de reincorporación. Si el delito no revertía mayor gravedad, se imponía una pena de privación de libertad en la cárcel de la fábrica, aunque se daba inicio a la causa procesal correspondiente en caso de que la cantidad hurtada fuese de importancia. Otras causas de despido como escándalos, reyertas o peleas quedaban sujetas a una posible reconsideración por parte de la dirección.

Por otro lado, si el primer tercio del S.XIX estuvo marcado por la transformación experimentada por la industria tabacalera a consecuencia de la ampliación del número de fábricas y por la entrada y generalización de la mano de obra femenina, la época de entre-siglos se caracterizó por el declive en el número de operarias debido a la reestructuración emprendida por la CAT con el inicio de la mecanización de los procesos a partir de 1887. Esta situación provocó no pocas revueltas de importancia, máxime considerando que la fábrica sevillana era la que ostentaba el mayor volumen de contratación, lo que desembocaría en la paralización temporal de la implantación del

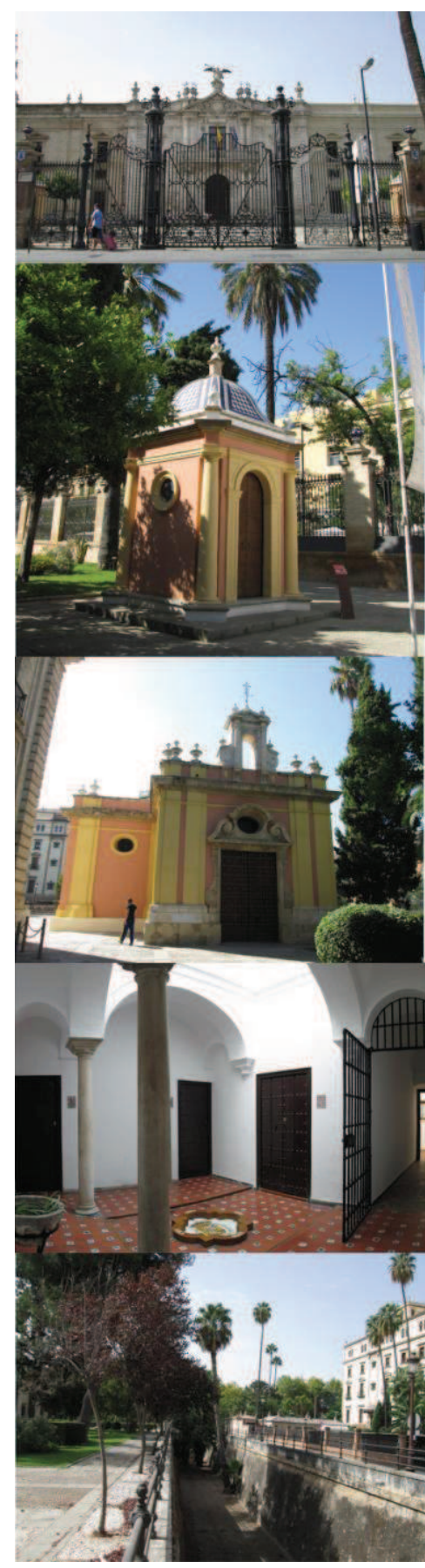

Figura 3.20. Verja, garita, cárcel y foso de la fábrica sevillana, 2015.

\footnotetext{
${ }^{53}$ Ver RODRÍGUEZ GORDILLO, J. M. (2005) op. cit., pp. 141-146.
} 


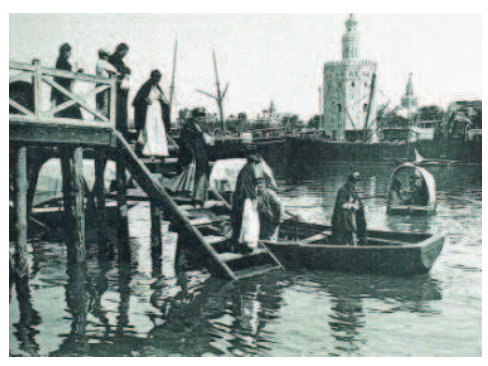

Figura 3.21. Cigarreras embarcando en Triana, en RODRÍGUEZ GORDILLO, J. M. (2005) op. cit., p. 173. programa de mecanización y tecnificación de las actividades productivas.

Al concluir la centuria, el inicio del maquinismo provocó la reducción sensible del número de cigarreras, iniciándose a un ritmo moderado el aumento del número de operarios que se encargarían del mantenimiento de la maquinaria. En pocos años el número de cigarreras quedaría reducido a la mitad, siendo un total de 3.300 entre maestras, porteras y operarias en 1906, reduciéndose a los dos millares en 1920 y llegando a las 1.100 en 1940. La imposición del ritmo de la técnica y el excedente de mano de obra imprimiría un cambio considerable en las formas tradicionales de la fábrica sevillana pero, aunque el descenso de mano de obra femenina fue notable, esta se mantuvo siempre en volumen superior al del personal masculino contratado y el tamaño de la plantilla se mantendría en niveles considerables, habida cuenta que algunas de las restantes fábricas tabacaleras peninsulares tan sólo alcanzaron el millar o los dos millares en su época de máximo apogeo.

En cuanto a las condiciones especiales del espacio productivo en relación a la presencia femenina, cabe destacar el hecho de que la empresa proporcionaba cunas que en muchos casos se situaban junto a las mesas de trabajo, como se puede apreciar en algunos de los cuadros del pintor Gonzalo Bilbao. La realidad concreta de estas trabajadoras estaba caracterizada por la conciliación de la vida doméstica con la vida laboral, en una clara interdependencia de ambas como muestra el hecho de que las madres lactantes acudiesen a su puesto de trabajo en compañía de sus pequeños. Esta situación se irá erradicando a medida que evolucione una racionalización del espacio productivo acompañando a la tecnificación y transformación del proceso industrial y se atiendan las necesidades espaciales particulares del colectivo femenino.

Profundizando en la cuestión de la conciliación del ámbito doméstico con el ámbito laboral, en el caso de las cigarreras es importante considerar los lazos de hermandad que se establecían entre ellas y la vinculación que se establecía entre fábrica y espacio doméstico por la cercanía de las viviendas al establecimiento tabacalero y la impronta que imprimía al paisaje urbano sevillano las idas y venidas de sus trabajadoras. La mayor parte de las cigarreras sevillanas residían en el barrio de Triana, en la margen contraria del río Guadalquivir, lo que conllevaba a una estampa en el cruce de las cigarreras en barca desde la margen derecha del río hasta las inmediaciones de la Torre del Oro en su camino diario a la fábrica. De esta forma, la vinculación entre la fábrica, la calle de San Fernando, el puerto y el barrio de Triana establecería el desarrollo de un tejido de relaciones en la extensión de las dinámicas de la fábrica a la ciudad, siguiendo una red que marcaría una impronta de gran relevancia en el paisaje urbano. 


\subsubsection{La Fábrica de Tabacos de Cádiz (1741-1988)}

\section{Contexto histórico hasta su cierre}

La historia de la Fábrica de Tabacos de Cádiz está íntimamente ligada a la de la ciudad en la que se instaló y a la tradición portuaria de la misma, así como su vinculación con la primera factoría tabacalera española: la Real Fábrica de Tabacos de Sevilla.

Cádiz se distingue por ser una ciudad de gran tradición comercial y portuaria desde la época fenicia y por la constante lucha de poder y competencia con Sevilla en el papel de sede del comercio marítimo del Sur peninsular. Precisamente, el comercio marítimo fue la actividad principal de la urbe en los siglos XVII y XVIII y la importancia de Cádiz en las relaciones comerciales con el continente americano se incrementó hasta el punto de que derogaría el monopolio que sobre esta actividad disfrutaba hasta ese momento la ciudad hispalense ${ }^{54}$.

A lo largo del XVIII sería Cádiz la capital llamada a desempeñar aquel papel director y hegemónico $\mathrm{y}$, en consecuencia, pese a la cercana y abrumadora presencia sevillana, a marchar en vanguardia de algunas de las costumbres generadas en la sociedad española a la sombra de nuestras relaciones con el Nuevo Mundo. Entre ellas, el uso del tabaco [...]

Cádiz pasó a monopolizar su comercio [...] Se manifestaría también en el crecimiento de una serie de centros y actividades tabaqueros que, salvo en Sevilla, no se generaron conjuntamente en ningún otro lugar del país a lo largo de aquel siglo: éstos eran una fábrica, una administración y una red de distribución y venta. Para mayor protagonismo Cádiz contó también con otra importante dependencia, la Factoría de tabacos, sin duda la de mayor relieve entre todas las establecidas en el país ${ }^{55}$.

También sería pionera en la contratación de personal femenino, y el mayor aprecio de los consumidores por las variedades de tabaco de humo elaboradas por la fábrica gaditana junto a la mayor competitividad en destreza y habilidad de los productos realizados por mujeres, decantaría la balanza de las elaboraciones a favor del modelo empleado en la fábrica gaditana.

Precisamente, el consumo de cigarros empieza a popularizarse en Sevilla y Cádiz en las primeras décadas del S.XVIII ya bajo el reinado de la dinastía de los borbones. Es este auge en el consumo y demanda de cigarros o "tabaco de humo" el que daría origen a la Fábrica de Tabacos de Cádiz como filial de la tabacalera hispalense en la elaboración de tabaco torcido, contando con diversas variedades como largos, medianos y chicos. Posteriormente, esta predilección del consumidor por el cigarro convertiría a la filial gaditana en modelo de las restantes fábricas tabacaleras de la Renta, tanto en materia de espacio productivo como en la organización y en la elección del empleo

${ }^{54}$ VV. AA. (2003) op. cit. En esta publicación se señala que ya existía actividad industrial tabaquera en Cádiz a finales del S.XVII.

55 RODRÍGUEZ GORDILLO, J. M. (2002b) op. cit., p. 222. 
de mano de obra femenina para la realización de las labores.

La primera fábrica tabacalera gaditana fue creada por Felipe $\mathrm{V}$ y data del año 1741 estableciéndose en un caserón frente a la que entonces se conocía como Puerta de Sevilla, en un enclave en el que posteriormente se alzó el edificio de la aduana. Este primer establecimiento daría empleo inicialmente a unas 180 operarias que a finales de siglo sobrepasarían los cinco centenares. Tras su traslado temporal a un inmueble de la céntrica calle del Rosario, ocupa su ubicación definitiva en 1829 al instalarse finalmente en el inmueble de la antigua alhóndiga en la actual calle Plocia, pasando a denominarse Fábrica Nacional de Tabacos de Cádiz. Posteriormente, el ayuntamiento cedió el inmueble al Estado con la condición de la reversión de su titularidad al cese de la actividad fabril tabacalera que albergaba ${ }^{56}$.

Testimonio de la importancia de la que gozaba la fábrica en la época de entre-siglos es el hecho de que su modelo productivo pasaría a ser el referente de los restantes inmuebles fabriles del monopolio, adoptando frecuentemente en su fundación el reglamento de la factoría de Cádiz, y enviando a cigarreras de la misma a las distintas fábricas de nueva creación para que instruyesen a las aprendizas ${ }^{57}$. Como indica Rodríguez Gordillo,

Alicante recibió de ella un inspector de labores y varias maestras encargadas del aprendizaje de las nuevas operarias. La Coruña se estableció según el modelo existente en la manufactura gaditana, e incluso Sevilla, al implantarse su establecimiento de mujeres, también recibió dos maestras y media docena de cigarreras, que ilustraron a las recién incorporadas aprendizas hispalenses ${ }^{58}$.

En 1828, un año antes del traslado de la factoría a su emplazamiento definitivo, se realizaría la cesión de su arriendo al Estado que pasaría a ostentar la titularidad de la misma. La creación de la que se denominaría como Fábrica Nacional de Tabacos de Cádiz y sus almacenes posteriores, se encuadra en el marco del periodo ilustrado de la urbe gaditana correspondiente a la primera revolución industrial (1830-1888) que se caracterizó por la confluencia de la tradición artesanal manufacturera y la modernización tecnológica de los procesos $^{59}$. La industria del tabaco fue precursora de un proceso de expansión, crecimiento y aporte científico a partir del empleo de nuevas fuentes de energía.

No obstante, la fábrica cesó su actividad por un breve periodo entre 1870 y 1871 al que siguió su reinauguración por cuenta del

56 SANTÍAS, A. y LERA, D. (1898) op. cit., p. 9.

57 En este sentido, tanto Paloma Candela Soto como Ana Romero Masiá o Luis Alonso Álvarez refieren la importación del modelo gaditano a las Fábricas de Madrid y La Coruña y al envío de elaborantas gaditanas para realizar tareas de instrucción del nuevo personal empleado. CANDELA SOTO, P. (1997) op. cit., p. 28.; ROMERO MASIÁ, A. (2007) op. cit., p. 24; y ALONSO ÁLVAREZ, L. (2001) op. cit., p. 27.

58 RODRÍGUEZ GORDILLO, J. M. La Fábrica de Cádiz, esa gran desconocida, recogido en Cadizpedia http://cadizpedia.wikanda.es/wiki/F\%C3\%A1brica_Nacional_de_Tabacos_(C\%C3\%A1diz) [acceso el 3-6-2015]. Pese al gran interés que podía suponer para la presente investigación la consulta de este documento de Rodríguez Gordillo, lamentablemente no se ha podido localizar. Tan sólo se cuenta con las citas de otros autores.

59 SANTOFIMIA ALBIÑANA, M. (2012) op. cit., p. 19. 
Ayuntamiento de Cádiz que se encargó de los costes de instalación de maquinaria y las pertinentes obras de reforma iniciadas en 1872. Con ello se perseguía la modernización de la que había sido una de las más significativas plantas fabriles del monopolio hacendístico tabacalero. Sin embargo, no sería hasta una década después que se acometería sobre la fábrica la gran reforma que configuró su fisonomía tal y como la conocemos actualmente. Como relata Francisco Javier Lomas Salmonte,

en 1881, el Ayuntamiento volvió a tomar la iniciativa sobre la Fábrica de Tabacos gaditana dándole nuevos impulsos. Se propuso la construcción de un nuevo edificio mejorando su arquitectura y procurando el embellecimiento de la ciudad. Bajo la alcaldía de don Enrique del Toro, las obras se iniciaron en febrero de 1883, según un proyecto de Federico Gil de los Reyes y con un coste aproximado de 680.000 pesetas. La obra se terminó a mediados de 1885 y la Hacienda pública se comprometió a dar trabajo a cerca de 4.000 operarios $^{60}$.

Respecto a la cifra de operarios indicada en el fragmento anterior, pese a las aspiraciones de la Renta de Tabacos, la fábrica gaditana no llegó a exceder los dos millares de cigarreras empleadas en sus momentos álgidos de contratación. La reinauguración de la fábrica se realizó en 1887 coincidiendo con la cesión del arriendo sobre el monopolio de tabacos a la CAT y con muchas de las obras de reforma que se estaban acometiendo sobre las fábricas decimonónicas para su adecuación a las nuevas condiciones de modernización de la producción.

A lo largo del S.XX, la fábrica gaditana experimentó una evolución similar al resto de sus homólogas con las progresivas mejoras de la CAT en materia de servicios complementarios para el personal y la progresiva mecanización de las labores, no sin cierta reticencia por parte de sus operarias -el motín de 1887-88 gaditano es de los más destacables en la historia del monopolio español-. También contribuiría al desarrollo de su producción en la época de la Guerra Civil, el hecho de que fuese una de las fábricas que ya desde inicios de la contienda se encontró ubicada en el territorio de los alzados.

Sin embargo, no sería hasta finales de la década de los 60 que experimentaría las mayores reformas en el impulso de la mecanización. La concentración en el establecimiento gaditano de la producción de cigarros -junto a La Coruña, Gijón y Logroño- la convirtió en objeto de reformas para aumentar su parque mueble de liadoras, además de la "instalación completa de fabricación de tabaco-banda, de humectación continua de capas, de preparación de rama para tripa, además de calderas nuevas para sustituir a las antiguas y de transportadores de elaborados y carretillas eléctricas" ${ }^{61}$. Esto la convertiría en una de las unidades fabriles más productivas en la elaboración de cigarros.

En la década de los 80 se instalaría en Cádiz el Centro Industrial Tabaquero que contaba con una fábrica de cigarros y un área especializada en las labores previas a la fabricación de cigarrillos. Este centro integraría las labores de la antigua fábrica de la calle Plocia

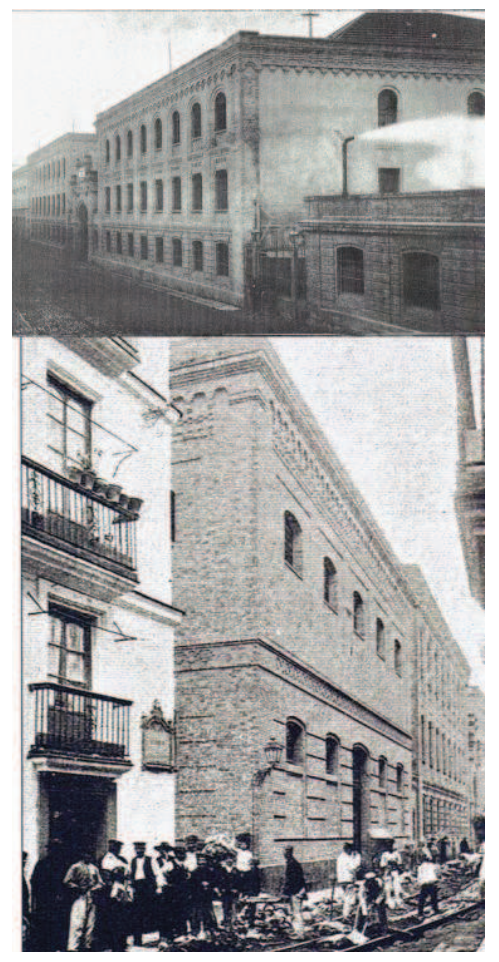

Figura 3.22. Fotos históricas de la Fábrica de Tabacos de Cádiz, en SANTÍAS, A. y LERA, D. (1898) op. cit., p. 8; y en 1906, en COMÍN COMÍN, F. y MARTÍN ACENA, P. (1999), op. cit., $p$. 229 . 


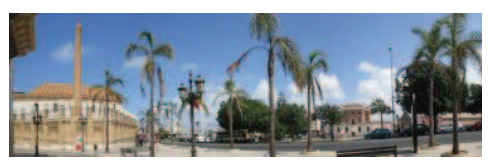

Figura 3.23. Entorno de la fábrica gaditana, 2015 . hasta el cierre definitivo de la misma en el año 1988, en que parte de su personal se trasladaría a las nuevas instalaciones cercanas a la zona franca del puerto. Por su parte, esta última planta cesó su actividad en 2014 trasladando sus efectivos a las plantas de Logroño -Polígono de El Sequero- y Santander -Polígono de Entrambasaguas-

\section{Motivos estratégicos de la fundación fabril e implantación en su entorno}

La fábrica de tabacos fue el centro fabril más importante del casco histórico gaditano, imprimiendo con la entrada y salida de las cigarreras el ritmo de los barrios colindantes. El recorte de su chimenea sobre el skyline de Cádiz junto al sonido emitido por la sirena, configuraban un paisaje urbano característico en la zona.

La Fábrica de Tabacos de Cádiz, como se apuntó en el anterior epígrafe, ocupó diversos emplazamientos en enclaves relevantes del núcleo urbano histórico gaditano, comenzando por la primera factoría cercana a la antigua Puerta de Sevilla en el espacio urbano conocido actualmente como plaza de Sevilla frente a la estación ferroviaria de 1861. Posteriormente, ocupó de forma temporal un inmueble de la calle Rosario y finalmente se trasladaría en 1829 a la antigua alhóndiga de la calle Plocia -muy cercana a los enclaves anteriores- sobre la que se construiría en 1883 el inmueble que conocemos hoy en día como la Fábrica Nacional de Tabacos de Cádiz bajo proyecto del ingeniero Federico Gil de los Reyes.

Precisamente, esta situación privilegiada en el borde del casco histórico gaditano situaba a la fábrica en una conveniente relación de cercanía con el puerto y, posteriormente, con el ferrocarril, dos de los recursos más importantes en el correcto desarrollo de la industria tabacalera en la adquisición de materia prima y distribución del producto elaborado. Además, se encontraba en una posición muy cercana a la entrada terrestre del istmo protegida por la fortificación de la Puerta de Tierra.

Tras el derribo de las murallas que rodeaban el núcleo urbano principal, se creó la plaza de Sevilla contigua a la fábrica, recordando mediante su topónimo la anterior Puerta de Sevilla que se ubicaba en el mismo espacio. Frente a la misma, se construiría la estación de ferrocarril en la segunda mitad del S.XIX en una operación que remodelaría el entorno próximo a la fábrica de tabacos ${ }^{62}$. La presencia del ferrocarril resultó de capital importancia en el funcionamiento de la fábrica, puesto que suponía la conexión por medios terrestres, no sólo

62 "La llegada del ferrocarril será el comienzo de la transformación del frente portuario [...] En 1861, el ferrocarril llega a Cádiz a través del arco general de la bahía, enlazando además las localidades de Puerto Real y San Fernando. Para su construcción se realiza un relleno al pie de la muralla, inaugurando un nuevo acceso a la ciudad alternativo a la entrada desde tierra firme por las Puertas de Tierra y cercano a la auténtica puerta de la ciudad: la Puerta del Mar en la muralla, ante la plaza del Ayuntamiento." JIMÉNEZ MATA, J. J.; MALO DE MOLINAMONTALVO, J. Y RUIZ NIETO-GUERRERO, M. P. (2011) Cádiz: guía de arquitectura del siglo XIX, Consorcio para la Conmemoración del Bicentenario de la Constitución de 1812, p. 121. Sobre el edificio de la estación de ferrocarril, se trata de una arquitectura de hierro de 1890 y "contribuía a la configuración del espacio portuario ante la ciudad, como réplica del edificio de la Aduana Vieja en el lado opuesto (actual Diputación).” JIMÉNEZ MATA, J. J.; MALO DE MOLINA-MONTALVO, J. Y RUIZ NIETO-GUERRERO, M. P. (2011) op. cit., p. 166. 
con la factoría sevillana, si no que se permitía la posibilidad de su enlace con las restantes tabacaleras existentes.

El entorno se completaría muy posteriormente con la construcción de la nueva sede de la Aduana según un diseño racionalista propio de la estética oficial del régimen franquista, que trataba de armonizar con las líneas clásicas de la antigua aduana situada en el otro extremo del puerto, completando el cierre que delimitaba este espacio urbano ${ }^{63}$.

Por otra parte, cabe destacar que la influencia de la Fábrica de Tabacos de Cádiz no se limitó sólo a su entorno inmediato, sino que también se extendió a lo que en aquellos tiempos constituía la periferia urbana.

A medida que creció la producción de labores, fueron proliferando los almacenes de tabaco en las cercanías de las fábricas, ubicados en locales alquilados e inadecuados para esa función [...] la Hacienda no había podido construir almacenes por falta de fondos, y obligó a la Arrendataria a establecer tres depósitos generales de tabaco, para abastecer centralizadamente a las fábricas [...] La Compañía propuso [...] que dichos depósitos se construyeran en Santander, Cádiz y Madrid [...] la [construcción] del depósito de Madrid concluyó en 1895; los otros se acabaron aún más tarde: el de Santander en 1901 y el de Cádiz en $1910^{64}$.

Por tanto, las necesidades del proceso productivo tabacalero y su constante demanda de espacio libre para el almacenaje, conllevó a la construcción de unos depósitos para tabaco a principios del S.XX en la zona franca del puerto de Cádiz, de forma análoga a los que se construyeron en el puerto santanderino para dar servicio a la tabacalera montañesa ubicada en la popular calle Alta de la ciudad.

Colmatados los espacios intramuros, las industrias buscaron su sitio extramuros aprovechándose de una mejor accesibilidad a los sistemas de distribución.

En un solar situado en las cercanías de la zona franca del puerto de Cádiz, con la que se conectaba originalmente a través del ferrocarril, encontramos los depósitos de Tabacalera (1910), producto del incremento del consumo derivado del aumento de la población y de la extensión del hábito al medio rural ${ }^{65}$.

De esta forma, como señala Santofimia Albiñana, dentro del contexto de la nueva política de gestión promulgada por la CAT se construyen en 1910 los nuevos depósitos de la fábrica de tabacos, facilitando los requerimientos espaciales de almacenaje. Este complejo se componía de un área de almacenaje y distribución, junto a un área residencial que se

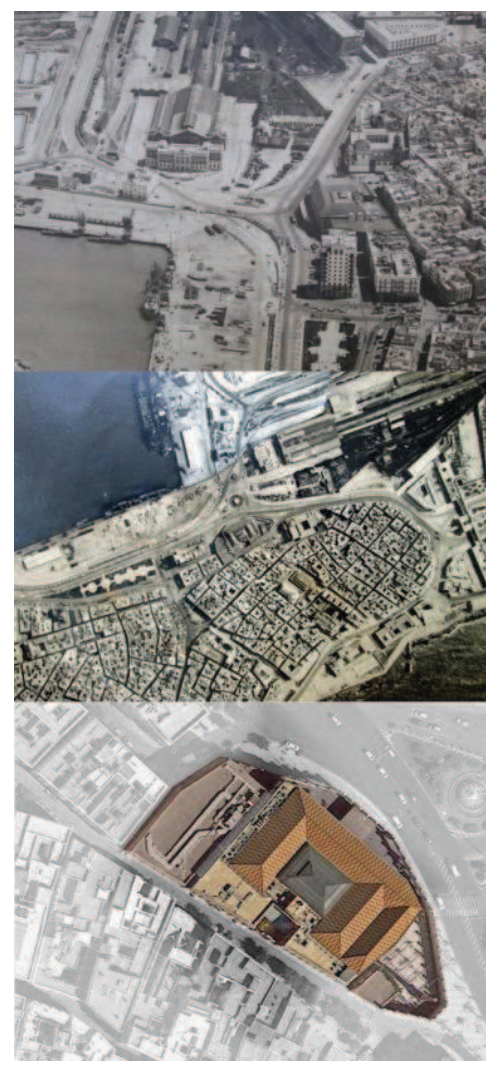

Figura 3.24. Ubicación de la Fábrica de Tabacos de Cádiz, fotografías aéreas, en $A H M C$, y emplazamiento en la actualidad.

63 "La Aduana Nueva data de la década de los 50, y fue proyectado por el arquitecto Manuel Ródenas López [...] El estilo oficial o la tendencia consagrada, se plasma en una serie de rasgos concretos, como la combinación de piedra y ladrillo, que permite obtener calidades de expresión, o la aplicación de principios compositivos y elementos propios de un lenguaje formal y decorativo de corte clasicista, caso de severidad, la simetría y la resolución del cuerpo central mediante un basamento almohadillado y un orden de columnas jónicas rematado con un gran escudo nacional." En Base de datos Patrimonio Inmueble de Andalucía www.iaph.es/patrimonio-inmuebleandalucia/resumen.do?id=i29364 [acceso el 25-6-2015]

${ }^{64}$ COMÍN COMÍN, F. y MARTÍN ACEÑA, P. (1999) op. cit., p. 147.

65 SANTOFIMIA ALBIÑANA, M. (2012) op. cit., pp. 19-20. Los depósitos de tabaco gaditanos ocupan una extensión de casi $50.000 \mathrm{~m}^{2}$ en el barrio de Loreto y, en la actualidad, se prevé su recuperación para la ciudad como equipamiento urbano. 


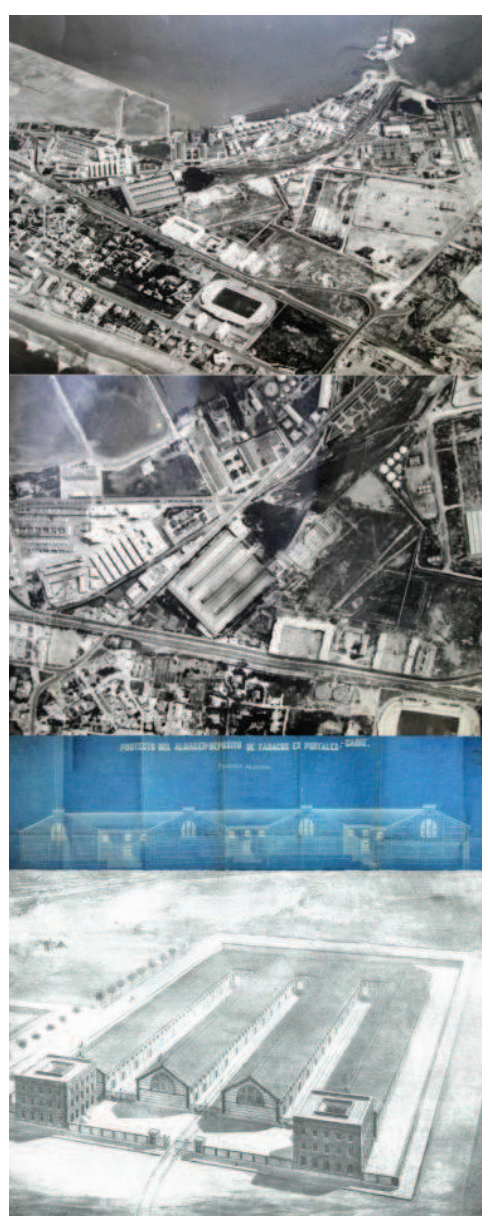

Figura 3.25. Depósito de tabaco de Puntales: vista aérea, ortofoto y alzado, en $A H M C$; y perspectiva, en COMÍN COMÍN, F. y MARTÍN ACEÑA, P. (1999), op. cit., p. 277. desarrollaba en dos edificios de planta cuadrada organizados en torno a un patio y una altura de tres pisos, compuestos según un lenguaje ecléctico acorde al gusto de la época.

El área de almacenaje, por su parte, constaba de cuatro naves paralelas y una perpendicular a ellas, entre las que se situaban los andenes del ferrocarril que optimizaban la descarga y distribución del material procedente del puerto. De esta forma, la fábrica de tabacos, el puerto y sus dependencias auxiliares estaban estrechamente vinculados mediante la infraestructura ferroviaria, quedando aprobada en 1911 la "construcción de una vía férrea para enlazarlo [el depósito de tabacos] con la estación de Puntales, una carretera de servicio y unos pabellones para oficinas y viviendas" 66 .

Anexa a la nave transversal de almacenaje, se encontraba el área de distribución que se componía de dos naves en L destinadas a carga de mercancías para su reparto por vía rodada. El conjunto estaba rodeado por una cerca de ladrillo visto color rojizo y piedra ostionera del lugar, como en la fábrica de tabacos, característico de la condición defensiva que adquirían todas las construcciones de la industria tabacalera-. La ordenación de los depósitos se completaba mediante un jardín de trazado regular junto al acceso principal que se encontraba flanqueado por dos garitas que controlaban la entrada y salida de trenes a los andenes. Este conjunto, valorado desde su interés patrimonial, se encuentra a la espera de una intervención de recuperación.

Queda patente, por tanto, la relevancia que la Fábrica de Tabacos de Cádiz como elemento urbano aglutinador de dinámicas ostentaría en la transformación del paisaje de la ciudad gaditana, tanto en su entorno inmediato y en la próxima relación establecida con el centro histórico, como en la periferia industrial y portuaria.

\section{Características de la arquitectura fabril}

Dado que de las primeras localizaciones de la fábrica gaditana no se puede determinar ninguna conclusión sobre su arquitectura por la imprecisión de su ubicación o la falta de vestigios materiales, centraremos la atención en el inmueble que ha llegado a nuestros días. En 1881 una ley acuerda ampliar la factoría de Cádiz, siendo el ayuntamiento el que toma la iniciativa de negociar con la Hacienda Pública una ampliación de la plantilla de cigarreras en un incremento de 1.000 a 2.000 operarias. El Estado puso como condición la acometida de una reforma del inmueble para la ampliación y adaptación del mismo a las nuevas exigencias espaciales y técnicas acordes a la modernización de la producción y cuyos gastos correrían por cuenta del consistorio gaditano.

El convenio se estableció, pues, en septiembre de 1881, procediendo a iniciar los trabajos de reforma con arreglo al proyecto del ingeniero

${ }^{66}$ COMÍN COMÍN, F. y MARTÍN ACEÑA, P. (1999) op. cit., p. 236. 
Federico Gil de los Reyes ${ }^{67}$ asistido por el ingeniero de la Dirección de Rentas Estancadas Mauro Serret. Los trabajos de reforma finalizaron en 1885 procediendo a la reinauguración de la fábrica el 27 de junio de 1887. Este gran proyecto de reforma alteraría las estructuras de la antigua alhóndiga que se había reaprovechado para la instalación de la nueva fábrica de tabacos, exceptuando la zona de bóvedas situada en planta baja. No en vano, el resultado de este proyecto configuraría de forma decisiva la imagen del edificio que ha llegado a nuestros días.

La configuración del conjunto en su maciza fachada ejecutada en ladrillo visto adoptó un lenguaje de corte neomudéjar, estilo que respondía al gusto ecléctico de la época y que se encontraba en otros ejemplos de arquitectura civil como estaciones de ferrocarril, mercados o plazas de toros, presentando en algunos aspectos rasgos comunes con las fábricas inglesas y la construcción tradicional en ladrillo en la resolución de detalles. De esta forma, la fachada contaba con la sencillez de las construcciones industriales de la época, sin renunciar a ciertas concesiones decorativas y al carácter monumental tan característico de las fábricas tabacaleras en su lienzo exterior. Precisamente, el neomudéjar será el estilo empleado años más tarde en la construcción de la nueva fábrica de tabacos valenciana. Además del ladrillo mediante el que se ejecutaron los paramentos, también se emplearían piezas de cerámica vidriada en las cubiertas, que otorgan al inmueble el característico perfil que se observa hoy en día.

El inmueble fabril presentaba tres accesos, siendo la puerta del ingreso principal de medio punto, con un frontón que se remataba con el escudo de Cádiz y que presentaba una altura menor que el resto del edificio. La portada principal se configuraba en dos cuerpos, presentando el primero una placa de mármol con el nombre de la factoría y, sobre la misma, el mencionado escudo de la ciudad. Por su parte, el segundo cuerpo presentaba otra placa con la fecha en la que se había renovado el inmueble -1883-1884-, y debajo de esta placa se alojaba el primer reloj eléctrico de la ciudad.

A través del zaguán y del marcado acceso principal, el conjunto se dividía en dos cuerpos simétricos conectados al fondo del vestíbulo previo al aire libre, en el que se alzaba la gran fachada sobre la que se proyectaba el frontón. Esta segunda fachada presentaba líneas más severas y sobrias pero sin restar elegancia al conjunto de la composición. Tras el zaguán, se accedía a un vestíbulo que ejercía de espacio distribuidor con la presencia de las escaleras que comunican verticalmente con los pisos superiores. Tras este segundo vestíbulo interior se encontraba el patio principal, elemento vertebrador de la espacialidad del conjunto y que se hallaba cubierto por una montera de

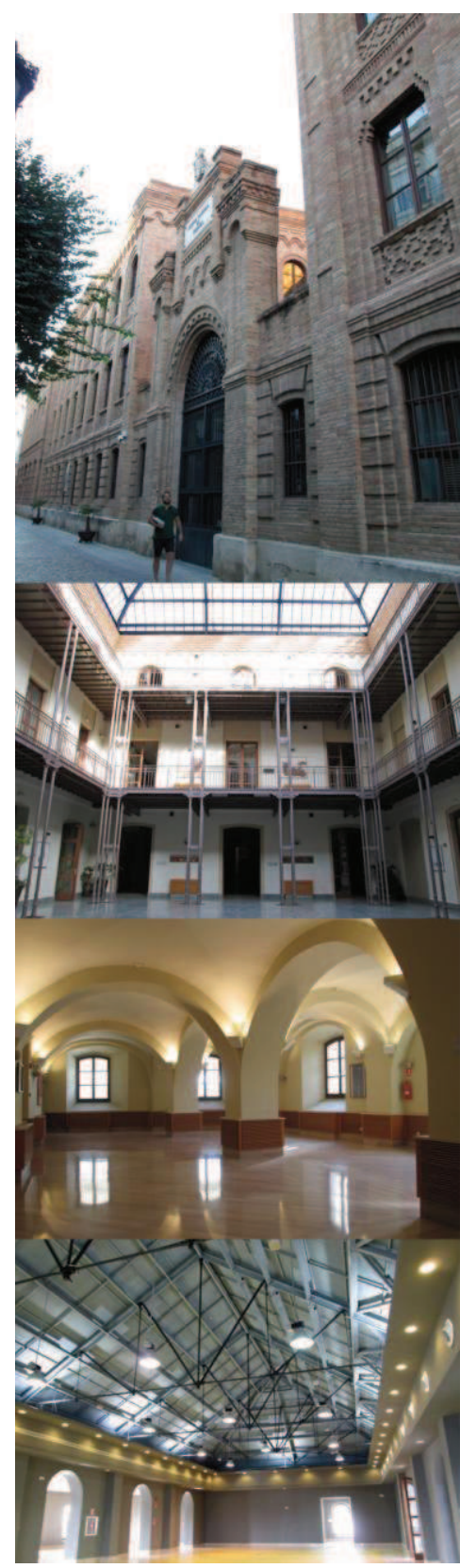

Figura 3.26. Elementos característicos de la Fábrica de Tabacos de Cádiz en la actualidad: acceso principal, patio y talleres, 2015 .

67 El ingeniero industrial Federico Gil de los Reyes (1834-1906) desarrollaría su obra fundamentalmente en la capital gaditana. Hermano probablemente de Juan Gil de los Reyes -inspector del alumbrado municipal de Cádiz-, se convirtió en el empresario de gas de San Fernando y tuvo un papel crucial en el desarrollo del sector de los telégrafos, con la redacción de un estudio para una línea de Málaga a Almería. Además de la reforma de la Fábrica de Tabacos de Cádiz (1881-1885), su proyecto para la línea de Sevilla a Jerez y Cádiz en 1879 permitió el enlace ferroviario en San Fernando. También tuvo un papel destacado a finales del S.XIX en el desarrollo de la industria del gas en Cádiz. Se recomienda la consulta de FERNÁNDEZ-PARADAS, M. (2015) La industria del gas en Cádiz (1845-2012), LID. 


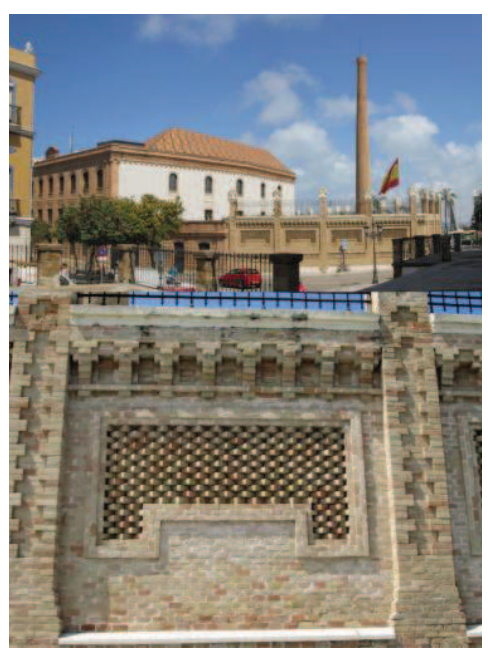

Figura 3.27. Vista de la fábrica desde el exterior y detalle de los motivos decorativos del aparejo,

2015. fundición y hierro.

Finalmente, la tapia exterior que cercaba el conjunto presenta motivos decorativos de sebka -que con su entrelazado geométrico de retícula oblicua presentaba paralelismos con las arquitecturas de origen islámico, en esta composición estilística de carácter neomudéjar- y remates almenados cuyos interespacios se cuajaban mediante rejas. El resto de los paramentos murarios presentaban el ladrillo cara vista con un aparejo inglés 68.

Alcanzando una altura de tres pisos, el espacio se distribuía sobre una planta irregular que conformaba una manzana exenta, encontrándose en su interior interesantes estructuras de hierro, entre las que sobresalían las que resolvían las conexiones del patio y el gran lucernario de fundición y vidrio que lo cubría ${ }^{69}$. En el lateral Norte se ubicaban los almacenes de productos elaborados, mientras que la parte posterior albergaba los talleres de elaboración y antiguamente disponía de un corredor que rodeaba esta zona de la fábrica. Todos los talleres daban al patio principal, siendo las ventanas y puertas del primer piso adinteladas, mientras que las del segundo se remataban con un arco de medio punto. La estructura en corredor que doblaba el lienzo murario del patio era de hierro, estando soportada por columnas pareadas de fuste liso que presentaban elementos decorativos de hierro fundido propios de la época.

El conjunto se completaría con la construcción entre 1895 y 1897 de un almacén anexo adosado al lienzo Noroeste y cuya fachada de ladrillo fino visto se diferenciaba de la del edificio original mediante un aparejo distinto. Sus líneas de proporciones racionalistas denotaban su clara función industrial y su carácter de depósito. Estos almacenes guardan una composición en fachada similar a los que se ejecutarían en la fábrica de tabacos coruñesa y en los proyectos de las fábricas tarraconense y malagueña a principios del S.XX.

Este tipo de intervención se alinea con las reformas efectuadas a la sazón en otras fábricas decimonónicas que adolecían desde su fundación de un problema endémico de carencia de espacio y buscaban su ampliación por todos los medios posibles, incluso arrendando para tal efecto espacios deslocalizados en otros puntos de la ciudad. Según la publicación de Santías y Lera, coetánea a la construcción del nuevo almacén,

por todas estas circunstancias y las que reúne el edificio, que se completó no ha mucho con la construcción de un magnífico almacén anexo capaz

\footnotetext{
68 Se recomienda la consulta de la ficha correspondiente a la fábrica de tabacos en la Base de datos de Patrimonio Inmueble de Andalucía http://www.iaph.es/patrimonio-inmueble-andalucia/resumen.do?id=i1434 [acceso el 4-62015].

69 VV. AA. (2003) op. cit. Durante la visita realizada en agosto de 2015 a la antigua fábrica -actual Palacio de Congresos- como parte del trabajo de campo sobre el caso estudio gaditano, diversas fuentes locales apuntaron a la posible atribución de las estructuras metálicas del patio principal a un discípulo del afamado Gustave Eiffel.
} 
para contener todo el surtido de la Fábrica, bien se puede decir que ésta llena el fin que sus iniciadores propusieron al reedificarla, de que fuese modelo entre los de su clase ${ }^{70}$.

Como se puede comprobar, a principios del S.XX la fábrica gaditana conformaba un complejo industrial constreñido dentro del muro que cercaba su parcela y que constaba del edificio principal de la fábrica, el almacén adosado a la misma y un pabellón de maquinaria eléctrica que se ubicaba en la parte Sureste del solar junto a la alta chimenea de ladrillo. Como apunta Paloma Candela Soto, se trataba de un moderno ejemplar dentro del conjunto de fábricas del monopolio, albergando en su interior un equipamiento mecánico en el que se combinaban las aplicaciones tecnológicas del vapor, la fuerza hidráulica y la energía eléctrica ${ }^{71}$.

\section{El espacio productivo y su evolución hasta 1945}

La gran significación de la Fábrica de Tabacos de Cádiz en la historia de las arquitecturas fabriles del monopolio tabacalero español radica en que, además de constituir cronológicamente la segunda fundación tras la Real Fábrica de Tabacos de Sevilla, fue tomada como modelo organizativo y espacial para las generaciones decimonónicas de fábricas que establecieron la expansión territorial de la industria tabacalera en el contexto peninsular.

Como se ha señalado anteriormente, la vinculación del trabajo de producción tabacalero a la figura de la mujer nació en este mismo establecimiento y promovería su modelo en las restantes fábricas que verían sus comienzos fuertemente influenciados por la factoría gaditana. Las preferencias de los consumidores por los productos de tabaco de humo hizo que el proceso de liado por las hábiles manos femeninas, junto a la reorganización del espacio en función de este cambio cualitativo del proceso productivo en mesas agrupadas en ranchos y partidos, plantease la adecuación de la primera factoría tabacalera española y sentase las bases para la fundación de nuevos establecimientos en la península. Ya a finales del S.XVIII, en la localización anterior al que sería el establecimiento fabril definitivo, la fábrica se estructuraba en 90 ranchos y contaba con 580 operarias. El traslado definitivo al solar que anteriormente ocupaba la alhóndiga le permitiría un sustancial crecimiento del volumen de mano de obra, pasando a dar ocupación a unas 1.500 operarias y 100 varones, y se comenzarían las labores de cigarrillos de papel ${ }^{72}$.

La organización de los espacios productivos en el inmueble de la calle Plocia se realizaba de forma vertical y en las distintas estancias configuradas en torno al patio principal. En la planta baja se ubicaban los talleres de desvenado y preparación de rama, así como los destinados a picaduras y empaquetados mecánicos por fuerza hidráulica, siguiendo la lógica que imperaría en las restantes fábricas en la ubicación en los pisos inferiores de las tareas que más desperdicios

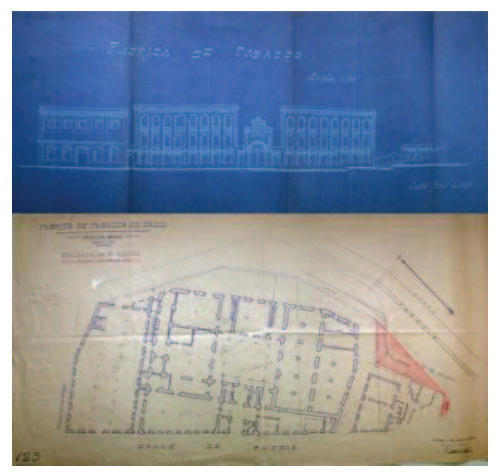

Figura 3.28. Planimetría de la Fábrica de Tabacos de Cádiz: alzado de 1925 y planta de 1939, en $A H M C$.

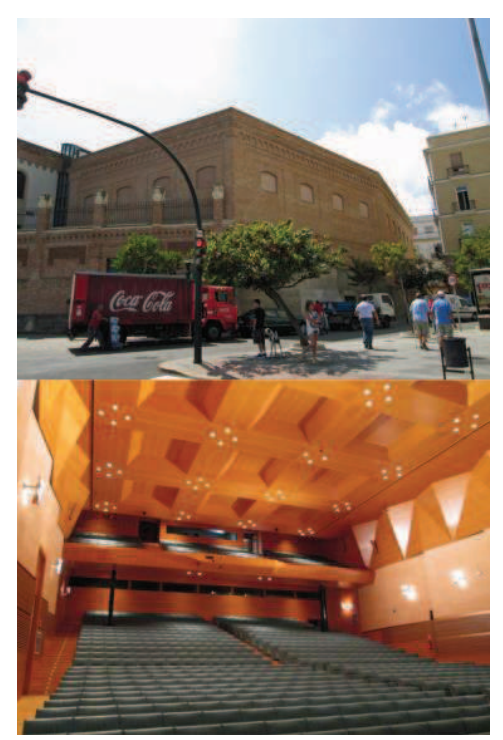

Figura 3.29. Fachada e interior actual del almacén de la fábrica gaditana, 2015 .

\footnotetext{
${ }^{70}$ SANTÍAS, A. y LERA, D. (1898) op. cit., p. 11.

${ }^{71}$ CANDELA SOTO, P. (1997) op. cit., p. 29.

72 COMÍN COMÍN, F. y MARTÍN ACEÑA, P. (1999) op. cit., p. 75.
} 


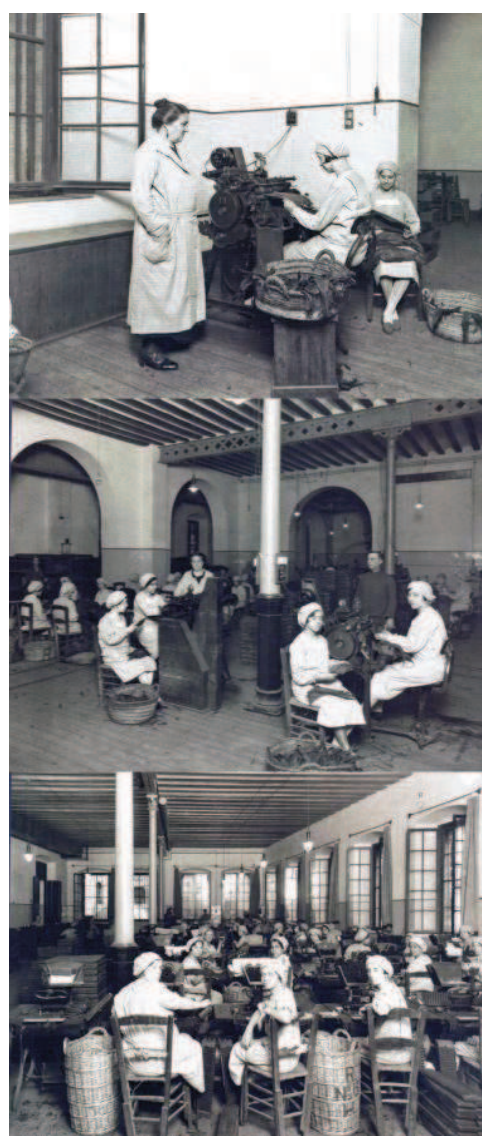

Figura 3.30. Espacios productivos de la fábrica de Cádiz, en COMÍN COMÍN, F. y MARTÍN ACEÑA, P. (1999), op. cit., pp. 224-225 y 241.

generaban. También en planta baja se ubicaban próximas al ingreso principal las oficinas de Administración e Intervención y los almacenes de tabacos en rama y elaborados, así como el oreo de las picaduras. En toda la planta baja existía una completa red de línea Decauville mediante la cual circulaban vagonetas que facilitaban el transporte de materia prima y productos elaborados. El empleo de transporte interno por líneas ferroviarias era una constante tanto en el monopolio francés como en algunas de las tabacaleras que integraban el parque del monopolio español.

Por su parte, la primera planta albergaba los talleres de cigarros peninsulares, marca chica y comunes fuertes, así como el oreo de cigarros y el despacho del ingeniero director de la fábrica. En el segundo piso se ubicaban los talleres de cigarrillos finos y comunes, además de los departamentos de recepción y encajonado de estas labores y las oficinas en las que se efectuaba la inspección de los elaborados. Finalmente, en el tercer piso había un local destinado al reloj de la torre.

Además del edificio principal y el anexo de almacenaje, la fábrica contaba con un pabellón de máquinas donde se ubicaban los generadores y el motor de vapor, transmisiones y dinamos para el alumbrado eléctrico y el funcionamiento de los montacargas, además de una gran báscula de puente fijo y una grúa hidráulica a la entrada de dicho pabellón.

Los espacios productivos de la fábrica presentan los rasgos comunes a las restantes tabacaleras españolas. Los distintos departamentos destinados a talleres eran amplios y disponían de buena ventilación y condiciones lumínicas. El patio interior principal se hallaba cubierto por una montera de hierro y cristales curvados y planos, y las galerías a modo de corredor que recorrían las fachadas del mismo, contaban con un pavimento de baldosas de vidrio que coadyuvaban a la buena iluminación del interior. Entre las mejoras técnicas, Santías y Lera destacan a finales del S.XIX

diversas aplicaciones prácticas del vapor, la electricidad y la fuerza hidráulica.

Entre las múltiples de la electricidad podemos contar el alumbrado por arco voltaico e incandescencia, teléfonos, timbres, avisadores electroautomáticos para casos de incendio, pararrayos, montacargas eléctrico y la unificación de la hora por un péndulo regulador que la transmite a los diferentes talleres y departamentos por 17 relojes simpáticos y uno de torre $^{73}$.

Es interesante destacar en este punto la descripción de la fábrica que el ingeniero Antonio Muncunill realiza en 1905:

La Fábrica de Tabacos consta de planta baja, piso principal y segundo. Una parte está cubierta con azoteas y otra con teja plana vidriada,

${ }^{73}$ SANTÍAS, A. y LERA, D. (1898) op. cit., p. 11. 
apoyada sobre un armazón de hierro formado por cuchillos sistema inglés, con sus correspondientes correas y cabrios. La puerta principal de entrada al establecimiento la cierra una elegante, sólida y bien construida cancela de hierro; a derecha e izquierda del zaguán y frente una de otra se encuentran dos pequeñas habitaciones, destinadas la primera a la portera mayor y la segunda a retretes para empleados. Está cubierto por una esbelta bóveda de cañón el mencionado zaguán, el cuál comunica con el patio del vestíbulo mediante una segunda cancela de cristales. Este patio es de forma rectangular, de 12,05 metros de longitud por 4,40 metros de ancho y cubierto por una elegante montera curva de cristales, de ligero armazón de hierro, y sirve de paso para las oficinas del Jefe, Intervención y Caja. A continuación del mismo y frente a la puerta principal, desembocan a derecha e izquierda dos escaleras de mármol, que dan comunicación con los talleres de los pisos superiores y azoteas. Sigue luego el patio central, de forma rectangular también, de 24,24 por 15,80 metros, cubierto de cristales apoyados sobre una esbelta armadura curva de hierro. Está rodeado este patio en los pisos principal y segundo por amplias y hermosas galerías de hierro, con pavimento de baldosa de cristal, las que sirven de paso para los diferentes servicios del establecimiento, las cuales apoyan sobre elegantes y ligeros pares de columnas de fundición ${ }^{74}$.

Los espacios que ocupan las dependencias junto al acceso principal de la fábrica gaditana -tradicionalmente los espacios administrativos, de registro y de representación de la cúspide jerárquica- están precedidos de espacios representativos como el zaguán y el vestíbulo principal y enmarcan claramente su condición de "exclusa" entre el ámbito exterior y el interior. En comparación, la fábrica hispalense disponía de un conjunto de espacios organizados en torno a patios que colindaban con la fachada principal y que suponían el ambiente previo al espacio productivo en sí.

Finalmente, como destaca Paloma Candela Soto:

la factoría de Cádiz emergía como modélica en el plano organizativo. El apropiado diseño de su estructura al uso industrial se reflejaba en la distribución espacial de sus dependencias: oficinas, patios, talleres y almacenes. En el plano de la fabricación, el trabajo se organizaba en función de los talleres existentes, es decir, la organización interna dependerá, como en el resto de las fábricas, de la labor destinada a cada taller ${ }^{75}$

\section{Las cigarreras y la dimensión humana de la fábrica}

A lo largo de los epígrafes anteriores, se ha referido la influencia que la fábrica gaditana tuvo en los restantes establecimientos del monopolio como modelo tanto del espacio productivo como de la organización de la producción tabacalera. Sus métodos productivos basados en la elaboración de tabaco en humo y el empleo de mano de obra femenina para tal fin, sentaron el precedente que se implantaría en las sucesivas fundaciones que se realizaron a lo largo del S.XIX. En este sentido, Paloma Candela Soto refiere en su obra la importancia que tuvo la

${ }^{74}$ MUNCUNILL, A. (1906) op. cit.

${ }^{75}$ Este fragmento y el siguiente en CANDELA SOTO, P. (1997) op. cit., pp. 29 y 27, respectivamente. 
fábrica de Cádiz en el establecimiento de una nueva factoría en Madrid:

el trabajo de las mujeres, expresión de mano de obra más barata, junto con la idea preconcebida de la mayor habilidad y docilidad resultaron determinantes. La habilidad en el aprovechamiento y cuidado de las labores puesta de manifiesto por las cigarreras de la Fábrica de Cádiz fueron la experiencia piloto que se exportó al resto de las fábricas emergentes en la península.

En el caso de la factoría madrileña, Candela Soto destaca que en la segunda década del S.XIX se estableció una estancia que se denominaba "Establecimiento de mujeres" en la que las futuras cigarreras de la tabacalera capitalina recibían una formación instruida por empleadas de la Fábrica de Tabacos de Cádiz. De igual forma, otros autores refieren el papel clave en la formación recibida por las cigarreras aprendizas de veteranas gaditanas que se trasladaban a las nuevas fundaciones fabriles para ejercer la instrucción: La Coruña, Gijón, Santander, Sevilla, etc. En el caso de la fábrica hispalense, se produjo una reconversión de la organización productiva, ya que como se refirió anteriormente, su fundación estaba condicionada por el método de elaboración del tabaco en polvo.

En su obra de finales del S.XIX, Santías y Lera describen los espacios interiores de la fábrica gaditana de la siguiente forma "los departamentos destinados a talleres son muy amplios y con buena luz y ventilación, su mobiliario moderno y cómodo para la operaria y los comedores que hay en ellos con mesas de mármol y cocinas económicas"76. Los mismos autores señalaban que el número de operarias en ese momento ascendía a 1.561 empleadas. Pese a ser una de las fábricas que mayor volumen de contratación alcanzó sobrepasando los dos millares en sus momentos álgidos-, nunca llegó a los tres o cuatro millares de operarias a los que se había comprometido el Estado a cambio de que el ayuntamiento gaditano costease las obras de reforma de la fábrica de los años 1883 y 1884 .

Por otra parte, existe un amplio registro fotográfico de los ambientes productivos de la fábrica gaditana, parte del cual se recoge de forma profusa en la obra de Comín Comín y Martín Aceña y que supone el registro de la memoria de una fábrica pionera en el empleo de mano de obra femenina.

\subsection{La primera generación de fábricas del S.XIX}

Ante la popularización del consumo del tabaco entre las clases populares y la expansión de las prácticas contrabandistas, el monopolio hacendístico vio necesario el desarrollo de una estrategia que paliase el fraude que proliferaba principalmente en los puertos peninsulares en los que se recibía hoja de tabaco. Por una parte, se necesitaba aumentar la producción para que los niveles de consumo oficial se equiparasen a los que se nutrían de la venta ilícita. Por otra parte, este

${ }^{76}$ SANTÍAS, A. y LERA, D. (1898) op. cit., p. 11. 
desarrollo difícilmente podía ser asumido por las dos únicas fábricas existentes en España, a lo que se añadían las dificultades del control territorial peninsular debido a la circunstancia de que la entrada de tabaco en un puerto determinado conllevaba con toda seguridad la elaboración fraudulenta de tabaco en dicha urbe.

Por tanto, en la época de entre-siglos se decide que la mejor estrategia para abordar esta situación sería una expansión territorial gradual de la producción tabacalera, acercando el producto a los centros de consumo y paliando la elaboración fraudulenta con la instalación de fábricas en aquellos puertos receptores de hoja de tabaco. De igual forma, la ubicación de estas factorías en diversos puntos de la costa peninsular y alejados entre sí respondía a dos motivos: la mayor cubrición de territorio para la posterior distribución a las expendedurías provinciales, y evitar la concentración de mano de obra en ciudades próximas.

En estos términos, asistimos a una primera generación de fábricas decimonónicas que se ubicarían en Alicante, La Coruña y Madrid, cubriendo el Norte, Este y zona centro de la península. Estas fábricas, fundadas en la primera década del S.XIX y que se añadían a los pioneros establecimientos de Sevilla y Cádiz, compartirían entre sí la elección de un edificio preexistente para su fundación, adaptando espacios concebidos para usos, en algunos casos, radicalmente diversos a la producción tabacalera. Esta estrategia de reutilización de un inmueble preexistente, que suponía la disposición rápida y poco costosa de un establecimiento fabril tabacalero que en poco tiempo podía iniciar la producción, fue una práctica extendida a lo largo del S.XIX que, con la evolución de la producción y sus requerimientos espaciales a lo largo del tiempo, acarreó no pocos problemas con la incipiente mecanización de finales de siglo.

\subsubsection{La Fábrica de Tabacos de Alicante (1801-2001)}

\section{Contexto histórico hasta su cierre}

Estableciendo un recorrido cronológico, el primer inmueble religioso que se adaptó con fines industriales tabacaleros es la Fábrica de Tabacos de Alicante, constituyéndose como el tercer inmueble fabril creado por el monopolio tras la Real Fábrica de Tabacos de Sevilla y la Fábrica de Tabacos de Cádiz. Perteneciente a la primera generación de fábricas decimonónicas, se instaló en 1801 en la Casa de la Misericordia Obispal propiedad de la iglesia. Construida entre 1751 y 1752, funcionaba también como casa conventual y albergue de mendigos.

La importancia de la urbe alicantina como ciudad portuaria y punto de partida del eje comercial hacia Castilla resultó decisiva para la ubicación de un establecimiento tabacalero en Alicante. En su obra, Caridad Valdés Chápuli indica que "son muy pocos los datos que sobre producción se han encontrado de la fábrica de Tabacos de Alicante en el 
primer periodo de explotación directa por la Hacienda Española"77, limitándose al registro de entradas y salidas del producto en el puerto de Alicante en 1801, año de apertura de la fábrica.

La fábrica alicantina fue una de las más longevas y su historia comienza con la cesión por parte del obispo a la Dirección de Rentas Estancadas de las estancias que anteriormente habían sido reservadas para los Prelados de Orihuela y para un colegio, a fin de que se estableciese en ellas la nueva fábrica de tabacos. Como relata Valdés Chápuli, esta práctica se trataba más bien de una venta o expropiación que de una cesión dado que se apoyaba en el instrumento legal que proporcionaba la Ley de Enajenación de Casas de la Misericordia, Hospitales, Hospicios, Cofradías, Obras Pías y patronatos legos de septiembre de 1798 siguiendo la política de Floridablanca según la cual el Estado debía ostentar la competencia de las funciones sociales. De esta forma, la Casa de Misericordia Obispal de la urbe alicantina, que hasta el momento había funcionado como albergue de mendigos y residencia habitual del Obispo de la Curia, pasó a destinar parte del inmueble como factoría tabacalera.

El edificio en que se halla instalada se construyó á [sic] mediados del pasado siglo para albergue de pobres, tomando el nombre de Casa de Misericordia, hasta que en 1801 el Obispo en aquel entonces, D. Francisco Cebrián y Valda, cedió al Estado las habitaciones dispuestas para convento de monjas salesas y algunas otras [...] en el año de 1838, y debido á [sic] la importancia que adquirió la fabricación de tabacos, ocupó todo el edificio menos algunas habitaciones que se reservaron á [sic] la iglesia ${ }^{78}$.

En este sentido, la fábrica alicantina presenta ciertas diferencias con sus homólogas de Gijón, Santander y Logroño. No se trataba precisamente de un edificio conventual, aunque su origen era ciertamente religioso y conservaba muchas de las particulares características de este tipo de inmuebles. La especial condición de edificio-albergue y casa episcopal indicaba que no se trataba de una expropiación al uso como las acometidas con la posterior desamortización de Mendizábal, en la que la titularidad pública de este tipo de edificios puso en bandeja a los consistorios la opción de ofrecerlos al monopolio tabacalero como sede para la fundación de un nuevo establecimiento tabacalero en su correspondiente ciudad. La situación especial de la factoría alicantina radica en que sólo parte del inmueble fue cedido, conviviendo la industria tabacalera con las estancias episcopales y la iglesia durante décadas, hasta que en los años 50 del S.XX fue posible la adquisición del inmueble en su conjunto. Esta tensión dialéctica entre la fábrica y las estancias religiosas motivó no pocos conflictos en la complicada convivencia entre estas funciones tan dispares y de las que se darán cuenta con posterioridad.

77 VALDÉS CHÁPULI, C. (1990) op. cit., p. 43. Para el caso estudio de la Fábrica de Tabacos de Alicante se seguirá especialmente esta publicación de Caridad Valdés Chápuli.

78 SANTÍAS, A. y LERA, D. (1898) op. cit., p. 5. 
La Fábrica de Tabacos de Alicante constituyó la primera factoría de la primera generación de fábricas decimonónicas, seguida de la fundación de las fábricas de La Coruña y Madrid. Ante la crisis experimentada en la época de entre-siglos

la reorganización de la renta no había de pasar por un descenso de los precios, sino por la mejora de la calidad del producto, ampliando el abanico de ofertas y asegurando un abastecimiento pleno del mercado. Con ese objetivo se decide emprender la construcción de un segundo grupo de fábricas (Alicante, Coruña y Madrid) cuya finalidad sería la de elaborar una producción de calidad (cigarros de la Habana y Virginia) con menores costes que en las viejas factorías al emplear personal femenino, y asegurando una producción abundante, al proceder al empleo masivo ${ }^{79}$.

A mediados del S.XIX, la fábrica sería objeto de importantes reformas de ampliación y adecuación iniciando las tareas de acondicionamiento de los talleres para su mecanización, especialmente los de picado ${ }^{80}$. Dada la gran tradición de la factoría alicantina en el modelo de elaboración manufacturero, la reestructuración iniciada con la implantación de los métodos mecanizados provocó serios conflictos que desembocaron en las protestas luditas de finales del S.XIX y principios del S.XX.

Finalmente, la realidad se impuso a las protestas de las cigarreras y, al igual que en las restantes factorías del monopolio, los años veinte del S.XX constituyeron un periodo de fuerte mecanización con la instalación de nueva maquinaria y la reorganización de los talleres que desembocó en una reducción del personal. No sería hasta mediados del S.XX que la fábrica ocuparía en su totalidad el antiguo inmueble religioso, experimentando numerosas reformas con los planes de modernización acometidos por Tabacalera como sucesora de la CAT.

Pese a las sucesivas reestructuraciones que se acometerían en la fábrica durante las décadas siguientes con objeto de adaptarse al mercado y a los requerimientos del sector impuestos por la entrada de España en la Comunidad Económica Europea, la creación de Altadis y la privatización del sector abocó al cierre de la fábrica alicantina en 2001 y su traslado a las nuevas dependencias sitas en el Polígono de Las Atalayas, inauguradas en julio de 2002. Esta nueva unidad fabril, creada en su momento como una de las más modernas del grupo Altadis, concentró la producción de cigarrillos negros que anteriormente se elaboraban en las fábricas de Valencia, San Sebastián y Madrid. No obstante, en 2008 se anunció su cierre, haciéndose efectivo en 2010 con el consiguiente traslado de sus efectivos a la planta logroñesa ubicada en el Polígono de El Sequero.

\footnotetext{
79 ALONSO ÁLVAREZ, L. (1984) op. cit., p. 17.

${ }^{80}$ En este punto, cabe recordar la existencia de un establecimiento subalterno de la factoría alicantina en Alcoy que llevó a cabo su actividad entre 1858 y 1872. En este sentido, también la fábrica gijonesa contó con un establecimiento auxiliar en Oviedo, que finalmente serían reabsorbidos por las fábricas de las que dependían. En el caso de la factoría de Alcoy, se dedicaba principalmente a la elaboración especial de cigarrillos de papel, así como a la producción del propio papel dada la tradición industrial de la localidad alicantina en este sector. Para más información sobre la Fábrica de Alcoy, BENEITO LLORIS, A. y SALINAS SALINAS, C. (1991) op. cit.
} 


\section{Motivos estratégicos de la fundación fabril e implantación en su entorno}

Como se apuntaba en el epígrafe anterior, la importancia de la urbe alicantina como ciudad portuaria y punto de partida del eje comercial hacia Castilla resultó decisiva para la ubicación de un establecimiento tabacalero en Alicante. No en vano, existen documentos que indican la presencia de una primera factoría en el puerto alicantino entre la calle Génova y la calle Mayor, aunque probablemente se tratase de un depósito de almacén, dado que en los siglos XVII y XVIII este tipo de edificios adoptaba la denominación de "factoría", tal y como se apuntó en el capítulo segundo de la presente investigación.

A lo largo del S.XVIII Alicante vive una etapa de recuperación económica que se centra en el comercio y su movimiento portuario, principalmente en su primera mitad.

Por un lado llegaban a su puerto mercancías extranjeras necesarias para la propia subsistencia de la ciudad, por otro el comercio exterior se vio favorecido por la preferencia que Castilla manifestó al elegir la vía Castilla-Alicante, a través del valle Vinalopó ${ }^{81}$.

Debido a esta coyuntura favorable, el puerto alicantino se declaró a mediados del S.XVIII como puerto exclusivo de entrada de tabaco importado de Lisboa, Amsterdam y Virginia, completando el grupo de puertos peninsulares relevantes en el comercio del tabaco junto con Sevilla, Cádiz, Málaga y Barcelona. Pese a que durante la segunda mitad del S.XVIII Alicante experimentó un crecimiento regresivo del comercio portuario, la Hacienda Española decide establecer su tercera fábrica de cigarros en la ciudad, reactivando la actividad de su puerto.

La significación de la instalación de la factoría tabacalera en Alicante no se lee sólo respecto a su posición estratégica por su carácter portuario en el contexto territorial del monopolio, sino también por la influencia que el edificio ejercería en la evolución urbanística de la ciudad. Su ubicación a los pies del monte Benacantil motivaría una expansión de la ciudad hacia dicha zona, acompañando el recorrido diario de las cigarreras hacia sus puestos de trabajo. Esta expansión hizo necesaria la creación de un sistema de transportes urbano por tranvías de tracción animal que comunicaban la ciudad con San Vicente del Raspeig y otros pueblos periféricos como San Juan de Alicante, Muchamiel y Santa Faz, en atención a las numerosas cigarreras que acudían a su turno de trabajo desde estas localidades. En este sentido, destaca Valdés Chápuli que "es curioso como el camino diario de estas mujeres ocasionó además, la extensión y creación de determinados barrios, ubicados cerca de la fábrica, en los caminos de acceso a estos pueblos, como por ejemplo el del Pla del Bon Repos".

81 VALDÉS CHÁPULI, C. (1990) op. cit., pp. 21-22, citando a GIMÉNEZ LÓPEZ, E. (1981) Alicante en el siglo XVIII. Economía de una ciudad portuaria en el antiguo régimen, Institución "Alfonso el Magnánimo", Diputación Provincial de Valencia. 
La mayor parte de las fábricas de origen religioso o conventual contempladas en la presente investigación se localizaban en el tejido urbano colmatado, lo que impedía su expansión acorde a las necesidades productivas y las privaba de una adecuada red viaria para el abastecimiento y la exportación de materia prima y producto. Sin embargo, la factoría alicantina supuso una excepción a esta regla, ya que su ubicación relativamente periférica junto al monte Benacantil posibilitaba la adquisición de parcelas adyacentes a la antigua Casa de la Misericordia obispal para la ampliación de la fábrica. Este hecho propició que las sucesivas reformas de ampliación configurasen la factoría a través de una organización más estructurada que en sus homólogas de Gijón, Santander y Logroño. La progresiva ampliación de la parcela inicial que ocupaba el inmueble preexistente junto a las sucesivas reformas urbanísticas de las que fue objeto el entorno de la fábrica, han forjado a lo largo de los dos últimos siglos una interacción mutua entre la fábrica y el desarrollo urbanístico circundante a través de la modificación de sus condiciones de borde, configurando la imagen actual del paisaje urbano de la zona.

A finales del S.XIX ya se ve necesaria la adquisición de parcelas colindantes para permitir la expansión del recinto, así como la acotación del espacio mediante la construcción de un cercado que protegiese el ámbito interior del entorno. De esta forma, en 1918 se acomete el cierre perimetral del conjunto, habilitando delante de la fachada principal un gran jardín de ingreso que dejaba un espacio representativo de respeto y permitía la creación de una calle interior que organizaba la circulación del ingreso a la fábrica. El cierre se realizó mediante verjas que dejaban libre el paso hacia el espacio eclesiástico que, recordemos, mantuvo su uso original hasta mediados del S.XX.

En 1923 se continuaría la redefinición de las condiciones de borde de la fábrica mediante la elevación del muro de la cerca, acentuando el carácter fortificado y coercitivo, así como la ampliación de los límites de la fábrica con objeto de construir nuevos edificios auxiliares hacia la calle Sevilla. Estos nuevos pabellones surgirían como consecuencia de la primera alineación de la anterior vía y la actuación se completaría con la instalación de un nuevo trazado del tendido del tranvía.

Sin embargo, el gran proyecto de modificación del entorno de la fábrica se iniciaría en 1926 con la adquisición de unos terrenos al Norte de la parcela hacia la calle San Carlos, al tiempo que el ayuntamiento expropiaba parte del terreno de la fábrica para el proyecto de realineación de la calle Sevilla. La fábrica de tabacos alicantina aprovechó esta circunstancia para realizar una obra de gran envergadura con objeto de solventar las constantes carencias de espacio en el interior de la fábrica, con la construcción en la década de los treinta de nuevos almacenes en la parte Norte de la parcela.

En primer lugar, la nueva alineación hacía necesario derribar una serie de pabellones antiguos y en mal estado, dedicados a taller de recomposición de cajones y contrarregistro, adosados a la C/ Sevilla a la izquierda del edificio de la fábrica, reconstruyéndose en el proyecto

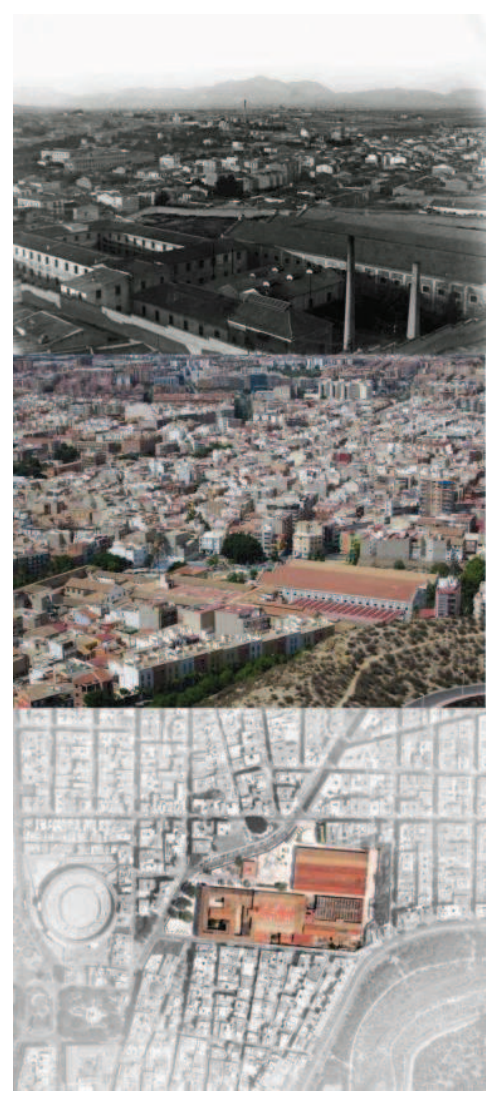

Figura 3.31. Fotografía histórica del entorno de la fábrica, en $A M A$; y emplazamiento en la actualidad, 2015. 


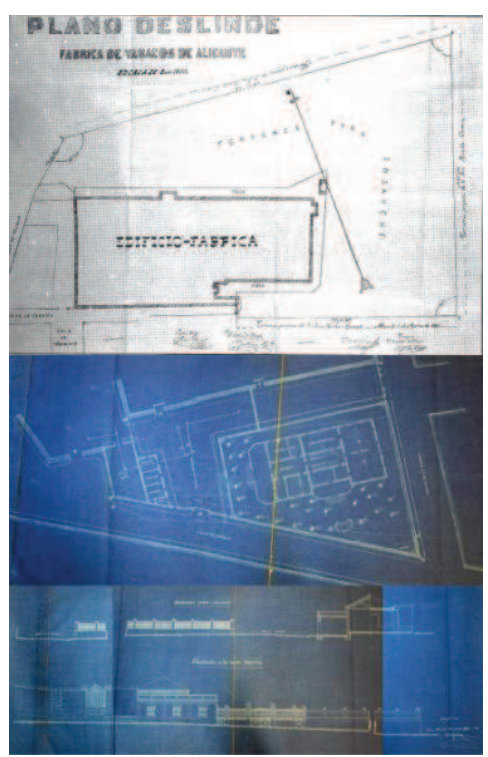

Figura 3.32. Proyecto de ampliación de la parcela de 1885, en VALDÉS CHÁPULI, $C$. (1990) op. cit., p.30; y proyecto de nueva entrada y edificios auxiliares de 1923, en $A M A$. estos pabellones. Así mismo, requería el derribo del muro de cerca en esta calle, y considerando la primacía que con los ensanches sufridos tenía la misma sobre la c/ Fábrica, hasta ese momento calle de acceso al edificio, se plantea la necesidad de mejorar el aspecto externo de esta fachada y de crear un nuevo acceso por esta calle, independizándose a su vez de la entrada a la Iglesia, mediante la colocación de puertas y verjas de hierro en la C/ Sevilla, reparando y homogeneizando con el proyectado, el muro de la cerca de la C/ Fábrica que amenazaba ruina ${ }^{82}$.

Aunque se tratará en un epígrafe posterior, cabe destacar nuevamente el papel fundamental que tuvo la fábrica de tabacos como hito urbano configurador de las dinámicas de su entorno y que, dada la presencia próxima de las viviendas de las cigarreras, contribuía a generar un particular paisaje urbano en el que se entretejían distintas capas de lectura: la trama urbana, la trama de la producción y la trama de las operarias.

\section{Características de la arquitectura fabril}

El origen episcopal del edificio en el que se estableció la fábrica influyó decisivamente en el proyecto de adaptación de la misma, manteniendo incluso la convivencia con las funciones religiosas hasta mediados del S.XX. Partiendo de la configuración del inmueble preexistente, se produjeron una serie de adiciones en los años veinte del S.XIX hacia el Este del complejo, ampliando el conjunto mediante una configuración claustral de tres pabellones alrededor de un patio. Con el tiempo, la progresiva complejización de las necesidades productivas tabacaleras provocaron la transformación de las dependencias existentes y la aparición de otras nuevas, como las tres naves destinadas a almacenes que se construyeron en la parte Norte del recinto a finales del primer tercio del S.XX. El conjunto fabril se extendió en un solar cercado de más de $25.000 \mathrm{~m}^{2}$ de los que más de $13.000 \mathrm{~m}^{2}$ correspondían a la superficie ocupada por el inmueble fabril.

\section{La preexistencia: la Casa de Misericordia Obispal}

Para conocer a fondo la repercusión que el edificio preexistente construido entre 1751 y 1752 , medio siglo antes de la fundación fabriltendría en la configuración de la nueva fábrica, resulta conveniente analizar sus características fundamentales según la descripción del inmueble realizada por el cronista Vivarens, recogida en la obra de Valdés Chápuli:

El edificio consta de tres cuerpos de obra y se erigió sobre un perímetro de $3.166 \mathrm{~m}^{2}$.

La casa estaba rodeada por un foso, delante del mismo, se extendía una plazuela donde estaban las caballerizas, una cochera para los carruajes

82 VALDÉS CHÁPULI, C. (1990) op. cit., p. 36. 
de los lacayos y un hermoso jardín que se extendía en la parte opuesta de aquella ${ }^{83}$.

Encontramos aquí una característica muy determinante en la arquitectura de las fábricas de tabacos en España y que respondía a su hermetismo frente al exterior: el control y defensa del espacio interior con elementos propios de otras arquitecturas coercitivas. En este caso, el foso del edificio en el que se instaló la fábrica de tabacos alicantina recuerda al foso construido ex profeso para la fábrica de nueva planta sevillana y que fue tomada, salvando la diversidad de arquitecturas en las que se instalaría la industria tabacalera en España y sus características particulares, como ejemplo de las primeras fundaciones fabriles del monopolio que respondían al modelo de fábrica compacta.

El frontispicio principal, que presenta el aspecto de un palacio, tenía en su primer cuerpo diez ventanas de rejas y una gran puerta en el centro que daba entrada a todo el edificio; en el segundo cuerpo había doce balcones con vistosas repisas; en el tercero se ven igual número de ventanas, y la fachada está rematada por una cornisa de piedra de las canteras de esta ciudad y en sus alturas se descubría la torre campanil, que ya no existe, la del reloj, que se conserva, y una esbelta cúpula con su linterna vestida de tejas azules, que dan al conjunto una agradable perspectiva.

La puerta de este gran edificio muestra una portada que luce labores bastante buenas; es de piedra blanca labrada y pertenece al orden toscano; a los lados pedestales sosteniendo hermosas estatuas de S. Pedro y S. Pablo; en el dintel se ve una cornisa, destacándose sobre ella el escudo de armas que usaba el Sr Gómez de Terán; en el centro de la portada, sobre la puerta que exorna, se descubre una hornacina adornados sus lados con jarrones y ramaje, en el cual se venera una imagen en piedra que representa a la Virgen de la Misericordia cobijando en su manto a hombres, mujeres y niños y el remate de toda esta costosa obra consiste en un hermoso relieve que se ostenta sobre aquella hornacina y representa el corazón de Jesús adornado por serafines.

Además de la reiteración del carácter coercitivo del inmueble, materializado en las rejerías de la planta baja, y la aparición del reloj, símbolo que marcaría el ritmo de la vida de las fábricas en la reorganización de finales del S.XIX con las pautadas entradas y salidas a la misma, se encuentra en este pasaje otro de los motivos principales que caracterizan la arquitectura fabril tabacalera en España, esto es, la importancia de la fachada principal como elemento de significación de la fábrica que adopta un valor monumental y que define la relación que el conjunto establece con su entorno.

Penetrando en el edificio por la puerta que luce estos detalles, se encuentra en primer término un atrio en cuyas paredes había cuatro puertas: las del lado izquierdo daban paso, la primera a una gran escalera que subía a las habitaciones del Sr. Obispo, consiste en una antesala, dos salones adornados con boceles a la Romana, Oratorio,

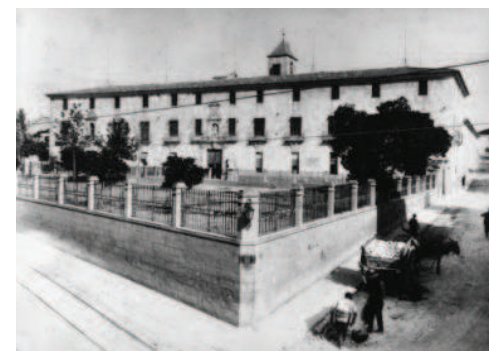

Figura 3.33. Acceso principal a la fábrica, fachada del antiguo inmueble religioso, en $A M A$.

83 Este pasaje y siguientes corresponden a VALDÉS CHÁPULI, C. (1990) op. cit., pp. 24-25. 
departamentos para la Secretaria de su Ilma., y muchos dormitorios para familiares, comedor, cocina y despensa; y por la segunda puerta se entraba a la estancia para mujeres acogidas en esta casa, y a otras habitaciones que estaban destinadas a señoras de distinción, que por haber llegado a la indigencia acababan su vida en el asilo de la misericordia.

Había también en esta parte del edificio un claustro cerrado con verjas, que tenía una fuente y pozo; una sala para depositar a las doncellas que salían de sus casas por no asentir los padres o tutores a sus contratos matrimoniales; otra para las peregrinas que pasaban esta ciudad; once cuartos para matrimonios pobres; que buscaban albergue en esta casa, una sala para las mujeres escandalosas..., salones para las labores de las acogidas, una pieza de seis encierros para castigar a éstas si se desmandaban en alguna desvergüenza; un refectorio muy espacioso y un patio donde había un gran lavadero para limpiar la ropa de las asiladas.

La configuración claustral como principio ordenador del conjunto es otro de los invariantes de las fábricas de tabacos en España que encontramos en Alicante. Como se apreciará más adelante, las reformas de expansión de la fábrica que permitieron su crecimiento hacia el Este, replicaron esta configuración en torno a un gran patio de mayores dimensiones.

Por la puerta practicada en el lado derecho del atrio se encontraba el cuarto del portero, que tenía dos dormitorios, y se comunicaba por otra puerta con el local destinado para hospedar a peregrinos y viandantes y con las cuadras que habitaban los acogidos quienes tenían junto a sus departamentos un claustro muy anchuroso para esparcirse, en cuyo centro se abrió una fuente para limpieza de aquellos.

\section{La Fábrica de Tabacos de Alicante}

Con posterioridad a la gran reforma de adecuación del edificio preexistente a la nueva función industrial, el progresivo crecimiento de la fábrica de tabacos obligó a nuevas reformas que se materializaron en 1828 bajo la dirección del arquitecto de la plaza Antonio Jover. Estas obras correspondían a la apertura de espacios diáfanos en las crujías, dada la necesidad de incremento de superficie productiva demandada por una actividad en constante crecimiento. Estas nuevas ampliaciones se realizaron, en un primer momento, dentro del propio recinto preexistente. En 1838 quedó suprimido el asilo que se había fundado en 1751, tras lo cual el Estado incautó el establecimiento para ampliar la fábrica, respetando sólo la iglesia, las estancias del Obispo y algunas otras dependencias.

Sin embargo, como solía ocurrir con frecuencia en las tabacaleras decimonónicas, el 20 de mayo de 1844 acaeció un incendio que destruyó gran parte de las instalaciones en su parte Este, entre ellas el establecimiento de molido mecánico de picaduras. Este hecho tendría gran trascendencia en la memoria colectiva de la fábrica, como evento traumático que fue, pero también como símbolo de la recuperación de un establecimiento fabril tan valioso para la urbe y para sus 
ciudadanos. Los trabajos de reedificación fueron acometidos por el Estado, aprovechando este contratiempo para efectuar una ampliación del inmueble, lo cual acarreó cuantiosos gastos. Esta circunstancia da testimonio de la importancia que la factoría alicantina tenía para la Dirección General de Rentas Estancadas.

Las obras de reconstrucción se llevaron a cabo por el arquitecto de la plaza Emilio Jover, aprovechando la remoción de las partes afectadas para la reparación de otros desperfectos que venía acarreando la construcción original, concerniente al deterioro de la obra de fábrica, forjados y cubiertas. La reforma se llevó a cabo en dos fases, correspondientes a la reconstrucción de las zonas derruidas y a la reparación de la parte afectada por el incendio.

Como se apuntaba en el epígrafe anterior, este establecimiento fabril, al contrario que la mayoría de las tabacaleras de origen diverso a la función industrial ubicadas en el tejido urbano colmatado, gozaba de una localización periférica lo que le permitía adquirir parcelas colindantes para ejecutar una progresiva expansión del conjunto. En 1885, dos años antes de la cesión del arriendo del monopolio a la CAT, se realizarían una serie de modificaciones debidas al aumento del consumo tabacalero -que requerían el correspondiente aumento de producción- pero también a la incipiente mecanización del proceso manufacturero. De esta forma, se agrandó el perímetro del conjunto fabril mediante la adquisición de nuevos terrenos adyacentes y la ampliación de las instalaciones, que supuso un aumento de la superficie total a más de 25.500 metros cuadrados, ocho veces superior a la extensión inicial de la preexistente Casa de Misericordia Obispal.

Con la cesión del arriendo a la CAT en 1887 se inició un nuevo periodo de reformas dentro de la nueva política promulgada por la empresa arrendataria, concerniente a las mejoras e innovaciones en la organización y producción de las fábricas. Desde el año de cesión del arrendamiento hasta 1900 se instalarían nuevos talleres como el Taller Mecánico de Picado, la construcción de almacenes interiores y del muro de cerca -1897-1899-, así como la instalación eléctrica -1898- y la creación de una red de alcantarillado -1889-1891-.

Sin embargo, en 1900 aconteció un nuevo incendio en el que resultaron totalmente destruidas algunas naves y maquinaria, así como dos pisos ocupados por depósitos de materiales y accesorios para los talleres mecánicos.

El incendio ha destruido totalmente estos locales habiendo sido derribado toda la construcción excepto paredes y vigas que sostenían la cubierta en la crujía de la izquierda donde la pila de cajones preservó siete vigas de la cubierta que se conservan casi intactas; pero los cajones quedaron perdidos por la acción del humo y del agua ${ }^{84}$.

Durante las dos primeras décadas del S.XX continuarán las reformas promulgadas por la CAT, centradas fundamentalmente en aspectos

84 VALDÉS CHÁPULI, C. (1990) op. cit., p. 32. Refiere como fuente de esta información Archivo de la Fábrica de Tabacos de Alicante A.F.T.A. Copiadores de Cartas, 1 y 3 Octubre 1900. 


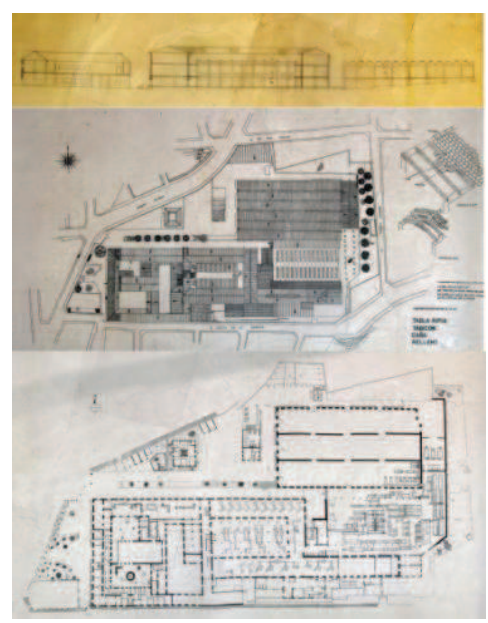

Figura 3.34. Sección longitudinal de 1975 y plantas de 1989-1991 de la fábrica alicantina, en $A M A$. relativos a servicios higiénicos, seguridad y embellecimiento de la fábrica, así como la continuación de la adecuación de los locales para la instalación de maquinaria. Entre 1904 y 1908 se realizan una serie de planes parciales que mejorarían la seguridad en accesos y comunicaciones verticales. También se reforzarían las estructuras para acondicionar el edificio existente a las nuevas sobrecargas que presentaría, sustituyendo las vigas de madera y construyendo forjados de bovedillas cerámicas, además de la reparación de cubiertas y la colocación de un pararrayos.

Dada la falta de espacio de almacenaje y la necesidad de arrendar locales deslocalizados en la ciudad, esta carencia trató de paliarse a través de sucesivas reformas y ampliaciones de la parcela ocupada por el conjunto mediante la adquisición terrenos colindantes. Tras la gran adecuación de las condiciones de borde de la fábrica en los años 20 , se procedió a la construcción de tres nuevos almacenes; a tal fin, el ayuntamiento expropió terrenos al Norte de la parcela colindantes a la calle San Carlos, ejecutando la obra en 1936 a partir del estudio redactado en 1932. Anteriormente, se había ampliado la factoría con la construcción de una nave para el torrefactor, refrescador y demás aparatos de picadura de hebra en 1923, el refuerzo del envigado en el mismo año o la ampliación del almacén interior en 1924.

\section{El espacio productivo y su evolución hasta 1945}

La producción de la fábrica alicantina desarrolló inicialmente un marcado carácter manufacturero dada su temprana fundación y progresivamente reconvertiría sus métodos -y por ende, sus espacioshacia la mecanización de todas las fases productivas. La zonificación del espacio fabril seguía la misma distribución programática iniciada con las fábricas hispalense y gaditana, y que se reproduciría sin grandes diferencias en los esquemas espaciales productivos de las tabacaleras de origen conventual.

En la parte del acceso principal, colindante con el templo eclesiástico y las dependencias que aún pertenecían a la curia, se ubicaban las estancias administrativas y la portería donde se efectuaban exhaustivos registros a la entrada y salida de las cigarreras al edificio. Los talleres se distribuían en torno a los patios en planta baja y primera planta, mientras que las construcciones que se fueron materializando con la progresiva expansión del conjunto hacia el Este de la parcela ampliaron el espacio de almacenaje que se constreñía en el interior del inmueble original. En cuanto a la organización del trabajo anterior a la cesión del arriendo a la CAT en 1887, no todos los talleres eran iguales y cada uno adquiría la función de elaboración de distintas clases de productos tabacaleros. La separación de los talleres no implicaba la división del trabajo y su especialización se realizó de forma tardía, aunque las fases se realizaban de forma clara y ocupando su espacio propio en el inmueble. De esta forma en 1858 se realizaba en la fábrica el desvenado, picado y la elaboración de cigarros y cigarrillos 
Peninsulares y Comunes.

En cuanto a la configuración de los espacios productivos a finales del S.XIX, según Santías y Lera, se estaba realizando un muro de cerca que protegía el conjunto y una serie de almacenes interiores. A la sazón se situaban en planta baja los talleres de desvenado y empaquetado de picaduras, destinando la planta primera a los talleres de cigarros marca chica, cigarros y cigarrillos comunes. Finalmente, en la planta superior se ubicaban los talleres destinados a Cigarrillos Superiores y Cigarrillos Finos, contando con dos máquinas de 90 caballos y dos calderas de vapor para suministrar la fuerza motriz necesaria a la maquinaria del taller de picaduras. Refieren, así mismo, que en aquel momento trabajaban en la factoría unas 4.200 operarias $^{85}$.

Como comenta Valdés Chápuli, la época que va desde la cesión del arriendo a la CAT hasta la segunda década del S.XX constituye un periodo en el que se intentan imponer las medidas promulgadas por el nuevo Reglamento Orgánico que, por otra parte, no gozaban de simpatía por parte de las operarias, que veían cómo su puesto de trabajo peligraba. Hasta los inicios del S.XX, las reformas se centrarán en adecuar el inmueble con obras básicas concernientes a la mejora de sus infraestructuras, como la disposición del alcantarillado aprovechando el proyecto de 1889 del ayuntamiento que dotaba al barrio de San Antón de una apropiada infraestructura sanitaria. De igual forma, se habilita la instalación eléctrica que se reformaría en 1909.

Por otra parte, se procedía a la instalación de los primeros talleres mecanizados, comenzando, como era habitual, por la fase de picado, obra acometida durante julio de 1888 y que enlazaba las estancias de nueva construcción con el antiguo edificio que la albergaba. Nuevamente, tras el incendio de 1900, se aprovecharían las obras de reparación de los desperfectos y reconstrucción de las partes afectadas para continuar las mejoras en materia de infraestructuras.

En la década de los 20 y hasta la Guerra Civil se llevarán a cabo medidas que afectaron a todas las fábricas y que continuaron la adecuación industrial que requería la progresiva mecanización que concentraría todos los esfuerzos de las fábricas.

Desde 1920 a 1925 la adquisición e instalación de máquinas es constante. Las innumerables obras que se realizan en los diferentes talleres y en el edificio de la fábrica de Alicante tienen la finalidad de adecuarse a las nuevas características que dicha fábrica ha ido adquiriendo. Este es el objeto del cambio de envigado de todos los suelos que ahora tienen que ser reforzados por vigas de hierro para soportar el peso de las máquinas [...]

La adquisición de maquinaria implicaba la apertura de la norma rigurosa del "no ingreso" de nuevas aprendizas, obteniendo así esta medida de implantación industrial, un éxito absoluto. Incluso el

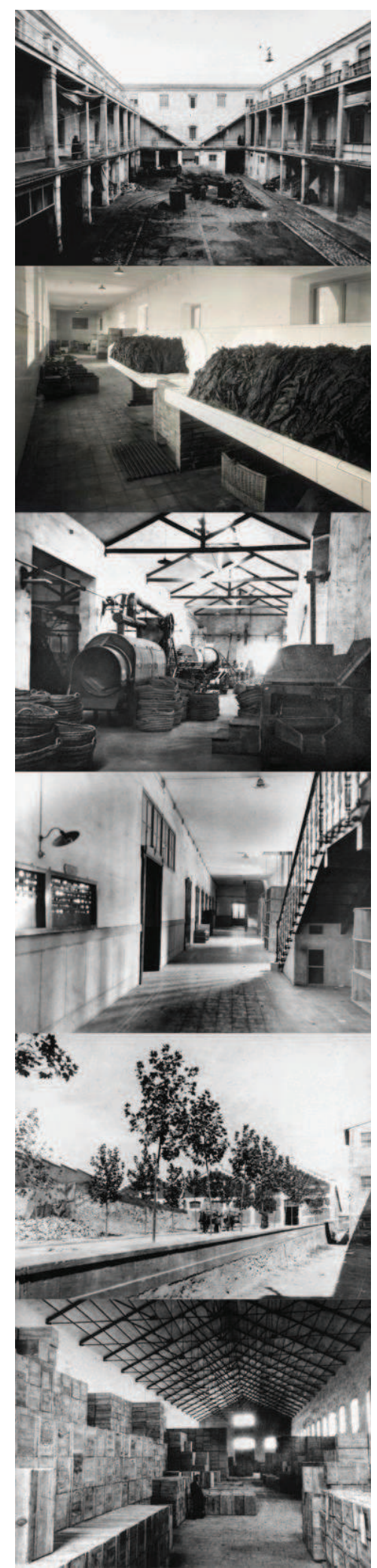

Figura 3.35. Fotos históricas del patio principal, talleres, vestíbulo principal y almacenes de la fábrica alicantina, en $A M A$.

${ }^{85}$ SANTÍAS, A. y LERA, D. (1898) op. cit., p. 6. 
personal obrero llegó en alguna ocasión a oponerse al traslado de las máquinas almacenadas en la fábrica, mientras no ingresara todo el personal que permitiera la cabida del establecimiento ${ }^{86}$.

Para ello se construyó una nave para el torrefactor, para el refrescador y demás aparatos de picadura de hebra en 1923, procediéndose al refuerzo y envigado del piso superior con objeto de soportar el peso de las máquinas ${ }^{87}$. Las obras que tuvieron lugar en los años 30 concentrarían nuevamente las preocupaciones de carácter social que cobrarían relevancia y se situarían en la primera línea de la actividad. Las reformas se dedicarían principalmente a la ampliación y mejora de los servicios higiénicos del edificio.

Llegado este punto, conviene incidir en los problemas endémicos que acompañarían la evolución del espacio productivo en la factoría alicantina. La relación entre la Iglesia, como anterior propietario del inmueble y titular del templo y algunas dependencias, y el Estado, como responsable de la industria tabacalera que se desarrollaba en el interior, mantuvo un carácter tenso dadas las diferencias entre ambos y la obligación a establecer una difícil convivencia entre ambas actividades. El origen de los roces radicaba principalmente en el contrabando, motivo por el que la CAT mostraba gran interés en lograr una total incomunicación con las dependencias ocupadas por la curia.

Por eso cuando en 1922, la Compañía Arrendataria inicia el proceso de modernización y maquinización de las fábricas, se plantea la necesidad imperante de acabar con esta relación. Este innovador proceso no sólo suponía la introducción de maquinaria sino también la modernización y revisión de los edificios destinados a fábrica de tabacos, preveyendo [sic] su traslado a edificios de nueva planta, si eran imposible [sic], a pesar de la realización de mejoras, que éstos reunieran las condiciones necesarias para lograr un centro fabril moderno.

Para conservar la fábrica de Alicante en su actual emplazamiento y aprovechar pues el edificio actual era necesario, si éste se avenía a mejoras, acceder a la propiedad de todo el edificio. Posibilidad que se preveía factible tras las conversaciones mantenidas con el Obispado, iniciándose con tal fin, el principio de unas largas negociaciones que durarían casi 40 años ${ }^{88}$.

Tras la incautación del templo en 1936 para ampliar los locales de la fábrica con la ubicación en el mismo de un servicio de recomposición de cajones, las arduas negociaciones se reanudaron en 1943 hasta que en 1951 se formalizó un acuerdo según el cual el edificio pasaba a registrarse en su totalidad como propiedad del Estado. Se daba fin, pues, a una difícil situación que obstaculizó el normal desarrollo de la

86 VALDÉS CHÁPULI, C. (1990) op. cit., p. 53. Sobre la oposición del personal obrero refiere el documento A.F.T.A. Copiadores de Cartas, Abril 1932.

87 Para la confección de cigarros se instalaron máquinas de mojar tabaco, desvenadoras, tiruleras y mesas de succión; para la confección de cigarrillos se emplearon picadoras de hebra y al cuadrado, clasificadora, torrefactor y refrescador y máquinas para liar cigarrillos. De igual forma, se instalaron máquinas empaquetadoras.

88 VALDÉS CHÁPULI, C. (1990) op. cit., "Apéndice II: Relaciones de la fábrica de tabacos de Alicante con la jerarquía eclesiástica”, pp. 107-111. 
producción tabacalera en la factoría alicantina y que se había prolongado durante siglo y medio.

Otro de los problemas endémicos que sufriría la fábrica alicantina era la constante falta de espacio para el desarrollo normal de la producción y su progresiva evolución, que en el caso de esta factoría se pudo compensar con las sucesivas ampliaciones mediante la adquisición de terrenos colindantes. No obstante, dada la antigüedad del edificio, la CAT recurría frecuentemente a la solución de alquilar grandes locales en la ciudad que sirvieran para almacenar el producto elaborado o la materia prima. A pesar de ello la carencia de espacio persistía y la solución de alquilar almacenes distanciados de la factoría generaba problemas en la circulación de producto elaborado y materia prima. Por ello, se procedió en diciembre de 1892 a la enajenación de máquinas de algunos talleres para ampliar los almacenes sitos en el interior del inmueble.

No en vano, la ampliación gradual de la parcela permitió paliar la situación de ocupación de espacios interiores a la fábrica para el almacenaje que se había sucedido desde finales del S.XIX hasta la tercera década del S.XX, llegando finalmente a la construcción de tres almacenes especializados y exentos al edificio principal que tendrán gran relevancia en el proyecto de rehabilitación que se comentará en capítulos posteriores.

\section{Las cigarreras y la dimensión humana de la fábrica}

La influencia de las cigarreras alicantinas en el inmueble fabril se refleja los espacios destinados a cubrir sus necesidades como trabajadoras, pero también se puede hacer una lectura externa a la fábrica que explique la idiosincrasia de su ámbito interno, por la condición de sus operarias como pilares centrales del ámbito doméstico. Las particularidades específicas de la cigarrera por su condición de género y por su doble labor como eje del núcleo familiar y trabajadora conllevaron a planteamientos específicos en el programa espacial de necesidades de la producción. Por este motivo, ya en la década de los veinte del S.XX se intenta seguir la línea iniciada por otras factorías como Madrid, Valencia o La Coruña en la construcción de espacios específicos para las cigarreras aprovechando el proyecto de reordenación del contorno de la fábrica con la alineación de la calle Sevilla.

Finalmente el proyecto contemplaba un fin ambicioso, como era construir unos locales que sirvieran para las necesidades sociales de las operarias, aprovechando el jardín existente delante del edificio, presentando dos proyectos el primero de una planta serviría para Sala de Lactancia y Escuela. El segundo de igual diseño, pero de dos plantas, dispondría de la Sala de Lactancia y Sala Cuna en la planta baja, y de Escuela y Habitaciones y Comedor para las cuidadoras en el piso alto. La idea de presentar estos dos proyectos respondía a razones económicas, indicando así en la memoria presentada a la Dirección, que sería posible de este modo pasar mediante la elevación de un piso

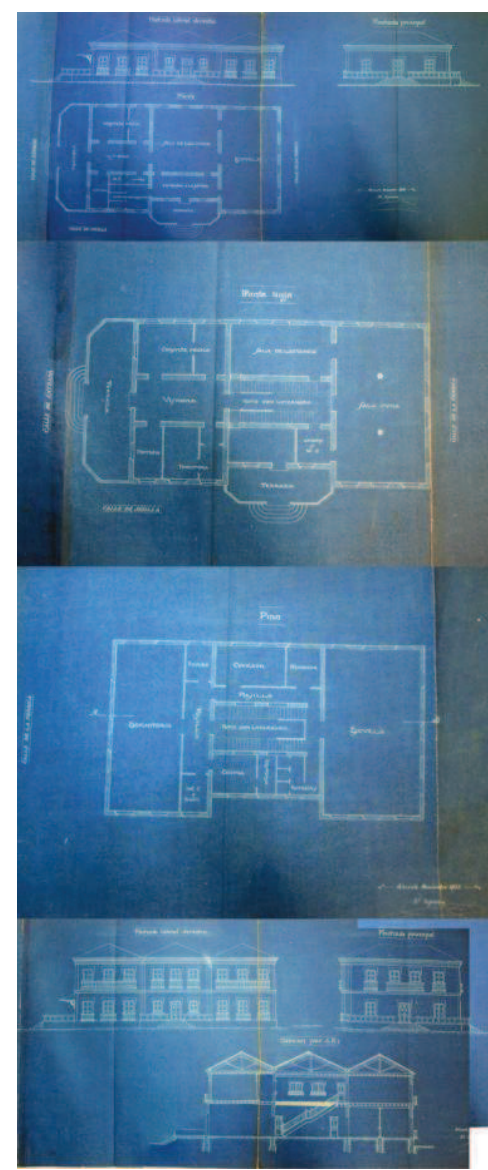

Figura 3.36. Proyecto de pabellón de lactancia y casa cuna para la Fábrica de Tabacos de Alicante de 1923, en $A M A$. 


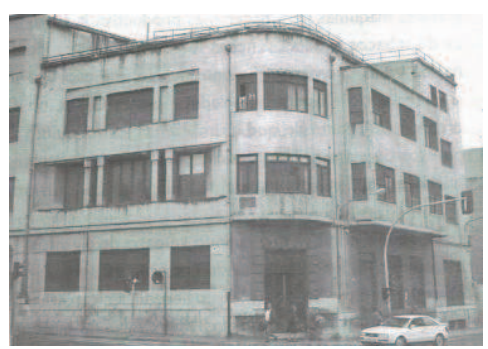

Figura 3.37. Casa de las

Cigarreras de Alicante, en LANCETA ARAGONESS, T. (2013) op. cit., p. 68. proyectado a otro, regularizando al construir este edificio social, el ancho de la acera de la actual calle de acceso a la Iglesia y a la fábrica, reduciendo ésta en $10 \mathrm{mts}$., cercándola con zócalos y mampostería y verjas de hierro, suprimiendo el deplorable aspecto que presentaba con su cerca de madero. Se adosa edificio social a perímetro cerca ${ }^{89}$.

Lamentablemente, sólo se aprobó en 1924 el edificio para armado de cajones y resguardo y las obras auxiliares de alineación -mencionadas en anteriores epígrafes- que también se planteaban en el conjunto de actuaciones propuestas en la reforma de 1923. Pese a que este primer proyecto no prosperó, posteriormente se llevaría a cabo la construcción de la "Casa de las Cigarreras", inmueble externo a la fábrica y situado en sus inmediaciones que complementaría el programa social de la tabacalera alicantina.

Se conjugaron varios intereses en el proyecto, el deseo de acceder a la cultura, al teatro, a la poesía o a la música, el de las madres-trabajadoras de encontrar un espacio para sus hijos y el de las mujeres de las poblaciones vecinas de tener un lugar donde comer y descansar al mediodía porque el horario estaba partido.

La Casa de las Cigarreras era una iniciativa colectiva pionera. Había una cierta experiencia en el sistema y uso de los bienes comunales, sin ir más lejos, el sistema de riego de la huerta [...] Era eficaz y no creaba excesivos problemas. Las trabajadoras que venían de Sant Joan, de Mutxamel o de Sant Vicent procedían de familias que todavía cultivaban la tierra y compartían el agua o los bienes comunales ${ }^{90}$.

El proyecto de la Casa de las Cigarreras fue iniciado en 1933 por la Asociación Tabaquera que era una agrupación similar a lo que hoy entendemos por Grupo de Empresa. En dicho año, la asociación adquirió mediante compra un solar perteneciente a la Diputación Provincial de Alicante en la calle Sevilla frente a la fachada principal de la fábrica. El edificio que había de ser construido en el mismo estaría destinado a la Sociedad Unión Tabaquera, sección alicantina, con objeto de desarrollar actividades culturales y sociales.

Tras el derribo de una antigua casa que ocupaba el solar de unos 500 metros cuadrados en el número 2 de la calle Sevilla -en una estratégica posición entre la entrada de la fábrica y la iglesia parroquial de la Misericordia- se construyó el nuevo edificio de estilo racionalista. La planta baja estaba destinada a la escuela para los hijos de las cigarreras y se complementaba con un economato y una enfermería. La planta superior albergaba una sala de reuniones, biblioteca, comedor con cocina, oficinas, vivienda para el conserje y una sala de espectáculos equipada con platea, anfiteatro e incluso camerinos, en la que los trabajadores realizaban actuaciones teatrales.

Como señala Teresa Lanceta en su obra, este nuevo inmueble tendría gran importancia para las cigarreras puesto que "la guardería y el comedor cubrían unas necesidades primordiales. Por fin las [cigarreras]

89 VALDÉS CHÁPULI, C. (1990) op. cit., p. 37.

90 Este pasaje y siguientes en LANCETA ARAGONÉS, T. (2013) op. cit., pp. 69-70. 
que venían de los pueblos podían calentar las tarteras o cocinar algo rápido en un lugar limpio y cuidado y los niños dejaban de ser una preocupación".

Como se señalaba anteriormente, fue una iniciativa de carácter colectivo puesto que cada trabajador pagó a plazos su contribución y, una vez completada, se otorgaba el título de propietario que podía pasar a su descendencia. Esta última circunstancia es significativa, ya que habitualmente las nuevas remesas de trabajadores solían tener lazos familiares con los empleados de la fábrica.

Sin embargo, con la llegada de la dictadura franquista, toda iniciativa asociacionista obrera fue perseguida y, en consecuencia, la Casa de las Cigarreras fue expropiada y pasó a ser la sede del sindicato vertical de la Falange y las JONS. Tras el fin de la dictadura, el edificio pasó a formar parte del Patrimonio del Estado, instalándose en el mismo los antiguos juzgados alicantinos. Pese a que los descendientes de los trabajadores que ostentaban el título de propietarios reclamaron el inmueble, este continuó siendo utilizado como sede judicial hasta que en 1997 se traspasa a la Comunidad Valenciana y, posteriormente, se procede a su derribo, perdiendo para siempre el vestigio material de parte importante de la historia de la fábrica.

Por otra parte, en la elaboración del tabaco tanto manual como mecánica es indudable el papel fundamental de la mujer como operaria. No hay que olvidar que las condiciones de confort en algunos espacios en los que se desarrollaba la producción no eran precisamente las más idóneas:

La gente cuenta que, en la planta de preparación en rama, en invierno se helaban, en verano se abrasaban y el olor era tan fuerte que daba lugar a mareos e indisposiciones; en resumen, el trabajo era muy severo [...] A pesar de todos los hándicaps y la dureza de esta faena, los empleados sienten una cierta atracción por este proceso y, frente a la rivalidad y a los conflictos que se producían entre las maquinistas y los mecánicos, en el taller de preparación en rama, las mujeres y los hombres se entendía bien.

Finalmente, otro aspecto a destacar en la Fábrica de Tabacos de Alicante, común a sus homólogas y en relación a los vínculos de las cigarreras con su espacio fabril, son los estrechos lazos de convivencia entre las mismas y la idiosincrasia particular del ambiente de trabajo que se establecía por la proximidad en la distribución geográfica de las viviendas y la fábrica. Frecuentemente, las trabajadoras eran familiares, vecinas y amigas, lo que reforzaba el sentimiento de comunidad y la transferencia de esta circunstancia de la fábrica al espacio doméstico y viceversa:

La mayoría de operarias del turno A procedía de Alicante, también de Sant Vicent del Raspeig y del Palamó, mientras que las del turno B eran mayoría las de Sant Joan, Mutxamel y Campello. Las del turno A se consideraban más luchadoras y reivindicativas, en lo que estaban de acuerdo las del turno B. Eran más buenecitas, más de pueblo...

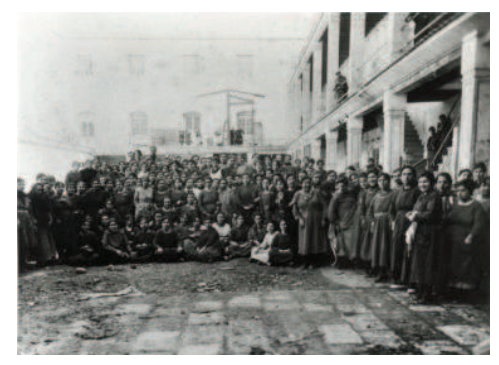

Figura 3.38. Cigarreras de Alicante, en $A M A$.

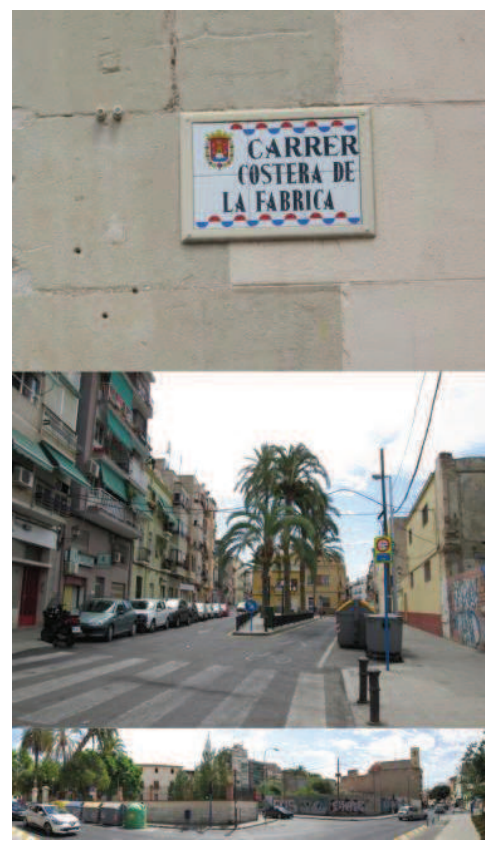

Figura 3.39. Zonas residenciales de las cigarreras colindantes con la fábrica y panorámica de la entrada a la fábrica con el antiguo solar de la Casa de las Cigarreras al fondo, 2015. 
Esta proximidad de la residencia de las cigarreras a la fábrica, no sólo marcaba el carácter de los barrios colindantes, si no que extendía la realidad de la misma fuera de sus muros. Especialmente significativos son los testimonios recogidos por Teresa Lanceta Aragonés en los que los hijos de las cigarreras relatan la constante presencia de la factoría en su vida cotidiana, máxime habiendo cuenta del papel principal de la mujer en el ámbito doméstico y en la difícil conciliación entre su papel de madre y trabajadora, de los que se ha dado cuenta en el capítulo segundo.

\subsubsection{La Fábrica de Tabacos de La Coruña (1804-2002)}

\section{Contexto histórico hasta su cierre}

La Fábrica de Tabacos de La Coruña tiene su origen en un contexto histórico convulso y de enormes dificultades para la Hacienda Real debido a los conflictos bélicos, el descenso del consumo tabacalero oficial y el aumento del contrabando. La fundación de factorías tabacaleras a lo largo del S.XIX y en diversos puntos que cubrían el borde costero peninsular respondían a una estrategia de dominación del territorio en la cual nacería la Fábrica de Tabacos de La Coruña, convirtiéndose en la cuarta fábrica tabacalera que abría sus puertas tras las fundaciones de Sevilla, Cádiz y Alicante, y en la segunda fábrica de la primera generación de factorías pertenecientes a la Renta de Tabacos del S.XIX.

En este contexto se funda la Fábrica de Tabacos de La Coruña en 1804 por Real Orden de Carlos IV que le concedía a la ciudad este privilegio en compensación por el traslado de los Correos Marítimos a Ferrol. Precisamente, la fábrica se instaló en los inmuebles de la periferia urbana que habían ocupado los citados Correos Marítimos, en el sector oriental de la bahía coruñesa en el enclave denominado como la "Palloza" o "Península de los Judíos". Sin embargo, señala Alonso Álvarez que la producción no comenzó hasta el año 1809, destinándose probablemente las dependencias a almacén de productos semielaborados procedentes de la fábrica hispalense.

En 1807 se daría a conocer por Real Orden el reglamento provisional de la fábrica coruñesa, nombrándose como director a Julián López que había sido inspector de labores de la fábrica sevillana. Sin embargo, no sería hasta el año 1808 en que se iniciarían las obras de reforma de los locales ocupados anteriormente por los Correos Marítimos para su adecuación a la nueva función, reformas que se prolongarían hasta $1828^{91}$

\footnotetext{
${ }^{91}$ Como se verá en epígrafes siguientes, estas obras no fueron de gran importancia en relación al resultado obtenido, puesto que "fue tan elemental, si nos atenemos a lo menguado del costo — no alcanzó los 150.000 reales-, que hizo escribir a un funcionario de la Real Hacienda: "y es el edificio tan reducido que todo él está lo uno sobre lo otro», y sentenciar: "ésta no es una fábrica, sino una semejanza de ella»". ALONSO ÁLVAREZ, L. (1984) op. cit., p. 18, citando Archivo del Reino de Galicia, Intendencia, 12/46, 3.' pieza, fol. 128 v. Para el estudio del caso coruñés se partirá fundamentalmente de la obra de los autores Luis Alonso Álvarez y Ana Romero Masiá.
} 
Los comienzos de la tabacalera coruñesa fueron accidentados. $\mathrm{Al}$ año de su puesta en funcionamiento, la ciudad fue objeto de la invasión de las tropas francesas napoleónicas en enero de 1809 y la fábrica fue ocupada por los invasores con los consiguientes destrozos y pérdida de existencias. Debido a que la fábrica coruñesa fue durante gran parte de la guerra la única unidad del monopolio ubicada en territorio liberado, la Junta Central resolvió que abasteciese a las provincias que fuesen ganándose a los franceses, con lo que hubieron de fabricarse también labores para el consumo popular.

El conflicto ciertamente dañó tanto las instalaciones de la fábrica como su estructura productiva. Al desaparecer las viejas redes de distribución del Estanco, la guerra contribuyó a la extensión del fenómeno del contrabando, agravado por la falta de liquidez para el pago de las cigarreras -que resolvieron ocuparse en la elaboración clandestina del tabaco-, así como por el mal estado de la materia prima que llegaba a la fábrica. Cabe afirmar que pese a su temprana fundación, el arranque real de la fábrica ubicada en la Palloza no se efectuaría hasta 1817, año en el que se confirmaría su condición de fábrica estatal y no sólo como abastecedora regional. Este hecho fue motivado por el desestanco del tabaco en $\mathrm{Cuba}^{92}$, en el mismo año, y por la uniformización del reglamento que se estableció en las cinco fábricas existentes -a la sazón Sevilla, Cádiz, Alicante, La Coruña y Madrid- y la reorganización de la distribución a nivel provincial en tercenas, estancos, estanquillos y, en las zonas rurales, en verederos.

En 1828 culminaban las primeras reformas de la fábrica gallega y se daba inicio a otras renovaciones por la insuficiencia de las intervenciones acometidas en los primeros años de vida de la factoría. Por tanto, se iniciaría un periodo en el que la tabacalera coruñesa experimentaría profundas transformaciones que afectarían a sus instalaciones, pero también al número de cigarreras empleadas. De esta forma, coincidiendo con las nuevas fundaciones fabriles de mediados del S.XIX, la fábrica coruñesa experimentaría el inicio de su ampliación, acometiendo la construcción de inmuebles complementarios para las necesidades productivas.

Estas medidas conducirían a la creación de un nuevo edificio denominado comúnmente "Fábrica de Abajo" -para distinguirlo de las primeras instalaciones que recibían el nombre de "Fábrica de Arriba", como se verá en epígrafes siguientes-, y que tendría un papel determinante en la evolución del conjunto de la Palloza en años subsiguientes. La gran reforma que se acometió a finales del S.XIX con las mejoras implantadas en este nuevo inmueble coincidió con la cesión del arriendo del monopolio a la CAT. Por tanto, la fábrica de tabacos coruñesa no sería ajena a las reformas promulgadas por la nueva gestora, aunque hubieron de implantarse de forma paulatina debido, sobre todo, a la oposición de las cigarreras que veían peligrar sus

92 "O desestanco restableceu a libre produción e venda na illa -non así na metrópole, que seguiu vencellada ao monopolio- e habilitou tres portos peninsulares para a importación de tabaco en rama ou elaborado procedente de Cuba: Cádiz, A Coruña e Alacante”. ALONSO ÁlVAREZ, L. (1998) op. cit., p. 50 citando Novísima recopilación, 1850 . 
puestos de trabajo, de forma análoga a como sucedería en las restantes unidades fabriles del monopolio.

La invención del puro mecanizado o "Farias" por Heraclio Farias en 1889 sería un hecho capital para la factoría gallega, puesto que pasaría a formar parte de las elaboraciones coruñesas en 1890. No en vano, dentro del contexto productivo peninsular, el grueso de la producción de Farias se ubicaría precisamente en la ciudad herculina. Por tanto, la reforma comenzada a finales del S.XIX se prolongaría hasta bien entrado el S.XX en una sucesión de fases en las que se acometerían intervenciones paulatinas sobre el conjunto fabril para la adaptación de sus espacios a las sucesivas etapas de mecanización. De esta forma,

o Farias resultou ser unha das partes da reforma inicial de 1895-97, aínda que como sinalamos comezou a fabricarse dunha maneira totalmente manual. Sería nesta segunda fase da reforma da fábrica, que podemos situar entre 1905 e 1914, cando se mecanizaron algunhas das operacións de elaboración -a colocación da capa, polo que se falaba dunha elaboración semimecánica-, pero sen constituír aínda una operación totalmente mecanizada ata ben entrados os anos vinte e trinta $^{93}$.

Sin embargo, la reforma inicial entre 1895 y 1897, como indica Alonso Álvarez, resultó insuficiente, por lo que las obras que subsiguieron en 1905 constituyeron más la terminación de una intervención inconclusa que una verdadera nueva etapa de modernización del conjunto. El grueso de estas obras se completó en 1910, siendo destacable la conformación de la "Fábrica de Abajo" según una imagen muy similar a la que presenta en nuestros días y la ampliación del conjunto fabril hasta los límites del trazado ferroviario dispuesto en las inmediaciones de la fábrica a finales del S.XIX.

En vísperas de la I Guerra Mundial, la fábrica se encontraba en condiciones de recibir la maquinaria necesaria para la mecanización de la práctica totalidad de las labores, no sin reticencias por parte de las cigarreras que, en 1911 y ante la llegada de las temidas máquinas, amenazaban una huelga general inminente. Sin embargo, fueron más dañinos para estas reformas los efectos de la I Guerra Mundial por las dificultades en el abastecimiento de materia prima americana y de maquinaria inglesa y alemana. Pese a este bache inicial, la década de los años 20 constituyó un periodo especialmente productivo para la CAT con la acometida de importantes reformas en todo el parque fabril.

Sin embargo, la historia particular de la fábrica coruñesa aguardaba un nuevo giro en esta época de reorganización general. El 25 de junio de 1920 se inició un incendio en el tabaco picado amontonado en los talleres de "a cuarto" que rápidamente se propagó por el interior del inmueble alimentado por las corrientes de aire que circulaban por las tuberías de secado. Los daños sufridos fueron considerables habida cuenta que la extinción fue laboriosa y lenta, quemándose una

${ }^{93}$ ALONSO ÁLVAREZ, L. (1998) op. cit., p. 169. 
importante cantidad de picadura, así como numerosa maquinaria de picado que quedó totalmente destruida. De igual forma, los efectos en el edificio también fueron devastadores, afectando por completo a la crujía que daba frente a la explanada de la Palloza y a la nave que se asomaba hacia la bahía, al igual que la nave central que separaba los patios interiores y en la que se ubicaban los talleres de desvenado y embotado.

Resulta interesante citar la reconstrucción de los hechos que se relata en la obra de Romero Masiá:

as cigarreiras choraban e se desesperaban fronte á súa casiña devorada polo lume. O servicio contra incendios practicamente non fixo nada, entre o retraso e a inutilidade das bombas de vapor que non comenzaron a funcionar ata varias horas despois de iniciado o lume.

O incendio iniciouse ás 22,30 h. [...] as alarmas dos barcos comunican o suceso á cidade, que se achega en masa a ve-lo que sucede na Palloza; as autoridades coordinan os esforzos, pero o lume tarda demasiado en controlarse $^{94}$.

Este relato ayuda a entender, no sólo la importancia que este hecho tuvo en la historia de la fábrica, sino que también apunta características específicas sobre el ambiente de la ciudad, las consecuencias de la proximidad de la fábrica al puerto, la cercanía de las viviendas de las cigarreras o el cariño que estas profesaban a su lugar de trabajo, así como el interés y preocupación de la ciudadanía en general por la que era la fábrica más importante de la urbe herculina.

Pese a que la producción no se detuvo a causa del incidente, hubo que esperar cuatro años para que se acometiesen definitivamente las obras de reconstrucción de la parte afectada por el incendio. En 1924, en el mismo año, también se inició la construcción de nuevos almacenes cuyo proyecto, junto a las obras de reparación, había sido aprobado por Real Orden en 1922. Todos estos incidentes no perjudicaron el estatus de la fábrica que, a finales de la década de los veinte, se enorgullecía de estar entre las primeras del territorio peninsular y gozaba de un segundo puesto por el número de operarias contratadas. Esta posición meritoria se completaría con la introducción de nueva maquinaria y el inicio de elaboración de nuevas marcas comerciales como los famosos "Bisonte".

Tras las mejoras acometidas en los años 30, tanto en materia de mecanización como en medidas sociales y espacios para las cigarreras de entre ellos destaca la "Casa das Cigarreiras" de la que se hablará posteriormente- el conflicto de la Guerra Civil y la pronta caída de la ciudad en manos de los franquistas iniciaron una época oscura en la que dominaron los expedientes depurativos del personal empleado y las denominadas "labores de guerra". Sin embargo, tras la dura etapa de la posguerra, y ya en 1945 en que la gestión del monopolio recayó en Tabacalera, la fábrica continuó la modernización de la maquinaria y el aumento progresivo de su producción. Durante esta etapa, la fábrica de la Palloza también mantendría una característica singular respecto a

${ }^{94}$ ROMERO MASIÁ, A. (1997) op. cit., p. 122. Según esta autora en 1929, casi una década después, la fábrica contaba con más de 2.000 cigarreras y 150 varones. 
sus homólogas en la fabricación mixta de cigarros y cigarrillos, siendo sus Farias uno de los productos más afamados de la factoría.

A partir de la década de los setenta y tras el gran impulso modernizador de los años sesenta, la fábrica coruñesa siguió ocupando la primera línea de las fábricas del monopolio. El nuevo marco legal instaurado tras la muerte de Franco, recuperó la intensa vida sindical anterior y permitió a la fábrica de la Palloza la adaptación a las nuevas necesidades de fabricación y mecanización, en las cuales nuevamente fue pionera.

Diez años después, en 1985, las mejoras acometidas culminaban un proceso de modernización que convertía a la fábrica de La Coruña en un ejemplo a seguir por sus homólogas desde el punto de vista tecnológico y de capacidad productiva. No obstante, estas mejoras tuvieron su repercusión negativa en la reducción de la plantilla y en la redefinición del tipo de labores a realizar. Los gustos del consumidor se orientaban definitivamente hacia los cigarrillos en perjuicio de los cigarros, por lo que las cigarreras tradicionales experimentaron un descenso notable de este tipo de elaboración, perdiendo además la fábrica su condición de producción mixta. Con la reorganización en términos productivos del conjunto del parque fabril acometida por Tabacalera S.A., los tradicionales Farias desaparecerían de la fábrica herculina al tiempo que se intensificaba la fabricación de cigarrillos de tabaco rubio y negro, elaborando las populares marcas "Fortuna" y "Gold Coast".

Pese a que todas estas reformas pronosticaban un gran futuro a la centenaria tabacalera coruñesa, el final de la década de los 90 le deparaba un desenlace bien distinto. Al igual que otras siete fábricas fundadas a lo largo del S.XIX y durante la gestión de la CAT, el "Plan Industrial" del año 2000 preveía el cese de actividad de la Fábrica de Tabacos de La Coruña, haciéndose efectivo su cierre en el año 2002.

\section{Motivos estratégicos de la fundación e implantación en su entorno}

La Fábrica de Tabacos de La Coruña fue una de las primeras industrias del monopolio que se estableció en un inmueble reutilizado para llevar a cabo la producción tabacalera, ocupándose para tal fin las instalaciones portuarias preexistentes de los Correos Marítimos situados a las afueras de la ciudad en la Palloza o Península de los Judíos. Debido a la alta demanda de los productos tabacaleros, Carlos IV decide establecer en 1804 una nueva fábrica de tabacos en la ciudad herculina, cuya condición de plaza portuaria marítima resultaba ideal para la ubicación de una industria de tales características. Esta fundación se producía en un contexto bélico y de dificultades financieras que, no obstante, motivaron en gran parte la creación de la Fábrica de Tabacos de La Coruña.

Las guerras navales de la Corona Española con Francia e Inglaterra a finales del S.XVIII habían paralizado el tráfico comercial marítimo en 
el Atlántico y generaban gran inseguridad. Esta circunstancia motivó en 1802 el traslado de los Correos Marítimos herculinos al puerto ferrolano que, por su condición militar, se encontraba mejor defendido ${ }^{95}$. Para paliar el perjuicio que podía ocasionar a la urbe coruñesa este traslado, Carlos IV concedió a la ciudad en 1804 el privilegio de instalar una tabacalera perteneciente a la Renta de Tabacos que repercutiría en la economía de la ciudad y cuya producción abastecería, no sólo a las provincias gallegas, sino también a Asturias y el occidente de Castilla y León. Aprovechando que las instalaciones de los Correos Marítimos se habían quedado inservibles, se resolvió que la nueva factoría ocupase sus inmuebles con las pertinentes reformas previas de acondicionamiento de los locales ${ }^{96}$.

Cabe destacar que los motivos de elección tanto de La Coruña como de las antiguas instalaciones de los Correos Marítimos para la instalación de la nueva fábrica tabacalera no fueron puramente casuales, sino que obedecían a otros intereses de fondo en la ubicación estratégica costera de las fábricas pertenecientes al monopolio tabacalero español. Entre los motivos de su elección se encontraba el hecho de que los sucesivos rellenos y ensanches del puerto y la mejora de sus infraestructuras sentaron las bases para el desarrollo de un importante comercio marítimo ${ }^{97}$. Por otra parte, había una presencia de mano de obra especializada local por la existencia de cigarreras adiestradas en el laboreo clandestino del tabaco en Betanzos y en el barrio de Santa Lucía en La Coruña, muy próximo éste último a las instalaciones llamadas a convertirse en tabacalera. Finalmente, la disponibilidad de los inmuebles de los Correos Marítimos y sus terrenos -propiedad de la Hacienda Real-, junto a su cercanía al puerto, contribuyeron a la decisión de establecer la nueva factoría tabacalera en La Coruña. Se garantizaba, por tanto, una mínima inversión en las obras de adecuación, la proximidad de un puerto conectado con los enclaves atlánticos de mayor relevancia y el control y eliminación de un importante foco de contrabando.

La estrategia de ubicación de la Fábrica de Tabacos de La Coruña fue fundamental en la relación de la misma con la ciudad y con el puerto. Situada extramuros a la ciudad, establecería una relación dialéctica entre la misma y el pujante puerto colindante. La conexión entre éste y

95 Los Correos Marítimos eran los servicios de transporte que utilizaban los comerciantes coruñeses para sus transacciones con el continente americano. Matiza Romero Masiá "a fábrica queda instalada nuns locais que deixaran baleiros os Correos Marítimos con América (La Habana e Montevideo-Buenos Aires) polo seu traslado a Ferrol en 1802, ano no que foi habilitado o porto ferrolán para o libre comercio con América nos mesmos termos que estaban os da Coruña e Vigo". ROMERO MASIÁ, A. (1997) op. cit., p. 47.

${ }^{96}$ Los Correos Marítimos se habían instalado "na antiga península dos Xudeus, cemiterio dos ingleses e as terras adxacentes ao leste das chamadas Aceñas de Jaspe, no lugar da Palloza, extramuros da cidade. [...] Tratábase dun terreo próximo ao mar, na desembocadura do río de Monelos, que conformaba una braña que se asulagaba nas marés altas". ALONSO ÁLVAREZ, L. (1998) op. cit., pp. 23-24.

97 Sobre las mercancías que llegaban al puerto coruñés: "Las materias primas [...] van a importarse de la isla de Cuba y de los Estados Unidos (Virginia, Kentucky y Maryland) [...] De este modo llegaría hoja de tabaco a La Coruña no sólo desde cualquier puerto de Galicia, sino también del norte y hasta del sur de la Península, del mismo modo que el tabaco de calidad inferior era remitido de La Coruña a otras factorías para fabricación de polvos y picaduras”. ALONSO ÁLVAREZ, L. (1984) op. cit., pp. 18-19. Por otra parte, a su condición de receptora y distribuidora del producto tabacalero por la presencia de los Correos Marítimos, se unía el hecho de que el tráfico de materia prima generaba una actividad paralela "extraoficial" de manufactura tabacalera en Betanzos y La Coruña. 


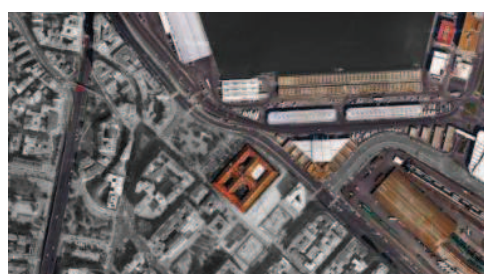

Figura 3.41. Emplazamiento de la fábrica y su cercanía al puerto comercial.

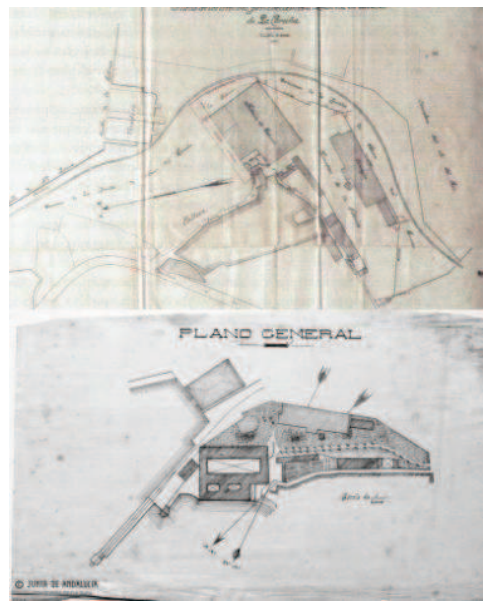

Figura 3.42. Plano del conjunto en 1904, en ROMERO MASIÁ,

A. (1997) op. cit.; y en 1901, en AHPS, 8748_121aPL. la fábrica fomentaría la creación de infraestructuras que facilitasen la circulación de producto, ganando terreno al mar y modificando los límites geográficos. Su condición periférica actuaría como detonante para la creación de distintas industrias en su entorno, estableciendo un patrón de conducta que declinaría finalmente el tráfico marítimo comercial y pesquero hacia la nueva zona industrial ${ }^{98}$. Por otra parte, la necesidad de conectar la fábrica de tabacos con los barrios populares en los que residían las empleadas, establecería una relación entre el centro de la ciudad y la fábrica periurbana en la conexión creada por la circulación de las obreras, generando un nuevo eje para la expansión urbana.

En este sentido, la ciudad de La Coruña experimentaría un importante crecimiento desde finales del S.XIX hasta el primer tercio del S.XX de forma que en 1940 casi se triplicaba la población de 1857. Precisamente, a mediados del S.XIX, la ciudad sería objeto de importantes cambios que, a su vez, influirían en la tabacalera herculina: en 1858 se inaugurarían las obras de la línea ferroviaria a Madrid, mientras que en la década de los sesenta se acometerían los primeros ensanches urbanos y los rellenos del puerto y, al término de la década, se derribarían las murallas que acordonaban la ciudad. Estas circunstancias, junto a la intensa actividad fabril con la tabacalera de la Palloza a la cabeza, sentaron las bases para la creación de una "ciudad abierta y liberal, portuaria y comercial, con una pujante burguesía y un incipiente y activo proletariado"99.

Las condiciones de borde de la fábrica eran muy propicias para el desarrollo de la producción tabacalera en los términos en que fue fundada con el inicio del S.XIX. Las instalaciones de los Correos Marítimos se hallaban en una amplia explanada denominada la "Palloza" en el límite occidental de la urbe y con posibilidad de atracadero propio por su cercanía al borde costero de la bahía herculina. Además, se encontraba próxima a los arrabales que tiempo después nutrirían de mano de obra femenina a las instalaciones de la Renta de Tabacos, tales como Santa Lucía, Atocha o Monelos. Sin embargo, hasta que las conexiones de transporte y las infraestructuras viarias entre el casco urbano y el área de la fábrica no fueron desarrolladas, parece que el entorno resultaba un tanto inhóspito para

\footnotetext{
98 Sobre los ejes de crecimiento en la ciudad herculina, "existía, no obstante, un subcentro, formado por el sector comprendido entre Cuatro Caminos, La Palloza (en el entonces barrio de Santa Lucía) y el núcleo de Monelos, que constituía un espacio predominantemente industrial" a principios del S.XX y cuyo eje de expansión "se orientaba siguiendo la trayectoria marcada por el río Monelos y por la Estación de Ferrocarril". Como coadyuvante de este crecimiento motivado por la actividad industrial "destacaba la presencia de la Fábrica de Tabacos como poderoso núcleo aglutinador, y otras numerosas industrias de bienes de consumo". El traslado del puerto pesquero al vecino muelle de Santa Lucía intensificó el desarrollo industrial de la zona, a lo que contribuyó la cercanía del ferrocarril, la facilidad de salida hacia la carretera de Madrid, la disponibilidad de espacio edificable y la ubicación del mercado. Además, "para aprovechar las ventajas de localización industrial, el transporte urbano siguió las líneas de crecimiento urbano, de manera que se construyó un ramal del tranvía, que conectaba con la ciudad central”. MIRÁS ARAUJO, J. (2007) "Crecimiento urbano y transformaciones en la localización de la actividad económica en A Coruña 1914-1935” en Scripta Nova. Revista electrónica de Geografía y Ciencias Sociales, Universidad de Barcelona, vol. XI, nº 252, 15 de noviembre de 2007.

99 FREÁN HERNÁNDEZ, O. (2003) "La sociabilidad obrera coruñesa a través de una obra de Emilia Pardo Bazán: La Tribuna (1882) en Zainak. Cuadernos de Antropología-Etnografía, nº 23, p. 328.
} 
las cigarreras en su trasiego diario entre los barrios populares y el centro de trabajo ${ }^{100}$.

Sin embargo, la prosperidad que trajo consigo la fábrica hasta posicionarse como una de las primeras unidades del monopolio tabaquero y la "decana de las fábricas coruñesas" en palabras de Romero Masiá, le reservaría un papel importante en la expansión urbana de La Coruña. Avanzando hacia los primeros años del S.XX, se observa cómo las condiciones de borde de la fábrica experimentarán notables cambios en paralelo al crecimiento urbano y a las remodelaciones del propio conjunto fabril que seguían las premisas proyectuales de sus homólogas españolas. En 1904 el ayuntamiento, a través de la Comisión del Ensanche creada para la planificación de las nuevas zonas urbanas que crecían a un ritmo notable, actuará en el entorno de la fábrica modificando su perímetro. Los terrenos en los que se ubicaba el conjunto tabacalero quedaban afectados por el proyecto de construcción de una amplia vía que conectase el núcleo de La Coruña con Pasaje, al Este de la ciudad, por lo que hubo que elaborar un informe sobre cómo se podía compensar a la fábrica por la apertura de la nueva vía de comunicación ${ }^{101}$.

Precisamente, en 1905, la Junta de Obras del Puerto realizaría importantes obras de relleno para ganar terreno al mar, puesto que la línea de costa inmediata a la fábrica no sólo era utilizada por la tabacalera, si no que crecería hasta convertirse en el puerto comercial principal de la ciudad. Estas obras modificaron sensiblemente la situación de la denominada "Fábrica de Abajo", el más próximo a la costa de los inmuebles que integraban el conjunto fabril, puesto que inicialmente se situaba sobre rocas en las que batía directamente el mar. De esta forma, todo el perímetro de la fábrica, gracias a los trabajos de relleno, quedó totalmente rodeado por tierra firme con el consiguiente derribo del almacén del muelle y las propias rampas del mismo que daban servicio directo a la fábrica. Quedaba, finalmente, aprobado el plan de remodelación de la costa de la Palloza en 1906, mostrando la Administración de la fábrica interés en adquirir una parcela de 300 metros cuadrados para la instalación de una rampa para su servicio exclusivo que se conectaría con la fábrica a través de la nueva carretera del Pasaje.

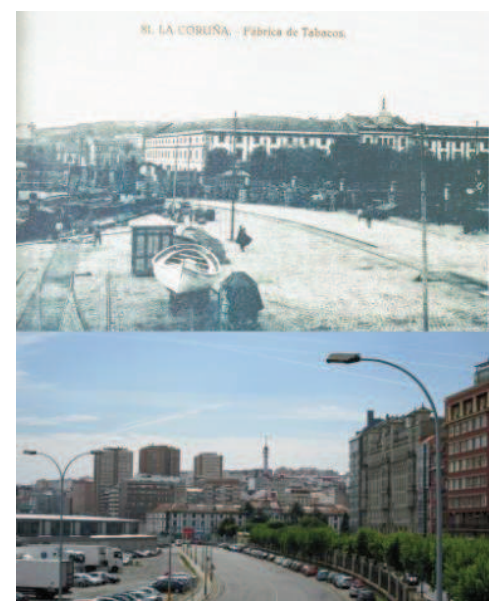

Figura 3.43. Vista del entorno de la fábrica tras los rellenos, en ROMERO MASIÁ, A. (1997) op. cit.; y vista en la actualidad, en la que se aprecia la avenida a Pasaje y el resultado de la expansión urbana, 2014.

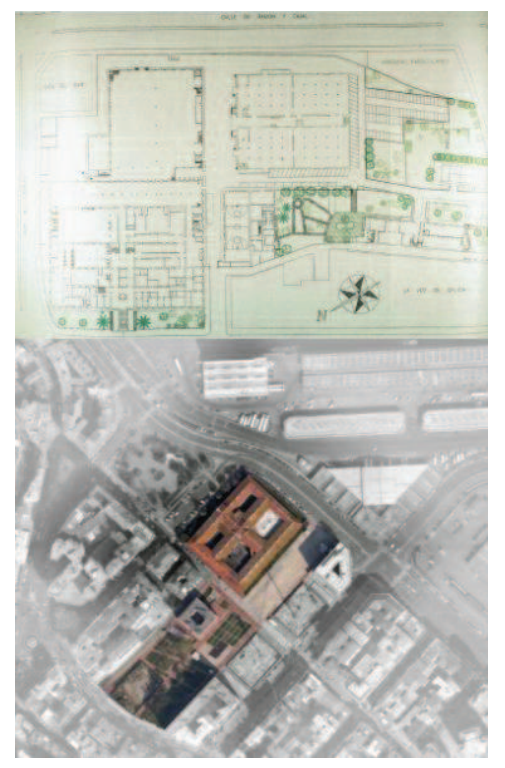

Figura 3.44. Plano del conjunto a finales de los años 90 , en ROMERO MASIÁ, A. (1997) op. cit.; y en la actualidad tras las demoliciones y la adecuación del entorno.

100 "En cuanto a las operarias no sé que le diga; pues como está la fábrica tan desproporcionada de lejos, el camino todo orilla del mar, descampado, unos vientos nordestes que le hacen a uno andar con el cuerpo doblado. Los inviernos de mucha agua y largos [...]". ROMERO MASIÁ, A. (1997) op. cit., p. 49 citando a PAMPILLÓN, F., Correspondencia familiar, [11-VII-1808] A.R.G. Intendencia, Leg. 12, nº 46, $3^{\text {a }}$ peza, fols. $127 \mathrm{v}, 129 \mathrm{v}$.

101 En 1904 se aprobó una cesión a la Hacienda Pública por parte de la Junta de Obras del Puerto de los terrenos ganados al mar $-12 \mathrm{~m}$ de ancho en todo el frente de la fábrica y $7,5 \mathrm{~m}$ por la fachada que mira al cargadero del ferrocarril- a cambio de los terrenos que lindaban con el río y el puente de la Gaiteira, necesarios para construir un ramal de vía hasta los nuevos muelles que unirían la estación de ferrocarril con el puerto. Los viejos embarcaderos quedarían soterrados por el relleno, lo que permitiría el establecimiento de una nueva fachada principal para la factoría, que quedará mirando definitivamente hacia la ciudad. La tabacalera le cedería, además, al municipio el triángulo que lindaba con la vieja carretera que iba a la estación para la construcción de un camino nuevo a Pasaje, con lo que se derrumbaría parte de la muralla. ALONSO ÁLVAREZ, L. (1998) op. cit., p. 140. 
Las obras continuarían en 1911 en paralelo a la profunda remodelación que en estos años estaba sufriendo la fábrica en términos arquitectónicos y espaciales. Se acometió entonces la construcción de un muro de cierre que cercaba los espacios de la fábrica, alterada por la construcción de las vías del ferrocarril del puerto y la cesión a la Junta de Obras del Puerto del espacio en el que se hallaba el Almacén del Puerto para la construcción de la avenida del Pasaje que afectaban a los límites Norte y Este del conjunto. El muro se alzaría con una altura de 3,5 metros en la zona posterior de la fábrica lindando con la calle Ramón y Cajal y la avenida de García Prieto.

Esta considerable pérdida de espacio, sin embargo, traería una consecuencia importante para el planteamiento arquitectónico de la fábrica en términos de significación y relación dialéctica con su entorno. En las mismas fechas, la explanada de la Palloza se convertiría en una gran plaza urbana que actuaba como espacio de representación para la fábrica. Teniendo ésta tradicionalmente su ingreso principal en la parte Sur, a espaldas de la ciudad, la ordenación de la plaza, así como la adquisición de nuevos terrenos compensatorios colindantes con la misma, fueron aprovechados por el arquitecto Antonio de Mesa para su proyecto de remodelación de 1910 que giró el ingreso principal hacia el nuevo espacio urbano.

Como se relatará en posteriores epígrafes, este proyecto aprovechó la circunstancia de que en 1904 la Junta de Obras del Puerto compensase a la fábrica con una franja de 12 metros de anchura que corría paralela a la que se convertiría en fachada principal y colindante con la explanada de la Palloza. Antonio de Mesa diseñó entonces un elaborado cierre de forja y mampostería que cercaba un primer espacio de ingreso a la fábrica ajardinado, de forma análoga a como se producía en Alicante o Sevilla y a como Mauro Serret y sus sucesores habían dispuesto en la nueva Fábrica de Tabacos de San Sebastián.

El entorno de la fábrica cambiaría notablemente a lo largo del S.XX, llegando a quedar el conjunto de la misma fagocitado por la expansión urbana, pasando de ser una pieza periférica a un elemento urbano más del tejido consolidado. Sin embargo, el espacio público de la plaza de la Palloza, así como los límites establecidos a principios de siglo serían respetados, sufriendo únicamente el espacio de la plaza una remodelación en los años ochenta, que incluyó el homenaje a la figura de las cigarreras a través de una escultura en el centro de la misma. Este espacio urbano y su carácter representativo dando frente al edificio principal de la fábrica quedarían, por tanto, vinculados a la memoria colectiva de la ciudad sobre la que fue una de sus más emblemáticas industrias.

La Fábrica de Tabacos de La Coruña, por tanto, se estableció como núcleo aglutinador de una serie de relaciones entre la periferia y la ciudad burguesa, y como revulsivo de crecimiento urbano que surge con la presencia del puerto industrial. Con el tiempo, la fábrica fue fagocitada por la propia expansión urbana que había generado, pero el 
establecimiento de corredores industriales y viales en paralelo al puerto, junto a su buena conexión con las infraestructuras a que había dado pie, la mantuvo en una posición privilegiada respecto a la ciudad y al puerto, aunando carácter industrial y representatividad en un mismo edificio como hito urbano hasta su cierre en el año 2002.

\section{Características de la arquitectura fabril}

El proyecto de instalación de la Fábrica de Tabacos de La Coruña en los antiguos Correos Marítimos hubo de heredar necesariamente las condiciones de partida que suponía la configuración arquitectónica y espacial de los inmuebles a reutilizar. No obstante, y al igual que en otras fábricas tabacaleras que fueron implantadas en edificios preexistentes, la condición de almacén o depósito de los inmuebles originales cumplía sin grandes intervenciones los requerimientos espaciales de la producción tabacalera a inicios del S.XIX que se caracterizaba por su condición eminentemente manufacturera.

\section{La preexistencia: los Correos Marítimos coruñeses}

Los terrenos sobre los que se construyeron los Correos Marítimos pertenecían inicialmente al ayuntamiento, que los cedió a la Corona en 1764 para tal fin. La parcela se extendía desde el puente de la Gaiteira, que salvaba el camino hacia Pasaje, hasta la Palloza y en ella se construyeron varios edificios que cubrían las necesidades de los Correos, tales como la casa de la Fragua, el depósito de cal, el taller de maestranza o el almacén general de víveres y los almacenes auxiliares.

Para la construcción de los Correos Marítimos se sucedieron diversos proyectos, acometiéndose definitivamente la segunda versión del proyecto que el arquitecto compostelano Miguel Ferro Caaveiro realizó en $1776^{102}$ tras la ejecución de rellenos para el acondicionamiento del borde costero, y que implicaba la canalización del río Monelos desde el puente de la Gaiteira, evitando las crecidas del mismo y ganando terrenos al mar. El mencionado proyecto contemplaba también la incorporación de las edificaciones preexistentes y cercaba el espacio mediante una muralla que lindaba con el puente y la canalización del río, el camino de Pasaje y el castillo de San Diego. De igual forma, se preveía la construcción del que sería el edificio principal del conjunto que lindaría con el mar.

La adquisición de los terrenos por parte de la Renta de Correos comenzó en el mismo año 1776 con objeto de que las obras no se dilatasen más de lo necesario. Los planos de la ciudad de 1788 y 1803 -este último probablemente requerido por los expertos que aconsejaron la instalación de la nueva tabacalera en los antiguos Correos Marítimos que hicieron

102 "Os proxectos máis antigos [...] son os de Antonio Valzanía, anterior a 1776, e mais o do arquitecto compostelán Miguel Ferro Caaveiro, do mesmo ano”. ALONSO ÁLVAREZ, L. (1998) op. cit., p. 24. Sobre los proyectos elaborados para los Correos Marítimos coruñeses se recomienda la consulta de la tesis doctoral de CASABELLA LÓPEZ, X. M. (1991) La Coruña: Ciudad y Arquitectura, 1700-1868, pp. 126-127 y pp. 155-164. 
efectivo su traslado a Ferrol el 27 de marzo de 1802 ${ }^{103-}$ constituyen documentos muy significativos para verificar la configuración que adoptó el conjunto de los Correos tras las modificaciones del Conde de Floridablanca al proyecto inicial de Caaveiro y su estado en los momentos previos a la adquisición de las instalaciones por la Renta del Tabaco ${ }^{104}$.

El primero es especialmente relevante por la definición realizada sobre las construcciones, en las que incluso se apunta su distribución en planta. Se observan, así mismo, las consecuencias de la ejecución de los rellenos en la superficie ganada al mar, la construcción de los dos muelles que daban servicio al conjunto y la muralla colindante con la calle Primavera. Por otra parte, también se aprecia la disposición de los dos edificios al Sur del conjunto que constituirían respectivamente la fábrica vieja y la fábrica nueva, denominada en conjunto "Fábrica de Arriba", y el embrión de lo que sería la "Fábrica de Abajo", que a finales del S.XVIII se disponía totalmente alineada con el borde costero.

Por su parte, el segundo plano describe con detalle en su leyenda los edificios que componían el conjunto de los Correos tal y como llegó a manos de la Renta de Tabacos:

\begin{abstract}
a muralla circundante, que se abre pola actual rúa da Primavera e que aínda conserva na súa portada o escudo de armas da Armada española, as dezasete edificacións integradas no conxunto -casa do alistador, almacén xeral de víveres, obradoiro, aceas antigas, fogón da breu, cuberto, almacén da pólvora, fábrica de enxarcia, fundición nova (inacabada), almacén de madeirame, capela, serradoiro, casa da ferramenta, almacén da madeira, fundición vella, almacén do breu e edificios vellos- a máis dun fondeadeiro inacabado, dous peiraos (os chamados do leste e do oeste) e un pequeño estaleiro.
\end{abstract}

\title{
La Fábrica de Tabacos de La Coruña
}

Cuando la fábrica de tabacos se instaló en las antiguas dependencias de los Correos Marítimos hubieron de ser acometidas diversas reformas que no comenzaron hasta 1808 , cuatro años después de la fundación de la tabacalera. Como indican Santías y Lera ${ }^{105}$, inicialmente se ubicó en el conocido como almacén de víveres, aunque pasarían pocos años hasta que se volviesen a acometer nuevas reformas. Por una parte, parece que la intervención desarrollada en 1808 fue de muy escasa relevancia, mientras que la invasión de las tropas francesas en 1809 generó numerosos destrozos tras la ocupación del inmueble.

La elección del almacén de víveres parecía lógica por su cercanía a la entrada del recinto y tener, en palabras de Alonso Álvarez, "un

103 BURGOA, J. J. y DE ARACIL, C. (2012) FERROL. La historia y los símbolos de la ciudad ilustrada, Visión Libros, p. 22.

${ }^{104}$ Este pasaje y siguiente en ALONSO ÁLVAREZ, L. (1998) op. cit., pp. 25-26.

105 SANTÍAS, A. y LERA, D. (1898) op. cit., p. 13. 
atractivo trazado en planta" por lo adecuado de su configuración a las necesidades espaciales de la producción tabacalera en el momento histórico en el que se fundó la fábrica herculina. No obstante, bajo la gestión de Manuel Vizcaíno -procedente de la fábrica hispalense- como administrador de la fábrica iniciada en 1807, se acometen unas modestas reformas consistentes en dotar de un piso superior al almacén, debido a la escasez de espacio de la preexistencia. Esta obra se prolongó hasta diciembre de 1808 bajo la dirección facultativa del arquitecto Fernando Domínguez y Romay. No obstante, esta intervención no debió ser de muy buena calidad dado que desde este momento hasta 1828 se sucederían nuevas reformas en la adecuación de espacios. Por otra parte, a mediados de los años veinte, además de la insuficiencia de las obras iniciales para el tamaño de la producción, las construcciones adolecían de sus más de seis décadas de vida.

Nunha inspección realizada á fábrica polo arquitecto da cidade, púidose apreciar claramente a rotura dunha viga mestra, o que provocara o derrubamento do teito, polo que o dito arquitecto recomendaba no seu informe "atender a la mayor brevedad a su reparación para evitar en lo sucesivo mayores gastos, y al propio tiempo no cause desgracias a las operarias que indudablemente sucederían sin dicha reparación”106.

Las obras que concluyeron en 1828 culminaron una primera ampliación con la construcción de un nuevo edificio denominado "fábrica nueva" por oposición al edificio antiguo inicial conocido como "fábrica vieja" que constituía el antiguo almacén de víveres que databa de 1788 y había sido ampliado en $1808^{107}$. Estas nuevas reformas respondían a la estrategia de la Renta de Tabacos en tiempos de Fernando VII en que se trataba de igualar el nivel de producción al nivel de consumo real.

El alcance de la obra realizada fue considerable, habida cuenta que tuvieron que realizarse desmontes que obligaron a la nivelación del terreno y se dotó al conjunto de las instalaciones suficientes como para duplicar la producción, lo que según Alonso Álvarez "nos confirma que non era unha simple obra de reforma, senón o establecemento do que empezou sabiamente a coñecerse co nome popular de Fábrica Nova”. Por tanto,

106 ALONSO ÁLVAREZ, L. (1998) op. cit., p. 55. El entrecomillado es una cita de AHN, Fondos modernos de hacienda, atad. $4626, \mathrm{n}^{\circ} 11$.

${ }^{107}$ Cabe destacar la confusión en torno a la denominación de los inmuebles del conjunto coruñés a lo largo de su evolución. Mientras que Romero Masiá las denomina "Fábrica Nueva o de Abajo" y "Fábrica Vieja o de Arriba", Alonso Álvarez las denomina "Fábrica Nueva y Fábrica Vieja", entendiendo estas dos como el conjunto que forma la "Fábrica de Arriba". Resulta más factible la hipótesis de Alonso Álvarez por los datos precisos que aporta sobre la ubicación de los edificios en su contexto histórico y en relación a la estructura urbana actual. ALONSO ÁLVAREZ, L. (1998) op. cit., p. 56 y ROMERO MASIÁ, A. (1997) op. cit., p. 59. Alonso Álvarez señala que la "Fábrica de Abajo" era el edificio preexistente como almacén del puerto y que, tras las reformas pertinentes de finales del S.XIX pasaría a instaurarse como edificio principal de la fábrica. Esta confusión se acrecienta con el informe desarrollado por Proyfe, constructora que redactó un proyecto de recuperación de la fábrica como dependencias judiciales y que en la documentación en la que realiza una restitución gráfica de la evolución histórica de la misma identifica todas las reformas descritas por los anteriores autores como ejecutadas en un mismo edificio, el de la Fábrica de Abajo. También otras descripciones de la época refutan la hipótesis de Alonso Álvarez: "Es un establecimiento muy extenso que comprende varios edificios; siendo los principales, conocidos por Fábrica Vieja uno y por Fábrica Nueva el otro [...] Los otros edificios son almacenes". COUMES-GAY, A. (1877) Guía de La Coruña citado por ROMERO MASIÁ, A. (1997) op. cit., p. 62. 
en 1828 se amplía la factoría, añadiéndosele un segundo edificio, la llamada "fábrica nueva", para distinguirla de la "vieja» construcción de 1808. Ambas albergarán los dos tipos de labores que a partir de entonces van a constituir su especialidad durante muchos años - mixtos y Virginias-, sin abandonarse del todo la producción de habanos. La fábrica vieja incluiría los talleres de Habana y Virginia, con sus respectivos almacenes de oreo, distribución de hoja y oficinas; mientras que en la nueva se situaría el taller de mixtos, con sus dependencias. Los depósitos auxiliares (almacén de cajones, carpintería, etc.) quedarían ubicados en la casona de los Correos marítimos. Todo el conjunto estaba rodeado por una muralla que se abría sobre los muelles de la fábrica ${ }^{108}$.

La Fábrica Nueva se construyó a distancia del lugar que ocupa en la actualidad la fachada principal tras la ganancia de terrenos al mar, y muy cerca de la calle Primavera. El nuevo edificio presentaba en alzado una estructura similar al del almacén de víveres puesto que constaba de planta baja, primera y buhardilla, aunque era más funcional puesto que contaba con más luz.

A organización do espacio industrial que podemos chamar a partir de agora Fábrica de Arriba para distinguila da que se construirá a principios do século XX, conserva una gran racionalidade para a súa época: cada un dos edificios, a Fábrica Vella e a Nova, que se encontraban un en diagonal ao outro, especializáronse en distinto tipo de labores. O primeiro, "de figura rectangular en su centro -segundo indica Pascual Madoz no seu coñecido Diccionario-, con dos alas a derecha e izquierda, ocupa una superficie de 9.269 pies cuadrados; tiene taller capaz para 1.760 mujeres, un oreo que admite 21.400 libras de tabaco en 85.600 atados de cigarro, y un almacén para 200 barricas, quedando suficiente espacio para distribuir el tabaco a las cuadrillas y demás operaciones, así como el suficiente local para las oficinas".

La "Fábrica nueva", por tanto, era parte de la denominada como "Fábrica de Arriba" puesto que se disponía al Sur del conjunto según aclara Leclercq en su descripción. Resulta curioso que Alonso Álvarez mencione la "gran racionalidad" de estos edificios cuando, a pesar de la entidad de la obra, la Fábrica de Tabacos de La Coruña no contó con una verdadera estructura espacial organizada hasta las grandes reformas de la "Fábrica de Abajo" de finales del S.XIX y principios del S.XX. Todo ello habida cuenta de que existían en aquel momento otras unidades fabriles de modelo compacto más ajustadas a las características de la producción tabacalera. El conjunto se completaba con otros edificios como el almacén de San José o del prado, el almacén del muelle, y otros tres almacenes menores, hallándose cercado por una muralla y con dos muelles propios al servicio de la fábrica, como se comentó anteriormente.

Por tanto, tal y como se diseñó el espacio industrial en 1827, la fábrica constaba de dos edificios principales -así como varios almacenes

108 Este pasaje y siguiente en ALONSO ÁLVAREZ, L. (1984), op. cit., pp. 30 y 59-60. Sobre estas cuestiones refiere una obra interesante para el conocimiento de la historia de la fábrica: LECLERCQ, A. (1839) "Notice sur la Fabrique Royale de Cigarres de la Palloza" en Archives du Ministère des Affaires Etrangères : Correspondence Consulaire et Comerciale. La Corogne; v.22. 
menores-, similares en superficie y situados uno frente a otro cerca de la entrada a la calle Primavera, al Sur del conjunto y en la zona de la parcela más alejada de la línea de costa ${ }^{109}$. Si bien constituyeron una ampliación importante del espacio laboral que permitió duplicar la producción, denotaban una cierta improvisación más que una verdadera organización industrial que contribuyese a una mayor operatividad de la producción. En este proyecto también se había contemplado la construcción de una escuela de párvulos dentro del recinto amurallado, que finalmente no se llevó a cabo.

Para que los edificios de la fábrica nueva y vieja tuviesen una organización más articulada se construyó un cierre que las unía dejando un gran patio en su interior:

Tratábase, pois, de unir ambas as construcións con dúas naves laterais de uns 300 metros que integrasen todo o conxunto, establecendo un patio central, necesario para as actividades fabrís, que superaba os 18.000 pés cadrados (algo máis de 5.000 metros cadrados) [...] As obras principiaron en $1846^{110}$.

El Sr. Peralta, actual director, ha dado principio a la obra de una línea de edificio delante de la Fábrica Vieja [...] que uniendo uno y otro por dos ángulos, dejará en el centro un patio [...] quedará la fábrica reducida a un solo edificio donde podrán trabajar 3.000 mujeres con sus oreos y almacenes correspondientes, y será una de las que merezcan la preferencia entre las ocho fábricas de esta clase que existen en la Península111.

Con el aumento del volumen de la producción y la mayor contratación de personal que acarreaba, en 1860 se deciden recuperar para el conjunto fabril los edificios que se encontraban en el mismo y que, al menos desde 1853, se hallaban ocupados por mujeres presas al reconvertirse en casa-galera. La falta de espacio para que las cigarreras desarrollasen su trabajo será lo que motivará la recuperación de estos locales que, además, no contaban con las condiciones necesarias para desempeñar la función de penal. Tras la incorporación del inmueble de la casa-galera a los espacios productivos para el acomodo de las cigarreras, la fábrica alcanzaría en este periodo un volumen de unas 3.000 operarias contratadas.

La tercera gran ampliación de la Fábrica de Tabacos de La Coruña se iniciaría en 1882, presentándose en el consistorio municipal los planos para la nueva obra que se finalizaría tres años más tarde. Esta nueva intervención consistía en la creación de un tercer edificio a partir de uno de los almacenes del S.XVIII situado frente al mar y conocido como Almacén del Muelle que, al igual que en la operación de la recuperación de la casa-galera, su objeto era el aumento de superficie productiva para incrementar la contratación de operarias. Este edificio estaría

109 En tiempos de la obra de Alonso Álvarez aún se conservaba esta muralla así como un escudo situado en el acceso al conjunto desde la calle Primavera. Señala, así mismo, que los muelles a disposición de la fábrica eran incluso de mayor entidad que los de la propia ciudad.

110 ALONSO ÁLVAREZ, L. (1998) op. cit., p. 88.

${ }^{111}$ ROMERO MASIÁ, A. (1997) op. cit., p. 60. Por aquel entonces ya se encontraban en funcionamiento las fábricas de Sevilla, Cádiz, Alicante, La Coruña, Madrid, Gijón, Santander y Valencia. 
llamado a desempeñar un importante papel puesto que, con el tiempo, pasó a constituirse como edificio principal del conjunto e inmueble que ha perdurado hasta nuestros días.

En 1885 a obra xa rematara. En conxunto, consistira na consolidación e ampliación do vello casarón próximo ao porto, duns 70 metros de longo por 17 de ancho, sen nenguna división no seu interior e composto de soto, baixo, principal e bufarda, conformando o que se empezará a denominar como "Fábrica de Abaixo", o edificio senlleiro do espacio industrial situado intramuros ${ }^{112}$.

Señala Romero Masiá que la actividad constructora a finales del S.XIX y principios del S.XX fue muy intensa, por lo que se puede asumir que a la tercera ampliación de la fábrica de 1882, aprobada por el arquitecto municipal Juan de Ciórraga en dicho año ${ }^{113}$, le sucedieron una serie de intervenciones y reformas imbuidas en el espíritu de racionalización y modernización de los espacios fabriles de la CAT. Estas reformas, que se prolongarían hasta 1910-1912, conformarían la configuración prácticamente definitiva de la fábrica tanto en el aspecto exterior como al interior. Además, quería aprovecharse la coyuntura para realizar las pertinentes obras necesarias en materia de higiene, como venía denunciando públicamente el médico José Rodríguez Martínez puesto que "la falta de medios higiénicos era de tal notoriedad en la fábrica de tabacos de la Coruña, que ella fue la causa eficiente de las obras que ahora se acometen"114.

En medio de estas obras aconteció un incendio fortuito el 25 de junio de 1896, que sumió a la ciudad en un ambiente similar al descrito en epígrafes anteriores con motivo del incendio de 1920. Los estragos causados por el mismo fueron notables, no sólo en pérdidas de materia prima y máquinas de picadura, sino que la mitad del edificio se hundió, salvándose la parte correspondiente a oficinas, taller de habanos, de puros comunes, así como la caja fuerte y parte de la maquinaria.

Moi pouco tempo despois do incendio a dirección notificaba o comezo dos traballos de reparación, para o que viñeran de Madrid o enxeñeiro xefe da CAT, Mauro Serra, e mais Pedro Cuesta López, o contratista das obras que, segundo fontes da empresa, serían as seguintes: en primeiro lugar, procederíase a achanzar o terreo, moi irregular no seu conxunto e con fortes desniveis contra a parte posterior [...] De seguido acometeríase a construción duns muros para levantar un pavillón que tería una superficie de 3.000 metros cadrados e no que habían de traballar as case 4.000 operarias existentes mentres se realizaba a construción do edificio. Paralelamente, construiríanse varios pavillóns secundarios para oficinas e despachos do persoal de administración e técnico ${ }^{115}$.

Una vez desalojada la Fábrica de Abajo, se procedió a la elevación de la altura de los talleres de la primera planta, con objeto de conseguir una

112 ALONSO ÁLVAREZ, L. (1998) op. cit., p. 89.

113 ROMERO MASIÁ, A. (1997) op. cit., p. 91.

114 ALONSO ÁLVAREZ, L. (1998) op. cit., p. 138, citando La Voz de Galicia 20-6-1899.

115 Cabe destacar de este pasaje la presencia de Mauro Serret o "Mauro Serra", cuya influencia pudo ser capital en el diseño definitivo de la conocida como "Fábrica de Abajo". ALONSO ÁLVAREZ, L. (1998) op. cit., pp. 139-140. 
mayor renovación de aire y evitar la concentración de olores insanos y la acumulación de polvo de tabaco en el ambiente. De igual forma, se procedió a la construcción de una segunda planta sobre los desvanes anteriores en la que se dispondrían columnas de hierro fundido para el soporte de la cubierta, conformando una superficie total con capacidad para 3.000 operarias y para la instalación de máquinas elaboradoras de tabaco. Estas obras suponían una distribución más racional del espacio industrial que se emplearía fundamentalmente en talleres de cigarros y puros comunes y que se complementaría con una moderna red de sumideros.

No obstante, todas estas mejoras no paliaron los comentarios críticos del médico Rodríguez Martínez en prensa, que reflejaban las preocupaciones de la época en materia de habitabilidad e higiene y que ponía en el punto de mira al proyecto original del ingeniero Pascual Vicent, puesto que intuía que muchas de las medidas reflejadas en el mismo eran, a su juicio, insuficientes. No contribuiría tampoco a paliar las críticas sobre las condiciones del espacio de trabajo de las cigarreras la construcción del barracón o tendejón provisional en el que fueron realojadas durante el periodo en el que se prolongaron las obras.

El plan de las obras que se acometieron a principios del S.XX fue muy ambicioso y se halla debidamente documentado a través de la planimetría del proyecto. Se observa que esta reforma, no sólo determinaría el aspecto de la Fábrica de Abajo tal y como la conocemos en la época presente, sino que definiría la relación del conjunto con su entorno a lo largo del S.XX. Como se apuntó anteriormente, para la realización de estas obras, se construyó un edificio provisional en marzo de 1901 -conocido como el "tendejón"- que daba abrigo a las operarias del taller de cigarros puros comunes durante las sucesivas etapas de la obra para que pudieran continuar desarrollando su labor. En esta construcción provisional se alojaron 256 ranchos de seis operarias cada uno y fue la primera fase de las mencionadas obras.

La realización de estas obras está dividida en cuatro períodos: Comprende el primero: la construcción de un cobertizo para taller provisional. Ya se levantó este cobertizo. De este período forman parte además la construcción de dos nuevas crujías al patio grande y las obras necesarias en las crujías que corresponden a las fachadas laterales, derecha y posterior.

El segundo período comprende: obras de reforma de la crujía larga entre patios y la perpendicular de la derecha.

El tercer período lo constituyen las obras en la crujía que da al mar; la transversal izquierda; los retretes generales de operarias en el patio exterior y la construcción de otra nueva crujía en el mismo patio.

En el cuarto período se realizarán las obras de la crujía que corresponde a la fachada principal [...]

Gracias a las obras, a Fábrica de Tabacos perderá el feo aspecto de

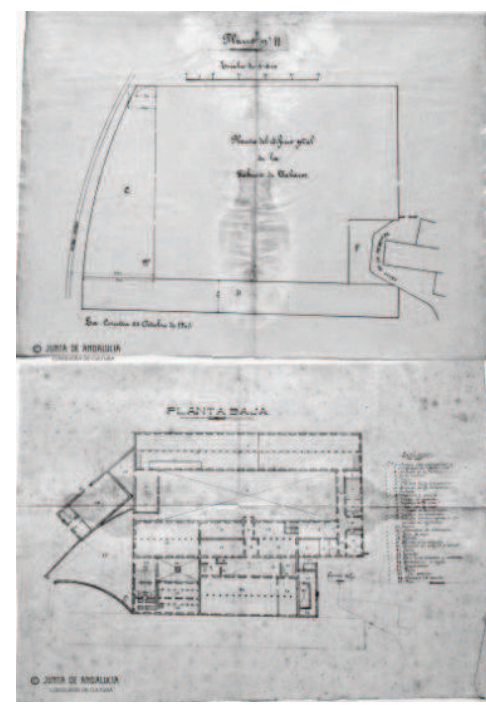

Figura 3.45. Planos de la fábrica de 1901, en AHPS, 8748_121cPL y 8748_121bPL. 


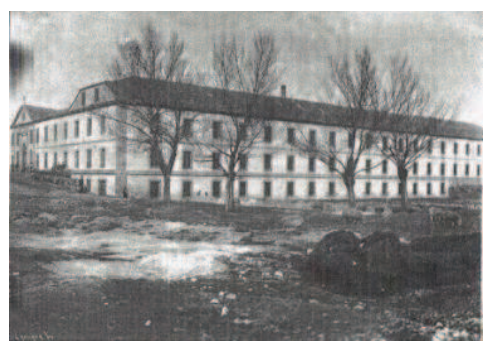

Figura 3.46. La "Fábrica de Abajo" a finales del S.XIX, en SANTÍAS, A. y LERA, D. (1898) op. cit., p. 12 .

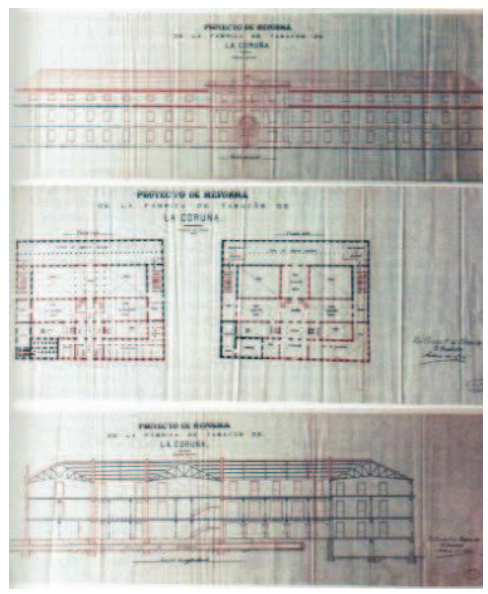

Figura 3.47. Planimetría del proyecto de Antonio de Mesa de 1908, en ROMERO MASIÁ, A. (1997) op. cit., p. 97. caserón ruinoso que tiene en la actualidad. A ello contribuirán el nuevo piso, la uniformidad de las ventanas, lo nuevo de las techumbres y el general enlucido y blanqueo del edificio ${ }^{116}$.

Por las indicaciones de la obra de Romero Masiá, cabe pensar que estas obras sobre la Fábrica de Abajo pueden ser una demora de las contempladas en 1882. Este retraso venía en perjuicio de las cigarreras destinadas a las labores del tendejón, cuya construcción provisional no cumplía las mínimas condiciones de confort y cuyo estado se volvía más precario con el tiempo ${ }^{117}$. Entre los perjuicios que sufrían sus ocupantes, destacaban el hacinamiento y el frío en los meses invernales, lo que provocaba enfermedades e incluso muertes.

Es en 1904 cuando se inicia la reforma del edificio principal de la fábrica, focalizando las obras en la consolidación de sus estructuras y en una nueva distribución de los corredores y los patios que modificarían sustancialmente la distribución interior. Muy significativo sería el cambio de orientación del acceso principal de la Fábrica de Abajo hacia la explanada de la Palloza, puesto que anteriormente se encontraba en la fachada Sur del inmueble en relación con el resto del conjunto y con la posición de la Fábrica de Arriba ${ }^{118}$. Esta obra fue posible, en gran parte, por la solicitud del jefe de la fábrica Eduardo Fuentes Urquidi de los permisos necesarios y el inicio de las gestiones con la Junta de Obras del Puerto para la cesión a la fábrica de una parcela de terreno colindante con la explanada de la Palloza, que se ha comentado anteriormente. Antonio de Mesa, arquitecto al servicio de Hacienda, se encargó, no sólo de la medición y valoración de esta nueva superficie adherida al conjunto, sino que también fue el autor de los planos que recogerían las reformas de los años subsiguientes sobre el edificio principal de la Fábrica de Abajo. El groso principal de las obras anteriormente descritas finalizaría en 1906 pudiendo reubicar a las cigarreras que se hacinaban en el tendejón y que se instalaron en el edificio principal.

Dos años después se reanudaría esta fase de reformas con una nueva obra fundamental que se contextualizaba en la nueva situación de contorno de la fábrica tras el terreno ganado al mar con los sucesivos rellenos. Nuevamente, con informe y planos del arquitecto Antonio de Mesa y la aprobación del arquitecto municipal Pedro Marí, así como del inspector de Sanidad y de la Comisión del Ensanche, las obras darían comienzo en mayo de 1908 prolongándose por espacio de varios años.

\footnotetext{
116 ROMERO MASIÁ, A. (1997) op. cit., p. 92 citando a La Voz de Galicia 8-3-1901.

117 "Este edificio estaba destinado, basicamente, á elaboración de cigarros puros de tipo forte, e ocupaba una superficie de $2.532 \mathrm{~m}^{2}$. Estaba construido a base de pés dereitos e armaduras de madeira que distribuían o espacio en dúas naves. Unha vez rematadas as obras de reforma da fábrica de abaixo, foi derrubada una parte do tendejón, manténdose outra parte como almacén ata súa desaparición definitiva cando se constrúa o almacén de tabaco en rama”. ROMERO MASIÁ, A. (1997) op. cit., nota 67, p. 92. Completando la descripción de Romero Masiá, Alonso Álvarez señala que el cubierto o barracón de planta rectangular medía 97 por $30 \mathrm{~m}$. Era de madera, con zócalo de piedra y cubierta embreada y en él trabajaban 1.800 mujeres en la elaboración de puros comunes fuertes. Contaba con una iluminación vespertina con faroles de petróleo hasta 1901 en que se instaló la iluminación eléctrica. ALONSO ÁLVAREZ, L. (1998) op. cit., p. 143, haciendo referencia a La Voz de Galicia 12-1-1901.

118 Actualmente, aún se conserva la puerta que daba acceso a la "Fábrica de Abajo" así como un labrado que reza "Fábrica de Tabacos" sobre la misma, indicando el antiguo ingreso principal de este inmueble.
} 
Esta nueva intervención afectaría principalmente a la elevación de un ático en el edificio de la Fábrica de Abajo y al frente de la misma hacia la Palloza reconfigurando lo que, como se adelantó anteriormente, pasaría a constituir la fachada principal del inmueble. Al objeto de cerrar el espacio del conjunto fabril en esta zona se emplearon los terrenos cedidos que comprendían la franja de 12 metros de anchura y paralela a la que sería la nueva fachada. El cierre se configuró a través de un zócalo de piedra coronado por un enrejado de hierro que seguía la alineación de la calle Concepción Arenal y que se finalizaría en 1910 con un total de más de 140 metros de largo. Para ello, hubo de derribarse el antiguo almacén de embotado y proceder a la nivelación del terreno.

O proxecto incluía o peche da muralla fronte á praza xurdida nos terreos gañados ao mar-que se chamaría da Palloza-, que pasaron a se converter nun xardín cerrado por un grande enreixado [...] Contemplábase ademais a decoración da fachada, agora convertida na principal da fábrica, cunha lonxitude que acadaba os 90 metros. A nova fachada constaría de tres corpos: o central, que acollería a porta principal, á que se accedería por una escalinata, e dous corpos laterais ${ }^{119}$.

Cabe resaltar que la formalización de fachada de la fábrica herculina, así como su disposición en planta, guardarían gran relación con el proyecto de nueva planta de la fábrica donostiarra cuya construcción finalizaría aproximadamente en las mismas fechas.

El objeto de esta importante obra es dotar a aquel establecimiento de las condiciones necesarias para ser, en muy breve plazo, uno de los más principales centros productores de la Renta, adaptando su nueva distribución a las modificaciones que ha sufrido aquella zona de la ciudad en los últimos años y a los modernos adelantos del género de fabricación a que se destina.

Los terrenos ganados al mar que quedan colindantes con la fachada del Oeste de aquel establecimiento, han sido destinados por la Junta de Obras del Puerto a una espaciosa plaza, a la cual dará frente la nueva fachada principal, armonizando sus huecos de luz y sus alturas de piso con las existentes en el pabellón extremo de la izquierda, que ocupa actualmente el motor y las máquinas picadoras, cuya moderna construcción ha de conservarse a fin de no interrumpir las labores con la paralización de los elementos mecánicos, limitándose en dicho pabellón la reforma a la elevación del piso ático sobre los dos cuerpos de que hoy consta.

La parcela cedida por el Excmo. Ayuntamiento de esta capital, en unión de otra también cedida por la Junta de Obras del Puerto, se incorpora al solar del edifico, completando la longitud de la nueva fachada principal y haciendo desaparecer la fea rinconada que hoy existe en la entrada de la calle de la Primavera ${ }^{120}$.

Las obras de la Fábrica de Abajo se realizaron con entramados metálicos en las armaduras de cubierta y en los forjados, siguiendo la
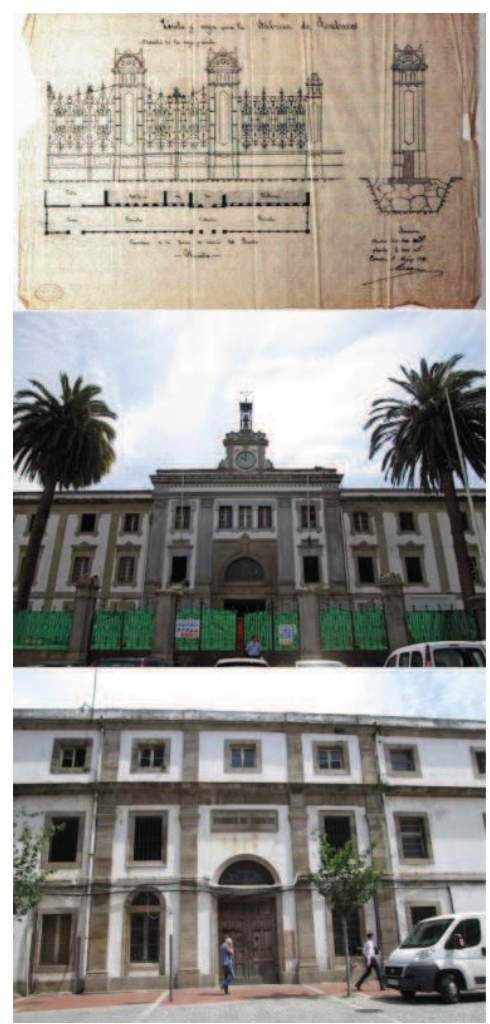

Figura 3.48. Proyecto de cierre de la nueva fachada principal de la fábrica coruñesa de 1910, en ROMERO MASIÁ, A. (1997) op. cit., p. 96; fachada principal y antiguo acceso de la Fábrica de Abajo, 2014.

119 ALONSO ÁLVAREZ, L. (1998) op. cit., p. 171-172 citando a La Voz de Galicia 12-7-1909.

120 ROMERO MASIÁ, A. (1997) op. cit., p. 98 citando DE MESA, A. (1908) Memoria explicativa de la reforma de la fábrica de tabacos, 1-V-1908. 
tendencia de las obras de reforma acometidas por la CAT en las restantes unidades fabriles en los primeros años del S.XX. Los muros se construyeron en mampostería combinada con ladrillo y se acometió, así mismo, la construcción de un foso en el perímetro del edificio para sanear la planta de sótano. Además, se inició la construcción de un edificio destinado a pabellón de motores para la instalación de las calderas y de la máquina de vapor que accionaba la dinamo de $180 \mathrm{CV}$ que suministraba energía a la fábrica ${ }^{121}$.

El grueso de las obras se finalizó en 1910 con la ampliación de la parte posterior del conjunto hasta enrasar los límites del mismo con el trazado del ferrocarril que distaba tan sólo 5 metros del cercado de la fábrica. La arquitectura de la Fábrica de Abajo quedaría prácticamente definida con la ampliación de los patios y la definición de la planta en una proporción más semejante a un cuadrado. Al igual que en otras fábricas, en 1911 se colocaría el reloj rematando la composición del cuerpo central de la fachada y marcando el ritmo de idas y venidas de las 2.500 cigarreras que en aquella época empleaba el establecimiento coruñés.

Nuevamente, tal y como se apuntaba en epígrafes anteriores, el incendio de 1920 trastocaría los planes de reforma de la fábrica. Si bien este incendio supuso un contratiempo inicial, en los años siguientes al accidente, y sobre todo gracias a la llegada de Francisco Wirtz Prieto ${ }^{122}$ como administrador de la fábrica en 1921, se aceleró el proceso de reformas hacia la total mecanización de la fábrica llegando a obtener uno de los mayores niveles de modernización del parque fabril del monopolio. En los seis años siguientes a su llegada, Wirtz acometería la reconstrucción de la parte incendiada así como la creación de un nuevo suministro de energía instalando definitivamente un sistema eléctrico y abandonando el anterior a vapor. Además, también se llevaría a cabo la construcción de unos nuevos almacenes de tabaco en rama aprobados por Real Orden el 22 de octubre de 1922 con arreglo a un proyecto de 1922.

Como reflejan los planos de 1922 custodiados en el Archivo Municipal de La Coruña, estos depósitos constaban de dos cuerpos iguales separados por unas pasarelas centrales de 6 metros de ancho. Cada cuerpo estaba dividido en otros dos por un muro cortafuegos y en total se elevaba unas cuatro plantas rematadas por una terraza-aljibe. La decoración de la fachada se realizó con arreglo a una composición de puertas y ventanas dobles circundadas por dinteles y jambas de ladrillo visto, así como un zócalo y esquinas de cantería. La estructura interior, sin embargo, se realizó con forjados y pilares de hormigón

121 "Este edificio non se chegou a rematar e, coas reformas necesarias, foi adaptado para instalar dous grupos electróxenos. Tamén deste período de obras que remata en 1910 data a construcción dun pavillón de planta baixa, de construcción lixeira que apoiaba na cerca que dá á rúa Primavera; nel se instalou un taller de armazón de caixóns e depósito de madeiras para os mesmos. Outro pequeno almacén foi tamén construído ó abri-la estrada do Pasaxe". ROMERO MASIÁ, A. (1997) op. cit., p. 99.

${ }^{122}$ Francisco Wirtz había sido ingeniero jefe en las fábricas de Gijón, Cádiz y La Coruña y administrador en las de Santander y Alicante, por lo que contaba con una larga experiencia. 
armado. Cabe destacar la gran similitud de estos almacenes con los construidos para la fábrica de Cádiz, en el caso del lenguaje adoptado en fachada, y con los realizados en los proyectos de las fábricas de Tarragona y Málaga en la concepción del conjunto. Lamentablemente, en el caso coruñés no queda testimonio material del citado almacén, aunque sí se cuenta con la planimetría del proyecto y documentación gráfica del mismo.

El resultado fue la disposición de un conjunto industrial más racional, para lo cual se derribaron construcciones anteriores que no reunían las condiciones suficientes: desaparecieron el almacén de la capilla, el tendejón, la caseta del pozo, el almacén de carpintería y el antiguo horno de quema. Se construyeron nuevos inmuebles en la parte Sureste para el taller de armado de cajones y el depósito de madera, así como un taller de reparación de máquinas. En cambio, el antiguo pabellón de motores se mantuvo con la excepción de que las antiguas máquinas de vapor fueron sustituidas por grupos electrógenos modernos. Finalmente, las construcciones que anteriormente habían integrado la denominada como Fábrica de Arriba se reutilizaron para servicios complementarios a la plantilla con la instalación de comedores y cocina, así como servicios sanitarios con lavabos, retretes, duchas y vestuarios.

Estas últimas reformas pueden ser consideradas como las definitivas dentro de la apariencia que la fábrica mantendría hasta su cierre a principios del S.XXI. En las décadas subsiguientes tan sólo se acometerán las adecuaciones pertinentes a las nuevas innovaciones tecnológicas en materia de mecanización de las fases productivas ${ }^{123}$.

Se puede observar que la Fábrica de Tabacos de La Coruña, en cuanto a su configuración arquitectónica adoleció de una cierta desorganización o falta de racionalidad hasta la instauración definitiva de la Fábrica de Abajo como edificio principal del conjunto a finales del S.XIX, único inmueble que ha conseguido conservarse hasta nuestros días. Esta circunstancia pudo estar motivada, en parte, por las condiciones heredadas de los inmuebles preexistentes de los Correos Marítimos y por la temprana época de la fundación fabril cuyas reformas acometidas a lo largo del S.XIX se caracterizaron por una cierta improvisación.

\section{El espacio productivo y su evolución hasta 1945}

Resulta complejo evaluar la configuración del espacio productivo de la Fábrica de Tabacos de La Coruña, no sólo por las propias reformas de reorganización a las que se vio sometido a lo largo de su historia en las diferentes reestructuraciones acometidas por la gestión del monopolio, sino también por la propia idiosincrasia de su configuración arquitectónica en un conjunto fabril caracterizado por su fragmentación

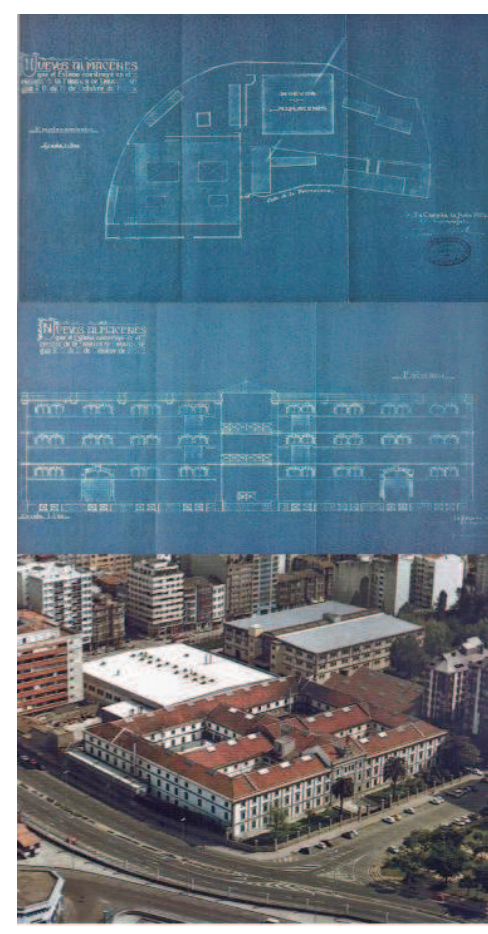

Figura 3.49. Planimetría de los nuevos almacenes de 1922 , en ROMERO MASIÁ, A. (1997) op. cit., p. 125; y vista del conjunto antes del cierre en la que se aprecian los almacenes y la "Fábrica de Arriba", actualmente desaparecidos, en COMÍN COMÍN, F. y MARTÍN ACEÑA, P. (1999), op. cit.,p. 501.

${ }^{123}$ La reforma arquitectónica de los años 20 fue de tal envergadura que dos décadas después apenas había variado su configuración, manteniéndose los siguientes inmuebles: edificio principal, almacén de tabaco en rama y elaborado, almacén de empaquetados, taller de reparaciones, taller de armado de cajones y depósito de envases desarmados, horno de quema de tabaco inservible, central de reserva, servicios auxiliares para la plantilla comedores, retretes, lavabos y cocina- viviendas, depósito de polvo y pabellón de reconstrucción de cajas, carpintería y confección de pegamentos. ROMERO MASIÁ, A. (1997) op. cit., p. 150. 
hasta finales del S.XIX y principios del S.XX.

La distribución del espacio industrial en los inicios de la fábrica coruñesa estaría muy supeditada a las condiciones de partida heredadas de la arquitectura de los inmuebles preexistentes de los Correos Marítimos. En un primer momento, y sin acometer más reformas que las necesarias para acondicionar el espacio del almacén de víveres, se disponen en la planta baja del inmueble las oficinas de la dirección y administración de la fábrica -integrada esta última por la superintendencia, la contaduría, el fielato y la tesorería- así como un depósito de hoja. Por su parte, la planta principal alojaba los talleres de Habana, Virginia y mixtos, así como diversos depósitos y talleres auxiliares -almacenes de pesado, oreo, distribución, carpintería y embalado-.

A través del informe sobre los desperfectos ocasionados por la ocupación de las tropas francesas en 1809 se puede también adquirir una idea aproximada de la distribución de los espacios productivos en los primeros años de funcionamiento de la fábrica. Más concretamente, Alonso Álvarez realiza una detallada descripción de los espacios de la fábrica a partir de la interpretación del citado informe:

Nun edificio edificio anexo á propia fábrica había un almacén xeral de folla cun cuarto contiguo -sala de data- onde se lles entregaba semanalmente a folla ás operarias. O recinto abríase sobre un patio, con pozo e pías para mollar cada día o tabaco. Lateralmente aparecía o edificio da fábrica propiamente dita, que estaba constituído na súa planta baixa polas oficinas de superintendencia, contadoría, fielato, tesourería, portería, corpo de garda e entrada. Nunhas dependencias separadas estaban os almacéns de delouro -co cuarto da porteira-, distribución, almacén de aparellos, carpintería e almacén de táboas. Na planta superior situábanse os talleres das operarias. No primeiro obradoiro de virxinias aliñábanse 110 mesas de madeira [...] Unido a este obradoiro estaba o cuarto para a recollida de vea, que daba acceso ao taller de habanos, de menor volume con 24 mesas de madeira [...] Ao fondo -e esa é una novidade introducida durante a ocupación francesaconstruírase un novo taller para a elaboración de rapé, establecido polo novo director ${ }^{124}$.

Además de los dos edificios principales que constituían el núcleo del espacio productivo, el conjunto fabril se complementa con construcciones auxiliares, algunas de ellas en estado bastante ruinoso, y disponía de rampas con acceso directo a los muelles que daban servicio a la fábrica, quedando los límites de la misma definidos por la línea de costa y la muralla que cercaba la factoría tierra adentro. Pese a la dispersión de la producción en diversos edificios, parece que en todos ellos trataba de reproducirse el modelo de espacio productivo compacto que se empleaba en las restantes fábricas existentes, no siendo su segregación en varios inmuebles más que el producto de la herencia arquitectónica de las instalaciones preexistentes.

${ }_{124}$ ALONSO ÁLVAREZ, L. (1998) op. cit., p. 34. 
A mediados del S.XIX el espacio productivo debía adaptarse a los cambios de gusto en el consumo puesto que se afianzaba la preferencia de la demanda por las labores más populares como picadura y cigarrillos en perjuicio de las selectas, constituidas por los Habanos, Virginias y mixtos. Esto implicaba ya la mecanización del proceso, comenzándose las pruebas en 1857 con una máquina de picar hoja y otra de liar y engomar, no sin el lógico rechazo de las cigarreras empleadas que protagonizaron escenas de violencia ludita contra las máquinas. Nuevamente, un escrito de la época arroja luz sobre la configuración del espacio productivo de la fábrica herculina a mediados del S.XIX:

Está dividida en varios edificios, siendo los principales el llamado Fábrica Vieja y la Nueva. El primero de figura rectangular en su centro con dos alas a derecha e izquierda, ocupa una superficie de 29,269 pies cuadrados; tiene taller capaz para 1.760 mujeres, un oreo que admite 21.400 libras de tabaco en 85.600 atados de cigarro, y un almacén para 200 barricas, quedando suficiente espacio para distribuir el tabaco a las cuadrillas y demás operaciones, así como el suficiente local para las oficinas: el segundo, o Fábrica Nueva, está enteramente aislado y al Sur del anterior: su figura es rectangular sobre un área de 10.520 pies cuadrados; en su taller trabajan 640 cigarreras, en el oreo caben 8.000 libras o 32.000 atados, y en su almacén pueden colocarse 360 barricas: los otros edificios son, el almacén titulado de San José o del Prado, capaz de 1.000 barricas; el llamado del Muelle que está reducido a la mitad, pero que admite 480 barricas; tres almacenes insignificantes, por su mal estado y cuatro casas ruinosas. Todos se hallan comprendidos en el circuito de una muralla de 4.760 pies de long. y 14 de elevación, con dos muelles propios del establecimiento, si bien el comercio utiliza uno de ellos en razón a que aún en las mareas bajas le baña el agua y pueden atracar las gabarras ${ }^{125}$.

Por su parte, Romero Masiá proporciona una detallada descripción de los inmuebles que componían el conjunto fabril en 1887, en el momento de cesión del arriendo del monopolio a la CAT. El conjunto ocupaba un total de algo más de 25.000 metros cuadrados y estaba integrado por diversos inmuebles ${ }^{126}$ entre los que destacaban tres construcciones principales. La Fábrica de Abajo era un edificio de tres plantas que constituía la construcción principal del conjunto habiendo sido remodelado el Almacén del Muelle ${ }^{127}$ y ocupaba casi 7.000 metros cuadrados de los que más de 1.600 estaban destinados a patios. Por otra

125 ROMERO MASIÁ, A. (1997) op. cit., p. 60, citando la descripción de Pascual Madoz en su Diccionario geográficoestadístico-histórico de España y sus posesiones de Ultramar.

${ }^{126}$ En 1890 la fábrica seguía manteniendo su configuración fundamental tras la ampliación de 1882, pero pronto se iniciarían las reformas de principios del S.XX que, sin alterar profundamente la configuración del conjunto, sí que serían significativas en orden de funcionamiento espacial y diálogo con el entorno. "Consta de dos edificios incluidos dentro de murallas, en cuyo interior existen, no sólo los patios de la misma, sino patios para la quema y servicios, almacenes para tabaco en rama, tres llamados la Capilla, Carpintería y Subterráneos. Existe el edificio del pozo, las casas de los rondines y porteros, y la habitación del Jefe con una magnífica huerta y jardín”. FAGINAS ARCUAZ, R. (1890) Guía-indicador de La Coruña y de Galicia para 1890-91, Brigantium Gestión, [fac. 2008].

127 Romero Masiá vuelve a citar en esta relación otro almacén del muelle, de dimensiones mucho menores. Coincidiendo con la descripción de Alonso Álvarez como la más acertada, hemos de suponer que además del gran almacén del muelle que se interviene para su adecuación a los locales de laboreo como "Fábrica de Abajo", existía otro "almacén del muelle" mucho menor. Precisamente el plano de 1803 de La Coruña antes citado, muestra una construcción cercana al muelle que se corresponde sin lugar a dudas con la que un siglo después tomaría el nombre de "Fábrica de Abajo". 
parte, la Fábrica de Arriba ocupaba en 1887 algo más de 700 metros cuadrados y se dedicaba por entero a la fabricación de puros. Sus muros eran de mampostería y entramado de madera con un corredor de arcadas de piedra, ocupando parte del edificio la vivienda del director. Finalmente, el Almacén del muelle estaba situado muy próximo al mar, ocupando una superficie de 375 metros cuadrados. Contando con una sola planta, estaba destinado al almacenaje de las mercancías que entraban y salían por mar o ferrocarril.

Aunque la obra de Santías y Lera nos aporta, nuevamente, datos precisos sobre la configuración del espacio productivo a finales del S.XIX con su relación pormenorizada de los inmuebles que componían los locales de elaboración y la distribución de las diversas tareas en los mismos ${ }^{128}$, la presente investigación quiere destacar la descripción del espacio productivo finisecular realizada por Alonso Álvarez. Encuadrada en las acciones llevadas a cabo por la CAT, la gran transformación de la Fábrica de Tabacos de La Coruña para adquirir la configuración espacial con la que llegaría a su cierre en 2002 tuvo lugar, fundamentalmente, entre la década de los noventa del S.XIX y los años veinte del S.XX. Durante cuatro décadas, el groso de las actuaciones se encaminó a una reorganización del espacio para dotarlo de mayor racionalidad y un sentido de la distribución productiva más lógica y eficiente.

Según Alonso Álvarez ${ }^{129}$, estas obras podrían dividirse en tres fases. En lo relativo a la primera etapa de transformaciones, Alonso Álvarez señala que eran tres y no dos los edificios que conformaban el espacio industrial de la Palloza, puesto que distingue el conjunto formado por la Fábrica de Arriba en la Fábrica Vieja y la Fábrica Nueva. Recordemos que la Fábrica Vieja era el más antiguo ya que tenía su origen en los depósitos dieciochescos de los Correos Marítimos, readaptado en 1808 como inmueble para la producción tabacalera en su distribución en planta baja, principal y ático. Señala que tras ser readaptado a lo largo del S.XIX como cárcel de mujeres -episodio que ya se ha relatado en anteriores epígrafes- se convertiría en un espacio fabril polivalente que contenía "o almacén de carpintería, delineación, cortes y corpo de garda”. Por su parte, la Fábrica Nueva era un edificio de nueva construcción ejecutado en el año 1827 que tras las renovaciones acometidas en la década de los cuarenta del S.XIX contaba también con tres alturas distribuidas en bajo, planta y ático. En la planta baja acogía los almacenes de escogido y elaborados, mientras que en la planta principal albergaba el taller de puros "marca chica" con su cuarto de oreo y en el ático, el secadero. Ambos edificios formaban el conjunto conocido como Fábrica de Arriba y estaban conectados a través de un corredor lateral que se abría sobre un patio interior.

128 SANTÍAS, A. y LERA, D. (1898) op. cit., pp. 14-15.

${ }^{129}$ Ver ALONSO ÁLVAREZ, L. (1998) op. cit., pp. 134-137. 
Por su parte, la denominada Fábrica de Abajo - para distinguirla de la anterior- era un edificio exento resultado de la renovación de unas instalaciones preexistentes a principios de la década de los ochenta del S.XIX, y que en esta etapa albergaba ya el grueso de la producción, estando llamada a convertirse en el edificio principal del conjunto fabril. En la planta baja se ubicaban los talleres de desvenado, oreo de cigarros comunes, almacenes de repuesto, de escogido y de tabacos elaborados, la portería general de registro de operarias, un generador y el aerocondensador. Por su parte, el piso principal albergaba los talleres de cigarros comunes, de cigarrillos finos y de picados finos, contando estos últimos ya con dos prensas de metal y su motor y el taller de máquinas que contaba con dos unidades para la picadura al cuadrado, otras dos de virutar vena, una laminadora, otra para la picadura en hebra y el torrefactor y oreo de las picaduras. Por último, el piso segundo o desván estaba destinado a taller de cigarrillos comunes.

Señala Alonso Álvarez que tras el incendio fortuito de 1896, su distribución no sufrió grandes alteraciones, con la excepción de la mayor altura de la que se dotó a las naves, que "proporcionábanlle ao conxunto niveis superiores de ventilación, luz e espacio que permitían o desenvolvemento das actividades produtivas de maneira funcional e con grande aforro de tempo".

En la segunda etapa descrita de mediados de la primera década del S.XX, se acometerían obras de capital importancia para la definición final de la configuración de la fábrica, con las reformas realizadas con arreglo al proyecto del arquitecto Antonio de Mesa. Estas intervenciones responderían a la progresiva introducción de la nueva maquinaria, a la sustitución de los productos y marcas heredadas de la administración previa a la CAT que no gozaban de la suficiente aceptación entre los consumidores y al inicio de la fabricación de los Farias. Sin embargo, como señala Romero Masiá, no hay que olvidar que esta incipiente mecanización no sustituía en su totalidad al trabajo manual, que continuaba siendo fundamental y que ocupaba a la inmensa mayoría de las operarias empleadas en la fábrica ${ }^{130}$.

En las obras de la segunda etapa se entrelazarían operaciones relativas al reacondicionamiento de los límites del conjunto paralelamente a las profundas reestructuraciones acometidas en el seno de los espacios productivos con la consiguiente reforma de los inmuebles. En 1906 la CAT decidía ampliar el tipo de labores realizadas en la fábrica herculina incorporando la marca chica y marca grande, para lo cual era necesaria la renovación de los servicios y habilitar locales adecuados para estas elaboraciones. Estos talleres fueron ubicados en los espacios de la planta baja de la Fábrica de Abajo, en los que ya se hallaban las

\footnotetext{
130 “As máquinas tiruleiras (liadoras de tirulos ou parte interior dun cigarro puro), permitiron grandes adiantos na producción. Este tipo de máquinas coñeceu, neste período que estamos a analizar, varios modelos que ían perfeccionando ós anteriores. Á altura de 1910/1911 estas máquinas confeccionaban xa todo o corpo do cigarro. Á fábrica da Coruña chegan, trala experiencia noutras fábricas españolas, as liadoras mecánicas para a elaboración de pitos ou tabaco de picadura [...] As fases de empaquetado tamén se viron afectadas pola introducción de novas máquinas que axilizaban e regulaban as operacións manuais". ROMERO MASIÁ, A. (1997) op. cit., p. 85.
} 


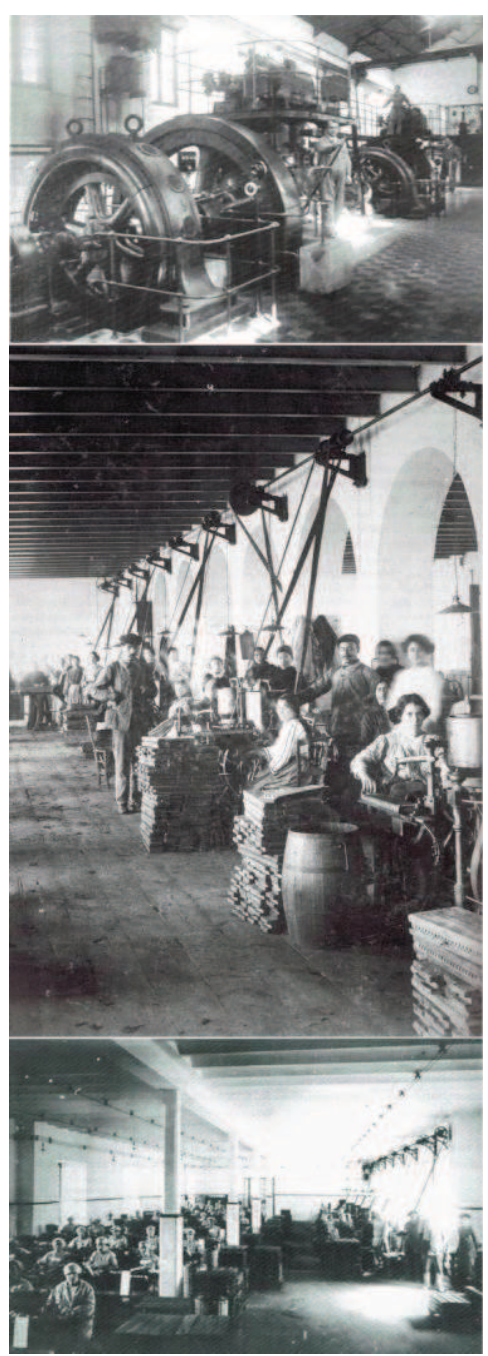

Figura 3.50. Grupo electrógeno y espacios productivos de la fábrica, en ROMERO MASIÁ, $A$. (1997) op. cit., pp. 129, 36 y 44, respectivamente. operarias que producían Farias.

La Fábrica de Abajo remató la primera parte de sus obras en 1906, estableciéndose en la misma las casi 1.300 operarias que elaboraban puros comunes en el tendejón y que ocuparían la segunda planta. Aún se mantenía el ingreso principal por la calle Privamera y sus naves acogían modernas y amplias salas que contaban con luz y ventilación tras la remodelación. En la planta baja, el espacio que antiguamente había estado definido por arquerías de perpiaño similares a las de otras fábricas - como Cádiz o Alicante- disponía ahora de amplios espacios encalados y ventilados, y en ella se situarían los talleres de picadura. El grueso de los talleres de cigarros comunes o puros se situaba en la primera planta, mientras que en el segundo piso de nueva construcción se situaba el taller de cigarros en el que trabajaban unas 1.000 pitilleras. Esta nueva planta no disponía de pilares, sino que la cubierta era soportada por cerchas de hierro que conferían al espacio una imagen de diafanidad propia de la arquitectura industrial. En el sótano, que en la última reforma había sido saneado, se dispusieron todos los procesos previos de preparación de hoja que exigían maquinaria pesada como el torrefactado o el oreo. Todas las plantas se comunicaban entre sí por espaciosos montacargas movidos por energía eléctrica que facilitaban el funcionamiento de la producción en la conexión de sus distintas fases.

La tercera etapa estaría constituida por las obras restantes de la segunda década del S.XX, centradas en la instalación de maquinaria para algunas labores y se procedería al mecanizado de algunas fases ${ }^{131}$, proceso que se vio coadyuvado por la sustitución de la vieja máquina de vapor de $50 \mathrm{cv}$ por dos generadores eléctricos, aunque no sería hasta 1929 que se completaría la instalación eléctrica de todas las salas y la dotación de medios de elevación y transporte al depósito, en 1930. Curiosamente, como señala Romero Masiá132, la mecanización de las fábricas de tabacos llevada por la CAT de modo progresivo, experimentó una aceleración como consecuencia de la carestía de tabaco durante la I Guerra Mundial. En cuanto al almacenaje, en la etapa previa manufacturera, los almacenes se situaban en los sótanos, con poca luz pero suficientemente aireados. Sin embargo, con la construcción en los años veinte de los nuevos depósitos de tabaco en rama en La Coruña, se introdujeron modernas tecnologías de control de humedad y temperatura.

Aunque, en las décadas restantes del S.XX se continuaron realizando reformas periódicas y se impulsó la mecanización total de las labores, la distribución del espacio productivo no llegaría a diferir mucho de la

\footnotetext{
131 En 1908, ya se habían instalado máquinas de colocar capas a puros -tiruleras-así como liadoras, picadoras y prensas estandarizadoras del producto. Dos años después se mecanizarían los cigarros y las picaduras. ALONSO ÁLVAREZ, L. (1998) op. cit., pp. 174-175.

132 De esta forma, llegarían a la Palloza máquinas construidas por empresas españolas como Maquinista Valenciana, Sociedad Corcho de Santander o Fombuena de Madrid. Este incremento de la tecnificación de la producción continuaría en la década de los años veinte, durante la tercera etapa señalada anteriormente, en la que se realizaría una gran inversión en tecnificación. ROMERO MASIÁ, A. (1997) op. cit., p. 85.
} 
de los años veinte. Bajo la gestión de Tabacalera a partir de 1945, los espacios se reorganizaron, integrando la Fábrica de Abajo enteramente todas las fases productivas y relegando algunos locales de la Fábrica de Arriba a dependencias residenciales del cuerpo administrativo de la fábrica.

\section{Las cigarreras y la dimensión humana de la fábrica}

En lo relativo a la dimensión humana de la Fábrica de Tabacos de La Coruña, sus condiciones espaciales como hábitat de las cigarreras y las influencias particulares de éstas sobre el espacio productivo industrial, cabe destacar que "es, probablemente, el establecimiento fabril más antiguo de la ciudad y, sin duda, una de las escasas posibilidades de trabajo fuera del hogar que tuvo la mujer de la ciudad y su comarca a principios del S.XIX"133.

Las implicaciones de la presencia de las cigarreras en el espacio laboral debían mucho a la proximidad de sus residencias y a los lazos de familiaridad y vecindad entre ellas ${ }^{134}$. En el caso de la fábrica herculina, más de la mitad de las cigarreras procedían de la ciudad de La Coruña, mientras que un cuarto de las operarias procedían de otros puntos de la provincia aunque residían en la ciudad, y el cuarto restante, en considerable inferioridad, se componía de cigarreras venidas de otras provincias, principalmente Asturias. De hecho, entre las cigarreras de procedencia local se establecía una cierta diferenciación de clases entre las residentes de la periferia rural y las que habitaban en los barrios del núcleo urbano coruñés.

Dentro de todo el contexto obrero de la ciudad, las cigarreras tenían cierto estatus social, compartido con otros colectivos obreros [...] No obstante, a lo largo del S.XIX, según la historia oral todavía guardada por las cigarreras jubiladas, hijas de cigarreras, podemos diferenciar dos modelos de obreras [...] las señoritas cascarilleiras. Son las mujeres procedentes de la ciudad [...] [y] las aldeanas, peyorativamente referidas por las primeras. Procedían en su mayoría de los municipios limítrofes de la urbe: Cambre, Oleiros, Culleredo, etc. ${ }^{135}$.

Lo que resulta realmente interesante a efectos de comprender el espacio del trabajo en la fábrica en su relación con las cigarreras, no es tanto el estatus social o procedencia de cada una, como su distribución geográfica en los aledaños del inmueble, de forma que se establecía un vínculo indisoluble entre el espacio laboral y el espacio doméstico en razón de su proximidad. Paralelamente al crecimiento urbano experimentado desde mediados del S.XIX surgían barrios obreros como

133 BARBOSA VÁZQUEZ, A. M. (1998) op. cit., p. 426. La autora destaca que la comunicación forma parte de la tesis doctoral El proceso de industrialización en La Coruña: el caso de la Fábrica de Tabacos, en el Departamento de Sociología y Ciencia Política de la Universidad de La Coruña, de la que no se ha podido obtener una copia ni referencias.

134 "A Palloza, por ser unha empresa que dependía directamente do Estado e non dun empresario privado, tiña unha peculiaridade: a de que as súas traballadoras tivesen grandes posibilidades de herdar o posto de traballo polo feito de pertencer a unha determinada saga familiar [...] Estes trazos das fábricas de tabacos españolas manteranse mesmo despois de 1887, tras a constitución da Compañía Arrendataria de Tabacos, cando a xestión e a explotación do monopolio do tabaco pasou a mans privadas". ROMERO MASIÁ, A. (2007) op. cit., p. 55.

135 BARBOSA VÁZQUEZ, A. M. (1998) op. cit., p. 427. 
Atocha o Santa Lucía, caracterizados por una "convivencia comunitaria, puertas afuera de las casas, sobre la privacidad propia de los centros urbanos y de los ensanches en los que residía la burguesía"136. Este último rasgo constituye una de las características comunes a las restantes fábricas tabacaleras estudiadas en la formación de un sentido de comunidad establecido entre la fábrica y su entorno y trascendiendo los límites de la misma.

Señala Romero Masiá que los principales barrios de origen de las trabajadoras eran la Ciudad Vieja - una minoría puesto que eran las zonas más exclusivas de la ciudad-, la zona de la calle Orzán, los barrios obreros de la zona de Montealto y, por último, los barrios que con gran diferencia concentraban el mayor número de cigarreras: Camiño Novo -actual Juan Flórez- y Garás -actual Linares Rivasvertebraban la expansión de estos barrios populares -los núcleos rurales próximos de Gaiteira, Monelos y Palloza- conectándolos con el núcleo consolidado de la ciudad -Ciudad Vieja y Pescadería- de forma que las cigarreras se concentraban en torno a las calles próximas a la fábrica -Falperra, Santa Lucía, Camiño Novo, Garás y Castiñeiras de Abaixo-. Existía también un importante grupo de cigarreras que se concentraba en el entorno de Riazor. Las condiciones básicas de estos barrios eran la proximidad de la fábrica y los bajos precios de las viviendas que eran, en un porcentaje alto, ranchos periurbanos concentrados en zonas de potencial expansión urbana, pero escasamente urbanizadas a finales del S.XIX.

Con el tiempo, las cigarreras preferirían habitar zonas próximas a la fábrica para poder realizar sus desplazamientos diarios en el menor tiempo posible pudiendo atender tanto sus obligaciones domésticas como el trabajo en el interior de la fábrica137. No obstante, "estos barrios sufrían carencias principalmente de tipo higiénico, ya que sus calles estaban sin urbanizar y pavimentar y las viviendas no tenían luz eléctrica, entre otras cosas. Unas viviendas, además, que solían ser de reducidas dimensiones y que debían albergar a un elevado número de personas en su interior" 138 .

Esta proximidad geográfica de las viviendas, junto a la organización de los talleres en los que las cigarreras pasaban largas jornadas laborales de doce horas, fomentó un sentimiento de unión que coadyuvó a la formación de una identidad colectiva y que determinaría una crucial relevancia a la hora de desarrollar sus acciones reivindicativas.

Como se ha referido anteriormente, la novela de Emilia Pardo Bazán constituye una fiable fuente de datos para el conocimiento del espacio laboral de la fábrica de tabacos herculina decimonónica. En una elocuente comparación de carácter alegórico, la autora asemeja las

\footnotetext{
136 FREÁN HERNÁNDEZ, O. (2003) op. cit., p. 328.

137 Debe tenerse en cuenta el carácter casi rural de las inmediaciones de la fábrica en esa época y que resultaba más adecuado para las economías de las familias trabajadoras, por lo que resolvían instalarse en estas zonas de crecimiento de la ciudad. ROMERO MASIÁ, A. (2007) op. cit., pp. 58-60.

138 FREÁN HERNÁNDEZ, O. (2003) op. cit., p. 329.
} 
condiciones espaciales de las distintas fases del proceso productivo al Infierno, Purgatorio y Paraíso. A las condiciones benévolas de los talleres de liado de las plantas superiores a las que Amparo, la protagonista de La Tribuna, aspira a ingresar, se contraponen las labores realizadas en la planta baja y que correspondían a las fases iniciales del proceso productivo realizadas en un ambiente menos confortable.

Llegados a este punto, cabe analizar las carencias de las que adolecían las cigarreras en su espacio de trabajo y que motivaron muchas de las mejoras acometidas en las reformas de finales del S.XIX y principios del S.XX en materia de higienismo y servicios sociales. Parte de las incomodidades a que estaban sometidas las cigarreras versaban en la inadecuación de los locales al ingente número de operarias que trabajaban a destajo en los mismos. Para ello baste señalar que, durante la época inicial de puesta en funcionamiento de la fábrica y en tan sólo diez años de 1819 a 1829, la mano de obra se duplicó del millar de mujeres a las dos mil, cifra que en décadas siguientes alcanzaría los tres millares. Estas condiciones fueron motivo constante de revueltas y protestas puesto que

ademais do sistema de traballo axustado, que obrigaba a permanecer moitas horas na fábrica, as condicións laborais víanse empeoradas pola aglomeración das cigarreiras en talleres de non excesiva capacidade, como nos amosan as escasas reproducións realistas que se conservan desta época e a reducida ventilación disponíbel, co que estaban abocadas a desenvolverse no ambiente insalubre procedente do depósito de milleiros de quilogramos de folla que despedían un cheiro insoportábel e insán ${ }^{139}$.

Este hecho venía a reforzarse con los resultados arrojados por los diversos informes de la Comisión de Reformas Sociales, que denunciaba la situación en que se encontraban las cigarreras y exigían reformas que atendiesen, no sólo las mejoras relativas al incremento y beneficio de la producción, sino también a las necesidades de las trabajadoras:

las salas de labor de los establecimientos antiguos de la renta del tabaco, dejan bastante que desear en sus condiciones de higiene y salubridad; aún cuando constituidas por regla general en locales espaciosos, altos de techo y ventilados, están demasiado hacinadas; y esto unido a las emanaciones del tabaco que se desarrollan en las operaciones de su manipulación hace que se respire una atmósfera densa, insoportable a veces en la estación de los calores.

Para paliar esta situación, ya a finales del S.XIX surgen voces de apoyo a las cigarreras que refrendan con sus denuncias públicas ciertas medidas e iniciativas de carácter social que mejorarían las condiciones laborales de las operarias. Anteriormente se había contemplado la creación de unas escuelas primarias y de párvulos en el recinto de la fábrica durante las reformas de finales de la década de los 20 del S.XIX,

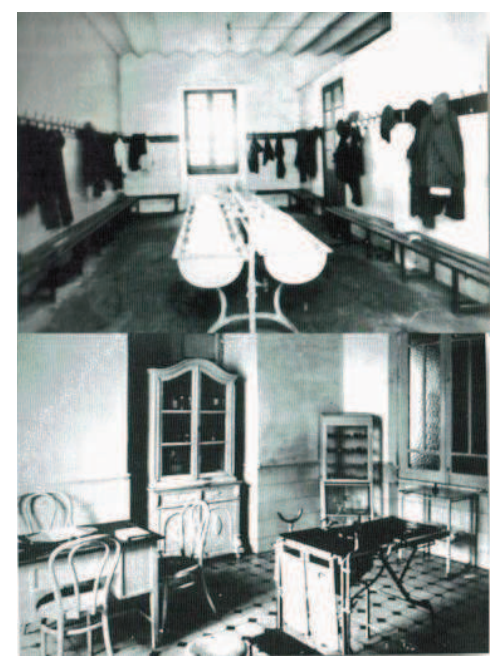

Figura 3.51. Vestuario y clínica de la Fábrica de Tabacos de La Coruña, en ROMERO MASIÁ, A. (1997) op. cit., pp. 120-121.

139 Este pasaje y siguiente en ALONSO ÁLVAREZ, L. (1998) op. cit., pp. 100-101, citando el informe sobre las fábricas del Estado de la Comisión de Reformas sociales de 1884. 


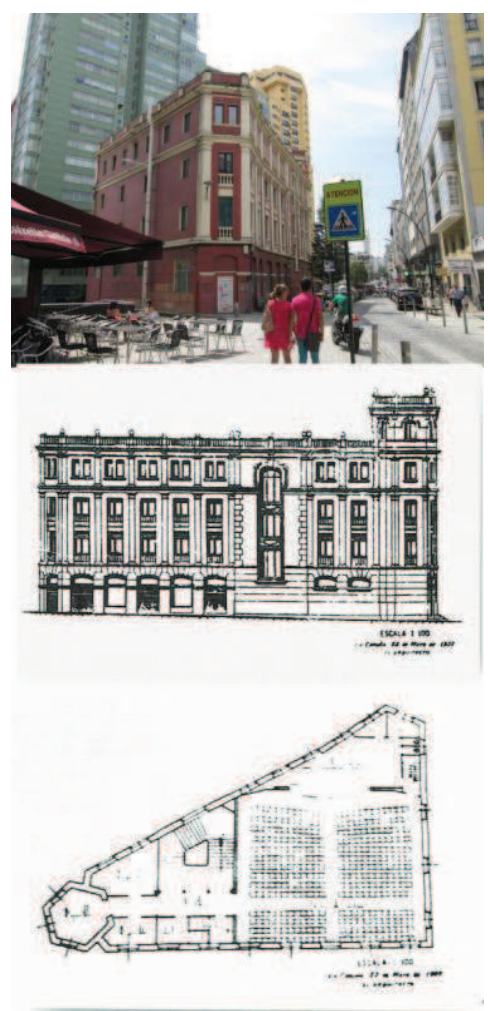

Figura 3.52. La "Casa das Cigarreiras" en la actualidad, 2014; y planimetría del proyecto, en ROMERO MASIÁ, A. (1997) op. cit., pp. 136 y 138 . iniciativa que hubo de desestimarse finalmente.

En el caso de la Fábrica de Tabacos de La Coruña, dos serían los filántropos que lucharían por los derechos y bienestar de las cigarreras: el médico José Rodríguez Martínez, a finales del S.XIX, y Severino Chacón, a principios del S.XX. El primero, del que ya se ha hecho referencia en epígrafes anteriores, fue uno de los más arduos defensores del bienestar de las cigarreras, siendo frecuentes sus denuncias públicas en la prensa local. Para ello baste una muestra recogida en la obra de Alonso Álvarez y Romero Masiá:

Nunha carta dirixida a Marcelino Dafonte, director de La Voz de Galicia, co gallo da reforma realizada na Palloza, [José Rodríguez] escribía: “¿Cuánto apostamos a que no se ocupan ni de ventilación, ni de lavatorios, ni de comedores los tales planos? ¿Y [...] del asilo de los hijos de las cigarreras? [...] Mucho, pero muy mucho hay aún que criticar respecto a las reformas proyectadas y aprobadas por la dirección." Segundo as súas informacións, reduciran o orzamento oficial dos máis de 100 mil pesos que custaba o proxecto inicial do enxeñeiro Pascual Vicent a só uns 60 mil. Non se falaba en ningures, por exemplo, da "ampliación de los locales, como está proyectada; ventilación por el sistema ideado por el referido ingeniero; comedores, cocinas y lavatorios para las operarias y operarios; una pequeña enfermería y botiquín consiguiente; un asilo para los hijos de las cigarreras; un banco-caja de ahorros y descuentos para librar a estas infelices de los préstamos usurarios, las compra-ventas inverosímiles, empeños y demás zarandajas de la vida íntima y económica de estas simpáticas obreras" 140 .

No obstante, estas denuncias no tuvieron efecto en el momento en el que se produjeron, pese a la notoriedad del médico Rodríguez como figura pública de la ciudad herculina, y hubo que esperar a las reformas acometidas entre mediados de la segunda década del S.XX y los años veinte para que dentro del programa de reformas de la fábrica se incluyese la creación de espacios secundarios al servicio de la plantilla. Tiempo después y gracias a la mediación y empeño del sindicalista gallego Severino Chacón, se consiguió realizar uno de los proyectos más esperados por las cigarreras: la construcción de un centro social propio, conocido popularmente como "Casa das Cigarreiras" y que, al igual que el inmueble homólogo de la fábrica alicantina, estaba llamado a cumplir una función similar a los dopolavoro de las tabacaleras italianas.

A idea de contar cun Centro Social propio foi lanzada por Severino Chacón, como secretario da Federación Tabaquera Española, en 1931, durante un apoteósico mitin no teatro Linares Rivas. Chacón inicia as xestións na alcaldía para tratar da posibilidade de que o concello lles ceda un solar próximo, á fábrica, no que poder construí-lo Centro Social ${ }^{141}$.

\footnotetext{
140 ALONSO ÁLVAREZ, L. (1998) op. cit., pp. 142-143 citando a La Voz de Galicia 20-6-1899 y 6-7-1899. También se hace eco de estas denuncias publicadas en prensa, ROMERO MASIÁ, A. (1997) op. cit., p. 92.

${ }^{141}$ La parcela en la que se construiría el edificio se situaba en un jardín de la actual calle de Fernández Latorre muy próxima a la fábrica. ROMERO MASIÁ, A. (1997) op. cit., p. 134.
} 
Afortunadamente, el Centro Social que se inauguró en 1935 se conserva en la actualidad prácticamente con las mismas características que en el proyecto original, salvo algunas reformas interiores. Según el proyecto del arquitecto Eduardo M. Losada, se configuró como un edificio de tres alturas y azotea, con una planta sótano, y que adoptaba una forma torreada en su frente. En la planta sótano se ubicaban la sala de juntas para asociados y un despacho para secretaría, así como servicios. En la planta baja se alojaban la cooperativa de consumo, una sala de juntas, cuatro secretarías y un local para el conserje. El salón de actos, con doble altura y aforo para 532 asientos, se ubicaba en la primera planta y reservaba algunos locales para futuras ampliaciones. La planta segunda, por su parte, albergaba la biblioteca. Finalmente, la tercera planta estaba destinada a despachos, dos aulas para niños y niñas respectivamente, la vivienda del conserje y más locales para ampliar la superficie en futuras reformas. La azotea podía ser utilizada por los niños que ocupaban las aulas.

Lamentablemente, las cigarreras no tuvieron ocasión de utilizar el inmueble debido a que, con el estallido de la Guerra Civil, el edificio fue finalmente incautado por el Régimen, -al igual que ocurrió con la Casa de las Cigarreras de Alicante- y la Unión Tabaquera que había promovido su construcción fue declarada ilegal.

Afortunadamente, no sólo se conserva hoy en día este edificio, sino que la toponimia recuerda a las cigarreras que marcaron el ritmo del barrio con sus idas y venidas -como la calle de las Cigarreras-. De igual forma, la escultura homenaje a las mismas dispuesta en el centro de la plaza de la Palloza -obra de María Jesús Urgoiti de 1986- tras la reordenación de la misma en los años 80, constituye un recuerdo material, al igual que el edificio fabril llegado a nuestros días, de la fuerte impronta que estas mujeres y sus circunstancias marcaron en la memoria colectiva de la urbe herculina.

\subsubsection{La Fábrica de Tabacos de Madrid (1809-2000)}

\section{Contexto histórico hasta su cierre}

Para tratar de paliar la situación de desabastecimiento durante la ocupación francesa y la situación de incomunicación entre las fábricas de tabacos existentes, José Bonaparte decide instalar una nueva factoría tabacalera en Madrid en 1809 que se dedicase a la elaboración de cigarros y polvo de tabaco, en el que sería el tercer establecimiento fabril fundado durante la primera expansión geográfica de fábricas del S.XIX.

La carestía provocada por la guerra favoreció en la urbe madrileña la constitución de un foco de mercado negro en las zonas adyacentes a la Puerta de Embajadores. A esta situación se uniría la supresión de algunos monopolios reales con la llegada de José I; entre ellos, el de Naipes. Precisamente, la factoría de esta última industria se encontraba en el límite periférico Sureste de la ciudad y su cierre conduce a la improvisación de un establecimiento tabacalero en dicho

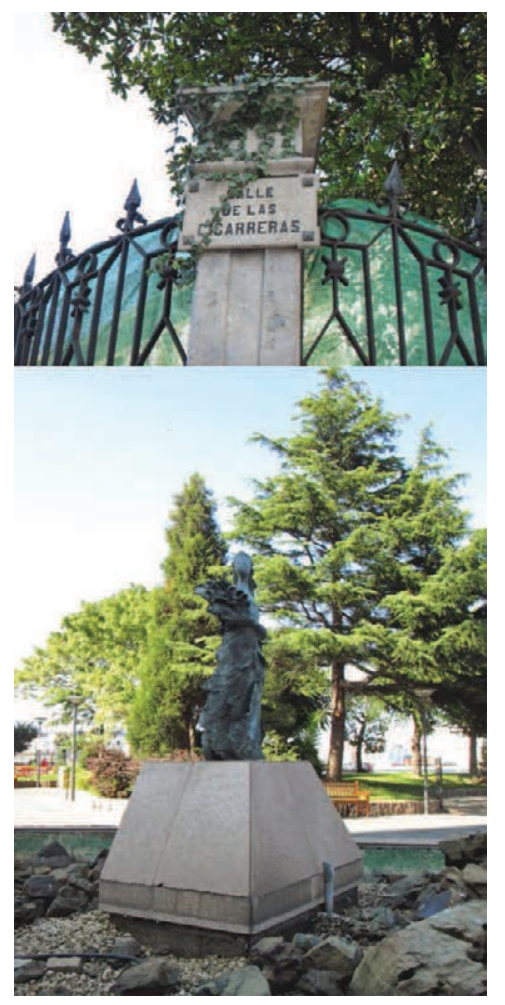

Figura 3.53. La memoria de las cigarreras coruñesas en el entorno de la antigua fábrica, 2014. 
enclave de la capital. Disponiendo, pues, de un inmueble potencialmente reutilizable para la nueva producción tabacalera, se decide instalar la Fábrica de Tabacos de Madrid en la antigua Real Fábrica de Aguardientes y Naipes proyectada por arquitecto Manuel de la Ballina ${ }^{142}$.

Tras una serie de reformas, la actividad fabril se iniciaría el 4 de abril de 1809 con una plantilla de unas 800 operarias instruidas por maestras de origen gaditano ${ }^{143}$. Aunque desde la Guerra de Independencia hasta 1816 trabajarían entre 400 y 500 cigarreras en la elaboración de cigarros comunes virginia, mixtos y cigarrillos de papel con un carácter provisional, su funcionamiento se ratificó por Real Orden del 23 de enero de 1816 en la que se autorizó, a petición de la Dirección General de Rentas Estancadas, un reconocimiento del inmueble madrileño por parte del superintendente de la fábrica hispalense.

Como señala Candela Soto,

tras varios meses de estudio, el Comisionado desplazado a Madrid informó favorablemente sobre las posibilidades productivas del establecimiento de la Corte. En el informe remitido al Director General de Rentas Estancadas, se reconocían algunas de las ventajas que beneficiarían al Erario Público. En primer lugar, las observaciones del informante constataban la creciente demanda de consumo de tabaco en Madrid y su provincia, que además reflejaba el alto nivel de calidad conseguido en la producción madrileña. En segundo lugar, se destacaban importantes ventajas económicas como el ahorro en el gasto de la fabricación de cajones para el transporte del producto a las administraciones de las provincias centrales de la península o el aprovechamiento de los útiles de fabricación y reservas de tabacos encontradas en la fábrica ${ }^{144}$.

Se argumentaba, además la idoneidad del edificio que contaba con un espacio capaz para almacenaje y recibo de la hoja, oreo, distribución y contaduría, además de amplias salas para la disposición de mesas en las que se podría dar ocupación a las cigarreras. Sería finalmente en junio de 1825 cuando se restableciese el trabajo en la fábrica madrileña

142 Manuel de la Ballina López de Castro (1750-1818) fue un arquitecto madrileño hijo del arquitecto zaragozano José de la Ballina. Durante toda su vida se vería eclipsado por figuras como Francisco Sabatini o Juan de Villanueva. En su trayectoria destacan cometidos como "Medidor de las obras del Real Palacio Nuevo" y "Aparejador Principal" del mismo a la muerte de su padre, o el trazado del Convento de las Comendadoras de Santiago de Granada. URRUTIA NÚÑEZ, A. (1982) op. cit., pp. 120-121. En el contexto en el que se sitúa su obra, "a los arquitectos de la segunda mitad del siglo XVIII se les viene definiendo como arquitectos neoclásicos y así han sido definidos José y Manuel de la Ballina, sus contemporáneos, viven por tanto una situación indecisa y problemática. Se encuentran con una corriente que intenta una reconstrucción de la antigüedad que reacciona dialécticamente con otra corriente todavía viva en la época, el barroco". TOVAR MARTÍN, V. (1985) "La arquitectura de José y Manuel de la Ballina. Entre el Barroco y el Neoclasicismo" en Archivo español de arte, tomo 58, n 230, p. 128

143 "Existen datos en la Instrucción de 1726 de los que se deduce que Madrid contaba ya por entonces con Fábrica y Estanco Real "para la labor, entriego y recibo de Tabacos», bien es verdad que debía ser de corta entidad, pues se afirma que «no pasan de dos o tres molinos para remoler o labrar algunas cortas porciones de Tabacos, y no siempre seguida esta labor, sino en tiempos»". COMÍN COMÍN, F. y MARTÍN ACEÑA, P. (1999) op. cit., p. 169.

144 CANDELA SOTO, P. (1997) op. cit., p. 60. Para el conocimiento de este caso estudio se seguirán fundamentalmente las obras de Candela Soto y Urrutia Núñez. 
con carácter definitivo ${ }^{145}$.

El creciente consumo y la ampliación de la producción provocaron una expansión en el seno del inmueble fabril que pronto manifestó la poca adecuación de su espacio para las necesidades del crecimiento productivo. Durante los primeros años, una de las principales dificultades que experimentó fue la carencia de un adecuado suministro de agua que resultaba fundamental tanto para las tareas productivas como para las casi 3.000 operarias que llegó a emplear la fábrica en las primeras décadas. De esta forma, "en 1829 fue necesaria la intervención del Ministerio de Hacienda y del propio monarca para que el Ayuntamiento autorizara el aumento de la dotación de agua para el consumo de las obreras"146.

Los nuevos requerimientos espaciales de la producción provocaron que las reformas sobre la estructura y los espacios de la fábrica fuesen constantes durante la segunda mitad del S.XIX. Las obras de acondicionamiento fueron especialmente cruciales a finales del S. XIX en que, al igual que en las restantes fábricas, era necesaria una adecuación de los locales del inmueble dieciochesco para su adaptación a los requerimientos de un espacio productivo en constante reorganización hacia procesos mecanizados. El informe de 1881 de la comisión encargada de estudiar el plan general de reformas de las fábricas, señalaba la apremiante necesidad operar mejoras de acondicionamiento sobre la fábrica madrileña, por ser la factoría sita en la capital y por los numerosos problemas endémicos que venía padeciendo desde su puesta en funcionamiento. Al deficiente suministro de agua se unía el hacinamiento del personal, en algunos casos ubicado en los desvanes faltos de luz y ventilación. De igual forma, la ampliación de algunos talleres había conllevado el empeoramiento de las condiciones de otros favoreciendo la situación de hacinamiento. Por otra parte, la dotación de la fábrica era muy deficiente, así como las condiciones generales de sus instalaciones.

Con la cesión del arriendo del monopolio a la CAT en 1887, se impulsarán importantes reformas en el seno de la fábrica en materia de saneamiento e introducción de la mecanización en algunas labores como la picadura. Estas mejoras conllevaron la restructuración tanto de la organización de la producción como de los espacios de la fábrica. Sin embargo, Candela Soto señala que "durante varias décadas, el interés por el desarrollo técnico como única vía para aumentar y mejorar la producción descuidó las condiciones ambientales del trabajo". De esta forma, el inmueble adolecía, además del hacinamiento anteriormente mencionado, de ausencia de mecanismos contra el fuego y un exceso de humedad que, unido a la escasa ventilación, convertía las estancias de laboreo en insalubres.

145 Señalan COMÍN COMÍN y MARTÍN ACEÑA que "su funcionamiento como fábrica de tabacos fue irregular hasta 1825, debido a los conflictos bélicos y políticos, y al abandono en que la Hacienda tuvo a sus fábricas; desde entonces se estableció con carácter definitivo la producción en la fábrica de Madrid, gracias a la rehabilitación de las Reales Fábricas del absolutismo". COMÍN COMÍN, F. y MARTÍN ACEÑA, P. (1999) op. cit., p. 77.

146 CANDELA SOTO, P. (1997) op. cit., p. 61. 


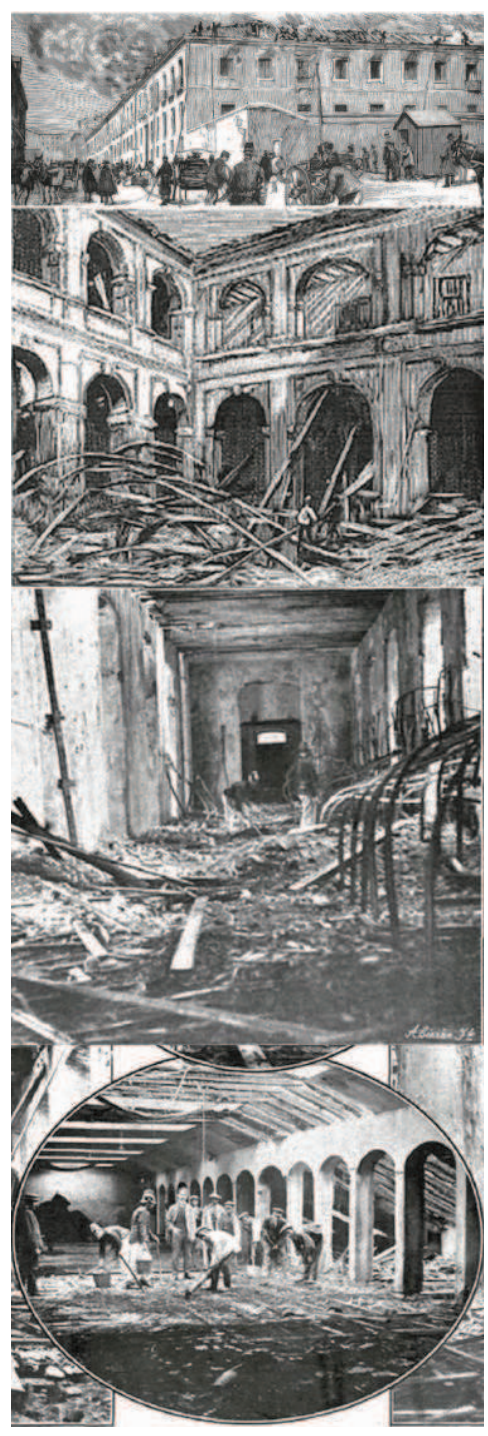

Figura 3.54. Grabado del incendio de 1890 y fotografías del incendio de 1906, en La ilustración española y americana, $n^{\circ} 42, p .292$, y $n^{\circ} 37$, p. 201, respectivamente.

Ante esta situación, se resolvió acometer una mejora sustancial de los locales junto a la ampliación de los espacios de la fábrica que paliaría las carencias anteriormente mencionadas. De esta forma, durante la última década del S.XIX se acometieron las primeras obras de una serie de reformas que modificarían en gran parte tanto la superficie productiva como la sección del edificio original. Fruto de estas obras aparecerían servicios higiénicos en el interior del edificio o las torres garitas que se construyeron hacia las calles Miguel Servet y Provisiones.

No obstante, a lo largo de la vida de la fábrica se sucedieron numerosos incendios, siendo los más destacables el acontecido el 10 de julio de $1887 \mathrm{y}$, especialmente, el del 11 de noviembre de 1890 del que dio noticia La Ilustración Española y Americana a través de los grabados de Comba. Los destrozos ocasionados por este último obligaron a la instalación provisional de varios talleres de cigarros en el Palacio de la Industria durante más de un año ${ }^{147}$.

Las reformas continuarían a principios del S.XX con la cubrición de los patios laterales en 1901 con ligeras cerchas metálicas y la disposición de una galería acristalada en el central. En junio de 1903 se inició un importante proyecto de reforma que elevaría una planta las crujías adyacentes a las calles Provisiones, Embajadores y Miguel Servet. Además de incrementar la superficie productiva en unos 3.710 metros cuadrados, se aumentaría la altura de los desvanes que tantos problemas habían ocasionado anteriormente por las condiciones de hacinamiento a que estaban expuestas las operarias. Esta ampliación se completó con la construcción de un pabellón en el patio posterior destinado al departamento de motores, así como otro de generadores ${ }^{148}$.

Así mismo, unos años más tarde se procedería a la construcción de un nuevo cierre conforme a la permuta de terrenos establecida entre la Dirección de la CAT y el consistorio local con objeto de adecuar el perímetro de la fábrica a la nueva ordenación de la Glorieta de Embajadores.

$\mathrm{Al}$ igual que en las restantes fábricas, la década de los veinte sería un periodo de intensa actividad en materia de reformas para el acondicionamiento del inmueble. Estas obras tuvieron por objeto la mejora de los locales y, fundamentalmente, la modernización de las instalaciones de saneamiento y servicios higiénicos, así como vestuarios, comedores o locales para la atención médica de las operarias y la electrificación y ampliación de la capacidad de los locales. Previamente se habían instalado, así mismo, escaleras y montacargas que facilitaban la comunicación vertical entre todas las fases del

\footnotetext{
147 (1890) La Ilustración Española y Americana, año XXXIV, nº 42, 15-11-1890, p. 292; y (1906) La Ilustración Española y Americana, año L, no 37, 8-10-1906, p. 201.

148 Señalan Comín Comín y Martín Aceña que la instalación de luz eléctrica en la fábrica madrileña se produjo en 1896, aplicándose primero a "los talleres cuya producción debía aumentar, como los de cigarrillos Superiores, de empaquetado de picaduras y de desvenado, en el caso de la fábrica de Madrid". COMÍN COMÍN, F. y MARTÍN ACEÑA, P. (1999) op. cit., p. 194.
} 
proceso productivo. Durante esta época, se incrementó la producción de cigarros y cigarrillos y se redujo el volumen de ocupación laboral a 2.000 operarias, consecuencia de la reorganización productiva que también afectó a la distribución espacial del inmueble.

La Guerra Civil daría paso a una época convulsa que ralentizaría las mejoras experimentadas en la década anterior. De igual forma, la Fábrica de Tabacos de Madrid tendría un papel importante durante los primeros meses del conflicto puesto que actuaría como sede de la CAT republicana hasta el traslado de la dirección de la misma a Valencia en diciembre de $1936^{149}$.

Sin duda, una de las principales repercusiones de los nuevos tiempos fue la reducción de plantilla que en 1950 contaba con 484 operarias ocupadas en la confección de labores y 57 como personal de mando, limpieza, etc., cifra muy alejada de las más de 4.000 cigarreras de tiempos pretéritos; mientras que el personal masculino integraba unos 200 empleados en todas sus categorías. No obstante, se trataba del segundo establecimiento más grande de Tabacalera, posición que compartía con la fábrica coruñesa. Sin embargo, la fábrica madrileña adolecería de problemas de espacio para el almacenamiento de la materia prima con la instalación de los nuevos talleres y su correspondiente maquinaria. En la política de especialización que surgió con los planes de modernización de Tabacalera, la fábrica madrileña pasaría a especializarse en la producción de cigarrillos, especialmente la marca Fortuna, y filtros para cigarrillos.

Finalmente, a partir de los años 70 se produce una reconversión del sector mediante la reestructuración de la plantilla y el establecimiento de nuevas categorías profesionales, así como la aparición de nuevas secciones fundadas sobre los principios de control de calidad del producto. En 1983, así mismo, se creó un Centro de Investigación y Desarrollo que coordinase todas las actividades de I+D de la compañía e impulsase la investigación en el campo de nuevos productos, ligas, tratamiento del tabaco, controles de materias en recepción, análisis de humos, calidad de los productos, equipos de medición y nuevas tecnologías. Con objeto de reforzar la infraestructura de distribución, el consejo de administración aprobó en diciembre de 1992 la construcción de un nuevo centro de distribución en Leganés en el que se ubicaría un centro de investigación y desarrollo y una fábrica de filtros. Este centro contaba con modernos sistemas de clasificación y gestión automática de transporte ${ }^{150}$.

La Fábrica de Tabacos de Madrid, no sólo fue objeto de las numerosas reestructuraciones acaecidas en la década de los 80 y 90, sino que pasó a formar parte de las ocho tabacaleras centenarias objeto de cierre mediante el "Plan Industrial" del año 2000 cesando su actividad en dicho año, tras lo cual pasó a formar parte del patrimonio del Estado bajo titularidad de la Dirección General de Bellas Artes del Ministerio

149 En agosto de 1939 se trasladarían nuevamente de San Sebastián a Madrid, ya bajo la tutela de la CAT Nacional. 150 Precisamente, al cierre de la fábrica madrileña, parte de sus activos fueron trasladados al centro sito en Leganés. COMÍN COMÍN, F. y MARTÍN ACEÑA, P. (1999) op. cit., p. 506. 


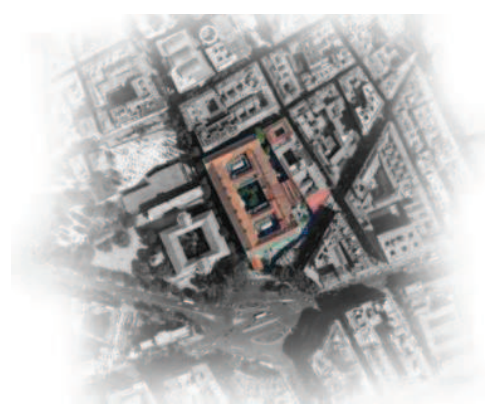

Figura 3.55. Emplazamiento de la Fábrica de Tabacos de Madrid. de Cultura.

\section{Motivos estratégicos de la fundación e implantación en su entorno}

La relevancia de la fábrica de tabacos como patrimonio industrial de Madrid versa en su caracterización como establecimiento perteneciente a la primera generación de fábricas tabacaleras del S.XIX y a su importancia como núcleo central de la red radial que conformó la expansión geográfica peninsular del parque fabril tabacalero. Esta circunstancia la llevaría a asumir competencias propias como fábrica situada en la capital del reino, equiparándose en importancia a la pionera Real Fábrica de Tabacos de Sevilla. Por otra parte, su situación en las inmediaciones de Embajadores influiría enormemente en el vecino barrio de Lavapiés e iniciaría la expansión industrial del S.XIX en el madrileño distrito de Arganzuela. La ubicación de la fábrica de tabacos en la anterior Real Fábrica de Aguardientes y Naipes, surgida como fruto de la política de obra pública en el Madrid de Carlos III, supondría un hito histórico urbano e industrial.

Pese a la tradición portuaria en la ubicación de las fábricas de tabacos en España, el caso de Madrid supuso una excepción a esta dinámica. La capital peninsular complementaba la función de Sevilla como centro neurálgico de las relaciones comerciales con las colonias americanas, por su carácter de capital del reino y por instaurarse como epicentro peninsular de las redes distributivas a través de los Almacenes Generales de la Corte ${ }^{151}$.

En el contexto general de la industria madrileña del S.XVIII,

la introducción del nuevo modelo económico, y tipo arquitectónico, que representan las Reales Fábricas en el Madrid del siglo XVIII, y su localización primordial en los arrabales de la ciudad, supuso un primer intento de diferenciación funcional entre centro y periferia, entre zona residencial y comercial, y zona industrial, regulándose por primera vez el espacio urbano en una auténtica sectorización de la ciudad según la función desempeñada por sus diferentes áreas ${ }^{152}$.

Señala Rabanal Yus que, aunque las reales fábricas comenzaron a instalarse en Madrid en fecha temprana, su desarrollo se realizó de forma lenta, no activándose hasta los años ochenta del S.XVIII. El incremento del número de establecimientos, tanto estatales como privados, indica el comienzo de la aceptación de la industria en la nueva ciudad que nace con la Ilustración. De esta forma, Madrid como capital, centro administrativo y comercial, además de urbe residencial

151 "Los cargamentos desde las colonias llegaban a otros puertos peninsulares y desde ellos se distribuían vía Madrid, donde se encontraban los Almacenes Generales de la Corte, sin contabilizarlos en Sevilla [...] En la ciudad hispalense se realizaba un mayor control que en el resto de partidos por la necesidad o la malicia”. RODRÍGUEZ GORDILLO, J. M. (2007) op. cit., p. 46.

152 RABANAL YUS, A. M. (1984) "En torno a la introducción y localización de las reales fábricas en el Madrid del siglo XVIII” en Anales del Instituto de Estudios Madrileños, n²1, p. 69. 
y cortesana, comenzará a albergar un incipiente desarrollo industrial ${ }^{153}$.

Durante el reinado de Carlos III se dio un impulso transformador en materia urbanística y arquitectónica en la urbe madrileña, localizando los establecimientos fabriles surgidos con el fomento de una incipiente industria de carácter estatal en los terrenos ubicados al Sureste de la ciudad, de ocupación primordialmente conventual. Este impulso reformador no atendería únicamente a la fundación de nuevas industrias y a la polarización de la ciudad en centro histórico y periferia industrial, sino que además respondería a los criterios arquitectónicos que caracterizarían la fábrica moderna y que, como se verá a continuación, convergían en muchos de sus planteamientos con los invariantes arquitectónicos característicos de las fábricas de tabacos en España ${ }^{154}$. De esta forma, la situación del inmueble que se convertiría en la Fábrica de Tabacos de Madrid respondía a las ordenanzas de 1719 en las que se obligaba a establecer fuera de la urbe madrileña aquellas industrias que pudiesen comportar incomodidad, insalubridad o peligrosidad para sus ciudadanos ${ }^{155}$, constituyéndose como un elemento de borde generador de crecimiento urbano.

Cabe destacar la reflexión que Casas Torres realiza sobre la actual posición de la fábrica de tabacos en el contexto urbano contemporáneo madrileño, por su localización en el eje cultural de la capital formado por el Museo del Prado, el Jardín Botánico, el Museo Reina Sofía, y la actual prolongación hacia el Sur con Matadero:

esta situación de eje interior de Madrid contrasta con la que existía cuando el inmueble se construyó a finales del siglo XVIII (1790) [...] Entonces esta zona se podía considerar como extrarradio de la Villa y Corte, tanto que junto al vasto edificio a edificar se encontraba uno de los portillos que abrían la ciudad hacia el exterior ${ }^{156}$.

La tabacalera de Madrid tendría un destacado papel en este crecimiento expansivo de la urbe madrileña hacia la zona Sur caracterizada por la ubicación de industrias de diversa naturaleza. Esta situación se vio favorecida por la aparición de infraestructuras como el ferrocarril en la segunda mitad del S.XIX -estaciones de Atocha y Delicias, y en gran medida las estaciones de Peñuelas e Imperial- y la mejora de las conexiones rodadas con el Plan Bidagor de mediados del S.XX, además del límite natural Sur del río Manzanares ${ }^{157}$. De esta forma, la Fábrica

153 En esta época de auge industrial, se conoce la existencia en la Carrera de San Francisco a mediados del S.XVIII de la fábrica de naipes que más tarde integraría la Real Fábrica de Aguardientes y Naipes sita en las inmediaciones de Embajadores en un edificio construido a finales del S.XVIII y que entró en funcionamiento en 1792. RABANAL YUS, A. M. (1984) op. cit., p. 79, citando a ALONSO, M. (1783) Lazarillo o nueva Guía para los naturales y forasteros de Madrid, Madrid, p. 111.

154 URRUTIA NÚÑ̃E, A. (1982) op. cit., p. 119.

155 "Las nuevas ordenanzas de 1719 redactadas por Teodoro Ardemans mantienen muchas de las normas de Torrija de 1661, en cuanto a la obligación de establecer fuera de la ciudad industrias que supusieran incomodidad, insalubridad y peligrosidad. Por ello, las nuevas fábricas se localizaron principalmente dentro de los arrabales de la ciudad y algunas, incluso, fuera de los límites de la cerca con una clara intención de diversificar su instalación entre las diferentes zonas de la capital según su función”. REVILLA, F. y RAMOS, R. (2008) La arquitectura industrial de Madrid, Colección Recorridos didácticos por Madrid, Madrid: La Librería, p. 18

156 CASAS TORRES, E. (1988) op. cit., p. 75.

${ }^{157}$ A la Real Fábrica de Salitre y la Real Fábrica de Aguardientes y Naipes dieciochescas se unieron otras muchas industrias en el entorno del distrito de Arganzuela. "Industrias de transformados metálicos, con ejemplos como 


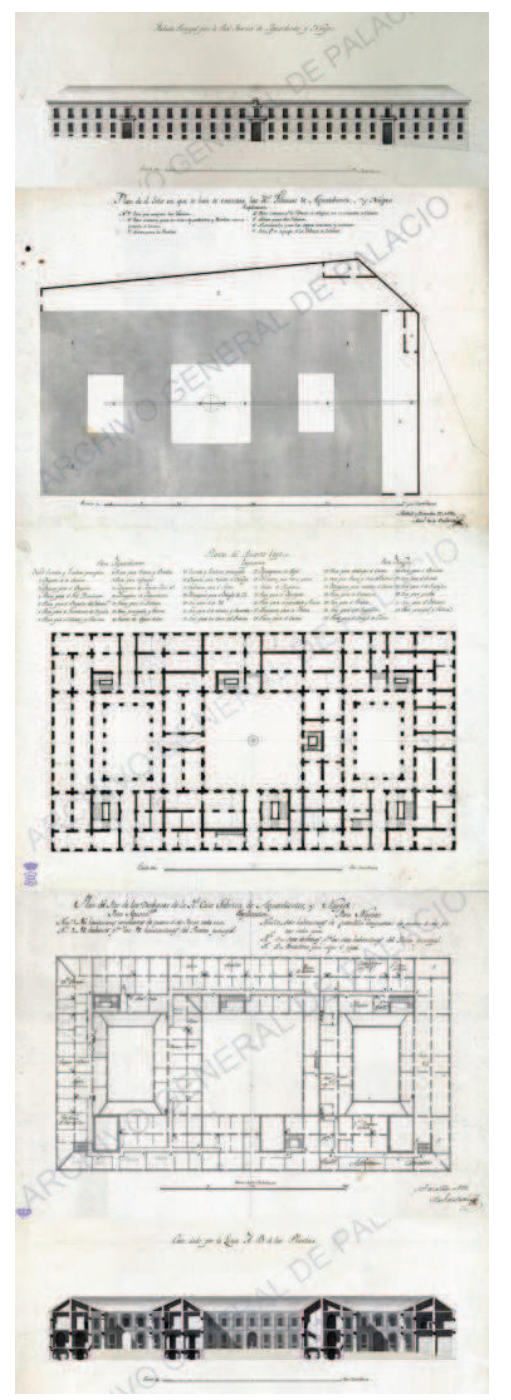

Figura 3.57. Proyecto de Manuel de la Ballina de 1780-92, en AGP, sección de planos, 283, $284,280,278$ y 282. de Tabacos de Madrid ejercería un papel de rótula entre el núcleo urbano consolidado y las dinámicas de circulación e intercambios establecidos entre la ciudad existente y las infraestructuras para el desarrollo de una periferia meridional en expansión, en una situación similar a la observada en la fábrica herculina.

Por tanto, la escala y significación de la tabacalera madrileña como nodo de su entorno inmediato, la caracteriza como hito peculiar, constituyendo una pieza fundamental del paisaje urbano. Sintomático de las relaciones de su borde con el entorno es el hecho de que la formalización de la Glorieta de Embajadores en $1905^{158}$ condicionaría la reformulación de su muro de cierre al Sur de la parcela con objeto de adecuarlo a la forma establecida por el nuevo nodo viario.

\section{Características de la arquitectura fabril}

\section{La preexistencia: Real Fábrica de Aguardientes y Naipes}

La Fábrica de Tabacos de Madrid forma parte de los edificios preexistentes que la Renta de Tabacos reutilizó a lo largo del S.XIX para la instalación de una nueva fábrica de tabacos como medida de estrategia expansiva que, a corto plazo, permitía la ampliación del parque fabril monopolístico ahorrando los costes que supondrían la construcción de fábricas de nueva planta. El inmueble elegido fue la Real Fábrica de Aguardientes y Naipes fundada en 1780 y cuya actividad se prolongó hasta su reconversión en factoría tabacalera en 1809. Este edificio fue concebido por el arquitecto Manuel de la Ballina y construido en terrenos anteriormente destinados a huertas de la Congregación de Clérigos Reglares de San Cayetano, siguiendo las premisas establecidas durante el reinado de Carlos III en la ubicación de las nuevas fundaciones industriales en propiedades de origen conventual de la periferia Sudeste madrileña.

En 1780, se hallaban ideados planes de situación de la Real Fábrica de Aguardientes y Naipes en los terrenos delimitados por la "Calle del Amor de Dios baxa" (actual Provisiones), "Camino que baja del Portillo de Embajadores" (actual Embajadores) y "Barranco o arroyo del Abapies" (actual Miguel Servet), los cuales estaban ocupados por una casa y huerta de la Congregación de Clérigos Reglares de S. Cayetano. Es así como la Real Hacienda hubo de adquirirlos en 1781, previamente tasados por José y Manuel de la Ballina, para la consiguiente construcción

Standard o Jareño y Cía [...] industrias de bebidas tan importantes como El Águila y Mahou, y otras de agua, gas y electricidad, de alimentos, etc.”, así como la presencia de los mercados formando un cordón paralelo al río Manzanares. A este desarrollo contribuyeron la instalación de centrales eléctricas -Mediodía-, el ferrocarril estaciones de Atocha y Delicias y las desaparecidas Peñuelas e Imperial para mercancías- y la proximidad al centro y al río junto al desarrollo de carreteras. "El Plan Bigador, aprobado en 1946, establece un nuevo ordenamiento urbano [...] Se plantean nuevos accesos que faciliten la conexión de las carreteras nacionales con las calles céntricas de la ciudad. Esto benefició a Arganzuela, que contó con mejores accesos”. REVILLA, F. y RAMOS, R. (2008) op. cit., pp. 54-57.

158 CASAS TORRES, E. (1988) op. cit., p. 76. 
iniciada de inmediato, realizada también durante el reinado de Carlos IV y concluida en $1792^{159}$.

La Fábrica de Tabacos de Madrid heredó una importante base edilicia de la anterior Real Fábrica de Aguardientes y Naipes por las similitudes entre los planteamientos espaciales de sus procesos productivos debido a su origen manufacturero. El edificio ideado por Manuel de la Ballina a finales del S.XVIII se basa en la idea abstracta de un contenedor configurado a través de una serie patios jerarquizados sobre dos ejes de simetría, manifestando una indeterminación programática del espacio interior propia de las industrias manufactureras del Antiguo Régimen ${ }^{160}$.

La jerarquización de los patios indica la intencionalidad proyectual de materializar espacialmente las dos industrias que albergaba, con la inclusión de un patio de honor central que marcaba el acceso principal y que trasladaba dicha ordenación a la composición en fachada. El proyecto readaptaba la parcela trapezoidal irregular a la forma de rectángulo perfecto en planta, manifestando el carácter racional del mismo ${ }^{161}$. Coincidiendo con el eje longitudinal formado por las alcantarillas que discurrían hacia el arroyo de Lavapiés, se disponen los tres patios, de forma que servían a las necesidades productivas de los mismos. En el caso del patio central, se dispone una fuente que, junto al ajardinamiento de este espacio, remarca su carácter de patio de honor representativo. Señala Urrutia que

estos tres patios, de entre los que prevalece en importancia el cuadrado, son al tiempo imprescindibles. Debido a la extensión y profundidad de la obra, sus vacíos propician una mejor arquitectura; de tal modo que la compartimentación laberíntica obtiene multiplicidad de huecos modulados con suficiente ventilación e iluminación, enrarecida en los puntos interseccionales de las T componentes del rectángulo ${ }^{162}$.

Este esquema no era precisamente novedoso, dado que repetía fórmulas ya utilizadas en otros edificios madrileños como el Cuartel del Conde Duque. A este respecto, señala Urrutia el empleo recurrente de este esquema espacial en planta en arquitecturas de diverso tipo a lo largo de la historia:
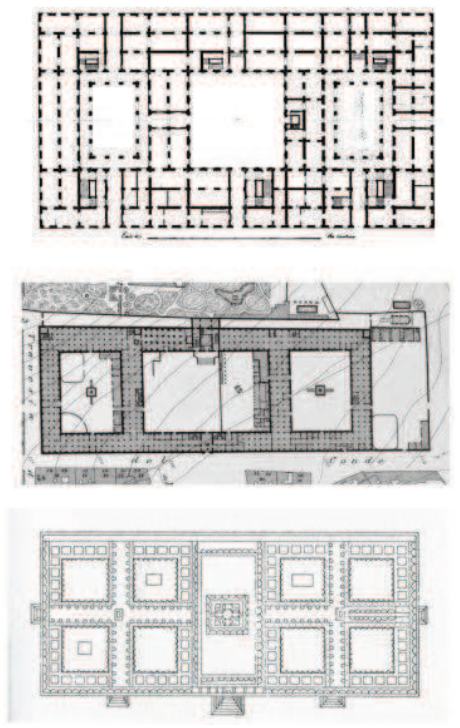

Figura 3.58. Comparación del trazado del proyecto de Manuel de la Ballina con el Cuartel del Conde Duque de Pedro de Ribera de 1720 tomado del plano de Madrid de Carlos Ibáñez de Ibero de 1875 , en http://bibliotecavirtualmadrid.or g/bvmadrid_publicacion/i18n/con sulta/registro.cmd?id=18; y con el proyecto para el Ospedale Maggiore de Milán de Filarete a inicios del S.XV, en PEVSNER (1976 [1997]) op. cit., p. 143.

\footnotetext{
159 URRUTIA NÚÑ̃Z, A. (1982) op. cit., p. 120. Además de la obra de Urrutia Núñez también se recomienda la profusa descripción de la fábrica en RABANAL YUS, A. M. (1988) op. cit., pp. 328-330.

160 "Este sentimiento del espacio estructurador y localizador de los edificios públicos neoclásicos da lugar a unos tipos arquitectónicos que servirían para múltiples funciones. Así vemos cómo cuarteles y nacientes fábricas de fundación real corresponden a la misma tipología y por tanto son susceptibles de radicales cambios de uso". CANDELA SOTO, P. (1997) op. cit., p. 55.

161 "Se obtiene, de esta forma una planta de unos 122 por 66,25 metros, aproximando sus proporciones a un doble cuadrado. El módulo intereje entre vanos arroja una dimensión de unos 15 pies o tres varas castellanas, de forma que el patio central cuadrado tiene una dimensión de 7 módulos, mientras que la crujía se define mediante 4,5 módulos. En el punto medio entre el límite del patio principal y las fachadas laterales se sitúan los ejes secundarios en cuyo punto medio se ubican los patios laterales de 3 x 7 módulos”. RIVERA POSSE, P. (2014) op. cit., p. 12.

162 Este pasaje y el siguiente en URRUTIA NÚÑEZ, A. (1982) op. cit., p. 122. Señala Urrutia Núñez la relación que Virginia Tovar establece entre estas diversas tipologías con la tradición clásica romana como eterna fuente de inspiración. TOVAR MARTÍN, V. (1980) “D. Melchor Gaspar de Jovellanos y el arquitecto D. Ramón Durán en la obra del Colegio de la Orden de Alcántara en Salamanca (1790)" en Academia: Boletín de la Real Academia de Bellas Artes de San Fernando, n 51, pp. 41-105.
} 
su planta no es plenamente original, claro está, dada la endeble tradición de estos establecimientos concebidos como obra arquitectónica propiamente dicha. Ha servido con ligeras variantes en otros muchos casos para estructurar edificios con funciones de diversa índole (militares y civiles) -indiscutiblemente, aún siendo el lenguaje al uso en la época, lastre endémico de toda arquitectura neoclásica-, tanto en Madrid (Cuartel del Conde Duque, por ejemplo), como en Italia (recuérdense algunas tipologías hospitalarias del Filarete), pero siempre dependiendo en última instancia de la gloriosa Roma Imperial.

Matiza Tovar Martín que esta disposición en planta basada en la antigüedad "pero utilizada incansablemente por el barroco a través de distintos artistas y escuelas" ha estado presente en diversas tipologías como la arquitectura palacial del S.XVII - señala el Palacio de Uceda o la Cárcel de la Corte-, así como en el S.XVIII en la obra de Ribera, el Cuartel de las Guardias Walonas o el Convento de San Pedro de Alcántara sito en la plaza de España. Por tanto, este esquema distributivo espacial "tuvo amplia incorporación a la etapa del barroco [...] por la pródiga utilización que de él hizo en Francia Wauvan" pero también por "su apariencia monumental que dio ocasión a cada arquitecto a ingeniar una manera personal de armonizar la longitud de extensión prodigiosa, con la anchura, subdividiendo de variadas maneras y en bloques distintos la poderosa fortaleza de sus masas" 163 .

Por su parte, la fachada se configuraba a través de un lenguaje neoclásico de estilo dórico, considerado por su sencillez como recurso compositivo adecuado para la función industrial a la que se destinaba el edificio. La organización tripartita del espacio, se manifestó en el diseño compositivo de fachada, organizada en dos niveles originalmente, que mediante sus tres accesos reproducía la división interna en tres patios. Esta fachada principal hacia Embajadores destacaba la puerta central o principal flanqueada por pilastras neoclásicas dóricas con triglifos y metopas en el friso. La severidad de la composición remite a la obra de Sabatini en su composición lingüística, en la ordenada sucesión de ventanas y balcones que aportan un equilibrado ritmo 5-8-8-5. Los huecos son sencillos en la planta sótano y dobles en la planta baja y alta, con la particularidad de que aquellos situados sobre los accesos se ornamentan con la formalización de un balcón. La cornisa en su posición a eje con el acceso principal central se dobla para formalizar un arco sobre el dintel, dando cobijo al escudo de armas, motivo que también utilizó Villanueva en su obra. Por otra parte, como señala Urrutia Núñez la voluntad de dar una apariencia clásica y racional a este edificio industrial a través del lienzo de fachada de proporciones rectangulares, contrastaba con la pendiente natural del terreno en el Camino de Embajadores, haciendo obligada la adaptación del diseño apaisado al desnivel ${ }^{164}$.

En cuanto a los aspectos constructivos, señala Urrutia que "el proyecto, sencillo ya de por sí en sus trazas, se tradujo a la realidad viéndose

${ }^{163}$ Sobre este particular TOVAR MARTÍN, V. (1985) op. cit., pp. 134-136.

164 URRUTIA NÚÑEZ, A. (1982) op. cit., pp. 123-124. 
robustecido en sus muros" ejecutados en ladrillo que adelgazaban su espesor conforme crecían en altura y que se remataban con un acabado enfoscado y revocado en ocre. El zócalo de piedra granítica, material que también integraba los sillares esquinados, jambas y las arqueríasdiafragma de los patios, resalta sobre el lienzo general ejecutado en ladrillo. Estructuralmente, el contenedor se formalizaba con muros de carga de ladrillo mientras que el sótano se hallaba abovedado y en las restantes plantas se disponían forjados de viguetas de madera.

Señala Tovar Martín que la Real Fábrica de Aguardientes y Naipes no constituyó una ruptura con el pasado puesto que su esquema claustral rectangular, la profusión de huecos unidos por finas molduras continuas, el establecimiento de una relación definida entre el piso superior y el inferior, la gradación de los marcos en cada vano, la cornisa de modillones o la acentuación de la entrada enmarcada entre pilastras sobre la que se sitúa una ventana a la manera de Sabatini, manifiestan claramente sus antecedentes en el barroco clásico madrileño del S.XVIII ${ }^{165}$.

La zonificación de este espacio indeterminado a través de las funciones destinadas a los distintos talleres era el recurso configurador de las relaciones sociales y laborales del edificio, en un modelo característico de las instalaciones manufactureras del S.XVIII. De esta forma, la parte central del inmueble aglutinaba los espacios y significaciones de representatividad, mientras que se relegaba a los patios laterales secundarios la actividad productiva generadora de mayor número de residuos ${ }^{166}$.

Por tanto, se aprovechaban los espacios sobrantes de la irregular parcela para la formalización de elementos complementarios a la producción como construcciones auxiliares y paso de carros. La distribución programática en el interior del edificio se correspondía con su estratificación vertical, puesto que en sótano y planta baja se disponían las calderas, tinajas, almacenes y espacios de trabajo, en el piso noble los espacios administrativos, y en el desván abuhardillado los espacios de secado para naipes y algunos espacios residenciales. Para agilizar la comunicación entre los distintos pisos, se situaron las cajas de escaleras en los flancos de los accesos a los patios, conectando entradas, rampas, pasadizos, galerías o corredores.

\footnotetext{
165 Según Tovar Martín, no existía plena concordancia entre fondo y forma en la fábrica, puesto que aparenta, a su juicio, un lenguaje clásico que, sin embargo, altera su esquema a través de licencias estilísticas que indican aún la influencia del barroco. No obstante, nos encontramos ante un período en el que "el Neoclasicismo por su parte trata de crear nuevas imágenes artísticas para las nuevas ideas que ofrecen los ilustrados”. TOVAR MARTÍN, V. (1985) op. cit., pp. 134 y 136.

${ }^{166}$ Los planos originales de Manuel de la Ballina custodiados en el Archivo General de Palacio detallan los usos, pero faltan las indicaciones sobre la planta. Se conserva un levantamiento de 1821, atribuido a Isidro González Velázquez que indica la zonificación: la práctica totalidad de la planta estaba ocupada por tinajas, destinando el patio Norte a la producción y venta de aguardientes, el Sur a la fabricación de naipes, y el central, el patio de honor, a los administradores. Así, el sótano se abre a los patios auxiliares, aprovechando el desnivel de la zona, empleándose principalmente como almacén de aguardientes. La planta primera se destina a dependencias de administración y a alojamiento de oficiales y administradores, y la de buhardillas a viviendas para los trabajadores. En ambas plantas, la crujía meridional funciona como secadero de naipes. URRUTIA NÚÑEZ, A. (1982) op. cit., p. 123.
} 
A la convergencia de planteamientos espaciales adecuados para albergar la nueva actividad industrial tabacalera se unía el cumplimiento de las premisas blondelianas para los edificios de carácter industrial -sencillez, solidez y ubicación conveniente junto a un arroyo- por parte del inmueble proyectado por de la Ballina, lo que coadyuvó a la elección del mismo para fundar el último establecimiento de la primera generación de tabacaleras del S.XIX.

\section{La Fábrica de Tabacos de Madrid}

Señala Urrutia Núñez que la Real Fábrica de Aguardientes y Naipes entró en funcionamiento por breve periodo, cambiando paulatinamente de uso con la ocupación francesa hasta su establecimiento definitivo como fábrica de cigarros y rapé, una vez liberalizado el sistema monopolístico de naipes por José Bonaparte. La reconversión de la antigua Real Fábrica de Aguardientes y Naipes en fábrica tabacalera no comportó mayor dificultad, máxime el origen manufacturero del inmueble preexistente cuyo carácter de contenedor, unido a la presencia de los invariantes arquitectónicos comunes a las fábricas precedentes, lo convertían en un establecimiento del agrado de la Renta del Tabaco.

Con su reconversión en Fábrica de Tabacos de Madrid se operaron una serie de reformas que no alteraron en gran medida la fisonomía original del establecimiento descrita anteriormente, de forma que cada patio se dedicó a un proceso de pretratado de la materia prima, mientras que en las plantas superiores se situaban los espacios representativos de administración y vivienda del director, así como los talleres de elaboración de cigarros. "Aquella obra sin identidad, aquella caja susceptible de contener cualquier programa de necesidades, se convirtió en la Fábrica de Tabacos que ha llegado hasta nuestros días contando con no pocas transformaciones de diversa índole"167. Las diversas reformas e intervenciones acometidas sobre la Fábrica de Tabacos de Madrid en sus casi dos siglos de vida responden al proceso histórico de la evolución de la producción tabacalera común a todos los establecimientos del monopolio.

De esta forma, a mediados del S.XIX Madoz describe la fábrica como un suntuoso edificio de 428 por 237 pies -un rectángulo perfecto de 117 por $65,49 \mathrm{~m}$, contrastando con la de Sevilla que contaba con 172 por 134,40 metros- que consta de zócalo de granito y piso bajo y principal con 29 vanos decorados con jambas en su fachada. Destaca, así mismo, la presencia de las tres portadas de granito de la fachada principal, haciendo especial mención a la central, decorada con dos pilastras dóricas con triglifos en el cornisamento que hace las veces de repisa para el balcón del piso superior cuyo guardapolvo presenta un escudo

167 Es interesante el apunte que Urrutia Núñez realiza sobre el carácter de cierta improvisación en la fundación de una fábrica tabacalera en el inmueble sito en Embajadores, y su posible uso como cárcel, respaldando las conexiones que la espacialidad de las tabacaleras tienen con espacios de tipo coercitivo. URRUTIA NÚÑEZ, A. (1982) op. cit., p. 126. 
de armas. De igual forma, señala la coronación en todo el perímetro de la fábrica mediante una cornisa de piedra ${ }^{168}$.

Las reformas en el edificio original durante el periodo fabril tabacalero serían constantes y atendían, no sólo a las mejoras y adecuación del inmueble a los cambios experimentados por la producción, sino también a los numerosos accidentes fortuitos, tales como incendios -en 1862, en 1890 o en 1905- que demandaban posteriormente el remozado de las partes afectadas, alterando en algunos casos el ritmo de la producción con las pertinentes obras. Entre los proyectos de ampliación más importantes que se comentarán a continuación, destacan también pequeñas intervenciones como la disposición de dos torres garitas de estilo afro-oriental hacia las calles Miguel Servet y Provisiones diseñadas por el ingeniero Lorenzo Lapuyades en abril de 1891, y la pequeña reforma de 1899 del arquitecto Manuel Pardo que se centraba en la instalación de retretes y sifones inodoros que exigían las ordenanzas municipales.

Para paliar los problemas que el inmueble fabril sufría ya a finales del S.XIX, relativos fundamentalmente al hacinamiento, falta de espacio y malas condiciones del mismo, el ingeniero Mauro Serret concibe en 1883 un proyecto de reforma en el que propone el crecimiento en altura del inmueble añadiendo un nuevo piso sobre la planta principal, así como el empleo de estructuras metálicas para la resolución de la cubierta, consiguiendo mayor diafanidad en la sustitución de los muros de traviesa por columnas de fundición con objeto de adecuar el edificio a las condiciones necesarias para acoger la renovación mecanizadora. Pese a que el proyecto de Serret no se llevó a cabo finalmente, constituyó una importante referencia para las obras que realizarían sus sucesores.

Señala Rivera Posse que, gracias al informe de la Junta Consultiva de Caminos, Canales y Puertos, podemos discernir los detalles del proyecto de Serret:

consiste en la adición de un piso sobre el principal, supresión de las galerías de los patios actuales, y ensanche en la parte que por resultado de la alineación cede el Municipio a Hacienda en la calle de Embajadores [...] Quedan subsistentes los muros de fachada al exterior y a los patios suprimiendo las galerías que hay en estos; se modifica la situación de algunos muros de traviesa subordinándolos a las exigencias de la distribución [...] En la parte de ensanche del edificio, se sustituyen los muros de traviesa por columnas de fundición para mayor desahogo y diafanidad, y así los de fachada como los de distribución se proponen cimentados sobre fábrica de mampostería, sus zócalos de sillería de granito y el resto de ladrillo recocho [...] A los muros de nueva construcción cuya separación o ancho de crujía es de 16 ms se le dan espesores de 1,20 en el piso de sótano, 1,05 en el bajo, 0,90 en el

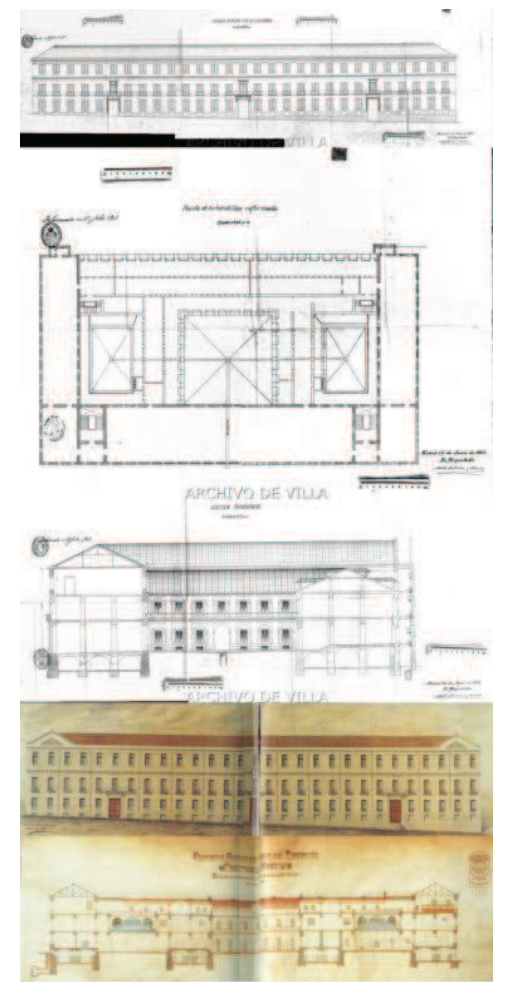

Figura 3.59. Proyecto de Amós Salvador de 1903, en $A V M$, planimetría del expediente 16 47-27; y planimetría tras la intervención de Dionisio Sáinz de 1908, en CASAS TORRES, E. (1988) op. cit.

\footnotetext{
168 MADOZ, P. (1846-50 [1981]) "Madrid: Audiencia, provincia, intendencia, vicaría, partido y villa" en Diccionario geográfico-estadístico-histórico de España y sus posesiones de ultramar, tomo XI, Valladolid: Ámbito, p. 435.
} 


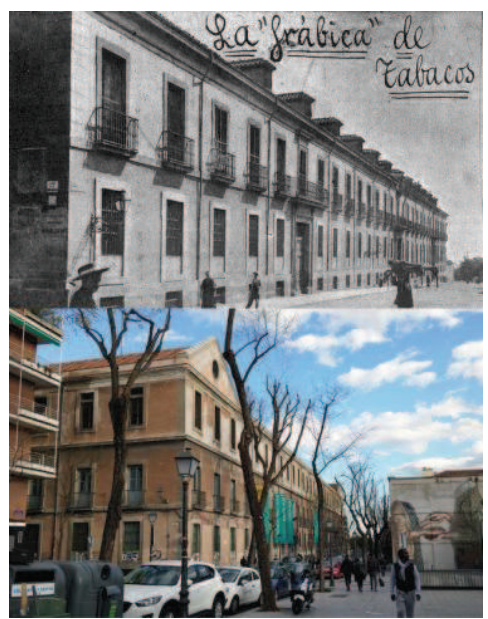

Figura 3.60. La altura original del edificio, en La revista moderna, $n^{\circ} 84$, año 2,1898, p.9; y el cambio de la relación con el entorno con la adición de un nuevo piso, 2016. principal y 0,75 en el segundo y para los del salón central son los espesores respectivamente $1,35-1,20-1,05$ y $0,90^{169}$.

De igual forma, en los forjados de preveía el uso de una estructura mixta con vigas metálicas en doble T y madera.

Como se comentó anteriormente, tras una serie de proyectos menores que concernían a la mejora de las instalaciones para el personal obrero -servicios higiénicos de Manuel Pardo en 1899-, a la vigilancia del inmueble -torres garitas de Lorenzo Lapuyades de 1891- y a la cubrición en 1901 de los patios laterales auxiliares, en 1903 se redactaría el gran proyecto de reforma que alteraría la fisonomía de la fábrica. Siguiendo los preceptos ideados por el ingeniero Serret, Amós Salvador Carreras ${ }^{170}$ concebiría un proyecto de reforma basado en la ampliación del edificio en una planta de cinco metros de altura que se desarrollaría en las fachadas hacia las calles Embajadores, Provisiones y Miguel Servet, configurando el remate del edificio en una suerte de U que abraza el conjunto en su parte superior. El ala Este colindante con el patio auxiliar trasero, mantendría la escala de las buhardillas originales que aún se puede apreciar hoy en día. La nueva cubierta se desarrollaría mediante cerchas metálicas que proporcionarían mayor diafanidad al espacio productivo, funcionando así mismo como elemento aislante a través de la colocación de un falso techo que generaría una cámara de aire en su interior.

La planta de buhardillas de la Fábrica de Tabacos de esta Corte, en donde se reúne numeroso personal obrero, no goza de las debidas condiciones de salubridad e higiene. Las obras que se describen en esta Memoria tienen por objeto demostrar las construcciones que se elevan sobre las naves que se extienden a lo largo de las calles Embajadores, Provisiones y Miguel Servet, alzando en su lugar un nuevo piso, con la disposición, forma y dimensiones convenientes para garantizar la comodidad de los servicios y la salud de las operarias, conforme a los deseos de la Compañía Arrendataria de Tabacos y a las ideas expresadas por la Junta de Reformas Sociales ${ }^{171}$.

El proyecto comprendía las obras necesarias para el desmontaje de la cubierta existente, con el desarmado de las armaduras y el derribo y desescombro de los muros de carga y traviesas. Posteriormente, se elevarían los nuevos muros de 5 metros de altura que delimitarían una superficie de 3.718,62 metros cuadrados comprendiendo las tres naves que configuraban la planta en $\mathrm{U}$ y los espacios destinados a servicios higiénicos y escaleras. Estos muros, de fábrica de ladrillo y con un acabado de revoco con pintura al exterior y blanqueados al interior,

\footnotetext{
169 RIVERA POSSE, P. (2014) op. cit., pp. 22-23, citando AGA 31/8274.

170 El arquitecto Amós Salvador Carreras (1879-1936) seguiría la vinculación con el monopolio tabacalero de su padre Amós Salvador y Rodrigáñez (1845-1922) ingeniero y político logroñés que fue presidente de la CAT. En 1903 redacta junto al ingeniero José Ortuño la memoria del proyecto de ampliación de la Fábrica de Tabacos de Madrid, que actualmente se encuentra custodiada en el Archivo de la Villa de Madrid. Sobre Amós Salvador Carreras CERRILLO RUBIO, M. I. (2011) "El arquitecto Amós Salvador Carreras" en Codal: revista de creación literaria y artística, $\mathrm{n}^{\circ} 4$, pp. 161-174.

171 URRUTIA NÚÑEZ, A. (1982) op. cit., p. 127, citando SALVADOR Y CARRERAS, A. (1903) Memoria del proyecto, Madrid 26 de junio de 1903, ASA: 16-47-27.
} 
contarían con un espesor de 75 centímetros, destacando tanto su función estructural como aislante. Sobre los muros se dispondrían las cubriciones de armaduras metálicas, forjando los espacios entre correas mediante bovedillas de ladrillo enrasadas, y rematando al exterior con teja árabe. El aislamiento lo aportaría un cielo-raso de yeso y láminas de metal Deployé que se colgaría de los tirantes de las armaduras formando una cámara de aire.

El incendio fortuito de 1905 que arrasaría la parte Sur del edificio demoraría las obras unos años, de forma que el proyecto de reconstrucción llevado a cargo por el arquitecto Dionisio Sainz aunaría los trabajos necesarios para la remoción de las partes afectadas por el suceso, así como el proyecto de reforma de Amós Salvador. Si bien respeta en líneas generales el proyecto original, modifica la definición de la cubierta introduciendo unos hastiales de remate en las naves laterales Norte y Sur hacia las calles Embajadores y Mesón de Paredes, que constituyen uno de los actuales aspectos característicos del edificio $^{172}$.

\section{A juicio de Urrutia Núñez}

la sustitución de la planta de desvanes por un nuevo nivel y su terminación en cámara aislante con tejado a dos aguas (1908), aunque vino a satisfacer una necesidad no demorable [...] supuso un duro golpe a la obra de Ballina. Ahora bien, conviene matizar. En principio debe decirse que el cuerpo superior añadido elevó la fachada en sus tres lados más visibles; de este modo, el edificio, que apenas se puede contemplar desde la angosta calle Mesón de Paredes, adquiere una paradójica uniformidad pese a su nueva planta alta en C. Las nuevas posibilidades del hierro utilizado en la armadura crean una conveniente levedad para el añadido que ha de descansar en la vieja obra y, sobre todo, una diafanidad ya requerida por los diferentes usos industriales ${ }^{173}$.

No en vano, cabe reflexionar sobre el cambio de escala a que fue sometido el inmueble y el impacto que esta reforma tuvo respecto a su entorno, puesto que como apunta Urrutia Núñez "del discreto cuerpo apaisado [...] pasó a transformase en una enorme masa que tuvo muchas más dificultades de armonizar correctamente con las simultáneas transformaciones urbanas de la zona”. Precisamente, a las operaciones que tratarían de armonizar el nuevo perfil de la fábrica con la reordenación experimentada por el entorno correspondería el proyecto de 1908 del arquitecto Manuel Pardo que definiría la nueva tapia de cerramiento hacia las calles Miguel Servet y Embajadores, formulando un cierre de cierta dignidad hacia la Glorieta de Embajadores.

Posteriormente se han ejecutado ciertas obras menores relativas a aperturas de muros y cierres de patios o las obras de consolidación,

172 RIVERA POSSE, P. (2014) op. cit., pp. 26-27. Señala en la p. 26, nota 64, que los planos de este proyecto se corresponden con los reproducidos en CASAS TORRES, E. (1988) op. cit., sin que se haya averiguado su procedencia. Señala así mismo, la fecha del proyecto como 1908, tal y como indican dichos planos.

173 URRUTIA NÚÑ̃EZ, A. (1982) op. cit., p. 127. 


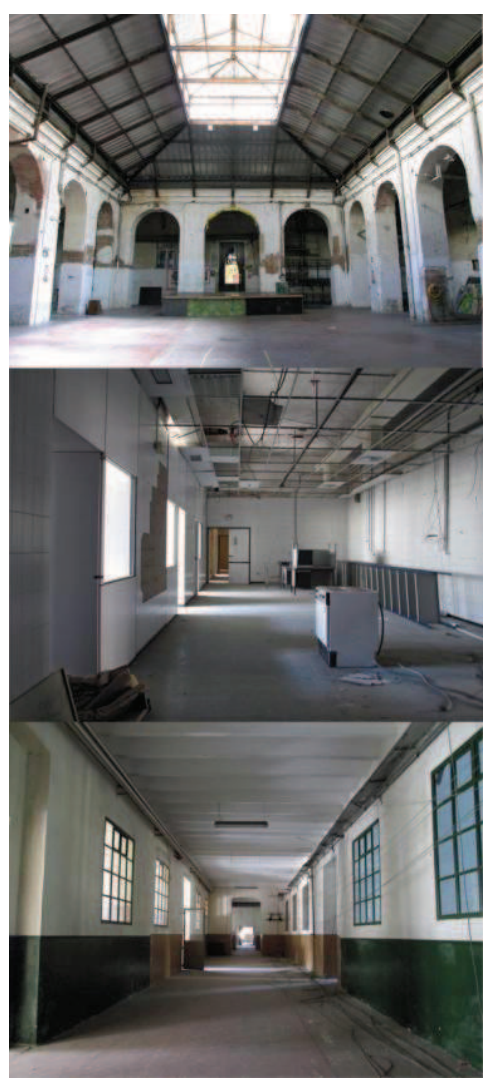

Figura 3.62. Patio, laboratorios y pasillos hacia talleres en la actualidad, 2015. reparación e higienización que se realizaron en 1919 coincidiendo con la disposición del reloj del patio principal rematado con una espadaña además, en los años 60 se añadió un almacén para funciones secundarias en el patio posterior-. Salvo estas adiciones menores, la fábrica que ha llegado a nuestros días no difiere en gran medida del resultado de las obras realizadas en 1908, lo que, junto a las intervenciones parciales de recuperación en una mínima parte de la misma, permite realizar una lectura bastante fiel del edificio fabril original, pese al tiempo transcurrido desde su cierre en el año 2000.

\section{El espacio productivo y su evolución hasta 1945}

$\mathrm{Al}$ igual que en las restantes fábricas centenarias, el espacio productivo de la Fábrica de Tabacos de Madrid acusaría la distinción de dos periodos muy significativos en la historia de la producción tabacalera en España, desde el periodo manufacturero inicial hasta el impulso de la mecanización de todas las fases productivas. En el caso de Madrid, esta evolución cualitativa del espacio productivo implicaría la constante renovación del inmueble heredado de la producción manufacturera anterior con la acometida de importantes reformas en la primera etapa del S.XX.

A mediados del S.XIX, Madoz recogía en su diccionario la configuración espacial de la producción en sus primeras décadas manufactureras, describiendo minuciosamente la composición de los diversos departamentos que integraban la fábrica. En primer lugar, señalaba la existencia del taller de picado en el que ya existían dos máquinas que reforzaban la producción del mismo, y en el que se empleaban 40 hombres, disponiendo además de 44 mesas en las que trabajaban 28 hombres en la producción manual a cuchilla de dicho elaborado. Seguidamente, señala la existencia de un taller de habanos peninsulares integrado por 24 ranchos de 6 operarias cada uno; un taller de mixtos, notablemente mayor que el anterior puesto que se componía de 400 ranchos en los que trabajaban 600 mujeres; un taller de cigarros comunes de 346 ranchos o 4.896 jornaleras; un taller de embotado que daba empleo a 426 mujeres; el taller de espalillado o desvenado que empleaba a 90 operarias; y el taller de tusas a contrata que daba ocupación a 42 operarias. Refiere, así mismo, que en aquellos tiempos el taller de cigarrillos de papel también era por contrata y daba empleo a 200 operarias ${ }^{174}$.

Sin embargo, la obsolescencia prematura de las primeras fábricas de tabacos quedó patente con las diversas reformas motivadas por la puesta en marcha de la mecanización y los sucesivos planes de renovación. En mayor o menor medida, todas ellas presentaron el mismo diagnóstico y las soluciones propuestas eran coincidentes en muchos casos. Señalan Comín Comín y Martín Aceña que a finales del S. XIX la fábrica de Madrid era la menos eficiente en la elaboración de cigarrillos manuales. Como se ha visto anteriormente, ya a mediados

${ }^{174}$ MADOZ, P. (1846-50 [1981]) op. cit., p. 435. 
de siglo era un taller relativamente pequeño comparado con otras elaboraciones de la tabacalera madrileña. Es por esto que en junio de 1895 recibió un plan especial para la reorganización de sus talleres, destinado a controlar mejor al personal obrero y a evitar las aglomeraciones en los talleres mediante su compartimentación en otros más pequeños y especializados en la producción de diversos tipos de cigarrillos. Señalan estos autores que este tipo de prácticas revelan la importancia que para la CAT tenía la aceptación de las mejoras por parte de las operarias, aunque en última instancia eran los jefes de fábrica los que tomaban la decisión definitiva sobre las reestructuraciones de sus fábricas ${ }^{175}$.

Nuevamente Santías y Lera aportan en su obra datos que permiten conocer las características del espacio productivo de la fábrica madrileña a finales del S.XIX, que a la sazón daba empleo a unas 4.200 operarias. Señalan que, de las 53 hectáreas de superficie con las que contaba el inmueble, los tres patios ocupaban una tercera parte. De igual forma, destacan la amplitud y elevación de las crujías en las que se ubicaban los talleres de laboreo que, junto con los fuertes muros de un metro de espesor, les otorgaban naturalmente condiciones térmicas adecuadas por la poca variación de temperatura a lo largo del año en los pisos bajo y principal, y muy particularmente en los sótanos.

En 1898 el edificio contaba con cuatro alturas correspondientes a sótanos, planta baja, planta principal y buhardillas. En los sótanos se ubicaban los almacenes de rama y elaborados, así como dos naves para el escogido de tabacos -de labores finas y de labores comunes, respectivamente- disponiéndose al frente de cada nave una caja de escalera provista de montacargas dobles que comunicaban el sótano con los diversos talleres. De igual forma, se disponían sendas rampas en los patios de servicio que facilitaban el traslado del tabaco, y un "autodescensor" para los cajones de picadura que arrancaba del taller de paquetes de 25 y 125 gramos del piso bajo. Por su parte, la planta baja albergaba los talleres de desvenado esmerado y común, de paquetes finos de 125 gramos y de paquetes comunes de 25 gramos, así como el taller de máquinas que alojaba un motor de vapor de 40 caballos y las transmisiones generales, suministrando energía a tres máquinas picadoras Fombuena, dos picadoras Flinsch de picadura al cuadrado, tres afiladoras y una cuadradora Boixader. Completaban los espacios de esta planta el taller de reparaciones y el nuevo taller de laminado de vena dotado con prensas, laminadoras Flinsch y aerocondensador. Así mismo, el piso principal estaba fundamentalmente destinado a las tareas de liado, albergando los talleres de cigarros peninsulares marca chica, comunes entrefuertes, fuertes y los oreos, así como el empapelado y encajonado. Finalmente, la planta de buhardillas alojaba el taller de cigarrillos finos ${ }^{176}$.

Destacan las repercusiones que la incipiente mecanización tenía en el espacio productivo, con la aparición de espacios específicos para el

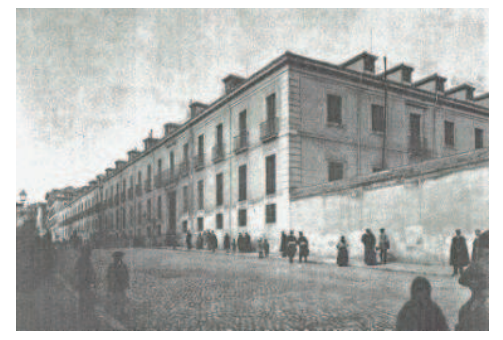

Figura 3.63. Fábrica de Tabacos de Madrid a finales del S.XIX, en SANTÍAS, A. y LERA, D. (1898) op. cit., p. 22. 
suministro de energía de la fábrica, como el

pabellón de maquinaria, situado en el patio trasero, y construido en hierro y ladrillo. Su apariencia puede verse en el citado artículo y en un grabado de la Ilustración Española y Americana sobre el incendio de 1890. Fue destruido por un incendio en 1905 , pero ya para entonces se había planteado su sustitución por el que existe en la actualidad, proyectado por el ingeniero J. Ortega, y que resulta un ejemplo interesante de arquitectura industrial en ladrillo, a medio camino entre el neomudéjar y el incipiente protorracionalismo de las obras de ingenieros ${ }^{177}$.

Sin embargo, pese al análisis optimista de Santías y Lera, la fábrica adolecía de ciertos problemas que venía arrastrando desde hacía décadas y que las reformas parciales acaecidas a lo largo del S.XIX no fueron capaces de atajar. El informe que Juan García de Torres, Director General de Rentas Estancadas, realiza en 1881 sobre la Fábrica de Tabacos de Madrid, expone algunos de los problemas que sufría el establecimiento de la capital en estos términos.

En 1881, la Comisión encargada de estudiar el plan general de reformas en las fábricas puso en evidencia la apremiante necesidad que revestía la factoría madrileña y «lo urgente que era normalizar un establecimiento de tanta importancia, que ni aún cuenta con los elementos más precisos para desarrollar sus operaciones, y que por hallarse situado en la capital de la monarquía reclama antes que otro alguno reformas esenciales». Asimismo, el informe técnico destacaba el lamentable estado del surtido de aguas para los usos fabriles y el consumo humano y lo que esto implicaba «en términos de amenazar la destrucción de parte del edificio, constituyendo un peligro constante para el numeroso personal obrero que allí trabaja, alarmado por los hundimientos que en ocasiones han sobrevenido» ${ }^{178}$.

A la carencia de almacenes suficientes ${ }^{179}$, se unía la problemática de falta de espacio generada por la ampliación de algunas labores que revertía en la reducción del espacio de las restantes y el consiguiente hacinamiento. Especialmente grave era el estado de congestión sufrido en las buhardillas dedicadas a taller de liado y en las que un numeroso contingente de cigarreras debía trabajar en condiciones deplorables. A esta situación se unirían los constantes problemas sufridos por la mala

177 RIVERA POSSE, P. (2014) op. cit., p. 24.

178 CANDELA SOTO, P. (1997) op. cit., p. 62, citando GARCÍA DE TORRES, J. (1884) op. cit., p. 116. También sobre este particular: "las salas de labor de los establecimientos antiguos de la renta del tabaco, dejan bastante que desear en sus condiciones de higiene y salubridad; aún cuando constituidas por regla general en locales espaciosos, altos de techo y ventilados, están demasiado hacinadas las operarias en muchos de ellos; y esto, unido a las emanaciones del tabaco, que se desarrollan en las operaciones de manipulación, hace que se respire una atmósfera densa, insoportable a veces en la estación de los calores". COMISIÓN DE REFORMAS SOCIALES (1985) Información Oral y escrita publicada de 1889-1893. Reedición al cuidado de Santiago Castillo, tomo II, Ministerio de Trabajo y Seguridad Social, Madrid, p. 33; citado por CANDELA SOTO, P. (1997) op. cit., p. 126.

179 La fábrica contaba también con los almacenes de la calle General Lacy que durante un tiempo albergaron talleres de laboreo. Señala Candela Soto que solía enviarse a las cigarreras problemáticas a estos talleres como medida de castigo ante los conflictos. Las condiciones de locales eran poco higiénicas y esto obligó a cerrarlos el 15 de octubre de 1923. CANDELA SOTO, P. (1993-1994) op. cit, pp.113-114. Construidos en 1891 con arreglo al proyecto del arquitecto Eduardo Hernández, actualmente se han recuperado como sede de la compañía Aguirre Newman. 
disposición del surtido de aguas, que repercutiría en el funcionamiento de la producción y en el propio abastecimiento para cubrir las necesidades de las trabajadoras.

Con objeto de paliar estas deficiencias, se redacta el proyecto de reforma de 1883 del ingeniero Mauro Serret, cuya medida más destacada, como se ha referido anteriormente, era el incremento en una planta de la altura de la fábrica. No en vano, es en 1887 cuando con la cesión de la gestión a la CAT se plantea la necesidad de una transformación de las tabacaleras españolas debido a las carencias que presentaban para el desarrollo de una moderna actividad productiva. A ello coadyuvaría la implantación del "Plan General de Fabricación" que estableció medidas de mejora en la organización y distribución del trabajo.

Como se comentó en el epígrafe anterior, si bien este proyecto se vio frustrado, sirvió de base para la gran reforma proyectada en 1903 por el arquitecto Amós Salvador Carreras y llevada a cabo por Dionisio Sainz años más tarde, que planteó el incremento en altura de la fábrica con una planta de cinco metros que se desarrollaría en los flancos colindantes a las calles Embajadores, Provisiones y Miguel Servet. En líneas generales, la adición de un piso superior no solo repercutió en la mejora de las condiciones de trabajo de los talleres de liado ubicados en la última planta de la fábrica, sino que modificó la escala de la misma en su relación con el entorno urbano adyacente. De igual forma, aún hoy en día puede apreciarse el cambio cualitativo que supuso el aumento de un piso comparando las secciones de las naves reformadas a principios del S.XX y el flanco Este que mantuvo la escala de las antiguas buhardillas.

$\mathrm{Al}$ igual que en las restantes fábricas, la década de los años 20 fue un periodo intenso de reformas y adecuación de la fábrica madrileña por parte de la CAT, orientadas a la reparación y mejora de las instalaciones de saneamiento y electrificación. Así mismo, se amplió la capacidad de los locales de la fábrica, que se adecuarían a las condiciones técnicas y organizativas derivadas de la modernización y mecanización de los procesos. De igual forma, también se enfocaron a la mejora de las condiciones del espacio fabril para el personal obrero, mediante la instalación de servicios higiénicos y vestuarios para las operarias, así como comedores con cocina que aportaban facilidades a las cigarreras que habitaban lejos de la fábrica. También se dispuso un local para consultas médicas y se higienizaron tanto retretes como algunos talleres, facilitando la ventilación de los mismos y equipando a la fábrica con instalaciones de calefacción y anti incendio.

El espacio fabril, por tanto, acusaba ya las mejoras en la mecanización del proceso productivo con un notable incremento de la dotación de maquinaria en los diversos talleres. El sótano continuaba siendo fundamentalmente un espacio de almacenaje de tabaco en rama y elaborado por las condiciones invariables de temperatura en su interior, y mantenía la conexión con los patios que ya se hallaban cubiertos por estructuras metálicas. Así mismo, albergaba aún las tareas de escogido y moja del tabaco. La planta baja tampoco había variado

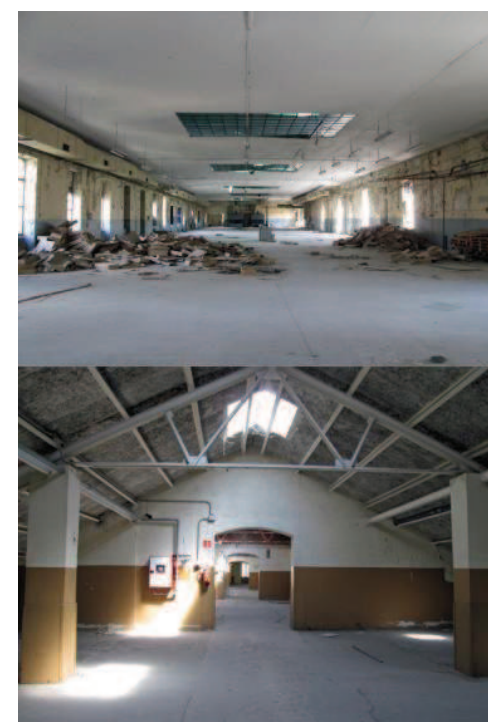

Figura 3.64. Comparación de la escala de la última planta con la intervención de principios del S.XX y con la crujía no reformada, 2015. 


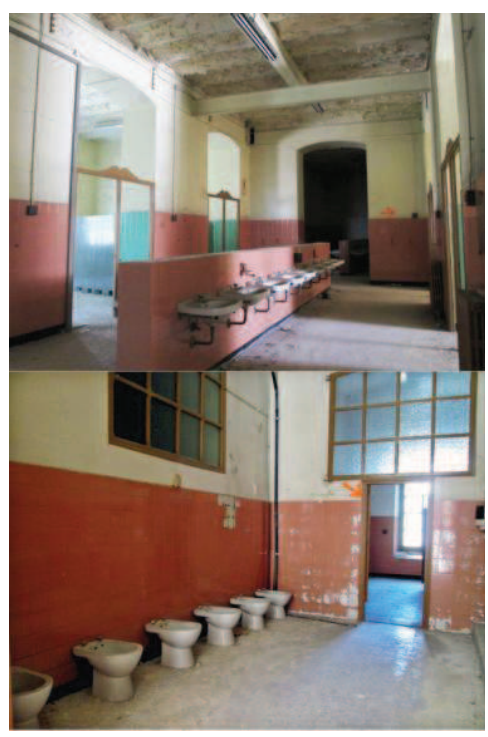

Figura 3.65. Servicios higiénicos de la Fábrica de Tabacos de Madrid, 2015. funcionalmente su ocupación, albergando los talleres de picadura que en esta ocasión concentraban todas las operaciones centrales y accesorias del picado mecánico, a través de la dotación de numerosas máquinas picadoras y de secciones destinadas al desvenado de la hoja y empaquetado manual y mecánico de la labor. De igual forma, se instalaron torrefactores y refrescadores para el tratamiento de la picadura, y en el espacio ocupado anteriormente por las calderas de vapor se instaló una central de reserva con dos motores diesel de $125 \mathrm{cv}$ acoplados a los correspondientes alternadores y cuadros de distribución de energía eléctrica.

Finalmente, el piso principal estaba ocupado por los talleres de elaboración de cigarros manual y semimécanica, así como la preparación de tabaco capero para los mismos, junto a las secciones de oreo, encajonado, empapelado y prensado de estas labores, mientras que en la segunda planta se albergaban los talleres de cigarrillos que a partir de 1929 se vieron dotados con máquinas liadoras Rapide, ampliadas en años sucesivos con máquinas Vilaseca. Estos espacios se corresponden con la reforma de 1903 que amplió la superficie productiva en $3.710 \mathrm{~m}^{2}$ y transformó la planta de buhardillas en amplios locales con buenas condiciones de luz y ventilación, contando con accesos directos a las nuevas terrazas que se asomaban a los patios.

\section{Las cigarreras y la dimensión humana de la fábrica}

La Fábrica de Tabacos de Madrid sería uno de los establecimientos pioneros en la proposición de proyectos a modo de obra social por parte de la Renta de Tabacos a lo largo del S.XIX. A iniciativa del filántropo y político Ramón de la Sagra ${ }^{180}$, a mediados de siglo se proponen tres espacios para las necesidades de los hijos de las cigarreras empleadas en la factoría madrileña: una sala de lactancia, un parvulario y una escuela de primaria para niños y niñas ${ }^{181}$. De estas propuestas, da cuenta Madoz en su diccionario, señalando que

existe en ese edificio una escuela de instrucción primaria para niños, otra para niñas y otra de párvulos, con sus correspondientes maestros y además la última con maestra: en ellas solo se admiten los hijos de las operarias del establecimiento, á cuyos maestros satisfacen con 8 cuartos cada una que tiene un niño, y 6 cuartos por cada rancho en todas las $\operatorname{datas}^{182}$.

De las tres propuestas sólo se llevarían a cabo el parvulario y las

\footnotetext{
180 Ver nota 144 sobre Ramón de la Sagra en el capítulo anterior.

181 Sobre las escuelas, ver SANCHIDRIÁN BLANCO, C. (1983) op. cit.

182 MADOZ, P. (1846-50 [1981]) op. cit., p. 435. Señala Rivera Posse que "se difundió una circular entre las trabajadoras en las que se informaba la instalación de esta guardería «en la llamada casa de licores», lo cual nos hace suponer que parte del edificio conservaba su antigua denominación, que la mayor parte de los talleres se habían situado aprovechando las instalaciones de la fábrica de naipes y las estancias de la planta primera, y que la escuela abarcaba el antiguo estanco y almacenes de la baja”. RIVERA POSSE, P. (2014) op. cit., pp. 20-21, citando Asilo para los niños de las cigarreras: a las operarias madres, de la Fábrica de Cigarros de Madrid, Madrid, Imp. del Colegio de Sordo-Mudos, 1840.
} 
escuelas primarias, que tendrían una corta vida tras la construcción en 1860 del Colegio San Alfonso en la misma manzana de la fábrica. En 1893 la fábrica cedería a la Casa de la Misericordia de San Alfonso los locales del cobertizo posterior de la fábrica unidos a la sala de lactancia de dicha institución. Parece que esta sala de lactancia se trasladó a la calle Casino $\mathrm{n}^{\circ} 3$ donde aparece localizada en 1905 junto al asilo de cigarreras ancianas. De igual forma, en la calle Embajadores y contigua a la Casa de Expósitos y Maternidad dependiente de la Diputación Provincial, se encontraba una escuela-asilo para los hijos de las cigarreras de la Fábrica de Tabacos.

Esta Escuela-Asilo fundada en 1888, estaba dedicada a recoger y cuidar a los hijos de las cigarreras durante las horas de trabajo en la fábrica. Según su reglamento, el asilo proporcionaba cien cunas o plazas destinadas a los niños de pecho, desde la edad de un mes, y para párvulos hasta que hayan cumplido los seis años [...] Las cigarreras podían ir hasta dos veces al día para dar el pecho a sus hijos dentro de un horario establecido183.

Por su parte, el Colegio de San Alfonso había sido fundado bajo patronato del rey en una parte del edificio de la fábrica cedida a tal efecto y con independencia del establecimiento. Estaba dirigido por las hermanas de la Caridad de la sociedad de San Vicente de Paúl y ofrecía enseñanza gratuita a los hijos de las cigarreras.

Aunque las propuestas de De La Sagra no llegaron a realizarse íntegramente según sus planes ${ }^{184}$, estos proyectos sirvieron como germen de iniciativas similares que sí tuvieron un desarrollo completo, como el asilo de lactancia construido frente a la nueva Fábrica de Tabacos de Valencia a principios del S.XX en la margen izquierda del río Turia.

Por otra parte, la introducción de la mecanización y la reestructuración organizativa de los espacios en las diversas reformas acometidas en la fábrica madrileña, sobre todo a partir de finales del S.XIX, conllevaron a una mejora de las instalaciones en materia de servicios higiénicos y médicos y vestuarios, y de estancias sociales como comedores y salas de reunión. A ello contribuiría también el aumento del volumen interior experimentado con la adición de una planta contemplada en los proyectos de Serret y Salvador y ejecutada por Sainz, que solventó de forma significativa la situación de hacinamiento anterior.

Por otro lado, uno de los aspectos más notables de la contextualización de la cigarrera en su espacio de trabajo era la extensión de la vida

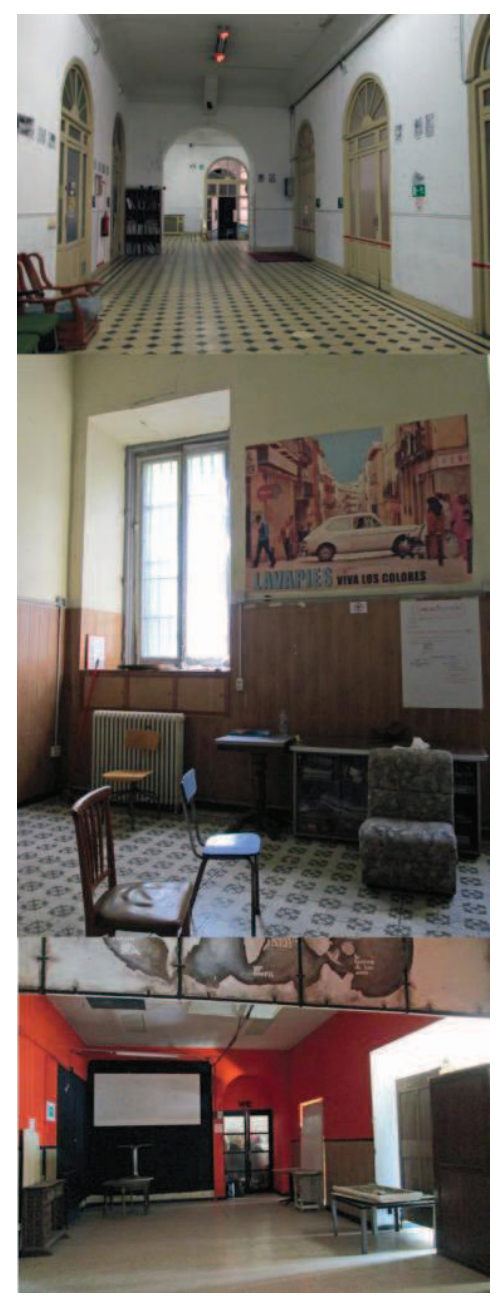

Figura 3.66. Pasillo de las oficinas administrativas y estancias sociales de las cigarreras, 2015 y 2013.

183 CANDELA SOTO, P. (1997) op. cit., pp. 145-146.

184 "La intención de De la Sagra era que una vez concluido el proyecto pudiera «servir de modelo tanto para las demás fábricas que el Gobierno sostiene en la Península, cuanto para las de particulares en las provincias manufactureras de España (...).» Por desgracia, el afán de protagonismo del superintendente de la fábrica provocó la salida de De la Sagra del proyecto, que quedó inacabado, sin que nunca se llegara a abrir la sala de lactancia". RIVERA POSSE, P. (2014) op. cit., p. 21, citando SAGRA Y PERIS, R. (1842) Noticia sobre el establecimiento de educación para los niños de las operarias de la Fábrica de Cigarros de Madrid, S.I., s.n.; GROIZARD, C. (1842) Comunicaciones al Ministerio de Gobernación. Boletín oficial de Instrucción Pública, no 24 15/02/1842, pp. 81-85; y SAGRA Y PERIS, R. (1842) Carta al Sr. don Carlos Groizard, Superintendente de la fábrica de cigarros de Madrid, sobre las escuelas para niños de las operarias establecidas en ellas, Madrid: Imp. del Colegio de Sordo-Mudos. 


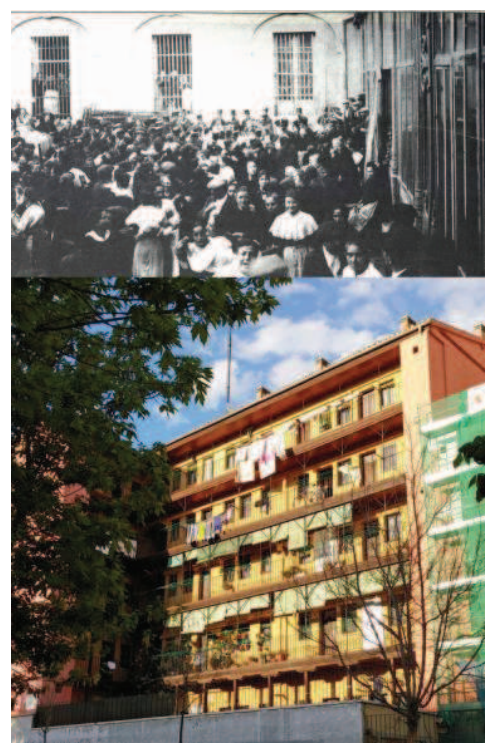

Figura 3.67. Cigarreras madrileñas en el patio principal, en CANDELA SOTO, P. (1997) op. cit., p. 166; y corrala de Lavapiés, 2016.

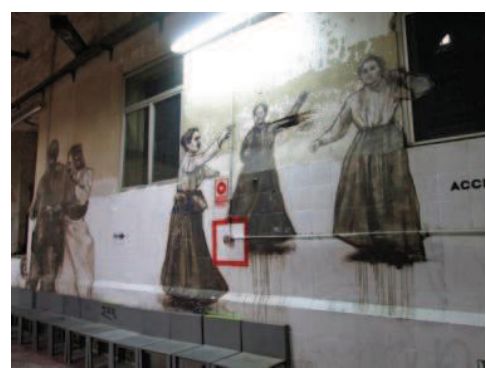

Figura 3.68. Mural en memoria de las cigarreras madrileñas en el CSA La Tabacalera de Lavapiés, 2015.

doméstica al ámbito laboral y viceversa. En muchos casos, la proximidad de las viviendas al entorno de la fábrica facilitaba la transferencia del rol femenino entre ambos espacios: la mujer como elemento aglutinador del ámbito doméstico, en su incorporación a la vida laboral, debía simultanear sendas labores.

El trabajo dentro de la fábrica ocupó un espacio esencial en la vida de las cigarreras, y en torno a su rol de trabajadora se estructura una parte fundamental de su experiencia y comportamiento colectivo. Sin embargo, la condición de mujer trabajadora llevaba implícito que, además, tuviera que hacerse cargo de las obligaciones domésticas y reproductivas que la sociedad reservaba al género femenino ${ }^{185}$.

La Fábrica de Tabacos de Madrid es un claro exponente de esta situación en las redes sociales tejidas en la fábrica y su entorno. En la distribución geográfica de las viviendas de cigarreras, se observa que casi tres cuartas partes de las mismas se encontraban en los barrios colindantes a la fábrica -Hospital, La Latina, Embajadores- y que más de la mitad se concentraba en las corralas del entorno inmediato -en las calles Ave María, Lavapiés, Maravillas, Barquillo, etc-

Una gran mayoría de mujeres con responsabilidades familiares y domésticas aprovechaban el descanso del mediodía para atenderlas. La sirena de la fábrica se escuchaba un poco antes de las doce para avisar el final de la jornada matinal y, minutos después, el barrio era testigo de la salida masiva de las obreras que apresuradas se disponían a hacer la compra, recoger a los hijos que esperaban hambrientos en la entrada o en la calle, arreglar la casa y preparar la comida [...] Qué duda cabe de que la proximidad de sus viviendas a la fábrica facilitaba esta simultaneidad de roles, espacios y tareas en el vivir cotidiano de centenares de mujeres. La invasión y el ajetreo diario que provocaba la salida de las cigarreras en la calle de Embajadores y sus travesías inmediatas eran un fiel reflejo de su presencia y protagonismo local y de la enorme influencia de la fábrica en el ritmo de vida del barrio.

La proximidad de las viviendas, que facilitaba la simultaneidad de roles entre espacios, y el ambiente fabril, así como los modos de vida en las zonas residenciales y la contratación por lazos familiares que favorecía el refuerzo de un sentimiento de comunidad, fomentó la formación de una conciencia de colectivo común que traspasó los límites del conjunto fabril ${ }^{186}$.

\footnotetext{
185 Este pasaje y siguiente en CANDELA SOTO, P. (1997) op. cit., pp. 138 y 116. Los barrios obreros madrileños por excelencia eran Hospital, la Inclusa, la Latina y Universidad. La tipología de vivienda en los mismos eran las casas de vecindad y corralas que se caracterizaban por el hacinamiento y la falta de luz y ventilación. Además estos barrios carecían de equipamientos y adolecían de una fuerte insalubridad. "A principios de siglo, aproximadamente el 70\% de las cigarreras madrileñas vivía en el distrito de La Inclusa concentrándose en los barrios colindantes a la fábrica. La evidencia de esta concentración espacial unida a la uniformidad de su situación sociodemográfica nos indica que las cigarreras comparten una misma experiencia social fuera de la fábrica”. CANDELA SOTO, P. (19931994) op. cit, p. 101-102.

186 Resulta especialmente significativa la investigación de Candela Soto sobre este particular, tanto en el caso madrileño, como en el entendimiento de la realidad de las cigarreras en general. "Desde épocas tempranas, el proceso de reclutamiento de las obreras se basaba en el aprovechamiento de las redes familiares existentes en la fábrica [...] El enorme peso familiar en la tradición de este oficio sugiere que el adiestramiento de la obrera en las
} 


\subsection{La segunda generación de fábricas del S. XIX}

Si la primera generación de fábricas tabacaleras decimonónicas se había visto muy influida por el marco histórico definido por la ocupación francesa y los problemas de desconexión entre fábricas que había ocasionado, la segunda generación de fábricas fundadas en el S.XIX respondería a las consecuencias arrastradas por dicho suceso y a los serios problemas de abastecimiento en un periodo histórico de constantes conflictos y trabas económicas para las arcas públicas.

Como medida de choque, se decide aumentar la producción en las fábricas existentes y continuar la expansión territorial fabril con otras tres fundaciones, situadas en este caso en Santander, Gijón y Valencia. Sin embargo, el carácter de cierta improvisación de estas fundaciones refleja la concepción manufacturera y artesanal, propia del Antiguo Régimen, en que aún se encontraba la Renta de Tabacos. De ello dan cuenta las accidentadas vicisitudes por las que pasaron sendas fábricas santanderina y gijonesa, cambiando frecuentemente de inmueble en el primer caso o siendo objeto de sucesivos cierres y aperturas en el segundo, hasta el establecimiento definitivo de ambas en edificios de origen conventual. Por su parte, la fábrica valenciana se instalaría inicialmente en la Aduana Provincial de la que se trasladaría a un edificio de nueva planta construido ex profeso a principios del S.XX.

Esta segunda generación de fábricas decimonónicas respondía, en primer lugar, a las necesidades de expansión territorial de la producción tabacalera, siguiendo el patrón de ubicación estratégica en localizaciones costeras. En segundo lugar, la invasión francesa de principios del S.XIX había dejado incomunicadas las fábricas existentes -Sevilla, Cádiz, Alicante, La Coruña-, desembocando en un problema de abastecimiento al que se daría solución en las décadas de 1820 y 1830 mediante la reapertura de Madrid -cuyo inicial carácter provisional había provocado su cierre temporal-, el aumento de la producción en Alicante y La Coruña -cuya actividad se concentró en las labores más rentables-, y la creación de la segunda generación de fábricas del S.XIX con salida al mar -Santander, Gijón y Valencia-.

Nuevamente, asistimos a la elección de ciudades portuarias a las que llegaba la materia prima, como medida de control territorial en el establecimiento de la producción tabacalera del monopolio cubriendo, además, una mayor porción de sector costero peninsular.

labores del tabaco se completara en el espacio doméstico bajo la tutela de la madre. De este modo, taller y hogar aparecen como espacios complementarios en la cualificación del oficio, y en general, en el proceso de integración de la disciplina fabril del tabaco [...] Desde una perspectiva experiencial, y de género, nuestro análisis muestra la debilidad conceptual de la separación vida/trabajo y permite entrever una vivencia específica de las relaciones entre trabajo y vida con una solución de continuidad menos definida que en el caso de los trabajadores varones". CANDELA SOTO, P. (1997) op. cit., pp. 96-97 у 201. 


\subsubsection{La Fábrica de Tabacos de Santander (1822-2002)}

\section{Contexto histórico hasta su cierre}

La fundación de la Fábrica de Tabacos de Santander el 13 de enero de 1822 por Real Decreto tendrá un primer recorrido incierto, puesto que su actividad cesa al año siguiente, reanudándose nuevamente por Orden Real el 20 de agosto de 1834.

El 14 de enero de 1835 se designaría definitivamente como inmueble para el establecimiento de la producción tabacalera montañesa un ala del Hospital de San Rafael187 -actual Parlamento del Gobierno de Cantabria-, aunque no sería el destino definitivo de la tabacalera cántabra, puesto que el 25 de junio del mismo año, una vez expulsadas las monjas que ocupaban el cercano Convento de Santa Cruz del Monte Calvario fundado en la segunda mitad del S. XVII, se decide instalar allí definitivamente la factoría con un total de cien operarias ${ }^{188 .}$ Además de las lógicas reformas que se hubieron de acometer para adaptar los locales del antiguo convento a la producción tabacalera, también se tuvieron que realizar importantes reparaciones por el Estado, dado que anteriormente había sido utilizado como cuartel ${ }^{189}$.

La ubicación de la nueva fábrica santanderina seguía la estrategia práctica de establecer la producción tabacalera en edificios preexistentes propiedad del Estado o enajenados a tal efecto. Así había sucedido con las fábricas de Cádiz, La Coruña y Alicante, teniendo en común con esta última la particularidad de instalarse en un inmueble de origen religioso.

A lo largo del S.XIX, la fábrica continuó aumentando su ritmo de trabajo y el volumen de contratación de mano de obra llegando a un millar de operarias en los primeros años de actividad. Durante un tiempo compitió con su homóloga gijonesa llegando a peligrar la conservación de la fábrica montañesa. Como indican Comín Comín y Martín Aceña,

poco después, el general Baldomero J. Fdez. Espartero, elegido regente por las Cortes de 1841, decretó el cierre de la fábrica (1842), procediendo más tarde a revocar la orden ante la instancia unánime de las

\footnotetext{
187 Sobre el Hospital de San Rafael, señala Madoz: “es de hermosa fáb., y fue construido en el año 1794 á espensas del ob. de Santander D. Rafael Tomás Menendez de Luarca: su arquitectura es moderna: se reduce á un cuadrilongo, en cuyo centro hay un gran patio cuadrado con dos galerías de arcadas, alta y baja, por las cuales se pasa á los departamentos ó habitaciones. La fachada principal se compone de una arquería de machones en el piso bajo y un segundo cuerpo liso con ventanas y un nichito adornado con pilastras, cornisamento y frontón de orden dórico. Las demás fachadas son muros lisos, en que se abren ventanas cuadrangulares. En el piso bajo, hay capilla para el servicio espiritual de la casa: tiene jardín, huerta, algibe y pozo. Se asisten en él un día con otro 400 enfermos, habiendo acomodo para más de 200". MADOZ, P. (1846-50 [1984]) "Santander" en Diccionario geográfico-estadísticohistórico de España y sus posesiones de ultramar, tomo XIII, Valladolid: Ámbito, p. 239.

188 LERMA BRAGADO, C.; CALLEJO SÁIZ, M. y BILBAO MARTÍNEZ, S. (1991) op. cit., p. 11. En este trabajo universitario se indica que existe escasa noticia del primer emplazamiento de la fábrica de Santander, anterior a su instalación en el Hospital de San Rafael, por lo que no ha sido posible precisar el local en el que se produjo la fundación original.

189 Las primeras informaciones sobre el uso del convento como cuartel anterior a la instalación de la fábrica provienen de SANTÍAS, A. y LERA, D. (1898) op. cit., p. 29.
} 
autoridades locales. Los principales problemas a los que hubo de enfrentarse la fábrica tuvieron que ver con la inadecuación del edificio, que vivió múltiples reformas a lo largo del siglo ${ }^{190}$.

Más aún, sobre su posible traslado a Gijón,

el 5 de Octubre de 1842, el regente, D. Baldomero Espartero ordena la supresión de esta fábrica y el traslado de todas sus existencias a la fábrica de Gijón. La repercusión social y económica de esta decisión fue tremenda pues unas mil operarias iban a quedar en la más absoluta miseria.

La Diputación provincial, el Ayuntamiento y la Junta de Comercio, comisionaron al diputado provincial, D. Juan Nepomuceno de la Torre, y al alcalde primero constitucional, D. José María Aguirre, para dirigirse al regente con el fin de que revocase la orden. Las razones que alegaron para ello fueron "[...] los portes desde la fábrica de Santander a los puntos de consumo resultan más baratos que desde Gijón, por las peores comunicaciones y la duplicidad de fletes. Si el Gobierno, accediendo a las reiteradas súplicas de la Corporación admitiese los tabacos a depósito, como lo aconseja los intereses de la Hacienda, del Comercio y de las Colonias, la fábrica de Santander podría ser de las más productivas de la Nación" ${ }^{191}$.

Finalmente, a la luz de las razones expuestas por la Corporación Municipal, el ruego fue admitido y se mantuvieron ambas factorías, coincidiendo precisamente este hecho en el mismo año en el que la fábrica gijonesa se instalaría en su ubicación definitiva en el convento de agustinas ubicado en el popular barrio de Cimadevilla. No obstante, la cercanía de estas fábricas permitiría establecer un fuerte vínculo entre las mismas, ya que la primera instalación de la fábrica gijonesa en el Palacio Valdés se reforzó con la presencia de dos maestras y tres operarias procedentes de Santander, que comandaban a 100 aprendizas empleadas fundamentalmente en la elaboración de tabacos torcidos.

En 1874 comenzaron las primeras reformas en materia de implantación de nuevas energías y mecanización, anticipando los principales objetivos de la CAT que asumiría la gestión del monopolio en 1887. De esta forma en Santander -así como en Alicante, Gijón, Madrid, Sevilla y Valencia- se instalarían generadores de vapor que contaban con una potencia de 64 caballos y que podían poner en funcionamiento unas 16 picadoras.

En 1896 la Fábrica de Santander ya estaba especializada en la elaboración de picadura por métodos mecanizados mediante máquinas Flinsch para la producción de cigarrillos Superiores. De igual forma, a finales del S.XIX Santander fue una de las unidades fabriles objeto de una mejora en la renovación del suministro de energía mediante la reposición de los generadores de vapor y las máquinas de vapor, con la

190 COMÍN COMÍN, F. y MARTÍN ACEÑA, P. (1999) op. cit., p. 75. El entrecomillado es una cita de AMOR, J. (1907) op. cit., p. 32. Dada la escasez de fuentes anteriormente referida para el estudio de la fábrica santanderina, se seguirán fundamentalmente las obras de Comín Comín y Martín Aceña; y Lerma, Callejo y Bilbao.

191 LERMA BRAGADO, C.; CALLEJO SÁIZ, M. y BILBAO MARTÍNEZ, S. (1991) op. cit., p. 12. El entrecomillado es una cita de (1842) Memoria que publica la Junta de Comercio de Santander de los asuntos que han sido objeto de sus trabajos en el año 1842, Santander. 
adquisición de un condensador.

En 1922, tras ser nombrado director-gerente de la CAT Francisco Bastos, se lleva a cabo un plan que pretendía la implantación de nuevas máquinas así como la reforma de la fábrica de Santander, junto con las de Alicante, Bilbao y Gijón. Todo ello contribuía a superar las dificultades sufridas por el monopolio tras la I Guerra Mundial que había provocado el desabastecimiento de materia prima y la imposibilidad de adquirir tecnología de origen extranjero. De esta forma, se renovó el patrimonio mueble de la fábrica montañesa con la adquisición de máquinas liadoras de cigarrillos en hebra Universal y de cigarrillos Superiores al cuadrado Rapide y Vilaseca. En los años subsiguientes se adquirirían, así mismo, máquinas empaquetadoras en las que se emplearían las operarias que anteriormente realizaban la operación de forma manual.

En 1924, en el marco de los nuevos proyectos fabriles de Tarragona y Málaga, Francisco Bastos quiso construir dos nuevas fábricas en Gijón y Santander que sustituyesen a las anteriores, puesto que adolecían de su configuración arquitectónica poco adaptable a los nuevos métodos productivos. Sin embargo, esta iniciativa, que hubiese contribuido notablemente en la mejora de la productividad de estas dos unidades fabriles del Norte, no fue llevada a cabo finalmente. Por otra parte, en febrero de 1925 tuvo lugar un incendio en el que resultaron destruidas dos terceras partes del edificio de la factoría, desapareciendo completamente los talleres de Superiores manuales, el oreo, preparado, escogido, oficinas y tornos clasificatorios de picaduras, así como los sótanos y el taller de empaquetado ${ }^{192}$.

Durante la Guerra Civil, la fábrica de Santander se uniría a los centros productivos en manos de las fuerzas alzadas tras la caída del Norte en 1937. Durante este tiempo se dedicó, al igual que el resto de las fábricas, a surtir los territorios controlados por Franco con las denominadas "labores de guerra". Precisamente en ese mismo año, con el cierre de la factoría bilbaína, Santander fue uno de los centros de la CAT que acogió parte de la plantilla de la fábrica clausurada.

Las mejoras productivas de la fábrica montañesa continuaron tras el cambio de compañía gestora en 1945 con Tabacalera. En la década de los 50 se sustituyeron las antiguas máquinas Pollard de empaquetado de picadura al cuadrado, especializando su producción desde finales de los años 40 en picadura al cuadrado y cigarrillos Ideales hebra y Entrefinos y Superiores al cuadrado. Para estas operaciones sería fundamental la dotación del parque mueble santanderino de liadoras Arenco-Mir de cigarros. La instalación de maquinaria renovada y la creación de nuevos talleres provocarían todo tipo de problemas en la factoría de Santander, desde falta de espacio para almacenamiento hasta rotura de pavimentación y desperfectos en el inmueble. No obstante, esto no impediría que a inicios de la década de los 70, Santander fuese la segunda factoría especializada en cigarros con

192 Episodio referido en REVUELTA, C. (2013) op. cit, p.35. 
mayor producción, tras la fábrica de Gijón y por delante de las fábricas de Logroño y Cádiz ${ }^{193}$. De igual forma, a partir de la década de los 70 Santander sería, junto con Cádiz, puerto de descarga de los tabacos oscuros, mientras que los claros se dirigirían al puerto tarraconense.

Tras los reajustes producidos en 1986 con la entrada de España en la CEE, la fábrica montañesa continuaría durante los años $90 \mathrm{su}$ ocupación exclusiva en la elaboración de cigarros junto a las fábricas de Cádiz, Gijón y Málaga, ocupándose concretamente de la fabricación de Ducados, Entrefinos, Farias y Montecristo. Con el "Plan Industrial" del año 2000, la fábrica montañesa hizo efectivo su cierre en el año 2002 dando por finalizado siglo y medio de producción en el antiguo inmueble conventual. No obstante, con este cierre no se dio por finalizada la producción tabacalera en Cantabria, puesto que Altadis construyó en el año 2000 un moderno centro industrial en el polígono de Entrambasguas que continúa funcionando en la actualidad, especializado en la fabricación de puros y cigarros, y que acoge la producción de las fábricas de Imperial Tobacco de Estrasburgo y Bristol que cerraron entre los años 2009 y $2010^{194}$.

\section{Motivos estratégicos de la fundación fabril e implantación en su entorno}

Durante el primer tercio del S.XIX, la ubicación estratégica de las fábricas de tabacos comienza a extenderse por el territorio peninsular a través de las dos primeras generaciones de fábricas tabacaleras decimonónicas. Sobre los motivos de la elección de Santander como nueva fundación fabril tabacalera, destaca Guerín:

\footnotetext{
Santander estaba bien situado a más de ochenta leguas de la Coruña. Surtiría a Castilla la Vieja, gran parte de la Nueva, Reino de León, mitad de Asturias, toda la Rioja, Navarra y porción de Aragón. Santander abundaba entonces en recursos de transportes y sería fácil establecer allí una fábrica de tabacos [...]

En Santander había menos contrabando que en cualquier sitio de España [...] Se trataba del así llamado Puerto Real de Castilla. Estaba declarado puerto en depósito de primera clase ${ }^{195}$.
}

De igual forma, el ayuntamiento tenía especial interés en que la fábrica fuese definitivamente instalada en un local apto para la misma siguiendo la Real Orden de 1822, por lo que urge al director de la factoría santanderina a localizar un inmueble a la mayor brevedad posible con objeto de dar empleo a los desocupados. Esta circunstancia no es ajena a las restantes fábricas estudiadas, puesto que en numerosas ocasiones el consistorio local intercedía para conseguir los apoyos necesarios para la instalación de una factoría tabacalera en su ciudad.

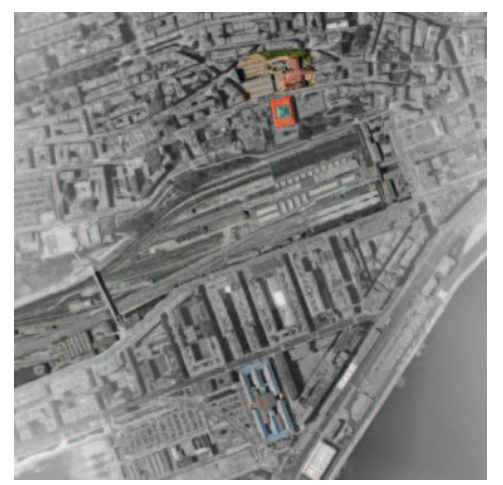

Figura 3.69. Emplazamiento de la fábrica montañesa, antiguo Hospital de San Rafael y ubicación de la estación ferroviaria y el depósito de tabaco del puerto.

${ }^{193}$ COMÍN COMÍN, F. y MARTÍN ACEÑA, P. (1999) op. cit., p. 461. Por aquel entonces, la fábrica contaba con una plantilla de casi 800 trabajadores, lo que la convertía en la segunda factoría en contratación por detrás de Cádiz y en paralelo a Logroño.

$194 \mathrm{http}: / / \mathrm{www}$.altadis.com/centros-de-trabajo-santander.php [acceso el 3-6-2014]

195 GUERÍN, P. (1986) op. cit., p. 44. De igual forma, a finales del S.XIX el puerto de Santander junto con el de Cádiz serían los principales destinos de hoja de Vuelta Abajo y de Partido cubanas. COMÍN COMíN, F. y MARTíN ACEÑA, P. (1999) op. cit., p. 43. 


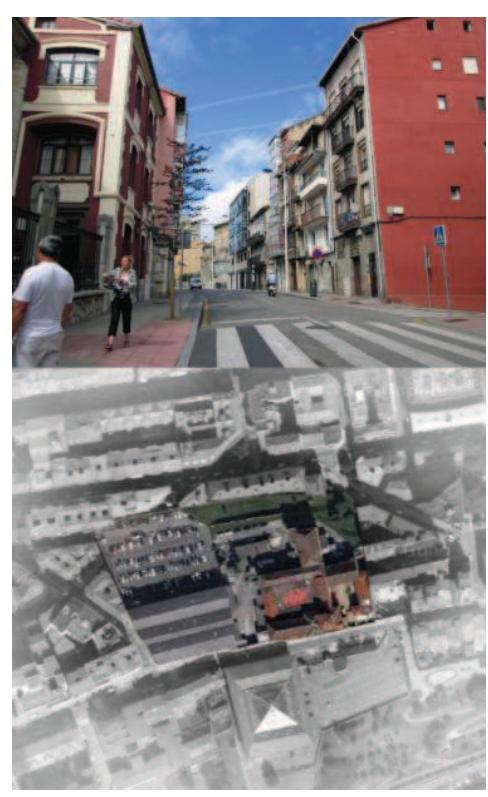

Figura 3.70. Calle Alta de Santander y emplazamiento de la fábrica, 2014.

La Fábrica de Tabacos de Santander se situó definitivamente en la calle Alta, como se comentó en el anterior epígrafe, en el Convento de Santa Cruz del Monte Calvario. La calle Alta se encuentra en una zona de la ciudad que hace honor a su nombre, sobre el promontorio ubicado al Norte del puerto, formando una atalaya natural sobre los dominios portuarios de la tabacalera. El conocido como barrio del Cabildo de Arriba sitúa sus orígenes en la puebla vieja medieval surgida en las inmediaciones a la "puerta de san Pedro" y extramuros al núcleo de nobles, hidalgos y clérigos que se localizaban en torno a la Rúa Mayor. Este barrio se componía de un tejido variopinto de huertas y pequeñas edificaciones que se apretaban en torno a estrechas calles cuya dirección discurría preferentemente de forma paralela al mar. La calle Alta constituía la vía principal del barrio como continuación de la Rúa Mayor y, con la expansión de la villa, este barrio se desarrolló como principal ubicación del colectivo de pescadores junto con el Arrabal. Cabe pensar que el carácter popular del barrio sentaba las bases para que la fábrica se nutriese de mano de obra femenina residente en sus inmediaciones.

Su verdadero desarrollo comenzaría en el S.XVIII cuando se inicia la moderna urbanización y continúa en el S.XIX, momento en que se comienzan a sustituir las edificaciones de origen medieval y se configuran sus principales calles -Alta, Cuesta del Hospital, San Pedro, etc.-. Su importancia como núcleo histórico radica en que es la única zona de origen medieval junto al entorno de las calles Arrabal y de En medio que pervive tras el incendio de 1941 que destruyó el casco antiguo montañés ${ }^{196}$.

La fábrica daba frente al edificio que la había albergado en origen, el Hospital de San Rafael, que actualmente se ha reconvertido en sede del Parlamento de Cantabria. El conjunto industrial adaptaba los antiguos espacios conventuales, tanto el inmueble principal como las huertas cercadas del predio anterior. Evidenciando una característica común a sus homólogas tabacaleras de origen conventual, el hecho de que la fábrica se ubicase en un tejido urbano colmatado obligaba a que las necesidades de expansión espacial productiva se acometiesen dentro del propio inmueble fabril y de las antiguas huertas conventuales, construyendo naves de almacenaje y otros edificios auxiliares en las mismas, y recurriendo a locales externos al conjunto cuando el espacio fabril se hallaba totalmente colmatado.

En el caso de Santander, tras la descarga del tabaco en el puerto, la materia se trasladaba al depósito general de rama situado en la propia fábrica y a los ocho almacenes restantes que ésta tenía arrendados en la ciudad, siete de ellos en la calle de Antonio López en las proximidades del puerto. El más relevante fue el construido a principios del S.XX en los arenales del muelle de Maliaño con arreglo a un proyecto de 1899 y conformado por ocho naves dispuestas en dos peines enfrentados, formalizando su lienzo exterior mediante machones

196 SIMÓN CABARGA, J. (1980) Santander en la historia de sus calles, Institución Cultural de Cantabria, Diputación Provincial, p. 160. 
de ladrillo y piedra de sillería en el zócalo, de forma análoga al que se construiría en Cádiz en 1910. Su proximidad al puerto facilitaba el transporte y las estibas, puesto que la mitad del tabaco que se recibía en España se almacenaba en este depósito, distribuyéndose posteriormente mediante ferrocarril, barcos de cabotaje o carretera a las once fábricas del monopolio. Las razones por las que este depósito adquirió tal importancia fueron, por una parte, el hecho de que en el puerto santanderino realizasen escalas los trasatlánticos proveedores de la materia prima, y en segundo lugar, el clima húmedo era un factor determinante para el almacenamiento y conservación del tabaco ${ }^{197}$. Sobre el contexto en el que se construyen estos depósitos y su importancia en el ciclo productivo peninsular, destacan Comín Comín y Martín Aceña que

\begin{abstract}
la incertidumbre en el abastecimiento de hoja, por los problemas de los mercados, por el incumplimiento de los contratistas y, sobre todo, por las dificultades de los transportes, exigía el mantenimiento de grandes volúmenes de existencias, o repuestos, para evitar la paralización de los talleres, algo temido por la dirección de la CAT, debido a las reacciones virulentas de las operarias. Durante la gestión por la Hacienda, los almacenes habían sido considerados como simples depósitos de la materia prima; y ni siquiera tenían la capacidad suficiente. En consecuencia, el Consejo emprendió una política de ampliación y mejora de los almacenes [...] La Hacienda no había podido construir almacenes por falta de fondos, y obligó a la Arrendataria a establecer tres depósitos generales de tabaco, para abastecer centralizadamente a las fábricas [...] El depósito del Norte surtiría a las fábricas de Gijón, Santander, Bilbao y San Sebastián ${ }^{198}$.
\end{abstract}

La propuesta de la CAT de ubicar este depósito tabacalero del Norte en Santander fue aprobada finalmente, pero su construcción y puesta en funcionamiento se llevó a cabo con ciertas dificultades. Finalizado en 1910, ya entrado el S.XX, la CAT hubo de alquilar almacenes exteriores durante el periodo de obras, puesto que el aumento de producción de las fábricas y "los espacios de éstas, incluidos los pasillos y los patios que se venían utilizando como improvisados almacenes, hubieron de despejarse por la racionalización de las fábricas para facilitar la crecida producción”, tal y como refieren Comín Comín y Martín Aceña. Por otra parte, la cadena industrial finalizaba con la distribución de los elaborados desde la fábrica de Santander hasta doce subalternas repartidas por la provincia de Cantabria que funcionaban como estancos.

\section{Características de la arquitectura fabril}

La Fábrica de Tabacos de Santander es uno de los casos de tabacaleras

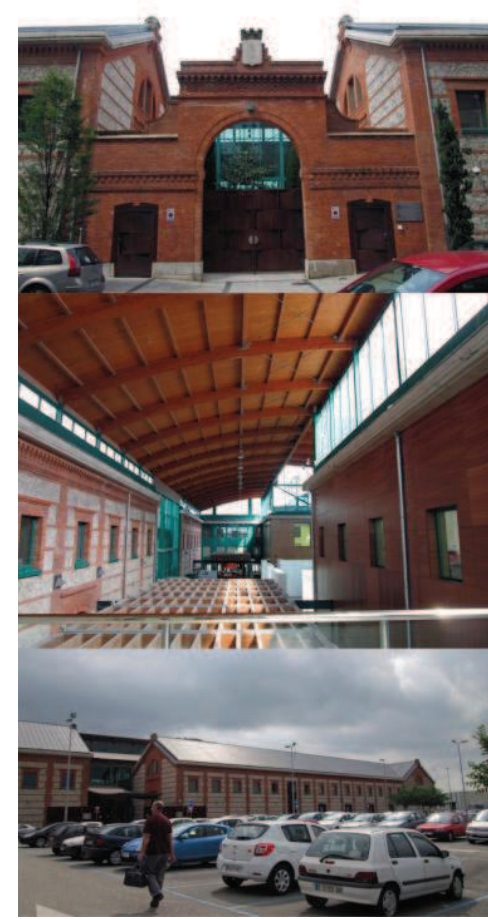

Figura 3.71. El antiguo depósito de tabacos de Santander en la actualidad, 2014.

197 Tras el incendio del 9 de abril de 1925 que destruyó las tres cuartas partes de la fábrica, los depósitos de rama se utilizarían durante el año 1928 como almacenes de elaborados. Durante la Guerra Civil su uso sufrió un paréntesis, transformándose en cárcel para los prisioneros republicanos. Tras este periodo reanudó su uso original como almacén, hasta que en 1986 se anunció su reutilización como posible sede del Gobierno de Cantabria, que finalmente no se produjo.

Los depósitos de tabaco santanderinos datan de 1900 y se construyeron en un área de más de $12.000 \mathrm{~m}^{2}$ en los arenales del muelle de Maliaño. Al igual que el complejo gaditano, se construyó en estilo neomudéjar -lo que puede indicar el empleo de un tipo concreto en ambos almacenes por parte de la CAT-.

198 COMÍN COMÍN, F. y MARTÍN ACEÑA, P. (1999) op. cit., pp. 146-147. 
instaladas en un edificio reutilizado en el S.XIX, concretamente en una preexistencia conventual desamortizada a tal efecto. Como se ha comentado anteriormente, el edificio elegido fue el Convento de Santa Cruz del Monte Calvario del S.XVII que anteriormente había acogido a una congregación de monjas clarisas, y que posteriormente había sido reutilizado como cuartel.

\section{La preexistencia: el Convento de Santa Cruz del Monte Calvario}

El antiguo Convento de Santa Cruz del Monte Calvario fue fundado por María de Oquendo y Lasarte el 6 de noviembre de 1656. Patricio Guerín señala que el primer documento que se refiere a la fundación del convento es del año 1634, en el que se declara la intención de doña María de fundar un monasterio y retirarse en el mismo. Ante las dudas iniciales para su instalación en Guipúzcoa o Santander, se decanta finalmente por esta última, indicando que la fundación sería de franciscanas descalzas de la primera Regla de Santa Clara ${ }^{199}$.

La autoría del edificio se atribuye al maestro de cantería fray Lorenzo de Jorganes quien firmó los planos del convento en mayo de 1641, obra que remató Juan Gómez de Somomayor ${ }^{200}$, contando con Vicente Herrera y Juan de Pontón como maestros canteros. Situado en el barrio del Cabildo de Arriba de Santander, fue construido entre 1641 y 1656. El conjunto constaba de iglesia, claustro y dormitorios para las monjas, y manifestaba una gran sencillez en el exterior -tal es así que José Amor lo califica de "edificio, de vulgar apariencia, no llama la atención por detalle alguno de su ornamentación, que es pobre, así como todo su plano arquitectónico"201-, situando su puerta principal hacia la calle Alta -en la actualidad tapiada- que presentaba un frontón semicircular partido. La capilla constaba de una sola nave cubierta con bóveda de cañón cuyo extremo se remataba con un ábside poligonal y coronando el templo con una cúpula de media esfera sobre pechinas.

\section{La Fábrica de Tabacos de Santander}

La comunidad permaneció en el convento casi 180 años hasta que a principios del S.XIX comenzaron a experimentar dificultades que desembocarían en su expulsión en 1835 tras la desamortización del edificio. Paralelamente a la crisis de la congregación se estaba buscando un edificio adecuado para la instalación de la fábrica de tabacos santanderina, para la que en un principio se estudió la viabilidad del monasterio de Corbán y el ex-colegio de los jesuitas que en la época era residencia episcopal. Aunque ésta última opción contó con un principio de acuerdo, el Obispo finalmente ofrece el convento de

199 GUERÍN, P. (1986) op. cit., p. 19. Se recomienda también la consulta de GARCIA GUINEA, M. A. (1988) Cantabria: Guía artística, Librería Estudio, p. 23.

${ }^{200}$ GUERÍN indica que no se conservan trazas de los planos y que este documento de mayo de 1641 son en realidad las condiciones de la obra firmadas por fray Lorenzo de Jorgades y Juan Gómez de Somomayor. GUERÍN, P. (1986) op. cit., p.21. Se recomienda también la consulta de GONZÁLEZ ECHEGARAY, M. de C. (1991) Artistas cántabros de la Edad Moderna: su aportación al arte hispánico, Universidad de Cantabria, p. 352.

${ }^{201}$ AMOR, J. (1907) op. cit., p. 27. 
Santa Cruz, por lo que las monjas fueron obligadas a desalojar el conjunto conventual para la instalación de la nueva fábrica. Los costes de traslado de la fábrica desde el Hospital de San Rafael hasta el Convento de Santa Cruz, así como el acondicionamiento de este último inmueble fueron costeados a partes iguales por el Consistorio y la Junta de Comercio montañeses.

Como ya se ha comentado previamente, tras su reconversión en fábrica de tabacos, el inmueble seguía adoleciendo de una "cierta vulgaridad" en palabras de Amor, puesto que Pascual Madoz también describía la fábrica en 1847 en los siguientes términos:

su edificio, sit. en la vertiente NO. de una de las colinas que forman la mayor parte del suelo de la c.; es sumamente irregular en su construcción; de mal aspecto, sombrio [sic], húmedo y pequeño para el objeto; careciendo por lo mismo de almacenes, y especialmente de oreos para que se enjuguen las labores ${ }^{202}$.

El inmueble montañés elegido para ubicar la nueva fábrica de tabacos, presentaba numerosas similitudes con su homólogo gijonés; no en vano, la fundación de sendas fábricas fue prácticamente coetánea. Al igual que en la Fábrica de Tabacos de Gijón, el Convento de Santa Cruz se había construido en el S.XVII siguiendo un estilo renacentista, y sus estancias fueron destinadas a funciones de carácter militar en diversas épocas: mientras que la Fábrica de Tabacos de Gijón tuvo un carácter de hospital militar en la revolución de 1934, el inmueble santanderino había sido habilitado anteriormente a la instalación de la fábrica como cuartel, aspecto coincidente también con el caso de la tabacalera de Logroño.

Con la instalación de la fábrica en el antiguo conjunto conventual, se modificó la distribución interior de éste, de forma que las construcciones de planta baja se elevaron a igual altura que el resto del edificio. Constaba de seis cuerpos en los que se distinguía la parte antigua por la notable solidez y anchura de los muros respecto a las construcciones restantes. Se llevarían a cabo muchas reformas importantes para que el espacio conventual diese cumplimiento a los requerimientos espaciales de la fábrica tabacalera, siendo algunas de ellas costosas y de difícil ejecución.

Las más importantes fueron proyectadas y dirigidas por el ingeniero de la compañía Alejo Sesé203, comprendiendo la ejecución de las armaduras a pendolón de la fachada Sur, las armaduras del pabellón, cielos rasos y cubiertas de teja plana, finalizando con la reforma más importante que fue la apertura de siete luceras sin las cuales los espacios destinados a la elaboración carecían de las condiciones necesarias de hábitat y confort. De esta forma, José Amor afirmaba en 1907 que "merced a tan

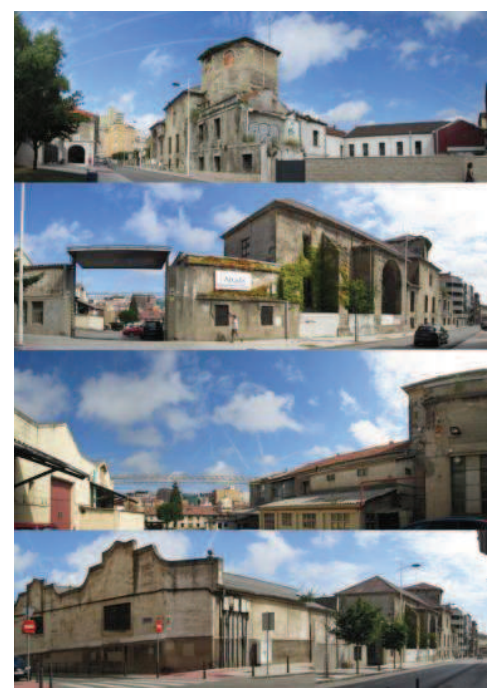

Figura 3.72. La Fábrica de Tabacos de Santander en la actualidad, 2014.

202 MADOZ, P. (1846-50 [1984]) op. cit., p. 241.

203 Alejo Sesé Echezarreta (1863-1933) fue un ingeniero industrial que prestó sus servicios profesionales en la Compañía Arrendataria de Tabacos, comenzando a trabajar en la Fábrica de Logroño. Posteriormente, trabajó en La Coruña antes de trasladarse a Santander, y finalizó su carrera en Madrid, llegando a asumir la jefatura de fabricación, desde la que pasó a la subdirección en 1920. COMÍN COMÍN, F. y MARTÍN ACEÑA, P. (1999) op. cit., p. 273. En todas las fábricas acometió importantes reformas de acondicionamiento para el aumento de producción de las mismas a través de las nuevas directrices de la CAT y la implantación de maquinaria que mecanizase las tareas. 


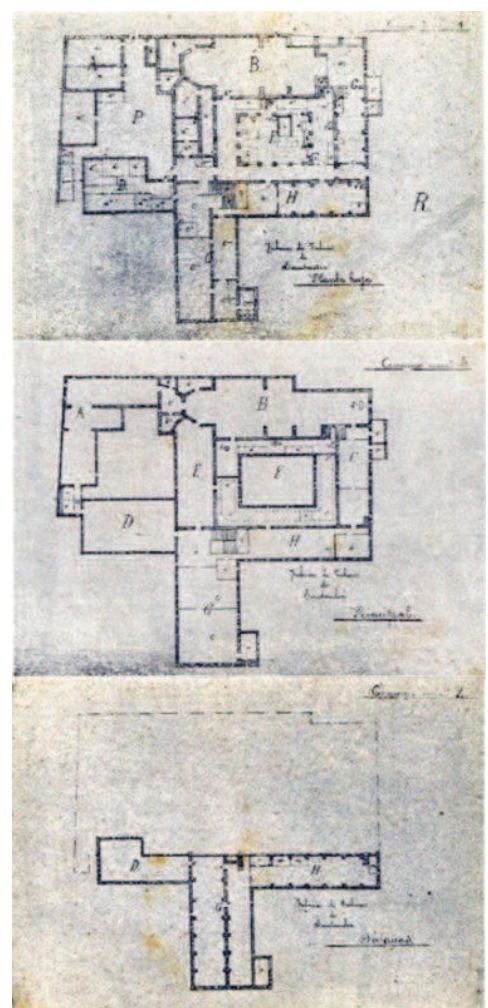

Figura 3.73. Planimetría de la fábrica de principios del S.XX, en AMOR, J. (1907) op. cit., pp. 30- importantes reformas y a las demás mejoras introducidas, los talleres de la Fábrica de Santander son hoy lo más higiénicos posible dentro de la configuración especial del edificio"204.

Las reformas que se llevaron a cabo en la Fábrica de Santander en la década de los 30 del S.XX se centraron fundamentalmente en el acondicionamiento interno para la creación de servicios auxiliares para el personal de la tabacalera. De esta forma, a la reconstrucción de los pabellones siniestrados durante el incendio de 1925 se sucederían reformas de carácter puntual que mejorarían las instalaciones, como la construcción de la escalera principal del edificio y las de acceso al sótano de los pabellones Norte y Noroeste en 1928, la pavimentación del patio de la entrada principal y la instalación de un pararrayos en 1929, la instalación de un montacargas en 1933, la pavimentación de las aceras de la calle Alta en 1935 y la mejora de la chimenea. La fabrica poseía, así mismo, un horno en el que se destruía tabaco o labor defectuosa.

\section{El espacio productivo y su evolución hasta 1945}

Para abordar el análisis del espacio productivo de la fábrica montañesa y su evolución, cabe tener en cuenta que su espacialidad se veía condicionada por la herencia de las características espaciales de la anterior función religiosa. La adaptación del edificio a la función industrial conllevó muchas reformas importantes en las que cabe destacar, como se indicaba anteriormente, la labor del ingeniero Alejo Sesé.

$\mathrm{Al}$ igual que en las fábricas gijonesa y riojana, la iglesia sería destinada a almacén de tabacos, mientras que en la entrada principal se disponían los espacios de control de acceso y registro, así como las dependencias administrativas. Nuevamente se situaría la principal maquinaria que dotaba de energía a la fábrica en el espacio claustral, manteniéndose la tradicional distribución productiva según un criterio vertical: almacenes, desvenado y taller de picado en la planta baja, mientras que en la planta alta se disponían los diversos talleres de liado. Así mismo, el inmueble principal se hallaba rodeado por una huerta en sus flancos Norte, Oeste y parte del Este, siendo su fachada Sur la que lindaba con la vía principal -calle Alta de Santander- y por donde se establecía el acceso principal ${ }^{205}$.

Según la descripción de Santías y Lera ${ }^{206}$ de finales del S.XIX, tanto el Estado como la CAT habían reformado notablemente la tabacalera montañesa para ponerla "en condiciones industriales y mejorar las higiénicas en beneficio del personal obrero". En la época de entre-siglos, la fábrica se distribuía de tal forma que el sótano era destinado a almacén de tabacos en rama, ubicando en planta baja, como solía ser

${ }^{204}$ AMOR, J. (1907) op. cit., p. 34.

205 Ante la falta de documentación planimétrica más precisa, resultan fundamentales para el conocimiento de la distribución del programa de usos de la fábrica los planos de principios del S.XX recogidos en AMOR, J. (1907) op. cit., pp. 28-36.

206 SANTÍAS, A. y LERA, D. (1898), op. cit., pp. 29-30. 
habitual, los talleres de desvenado, picados finos y comunes y las labores de envase, oreo de picaduras y almacén de tabacos elaborados. Por su parte, la planta principal albergaba los talleres de cigarros marca chica y comunes, de cigarrillos superiores, entrefinos y finos, el envase de estas labores, el oreo de cigarros y el de recibo de labores. En este momento, la fábrica contaba con unas 1.187 operarias y la incipiente mecanización se reflejaba en la instalación de máquinas picadoras y un generador de vapor de 25 caballos.

Poco tiempo después, José Amor realiza una descripción sobre el estado de la fábrica para el Anuario de la Renta de Tabacos de España del año 1907 en la que se aprecian pocas variaciones respecto al texto de Santías y Lera. En aquel momento los diferentes cuerpos de la fábrica comenzaban a denominarse por una letra, comenzando a racionalizarse los distintos espacios a que estaba destinado el inmueble fabril. Amor señalaba que "los cuerpos A, B, C, constan de planta baja y principal, y los H, E (en su parte G) y determinada porción del D tienen, además, sótano" lo que traducido a la configuración del antiguo convento resultaban como la portería al Sur para el cuerpo A, situándose junto al acceso principal que daba a un gran patio distribuidor; el cuerpo D era la edificación que cerraba este patio al Norte y que se adosaba al muro Este del convento; el cuerpo G era el pabellón Norte rectangular que lindaba con la antigua huerta conventual y que tomaba una directriz perpendicular a la fachada principal; el cuerpo E era la prolongación del anterior pabellón en el interior del conjunto hacia la iglesia; el cuerpo B era la propia iglesia, cuyo eje longitudinal se disponía paralelo a la calle Alta convirtiendo la fachada lateral Sur de la nave en la fachada principal del conjunto; el cuerpo $\mathrm{C}$ era la nave longitudinal Oeste que lindaba con la huerta, el acceso a la nave eclesial y la crujía Este del antiguo patio conventual; el cuerpo $\mathrm{H}$ era el pabellón que lindaba con la huerta; el cuerpo C, la crujía Norte del patio; y finalmente, el cuerpo F era el propio patio conventual.

De esta forma y siguiendo la gradación vertical del texto de Santías y Lera, encontramos sótanos en el cuerpo D que cerraba el patio de ingreso, empleados como trasteros, mientras que en los pabellones $\mathrm{G}$ y $\mathrm{H}$ al Norte del conjunto albergaban el almacén de tabacos caperos, en el primer caso, y desvenado para la obtención de picaduras, en el segundo.

En planta baja por su parte, el cuerpo G funcionaba en su ingreso como portería de talleres, a modo de segundo filtro de control que completaba a la portería general, albergando en sus naves longitudinales los talleres de picados comunes, así como retretes y almacenes auxiliares. En la planta principal funcionaba como comedor, oficinas de inspección y albergaba los talleres de cigarros comunes fuertes y cigarrillos entrefinos, así como nuevamente la instalación de servicios higiénicos.

El cuerpo $H$, por su parte, albergaba en planta baja el almacén de escogido y distribución así como el local para la moja preliminar, y en el ángulo que formaba con el cuerpo G, cerca de la portería de talleres, la escalera principal de comunicación con la planta alta. En la planta principal, sus dependencias se destinaban a depósito de capa y tripa

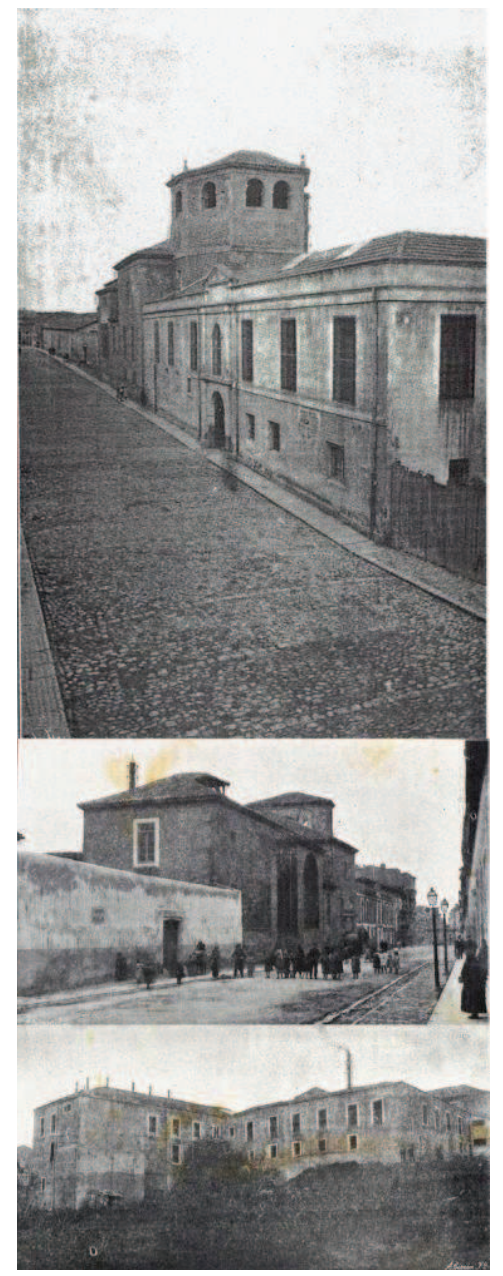

Figura 3.74. Fotos históricas de la Fábrica de Tabacos de Santander: acceso principal y vista desde la huerta, en SANTÍAS, A. y LERA, D. (1898) op. cit., p. 28; y en $A M O R$, J. (1907) op. cit., pp. 33 y 29. 
desvenadas, así como al recibo de labores.

El cuerpo D que junto con el $\mathrm{G}$ y el $\mathrm{H}$ cerraba el sector Norte de la fábrica colindante con la huerta tenía una función puramente administrativa y de representación al albergar las oficinas del Administrador Jefe, Ingeniero e Interventor, así como las oficinas de caja y pagaduría. Cabe destacar la lógica de que estos tres cuerpos contasen con espacio para sótanos dada la topografía del solar que desciende precisamente hacia el Norte. Continuando con las dependencias que cerraban el patio de ingreso a la fábrica, el cuerpo A situado en la esquina Sureste del conjunto acogía en su planta baja las habitaciones del portero, así como un almacén de empaques y un cuarto para que las operarias pudiesen amamantar a sus hijos.

El antiguo claustro conventual se transformó como el cuerpo $\mathrm{F}$ de la fábrica que albergaba el departamento de máquinas, como solía ser habitual en este tipo de tabacaleras de origen conventual. En este espacio, que constituía el interior más desahogado del conjunto, se instalaron las tolvas de las máquinas picadoras, el generador de vapor, la dinamo y los motores de generación de fuerza motriz, la laminadora, el perforador, el montacargas, la afiladora automática, así como estanques para la obtención de tinte y maceración de la vena, que aludían a su uso original en los primeros momentos de la manufactura. Una escalera de caracol permitía subir a las picadoras y, de igual forma, albergaba una fragua y una chimenea que salía a cubierta. En la planta alta, que había sido el antiguo orden superior del claustro, se albergaban las máquinas picadoras, la empaquetadora mecánica, el aerocondensador, así como el oreo de picaduras y cigarros.

El cuerpo B que correspondía con el antiguo espacio eclesial, contaba en planta baja con el almacén de tabacos en rama, destinando los cuartos de la sacristía a diversos trasteros, así como instalaciones y cocina del portero mayor. Como ocurrió en la fábrica riojana, la altura de la antigua nave fue dividida creando en la planta superior un espacio para los talleres de cigarros peninsulares marca grande y marca chica, el almacén de distribución de empaques y una mesa para el recibo de las labores que se confeccionaban en dicha estancia.

El cuerpo C que cerraba el área Oeste del conjunto contaba en planta baja con el desvenado para picaduras, mojas de las mismas y una pequeña área de servicios higiénicos, mientras que en planta alta sus estancias se destinaban a moja y preparado de capa y tripa para cigarros marca grande y marca chica, así como servicios higiénicos.

Cerraba el cuerpo E la articulación claustral, entre el patio de acceso y el patio interior, que en planta baja albergaba cuartos para el tabaco picado, así como la portería general, el cuarto de oficial de guardia y el acceso general a modo de exclusa entre el patio de acceso y el interior de la fábrica, como espacio distribuidor. En planta alta, la nave estaba destinada por entero al taller de cigarrillos finos.

La lógica de la distribución descrita anteriormente hace pensar en la articulación de las circulaciones de la fábrica en dos espacios 
fundamentales que constituyeron el eje vertebrador del conjunto, como son el patio de acceso y el patio interior claustral. De esta forma, se definían claramente como núcleo fabril las dependencias en torno al antiguo claustro conventual y se establecía un sistema de doble filtrado del acceso al interior a través de la entrada principal a la calle y de la entrada desde el patio de acceso al propio espacio productivo. Las construcciones que bordean este último patio claramente se destinan a la parte coercitiva de la fábrica: portería y zonas de representación de la compañía materializadas en las oficinas administrativas.

Por su parte, el área claramente industrial se articula en torno al antiguo patio conventual, disponiendo un núcleo general de comunicación vertical y el espacio distribuidor de acceso en la confluencia de las naves Norte y Este que cierran el mismo y que se comunican con el patio de acceso, dejando una segunda entrada secundaria para el producto en la parte Oeste que linda con la huerta y con el que posteriormente sería el segundo patio de acceso a la fábrica. Todos los talleres de laboreo y almacenes se disponían, de esta forma, en torno al patio como elemento articulador que, por la necesidad de nuevos espacios adecuados a la escala de la máquina, se convirtió en el recinto de motores y maquinaria de mayor tamaño.

Por otra parte, señala Amor que en la parte Oeste del edificio y unido al mismo mediante una tapia, se situaba un espacioso local dividido en dos por un muro longitudinal dedicado a almacenes de elaborados y de tabacos en rama que se trataba de una propiedad particular, al igual que la huerta que rodeaba al conjunto por la parte Norte, Este y Oeste. Es de suponer que dicha construcción fue predecesora de los tres almacenes con cubierta a dos aguas construidos en torno a los años cuarenta del S.XX y que actualmente completan el conjunto por la parte Oeste del recinto, lindando con la calle Alcázar de Toledo. Indica, de igual forma, una circunstancia que sería común a todas las tabacaleras de origen conventual y constituiría uno de los principales problemas endémicos en la adaptación de este tipo de edificios a la actividad productiva tabacalera puesto que,

pesar de los esfuerzos del Sr. Sesé y de sus dignos sucesores, no ha sido ni será posible industrializar las operaciones preliminares á [sic] la elaboración y las secundarias una vez obtenido el producto. El traslado de un punto á [sic] otro cualquiera del edificio, lo mismo del tabaco en rama que picado ó elaborado, ha de efectuarse á fuerza de brazos, por no ser posible establecer esos servicios en vagonetas, á [sic] causa de estar situadas en distintos planos las diversas dependencias relacionadas con tales servicios, y el trabajo del hombre no puede auxiliarse con alguno de tantos aparatos ideados para tales fines. Esta consideración demuestra, sin necesidad de otros argumentos, que las condiciones industriales del edificio no son del todo recomendables ${ }^{207}$.

Como señala el trabajo universitario facilitado por Sierra Álvarez, se dan dos fases en la organización de la producción en la fábrica hasta 1942, de forma que la primera fase se caracterizaba por los métodos propios del periodo manufacturero, mientras que en la segunda el

${ }^{207}$ AMOR, J. (1907) op. cit., pp. 34-35. 
tabaco semielaborado pasa a los distintos talleres de los que el producto salía elaborado y empaquetado. Esta segunda fase en la que se inició la mecanización del proceso no fue, sin embargo, homogénea, dando como resultado la aparición de talleres mecánicos y semimecánicos que convivían con los manuales. Las labores que se realizaban en este momento eran de cigarros peninsulares, marca grande y marca chica, cigarrillos superiores al cuadrado, cigarrillos finos y entrefinos, cigarros comunes fuertes y picado común.

Los talleres manuales continuaban la tradicional organización en ranchos o agrupaciones de seis cigarreras a las que controlaba el ama de rancho. Estos ranchos se agrupaban a su vez en partidos controlados por una maestra y el conjunto de partidos formaba el taller. En el caso de la fábrica montañesa los talleres manuales estaban dedicados a cigarrillos superiores.

Los talleres mecánicos se basaban en una organización que giraba en torno a la presencia de la máquina, puesto que las operarias se limitaban a suministrarla de materia prima y a recoger el producto elaborado por la misma, contando con la figura del mecánico que se ocupaba del mantenimiento de la máquina. El impulso mecanizador que intentó la CAT en los años 20 del S.XX consiguió, en el caso de Santander, introducir los nuevos métodos durante los años 30 a través de la mecanización de algunas operaciones específicas, como la introducción en 1931 de una máquina humectadora que reduciría el espacio utilizado para la tarea manual de moja y conseguiría un mejor uniformado de la operación. De igual forma, en 1932 se instalaría un nuevo montacargas que conectaría todos los pisos en los que se encontraban los talleres y almacenes, solventado el problema anteriormente señalado en la descripción de José Amor.

\section{Las cigarreras y la dimensión humana de la fábrica}

Al igual que en las restantes factorías, la Fábrica de Tabacos de Santander tuvo una gran significación en la historia de la ciudad montañesa tanto por su repercusión en el tejido urbano como por ser el centro fabril del municipio que concentraba mayor volumen de empleo femenino. Se incluía, de igual forma, dentro de los tres mayores establecimientos industriales de Cantabria, lo que indica la enorme importancia económica de su producción y el valor y volumen tanto de las materias primas como de los productos elaborados.

Como era frecuente al carácter coercitivo de las fábricas tabacaleras peninsulares, se establecía un férrea disciplina entre la mano de obra que atendía a la prevención frente al robo o fraude de producto y al orden moral de las operarias. Como ocurrió en las restantes tabacaleras, este control moral no sólo se imponía por los registros realizados en las porterías en el acceso y salida de la fábrica, sino también a través de lemas y arengas, como la que se materializó en la inscripción sobre una losa de mármol ubicada en la fábrica que hizo instalar en la escalera a comienzos del S.XX Ignacio Carbó -a la sazón director de la fábrica- que rezaba: "Moralidad, respeto y obediencia a 
los superiores; orden en los talleres, asiduidad y aplicación al trabajo y esfuerzo y limpieza en las labores, son las condiciones que se exigen a todos cuantos trabajan en esta fábrica”.

El personal obrero masculino despojaba su cabeza de las boinas, en señal de respeto, para saludar al Jefe. Las mujeres se levantaban de su puesto, se colocaban al lado de la máquina o junto a su labor correspondiente [...] Al paso del mando superior, saludaban con un leve movimiento de cabeza [...]

Durante el tiempo de la visita, los trabajadores permanecían quietos junto a su puesto de trabajo. Igual que si de un reconocimiento militar se tratase 208 .

Ya a mediados del S.XIX se inician tímidas mejoras relativas al bienestar de las cigarreras en el seno de la fábrica:

En ella hay establecida una hermandad de socorros para todos sus dependientes; la que por una contr. Pecuniaria de 3 rs. Mensuales, proporciona á [sic] sus individuos la asistencia de facultativos en sus enfermedades, y cuantos medicamentos puedan necesitarse, facilitando además socorros en dinero, cuando la enfermedad dura mas [sic] de ocho días, asi [sic] como lo necesario para los auxilios espirituales y gastos de entierro á [sic] los que fallecen. Se habría ya puesto por el actual director una escuela de $1^{a}$ enseñanza para los hijos párvulos de las operarias, si la capacidad del edificio lo permitiera; pero no teniendo las suficientes localidades para los objetos precisos de su instituto, no puede llevase á [sic] efecto este pensamiento, que proporcionaría inmensas ventajas á [sic] las operarias, libertándolas del cuidado de sus hijos durante las horas de trabajo en la fáb., pues podrían verlos á [sic] ciertas horas todos los días, y aun [sic] alimentarlos por si [sic] mismas $^{209}$.

Desde finales del S.XIX con los primeros informes que apuntaban la carencia de medidas higiénicas de las fábricas, las reformas de modernización y mecanización de los talleres de los años 20 y 30 del S.XX se acompañaron de la introducción de una serie de instalaciones dedicadas a servicios auxiliares para los empleados. Dada la importancia numérica del personal femenino y la implantación de nuevos horarios, se comienzan a ofrecer estos servicios por solicitud expresa de los empleados o por orden directa de la dirección central.

De esta forma, en 1929 las operarias exigirían a la dirección la instalación de calefacción en los talleres alegando que "durante los meses de invierno y al estarles prohibido usar pantalones, se ven obligadas a envolverse en sacos para soportar el frío" 210 . Tras esta demanda coincidente con las quejas de las empleadas de su homóloga gijonesa en el mismo periodo, en noviembre de 1930 se haría la instalación definitiva de calefacción. También en 1930 se autorizó la ubicación de un dispensario de urgencia donde se pasarían las consultas médicas en el interior de la fábrica y se completaría cuatro años más tarde con la creación de una clínica de urgencia en la fábrica.

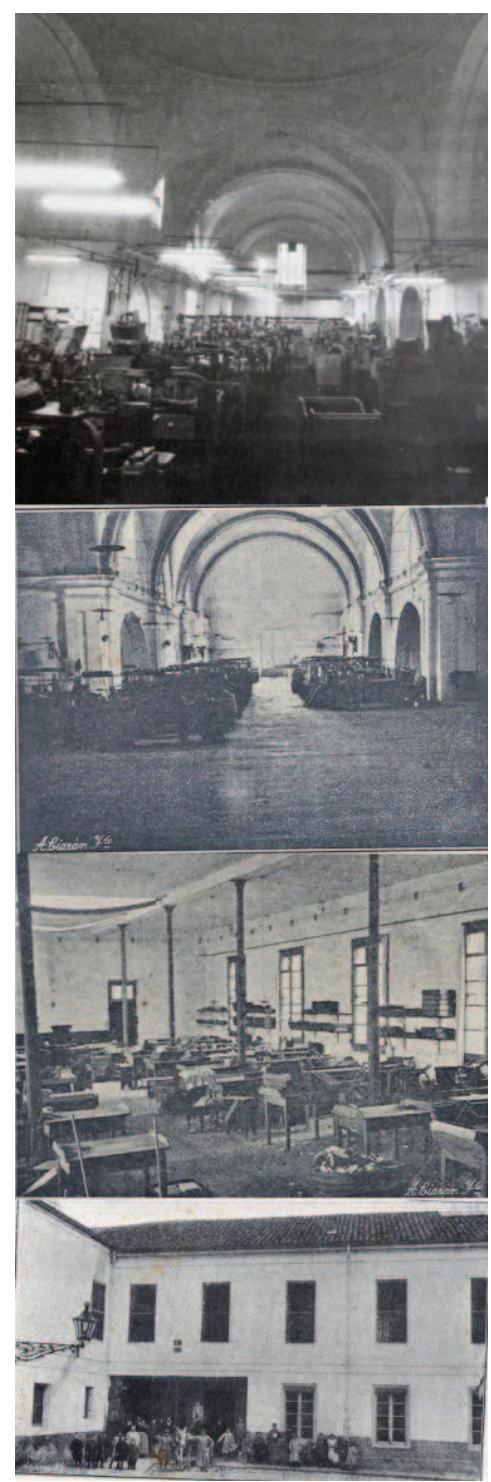

Figura 3.75. Espacios productivos de la fábrica montañesa: antigua capilla en los años 80, en GUERIN, $P$. (1986) op. cit.; la iglesia como taller de cigarros peninsulares marca chica y marca grande, taller de cigarrillos superiores y patio de acceso a principios del S.XX, en AMOR, J. (1907) op. cit., p. 35, 37 y 39 .

208 REVUELTA, C. (2013) op. cit., p. 376. 
Ya comenzaban a notarse los calores del verano y los talleres se convertían en hornos donde las mujeres no paraban de elaborar [...]

Se agradecía la luz natural de aquellos meses, los cuales, lógicamente, nada tenían que ver con las largas tardes de invierno, cuando la oscuridad exterior, unida al sonido casi constante de la lluvia, proporcionaba a la plantilla, sin ellas querer, un carácter más seco 211.

La necesidad concreta de espacios para mujeres, como salas de lactancia, se fue resolviendo a lo largo del S.XIX con cierto carácter de improvisación, disponiendo un cuarto para tal función en el cuerpo de la fábrica dedicado a portería, junto al acceso a la misma. Sin embargo, en 1932 dicha sala se mejoró habilitando un local en la portería de mujeres que contaba con sillas bajas, lavabo y las condiciones de ventilación y luz adecuadas, en un espacio alejado de la zona propiamente industrial. De esta forma, los niños se conducían a la sala y se disponía un espacio de espera en la portería general para evitar que el personal ajeno que los acercaba a sus madres penetrase en el local. Completando este tipo de iniciativas, en 1938 se estudia la aprobación de un proyecto de guardería que completaría las modestas instalaciones de la sala de lactancia. Pese a no constituir un gran proyecto como los asilos de lactancia y escuelas de párvulos y primarias que llegaron a contemplarse en Madrid y Valencia, constituía una acción novedosa que refería directamente la importancia del colectivo femenino en el espacio de trabajo.

También en 1938 se obliga a la Renta a la instalación de comedores para el personal obrero, que en el caso de Santander debía tener capacidad para albergar unas 75 u 80 plazas, estableciendo dos turnos que acogiesen a la cuarta parte de la plantilla. Según esta orden, cada obrero debía llevar consigo un acompañante y el comedor debía establecerse fuera de la zona de registros de la fábrica para contar con la mayor independencia posible. Sin embargo, sólo se ha registrado en la presente investigación la presencia de un comedor en el ala Norte del conjunto o cuerpo $\mathrm{G}$, en la primera planta.

Finalmente, fruto de las innovaciones en materia de racionalización del espacio productivo y las mejoras en formación del personal con la introducción de la mecanización, según orden del Ministerio de Industria y Comercio del 23 de febrero de 1940 se dispone la creación de escuelas de aprendizaje dentro de la fábrica de Santander para una mejor capacitación profesional del personal. No se debe olvidar que con la reorganización iniciada por la CAT, el ingreso a la fábrica por lazos familiares y otros privilegios se erradicaba a favor de un examen de capacitación que reforzaba el vínculo de las aprendizas con el nuevo sistema de producción basado en el empleo de maquinaria.

${ }^{211}$ REVUELTA, C. (2013) op. cit., p. 85. 


\subsubsection{La Fábrica de Tabacos de Gijón (1823-2002)}

\section{Contexto histórico hasta su cierre}

La Fábrica de Tabacos de Gijón pertenece a la segunda generación de manufacturas tabacaleras instauradas en la península en el S.XIX. No en vano, siguiendo el frecuente voluntarismo político que solía acompañar a la elección de una urbe determinada para la fundación de una nueva factoría adscrita al monopolio de tabacos, en el caso de Gijón se contó con un valedor de excepción como fue el Ministro de Hacienda José Canga Argüelles ${ }^{212}$. Desde su influyente puesto, el político ovetense no sólo impulsó la creación de la Fábrica de Tabacos de Gijón que se instalaría en un primer momento en el Palacio de los Valdés, sino que también consiguió que el Estanco del Tabaco se mantuviese en manos del Estado durante el Trienio Liberal ${ }^{213}$.

Por tanto, la incipiente industria tabacalera con la que contó Gijón desde $1823^{214}$ obedecía a la estrategia de acercamiento de la producción al consumo y a la dispersión de las fábricas que evitase grandes concentraciones de trabajadores. Por otra parte, la fábrica gijonesa abastecería fundamentalmente a Asturias, León y Zamora. Esta primera instalación estuvo ligada al movimiento revolucionario del Trienio Liberal que tuvo lugar entre 1820 y 1823 y que supuso un fracaso, puesto que tan sólo desarrolló su actividad durante poco más de un mes, al anular Fernando VII algunas resoluciones tomadas en este periodo, entre ellas la apertura de una fábrica tabacalera en Gijón.

A pesar de este arranque fallido, la fábrica fue reabierta en 1837 en el mismo inmueble a lo que nuevamente contribuyó en gran medida José Canga Argüelles, a la sazón Ministro de Fomento del Consejo Real de España e Indias.

Decididos los liberales [...] a aumentar y diversificar la producción de tabaco para reducir su precio y atender a una demanda creciente, no pierde Canga Argüelles la ocasión para restablecer una fábrica en Gijón, continuidad de la instalación fabril abierta y cerrada en 1823 [...] por el reducido coste de la producción en esta villa, frente a Santander, y por la idoneidad de la distribución del tabaco hacia toda la costa cantábrica y hacia las provincias castellanas ${ }^{215}$.

El inmueble elegido para la fundación de la fábrica gijonesa se hallaba al Este de la península que formaban el popular barrio de Cimadevilla y el Cerro de Santa Catalina, frente al mar y en situación diametralmente opuesta al puerto respecto al istmo que unía Cimadevilla con la ciudad restante. Sobre la ubicación en el Palacio de los Valdés señalan Arias González y Mato Díaz que

\footnotetext{
212 José Canga Argüelles (1770-1843) fue un político, escritor y académico ovetense que estableció los fundamentos para la creación de la Hacienda Pública en España, llegando a ser Ministro de Hacienda en dos ocasiones. Destaca entre sus publicaciones el Diccionario de Hacienda, con aplicación a España de 1834.

213 PIÑERA ENTRIALGO, L. M. (2011) op. cit., p. 135.

214 VV. AA. (2002) Diccionario histórico de Asturias, Oviedo: Prensa asturiana, pp. 417-418.

215 Este pasaje y siguientes en ARIAS GONZÁLEZ, L. y MATO DÍAZ, A. (2005) op. cit., pp. 25-28. En el estudio del caso gijonés se seguirá fundamentalmente la información aportada por esta publicación.
} 
el ayuntamiento gijonés había puesto en marcha una Comisión de tres personas, encargada de suministrar la información necesaria a Madrid para la puesta en marcha de la fábrica, que, ante la carencia de locales públicos, proponía su instalación en la Casa de los Valdés, aunque ofertaba otros dos edificios alternativos para lograr la rebaja del alquiler de la misma, cifrada en los 12.000 reales anuales que su propietario, el Marqués de San Esteban, había exigido en 1823.

Las razones ventajosas esgrimidas por esta Comisión atendían a la reducción de los costes de producción por el escaso gasto en el traslado de materia prima desde el puerto gijonés, que se hallaba muy próximo al inmueble, además del menor precio de elaboración respecto a la fábrica de Santander, puesto que en Gijón existía una numerosa mano de obra femenina residente en el núcleo urbano que carecía de otras alternativas de empleo. De esta forma,

tras la adecuación del local, la Fábrica de Tabacos de Gijón comenzó a funcionar, por segunda vez, a finales de 1837, aunque la fecha oficial de inauguración se retrasó hasta el 19 de abril de 1838 [...] Se inició la actividad con 100 operarias aprendizas, que fueron iniciadas en el laboreo por dos maestras y tres operarias procedentes de Málaga que ya habían realizado similar labor formativa en la fábrica de Santander. Las primeras labores obtenidas eran cigarros "torcidos" confeccionados manualmente a base de envolver la tripa (relleno interior) en una primera hoja o capillo y el rollo resultante en una hoja seleccionada lisa y seca.

En 1840 la fábrica gijonesa empleaba ya a 1.200 cigarreras, duplicando casi la plantilla de la Fábrica de Tabacos de Santander. Sin embargo, en 1841 peligraba la continuidad de la factoría de Gijón puesto que la Dirección General de Rentas Estancadas planteaba la desaparición de una de las tres fábricas del Norte o el traslado de la fábrica gijonesa a Oviedo. Aunque el cierre o traslado no se hizo efectivo, evidentemente la consolidación de la tabacalera gijonesa pasaba por la resolución de los problemas que ocasionaba el inmueble que la acogía, puesto que además de costear su alquiler, el espacio del mismo era muy reducido para la pretendida expansión productiva. Señalan Arias y Mato que "para solventar este problema se planteaba la utilización de la capilla del palacio como nueva nave de talleres, tal como solicitaba el director, propuesta que quedó pendiente pues tampoco solventaba las múltiples carencias del edificio".

La insuficiencia de las cualidades espaciales del Palacio de los Valdés para albergar una producción de este tipo, por tanto, determinó el traslado definitivo de la actividad tabacalera en 1842 al desamortizado convento de Agustinas Recoletas del S.XVII, a iniciativa del propio ayuntamiento gijonés, donde se mantuvo hasta el cierre definitivo de la fábrica en julio de 2002. Situado en el barrio de Cimadevilla, en el corazón del casco histórico de la ciudad, su elección vino dada por la reducción de costes que suponía la reutilización de la arquitectura conventual preexistente y su cercanía al puerto de la villa. La Fábrica de Tabacos de Gijón se instauró entonces como la primera industria de importancia de la ciudad asturiana, constituyendo junto con el Convento de La Vega en Oviedo uno de los pocos ejemplos en Asturias 
de desamortización eclesiástica para su reconversión industrial216.

Como destaca Pascual Madoz,

en lo más alto de la población hay un edificio que hasta hace poco ha fue convento de Agustinas Recoletas, del cual se han trasladado las monjas a una casa particular, y el edificio mencionado con algunas reformas practicadas en el mismo, sirve para las operarias de la fábrica de cigarros establecida en esta villa desde 1822, y restablecida en 1837.

Contiene las oficinas necesarias, almacenes para los tabacos y habitación para el portero y algún empleado subalterno ${ }^{217}$.

De esta forma, la nueva fábrica alcanzaría a mediados del S.XIX un volumen de plantilla de unas 1.500 personas en el nuevo inmueble fabril. Durante las primeras décadas en activo de la fábrica gijonesa en su nuevo emplazamiento se empleaban fundamentalmente hojas procedentes de Cuba y Filipinas y también "el boliche" originario de Puerto Rico. Por otra parte, ya en 1873 se hallaba totalmente mecanizado el proceso de picadura al cuadrado puesto que Gijón, junto a Sevilla y Valencia era una de las fábricas que había introducido la ayuda de una máquina de vapor para realizar esta labor, frente al método manual de grandes cuchillas manejadas por parejas de obreros que se empleaba en las fábricas de Cádiz o La Coruña.

Al igual que ocurrió con su homóloga Alicantina, la Fábrica de Tabacos de Gijón contaría desde 1858 con una filial sita en Oviedo que se dedicaba en exclusiva a la elaboración de cigarrillos. Los talleres, que se habían ubicado en una antigua fábrica de armas, fueron clausurados definitivamente en 1871 y su producción reabsorbida por la fábrica principal radicada en Gijón ${ }^{218}$.

Tras el arriendo del monopolio de tabacos a la CAT en 1887, se implantaría en la fábrica gijonesa un plan de modernización que centraría la producción en la elaboración de Farias, así como de cigarrillos Finos, Entrefinos y Superiores. Nuevamente, estas medidas modernizadoras contaron con la oposición de la plantilla de la tabacalera que veía peligrar sus puestos de trabajo con la llegada de la maquinaria.

No obstante, no sería hasta la tercera década del S.XX en la se diese el mayor impulso en materia de reformas mecanizadoras con la fabricación de cigarrillos con boquilla de cartón, lo que conllevó, lógicamente una reducción de plantilla. También hizo la CAT especial

216 ÁLVAREZ ARECES, M. Á. (coord.) (2009) op. cit., p. 80.

${ }^{217}$ Como únicas industrias de la ciudad, tan sólo destaca la fábrica de cigarros, la fábrica de vidrios planos y botellas sostenida por particulares, y la fábrica de salazón de sardinas. MADOZ, P. (1846-50 [1985]) "Asturias" en Diccionario geográfico-estadístico-histórico de España y sus posesiones de ultramar, tomo XI, Valladolid: Ámbito, p. 175.

${ }^{218}$ En 1859 "400 mujeres -al parecer, de origen madrileño-, comenzaron a elaborar cigarrillos en los talleres de una antigua Fábrica de Armas. Tras casi una década de existencia la fábrica no llegó a consolidar un funcionamiento regular, debido, fundamentalmente, a que desde el inicio de su andadura se vio amenazada por intentos de supresión y tuvo que enfrentarse a la inestabilidad del mercado de trabajo local". CANDELA SOTO, P. (1997) op. cit., p. 37. Sobre la elaboración de cigarrillos en Oviedo en la segunda mitad del S.XIX también se recomienda la consulta de TOMÉ FERNÁNDEZ, S. (1987) "Noticia sobre la Fábrica de Tabacos de Oviedo" en Astura: Nuevos cartafueyos d'Asturies, no6, pp. 33-36, y de ARIAS GONZÁLEZ, L. y MATO DÍAZ, A. (2005) op. cit., pp. 55-57. 
hincapié en la adecuación de las instalaciones de la fábrica en servicios auxiliares para los empleados como la mejora de los deficientes aseos, la creación de vestuarios diferenciados por sexos, así como de otros espacios como comedores para el personal. Durante el breve periodo que supuso la Revolución de Octubre de 1934 en Asturias, la fábrica funcionó como hospital de campaña para emergencias debido a los bombardeos de los acorazados que abrieron fuego sobre Cimadevilla para sofocar la insurgencia ${ }^{219}$.

La Revolución del 34 puso brutalmente de manifiesto la vulnerabilidad, la vetustez y la falta completa de adaptación y flexibilidad que el viejo caserón conventual presentaba a los nuevos tiempos que corrían y a los nuevos sistemas de transporte por automóvil. Así que en 1936 los responsables de la fábrica comenzaron a buscar terrenos para erigir una fábrica de nueva construcción que reuniera todos los condicionantes técnicos impuestos por el mercado. La zona escogida en los alrededores de Gijón fueron las praderías de La Braña, donde era posible la comunicación por carretera, más la cercanía tanto al [puerto del] Musel como a las vías de ferrocarrili220.

Sin embargo, esta iniciativa, que ya había sido contemplada en la década de los 20, no se llevaría a cabo y, en cambio, en los terrenos codiciados por el monopolio para la nueva instalación de la fábrica se edificaría parque residencial durante la época de expansión urbanística del desarrollismo gijonés.

En 1936 también se otorgó el derecho a la jubilación, pero todos los avances de corte social realizados hasta el momento se verían interrumpidos con el estallido de la Guerra Civil, pasando la fábrica a estar controlada por el bando alzado desde la caída de Asturias en 1937 y destinando su producción, al igual que en las tabacaleras restantes, a las "labores de guerra". Tras la Guerra Civil, asume la dirección Luis Cuevas Alcober 221 , especializándose la fábrica en los años siguientes a la contienda en la producción de cigarros Farias, así como en cigarros negros de picadura Ideales, que se convertirían en las marcas emblema del establecimiento gijonés.

Con el cambio de gestión del monopolio a Tabacalera, se abordaría un nuevo plan de modernización de las fábricas, una vez superada la autarquía económica e iniciado el periodo desarrollista a mediados de la década de los 50. Este plan promovía la especialización de cada

219 Desde Madrid, Franco dio personalmente por teléfono la orden de que el crucero "Libertad" abriese fuego contra el barrio de Cimadevilla donde se encontraban atrincherados muchos de los revolucionarios. El barrio se encontraba lleno de barricadas, de las cuales dos se situaban en las inmediaciones de la fábrica de tabacos. Los bombardeos se sucedieron desde la noche del 7 al 8 de octubre, prolongándose a lo largo del día siguiente. Los proyectiles eran de gran calibre e impactaron sobre varios edificios, la mayor parte viviendas, entre los cuales se encontraban la fábrica de tabacos, la torre de la iglesia de San Pedro y el edificio del Ateneo. Sobre este conflicto se recomienda la consulta de RODRÍGUEZ MUÑOZ, J. (2010) La revolución de octubre de 1934 en Asturias:orígenes, desarrollo y consecuencias, Oviedo: Prensa Asturiana.

220 ARIAS GONZÁLEZ, L. y MATO DÍAZ, A. (2005) op. cit., p. 204.

221 Este ingeniero fue jefe de la fábrica de Gijón entre 1938 y 1957 y también estuvo vinculado a la fábrica hispalense, siendo en esta última el artífice del montaje y traslado al ángulo poniente de la lonja exterior de la fuente original del patio de cuadras de Cayetano da Costa. FALCÓN MÁRQUEZ, T.; VALDIVIESO, E.; BERNALES, J. et al. (2001) Universidad de Sevilla: patrimonio monumental y artístico, Universidad de Sevilla, Secretariado de Publicaciones, p. 43 
factoría y la total mecanización de todas las fases productivas. En Gijón no se llegó a alcanzar hasta el año 1970, especializando su producción en cigarros puros, picadura al cuadrado y cigarrillos de picadura al cuadrado. La fábrica mantuvo el auge de la producción a corto plazo, aunque a largo plazo la situación se invertiría, puesto que las elaboraciones de la factoría gijonesa se alejaban de los gustos de los consumidores más proclives a los cigarrillos rubios y cigarrillos de hebra.

El sistema de trabajo sustituyó la antigua división en ranchos y talleres por la de Secciones, más acorde con la presencia masiva de máquinas y automatismos. A lo largo de la década de los 60, llegarían a la fábrica gijonesa nuevas máquinas como calderas de vacío para la humidificación, liadoras Molins, desvenadoras automáticas, picadoras Muller y, principalmente, máquinas MIR para la producción mecanizada de Farias. Por otra parte, se instalaron nuevas calderas, carretillas eléctricas para el transporte en el interior de la fábrica, empaquetadoras Arenco y Hauni, celofanadoras, cartoneadoras, envolvedoras y anilladoras. Así mismo, también se incorporaron las técnicas de fabricación de tabaco de banda continuo y se mejoró el sistema de humectación continua de capas y de preparación mecánica de la rama para el tirulo.

La situación se mantendría más o menos sin variaciones en la década siguiente hasta la incorporación de España a la Comunidad Económica Europea en 1986. La supresión del monopolio en la fabricación y comercio del tabaco en 1998 y la creación de Altadis en 1999, desembocaron en el establecimiento del "Plan Industrial" del año 2000, del que ya se ha hecho mención anteriormente, y que determinó el cierre de la planta fabril en julio de 2002 con el posterior traslado de sus activos y capacidades a la nueva planta cántabra.

\section{Motivos estratégicos de la fundación fabril e implantación en su entorno}

Tras su primera ubicación en el Palacio de los Valdés en la parte Este del istmo que conectaba Cimadevilla con el ensanche jovellanista - muy próximo a la iglesia parroquial de San Pedro y al emplazamiento del consistorio local-, la fábrica gijonesa pasaría a ocupar a mediados del S.XIX el antiguo convento de monjas agustinas situado a los pies del Cerro de Santa Catalina en el límite del barrio de Cimadevilla. Su desamortización unida a las reformas que permitían la liberación de espacio para el desempeño de las tareas productivas, así como su ubicación cercana al puerto, lo convertían inicialmente en el local ideal para tal función, con el consiguiente ahorro que suponía prescindir de la construcción de un edificio de nueva planta.

Gijón sería desde el S.XIX una de las ciudades de desarrollo industrial por excelencia de la provincia asturiana. Como se comentó anteriormente, Madoz destacaba entre sus factorías la fábrica de cigarros, así como la fábrica de vidrios y fundición de Begoña -fundada en 1844- y algunas otras pequeñas plantas destinadas a la industria conservera en Cimadevilla. A partir de mediados del S.XIX, el pequeño puerto gijonés adquiere un desarrollo de gran calado debido al

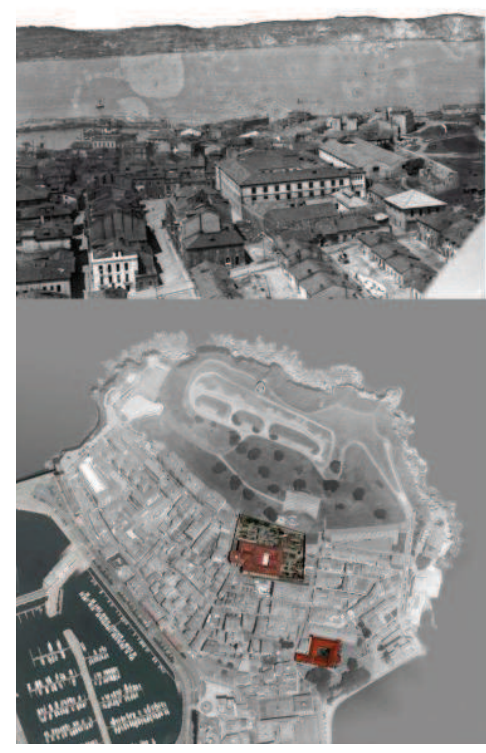

Figura 3.76. Vista aérea del barrio de Cimadevilla, Constantino Suárez, 1931, en fototeca del MUPA, 2965; y ortofoto con emplazamiento de la fábrica, elaboración propia a partir de ortofoto del Ayuntamiento de Gijón de 2011. 


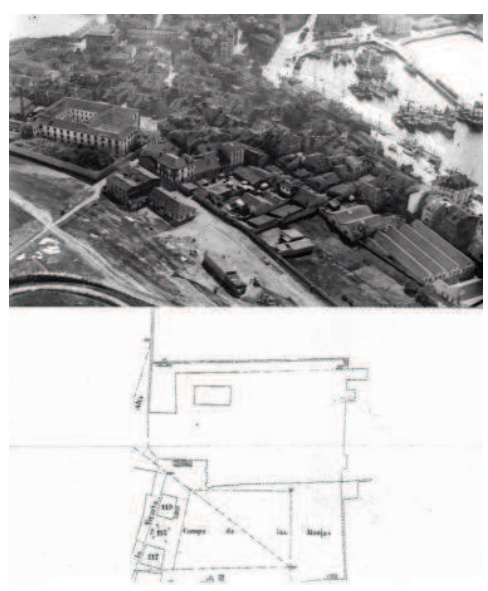

Figura 3.77. Vista aérea en la que se aprecia la cercanía de la fábrica con el puerto y las industrias conserveras,

Constantino Suárez, 1920, en fototeca del MUPA, 4170; y plano del entorno de la fábrica de 1867, en RADCLIFF, P. y DE FRANCISCO, M. J., (1998) op. cit., p. 9 .

transporte relacionado con la extracción del carbón, el comercio marítimo y, fundamentalmente, el sector pesquero. No en vano, la construcción de la llamada "carretera carbonera" en 1842 que conectaba Gijón con las cuencas mineras asturianas y la creación de la Estación de Langreo ${ }^{222}$, muy cercana a los muelles, contribuirían al desarrollo comercial y exportador de la plaza portuaria gijonesa. De igual forma, Gijón experimentaría un tímido crecimiento de su trama urbana coadyuvado por el incipiente desarrollo industrial de la segunda mitad del S.XIX y, sobre todo, alentado por el derribo de las murallas de 1836 en el año 1888.

En las inmediaciones del puerto de Gijón existían más de una veintena de instalaciones dedicadas a la conserva, escabeche y salazón del pescado asentadas en la zona litoral y, preferentemente, en el tradicional barrio pesquero de Cimadevilla. La presencia de la industria tabacalera y el sector pesquero en el reducido y apretado espacio del casco histórico gijonés contribuiría de forma indiscutible al establecimiento de vínculos y a la formación de un sentido de comunidad entre las cigarreras y sus convecinos como se comentará en epígrafes posteriores. No en vano, además de ostentar el título de primera fábrica instalada en Gijón, la tabacalera sería una de las que mayor contratación femenina fomentaría, llegando en su punto álgido a más de 2.000 operarias y, por mucho tiempo, sería la mayor industria de la ciudad.

Entre el S.XIX e inicios del S.XX, la industria que se asentó en Gijón atendía a sectores muy diversos, no siendo una urbe industrial que se especializase en una actividad determinada. La industria asociada al sector de la alimentación se asentaba fundamentalmente en Cimadevilla, con la fábrica de tabacos y las fábricas conserveras. El resto de empresas asociadas a los sectores restantes se ubicaban en barrios periféricos del núcleo urbano, como Begoña al Sur, el Natahoyo y la Calzada al Oeste o El Llano o Ceares al Sureste ${ }^{223}$. Con el crecimiento urbanístico experimentado por la urbe asturiana a partir de la primera mitad del S.XX, la mayor parte de las industrias a las que desbordaba la expansión de la ciudad pasaron a deslocalizarse en otras ubicaciones periféricas como el valle de Veriña o los nuevos polígonos industriales en Porceyo. Sin embargo, algunas industrias, como la fábrica de tabacos, continuaron su actividad en su emplazamiento original.

La creación de la Fábrica de Tabacos de Gijón respondería a las necesidades de expansión de la producción del monopolio en una segunda generación de tabacaleras decimonónicas. No obstante, la inadecuación de la fábrica de tabacos gijonesa como recinto industrial se pondría pronto de manifiesto debido a su ubicación en la parte alta del barrio de Cimadevilla, cuya complicada configuración urbana en estrechas y empinadas calles dificultaba el acarreo y transporte de la mercancía llegada al puerto. Esta situación se agravó con la 
construcción del nuevo puerto del Musel, al otro lado de la bahía en la parte Oeste de la ciudad, y la carencia de infraestructuras urbanas más adecuadas al nuevo tráfico. Como se comentaba anteriormente, mientras que el resto de establecimientos fabriles se fueron situando en el extrarradio urbano o formando corredores industriales en las principales vías de salida de la ciudad, la fábrica de tabacos continuaba ocupando una posición privilegiada en pleno centro urbano, conviviendo con las restantes industrias asociadas al antiguo puerto 224 .

Otros problemas específicos de la factoría gijonesa se derivaban de su ubicación en la parte alta de la ciudad, Cimadevilla, donde los accesos desde el puerto para carruajes, cargados de hoja de tabaco o de productos ya elaborados, estaban dificultados por la estrechez de las calles, en especial por la que llevaba desde la Plaza de los Remedios a la Fábrica de Tabaco. Ante las reiteradas peticiones de la Compañía de solucionar el problema de los accesos, el Ayuntamiento aducía la carencia de fondos para comprar y derribar los inmuebles-obstáculo 225 .

Las cigarreras manifestaron también en numerosas ocasiones su malestar ante el ayuntamiento por las malas condiciones y peligrosidad de los viales que las conducían a la fábrica. Esto motivó la expropiación de ciertas casas para realizar las alineaciones pertinentes de dichos viales a mediados de la década de los 90 del S.XIX. De esta forma, en 1893, ya bajo la gestión de la CAT, se produce el ensanche y alienación de la calle por la que las cigarreras llegaban a la fábrica -actual Vizconde de Campogrande-, cuyas lamentables condiciones habían sido denunciadas por las cigarreras y por una campaña de apoyo a las mismas en los periódicos locales. Fruto de estas presiones, el ayuntamiento procedió a expropiar las viviendas pertinentes y ejecutó las obras requeridas, lo que da cuenta de la influencia de las reclamaciones de las cigarreras ante el consistorio local.

El vínculo que se estableció entre la fábrica y el barrio de Cimadevilla en el que se ubicaba, traspasó en gran medida la mera relación circunstancial para convertirse en un hecho de gran significación para la definición del carácter del mismo y la construcción de la memoria colectiva de la ciudad.

El barrio de Cimadevilla, tómbolo origen de Gijón [...] sólo empezó a extenderse fuera de sus límites a finales del siglo XVIII. Hasta 1840 esta zona todavía alojaba a los habitantes ricos de la ciudad.

Sin embargo, la fundación de la fábrica de tabacos, en el convento situado en pleno centro, demostró ser uno de los puntos decisivos en la suerte del vecindario. Este acontecimiento, junto con el envejecimiento y decadencia de los edificios, inició el éxodo de los más pudientes económicamente y la afluencia de los obreros. Las autoridades de la ciudad pusieron su sello en esta metamorfosis al trasladar el aparato

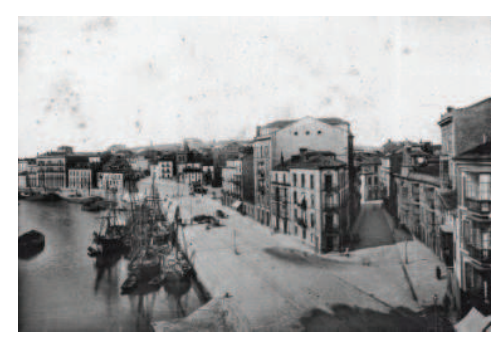

Figura 3.78. Puerto histórico de Gijón, en BELLMUNT Y

TRAVER, O. y CANELLA Y SECADES, F. (1895-1900)

Asturias, Gijón: Fototipia y Tipografía de O. Bellmunt, $p$. 159.

${ }^{224}$ La ubicación de la fábrica de tabacos gijonesa en el tradicional barrio pesquero de Cimadevilla, de marcado carácter popular, propició una convivencia en el corazón de la ciudad de la industria pesquera y conservera, y la tabacalera, arraigando el carácter solidario entre cigarreras y habitantes del barrio. Este carácter proletario y humilde del barrio contrastaba con las arquitecturas ornamentadas y elegantes de representación de las casas navieras y autoridades portuarias que, ocultando la trastienda popular, formaban la fachada de la ciudad hacia el puerto.

${ }^{225}$ ARIAS GONZÁLEZ, L. y MATO DÍAZ, A. (2005) op. cit., p. 71. 
administrativo al nuevo Ayuntamiento, fuera del barrio, en 1865. Hacia 1890, Cimadevilla había completado su transformación de próspero centro a barrio popular [...]

El bienestar de Cimadevilla creció dependiendo de la fábrica de tabaco y de la industria pesquera. Los puntos de concurrencia del vecindario fueron la gran plaza cuadrada que antes había delante de la fábrica y los muelles, donde los pescadores hacían entrar el pescado y ponían a secar sus redes ${ }^{226}$.

Por tanto, Cimadevilla se convirtió en un barrio popular al amparo de la industria tabacalera y pesquera, y ambas actividades estrecharían lazos más allá del espacio físico que compartían. Las interconexiones eran mutuas puesto que, no sólo algunas cigarreras que residían en las inmediaciones de la fábrica realizaban labores en sus casas ${ }^{227}$, si no que la propia fábrica prestaba al vecindario servicios gratuitos de primeros auxilios en la enfermería de la fábrica y en su dispensario médico 228 .

Al contrario que en casos como el de Valencia o San Sebastián, la Fábrica de Tabacos de Gijón no contó con un proyecto de moderna factoría de nueva planta en la periferia industrial, concentrando el desarrollo y expansión de su producción en el interior de los muros del vetusto convento en pleno centro urbano. El hecho de que circunstancias ajenas a las aspiraciones de construcción de una moderna factoría periurbana mantuviesen la fábrica de tabacos en su ubicación original ${ }^{229}$, impidió la evolución de la producción adaptada a las nuevas necesidades. Su emplazamiento, tremendamente dificultoso en su relación con el puerto y carente de infraestructuras adecuadas para su conexión con el mismo, obligó a deslocalizar los espacios de almacenaje y abocó a la factoría gijonesa a una situación de obsolescencia que culminó con su cierre en 2002.

\section{Características de la arquitectura fabril}

Antes de comentar las características arquitectónicas de la tabacalera gijonesa y las sucesivas reformas que el inmueble original experimentó con el paso del tiempo, conviene conocer la configuración espacial de su emplazamiento original, el Palacio de los Valdés, que explica en gran

${ }^{226}$ RADCLIFF, P. y DE FRANCISCO, M. J. (1998) op. cit., p. 22.

${ }^{227}$ FERNÁNDEZ, C. (1993) "La fábrica de tabacos de Gijón cumple hoy siglo y medio de existencia en el barrio de Cimadevilla" en El Comercio, 24 de septiembre de 1993. Por otra parte, "las mujeres de los pescadores, muchas de ellas empleadas en la venta y preparado de salazón veían con temor que los puestos de la fábrica eran ocupados por las mujeres de Bajodevilla. Los directores comprendieron la situación, por lo que fueron admitiendo mujeres del Barrio Pescador y establecerían el acuerdo de que las plazas que pudieran quedar vacantes, fueran exclusivamente ocupadas por las hijas o nietas". LABRADA, V. (1991) "La revolución industrial gijonesa en el siglo XIX" en Curiosidades de un Gijón inolvidable, Gijón: Víctor Labrada Ed., p. 164.

${ }^{228}$ GORDON, C. (2010) op. cit., p. 611, nota 11.

${ }^{229}$ Como se comentó en el epígrafe anterior, a lo largo del S.XX el monopolio del tabaco mantiene una suerte de contencioso con el ayuntamiento gijonés en la disputa sobre unos terrenos adquiridos por el primero para la construcción de una nueva fábrica de tabacos a la que se desplazasen los activos de la obsoleta factoría de Cimadevilla. El interés del ayuntamiento sobre dichos terrenos para la construcción de la nueva estación intermodal, coartaría en repetidas ocasiones las aspiraciones del monopolio hacendístico, cercenando finalmente cualquier proyecto del mismo con la expropiación de la codiciada superficie para la construcción de nuevo parque inmobiliario fruto de la gran expansión de la ciudad hacia su periferia durante el auge desarrollista. Ver ARIAS GONZÁLEZ, L. y MATO DÍAZ, A. (2005) op. cit., pp. 204-207. 
medida los motivos por los que se decidió su ubicación definitiva en el antiguo convento agustino.

\section{La preexistencia: fundación en el Palacio de los Valdés}

Cuando en 1823 se decide fundar una fábrica tabacalera en Gijón, el Palacio de los Valdés parecía un inmueble idóneo para tal fin puesto que se situaba a las puertas del barrio de Cimadevilla, frente a la playa de San Lorenzo y muy cercano al puerto gijonés. De igual forma, el inmueble contaba interiormente con estancias de gran amplitud puesto que

había trece almacenes en los bajos, una gran huerta, un patio exterior y un espacioso patio interior rodeado de amplias dependencias acristaladas "donde pueden trabajar de setecientas a ochocientas personas, sin incluir las dos torres que cada una de ellas tiene dos piezas más, que antes se destinaron a secaderos" 230 .

De antemano, parece que el palacio sentaba las bases espaciales requeridas por la configuración espacial productiva de la industria tabacalera al contar con amplias estancias ordenadas en torno a patios interiores que permitían el desarrollo de la elaboración del tabaco. Además, por su altura y mejor ventilación, y a falta de azoteas o espacios más adecuados, las torres que remataban los flancos de la fachada principal se destinarían al secado de hoja de tabaco.

El edificio palacial era una arquitectura que, por su propio diseño original, otorgaba el empaque y solemnidad pretendido por la Renta de Tabacos para sus plantas fabriles. Nuevamente, la fachada principal se alzaba como el lienzo tras el que se situaban las estancias de mayor representatividad puesto que albergaba las estancias del director de la fábrica, así como las oficinas y restantes espacios administrativos. Por otra parte, el edificio contaba con la configuración idónea para preservar la producción del medio externo puesto que

otra ventaja añadida del local era la existencia ya de un cierre divisorio de todo el perímetro, menos en la fachada donde estaba la dirección, lo que favorece que "desde ningún punto de las piezas a donde se trabaja ni de los almacenes puede tirarse a la calle ningún efecto". Como aportación municipal al proyecto figura el compromiso de limpiar todo el edificio y de blanquear las dependencias más importantes, sobre todo la habitación del Director y la oficina de contabilidad, con lo que la producción podría iniciarse "a los seis días del arribo de los efectos y aún antes" ya que no era necesario realizar obras previas. Bajo estos parámetros, el informe municipal defendía la alta rentabilidad de la instalación, tal como había calculado Canga Argüelles.

Se observa, por tanto, la férrea voluntad del consistorio local en facilitar la reapertura definitiva de la fábrica tras su corta actividad de 40 días trece años antes. No obstante, finalmente se resolvería su traslado definitivo al desamortizado convento agustino casi una década después, por las razones referidas en epígrafes anteriores y, fundamentalmente,

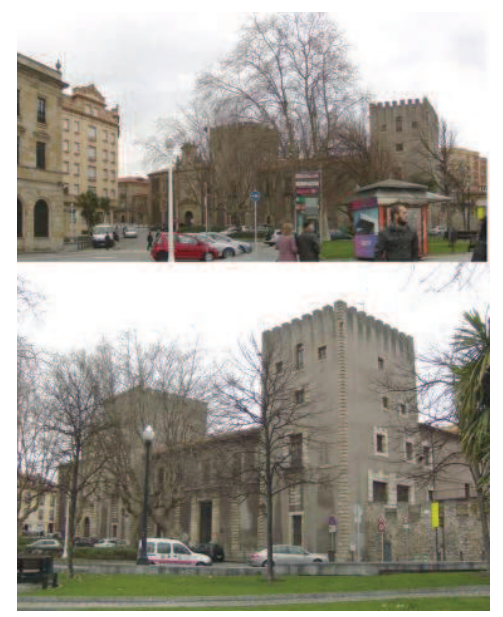

Figura 3.79. Palacio de los Valdés y su entorno en la actualidad, 2011.

230 Este pasaje y el siguiente en ARIAS GONZÁLEZ, L. y MATO DÍAZ, A. (2005) op. cit., pp. 26-27. El entrecomillado es una cita de "Carta del Alcalde de Gijón al Director General de Rentas Estancadas de 12 de junio de 1836” en correspondencia 1836-14, Archivo Municipal de Gijón. 


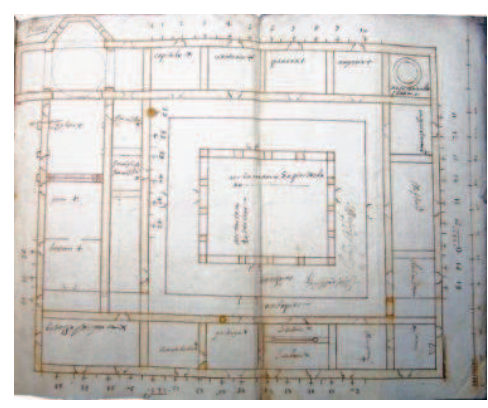

Figura 3.80. Planimetría histórica del proyecto original del Convento de Agustinas Recoletas de Gijón, en DE LA MADRID ALVAREZ, V. (2010) op. cit., p. 62. debido a la poca capacidad de adaptación del inmueble a la expansión productiva y a su costoso alquiler, poco conveniente para las arcas de la Renta de Tabacos.

\section{La preexistencia: el Convento de Agustinas Recoletas}

Cuando la fábrica gijonesa se traslada al Convento de Agustinas Recoletas enclavado en pleno barrio de Cimadevilla, la zonificación del espacio productivo hubo de adaptarse a las características arquitectónicas heredadas del inmueble preexistente. No en vano, el monopolio contaba con antecedentes en la adaptación de antiguos inmuebles religiosos o conventuales como la fábrica alicantina y la factoría de Santander.

El recinto conventual original construido con arreglo al proyecto de los maestros de cantería Ignacio de Palacio y Juan San Miguel a mediados del S.XVII era una obra de fábrica bastante modesta debido a los escasos recursos económicos de la orden agustina. Se trataba de una orden humilde que no podía costear una obra de calidad, en lo que intercedió de forma decisiva la madre María de Santo Tomé e, incluso, el consistorio, dado que parte de la financiación para concluir las obras se obtuvo de impuestos especiales sobre el vino a iniciativa del ayuntamiento local ${ }^{231}$.

Concebido en estilo renacentista con detalles de barroco inicial en la decoración de la iglesia y sus puertas, es un ejemplo tardoclasicista que responde a la tendencia a la continuidad de dicho estilo que se da en Asturias a finales del S.XVII y que progresivamente se contamina de formas barrocas. Las trazas iniciales definidas en el plano que se adjuntó al contrato de obra fueron ligeramente modificadas a favor de un diseño menos arcaizante y similar al convento de Nuestra Señora de la Encarnación construido también por Ignacio Cajigal en Llanes en 1662 para la misma orden ${ }^{232}$. Las principales diferencias se advierten en el diseño de la cabecera, rectangular en vez de achaflanada, y en la prolongación de la nave de la iglesia hasta la fachada principal, al contrario que en el citado plano en el que se preveía la prolongación de la crujía Sur de la panda claustral como remate de la fachada principal de la misma.

El inicio de la construcción está fechado en 1668 y su finalización en 1684, aunque el año de conclusión definitiva de los trabajos se fija en 1733 con la finalización de la cabecera de la iglesia y la elevación de la primera planta y desván de la casa conventual, convirtiéndola en un

231 DE LA MADRID ÁlVAREZ, V. (2010) op. cit., p. 70. Sobre el edificio conventual preexistente se seguirá fundamentalmente esta publicación. Muchos de los datos que avalan las conclusiones de este historiador se basan en el contrato de obra del convento, según la planimetría del proyecto de 1665, documento custodiado en el Archivo Histórico de Asturias. AHA, protocolos notariales de Oviedo, caja 7.343, f.214.

232 "El esquema propuesto por Ignacio de Cajigal para el convento de la Encarnación de Llanes supone una adaptación simplificada de la propuesta clasicista que Francisco de Mora (1552-1610) había configurado para la arquitectura religiosa del foco vallisoletano a principios de siglo y que alcanza su mejor expresión para los proyectos conventuales para el conjunto ducal de Lerma (Burgos). Sus templos suelen ser una cruz latina inscrita en un rectángulo, de una sola nave, con el crucero de brazos muy cortos y el testero plano con presbiterio rectangular, que se impone tras el éxito de El Escorial”. DE LA MADRID ÁLVAREZ, V. (2010) op. cit., p. 50. 
edificio monacal con claustro bajo y alto. El conjunto contaba con dos huertas, vicaría, iglesia y casa conventual, y además de residencia de las religiosas, proveía de asistencia espiritual a los vecinos del barrio y tenía una estancia destinada a escuela de niñas pobres.

La estructura principal constaba de muro de fábrica de mampostería de calidad modesta, a cal y arena, revestida con revoco adornado con un fingido que simula una sillería. En las cubiertas se disponía una estructura de armadura de madera con acabado en teja. El conjunto se dividía en cuatro partes diferenciadas que atendían a las exigencias del espacio autosuficiente que suponía el recinto conventual: la vicaría, la iglesia, la casa conventual y las huertas al aire libre. La vicaría tenía originalmente una sola altura y estaba adosada al muro Oeste de la iglesia. Además de servir de portería del recinto a través de la entrada a la calle por una pequeña escalera exterior, albergaba una alacena que servía para introducir agua en el convento, un locutorio con celosía y un cuarto-almacén. Tras la desamortización del convento y el inicio de las obras de reforma para su reconversión en fábrica de tabacos, este espacio sirvió como vivienda provisional de las religiosas hasta que finalmente fueron alojadas en una vivienda particular de la ciudad.

Por su parte, la casa conventual se alzaba sobre dos plantas y en su interior se disponía un patio central. Situada al Este de la iglesia, se trataba de un edificio de tipo claustral distribuido en cuatro pandas que circundaban el patio principal en el que había un pozo. Curiosamente, en las excavaciones arqueológicas realizadas en 2008 tras el cierre de la fábrica se halló un aljibe del S. IV de época romana, lo que indica la tradicional presencia de agua en los terrenos sobre los que se construyó el convento.

A la casa conventual se podía acceder desde el espacio público conocido como Campo de las Monjas a través de una puerta tapiada y desaparecida en la actualidad. Por esta entrada se accedía al claustro bajo de planta rectangular en cuyos muros de mampostería se abrían ventanas de cantería. Según Vidal de la Madrid, se dividía en trece estancias entre las que estaban el refectorio, cocina y bodegas mayores y menores en las pandas Este y Sur. Además contaba con sacristía en la panda anexa a la iglesia; algunas celdas, sala capitular y letrinas en la panda Norte; y un locutorio en la parte Sur. Hay que tener en cuenta que los espacios inmediatos a la citada entrada fueron probablemente los que se utilizaron como escuela de niñas pobres del barrio.

La primera planta o claustro alto se abría con columnas de piedra al patio en la panda Norte y cegada con paredes en las que se abrían varios huecos en las fachadas restantes. En esta planta se ubicaban 29 celdas divididas por paredes de ladrillo y de la misma salía una escalera desde la panda Oeste mediante la que se accedía a la sala de recreo, al coro alto de la iglesia y al campanario.

Finalmente, el tercer elemento que definía el conjunto era la iglesia de una sola nave con crucero y cabecera rectangular en la zona del presbiterio, que se disponía entre la vicaría y la casa conventual. Presentaba dos puertas como acceso al exterior, ambas cegadas tras las

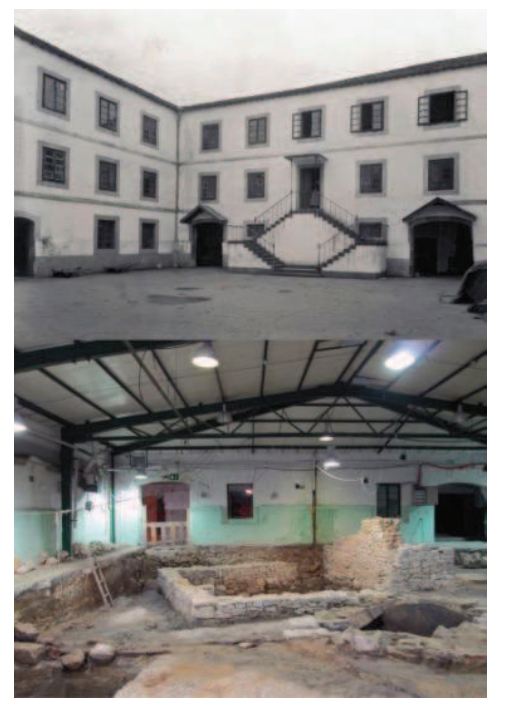

Figura 3.81. Patio principal de la fábrica y antiguo patio claustral del convento, Julio Peinado, 1909, en fototeca del MUPA, 25565; y en la actualidad con el aljibe romano aparecido en las excavaciones arqueológicas, 2012. 


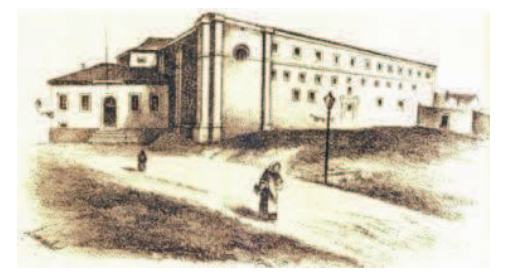

Figura 3.82. Grabado de la "Guía ilustrada de Gijón" de 1884 en el que se aprecia la fábrica tras las primeras reformas y el "Campo de las monjas", en $A R I A S$ GONZÁLEZ, L. y MATO DÍAZ, Á. (2005) op. cit., p. 30.

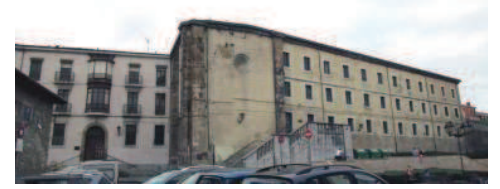

Figura 3.83. Fachada principal de la Fábrica de Tabacos de Gijón, 2013. obras de reconversión fabril, aunque la de la fachada Oeste aún conserva la moldura de elementos clasicistas y barrocos que la enmarcaba, y la puerta frontal Sur se aprecia desde el interior con la formación de un arco carpanel en la zona del dintel. También presentaba un acceso a la vicaría y los correspondientes pasos a la casa conventual a través del coro bajo y del coro alto.

Como se ha comentado anteriormente, la construcción era de calidad modesta, con fábrica de sillares en los soportes y mampostería revocada en los muros, que presentaban contrafuertes al exterior y rosetón en la fachada Sur hacia el Campo de las Monjas. En el interior, el muro presenta como única decoración una moldura horizontal que recorre todo el paramento, con cubierta de bóveda de cañón en la que resaltan los arcos fajones y los lunetos donde se abren tres huecos en el muro. En el crucero dichos lunetos se dotan de ventanas al exterior y cuatro arcos torales sustentan una cúpula esférica rebajada sobre pechinas, ornamentadas con el símbolo policromado de la orden de San Agustín. Toda la cubierta interior está decorada con casetones de escayola que forman un entrelazado geométrico donde se repiten motivos barrocos.

Como es lógico, el recinto se cerraba al exterior con una tapia de mampostería de unos cinco metros de altura que delimitaba los espacios al aire libre que completaban el conjunto, con la gran huerta Norte y la huerta Este en la que se ubicaba una panera. A la huerta Norte, que se encontraba a nivel del claustro alto, se accedía por un pasillo de carros y se destinaba al cultivo de hortalizas y árboles frutales.

\section{La Fábrica de Tabacos de Gijón}

Las reformas más importantes acaecidas en el edificio preexistente fueron las que se iniciaron con el traslado de la fábrica al mismo, en un intento de borrar toda huella de su función anterior y desacralizando el convento mediante el borrado de sus códigos arquitectónicos inherentes. Estas obras de adaptación acometidas para la reconversión en edificio fabril fueron ejecutadas fundamentalmente por ingenieros al servicio de la Renta de Tabacos y se realizaron con un cierto carácter de improvisación, exceptuando las que se llevaron a cabo en los diversos planes de modernización para la mejora de las condiciones de habitabilidad y la introducción progresiva de la mecanización desde la cesión del arriendo del monopolio a la CAT. No en vano, muchas de las actuaciones acometidas trataban de paliar los problemas endémicos de los que adolecía la pertenencia del inmueble a una tipología diversa a la función para la que estaría destinado durante siglo y medio.

Se pueden distinguir, no obstante, etapas destacadas en las reformas efectuadas en cuanto a alteraciones y añadidos en la arquitectura original: la adaptación inicial del convento a la función fabril, las reformas de finales del S.XIX con la aparición en escena de la CAT y los trabajos efectuados en los años 20 del S.XX con las mejoras en 
materia de servicios y mecanización.

La gran reforma inicial de reconversión industrial del antiguo convento agustino transformó los espacios identificadores de la tipología conventual -la vicaría como portería y espacio administrativo, la iglesia como almacén de tabacos y la casa conventual como núcleo de los talleres- de acuerdo con la nueva función productiva. Espacialmente, se buscó la diafanidad de las pandas claustrales y el aumento de superficie útil con la remoción de tabiques y la implementación de un segundo piso en la casa conventual que albergaría, principalmente, los espacios destinados a los diversos talleres de elaboración del producto. Así las primeras obras ejecutadas fueron el desmembramiento del espacio eclesial, mediante el tapiado de su cabecera y su compartimentación en altura, junto a los coros y las puertas de acceso en el exterior, mimetizándolas con el resto de la fachada.

El presbiterio [...] también padeció las reformas motivadas por la instalación fabril, pues fue aislado del resto de la iglesia por un muro de ladrillo, sus paredes fueron vaciadas por sendos arcos para permitir la circulación a través de ellos y se compartimentó su altura en distintos niveles. No obstante, aún conserva la bóveda original [...]

A los pies de la nave, en la cara interior del imafronte, aún se encuentra la puerta principal de la iglesia, que no puede apreciarse al exterior a causa de la desfiguración a que fue sometida la fachada. A su lado, en el primer tramo al lienzo occidental, se conserva otra puerta de menores proporciones que sí mantuvo su apariencia externa. Sobre la principal aún quedan las huellas en el muro de la existente de un coro alto, que, al igual que el bajo, estaría aislado del templo mediante rejas y celosías [...] Es probable que fuera destruido cuando el templo se convirtió en almacén de tabaco, para permitir un mejor aprovechamiento del espacio ${ }^{233}$.

Hasta 1889, las modificaciones en el espacio eclesial se limitaron a cegar las ventanas de la capilla y a sustituir el enlosado de la misma por un entarimado de madera, operaciones necesarias para lograr el nivel de estanqueidad y homogeneidad que se requería a fin de alcanzar la humedad y temperatura idóneas para la maduración y la conservación del tabaco. No se consideraba interesante conservar la iglesia neoclásica y su conversión en almacén de tabaco provocó el tapiado y la destrucción de la cabecera, y generó la instalación de una grúa eléctrica sobre raíles incrustada en el lado izquierdo en el año 1903, y la compartimentación del piso superior y el coro lateral, obras que no han conseguido afectar en exceso a esta parte del edificio ya que aún se distinguen las pechinas originales de la cubierta.

La apertura de espacios diáfanos en la distribución de las pandas claustrales y la conversión de la vicaría en portería completarían las

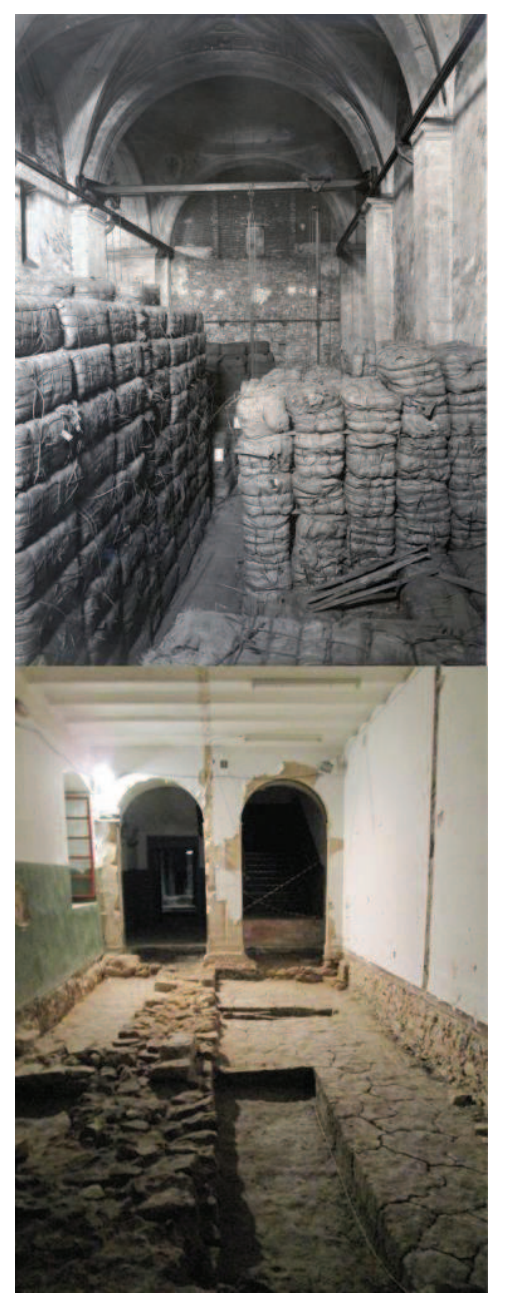

Figura 3.84. Antigua iglesia convertida en almacén de tabacos, Julio Peinado, 1909, en fototeca del MUPA, 25561; y paso a los talleres, 2012.

${ }^{233}$ DE LA MADRID ÁLVAREZ, V. (2010) op. cit., pp. 80-82. Además del tapiado de la puerta de entrada a la iglesia, también desapareció la de la casa conventual. Afirma De La Madrid que "las modificaciones contemporáneas de las cotas y la rasante de la plaza desfiguraron su apariencia primitiva, pues el acceso por la puerta principal se efectuaba prácticamente a nivel de calle". En el anexo IV de su obra, Vidal de la Madrid reproduce el Inventario del edificio desamortizado del convento de las agustinas recoletas de Gijón previo a su entrega para el establecimiento de la fábrica de cigarros, fechado el 8 de enero de 1843 en Gijón y custodiado en el AMG, expediente especial núm. 7, carpeta 3, f. 66-68. Este documento resulta de capital importancia para conocer el estado del inmueble previo a su transformación en planta fabril tabacalera. 


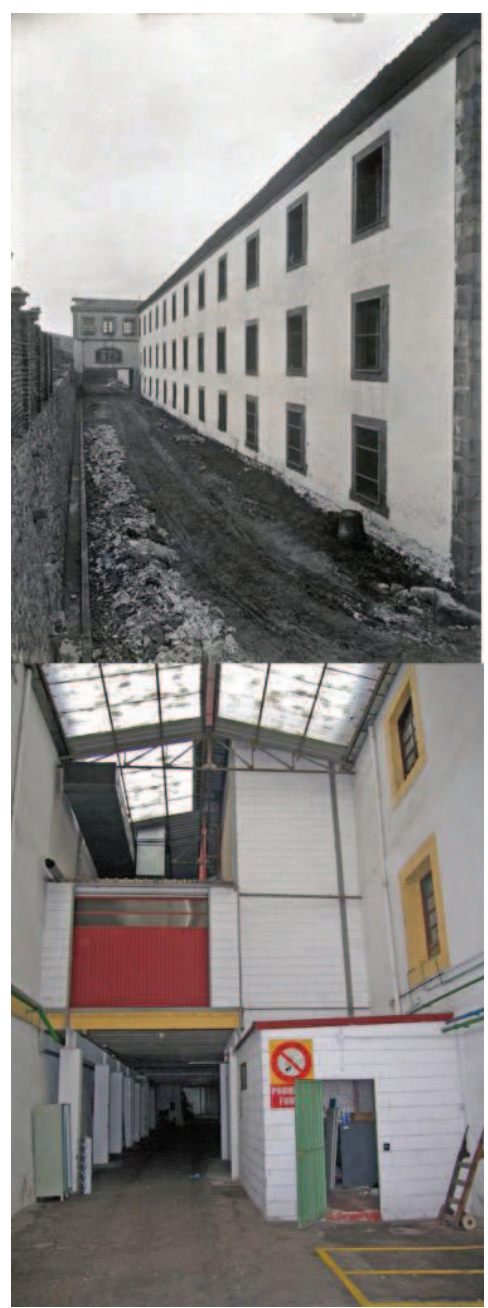

Figura 3.85. Paso de carros en 1909, Julio Peinado, en fototeca del MUPA, 25556; y estado antes de los derribos de 2006, cortesía de TAU Noriega s.l. intervenciones más relevantes en la reforma de acomodo de la fábrica al inmueble preexistente. El resto de las obras que se darían en el tiempo, se limitarían a la mejora constructiva y a la adaptación de los espacios según los cambios productivos, pero siempre partiendo de la rehabilitación inicial. Sin embargo, pese a la desfiguración de los códigos arquitectónicos conventuales, el rígido esquema espacial del edificio permanece implícito y aún hoy es posible interpretarlo en la iglesia y en la distribución claustral de los antiguos talleres. Para lograr convertir el espacio reducido e insuficiente de este cuadrilátero irregular de unos 62 por 45 metros de superficie en un complejo fabril, fue necesario hacer modificaciones que convirtieron el edificio en un complejo puzle de estancias, recrecidos y añadidos, todo lo cual le conferirá un aspecto interno laberíntico. Según Arias y Mato,

\begin{abstract}
las primeras cigarreras y operarios que entraron a trabajar aquí en 1843 se encontraron con una iglesia conocida y con un recinto abandonado apresuradamente que constaba de planta baja (con un alzado de 3,4 metros), planta principal (3,08 metros) y segundo piso (3,5 metros), amén de las huertas y de los dos anexos que rompían un tanto la disposición rectangular: la citada capilla de uso mixto (conventual y público) y un cuerpo saliente pentagonal conocido como la Vicaría (vivienda del sacerdote). En este lateral se abriría la entrada principal de la factoría mediante unas gradas que daban acceso a un amplio vestíbulo. Las dos primeras alturas presentaban en planta dos crujías paralelas pero de distintas luces: la más ancha -en torno a unos 5 metros- se abría al perímetro exterior, mientras que la otra - de 3 metros- se circunscribía únicamente al patio central del claustro [...]
\end{abstract}

En realidad, esta planta [el segundo piso] [...] se remataba con un desván bajo teja [...] se utilizó como secadero y centro de oreo en algún momento esporádico, porque el bosque de armaduras que sustentaban el tejado dificultaba mucho el tránsito por el mismo para trasladar los atados de hojas o los montones de picadura ${ }^{234}$.

Como se comentaba anteriormente, este conjunto de actuaciones se destinaron también a la desacralización del inmueble preexistente a través de la arquitectura implantando en el imaginario ciudadano la visión del antiguo convento como un edificio laico al servicio del monopolio. Con el tiempo, se introdujo progresivamente la mecanización de la producción y la fábrica se vio constreñida a crecer dentro de las tapias del convento, primero en sí misma, en el inmueble conventual, y más tarde, ocupando los espacios libres de las distintas huertas. Esta complejización espacial de la fábrica produjo una interesante hibridación arquitectónica entre el neoclásico edificio monumental del convento y las nuevas construcciones adosadas al mismo, de forma análoga a como sucedería en muchas de las fábricas tabacaleras estudiadas.

En el periodo posterior a la gran reforma de reconversión fabril y antes de las mejoras introducidas a iniciativa de la CAT, se suceden las pequeñas intervenciones de mejora y adaptación de los espacios, fundamentalmente para la creación de nuevos talleres en el seno del

${ }^{234}$ ARIAS GONZÁLEZ, L. y MATO DÍAZ, A. (2005) op. cit., p. 83. 
inmueble a partir de la década de los 60 del S.XIX. En 1866, ante el progresivo aumento de trabajadoras, se adosan dos pabellones por el lado Norte y Este y se construyen dos almacenes en la huerta Este produciéndose la apertura que comunica el paso de carros interno con el vial exterior.

Por otra parte, en 1880 se produjo la renovación de las fachadas Norte, Sur y Oeste del patio central y se recompuso el tejado y la escalera central. En 1882 comienzan los proyectos de reformas ante el fracaso del primer intento de mecanización, con ampliaciones ejecutadas por el arquitecto municipal. Ya en este momento surgen las primeras voces críticas por parte del jefe de la fábrica advirtiendo de la necesidad de una urgente ampliación ante la deficiencia de los espacios para desarrollar las labores productivas pertinentes. Dos años después se construiría el almacén de la esquina Sudeste con paredes de mampostería y cubierta a dos aguas, dedicado a almacén de elaborados y taller de reparaciones.

Durante el segundo periodo de reformas a finales del S.XIX y principios del S.XX con motivo de la aparición en escena de la CAT, se hacen patentes las limitaciones espaciales de la fábrica que afectan tanto a las condiciones de habitabilidad y salubridad de los talleres en los que se hacinan unas 2.000 cigarreras, como en la producción y disponibilidad de espacio para el almacenaje de producto en rama y elaborados.

No obstante, señala el ingeniero Ortiz de la Torre que

la norma de aquella época de habilitar para otros efectos los conventos, es indudable que nos trajo un atraso grandísimo, un atraso en la construcción higiénica, en las condiciones de habitabilidad, en las necesidades civiles é [sic] industriales. Así seguimos viendo hoy cuarteles insalubres, faltos de luz, ventilación y hasta alcantarillado; oficinas públicas con los mismos defectos y distribuciones tan caprichosas que se precisan guías ó [sic] prácticos para recorrer el dédalo de sus laberínticos pasos, pasillos y galerías [...] Esto dando de lado las mutilaciones y anomalías artísticas que se han cometido ${ }^{235}$.

En el caso de la tabacalera gijonesa, las intervenciones acometidas sobre el inmueble estarán encaminadas a la introducción de la mecanización de los procesos con el plan de modernización de la CAT, así como al inicio de obras de conservación y mejora del edificio. Las posibilidades cualitativas de cada espacio en términos de rendimiento productivo, se cuantificaban en volumen y altura de apilado del producto, en los espacios de almacenaje, y en rendimiento a destajo de las cigarreras. Por tanto, pronto se ve necesario un aumento de la superficie útil de los espacios fabriles para albergar mayor número de operarias y almacenaje de producto mediante la cubrición de los espacios libres -como el patio de moja- con estructuras metálicas. Otro rasgo característico de las reformas de esta época, es el interés en mejorar las condiciones de la arquitectura preexistente en materia de instalaciones o la ampliación y mejora de los servicios para la plantilla de trabajadores, según las medidas higienistas propuestas en las

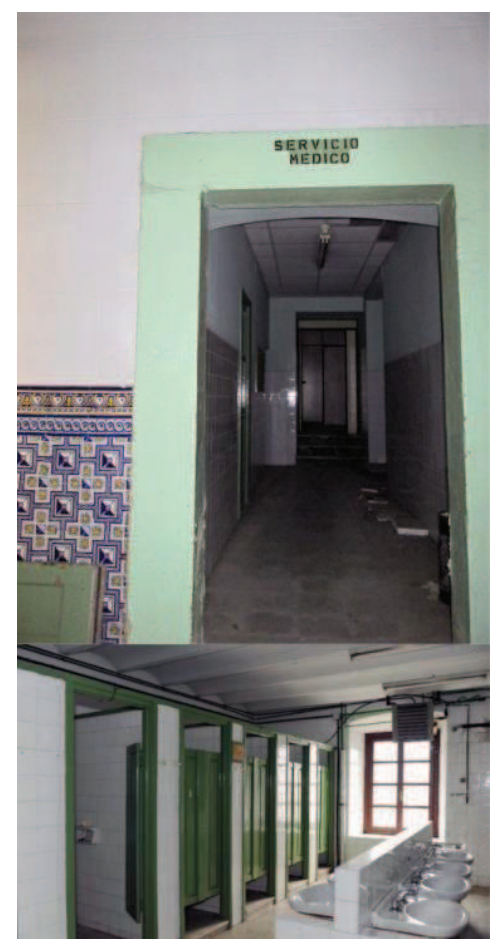

Figura 3.86. Acceso al servicio médico de la fábrica, 2012; y aseos de la fábrica, 2010 , cortesía de Román Villasana.

${ }^{235}$ Este pasaje y el siguiente en ORTIZ DE LA TORRE, J. M. (1908) op. cit., pp. 34, 36 y 41. 


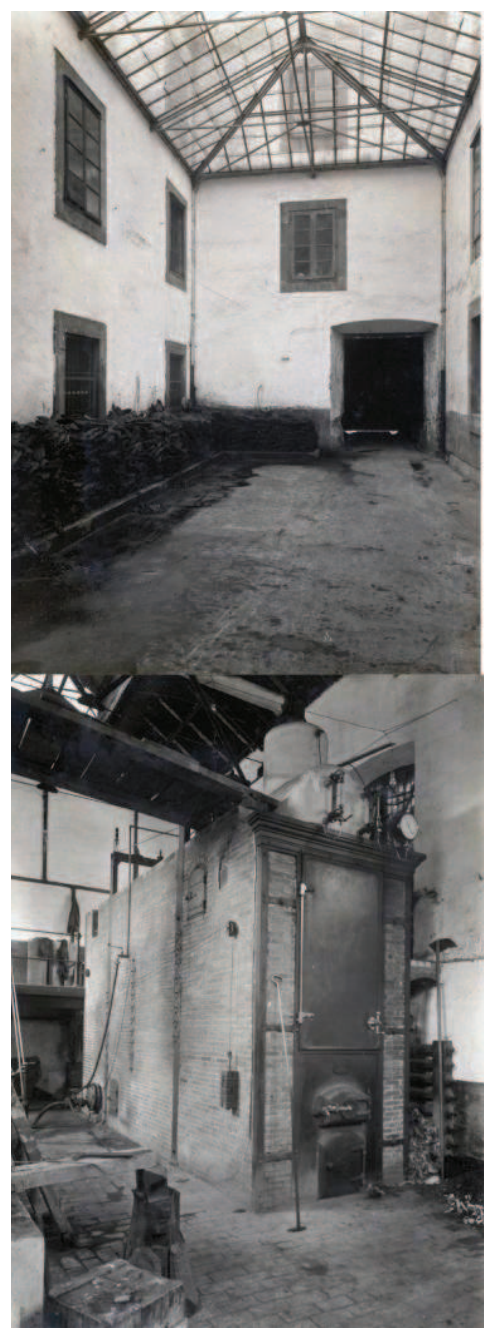

Figura 3.87. Patio de moja y caldera Naeyer, Julio Peinado, 1909, en fototeca del MUPA, 25554 y 25562 inspecciones técnicas.

Es interesante, en este sentido, hacer referencia en este punto al análisis que el ingeniero Ortiz de la Torre realiza sobre el edificio en 1908:

de cuantos edificios que hayan sido conventos conozco, uno de los que mejores condiciones reúnen para su nuevo objeto es éste de que se trata. $\mathrm{Su}$ situación en punto bien ventilado, su orientación y su amplio patio central, le proporcionan condiciones de salubridad muy recomendables.

Pese a que era evidente que el origen conventual del edificio y su siglo y medio de vida hacían mella en la posibilidad de una expansión productiva acorde a los nuevos requerimientos, así como en beneficio de su plantilla en materia de confort y servicios higiénicos, parece ser que este ingeniero valora positivamente, dentro de las limitaciones observadas, el estado de conservación del inmueble.

En 1889, siguiendo los principios higienistas, se produjo el primer gran cambio formal apreciable desde el exterior al sustituirse el sistema de ventanas irregulares y estrechas -probablemente cubiertas por unas celosías enrejadas de hierro como herencia de la anterior función conventual y propia del carácter coercitivo de las fábricas del monopolio del tabaco- por unas aperturas ensanchadas y simétricas que aumentaron la luz y las posibilidades de aireación, necesidades básicas en un ambiente tan enrarecido y lleno de polvo. Dos años después, las intervenciones se centrarían sobre la introducción de un sistema de bocas de incendio, instalación con la que hasta ahora no contaba la fábrica.

En 1893 se construye una chimenea en la huerta Este con ayuda del personal de la fábrica y al año siguiente se ampliaría el espacio productivo de la fábrica en esta misma huerta con la construcción de un pabellón adosado al muro Este de la fábrica. Este nuevo espacio, seguía criterios más propios de la estética industrial del momento, siendo ejecutado con paredes de mampostería y cubierta a dos aguas con linternón. No en vano, su función era la de acoger el motor diesel y la central de reserva que suministraría la fuerza motriz a la maquinaria instalada, mejora que se vería coadyuvada por la electrificación de la fábrica en 1899236. Unos años después, en 1906, se instalaría una caldera Naeyer en una de estas dependencias de la huerta Este, como testimonian las fotografías de Julio Peinado de principios del S.XX.

Ya a principios del S.XX se produce la construcción del almacén exento de la huerta Nordeste cuya zona oriental se vería profundamente reformada a finales del S.XX y que albergaría la carpintería. Continuando las pequeñas intervenciones parciales de mejora, entre 1902 y 1905 se realizarían una serie de intervenciones menores como la reforma de los huecos de las ventanas del piso bajo con la apertura de

236 Parece ser que esta obra fue parcial puesto que Arias y Mato señalan que la electrificación total de la fábrica se produce en el año 1921 con el cambio de la generación por vapor a la electricidad, con la instalación de la central de reserva con motor Diesel y, muy posteriormente, la estación transformadora. ARIAS GONZÁLEZ, L. y MATO DÍAZ, A. (2005) op. cit., p. 106. 
12 vanos en $1902^{237}$, el asfaltado de los patios y la instalación del puente grúa en el espacio eclesial convertido en almacén en $1903^{238}$ y la reforma del entarimado de los talleres entre 1904 y 1905.

Siguiendo la estrategia de expansión del espacio productivo en el interior del antiguo recinto conventual, el interior del inmueble ganaría espacio útil con la cubrición de patios, como el de moja en 1906 mediante una estructura metálica con cubrición vidriada dispuesta a la altura del primer piso, acristalando, también, los huecos del patio central. De igual forma, en 1907 se construiría un nuevo pabellón de retretes dotados de descarga automática de agua y de gran ventilación y luz sobre el paso de carros de siete metros de anchura -que también se ejecutó en esa obra-, adosado a la fachada Norte del edificio en la primera y segunda plantas y que comunicaba con la cota de la huerta Norte, así como un pabellón en la zona Nordeste de la huerta que complementaría a los pequeños pabellones que iban ocupando esta zona libre del antiguo recinto conventual ${ }^{239}$.

El tercer periodo de reformas espaciales importantes tiene lugar a partir de la década de los años 20 del S.XX, con el plan de modernización que pretende reforzar la incipiente mecanización de los talleres junto a la implementación de espacios destinados a servicios secundarios para los trabajadores. Sin embargo, pese a la optimización de las estancias del primitivo convento, la acuciante falta de espacio conllevó a la colonización de las áreas libres cercadas por las tapias conventuales. Todas estas intervenciones se realizarían al amparo del nuevo Reglamento Orgánico de la CAT del año 1927.

En este sentido, en 1927 se instalaría el botiquín medico y la pagaduría en las estancias próximas al paso hacia los talleres de la planta baja, al final del pasillo de acceso que atravesaba la antigua vicaría. En 1929 se construirían dos nuevos almacenes en la antigua huerta Norte que se destinarían al resguardo de rama y elaborados, empleando una estructura de cerchas metálicas roblonadas. Con estas nuevas dependencias se colmatará definitivamente toda la superficie del antiguo recinto conventual que hasta ahora se mantenía libre ${ }^{240}$. En el mismo año, la antigua vicaría experimentaba en paralelo una gran reforma con la adición de dos pisos y el ensanchamiento de su superficie con objeto de albergar las viviendas del portero y del director de la fábrica -en planta baja y planta segunda, respectivamente- mientras que el primer piso se destinaría por entero a oficinas administrativas. $\mathrm{Si}$ bien la fachada conservó las líneas estilísticas de la construcción precedente, el interior se decoró profusamente con motivos de inspiración art decó al gusto de la época.

Con la década de los 30 se inicia un periodo de escaso interés para los objetivos de la presente investigación. El estallido del conflicto bélico y

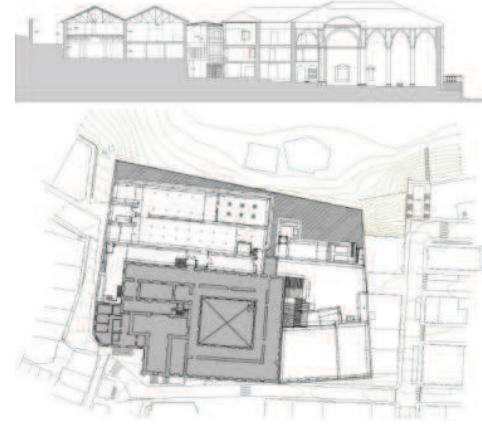

Figura 3.88. Planimetría de la fábrica, elaboración propia a partir de la documentación facilitada por Román Villasana y TAU Noriega s 1 .

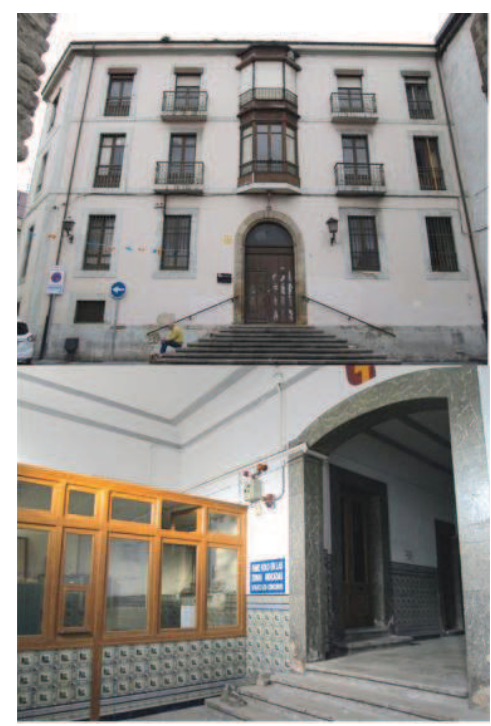

Figura 3.89. Fachada de la antigua vicaría y acceso principal de la fábrica tras las reformas de 1929, y vestíbulo del acceso histórico, 2012.

237 AMG Exp. 152/1902 según la documentación de GARCÍA QUIRÓS, P. y VILA, N. (2006-2010) Estudio documental sobre la Fábrica de Tabacos de Gijón, [inédito, trabajo elaborado entre 2006 y 2010], custodiado en el Museo del Ferrocarril de Asturias.

238 ÁLVAREZ ARECES, M. Á. (coord.) (2009) op. cit.

239 Estos espacios se mencionan como edificios independientes, siendo dos almacenes, un taller de carpintería y dos cobertizos junto al horno de quema en ORTIZ DE LA TORRE, J. M. (1908) op. cit., p. 46.

240 ARIAS GONZÁLEZ, L. y MATO DÍAZ, A. (2005) op. cit., p. 85. 


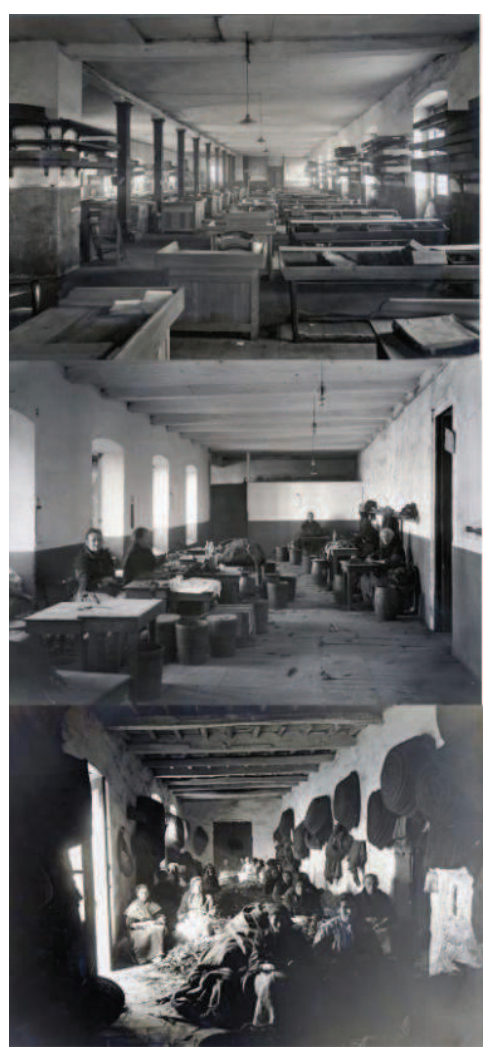

Figura 3.90. Taller de cigarrillos superiores, taller de preparado de capa y taller de desvenado fuerte de la Fábrica de Tabacos de Gijón, Julio Peinado, 1909, en fototeca del MUPA, 25555 25557 y 25559 . el posterior periodo de autarquía económica supusieron un freno a las mejoras de reestructuración iniciadas en la época precedente, por lo que habría que esperar a la constitución de Tabacalera Compañía Gestora del Monopolio del Tabaco y Servicios Anejos en 1945, y al levantamiento del racionamiento sobre el tabaco en los años 50, para que se iniciasen las obras que supondrían la base de las reformas operadas en la evolución última del periodo desarrollista.

\section{El espacio productivo y su evolución hasta 1945}

La evolución espacial de la Fábrica de Tabacos de Gijón a través de las diversas reformas de que fue objeto indica que la distribución de los diversos espacios que constituyeron la producción tabacalera obedeció tanto a aspectos prácticos, en cuanto a la circulación de producto y al máximo aprovechamiento para el alojamiento de cigarreras y maquinaria, como a las condiciones climáticas necesarias para la realización de las labores. De esta forma, las zonas menos soleadas y con relativo índice de humedad, como la iglesia ${ }^{241}$, resultaban adecuadas para la óptima conservación del producto almacenado. Por otra parte, ciertas tareas, como el oreo, precisaban de la ventilación y soleamiento de las que gozaban las estancias con orientación Este.

En otro orden, en cuanto a las circulaciones de materia prima y operarias, el producto llegaba desde el puerto a la fábrica, en la que realizaba un recorrido vertical desde el pretratado en la planta baja, donde se daban lugar las tareas que más desperdicios producían, hasta las plantas primera y segunda en las que tenía lugar el liado y empaquetado final del producto. Sin embargo, el recorrido de las cigarreras a través de la fábrica respondía al control de su trabajo y a la acción moralizante que la misma como institución ejercía sobre la plantilla, empleando el espacio laboral como instrumento de vigilancia. El único acceso de que disponían era la entrada a la vicaría, en la que se situaba el registro de empleados y desde la que realizaban un recorrido laberíntico por las distintas plantas de la fábrica hacia los talleres, donde permanecían vigiladas por su respectiva maestra.

En los primeros tiempos la materia prima se introducía en la fábrica por el paso de carros Norte y se almacenaba en la iglesia recorriendo la panda Oeste del patio central y a través del patio hacia la huerta Este. Posteriormente, con la creación de los almacenes Norte y la disposición de unas puertas de embocadura en todos los niveles de la fábrica para tal cometido, se introduciría la materia prima a través de las mismas mediante sistema de grúa en vertical.

El conjunto estuvo integrado a lo largo del tiempo por inmuebles de muy diverso tipo que mantuvieron prácticamente la misma función original pese a las reformas de que fueron objeto con la introducción de la mecanización. Dada la complejidad del conjunto gijonés, se pueden

241 Señala Cuevas Alcober que la fama de las labores asturianas se debe al fenómeno producido en la iglesia del antiguo convento destinada a almacén por el que los tabacos allí depositados experimentan una fermentación lenta y un envejecimiento o añejamiento sin apreciables aumentos de temperatura ni pérdida de peso, lo que aumenta el aroma y la combustibilidad de la materia prima. CUEVAS ALCOBER, L. (1955) op. cit., p. 39. 
destacar como elementos integrantes principales la casa conventual, la iglesia, la vicaría y los anexos y construcciones auxiliares ubicados en los espacios libres de las antiguas huertas conventuales.

La casa conventual se convertiría hasta el cierre de la fábrica en el contenedor arquitectónico en el que se albergaron los diversos talleres en los que trabajaban las cigarreras. La producción se organizó en sentido vertical, desde las labores con mayor generación de residuos en la planta baja, hasta la obtención del producto final en la planta alta. En las obras acometidas a partir de la desamortización del convento, se eliminaron los tabiques que dividían las pandas claustrales y se elevó una segunda planta con desván que funcionaba como secadero, con cubierta sustentada por armaduras de madera. Esta segunda planta se advierte claramente como posterior a la casa conventual debido a su mayor altura, aunque sus ventanas están alineadas con las que se rasgaron y uniformaron en las plantas originales del convento durante la remodelación acometida en la fachada a finales del S.XIX.

El primer periodo destacable en la evolución del espacio productivo de la fábrica comprende el inicio de la actividad en el antiguo convento agustino en 1843 hasta la cesión del arriendo del monopolio a la Compañía Arrendataria de Tabacos en 1887. Esta etapa se caracteriza por una producción y organización de carácter preindustrial artesanal que requiere un aumento exponencial de las operarias frente al escaso número de operarios varones, contando en este periodo con más de 1.500 cigarreras empleadas. Como se apuntaba anteriormente, la vicaría se convirtió en la entrada principal y acogió las dependencias de portería y dirección de la fábrica, mientras que la iglesia fue reconvertida en almacén de rama. Tras la cabecera de la misma se añadieron nuevas dependencias agrupadas en torno al denominado "patio de moja", albergando en la planta inferior las labores de desvenado y oreo, y diversos talleres de elaboración en las plantas superiores. El cuarto espacio conventual ocupado fue la huerta Este, en la que se establecieron diversas naves y cobertizos auxiliares que se destinaban a tareas secundarias como almacenaje de rama, ubicación de calderas, carpintería o retretes. Durante muchas décadas, la puerta principal de entrada y salida del producto era la situada en la tapia Oeste del convento, si bien a finales del S.XIX se abrió la puerta oriental que daba a la calle Batería.

La producción en la Fábrica de Tabacos de Gijón se inició en la confección de cigarros y tabaco torcido, configurando desde sus inicios el espacio laboral basado en la división en talleres subdivididos en partidos, y éstos, a su vez, en ranchos. Los restos de las principales labores, también se reaprovechaban en la elaboración de tabaco en picadura, que satisfacía una modalidad de consumo cada vez más extendida entre la población. Cabe destacar que esta última variedad fue de las primeras en las que se inició la mecanización, para lo que en 1861 se comenzaron a instalar las primeras máquinas picadoras a vapor. No en vano, en 1873 la tabacalera gijonesa era una de las seis fábricas de las ocho existentes en España que contaba con una máquina de vapor para la generación de energía. 